Hans-Markus Johannsen

\title{
Die ordnungspolitische Haltung Frankreichs im Prozeß der europäischen Einigung
}




\section{Die ordnungspolitische Haltung Frankreichs im Prozeß der europäischen Einigung}

Seit ihrer Gründung ist die Europäische Gemeinschaft hin- und hergerissen zwischen einer marktwirtschaftlichen und einer interventionistischen Wirtschaftsordnung. Über einen Zeitraum von 1955 bis heute wird die französische Europapolitik in dieser Arbeit auf ihre ordnungspolitischen Konstanten und deren Ursprungsmotive untersucht. Frankreich hat sich beharrlich für die Errichtung einer makroökonomischen Gesamtsteuerung in Europa eingesetzt. Statt an die Selbstheilungskräfte des Marktes zu glauben, hat sich die französische Europapolitik dem wirtschaftlichen Allgemeininteresse verschrieben, dessen Verwirklichung aus französischer Sicht ohne staatliche Interventionen in den Wirtschaftsablauf nicht denkbar ist. Die Ursprungsmotive der französischen Binnenmarktpolitik werden über die Wirtschaftsstilanalyse auf die Wertewelt und den Vernunftglauben der französischen Aufklärung zurückgeführt.

Hans-Markus Johannsen, geboren 1966 in Heide (Holstein), studierte nach der Ausbildung zum Offizier von 1988 bis 1992 Betriebswirtschaftslehre an der Universität der Bundeswehr Hamburg. Während seiner anschließenden Tätigkeit in der Bundeswehr war er zunächst externer Doktorand, ab 1995 dann Mitarbeiter am Institut für Wirtschaftspolitik dieser Universität. Promotion 1998. 
Die ordnungspolitische Haltung Frankreichs

im Prozeß der europäischen Einigung 


\title{
SCHRIFTEN ZUR \\ WIRTSCHAFTSTHEORIE UND WIRTSCHAFTSPOLITIK
}

\author{
Herausgegeben von \\ Rolf Hasse, Jörn Kruse, Wolf Schäfer, Thomas Straubhaar \\ und Klaus W. Zimmermann
}

\section{Band 15}

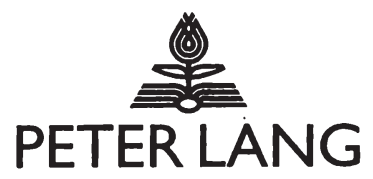

Frankfurt am Main - Berlin - Bern - New York - Paris - Wien 
Hans-Markus Johannsen

\section{Die ordnungspolitische Haltung Frankreichs im Prozeß der europäischen Einigung}

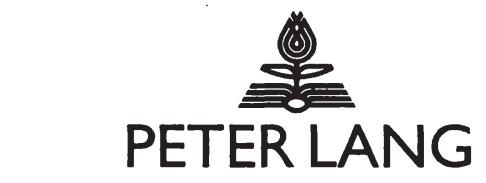

Europäischer Verlag der Wissenschaften 
Die Deutsche Bibliothek - CIP-Einheitsaufnahme

Johannsen, Hans-Markus:

Die ordnungspolitische Haltung Frankreichs im Prozeß der europäischen Einigung / Hans-Markus Johannsen. - Frankfurt am Main ; Berlin ; Bern ; New York ; Paris ; Wien : Lang, 1999

(Schriften zur Wirtschaftstheorie und Wirtschaftspolitik ;

Bd. 15)

Zugl.: Hamburg, Univ. der Bundeswehr, Diss., 1998 ISBN 3-631-34468-6

Open Access: The online version of this publication is published on www.peterlang.com and www.econstor.eu under the international Creative Commons License CC-BY 4.0. Learn more on how you can use and share this work: http://creativecommons.org/ licenses/by/4.0.

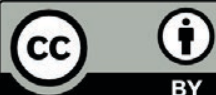

This book is available Open Access thanks to the kind support of ZBW - Leibniz-Informationszentrum Wirtschaft.

Gedruckt mit Unterstützung der Universität der Bundeswehr Hamburg.

Gedruckt auf alterungsbeständigem, säurefreiem Papier.

D 705

ISSN 1433-1519

ISBN 3-631-34468-6

ISBN 978-3-631-75122-0 (eBook)

(c) Peter Lang GmbH

Europäischer Verlag der Wissenschaften

Frankfurt am Main 1999

Alle Rechte vorbehalten.

Das Werk einschließlich aller seiner Teile ist urheberrechtlich geschützt. Jede Verwertung außerhalb der engen Grenzen des

Urheberrechtsgesetzes ist ohne Zustimmung des Verlages unzulässig und strafbar. Das gilt insbesondere für

Vervielfältigungen, Übersetzungen, Mikroverfilmungen und die Einspeicherung und Verarbeitung in elektronischen Systemen.

Printed in Germany 134567 
meinen Eltern gewidmet

Hans-Markus Johannsen - 978-3-631-75122-0

Downloaded from PubFactory at 01/11/2019 08:04:25AM

via free access 
Hans-Markus Johannsen - 978-3-631-75122-0

Downloaded from PubFactory at 01/11/2019 08:04:25AM

via free access 
„Das Schicksal einer Kulturepoche, die vom Baum der Erkenntnis gegessen hat, ist es, wissen zu müssen, daß wir den Sinn des Weltgeschehens nicht aus dem noch so sehr vervollkommneten Ergebnis seiner Durchforschung ablesen können, sondern ihn selbst $\mathrm{zu}$ schaffen imstande sein müssen, daß >>Weltanschauungen $<<$ niemals Produkt fortschreitenden Erfahrungswissens sein können und daß also die höchsten Ideale, die uns am mächtigsten bewegen, für alle Zeit nur im Kampf mit anderen Idealen sich auswirken, die anderen ebenso heilig sind, wie uns die unseren."

Max Weber 
Hans-Markus Johannsen - 978-3-631-75122-0

Downloaded from PubFactory at 01/11/2019 08:04:25AM

via free access 


\section{Vorwort}

Die vorliegende Arbeit wurde im Mai 1998 vom Fachbereich Wirtschafts- und Organisationswissenschaften der Universität der Bundeswehr Hamburg als Dissertation angenommen.

Sie entstand zunächst parallel zu meiner Berufstätigkeit; abschließen konnte ich sie als Mitarbeiter am Lehrstuhl meines Erstgutachters, Prof. Dr. Rolf H. Hasse, am Institut für Wirtschaftspolitik der Universität der Bundeswehr Hamburg. Herrn Professor Hasse bin ich für die Bereitschaft, mich als Doktoranden zu betreuen, zu großem Dank verpflichtet. Ohne seine Bereitschaft, stets für Fragen zur Verfügung zu stehen, und ohne die wertvollen Anregungen aus den Diskussionen mit ihm wäre es unendlich viel schwerer gewesen, diese Arbeit zu Ende zu führen.

Für die Übernahme des Zweitgutachtens danke ich Herrn Prof. Dr. Franco Rheiter. Auch er war mir stets Förderer und gab mancherlei Impulse, die wesentlich zum Fortgang der Arbeit beigetragen haben.

In meinen Dank einschließen möchte ferner ich alle Freunde und Kollegen, die mir mit kritischen Anregungen und hilfreichen Aufmunterungen halfen. Dies gilt vor allem für Herrn Dr. Michael Schleicher, der die Entstehung der vorliegenden Arbeit von der ersten Stunde an begleitet hat und jederzeit mit Rat und Tat zur Verfügung stand. Danken möchte ich darüber hinaus Herrn Peter und Frau Eva Lambrecht, die mir in schwierigen Tagen immer wieder das Refugium geboten haben, in dem ich Kraft und Motivation tanken konnte und in dem mehrere Abschnitte dieser Arbeit entstanden sind, sowie meiner Schwester, Ellen Johannsen, für ihre tatkräftige Mitarbeit bei der orthographischen Bereinigung der Arbeit. 
Hans-Markus Johannsen - 978-3-631-75122-0

Downloaded from PubFactory at 01/11/2019 08:04:25AM

via free access 
Abkürzungsverzeichnis $\quad 15$

$\begin{array}{ll}\text { Einleitung } & 17\end{array}$

A Wirtschaftsordnung und Ordnungspolitik

1 Die ökonomische Bedeutung der Wirtschaftsordnung 21

2 Die politische Bedeutung der Wirtschaftsordnung $\quad 29$

3 Die Kulturbedeutung der Wirtschaftsordnung $\quad 32$

4 Implikationen für den Gang der Untersuchung $\quad 38$

\section{B Der französische Ordnungsentwurf für den Gemeinsamen Markt}

1 Die Regierungsverhandlungen zum EWG-Vertrag

1 Die politische und wirtschaftliche Lage Frankreichs vor den Verhandlungen

2 Die Mitarbeit am Spaak-Bericht $\quad 49$

3 Die Vorbereitung der Regierungsverhandlungen 53

4 Die Positionen Frankreichs in den Regierungsverhandlungen

1 Die Harmonisierung der Wettbewerbsbedingungen 55

2 Die Harmonisierung der Soziallasten $\quad 57$

3 Interventionen und Schutzklauseln $\quad 59$

4 Der Investitions- und Anpassungsfonds $\quad 62$

5 Die Koordination der Wirtschaftspolitik 63

6 Die Koordination der Währungspolitik 66

7 Die Errichtung der Zollunion und Außenhandelspolitik 68

8 Die Koordination der Agrarpolitik $\quad 70$

5 Die ordnungspolitische Orientierung der französischen Europapolitik $\quad 75$

während der IV. Republik

2 Frankreichs Binnenmarktpolitik unter Charles de Gaulle 1958 - 1969

1 Die europapolitische Konzeption

1 Die wirtschaftlichen Rahmenbedingungen $\quad 79$

2 Der Inhalt der europapolitischen Konzeption $\quad 80$

3 Die Umsetzung der europapolitischen Konzeption $\quad 86$

2 Die Wirtschaftspolitik

1 Der Übergang zur Zollunion $\quad 92$

2 Die Landwirtschaftspolitik $\quad 98$

3 Die Koordinierung der Wirtschaftspolitik 104

4 Die Industriepolitik $\quad 112$ 
3 Die Währungspolitik

1 Die währungspolitische Ausgangssituation

2 Das „Collective Reserve Units“-Konzept Giscard d'Estaings

3 De Gaulle und die Rückkehr zum Goldstandard

4 Der Goldkrieg und die Verteidigung des Franc

4 Die ordnungspolitische Orientierung der französischen

Binnenmarktpolitik unter Charles de Gaulle

3 Frankreichs Binnenmarktpolitik unter Georges Pompidou 1969 - 1974

1 Die europapolitische Konzeption

1 Die wirtschaftlichen Rahmenbedingungen

2 Der Inhalt der europapolitischen Konzeption

3 Die Umsetzung der europapolitischen Konzeption 145

2 Die Wirtschafts- und Währungsunion

3 Die Wirtschaftspolitik

1 Die Industriepolitik

2 Die Sozialpolitik

3 Die Außenwirtschaftspolitik

4 Zusammenfassung

4 Die Währungspolitik

1 Europa als währungspolitische Einheit

2 Der Übergang zum Paritätengitter

3 Der Übergang zum Währungskorb und zum Floating

4 Zusammenfassung

5 Die ordnungspolitische Orientierung der französischen

Binnenmarktpolitik unter Georges Pompidou

\section{Frankreichs Binnenmarktpolitik unter Valéry Giscard d'Estaing}

$1974-1981$

1 Die europapolitische Konzeption

1 Die wirtschaftichen Rahmenbedingungen

204

2 Der Inhalt der europapolitischen Konzeption

3 Die Umsetzung der europapolitischen Konzeption 211

2 Die Wirtschaftspolitik

3 Die Währungspolitik

4 Die ordnungspolitische Orientierung der französischen

Binnenmarktpolitik unter Valéry Giscard d'Estaing 
5 Frankreichs Binnenmarktpolitik unter François Mitterrand

1981-1992

1 Die europapolitische Konzeption

1 Die wirtschaftlichen Rahmenbedingungen

2 Der Inhalt der europapolitischen Konzeption 241

3 Die Umsetzung der europapolitischen Konzeption 246

2 Die Wirtschaftspolitik

1 Die wirtschaftspolitische Konzeption 252

2 Die Industriepolitik

1 Erste Anläufe $\quad 259$

2 Eureka $\quad 267$

3 Die Außenwirtschaftspolitik 272

4 Die Sozialpolitik 278

5 Zusammenfassung 285

3 Die Währungspolitik

1 Die Stärkung des EWS 288

2 Die Wirtschafts- und Währungsunion 295

3 Zusammenfassung 306

4 Die ordnungspolitische Orientierung der französischen 309

Binnenmarktpolitik unter François Mitterrand

6 Ein interventionistischer Ordnungsentwurf für Europa 316

C Der französische Ordnungsentwurf und die Wirtschaftsordnung im Gemeinsamen Markt

1 Die ordnungspolitische Leitidee

2 Die Verträglichkeit von französischer Ordnungskonzeption und 332

Wettbewerbsordnung

3 Die Übertragbarkeit des französischen Ordnungsentwurfs auf den

Gemeinsamen Markt

Literaturverzeichnis 
Hans-Markus Johannsen - 978-3-631-75122-0

Downloaded from PubFactory at 01/11/2019 08:04:25AM

via free access 
BIZ

CRU

DGAEF

EA

ECU

EFWZ

EG

EGKS

ERE

EVG

EWA

EWG

EWV

EU

EUREKA

GATT

HDTV

IWF

MAE

MEF

PE

OECD

OEEC

SDI

SZR
Bank für Internationalen Zahlungsausgleich

Currency Reserve Unit

Direction Générale des Affaires Économiques et Financières

Europa-Archiv

European Currency Unit

Europäischer Fonds für Währungspolitische Zusammenarbeit

Europäische Gemeinschaften

Europäische Gemeinschaft für Kohle und Stahl

Europäische Rechnungseinheit

Europäische Verteidigungsgemeinschaft

Europäisches Währungsabkommen

Europäische Wirtschaftsgemeinschaft

Europäischer Wechselkursverbund

Europäische Union

European Research Coodination Agency

General Agreement on Tariffs and Trade

High Definition Television

Internationaler Währungsfonds

Ministère des Affaires Étrangères

Ministère de l'Économie et des Finances

La Politique Étrangère de la France - Textes et Documents (Bulletin des Außenministeriums)

Organization for Economic Cooperation and Development

Organization for European Economic Cooperation

Strategic Defense Initiative

Sonderziehungsrechte 
Hans-Markus Johannsen - 978-3-631-75122-0

Downloaded from PubFactory at 01/11/2019 08:04:25AM

via free access 


\section{Einleitung}

Seit ihrer Gründung ist die Europäische Gemeinschaft, jetzt Union, hin- und hergerissen zwischen einer marktwirtschaftlichen und einer interventionistischen Wirtschaftsordnung. Zwar wurde schon in den Römischen Verträgen festgelegt, daß die zu gründende Zollunion eine marktwirtschaftliche Wettbewerbsordnung erhalten sollte, gleichzeitig wurde diese aber mit zahlreichen Ausnahmebestimmungen durchsetzt. Die größte unter ihnen stellt die europäische Agrarpolitik dar. Sie repräsentiert ordnungspolitischen Interventionismus in Reinkultur, indem sie gleich einen gesamten Wirtschaftssektor vom Marktwettbewerb freistellt. Widersprüche dieser Art finden sich auch im revidierten EG-Vertrag von Maastricht, der eingangs die gemeinsame Wirtschaftspolitik auf die Prinzipien eines freien Wettbewerbs und offener Märkte festlegt, in Artikel 130 aber die Stärkung der Wettbewerbsfähigkeit europäischer Unternehmen zur Gemeinschaftsaufgabe erklärt.

Streitigkeiten über die ordnungspolitische Ausrichtung des Binnenmarktes haben den europäischen Einigungsprozeß von Beginn an begleitet. Mit der bevorstehenden Vollendung der Wirtschafts- und Währungsunion ist die Frage, wie die Ordnung der Wirtschaftsabläufe im europäischen Binnenmarkt erfolgen soll, aktueller denn je. Die gemeinsame Währung wird zu transparenteren Preisen und darüber zu mehr Wettbewerb zwischen den Unternehmen im Binnenmarkt führen. Um zu überleben, werden die Unternehmen mehr denn je auf die Wettbewerbsbedingungen vor Ort achten und so einen schärferen Wettbewerb der Standorte entfachen.

Seine Brisanz erhält dieser Standortwettbewerb aus der Tatsache, daß sich mit einer gemeinsamen Währung der verbleibende Handlungsspielraum der Regierungen zur Durchführung der notwendigen Strukturreformen deutlich verringert. So fallen nicht nur der Wechselkursmechanismus und die Geldpolitik als Anpassungsinstrumente weg, gleichzeitig steht den meisten Mitgliedstaaten durch die im Stabilitäts- und Wachstumspakt vereinbarte Begrenzung der Haushaltsdefizite auf drei Prozent des Bruttoinlandsprodukts auch die Fiskalpolitik nicht mehr zur Verfügung. Zur Schaffung wettbewerbsfähiger Wirtschaftsstrukturen bleiben den Regierungen nur Anpassungsmaßnahmen im Bereich der Wirtschafts-, Finanz- und Sozialpolitik. Angesichts der bisher heterogenen ordnungspolitischen Auffassungen über die „richtige“ Nutzung von Instrumenten aus diesen Bereichen, birgt die Währungsunion ein hohes Konfliktpotential. Frankreich und Deutschland waren in der Diskussion um die ordnungspolitische Ausrichtung des Binnenmarktes seit jeher Schrittmacher und Wortführer unterschiedlicher Lager zugleich. Die bevorstehenden Debatten um die weitere Ausgestaltung des Wirtschaftsstandorts Europa machen es daher aus deutscher Sicht mehr denn je erforderlich, sich mit den ordnungspolitischen Prioritäten der französischen Binnenmarktpolitik auseinanderzusetzen. 
Ziel der vorliegenden Untersuchung ist, den aus französischer Sicht optimalen Ordnungsentwurf für den europäischen Binnenmarkt zu ermitteln und diesen im Hinblick auf seine Ziele, seine Ursprungsmotive sowie seine Verträglichkeit mit einer marktwirtschaftlichen Wirtschaftsordnung zu untersuchen. Da die französische Europapolitik der gegenwärtigen Regierung ebenso wenig repräsentativ sein dürfte wie jene der letzten zwei oder fünf Regierungen, bleibt nichts anderes, als den Betrachtungszeitraum über den gesamten Prozeß der europäischen Einigung auszudehnen. Dabei soll die französische Binnenmarktpolitik auf ihre ordnungspolitische Konstanten hin untersucht werden, um diese anschließend zu einem einheitlichen, „idealtypischen“ Ordnungsgefuige zusammenzusetzen. Der auf diese Weise ermittelte Ordnungsentwurf bildet dann die Basis für die weitere Untersuchung hinsichtlich seiner Ursprungsmotive und seiner Verträglichkeit mit einer marktwirtschaftlichen Wirtschaftsordnung.

Die vorliegende Arbeit ist in drei Abschnitte gegliedert. Der Teil A. ist methodischen Überlegungen gewidmet. In ihm wird dargelegt, welche Herangehensweise dem Untersuchungsgegenstand ,ordnungspolitische Haltung Frankreichs im Prozeß der europäischen Einigung" am besten gerecht wird. Wirtschaftsordnungen sind letztlich Kulturprodukte, und so wird es im Verlauf der Untersuchung darum gehen müssen, neben den ökonomischen Ordnungsvorstellungen auch jene sozialphilosophisch begründeten Werte zu ermitteln, die dazu geführt haben, daß der französische Ordnungsentwurf für den Binnenmarkt „so und nicht anders“ aussieht. Als Verfahren dazu wird in dieser Arbeit auf die Wirtschaftsstilanalyse zurückgegriffen werden, für die im Falle Frankreichs bereits detaillierte Forschungsergebnisse vorliegen. Der Vergleich des französischen Ordnungsentwurfs für den Binnenmarkt mit einer marktwirtschaftlichen Ordnung setzt ferner die Benennung einer „klassisch-liberalen“ Wirtschaftsordnung als Richtmaß voraus. Als solches werden im Rahmen dieser Arbeit die „Prinzipien der Wettbewerbsordnung" Verwendung finden wie sie Walter Eucken formuliert hat.

Im Teil B. erfolgt die historisch-beschreibende Ermittlung der von Frankreich gewünschten Ordnungskonzeption für den Binnenmarkt, während in Teil C. die Auswertung der Ergebnisse vorgenommen wird. Festgehalten werden kann, daß Frankreich sich über den gesamten Prozeß der europäischen Einigung hinweg konsequent um eine „Politisierung“ der Wirtschaftsabläufe im Binnenmarkt bemüht hat. Nicht um die Koordination wirtschaftlicher Interessen und Abläufe im Wettbewerb ging es der französischen Binnenmarktpolitik, sondern um deren konsequente Ausrichtung auf politisch bestimmte, strategische Entwicklungsziele. In diesem Sinne drängte Frankreich über den gesamten europäischen Einigungsprozeß auf die Institutionalisierung einer makroökonomischen Gesamtsteuerung, bei der alle Bereiche der europäischen Wirtschafts- und Währungspolitik integriert und auf intergouvernementaler Ebene koordiniert werden sollten. Nachhaltig wehrte es sich gegen alle Versuche, die Gestaltungsmacht der nationalen Regierungen einzuschränken und bedeutende Entscheidungsrechte an Gemeinschaftsinstitutionen abzutreten. 
Der Ursprung des französischen Ordnungskonzepts für den Binnenmarkt, seine ordnungspolitische Leitidee, läßt sich über die Wirtschaftsstilanalyse auf bestimmte kulturgebundene Vorstellungen von Mensch, Welt und Gesellschaft zurückführen. Diese haben im Falle Frankreichs ihre Wurzeln in der Wertewelt und dem Vernunftglauben der französischen Aufklärung. Sie werden ergänzt durch eine Staatsauffassung, die grundsätzlich von einem starken, in seiner Autorität nie hinterfragtem Staat ausgeht, dem als oberste Pflicht obliegt, die Wirtschaftsabläufe durch Interventionen auf ein übergeordnetes Allgemeininteresse auszurichten. Frankreich, das sich seit der französischen Revolution an der Spitze des gesellschaftlichen Fortschritts sieht und eine historische Zivilisationsmission empfindet, ist seit Beginn der europäischen Einigung ungebrochen bemüht, seine wirtschaftlichen wie gesellschaftlichen Ordnungsvorstellungen auf Europa zu übertragen. Bezogen auf die Ausgestaltung der Wirtschaftsstrukturen im Binnenmarkt hat sich die französische Europapolitik ununterbrochen für einen interventionistischen Ordnungsentwurf eingesetzt.

Mit einer marktwirtschaftlichen Auffassung von der Ordnung der Wirtschaftsabläufe ist der französische Ordnungsentwurf für den europäischen Binnenmarkt nicht zu vereinbaren. Zu keiner Zeit hielten französische Staatspräsidenten und Minister mit ihrer Überzeugung hinter dem Berg, daß ein ungezügelter Wettbewerb zur uneingeschränkten Herrschaft des „Gesetz des Dschungels“ führen müsse. Statt an die Selbstheilungskräfte und die „unsichtbare Hand“ des Marktes, glaubten sie an die Existenz eines über den wirtschaftlichen Einzelinteressen stehenden Allgemeininteresses, dem über die staatliche Einflußnahme auf den Wirtschaftsablauf Geltung zu verschaffen war. Aus dieser grundlegenden Überzeugung heraus resultierten systematische Verstöße gegen alle Prinzipien der Wettbewerbsordnung wie sie Walter Eucken definiert hat. Die theoretische und praktische Unvereinbarkeit von französischem und „klassisch-liberalem“ Ordnungsentwurf ist letztlich auf ihre jeweils unterschiedlichen sozialphilosophischen Wurzeln zurückzuführen. Solange jedem Mitgliedstaat ein gewisses Maß an Selbstbestimmung belassen bleiben soll - auf das gerade Frankreich immer wieder bestanden hat - ist der französische Ordnungsentwurf in der Form, wie er in dieser Arbeit ermittelt wurde, nicht auf die Europäische Union übertragbar. 
Hans-Markus Johannsen - 978-3-631-75122-0

Downloaded from PubFactory at 01/11/2019 08:04:25AM

via free access 


\section{A Wirtschaftsordnung und Ordnungspolitik \\ A.1 Die ökonomische Bedeutung der Wirtschaftsordnung}

Wirtschaften als arbeitsteiliges soziales Geschehen bedarf der Koordination. Die Wirtschaftsordnung einer Volkswirtschaft legt die dafür relevanten Regeln fest. Sie umfaßt die Gesamtheit aller verhaltensbeeinflussenden Regeln, Normen und Institutionen zur Abgrenzung der Entscheidungs- und Handlungsspielräume der Wirtschaftssubjekte. ${ }^{1}$ Abstrakter gefaßt stellt die Wirtschaftsordnung ein System formaler und informeller Institutionen dar. Die formalen Institutionen liegen kodifiziert in den für wirtschaftliches Handeln relevanten Rechtsvorschriften eines Staates vor und umfassen Elemente wie die Eigentumsordnung, das Vertragsrecht oder die Geldverfassung. ${ }^{2}$ Die informellen Institutionen umfassen alle für den Gütertausch relevanten Sitten, Gebräuche, Traditionen, Konventionen sowie die moralischen Normen, welche sich im sozialen Miteinander täglich reproduzieren und sich mit der jeweiligen Gesellschaftskultur weiterentwickeln. Allen Bestandteilen der Wirtschaftsordnung gemeinsam ist die Funktion, das wirtschaftliche Handeln der Akteure zu erleichtern, indem es auf bestimmte Zielsetzungen hin koordiniert wird, die jedoch je nach Wirtschafts- und insbesondere Gesellschaftsordnung variieren.

Für das Wirtschaftssubjekt von unmittelbarer Bedeutung sind die ihm im Rahmen der Wirtschaftsordnung zugewiesenen Verfügungsrechte an tauschbaren Gütern. Die Verfügungsrechte umfassen das Recht zum Gebrauch eines Gutes, zu seiner Veränderung sowie zur Veräußerung eines Teils oder aller Rechte an ihm. ${ }^{3}$ Sie lassen sich als Verhaltensvorgaben auffassen, die dem Wirtschaftssubjekt mitteilen, in welchem Rahmen es ein Gut nutzen kann. Aus einzelwirtschaftlicher Sicht stellt sich die Wirtschaftsordnung somit in erster Linie als Verfügungsrechtsordnung dar. Diesen Aspekt hob schon Max Weber hervor, der die faktische Verteilung der Verfügungsrechte an Gütern sowie die Art ihrer Ausübung als konstitutiv für eine Wirtschaftsordnung bezeichnete. ${ }^{4}$ Zentrale Bestandteile der Verfügungsrechtsordnung sind die Eigentumsordnung sowie die im Vertragsrecht festgelegten Tauschregeln. Beide sind dem Tausch von Verfügungsrechten logisch vorgelagert und stellen somit die Voraussetzung für ökonomi-

\footnotetext{
' Vgl. Thieme, H.-J. (1990), Wirtschaftssysteme, S. 10, in: D. Bender et. al. (Hrsg.): Vahlens Kompendium der Wirtschaftstheorie und Wirtschaftspolitik, München, S. 1-51

${ }^{2}$ Vgl. Cassel, D. (1988), Wirtschaftspolitik als Ordnungspolitik, S. 316, in: ders. et. al. (Hrsg.), Ordnungspolitik, München, S. 313-333

${ }^{3}$ Der hier verwendete Begriff der Verfügungsrechte beinhaltet alle für die Disposition von Gütern relevanten Verhaltensvorgaben und ist damit bewußt weit gefaßt. Eine Übersicht über mögliche Definitionen findet sich bei Richter, R., Furubotn, E. (1996), Neue Institutionenökonomik, S. $87 \mathrm{ff}$., Tübingen

${ }^{4}$ Vgl. Weber, M. (1976), Wirtschaft und Gesellschaft, S. 181, Tübingen
} 
sches Handeln dar. Erst die Übertragung der Verfügungsgewalt über Güter macht eine planbare wirtschaftliche Nutzung möglich. ${ }^{5}$

Die verhaltenssteuernde Wirkung von Verfügungsrechten betrifft vor allem die Erwartungsbildung der Wirtschaftssubjekte sowie den Anreiz zu wirtschaftlichem Handeln. Wirtschaftliches Handeln findet im Normalfall unter Unsicherheit und bei begrenztem Wissen statt. Die Kenntnis des Inhalts von Verfügungsrechten an bestimmten Gütern hilft, die Unsicherheit über ihre Verwendungsmöglichkeiten zu reduzieren. Den gleichen Effekt haben klar definierte und in den Verfügungsrechten festgelegte Tauschregeln, die das Verhalten potentieller Tauschpartner kalkulierbar machen, vorausgesetzt, diese befolgen die bestehenden Tauschregeln und das Wirtschaftssubjekt vertraut in die Durchsetzbarkeit seiner Rechte. Den Anreiz zu wirtschaftlicher Tätigkeit bestimmen Verfügungsrechte hingegen, indem sie festlegen, in welchem Maße dem Wirtschaftssubjekt positive und negative Effekte seiner wirtschaftlichen Tätigkeit zufallen. Die Aussicht, den durch produktive Tätigkeit geschaffenen Mehrwert nach dem Tausch des Produkts zu bestimmten Teilen oder ganz in Anspruch nehmen zu können, motiviert zu wirtschaftlichem Handeln. Das Risiko, durch unüberlegten Umgang mit knappen Ressourcen die Verfügungsrechte daran zu verlieren, hält außerdem zur verantwortungsvollen Verwendung von Wirtschaftsgütern an. Die Ausgestaltung der Haftung im Rahmen der Verfügungsrechtsordnung ist daher von maßgeblichem Einfluß auf die einzel- wie gesamtwirtschaftliche Effizienz wirtschaftlichen Handelns.

Die konkrete Ausgestaltung der Verfügungsrechte innerhalb einer Wirtschaftsordnung konstituiert ein Gratifikations-Sanktions-Gefuge, das von zentraler Bedeutung für die individuelle wirtschaftliche Aktivität ist. ${ }^{6}$ Übertragen auf die gesamtwirtschaftliche Ebene bestimmt es den Umfang der Wirtschaftstätigkeit sowie den Ablauf von Allokations- und Verteilungsprozessen. Die Wirtschaftsordnung wird so zu einer wesentlichen Bestimmungsgröße für Ausmaß und Richtung des Wettbewerbs um knappe Ressourcen, für die Effizienz von Produktions- und Tauschabläufen und damit für die wirtschaftliche Wohlfahrt insgesamt.

Für ein optimales Wirken der Verfügungsrechte in diesem Sinne reicht allerdings die einfache Setzung eines entsprechenden Ordnungssystems nicht aus. Die Wirtschaftssubjekte müssen auf die Durchsetzbarkeit ihrer Rechte vertrauen können. Da wirtschaftliches Handeln immer zukunftsgerichtet ist, Abschluß und Erfüllung eines Tauschgeschäfts zeitlich aber in der Regel nicht zusammenfallen, muß das planende Wirtschaftssubjekt Annahmen über die Entwicklung tauschrelevanter Rahmenbedingungen und die tatsächlichen Intentionen seiner Tauschpartner treffen. Mangels vollständiger Information über beide Größen steht sein Handeln unter Unsicherheit, die

${ }^{5}$ Vgl. Eschenburg, R. (1978), Mikroökonomische Aspekte von Property Rights, S. 16, in: K.-E. Schenk (Hrsg.): Ökonomische Verfügungsrechte und Allokationsmechanismen in Wirtschaftssystemen, Tübingen, S. 9-28

${ }^{6} \mathrm{Vgl}$. Eschenburg (1978), a.a.O, S. 13 
sich im bilateralen Verhältnis der Tauschpartner konkret in der Gefahr opportunistischen Verhaltens äußert. Dieses droht grundsätzlich dann, wenn tauschrelevante Informationen asymmetrisch unter den vertragsschließenden Parteien verteilt sind und eine Seite damit die Möglichkeit zum Mißbrauch von Informationsvorsprüngen hat. Tauschregeln sowie güterspezifische Haftungsvorschriften können Unsicherheiten dieser Art reduzieren helfen, indem sie Rechte und Pflichten der Tauschpartner auch für die Zeit nach erfolgtem Gütertausch festlegen. Vertrauen in solche Regeln werden die Wirtschaftssubjekte jedoch erst dann haben, wenn ihre faktische Geltung und damit ihre Durchsetzbarkeit sichergestellt ist. Dazu bedarf es antizipierbarer Sanktionen bei Regelverstößen sowie einer glaubwürdigen, beidseitig anerkannten Autorität, einer „impartial third party“, was den Staat als ordnende Institution ins Spiel bringt. ${ }^{7}$ In Ausübung seiner rechtsetzenden Kompetenz und seiner hoheitlichen Durchsetzungsgewalt eröffnet sich dem Staat bei der Gestaltung der Verfügungsrechtsordnung ein weites Betätigungsfeld. Über die Gestaltung des formalen Teils der Wirtschaftsordnung erlangen seine Vertreter, d. h. die politischen Entscheidungsträger, direkten Einfluß auf das wirtschaftliche Verhalten der Akteure. Wie weit die staatlichen Eingriffe dabei gehen, hängt in erster Linie von den ordnungspolitischen Leitprinzipien ab, denen die jeweilige Regierung folgt.

Außer in der Durchsetzung von Verfügungsrechten ist der Staat auch bei der Anpassung bestehender Verfügungsrechtsstrukturen an die laufende Entwicklung von Produktion, Produkten und Märkten gefordert. Seine Hauptaufgabe besteht darin, die Zuordnung neu auftretender positiver wie negativer externer Effekte wirtschaftlichen Handelns unter den Beteiligten entsprechend den geltenden ordnungspolitischen Leitzielen sicherzustellen. Bei neu auftretenden positiven externen Effekten ist der Umgang mit „Trittbrettfahrern“ zu regeln, die von Leistungen profitieren, ohne zu ihrer Erbringung beigetragen zu haben. Geschieht dies nicht, so droht, der Leistungsanreiz für die wirtschaftlich Handelnden verloren zu gehen. Bei neu auftretenden „,negativen“ externen Effekten, die sich nicht auf die Tauschpartner eingrenzen lassen, ist zu entscheiden, wie und in welchem Maße sie ihren Verursachern zugerechnet werden können und sollen. Unbeteiligte Dritte sind vor Beeinträchtigung und Schaden zu schützen, um zu verhindern, daß sie von selbst und unvorhersehbar in Wirtschaftsabläufe eingreifen und diese so unkalkulierbar machen. Je nach Öffentlichkeitsgrad der Wirtschaftstätigkeit einzelner hat der Staat zu prüfen, ob und inwieweit ein schützenswertes Allgemeininteresse besteht, das regulierende Eingriffe in die Verteilung externer Effekte erfordert. Die Ausgestaltung und Anpassung von Verfügungsrechten stellt sich damit als die wirtschaftliche Variante der klassischen Staatsaufgabe dar, Einzelinteressen mit dem Allgemeininteresse zur Deckung zu bringen. Problematisch ist dabei jedoch, was konkret Gegenstand des Allgemeininteresses sein soll sowie die Frage, welche regulierenden Eingriffe zu seiner Wahrung notwendig sind. In einer dynamischen Umwelt ist ein Minimum an Interventionen zur Anpassung des bestehenden Ord-

\footnotetext{
${ }^{7}$ Vgl. North, D. C. (1986), The New Institutional Economics, S. 236, in: Journal of Institutional and
} Theoretical Economics, No. 142, S. 230-237 
nungsgefüges an sich wandelnde Rahmenbedingungen unabdingbar, um die bestehenden Leistungsanreize und das erreichte Niveau an verstetigter Erwartungsbildung zu erhalten.

So notwendig verhaltenssteuernde Eingriffe sind, aus Sicht des wirtschaftenden Individuums stellen sie immer eine Einschränkung seiner Handlungsspielräume dar. Sie lassen sich als „Ausdünnung“ seiner Verfügungsrechte an Gütern auffassen, die sich zwangsläufig unmittelbar auf deren Tauschwert niederschlägt. Für den Tauschwert eines Gutes ist nicht dessen physischer Besitz entscheidend, sondern der Umfang der jeweils an ihm bestehenden und übertragbaren Nutzungsrechte. ${ }^{8}$ Güter lassen sich in diesem Sinne als „Bündel“ von Verfügungsrechten auffassen, deren Quantität und Qualität den Tauschwert bestimmen. ${ }^{9}$ Je nach Grad der Ausdünnung bestehender Nutzungsrechte infolge von Interventionen in Verfügungsrechtsstrukturen ändert sich der Marktwert von Gütern. Dieser durchschlagende Effekt auf die Marktpreisbildung führt dazu, daß sich wirtschaftspolitisch motivierte Interventionen in ihren Auswirkungen nicht nur auf beabsichtigte Verhaltensänderungen begrenzen lassen. Bei interdependenten Preisen und Märkten beeinflussen sie gleichzeitig immer auch vor-, neben- oder nachgelagerte Allokationsprozesse. Sollen unerwünschte Nebeneffekte ausgeschlossen werden, so bedürfen Interventionen in bestehende Wirtschaftsordnungen zuvor einer umfassenden Evaluierung.

Dem einzelnen Wirtschaftssubjekt teilen sich die gegebenen Verfügungsrechte durch den Aufwand mit, den es bei ihrer Ausübung treiben muß. Die Wahrnehmung von Verfügungsrechten verursacht Transaktionskosten, die bei der Informationssuche, der Inspektion potentieller Tauschgüter, beim Vertragsschluß, seiner Durchführung sowie bei der Überwachung und Kontrolle von Verträgen anfallen. ${ }^{10}$ Die in den Verfügungsrechten spezifizierten Verhaltensvorgaben können dazu beitragen, die Transaktionskosten niedrig zu halten, indem sie das Verhalten der Tauschpartner berechenbar machen und so dazu beitragen, Durchsetzungs- und Überwachungskosten von Verträgen zu minimieren. Verfügungsrechte können aber auch die Transaktionskosten erhöhen, wenn die Ausübung von Handlungsrechten mit der Pflicht zur Leistung von Abgaben verbunden ist. Fälle dieser Art sind z. B. die Zahlung von Arbeitgeberanteilen für die Sozialversicherung des Arbeitnehmers, die bei der Nutzung seiner Arbeitsleistung zwingend vorgeschrieben sind, oder die Zahlung von Grundsteuern, die bei der Nutzung von Rechten an Grund und Boden entrichtet werden müssen.

Formellen wie informellen Verfügungsrechten ist gemein, daß sie sich nicht beliebig verändern lassen. Da letztlich alle ökonomischen Aktivitäten in interdependente insti-

${ }^{8}$ Coase, R. H. (1988), The Problem of Social Costs, S. 155, in: ders., The firm, the market and the law, Chicago, S. 95 ff.

${ }^{9} \mathrm{Vgl}$. North (1986), a.a.O., S. 232

${ }^{10}$ Vgl. Leipold, H. (1985), Ordnungspolitische Implikationen der Transaktionskostenökonomie, in: Ordo, Band 36, S. $31-50$ 
tutionelle Handlungsfelder eingebettet sind, beeinflußt jede Änderung bestehender Verfügungsrechte die Funktion anderer Institutionen. Kommt es dabei zu widersprüchlichen Verhaltensvorgaben, führt dieses auf Seiten der Wirtschaftssubjekte zu mehr Unsicherheit, deren Überwindung einen höheren Informationsbedarf voraussetzt und damit wieder höhere Transaktionskosten verursacht. Im schlechtesten Fall können Friktionen dieser Art die Transaktionsaufwendungen auf ein prohibitiv hohes Niveau heben, so daß eigentlich mögliche Tauschprozesse unterbleiben. Die Gefahr solcher institutioneller Spannungszustände ist von besonderer Relevanz bei der Integration von Wirtschaftsräumen mit unterschiedlichen Wirtschaftsordnungen. Dieser Fall ist mit dem europäischen Binnenmarkt gegeben, der den Versuch darstellt, derzeit 15 und demnächst 25 Volkswirtschaften in eine einheitliche Wirtschaftsordnung zu überführen.

Aus Sicht des einzelnen Wirtschaftssubjekts erweist sich eine Wirtschaftsordnung um so vorteilhafter, je niedriger die durch sie verursachten Transaktionskosten sind. Offene Volkswirtschaften stehen über den Ressourcenaufwand, den ihre Wirtschaftsordnung verursacht, in einem Standortwettbewerb, da Wirtschaftssubjekte ihre Niederlassungsentscheidung für den Standort mit den niedrigsten Transaktionskosten treffen. Fraglich ist somit, ob es eine ökonomisch ideale Wirtschaftsordnung gibt, welche Merkmale sie aufweisen sollte und wie sie zu realisieren wäre.

Eine Idealvorstellung, auf die in der ordnungspolitischen Diskussion immer wieder zurückgegriffen wird, ist die Marktform der vollständigen Konkurrenz. Bei „vollständiger" Konkurrenz aller Wirtschaftssubjekte, so die Annahme, würden selbstinteressierte, nutzenmaximierende Individuen ihre Präferenzen so auf Märkten offenbaren und den verfügbaren knappen Mitteln zuordnen, daß es zur maximalen Befriedigung ihrer Bedürfnisse kommen müsse. Voraussetzung für das Erreichen der gesellschaftlichen Maximalbefriedigung aller Bedürfnisse unter vollständiger Konkurrenz ist ein funktionsfähiger Preismechanismus. Dieser ermittelt auf vollkommenen Märkten die richtige gesellschaftliche Bewertung aller Güter und zeigt im totalen Preisgleichgewicht, dem die Güterpreise annahmegemäß von selbst zustreben, den Idealzustand von Produktion und gegebener Verteilung an. Im totalen Gleichgewicht kommt es zur Räumung der Gütermärkte, da hier die Preise aller Güter so bestimmt sind, daß alle produktiven Handlungen nutzenmaximal aufeinander abstimmt werden.

Die Funktionsfähigkeit eines solchen Preissystems ist an bestimmte institutionelle Voraussetzungen gebunden. ${ }^{11}$ Erforderlich ist der ungehinderte Zutritt zu allen Märkten, die vollständige Information der Marktteilnehmer über alle allokationsrelevanten Tatsachen, unendlich schnelle Anpassungsreaktionen der Wirtschaftssubjekte auf Preisveränderungen, der Handel homogener Güter, keine persönlichen, zeitlichen oder räumlichen Präferenzen sowie atomistischer Wettbewerb unter Anbietern und Nachfragern, bei dem das einzelne Wirtschaftssubjekt mit seinen Entscheidungen keinen

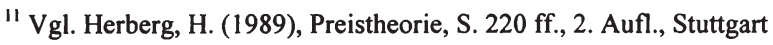


nachweisbaren Einfluß auf die Preisbildung ausübt. Bei Vorliegen dieser Bedingungen, so die Theorie, wird über den Marktpreismechanismus ein gesamtgesellschaftlicher Zurechnungszusammenhang erzeugt, der die Wirtschaftssubjekte dazu bewegt, von selbst die ideale Koordination ihrer Einzelpläne und damit die Allokation aller Produktionsfaktoren im Sinne eines gesamtgesellschaftlichen Maximalnutzens vorzunehmen. Wenn auch in der ökonomischen Theorie eingeräumt wird, daß tatsächlich existierende Märkte die Eigenschaften der vollständigen Konkurrenz bestenfalls nur näherungsweise aufweisen, ${ }^{12}$ so wird sie in der ordnungspolitischen Praxis dennoch als Idealmodell angesehen, auf das die tatsächlichen Wirtschaftsabläufe hin zu orientieren sind. Kernelemente einer solchen Politik sind die Präferenz für die freie Marktwirtschaft als Wirtschaftsform sowie ein möglichst weitgehendes Unterlassen staatlicher Eingriffe in das sich selbst regulierende Spiel der Marktkräfte.

Das Ordnungsideal der vollständigen Konkurrenz wirft jedoch Fragen auf wie zum Beispiel jene, worin konkret die abstrakte Zielgröße des sozialen Nutzens überhaupt besteht bzw. warum eine rein marktwirtschaftliche Ordnung notwendigerweise zu einem wertmaximalen Sozialprodukt führen muß. In der ökonomischen Theorie wird unterstellt, daß die auf Märkten stattfindende Preisbildung die materiellen Bedürfnisse konkurrierender Wirtschaftssubjekte interpersonell vergleichbar macht und zu einer den Gesamtnutzen wertmäßig maximierenden Entscheidung darüber führt, wessen $\mathrm{Be}$ dürfnisse bei der Zuteilung der verfügbaren knappen Ressourcen prioritär sind. Diese Deutung des Preiszusammenhanges erweist sich jedoch im Fall negativer externer Effekte, die sich nicht über bi- oder multilaterale Tauschgeschäfte unter den Betroffenen verrechnen lassen, als problematisch. Klassisch ist das Beispiel des Pkws, der für seinen Besitzer ein nützliches Transportmittel ist, für Nichtbesitzer jedoch negative Effekte in Form von Abgas- und Lärmemissionen zur Folge hat, ohne daß es möglich wäre, mit jedem Einzelbetroffenen eine Vereinbarung über den Ausgleich der erfahrenen Beeinträchtigungen zu treffen. Zur Beurteilung des sozialen Nutzens der PkwProduktion müßte die Bedeutung der Einzelbedürfnisse von Pkw-Besitzern und der sich beeinträchtigt fühlenden Nichtbesitzer für das Gesamtwohl ermittelt und bewertet werden. Eine solche Abwägung ist ohne Zuhilfenahme ethischer Maßstäbe jedoch nicht möglich. Da mindestens ein beteiligtes Individuum die Erfüllung seiner Bedürfnisse zurückstellen müssen wird, ist letztlich die Erreichung eines optimalen Sozialprodukts ausgeschlossen, bei dem alle Wirtschaftssubjekte eine Maximalbefriedigung ihrer Bedürfnisse erfahren.

Das Kernproblem bei der Feststellung des maximalen Gesamtnutzens liegt in dem für die ökonomische Theorie zentralen Bedürfnisbegriff und den sich daraus ergebenden Schwierigkeiten bei der Quantifizierung der Bedürfnisbefriedigung. Zur Feststellung seiner Bedürfnisbefriedigung müßte das wirtschaftende Individuum zunächst in der Lage sein, zu konkretisieren, worin diese genau besteht - ist es der erwartete Lustge-

${ }^{12}$ Vgl. Herberg (1989), a.a.O., S. 224 oder auch Schumann, J. (1992), Grundzüge der mikroökonomischen Theorie, Heidelberg, S. 37 
winn, die Zufriedenheit oder das Glücksgefühl beim Konsum eines Gutes oder einer Dienstleistung? Erst danach könnte das Wirtschaftssubjekt einen eindeutigen Wertmesser bestimmen, der eine vergleichende Bewertung der verschiedenen Bedürfnisse erlaubt. Bedürfnisse stellen ihrer Natur nach jedoch nur den Verweis auf einen Lebenswert dar, der über eine bestimmte Handlung verwirklicht werden soll, an sich aber keine quantitative Dimension hat. Die Bedeutung eines Wertes ergibt sich aus sich selbst heraus, aus seinem Eigenwert, der sich in der individuellen Wahrnehmung des jeweiligen Bedürfnisträgers konstituiert. Die Bedeutung eines Bedürfnisses ist eine Größe sui generis und als solche nicht mit anderen vergleichbar. Mangels eines objektiven Wertmessers ist die exakte Bestimmung der Bedürfnisbefriedigung und damit ein quantitativer Nutzenvergleich weder auf intrapersoneller noch auf interpersoneller Ebene möglich. ${ }^{13}$ Die Unmöglichkeit objektiver interpersoneller Nutzenvergleiche führt dazu, daß die Bedürfnisse mehrerer Wirtschaftssubjekte nicht in eine homogene Nutzensumme überführt werden können. Bei der gesamtwirtschaftlichen Bewertung externer Effekte, die sich nicht über Tauschbeziehungen auf Märkten verrechnen lassen, treten somit sozialphilosophische Probleme auf, die nur über den Rückgriff auf nicht ökonomisch begründete Wertkriterien entschieden werden können. ${ }^{14}$ In der wirtschaftlichen Praxis führt dies zur Notwendigkeit einer politischen Entscheidung, in der die soziale Wünschbarkeit der Produktion eines umstrittenen Gutes festzustellen ist. ${ }^{15}$

Angesichts dieser Probleme stellt sich die Frage, ob die Befriedigung individueller Bedürfnisse in der Praxis des wirtschaftlichen Handelns tatsächlich das zentrale Hauptantriebsmoment wirtschaftlichen Handelns darstellt wie in der ökonomischen Theorie angenommen. Praktisch ist der Mensch seinen Bedürfnissen nicht hilflos ausgesetzt, sondern in der Lage, zu den in seinem Bewußtsein erscheinenden Trieben Stellung zu nehmen und sie bewußt durch Willensakte zuzulassen oder zu hemmen. ${ }^{16}$ Eine vollständige Erklärung wirtschaftlichen Handelns muß dementsprechend auf das dem Akteur bewußte Handlungsmotiv zurückgeführt werden, das durchaus mehrere Antriebsmomente enthalten kann. ${ }^{17}$ Für die Handlungsmotivation des Individuums sind Bedürfnisse von hoher Bedeutung, nur eben nicht als die letzten gegebenen und unabhängigen Größen. Sie sind abhängige Größen, die schon in ihrer Entstehung, d. h. bei ihrer erstmaligen Wahrnehmung im Inneren des Individuums und bei seiner Entscheidung darüber, ob es sie für seine Handlung als maßgeblich zulassen will oder nicht, durch andere, meist gesellschaftliche Einflüsse mitgeprägt werden, und wenn es nur

${ }^{13} \mathrm{Vgl}$. Myrdal, G. (1964), Das politische Element in der nationalökonomischen Doktrinbildung, S. 37, Hannover

${ }^{14}$ Vgl. Münich, F. E. (1989), Gesellschaftliche Ziele und Organisationsprinzipien, S. 164, in: Erich Streissler; Christian Watrin (Hrsg.): Zur Theorie marktwirtschaftlicher Ordnungen, Tübingen, S. $163-196$

${ }^{15}$ Zur Gesamtproblematik bei der Sozialproduktbestimmung vgl. die Ausführungen bei Albert (1972), Ökonomische Ideologie und Politische Theorie, Göttingen, S. 135 ff. sowie Myrdal (1964), a.a.O., S. $128 \mathrm{ff}$.

${ }^{16}$ Vgl. Albert (1972), a.a.O., S. $56 \mathrm{f}$.

${ }^{17}$ Vgl. Myrdal (1964), a.a.O., S. 91 f. 
durch die Tatsache ist, daß auch Bedürfnisse in vorgefertigten Sprachformen gedacht werden müssen, die an sich schon nie frei von konnotierten Wertungen sind. Erst wenn das Individuum Wertqualitäten wahrgenommen hat, können sich Präferenzen bzw. für das wirtschaftliche Handeln bedeutsame Bedürfnisse bilden, die sich danach auf Märkten koordinieren lassen. ${ }^{18}$ Eine rein „ökonomische Erklärung“ wirtschaftlichen Handelns allein auf der Basis gegebener Bedürfnisse ist somit unvollständig. Bei näherem Hinsehen zeigt sich überdies, daß die Ökonomie selbst einen stark ethischphilosophisch geprägten Hintergrund hat, der eng mit den politischen Ideen und Idealen des Liberalismus, des Utilitarismus sowie der Naturrechtsphilosophie verknüpft ist. $^{19}$

In neueren Ansätzen der Institutionenökonomie hat sich die Erkenntnis durchgesetzt, daß die „reine“ Marktwirtschaft offensichtlich keinen hinreichenden Ansatz zur Beantwortung ordnungspolitischer Fragen darstellt. ${ }^{20}$ Schon früh brach der ,propertyrights"-Ansatz mit dem Glauben an das kostenlose Funktionieren der Märkte, indem er auf die Transaktionskosten verwies, die dem Wirtschaftssubjekt bei der Nutzung des Marktmechanismus entstehen. ${ }^{21}$ Die heuristische Reichweite der in diesem Ansatz dominierenden einzelwirtschaftlichen Perspektive wird jedoch im Fall negativer externer Effekte, die sich nicht exakt den Verursachern zurechnen lassen, überschritten. ${ }^{22}$ Gleiches gilt für die Kontrakttheorie bzw. für die ökonomische Theorie der Verfassung.

Die Institutionenökonomie stößt von ihrem Erklärungsvermögen in ordnungspolitischen Fragen vor allem dort auf Grenzen, wo sie sich vornehmlich auf die Ermittlung von Transaktionskosten konzentriert. Ein anschauliches Beispiel dafür stellt die Erfassung der Kosten von Kartellabreden dar. Aus einzelwirtschaftlicher Sicht haben sie den Vorteil, Transaktionskosten zu senken, indem sie die Wettbewerbsintensität reduzieren helfen. Aus gesamtwirtschaftlicher Sicht sind sie jedoch von genau entgegengesetzter Wirkung, weil sie den Wettbewerb unterbinden und damit die Intensität der Suche nach effizienteren Möglichkeiten der Leistungserbringung herabsetzen. ${ }^{23}$ Schwierigkeiten bereitet überdies die exakte Ermittlung der Transaktionskosten informeller Institutionen wie z. B. von moralischen Normen einer Gesellschaft oder von Tauschsitten und Geschäftsbräuchen. Die Tatsache, daß sie Unsicherheit im Verhältnis

${ }^{18}$ Vgl. Koslowski, P. (1991), Gesellschaftliche Koordination, S. 84, Tübingen

${ }^{19}$ Zum ethischen Anliegen des Utilitarismus und der Naturrechtsphilosophie und dessen Fortleben in der Wirtschaftswissenschaft vgl. die ausführlichen Darstellungen bei Ulrich, P. (1986), Transformation der ökonomischen Vernunft, S. 184 ff., Bern sowie Myrdal (1964), a.a.O., S. 19 ff.; zum Einfluß des Liberalismus auf die Ökonomie siehe Myrdal (1964), a.a.O., S. $101 \mathrm{ff}$.

${ }^{20}$ Vgl. Hartwig, K.-H. (1988), Ordnungstheorie und die Tradition des ökonomischen Denkens, S. 35, in: Dieter Cassel et. al. (Hrsg.): Ordnungspolitik, München, S. 31-51

${ }^{21} \mathrm{Vgl}$. Coase, R. H. (1988), The Nature of the Firm, S. 40, in: ders, The firm, the market and the law, Chicago, S. $33 \mathrm{ff}$.

${ }^{22} \mathrm{Vgl}$. Ribhegge, H. (1991), Der Beitrag der Neuen Institutionenökonomik zur Ordnungspolitik, S. 56, in: Jahrbuch für Neue Politische Ökonomie, $10 \mathrm{Jg}$., S. 38-60

${ }^{23}$ Zur Problematik der Anwendung des Transaktionskostenansatzes in ordnungspolitischen Fragen siehe Ribhegge (1991), a.a.O., S. 46 
von Tauschpartnern abbauen und so Transaktionskosten senken helfen, ist offensichtlich und unbestritten. Ihrer Natur nach sind diese sozialen und psychologischen Phänomene jedoch zu komplex, begrifflich zu unklar definiert und in ihrem Einfluß auf ökonomische Transaktionen zu unerforscht, als daß sich ihre Wirkung exakt in kaufmännischen Rechengrößen erfassen ließe. Die schwierige Erfaßbarkeit informeller Institutionen macht sie zur großen Unbekannten bei der wissenschaftlichen Betrachtung von Wirtschaftsordnungen. ${ }^{24}$ Die Transaktionskostenökonomie erweist sich letztlich als unzureichend, wenn es um die Ermittlung der gesamtwirtschaftlichen Transaktionskosten einer Wirtschaftsordnung oder einzelner Ordnungselemente geht. ${ }^{25}$ Für ein umfassendes Verständnis der in dieser Arbeit untersuchten ordnungspolitischen Haltung Frankreichs ist es daher unabdingbar, über die rein ökonomische Perspektive hinauszugehen und die Untersuchung um politische sowie sozialphilosophische Aspekte zu ergänzen.

\section{A.2 Die politische Bedeutung der Wirtschaftsordnung}

Die Ausgestaltung der formalen Elemente einer Wirtschaftsordnung obliegt politischen Institutionen und damit den jeweiligen Amtsinhabern. Die Möglichkeiten, politische Motive und Ziele in die Gestaltung der Wirtschaftsordnung einfließen zu lassen, ergeben sich aus der Verfassung eines Staates. Die Staatsordnung erhält so Bedeutung für das konkrete Aussehen einer Wirtschaftsordnung, worauf in der deutschen Ordnungstheorie schon früh hingewiesen wurde. ${ }^{26}$ Bezogen auf die für das individuelle wirtschaftliche Handeln bedeutsame Ausgestaltung der Verfügungsrechte folgt daraus, daß eine Theorie der Verfügungsrechte nie vollständig sein kann ohne eine Theorie des Staates. ${ }^{27}$ Maßgeblich für die Ausgestaltung der Verfügungsrechtsordnung sind im Einzelfall die Kompetenzverteilung zwischen sowie die Entscheidungsstrukturen in den politischen Gremien, die persönlichen Anschauungen der jeweiligen Entscheidungsträger sowie die gegebenen sozialen Interessen- und Machtkonstellationen. ${ }^{28}$

Da die politische Setzung von Ordnungsregeln und ihre faktische Geltung zweierlei Dinge sind, ist eine verfassungstheoretische Ideallösung für die Frage nach der optimalen Wirtschaftsordnung von vornherein ausgeschlossen. Die faktische Existenz einer Wirtschaftsordnung, die sich letztlich im Grad ihrer praktischen Befolgung durch die Wirtschaftssubjekte ausdrückt, ist nur bei Vorliegen eines normativen Grundkonsenses über ihr Geltensollen gegeben. Der Inhalt eines solchen Konsenses und insbe-

\footnotetext{
${ }^{24}$ Vgl. Elster, J. (1988), Economic Order and Social Norms, S. 364, in: Journal of Institutional and Theoretical Economics, No. 144, S. 357-365

${ }^{25}$ Vgl. Leipold (1985), a.a.O., S. 40

${ }^{26}$ Vgl. Eucken, W. (1952), Grundsätze der Wirtschaftspolitik, Tübingen, S. 332

${ }^{27}$ Vgl. Furubotn, E. G.; Pejovich, S. (1972), Property rights and economic theory: a survey of recent literature, S. 1140, Journal of Economic Literature, S. 1137-1162

${ }^{28}$ Vgl. Albert (1972), a.a.O., S. 149 f.
} 
sondere der Grund seines Geltensollens variieren je nach Gesellschaft. ${ }^{29}$ Grundsätzlich setzt die Einigung auf einen solchen Konsens die Existenz einer regulativen Idee rationaler Konsensfindung voraus, weil sich eine tragfähige Lösung für die Abstimmung von Einzel- und Allgemeininteressen in wirtschaftlichen Sachfragen nur in kommunikativen Prozessen ermitteln läßt. ${ }^{30} \mathrm{Da}$ eine Wirtschaftsordnung nur solange $\mathrm{zu}$ stabilen und voraussehbaren Verhaltensweisen führt, wie die Betroffenen sich mit der jeweiligen Ordnungsidee identifizieren, ist es von hoher Bedeutung, worauf sich diese im einzelnen bezieht: je nach dem ob z. B. Gott, eine bestimmte Moralvorstellung oder einfach nur die Verfassungslegalität als Geltungsgrund für bestimmte Verhaltensvorgaben betrachtet werden, ist die Motivation handelnder Menschen zu ihrer Einhaltung eine andere.

Der in politischen Entscheidungsprozessen ermittelte Konsens über das Geltensollen konkreter Ordnungskonzeptionen bestimmt sich inhaltlich von konkreten Leitbildern her. Als Ausdruck gedachter und gewollter Ordnungen richtet sich ein solches ,... auf ein vorgestelltes Seinsgefüge (und) erhebt dieses zur Richtschnur für das Urteil über geschichtliche und gegenwärtige Daseinsformen und zum Ziel politischer Aktivitäten. ${ }^{131}$ Real wirksam wird es über die Verknüpfung mit dem gedanklichen Entwurf institutioneller Ordnungen, die auf diese Weise eine ethische Begründung erfahren. ${ }^{32}$ Die Analyse konkreter Wirtschaftsordnungen muß daher neben den bislang dargelegten ökonomischen und politischen Aspekten auch deren ethische Wertorientierung umfassen, wenn sie dem Anspruch auf Vollständigkeit genügen will. Wirtschaftsordnungen stellen weder die Offenbarung eines Gemeinwillens noch das Resultat effizienzorientierter Nutzenkalkulationen auf der Basis unverrückbarer Einzelinteressen dar, sondern den revidierbaren Kompromiß eines Diskussionsprozesses von Individuen mit unterschiedlichen Ansichten, Interessen und Informationen, der an sich keinerlei höhere Wahrheit verkörpert. ${ }^{33}$

Der vorrangige Zweck von Wirtschaftsordnungen bleibt, die Abstimmung von Einzelund Allgemeininteresse bei der Regelung der Güterproduktion sowie des Gütertausches und, damit verbunden, der Verteilung so vorzunehmen, daß sie gesellschaftlich akzeptabel erscheint. Welche höhere Zwecksetzung dabei als Leitlinie dient und wie sich diese im sozialen Miteinander bzw. im Rahmen der politischen Willensbildung zu konkreten Ordnungsformen entwickelt, ist im Einzelfall zu untersuchen. Die praktischpolitischen Probleme insbesondere im Zusammenhang mit nicht oder nur schwer zurechenbaren Externalitäten zwingen die Ordnungspolitik, Bezug zu nehmen auf ein fikti-

\footnotetext{
${ }^{29}$ Vgl. Ulrich (1986), a.a.O., S. 253

${ }^{30}$ Vgl. Ulrich (1984), a.a.O., S. 254

${ }^{31}$ Kloten, N.: Utopie und Leitbild im wirtschaftlichen Denken, S. 334, in: Kyklos, Vol. XX, 1967, S. $331 \mathrm{ff}$

${ }^{32}$ ebenda

${ }^{33}$ Vgl. Albert (1972), a.a.O., S. 157
} 
ves soziales Allgemeininteresse, das von den jeweiligen politischen Entscheidungsträgern zu definieren und im politischen Prozeß als geltensollend durchzusetzen ist.

Mit Blick auf die französische Verfassungsrealität ist bei der Untersuchung der ordnungspolitischen Haltung Frankreichs die besondere Stellung des Staatspräsidenten zu berücksichtigen. Nach Artikel 52 der französischen Verfassung liegt die Außen- und damit die Europapolitik vornehmlich in der Kompetenz des französischen Staatsoberhaupts. Seit den Anfängen der Fünften Republik wird die Ausgestaltung der gesamten französischen Außenbeziehungen faktisch als „domaine reservé“ des Präsidenten betrachtet. Dies trifft auch für den Bereich der Wirtschafts- und insbesondere der Währungspolitik zu, wo der französische Staatschef bei der Formulierung seiner Politik keinerlei unabhängigen Institutionen gegenübersteht, die einen verfassungsmäßig gedeckten Anspruch auf Mitgestaltung geltend machen können. ${ }^{34}$ Die französischen Aussen- sowie Wirtschafts- und Finanzminister wie auch der Gouverneur der Banque de France fungieren in erster Linie als Repräsentanten und technische Ratgeber des Präsidenten. Die Analyse der französischen Europapolitik wird sich dementsprechend vornehmlich auf die Leitgedanken und ordnungspolitischen Überzeugungen des französischen Staatsoberhaupts konzentrieren müssen. Dies gilt um so mehr, als daß die politische Kultur Frankreichs und insbesondere das französische Parteiensystem von einem starken Hang zum Personalismus geprägt sind. ${ }^{35}$

Der enge Zusammenhang von Verfassungsordnung und Wirtschaftsordnung führt unmittelbar zur Frage, welche Verfassungsstruktur Frankreich für Europa wünschte. Diese würde letztlich maßgeblich darüber entscheiden, wie und in welchem $\mathrm{Ma} ß$ politische Interventionen in den Wirtschaftsablauf von europäischer Ebene aus möglich sind. Das Verständnis der französischen Ordnungsvorstellungen für den europäischen Binnenmarkt setzt somit eine Untersuchung der europapolitischen Konzeption der jeweiligen französischen Regierung voraus. Diese Untersuchung muß Antwort auf die Frage geben, welche Idee von Europa Frankreich konkret verfolgte, wie diese praktisch, das heißt vor allem institutionell, umgesetzt werden sollte und natürlich, welche Rolle Frankreich selbst in dem von ihm angestrebten Europa zu spielen gedachte. Aufbauend auf diesen Ergebnissen wird es möglich sein, die ordnungspolitische Ausrichtung der französischen Binnenmarktpolitik in einen übergreifenden Sinnzusammenhang zu stellen und so ein vollständiges Leitbild herauszuarbeiten, das die ordnungspolitische Haltung Frankreichs im Prozeß der europäischen Einigung zu erklären vermag.

\footnotetext{
${ }^{34}$ Vgl. Kaltenthaler, K. (1997), The sources of Policy-Dynamics: Variations in German and French Policy Towards European Monetary Co-operation, S. 103, in: West European Politics, Vol. 20, No. 3, S. 91-110

35 Vgl. Zadra, D. (1995), Der Wandel des französischen Parteiensystems am Beispiel der „présidentiables“ in der V. Republik, Dissertation an der Universität der Bundeswehr Hamburg, Hamburg, S. 143 ff.
} 
Neben den konstituionell angelegten Einfluß- und Gestaltungsmöglichkeiten darf die Bedeutung der nationalen Wirtschaftspolitik fur die ordnungspolitische Haltung Frankreichs auf europäischer Ebene nicht übersehen werden. Demokratisch gewählte Politiker sind auf die Zustimmung bestimmter Wählergruppen angewiesen. Nationale wirtschaftliche Probleme zwingen politische Entscheidungsträger, die institutionelle Ausgestaltung von Produktions- und Verteilungsprozessen den Wählerinteressen anzupassen, wobei eine Lösung der Probleme auch auf supranationaler Ebene erfolgen kann. Von besonderem Interesse wird daher die Frage sein, ob und wo die französische Politik auf europäischer Ebene Lösungen für Probleme gesucht hat, die im nationalen Rahmen nicht mehr zu bewältigen waren.

\section{A.3 Die Kulturbedeutung der Wirtschaftsordnung}

Die ordnungspolitische Setzung von Verhaltensregeln ist solange ohne praktische Relevanz, wie diese Vorgaben nicht gelten. Erst die praktische Einhaltung durch die Wirtschaftssubjekte verleiht diesen Regeln Bedeutung für den Ablauf von Wirtschaftsprozessen. Auf seiten der wirtschaftlich handelnden Individuen setzt dies zum einen die Zustimmung über ihr Geltensollen voraus und zum anderen das Vertrauen darin, daß die beschlossenen Verhaltensvorgaben auch von einer hinreichenden Anzahl von Wirtschaftssubjekten eingehalten werden. Es bedarf kommunikativer Konsensfindungsprozesse, um zur Einigung über das Geltensollen bestimmter Ordnungselemente zu gelangen, sowie gewisser Gewöhnungsprozesse in Form von positiven Erfahrungen, ehe eine Wirtschaftsordnung Glaubwürdigkeit in dem Maß erhält, daß ihre Verhaltensvorgaben als verbindlich anerkannt werden und $\mathrm{zu}$ empirisch feststellbaren stabilen, antizipierbaren Verhaltensweisen führen.

In dem Maße, wie das Geltensollen bestimmter Verhaltensregeln einen Einigungsprozeß unter den Wirtschaftssubjekten voraussetzt, ist die Ausgestaltung von Wirtschaftsordnungen „soziales“ Handeln im Sinne Max Webers. Weber geht davon aus, daß alles Handeln in seinen Konsequenzen eine Parteinahme zugunsten bestimmter Werte und damit gleichzeitig gegen andere ist. ${ }^{36}$ In seiner Entscheidung für eine bestimmte Handlungsalternative wägt das Individuum die Folgen ab, welche aufgrund des Allzusammenhangs allen Geschehens zu erwarten sind. Dabei konzentriert es sich auf die Feststellung der „Kosten“ einer Entscheidung, die im Zuge der voraussichtlichen Verletzung nicht realisierbarer Werte möglicherweise entstehen. $\mathrm{Da}$ in den meisten Fällen jeder erstrebte Zweck etwas „kostet“, kommt das wollende Individuum in seiner Abwägung nicht um eine Selbstbesinnung herum, bei der es sich nach seinem Gewissen und seiner persönlichen Weltanschauung für einen prioritären Wert entscheiden muß, dem der Vollzug einer Handlung schließlich dienen soll. ${ }^{37}$ Der Sinn

\footnotetext{
${ }^{36}$ Vgl. Weber, M. (1968a), Die „Objektivität“ sozialwissenschaftlicher und sozialpolitischer Erkenntnis, S. 5, in ders.: Methodologische Schriften, Frankfurt a.M., S. 1-64

${ }^{37}$ ebenda
} 
menschlichen Handelns, sein Ursprungsmotiv, wird damit auf die Realisierung höchster Lebenswerte festgelegt. Die Geltung dieser Werte selbst ist, Weber zufolge, Sache des persönlichen Glaubens an selbige und damit nicht objektivierbar oder auf der Basis einer wissenschaftlich-objektiven Betrachtung bestimmbar.

Die hiermit formulierte Handlungstheorie hat Weber selbst nur in Fragmenten vorlegen können. Sie harrt aller unmittelbaren Evidenz zum Trotz bis heute ihres Ausbaus zu einer vollständigen Konzeption. ${ }^{38}$ Motivationspsychologisch läßt sie sich dadurch stützen, daß unter Unsicherheit handelnde Individuen nach Bestätigung suchen. ${ }^{39}$ Das Individuum muß empfinden können, daß es durch seine Existenz und sein Handeln Sinn stiftet und gleichzeitig, daß seiner Existenz und seinem Tun seitens der Umwelt Sinn zugestanden wird. Sinnhafte menschliche Existenz ist Existenz, die von innen und von außen Bestätigung bedarf und erfährt. Nach innen gewendet ist sie die Entdeckung der eigenen Identität, nach außen gewendet bedeutet sie soziale Geltung bzw. Status. Indem das Individuum Handlungsmöglichkeiten mit konkreten Wertbezügen verbindet und diese seinem inneren Empfinden nach wie auch hinsichtlich ihrer äußeren Geltung zu einem bestimmten Grad bestätigt findet, kann es Stellung zu der Unsicherheit nehmen, die mit der Realisierung einer bestimmten Handlung verbunden ist, und infolge dessen zu Entscheidungen gelangen und diese umsetzen.

Durch die Beziehung von Handlungen auf Werte erhält menschliches Handeln Kulturbedeutung. Kultur definiert Weber als „ein vom Standpunkt des Menschen aus mit Sinn und Bedeutung bedachter endlicher Ausschnitt aus der sinnlosen Unendlichkeit des Weltgeschehens. ${ }^{“ 40}$ Transzendentale Voraussetzung für die wissenschaftliche Betrachtung dieser „kultivierten Ausschnitte“ menschlichen Miteinanders ist nach Weber die Tatsache, ,...daß wir Kulturmenschen sind, begabt mit der Fähigkeit und dem Willen, bewußt zur Welt Stellung zu nehmen und ihr einen Sinn zu verleihen." ${ }^{\text {41 }}$ Diese allgemeine Feststellung für individuelles Handeln hat Relevanz für das soziale Handeln, welches sich nach Weber dadurch auszeichnet, daß es seinem gemeinten Sinn nach auf das Verhalten anderer bezogen ist und sich in seinem Ablauf daran orientiert. ${ }^{42}$ Eine „soziale Beziehung“ kennzeichnet darüber hinaus ein seinem Sinngehalt nach gegenseitig aufeinander eingestelltes und dadurch orientiertes Verhalten mehrerer Individuen. ${ }^{43}$ Soziales Handeln und insbesondere soziale Beziehungen können an der Vorstellung einer legitimen Ordnung orientiert sein. ${ }^{44}$ Der Sinngehalt einer sozialen

\footnotetext{
${ }^{38}$ Vgl. Albert (1994), a.a.O., S. 123

${ }^{39}$ Vgl. Krüsselberg, H.-G. (1989), Ordnungstheorie - zur Konstituierung und Begründung der Rahmenbedingungen, S. 119, in Bernd Bievert; Martin Held (Hrsg.): Ethische Grundlagen der ökonomischen Theorie: Eigentum, Verträge, Institutionen, Frankfurt a.M., S. 100-132

${ }^{40}$ Weber (1968a), a.a.O., S. 33

${ }^{41}$ ebenda

${ }^{42} \mathrm{Vgl}$. Weber (1968b), Soziologische Grundbegriffe, S. 280, in ders.: Methodologische Schriften, Frankfurt a.M., S. 279-340

${ }^{43}$ ebenda, S. 304

44 ebenda, S. 310
} 
Beziehung stellt dann eine Ordnung dar, wenn das Handeln an angebbaren Maximen durchschnittlich und annähernd orientiert wird. Das Gelten einer solchen Ordnung hingegen liegt nur dann vor, wenn die tatsächliche Orientierung des Handelns an bestimmten Maximen in einer praktisch ins Gewicht fallenden Zahl von Fällen deshalb erfolgt, weil sie als geltensollend und damit für das Verhalten als verbindlich oder vorbildlich angesehen wird. ${ }^{45}$

Legitime Geltung kann einer Ordnung nach Weber aus mehreren Motiven heraus zugeschrieben werden. So kann sich ihr Geltensollen für die Handelnden aus Tradition heraus ergeben oder aus ,affektuellem“ (emotionalem) Glauben an die Geltung des neu Offenbarten oder Vorbildlichen. Geltung kann eine Ordnung aber auch aus wertrationalem Glauben beziehen, der von der absoluten Gültigkeit letzter verpflichtender Werte ausgeht, oder schließlich kraft positiver Satzung, bei der die Geltung aus dem Glauben an die Legalität der Verhaltensmaxime resultiert. Legitimität kann einer Ordnung aber auch durch die Erwartung rein äußerer Folgen zugeschrieben werden. Konvention nennt Weber dabei Ordnungen, deren Geltung auf die allgemeine und praktisch fühlbare Mißbilligung ihrer Mißachtung zurückgeht. „Recht“ hingegen nennt Weber eine Ordnung, deren Nichteinhaltung durch die Ausübung psychischen oder physischen Zwanges durch einen eigens darauf eingestellten „Stab“ sanktioniert wird.

Das Handeln nach einer geltenden Ordnung besteht in der Befolgung ihres durchschnittlich verstandenen Sinnes. ${ }^{46}$ Die Handelnden müssen ihr Verhalten dabei nicht aus gleichen Motiven an bestimmten Ordnungsmaximen ausrichten. Dennoch ist die Stabilität einer Ordnung, so Weber, durchaus von der Art der Motivation abhängig, aus der heraus die Individuen sich ihr unterwerfen. Einer nur aus zweckrationalen Motiven eingehaltenen Ordnung schreibt Weber eine höhere Labilität zu als einer kraft Sitte befolgten Verhaltensvorschrift, die ihrerseits wieder labiler ist als eine mit dem Prestige der Vorbildlichkeit oder Verbindlichkeit versehene Ordnung, an deren Legitimität geglaubt wird. ${ }^{47}$ Die faktische Geltung einer Ordnung, ihr praktisches „Funktionieren“ und damit letztlich ihre Glaubwürdigkeit sind daher wesentlich von den Motiven ihrer Legitimationsgrundlage abhängig.

Für die Koordination wirtschaftlichen Handelns, das typischerweise unter Unsicherheit hinsichtlich der tauschrelevanten Rahmenbedingungen und der wahren Intentionen der Tauschpartner sowie permanent im Spannungsfeld von Eigen- und Gemeinschaftsinteresse stattfindet, sind Ordnungen in erster Linie wegen ihrer verhaltensstabilisierenden Funktion von Bedeutung. Ordnungen entlasten das Wirtschaftssubjekt in seinem Bemühen, über wirtschaftliches Handeln Lebenswerte zu realisieren. Sie unterstützen das von Unsicherheit belastete individuelle Streben nach Selbstentfaltung und Selbstbestätigung, indem sie dem Individuum Räume öffnen, um sinnstiftende Handlungen

\footnotetext{
${ }^{45}$ ebenda

${ }^{46}$ ebenda, S. 311

${ }^{47}$ ebenda, S. 311
} 
zu realisieren. Gleichzeitig erfährt der Einzelne sein Handeln als richtig seiend bestätigt und allgemein akzeptiert, wenn er es ordnungskonform ausrichtet und sich damit der Sinngebung einer Ordnung unterwirft. Menschen erfahren somit Identität in Ordnungen und durch Ordnungen. ${ }^{48}$ Dieser Aspekt ist von herausragender Bedeutung, wenn die Fähigkeit von Menschen, ihr Leben auf Werte zu beziehen und diese in ihren Interessen auszuleben, als Inbegriff der Menschenwürde betrachtet wird. ${ }^{49}$ Soziale Ordnungen und damit auch Wirtschaftsordnungen sind daher maßgebliche Voraussetzungen für das Erfahren von Menschenwürde. ${ }^{50}$ Hinweise auf diesen sozialethischen Aspekt haben die wissenschaftliche Betrachtung von Wirtschaftsordnungen von Beginn an begleitet, wie die grundlegenden Arbeiten Walter Euckens zur Ordnungspolitik zeigen. $^{51}$

In dem Maße, wie die Entscheidung für eine bestimmte Ordnung eine „Parteinahme zugunsten bestimmter Werte“ bedeutet, repräsentiert sie eine „Ordnungsethik“. 52 Die Wertvorstellungen, auf denen eine solche Ordnungsethik beruht, lassen sich in der Regel auf ein bestimmtes Menschenbild und damit auf eine bestimmte Auffassung von Menschenwürde und Lebenssinn zurückführen. ${ }^{53}$ Die jeweiligen ethischen Sollensnormen für menschliches Handeln werden dabei aus bestimmten Vorstellungen über die Natur des Menschen, seiner Stellung zur Umwelt sowie über die letzten Zielsetzungen menschlicher Existenz überhaupt abgeleitet. ${ }^{54}$ Der Ursprung derartiger Ausgangsvorstellungen ist in Ideologien bzw. Religionen zu suchen, die die grundlegenden Kategorien menschlicher Wahrnehmung bereitstellen und mit den Erstbezügen der Wahrnehmung die Letztbegründung ethischer Sollvorstellungen liefern. ${ }^{55}$ In welchem Maße religiöse Vorstellungen prägend für wirtschaftliches Handeln sein können, hat Max Weber in seiner Studie über die „Protestantische Ethik und den Geist des Kapitalismus" dargelegt. ${ }^{56}$

Für wirtschaftliches Handeln und seine Koordination ist der Sinn- bzw. Wertebezug von Ordnungen in mehreren Hinsichten von grundlegender Bedeutung. Aus der Sicht des einzelnen Wirtschaftssubjekts stellt er die Basis für die Anerkennung oder Ablehnung einer bestimmten Verhaltensvorschrift dar. Für die Gesamtheit aller Wirtschaftssubjekte hingegen bildet er die Grundlage des notwendigen Konsenses über das Gel-

${ }^{48}$ Vgl. Krüsselberg (1989),a.a.O., S. 105

${ }^{49}$ Vgl. Weber (1968a), a.a.O., S. 7

${ }^{50}$ Vgl. Myrdal (1964), a.a.O., S. 193

${ }^{51}$ Vgl. Eucken (1968), a.a.O., S. 369

${ }^{52}$ Schmitz, W. (1992), Ordnungsethik - Versuch einer Klärung ihres Gegenstandes und der Dimension ihres Anliegens, S. 216, in: Zeitschrift für Wirtschaftspolitik, Jg. 41, Heft 3, S. 213-230

${ }^{53}$ Vgl. Clapham, R. (1989), Zur Rolle der Ordnungsethik für das Konzept der Sozialen Marktwirtschaft, S. 32, in: Jahrbuch für Neue Politische Ökonomie, Bd. 8, S. 29-41

${ }^{54}$ Vgl. Schmitz, W. (1988), Die ethische Fundierung der Ordnungspolitik, S. 238 f., in: Wirtschaftspolitische Blätter, Heft 2, S. 232-241

${ }^{55}$ Vgl. Denzau, A. T., North, D.-C. (1994), Shared Mental Models: Ideologies and Institutions, S. 15, in: Kyklos, Vol. 47, Fasc. 1,3, S. 3-31

${ }^{56} \mathrm{Vgl}$. Weber, M. (1975), Die Protestantische Ethik und der Geist des Kapitalismus, Hamburg 
tensollen einzelner Verhaltensvorgaben. Angesichts im Normalfall asymmetrisch verteilter Informationen und der daraus resultierenden Unsicherheit über die tatsächlichen Intentionen des jeweiligen Tauschpartners wird ein Wirtschaftssubjekt nur dann bereit sein, sich einer Verhaltensvorschrift und deren Restriktionen zu unterwerfen, wenn es auf seiten seiner Tauschpartner einen ähnlich hohen Grad an innerer Verpflichtung zu deren Einhaltung unterstellen kann. Nachvollziehbar und hinreichend begründet ist eine derartige Vermutung bei nicht oder nur flüchtig bekannten Geschäftspartnern nur bei der Unterstellung gleicher Werte, die, um Glaubwürdigkeit zu erlangen, der Bestätigung in gesellschaftlichen Konsensfindungsprozessen bedürfen. Erst danach beginnt sich Vertrauen in die Wirtschaftsordnung auszubreiten und damit die Bereitschaft, die vereinbarten Formen des Einverständnishandelns auch tatsächlich zu praktizieren. Nur über einen gemeinsamen Wertebezug kann eine Ordnungsvorschrift letztlich in der alltäglichen Wirtschaftspraxis dauerhaft zu Geltung gelangen.

Je nach Grad ihrer Anerkennung wirken sich die als geltensollend vereinbarten Sinnund Wertebezüge auf die praktischen Ergebnisse bzw. auf die Koordination wirtschaftlichen Handelns aus. Mit der Festlegung bestimmter Verfügungsrechte definiert die Wirtschaftsordnung eine begrenzte Anzahl sozialer Interaktionsrechte. Den Wirtschaftssubjekten wird damit ein begrenzter Handlungsspielraum zur Realisierung ihrer Lebenswerte vorgezeichnet. ${ }^{57}$ Über die Vorgabe bestimmter Möglichkeiten des Werterlebens in den jeweiligen Sinn- oder Wertebezügen der geltenden Handlungs- bzw. Verfügungsrechte nimmt die Wirtschaftsordnung somit von vornherein passiv Einfluß auf die Bildung von Tauschwerten bzw. Preisen und damit auch auf den Ablauf von Allokationsprozessen.

Über ihre Wertbezüge beeinflußt die Wirtschaftsordnung außerdem die Effizienz der Koordination wirtschaftlicher Handlungen. Die mit den Wertbezügen verbundenen konkreten ethischen Sollensnormen eröffnen dem einzelnen Wirtschaftssubjekt die Möglichkeit zur Vorkoordination seiner Präferenzen. ${ }^{58}$ Die einzelnen Wertbezüge erlauben es ihm, die Verallgemeinerungsfähigkeit einer Handlung im Vorfeld ihrer Realisierung zu prüfen und dabei die Internalisierung der externen Effekte gedanklich vorwegzunehmen. Je nach Qualität dieser Vorkoordination gestaltet sich der verbleibende Koordinationsaufwand, der nach Offenbarung der jeweiligen Präferenzen durch die Tauschpartner noch betrieben werden muß. Die jeweilige Qualität der einer Wirtschaftsordnung immanenten Ordnungsethik bestimmt somit maßgeblich die Friktionsfreiheit wirtschaftlicher Koordinationsmechanismen und damit deren „Effizienz“ hinsichtlich Funktionsfähigkeit und Ressourcenverbrauch.

Von zentraler Bedeutung für die erreichte „Effizienz“ ist das Maß, in dem die jeweiligen Sinn- und Wertebezüge einer Wirtschaftsordnung zur Ausbreitung von Vertrauen in die Einhaltung ihrer Verhaltensvorgaben beitragen. Erst wenn dieses Vertrauen von

\footnotetext{
${ }^{57}$ Vgl. Ulrich (1986), a.a.O., S. 174

${ }^{58}$ Vgl. Koslowski (1991), a.a.O., S. $101 \mathrm{ff}$.
} 
einer hinreichenden Anzahl von Wirtschaftssubjekten geteilt wird, kommt es zur Stabilisierung bestimmter Verhaltensweisen und in deren Folge zur Verstetigung der Erwartungsbildung, die beide elementare Voraussetzungen für die Entfaltung wirtschaftlichen Handelns darstellen. In Tauschprozessen trägt derartiges Vertrauen dazu bei, die Such- und Inspektionskosten bei der Vorbereitung von Transaktionen sowie den Überwachungs- und Sanktionsaufwand im Zuge ihrer Kontrolle gering zu halten. Das in einer Gesellschaft vorhandene Vertrauen in die faktische Geltung von Verfügungsrechten bestimmt maßgeblich den Ressourcenaufwand, der mit ihrer Nutzung verbunden ist. In diesem Sinne kann es als ,,soziales Kapital“ aufgefaßt werden. ${ }^{59}$ Der einer Gesellschaft innewohnende kulturbestimmte Grad an Vertrauen wird so zu einer Bestimmungsgröße für die wirtschaftliche Wettbewerbsfähigkeit einer Volkswirtschaft und damit für den Wohlstand einer Nation. ${ }^{60}$

Allerdings verursacht die Erhaltung dieses „sozialen Kapitals“ auch Kosten, die sich insbesondere im Ressourcenaufwand für die Aufrechterhaltung des gesellschaftlichen Wertekonsenses sowie fur die politischen Prozesse zur Gestaltung bzw. Weiterentwicklung der Wirtschaftsordnung niederschlagen. ${ }^{61}$ Die Funktionsfähigkeit gesellschaftlicher Verständigungsprozesse über Sinnzusammenhänge bestimmt maßgeblich die Ausbreitungsgeschwindigkeit von Vertrauen. ${ }^{62}$ Sie kann allerdings auch empfindlich herabgesetzt werden durch vertrauenserschütternde Kollektiverfahrungen wie Krieg, religiöse Streitereien oder Inflationserlebnisse. Schwierig gestalten sich Kommunikationsprozesse über Sinnzusammenhänge in Wirtschaftsräumen mit heterogener Kultur wie z. B. in der Europäischen Union. Neben sprachlichen Problemen behindern hier unterschiedliche religiöse Wertauffassungen die Konsensfindung über eine einheitlich geltensollende Wirtschaftsordnung. Mit der schrittweisen Erweiterung der Europäischen Union sind neben Katholizismus und Protestantismus in verschiedenen Schattierungen mittlerweile auch orthodoxe und islamische Glaubensrichtungen von Bedeutung für die religiöse Orientierung der EU-Bürger. Die unterschiedlichen Auffassungen dieser religiösen Weltanschauungssysteme hinsichtlich der Rolle des Eigentums und seiner Verteilung, der Rolle des Staates in der Wirtschaft sowie seiner sozialen Verantwortung dürften auch in Zukunft die noch immer ausstehende Einigung über die ordnungspolitische Ausrichtung des Binnenmarktes schwierig gestalten.

Das Übersehen der Kulturbedeutung einer Wirtschaftsordnung im Verlauf ordnungspolitischer Gestaltungsprozesse kann zu einer eminenten Beeinträchtigung des Wirtschaftsablaufs führen. Die Funktionsfähigkeit von Wirtschaftsordnungen beruht zu weiten Teilen auf der Konsistenz ihrer Ordnungsethik. Die Ordnungspolitik ist ge-

\footnotetext{
${ }^{59} \mathrm{Vgl}$. Coleman, J.S. (1990), Foundations of Social Theory, S. 300 ff., Cambridge, MA sowie Tietzel, M. (1988), Ethische und theoretische Probleme interventionistischer Wirtschaftspolitik, S. 100, in: Dieter Cassel et. al. (Hrsg.): Ordnungspolitik, München, S. $77 \mathrm{ff}$.

${ }^{60} \mathrm{Vgl}$. Fukuyama, F. (1995), Konfuzius und die Marktwirtschaft, S. 21 f., München

${ }^{61} \mathrm{Vgl}$. Eschenburg (1978), a.a.O., S. 25

${ }^{62}$ Vgl. Ulrich (1986), a.a.O., S. 59
} 
halten, bei jeder Weiterentwicklung und Anpassung der Wirtschaftsordnung die Widerspruchsfreiheit mit gegebenen Sinnzusammenhängen zu überprüfen. ${ }^{63}$ In der wirtschaftlichen Praxis ist dies von hoher Relevanz, da der technologische Fortschritt und die zunehmende internationale Arbeitsteilung einen permanenten Druck zur Anpassung und Vereinheitlichung von Wirtschaftsordnungen erzeugen. ${ }^{64}$ So ist mittlerweile eine globale „Nachfrage“ nach Ordnungssystemen entstanden, die dazu geführt hat, daß die gegebenen, unterschiedlich durchdachten Sozialsysteme sich im Wettbewerb miteinander befinden. ${ }^{65}$ Durchsetzen werden sich dabei die Systeme, die die niedrigsten „Kosten“ verursachen. Dabei ist nicht nur an deren pekuniäre Dimension zu denken, sondern vor allem an das Vorhandensein funktionsfähiger wirtschaftlicher Interaktionsbeziehungen mit minimalen ethisch-ideellen Reibungsverlusten. ${ }^{66}$ Allen Bemühungen um die Weiterentwicklung bestehender Wirtschaftsordnungen gemeinsam ist, $\mathrm{da} ß$ sie auf Widerstände treffen werden, da bestehende Institutionen gleich welcher Art immer soziale Habitualisierungen darstellen, deren Veränderung das Brechen mit gewohnten Verhaltensweisen erfordert. ${ }^{67}$ Jede von ihnen bezieht ihre Eigenart aus niemals zureichend begründeten ethischen Auffassungen über das soziale Leben, von denen keine absolute Geltung beanspruchen kann. ${ }^{68}$ Bezogen auf die Europäische Union heißt dies, daß, mangels einheitlicher ethische Legitimationsgrundlagen, auf absehbare Zeit nichts anderes bleiben wird, als im permanenten Diskurs um eine international wettbewerbsfähige Wirtschaftsordnung für den Binnenmarkt zu ringen.

\section{A.4 Implikationen für den Gang der Untersuchung}

Die vorstehenden Überlegungen haben gezeigt, daß sich die bewußte Ausgestaltung von Wirtschaftsordnungen im Dreieck sachlicher Funktionsvoraussetzungen, politischer Machtverhältnisse und staatlicher Verfassungsstrukturen sowie der im jeweiligen Wirtschaftsraum herrschenden ethischen Wertvorstellungen bewegt. Sollen bestimmte Ordnungsvorstellungen mit einer Chance auf Erfolg in den politischen Entscheidungsprozeß eingeführt werden, so müssen sie einerseits den sachlichen Voraussetzungen für die Koordination wirtschaftlichen Handelns genügen und andererseits mit Wertbezügen verbunden sein, die mehrheitlich konsensfähig und darüber hinaus im politischen Prozeß durchsetzbar sind. Allen Einzelmaßnahmen zur Ordnung wirtschaftlicher Abläufe ist gemeinsam, daß sie einer bestimmten Vorstellung von der idealen Abstimmung von Einzel- und Gesamtinteresse folgen.

\footnotetext{
${ }^{63}$ Vgl. Schmitz (1992), a.a.O., S. 227

${ }^{64}$ Vgl. Gäfgen, G. (1988), Der Wandel moralischer Normen in der Entwicklung der Wirtschaftsordnung: Positive Erklärung und ethische Folgerungen, S. 106, in Helmut Hesse (Hrsg.): Wirtschaftswissenschaft und Ethik, Schriften des Vereins für Sozialpolitik, Band 171, Berlin, S. 85-107

${ }^{65}$ Vgl. Herder-Dorneich, P. (1989), Ordnungstheorie - Ordnungspolitik - Ordnungsethik, S. 9, in: Jahrbuch für Neue Politische Ökonomie, Band 8, Tübingen, S. 3-12

${ }^{66}$ Vgl. Schmitz (1992), a.a.O., S. 228

${ }^{67} \mathrm{Vgl}$. Albert (1972), a.a.O., S. 120

${ }^{68}$ ebenda, S. $120 \mathrm{f}$.
} 
Die Untersuchung der ordnungspolitischen Haltung Frankreichs im Prozeß der europäischen Einigung wird sich dementsprechend zunächst darauf konzentrieren, die von Frankreich für den europäischen Binnenmarkt gewünschte Ordnungskonzeption in ihren einzelnen Bestandteilen herauszuarbeiten. Im Rahmen einer historisch beschreibenden Analyse des europäischen Einigungsprozesses, die sich von dessen Beginn bis in die neunziger Jahre hinein erstreckt, sollen jene Institutionen festgestellt werden, die aus französischer Sicht für die Koordination der Allokations- und Verteilungsprozesse im Binnenmarkt unerläßlich waren. In einem zweiten Schritt wird die französische Ordnungskonzeption auf das ihr immanente Bild von der idealen Ordnung wirtschaftlicher Abläufe zu untersuchen sein. Ein dritter Schritt wird darin bestehen, dieses französische Ordnungsideal auf seine Verträglichkeit mit einer liberalen Wettbewerbsordnung, die seit Beginn des europäischen Einigungsprozesses als ordnungspolitisches Leitbild für den Binnenmarkt vertraglich vereinbart ist, zu überprüfen. ${ }^{69}$ Die praktischen Konsequenzen des Nebeneinanders unterschiedlicher ordnungspolitischer Präferenzen in der Europäischen Gemeinschaft, auf die das Ergebnis dieser Untersuchung hinausläuft, werden Gegenstand einer abschließenden Betrachtung sein.

Der Überlagerung ökonomischer, politischer und sozio-kultureller Motive in ordnungspolitischen Leitvorstellungen soll dadurch entsprochen werden, daß der $\mathrm{Be}-$ trachtung der einzelnen wirtschafts- und währungspolitischen Maßnahmen die europapolitische Konzeption der jeweiligen französischen Regierung vorangestellt wird. Um dabei den Einfluß nationaler Interessen zu verdeutlichen, sollen zunächst die grundlegenden nationalen wirtschaftlichen Probleme sowie die Ansätze zu deren Lösung dargestellt werden. In einem zweiten und dritten Schritt soll dann auf die Ziele der französischen Europapolitik sowie auf die angestrebten institutionellen Vorkehrungen zu deren Umsetzung eingegangen werden. In diesem Zusammenhang wird auch von Interesse sein, in welcher Rolle die französische Europapolitik sich selbst sah bzw. welchen Beitrag sie zum Fortgang der europäischen Integration zu leisten gedachte. Vor diesem Hintergrund werden dann die einzelnen wirtschafts- und währungspolitischen Initiativen Frankreichs mit Relevanz für die Wirtschaftsordnung im europäischen Binnenmarkt betrachtet. Aus Gründen der Übersichtlichkeit wird dabei die Analyse realwirtschaftlicher und monetärer Ordnungsvorstellungen getrennt erfolgen.

Eine gesonderte Herangehensweise erfordern die Wert- und Sinnbezüge der französischen Ordnungsvorstellungen. Sie liegen in der Regel nicht offen vor und werden im Rahmen der praktischen Politik selten direkt angesprochen. Ihre Ermittlung soll mittels eines deutend-verstehenden Erkenntnisverfahrens aus dem Bereich der Hermeneutik vorgenommen werden. ${ }^{70}$ Deutung eines Handelns heißt nach Max Webers Theorie des Verstehens, den Sinn einer Handlung aus der gegebenen Situation heraus zu erschlies-

${ }^{69} \mathrm{Vgl}$. von der Groeben, H. (1961), Wettbewerb im Gemeinsamen Markt, S. 644, EA, Folge 22, S. 643-650 sowie Petersmann, E.-U. (1993), Grundprobleme der Wirtschaftsverfassung der EG, S. 408, in: Aussenwirtschaft, 48, Jg., Heft IV, S. 389 ff.

${ }^{70}$ Vgl. Koslowski (1991), a.a.O., S. 82 f.f 
sen. $^{71}$ Weber geht dabei von der rationalen Motiviertheit einer Handlung aus, wobei die Deutung die Ermittlung des maßgeblichen Handlungsmotivs zum Ziel hat. Verstanden hingegen ist die Handlung vom Betrachter dann, wenn ihm die kausale Rückführung des Handelns auf ein bestimmtes Motiv aus dem Handlungszusammenhang heraus als adäquat erscheint und für ihn nacherlebbar ist. Die Veranschaulichung der jeweiligen Handlungsmotive erfolgt bei Weber im Rahmen einer idealtypischen Begriffsbildung. Bei dieser gelangt der Betrachter durch Steigerung eines oder einiger Gesichtspunkte und durch Zusammenschluß einer Fülle von diffus und diskret vorhandener Einzelerscheinungen, die sich einem herausgehobenen Gesichtspunkt fügen, zu einem einheitlichen Gedankengebilde. ${ }^{72}$ Voraussetzung für die Gültigkeit einer solchen Konstruktion ist, daß sie als zulänglich motiviert und objektiv möglich sowie nach vorhandenem nomologischen Wissen adäquat erscheint.

Weber weist explizit darauf hin, daß derartige Gedankengebilde in ihrer idealtypischen Reinheit nirgendwo in der Wirklichkeit empirisch vorfindbar sind. Er bezeichnet sie als Utopie, die an die Wissenschaft die Aufgabe stellt, in jedem Einzelfall herauszufinden, wie nahe oder fern die Wirklichkeit dem Idealbild ist. ${ }^{73} \mathrm{Ob}$ ein politischer Entscheidungsträger wirklich bewußt aus einem idealtypischen Motiv gehandelt hat oder nicht, kann nur im Rahmen von Befragungen ermittelt werden, und selbst dann wird die Richtigkeit der Antwort nie objektiv nachprüfbar sein. Idealtypisch geformte Begriffe haben keinesfalls die Erklärungskraft naturwissenschaftlicher Gesetze, sondern stellen einen Versuch dar, die Motivation des Handelnden deutend nachzuvollziehen, wobei deutend in diesem Sinne noch nicht einmal im strengen Sinne als „hermeneutisch“ zu bezeichnen ist. ${ }^{74}$ Ein Idealtypus hat bis zu seiner Verifizierung immer Hypothesencharakter. Er dient in erster Linie der denkenden Ordnung sozialer Wirklichkeit und ist ab einer gewissen Komplexität sozialer Handlungszusammenhänge allein aus der Notwendigkeit, klare Begriffe für ihre Erfassung haben zu müssen, unverzichtbar. Ausdrücklich warnt Weber vor der Gefahr, idealtypisch gebildete Ideen als reale Kräfte zu hypostasieren und zum eigentlichen Wesen der Realität zu machen. $^{75}$

Auf diesen grundlegenden Ideen der Weberschen Soziologie beruhend ist für den Bereich des wirtschaftlichen Handelns mit der Wirtschaftsstilanalyse ein Verfahren entwickelt worden, das zur Ermittlung der handlungsleitenden Wertideen herangezogen werden kann. ${ }^{76}$ Einer der maßgeblichen Begründer der Wirtschaftsstilanalyse war Alfred Müller-Armack, der den Stilbegriff der kunsthistorischen Betrachtung entlehnte,

${ }^{71}$ Vgl. Weber, M. (1968c), Idealtypus, Handlungsstruktur und Verhaltensinterpretation, S. 92, in ders.: Methodologische Schriften, Frankfurt am Main, S. 65-167

${ }^{72}$ Vgl. Weber (1968a), a.a.O., S. 43

${ }^{73}$ ebenda

${ }^{74}$ Vgl. Albert, H. (1988), Hermeneutics and Economics, S. 593 ff., in: Kyklos, Vol. 41, Fasc. 4, S. 573-602

${ }^{75}$ Vgl. Weber (1968a), a.a.O., S. 47

${ }^{76}$ Vgl. Weippert, G. (1967), Wirtschaftsstillehre als Kulturtheorie, S. 82 f, Göttingen, 
wo er die ,in den verschiedenen Lebensgebieten einer Zeit sichtbare Einheit des Ausdrucks und der Haltung" bezeichnet. Ein Wirtschaftsstil liegt dementsprechend dort vor, „wo die Erscheinungsformen im Bereich des Sozialen und Wirtschaftlichen den Ausdruck einheitlichen Gepräges aufweisen ${ }^{\text {“. }}{ }^{77}$ Müller-Armack betrachtet die Entstehung von Wirtschaftssystemen als Resultat der bewußten Gestaltung von Menschen, die nur aus den Bedingungen und Taten einer bestimmten Zeit heraus verständlich ist. Er geht davon aus, daß sich nur aus der Erforschung der in den einzelnen Epochen lebendigen und leitenden Werte begreifen läßt, was die Menschen erstrebten und warum dieser oder jener Stil entstehen mußte. ${ }^{78}$ Der Blick ist somit auf das Gemeinsame des Kulturausdrucks von Epochen gerichtet, wobei Müller-Armack vor allem auf die Bedeutsamkeit der großen weltanschaulichen Systeme verweist und wirtschaftliche Kulturerscheinungen in erster Linie auf die Säkularisierung religiöser Haltungen zurückführt. ${ }^{79}$

In Fortführung dieses kultursoziologischen Ansatzes hat Günter Ammon eine Arbeit über den französischen Wirtschaftsstil vorgelegt. In seiner Methodik stützt er sich auf einen weiter ausgearbeiteten Symbolbegriff, dessen identitäts- und kollektivitätsstiftende Funktion im Rahmen analytischer Durchdringung symbolischer Ausdrucksformen den Schluß auf kulturvermittelte Wertvorstellungen erlaubt. ${ }^{80}$ Wie schon MüllerArmack sieht Ammon die wirtschaftliches Handeln leitende Sinngebung als gesellschaftsgebunden an. Er spricht deshalb vom Gesellschafts- und Wirtschaftsstil, den er als Gefüge von Symbolen interpretiert, das als Ganzes auf das gesellschaftspezifische Sinnverständnis verweist. Die jeweiligen Sinngehalte bringt Ammon über „kulturelle Schlüsselwörter“ zum Ausdruck, die als rememorative, demonstrative und prognostische Begriffe den Zugang zu den kollektiv-unbewußten Motiven einer Gesellschaft, zur „mémoire collective“, öffnen. Ammon hat seine Untersuchungen auf die französische Wirtschaft und ihre Ausdrucksformen bezogen. Es wird zu prüfen sein, ob und inwieweit sich Parallelen zu den von Frankreich auf europäischer Ebene gewünschten Formen wirtschaftlichen Handelns ziehen lassen, deren Sinngehalt sich dann aus dem französischen Wirtschaftsstil herleiten und erklären ließe.

Zum Zweck der Gegenüberstellung von französischem und marktwirtschaftlichem Ordnungsentwurf ist die Benennung einer liberalen Ordnungskonzeption als Referenzmodell erforderlich. Eine derartige Ordnungskonzeption hat Walter Eucken mit seinem Entwurf der Wettbewerbsordnung vorgelegt, die er durch bestimmte Prinzipien charakterisierte. ${ }^{81}$ Eucken entwickelt diese Prinzipien aufgrund eines eigens von ihm ausgearbeiteten wirtschaftswissenschaftlichen Erkennntnisprogramms. ${ }^{82}$ Er geht davon

\footnotetext{
${ }^{77}$ Vgl. Müller-Armack, A. (1944), Die Genealogie der Wirtschaftsstile, S. 21, Stuttgart

${ }^{78}$ ders., S. 25

${ }^{79}$ ders. S. 5

${ }^{80}$ Vgl. Ammon, G. (1989), Der französische Wirtschaftsstil, S. 23 f., München

${ }^{81} \mathrm{Vgl}$. Eucken (1968), a.a.O., S. $254 \mathrm{ff}$.

${ }^{82}$ Vgl. Eucken, W. (1965), Die Grundlagen der Nationalökonomie, S. 162 ff., Berlin
} 
aus, daß sich das Handeln der Wirtschaftssubjekte in seinem Verlauf in idealtypischen elementaren Ordnungsformen beschreiben läßt, denen er Gesetzmäßigkeit zuschreibt. Diese Ordnungsformen treten je nach historisch gegebener Konstellation der Umweltdaten in bestimmter Zusammensetzung auf und geben so der Wirtschaftsordnung ihren eigenständigen Charakter. Mit seinen Prinzipien der Wettbewerbsordnung entwirft Eucken eine Wirtschaftsordnung, in der sich bestimmte Ordnungselemente in idealer Weise zusammengesetzt finden. Hauptanliegen ist dabei die Realisierung der „vollständigen Konkurrenz", die sich in erster Linie durch einen funktionsfähigen Preismechanismus auszeichnet, dazu allerdings der Stützung durch bestimmte institutionelle Vorkehrungen - den von Eucken benannten Prinzipien - bedarf, um die ideale Koordination wirtschaftlichen Handelns zu ermöglichen. Euckens Vorstellung von der „vollständigen Konkurrenz" ist nicht identisch mit jener der Gleichgewichtsökonomie, weil er dort das Problem der ökonomischen Macht in ihrer Auswirkung auf den Ablauf wirtschaftlicher Prozesse zu wenig berücksichtigt sah. Er bezieht sich dennoch im wesentlichen auf klassische ökonomische Ordnungsvorstellungen, was allein schon in seiner Einordnung als führender Kopf der Freiburger „ordo-liberalen“ Schule zum Ausdruck kommt. ${ }^{83}$

Die notwendigen institutionellen Vorgaben für eine funktionsfähige Wettbewerbsordnung, die durch die Ordnungspolitik zu realisieren sind, faßt Eucken in zwei Arten von Prinzipien zusammen. Die "konstituierenden Prinzipien" umfassen elementare Institutionen, die die Wettbewerbsordnung herstellen, während die "regulierenden Prinzipien" erforderlich sind, um sie zu erhalten. ${ }^{84}$ Innerhalb der konstituierenden Prinzipien unterscheidet Eucken sieben Prinzipien. Als "Grundprinzip" der Ordnungspolitik $^{85}$ betrachtet er das umfassende Streben nach Herstellung eines "funktionsfähigen Preissystems vollständiger Konkurrenz". Angestrebt werden soll ein Zustand, in dem die Aktivitäten der Wirtschaftssubjekte über Konkurrenzpreise aufeinander abgestimmt werden. Ein funktionsfähiger Preismechanismus ist die Voraussetzung dafür, daß die Konkurrenz zwischen den Marktteilnehmern überhaupt zur Geltung kommt.

Der Primat der Preisstabilität ${ }^{86}$ als zweites Prinzip verweist auf die Stabilität des Geldwerts als Voraussetzung für die Funktionsfähigkeit des Preismechanismus. Damit die Preise Knappheitsrelationen wiedergeben können und die Kostenrechnungen der Unternehmen und Haushalte nicht verfälscht werden, muß die Währungspolitik für stabile Wechselkurse sorgen sowie Inflation und Deflation vermeiden. Die Geldordnung soll möglichst automatisch funktionieren, Spar- und Investitionsvolumen ausglei-

\footnotetext{
${ }^{83}$ Vgl. Grossekettler, H. (1987), Der Beitrag der Freiburger Schule zur Theorie der Gestaltung von Wirtschaftssystemen, Volkswirtschaftliche Diskussionsbeiträge, Nr. 90, Westfälische WilhelmsUniversität Münster, S. 7

${ }^{84}$ Vgl. Eucken, a.a.O., S. 253

${ }^{85}$ Alle Ausführungen zum Grundprinzip vgl. Eucken, a.a.O., S. 254 - S. 255

${ }^{86} \mathrm{Vgl}$. Eucken, a.a.O., S. 256 - 264
} 
chen und damit konjunkturstabilisierend wirken sowie vorhersehbar und stetig sein, um Vertrauen für langfristige Investitionen zu schaffen.

"Offene Märkte" als dritter Grundsatz ${ }^{87}$ verpflichten die Wirtschaftspolitik, den Marktzugang für Anbieter und Nachfrager offen zu halten. Protektionistische Tendenzen in Form von tarifären und nicht-tarifären Handelshemmnissen, Marktzugangsbeschränkungen oder schlicht Behinderungswettbewerb sind zu verhindern. Als Ursache des Protektionismus sieht Eucken private und halböffentliche Macht- bzw. Interessengruppen sowie den Staat. Das Ergebnis des Protektionismus ist die verstärkte Bildung von Monopolen, welche letztlich die Koordination über den Marktmechanismus außer Kraft setzen.

Das „Privateigentum“ als viertes Prinzip zur Konstituierung der Wettbewerbsordnung ${ }^{88}$ dient dazu, unternehmerische Spontaneität zu entfalten, die notwendig ist, um die Produktion laufend den Marktveränderungen anzupassen und durch schnelles Entscheiden optimale Produktionsergebnisse zu erzielen. Das Wesen des Eigentums ist jedoch doppeldeutig, da Verfügungsrechte an Gütern Marktmacht begründen, die sich wettbewerbsschädigend einsetzen läßt und deshalb kontrolliert werden muß. Die wirksamste Kontrolle eigentumsbegründeter Marktmacht sieht Eucken in einer wirksamen Konkurrenz auf den Märkten.

Die „Vertragsfreiheit ${ }^{489}$ ist eine weitere Voraussetzung für einen funktionsfähigen Wettbewerbsmechanismus. Wie das Privateigentum hat allerdings auch dieses Prinzip eine doppeldeutige Natur: Inhalt einer vertraglichen Abrede kann die Schädigung eines dritten Marktteilnehmers sein und damit letztlich die Unterdrückung der Konkurrenz, die zur Außerkraftsetzung des Marktmechanismus führen kann. Auch bei diesem Prinzip ist die wirksamste Garantie für seine Aufrechterhaltung in einer wirksamen Konkurrenz unter den Marktteilnehmern zu sehen.

Der Vermeidung von Haftungsbeschränkungen bzw. der Einheit von Gestaltungsmacht und Haftung als weiterem konstituierenden Prinzip ${ }^{90}$ ordnet Eucken wichtige erzieherische Effekte zu. Sie zwingt die Marktteilnehmer in ihren wirtschaftlichen Kalkülen zu aufmerksamer Abwägung des Risikos und zur Prophylaxe. Gleichzeitig verhindert sie Verschwendung und sorgt für die Auslese derjenigen Marktteilnehmer, die den Marktanforderungen nicht mehr genügen. Die Einschränkung der Haftung würde den Ausleseprozeß des Wettbewerbs empfindlich stören und letztlich dazu führen, dessen Einfluß auf die Stabilisierung der Erwartungen zu unterbinden.

\footnotetext{
${ }^{87}$ Vgl. Eucken, a.a.O., S. 264 - 270

${ }^{88} \mathrm{Vgl}$. Eucken, a.a.O., S. 270 - 275

${ }^{89}$ Vgl. Eucken, a.a.O., S. 275 - 279

${ }^{90} \mathrm{Vgl}$. Eucken, a.a.O., S. 279 - 285
} 
Als letztes konstituierendes Prinzip führt Eucken die Stetigkeit und Vorhersehbarkeit der Wirtschaftspolitik an. ${ }^{91}$ Die durch die Wirtschaftspolitik gesetzten Daten wie z. B. Wechselkurse und Zölle sind wichtige Determinanten für Investitionsentscheidungen und müssen deshalb über längere Zeiträume konstant sein, damit die Wirtschaftseinheiten stabile und zutreffende Erwartungen bilden können. Eine zu hohe Unsicherheit über die langfristige Entwicklung wirtschaftspolitischer Rahmendaten unterbindet wirtschaftliche Aktivität und fördert den Zusammenschluß von Wirtschaftseinheiten und damit wieder die Konzentration von Marktmacht. Im Interesse einer funktionsfähigen Wettbewerbsordnung ist eine kontinuitätsorientierte und berechenbare Wirtschaftspolitik unabdingbar.

Erfahrungsgemäß hat die Marktform der vollständigen Konkurrenz Schwächen und Mängel, die dazu führen, daß "konkreten Wettbewerbsordnungen gewisse systemfremde Ordnungsformen" innewohnen. ${ }^{92}$ Um ihre Funktionsfähigkeit dennoch zu wahren, bedarf es zusätzlich bestimmter "regulierender Prinzipien".93

Da wirtschaftliche Macht zur Verwirklichung von Wirtschaftsplänen unumgänglich ist, Menschen aber natürlicherweise dazu neigen, sich dem Wettbewerb zu entziehen, indem sie monopolartige Stellungen auf Märkten anstreben, ist die Notwendigkeit einer wirksamen Monopolkontrolle gegeben. ${ }^{94}$ Diese soll die Träger wirtschaftlicher Macht zu einem Verhalten veranlassen als ob vollständige Konkurrenz bestünde. Eine ständige und unabhängige Monopolaufsicht sollte überall dort prophylaktisch eingreifen, wo die Gefahr des Mißbrauchs von Marktmacht besteht.

Des weiteren weist Eucken auf die Notwendigkeit einer gerechtigkeitsorientierten Korrektur der Einkommensverteilung hin. ${ }^{95} \mathrm{Da}$ die Einkommensverteilung durch den Preismechanismus nach ethisch indifferenten Prinzipien vorgenommen wird, können größere Einkommensunterschiede entstehen, die dazu führen, daß einkommensschwache Haushalte nicht in der Lage sind, existentielle Grundbedürfnisse zu befriedigen. Eucken sieht in einer laufenden Korrektur der Einkommensverteilung durch ein progressives Steuersystem ein geeignetes Mittel zur Lösung des Problems, das freilich die Investitionsneigung nicht gefährden darf.

${ }^{91}$ Vgl. Eucken, a.a.O., S. 285 - 289

${ }^{92} \mathrm{Vgl}$. Eucken, a.a.O., S. 291

${ }^{93}$ Eucken nennt insgesamt vier Prinzipien, von denen hier drei vorgestellt werden. Das vierte Prinzip, "anomales Verhalten des Angebots" behandelt das Problem von regional und strukturell bedingten Lohnrückgängen, die zu einem vermehrten, statt wie zu erwarten zu einem verringerten Arbeitsangebot führen. Um den Fall der Löhne ins Bodenlose zu verhindern, wird die Einführung von Minimallöhnen vorgeschlagen. Da es sich hier um ein Problem aus dem Bereich der Einkommenspolitik handelt und Minimallöhne in fast allen Sozialgesetzgebungen vorhanden sind, wird auf dieses Prinzip nicht weiter eingegangen.

${ }^{94}$ Vgl. Eucken, a.a.O., S. $291-299$

${ }^{95} \mathrm{Vgl}$. Eucken, a.a.O., S. 300 - 301 
Das Prinzip der Korrektur externer Effekte soll dazu führen, daß die gesamtwirtschaftlichen Kosten der Güterproduktion den sie verursachenden Wirtschaftssubjekten zugerechnet werden. Wo z. B. die Schädigung unbeteiligter Dritter infolge der Produktion eines Gutes nicht über eine exakte Zurechnung von Kosten verhindert werden können, sind Eingriffe „gewerbepolizeilicher“ Art in die Planungsfreiheit vorzunehmen.

Weiter verweist Eucken noch auf „potentielle Ergänzungsprinzipien“ als generelle Leitlinien für die Wirtschaftspolitik. Sie umfassen die Vermeidung von Punktualismus bei Eingriffen in Wirtschaftsabläufe, die Zurückhaltung bei konjunkturpolitischen Maßnahmen sowie die Integration von Wettbewerbsordnung, Gesetzgebung, Rechtsprechung und Verwaltungshandeln in ein einheitliches Handlungskonzept. ${ }^{96}$ Die „Staatspolitischen Prinzipien“ indessen mahnen zur Begrenzung der Macht von Interessengruppen und betonen den Subsidiaritätsgrundsatz bei der Definition neuer Staatsaufgaben. ${ }^{97}$

Diesen Prinzipien soll der in dieser Arbeit zu ermittelnde französische Ordnungsentwurf für den europäischen Binnenmarkt gegenübergestellt werden, um seine Vereinbarkeit mit den Grundsätzen einer klassisch-marktwirtschaftlichen Ordnungskonzeption zu prüfen. Da im Verlauf der europäischen Binnenmarktpolitik die Ausgestaltung des Vertrags- und Eigentumsrechts sowie die Wirtschafts-, Währungs-, Sozial- und Finanzpolitik ganz oder zu weiten Teilen in nationaler Zuständigkeit belassen wurde, wird sich der Schwerpunkt der ordnungspolitischen Konsistenzprüfung auf jene Aspekte konzentrieren, die das Wettbewerbsselement im Kern berühren. Im Vordergrund werden dabei die Frage nach der Rolle des Staates in der Wirtschaft, nach dem Verhältnis von Wirtschafts- und Währungspolitik sowie nach der Rolle des Marktes als Koordinationsinstrument stehen. Die Ergebnisse dieser Gegenüberstellung sowie die Ergebnisse der zuvor durchgeführten Analyse des Sinngehalts des französischen Ordnungsentwurfs sollen schließlich als Grundlage für eine abschließende Betrachtung des praktischen Integrationspotentials der französischen Ordnungsvorstellungen dienen. $\mathrm{Zu}$ klären ist dabei die Frage, ob der französische Ordnungsentwurf grundsätzlich als Basis einer gesamteuropäischen Wirtschaftsordnung geeignet ist.

Vom zeitlichen Rahmen her erstreckt sich die Analyse im Kern auf den Zeitraum von den Anfängen der Gründung der Europäischen Wirtschaftsgemeinschaft im Jahre 1955 bis zur Gründung der Wirtschafts- und Währungsunion am 7. Februar 1992. Aus der Vielzahl der in dieser Zeit getroffenen Entscheidungen sollen die ordnungspolitischen Konstanten der französischen Europapolitik herausgefiltert werden. Der Zuschnitt des französischen Regierungssystems auf den Staatspräsidenten, seine verfassungsrechtlich abgesicherte dominante Stellung im Bereich der Außen- und damit in der Europapolitik wie auch der Hang zum Personalismus im französischen Parteiensystem bringen mit sich, daß sich die Untersuchung der französischen Europapolitik in weiten Teilen

\footnotetext{
${ }^{96}$ Vgl. Eucken (1968), a.a.O., S. $304 \mathrm{ff}$.

${ }^{97}$ Vgl. Eucken (1968), a.a.O., S. 334 ff.
} 
auf die persönlichen Ansichten der jeweiligen Amtsträger abstützen wird. ${ }^{98}$ Als Quellen standen für den Zeitraum 1955 bis Anfang der sechziger Jahre die öffentlich zugänglichen Dokumente der Archive des französischen Außen- sowie des Wirtschaftsund Finanzministeriums zur Verfügung, die vor Ort untersucht worden sind. Für den nachfolgenden Zeitraum mußte hauptsächlich auf die Berichterstattung in der Presse sowie auf Veröffentlichungen amtlicher Organe wie dem Bulletin des französischen Außenministeriums zurückgegriffen werden. Um zu einer möglichst unverzerrten Darstellung der Willensbildungs- und Entscheidungsprozesse innerhalb der französischen Europapolitik zu gelangen, wird die vorliegende Untersuchung so nah wie möglich an den tatsächlichen Äußerungen der jeweiligen politischen Entscheidungsträger gehalten. Diese Herangehensweise verspricht, die Authentizität der sprachlichen und inhaltlichen Darstellungen weitestgehend zu wahren und den Zielen und Intentionen der französischen Europa- bzw. Binnenmarktpolitik in größtmöglichem Maße gerecht zu werden.

${ }^{98} \mathrm{Vgl}$. Zadra, (1995), a.a.O., S. $143 \mathrm{ff}$. 


\section{B. Der französische Ordnungsentwurf für den Gemeinsamen Markt B.1 Die Regierungsverhandlungen zum EWG-Vetrag B.1.1 Die politische und wirtschaftliche Lage Frankreichs vor den Verhandlungen}

Die französischen Regierungen waren Mitte der fünfziger Jahre stark durch innenpolitische Probleme gebunden als sie seitens ihrer europäischen Partner in der Europäischen Gemeinschaft für Kohle und Stahl (EGKS) mit den Bemühungen konfrontiert wurden, den europäischen Einigungsprozeß fortzusetzen. Seit Ende des zweiten Weltkrieges bemühten sie sich um den Erhalt des Großmachtstatus. Sie mußten jedoch feststellen, daß sich die Ordnung in den Kolonien nur noch mit einem hohen Einsatz an militärischen Mitteln aufrechterhalten ließ. Steigende Ausgaben für die Entwicklung der Kolonien und kostspielige militärische Auseinandersetzungen wie der verlorene Indochina-Krieg zehrten zunehmend die Staatsfinanzen auf. Hinzu kam eine schwelende Staatskrise, da die parteipolitisch zersplitterte Nationalversammlung, die nach der Verfassung der IV. Republik großen Einfluß auf die Regierungspolitik hatte, sich als zunehmend unfähig erwies, handlungsfähige Regierungen hervorzubringen. Bei kontroversen Fragen wurde die Suche nach tragbaren Kompromissen immer schwieriger. Koalitionsregierungen brachen nach immer kürzeren Amtszeiten auseinander, so daß sich in der Bevölkerung wie im Staatsapparat ein wachsender Vertrauensverlust in das parlamentarische System entwickelte. ${ }^{1}$

Wirtschaftlich entwickelte sich Frankreich in dieser Zeit von einer Agrarnation zu einem Industriestaat. ${ }^{2}$ Um den Industriealisierungsprozeß zu beschleunigen, wurden nach dem zweiten Weltkrieg wichtige Großunternehmen in ausgesuchten „strategischen“ Sektoren wie der Automobil-, Flugzeug-, Stahl- und Verkehrsbranche sowie im Banken- und Versicherungswesen verstaatlicht. ${ }^{3}$ Die Koordination dieses Entwicklungsprozesses fand im Rahmen der „Planification“ statt, einer volkswirtschaftlichen Rahmenplanung, die die gesamte französische Wirtschaft erfaßte und ihr über alle Branchen hinweg Produktions- und Entwicklungsziele vorgab. ${ }^{4}$ Frankreich realisierte Mitte der fünfziger Jahre ein durchschnittliches Wachstum des Bruttoinlandsprodukts von fünf Prozent. ${ }^{5}$ Außer im Montanbereich war der französische Markt durch hohe Importzölle abgeschirmt, so daß den Unternehmen der Wettbewerb mit ausländischen Unternehmen weitestgehend erspart blieb. ${ }^{6}$ Der französische Außenhandel wurde zum überwiegenden Teil mit den eigenen Kolonien und anderen Entwick-

\footnotetext{
${ }^{1}$ Vgl. Schütze, W. (1958), Frankreich zwischen Staatsstreich und Staatsreform, S. 10885, in EA, 5.7 .1958$, S. $10883 \mathrm{ff}$.

${ }^{2} 1955$ waren noch 26,2 Prozent aller Erwerbstätigen in der Landwirtschaft beschäftigt, vgl. INSEE (1990), Annuaire rétrospectif de la France 1948-1988, Paris, S. 61

${ }^{3}$ Unter anderem Renault, Air France, SNCF, BNP, vgl. Maillet, P. (1964), Le secteur public en France, Paris, S. 43-46

${ }^{4} \mathrm{Vgl}$. Tholl, G. (1965), Die französische Planification - ein Vorbild?, in: Ordo, Band 15/16, S. 201274, hier S. 213-216 sowie Weber, A. P. (1971), Les concentrations industrielles dans la France, Paris, S. 39 sowie S. 62-66

${ }^{5}$ Vgl. OEEC (1956), 7 th. report to the OEEC, Paris, S. 139

${ }^{6}$ Vgl. Maillet, P. (1958), La structure économique de la France, Paris, S. 52 und 81
} 
lungsländern abgewickelt und verharrte im Vergleich zur Bundesrepublik bei einem relativ geringen Volumen. ${ }^{7}$

Die wirtschaftliche Stabilität Frankreichs geriet ab 1955 mehr und mehr ins Wanken. Das zunehmende militärische Engagement in Nordafrika ließ die Staatsausgaben zwischen 1955 und 1957 um 43 Prozent und die Staatsverschuldung um 22 Prozent ansteigen. ${ }^{8}$ Weitgehend durch die Banque de France finanziert, führten die erhöhten Staatsausgaben in diesem Zeitraum zu einer Inflation von bis zu vierzehn Prozent, die in der Industrie durchschnittliche Lohnsteigerungen von achtzehn Prozent nach sich zog. ${ }^{9}$ Der dadurch verursachte Anstieg der Produktionskosten führte bei festen Wechselkursen zu einem Anstieg der Importe, während die französischen Exporte stagnierten. Entsprach die französische Ausfuhr 1955 vom Umfang her noch den Importen, so deckte sie diese 1956 und 1957 nur noch zu 82 bzw. 83,32 Prozent. ${ }^{10}$ Die defizitäre Entwicklung im Außenhandel schlug aufgrund der Kapitalverkehrsbeschränkungen ungedämpft auf die Devisenbilanz durch, die sich 1955 nach längerer Zeit erstmals wieder im Gleichgewicht befunden hatte. ${ }^{11}$ Die Finanzierung dieses neuen Defizits gestaltete sich zunehmend schwieriger, da die französischen Währungsreserven stark geschrumpft waren und die rasch zunehmende Staatsverschuldung auf den Finanzmärkten zu einem Vertrauensschwund in die Kreditwürdigkeit Frankreichs geführt hatte. ${ }^{12}$ Um dieser Entwicklung Einhalt zu gebieten, verschärfte die Regierung die ohnehin schon hohe Protektion der französischen Märkte. Sie erhöhte die Einfuhrabgaben weiter und versuchte mit zusätzlichen Subventionen den Export zu beleben, also eine steuerliche Ersatzabwertung durchzuführen. ${ }^{13}$ Die eigentliche Ursache der schwelenden Wirtschaftskrise jedoch, die zu hohen und über die Notenpresse finanzierten Staatsausgaben, blieb unberührt. Mitte 1955, zu Beginn der politischen Bemühungen, die wirtschaftliche Einigung Europas fortzusetzen, befand sich Frankreich somit am Beginn einer Staats- und Wirtschaftskrise, die sich im Verlauf der Verhandlungen zum EWG-Vertrag noch verschärfte.

Auf außenpolitischer Ebene wurde diese ungünstige wirtschaftliche Entwicklung von dem langsamen aber stetigen Abstieg Frankreichs als Weltmacht begleitet. Innerhalb Europas hatte es durch die Ablehnung der Europäischen Verteidigungsgemeinschaft

\footnotetext{
${ }^{7}$ Frankreichs Exporte gingen 1952 zu 57 Prozent in die eigenen Kolonien oder in andere Entwicklungsländer. 51 Prozent der französischen Importe wurden aus diesen bezogen. Vgl. Uterwedde, H. (1979), Wirtschaft im Vergleich, Tübingen, S. 56 sowie Mitchell, B. R. (1992), International historical statistics, New York, S. 564

${ }^{8}$ Die Ausgaben der Regierung stiegen von 3.945 Mrd. FF 1955 auf 5640 Mrd. FF 1957, vgl. Mitchell (1992), a.a.O., S. 802; die Staatsverschuldung nahm von 57,56 Mrd. FF im Jahre 1955 auf 70,41 Mrd. FF im Jahre $1957 \mathrm{zu}$, vgl. INSEE (1990), a.a.O., S. 594

${ }^{9}$ Vgl. Vesperini, J.-P. (1993), L'économie de la France sous la V $V^{e}$ République, Paris, S. 4, sowie INSEE (1990), a.a.O., S. 10 und Mitchel (1992), a.a.O., S. 185

${ }^{10}$ Vgl. INSEE (1990), a.a.O., S. 600

"Vgl. Mitchell (1993), a.a.O., S. 931

${ }^{12}$ Vgl. Vesperini (1993), a.a.O., S. 5

${ }^{13}$ ebenda
} 
(EVG) im Jahre 1954 seine Partner brüskiert und sich damit selbst isoliert. Versöhnende Gegenvorschläge Frankreichs zur Fortsetzung der europäischen Integration wie die Bildung eines „Conseil Confédéral Européen“ konnten die Enttäuschung der Partner nicht überwinden helfen. Um sich in dieser Situation nicht vollständig zu isolieren, verblieb der französischen Außenpolitik 1955 keine andere Wahl als auf die neuen Integrationsbemühungen der europäischen Partner einzugehen. ${ }^{14}$

In dieser Lage wurde Frankreich am 20. Mai 1955 mit dem Vorschlag der BeneluxLänder konfrontiert, die europäische Integration über die Fusion der Volkswirtschaften zu einer Zollunion sowie über die Schaffung eines gemeinsamen Marktes fortzusetzen. Zur Konferenz der EGKS-Außenminister in Messina, auf der dieser Vorschlag diskutiert werden sollte, reiste die französische Delegation ohne besondere Vorbereitung an. Anfangs widersetzte sich Außenminister Pinay der vorgeschlagenen vollständigen Integration der Volkswirtschaften in einen gemeinsamen Markt. Er plädierte statt dessen für eine Fortsetzung der sektoralen Integration. ${ }^{15} \mathrm{Da}$ seine Kollegen sich jedoch geschlossen für eine Fusion aller Wirtschaftsbereiche im Rahmen einer Zollunion aussprachen, sah er sich schließlich gezwungen, nachzugeben. Frankreich stimmte der Einsetzung eines Sachverständigenausschusses zu, der die Probleme der wirtschaftlichen Integration eingehend prüfen sollte. Es tat dies jedoch nur unter dem Vorbehalt, daß die Arbeiten völlig unverbindlich seien und keinen späteren Vertragsschluß präjudizierten. ${ }^{16}$ Außerdem forderte es, daß sich die Beratungen ausführlich mit der Harmonisierung der von den Unternehmen zu tragenden Soziallasten sowie mit der Errichtung eines europäischen Investitionsfonds befaßten - zwei Anliegen, die französischerseits als wesentliche Voraussetzung für eine erfolgreiche Fusion der Volkswirtschaften betrachtet wurden, gleichzeitig aber auch die reservierte Haltung der französischen Regierung dem Gesamtvorhaben gegenüber verdeutlichten.

\section{B.1.2 Die Mitarbeit am Spaak-Bericht}

Auf der Konferenz von Messina beschlossen die Regierungen der EGKS-Staaten, über die schrittweise Fusion ihrer Volkswirtschaften ,eine neue Phase auf dem Weg zur Schaffung Europas einzuleiten ${ }^{\text {(17 }}$. Eine Expertengruppe unter Leitung des belgischen Außenministers Paul Henri Spaak nahm am 1. Juli 1955 ihre Beratungen auf, um die notwendigen Schritte zur Realisation des Vorhabens zu prüfen. Da die französische

\footnotetext{
${ }^{14}$ Beim „Conseil Confédéral Européen“ handelte es sich um eine ständig tagende diplomatische Konferenz, zu der auch nicht-EGKS-Mitglieder zugelassen sein sollten. Sie sollte sich mit der Harmonisierung der exekutiven und legislativen Tätigkeiten der teilnehmenden Nationen beschäftigen sowie zur Bildung geeigneter ,internationaler Organisationen“ führen, mittels derer die gemeinsamen Positionen der europäischen Länder Drittstaaten gegenüber vertreten werden konnten. Näheres bei Küsters, H.-J. (1982), Die Gründung der Europäischen Gemeinschaft, Baden-Baden, S. 104

${ }^{15} \mathrm{Vgl}$. Küsters (1982), a.a.O., S. 121

${ }^{16}$ ebenda

${ }^{17}$ Vgl. das Schlußkommuniqué der Konferenz von Messina vom 3. Juni 1955, S. 7974, abgedruckt in EA, 5.7.1955, S. 7973-7975
} 
Regierung diese Arbeiten nur als eine technische Studie betrachtete, die keine weiteren Verpflichtungen nach sich ziehen würde, wurden der eigenen Delegation keine detaillierten Instruktionen erteilt. ${ }^{18}$ Als ,ligne directrice“ erhielt sie lediglich die Anweisung, Frankreichs Willen zu konstruktiver Mitarbeit zu demonstrieren, gleichzeitig aber zu verhindern, daß am Ende ein Dokument mit Programmcharakter entstünde, welches einen späteren Vertrag präjudizieren könnte. ${ }^{19}$ Inhaltlich sollten sich die französischen Vertreter vor allem bei den Beratungen über die Harmonisierung der Sozialgesetzgebungen engagieren. Weitere Instruktion würden bei Notwendigkeit folgen. ${ }^{20}$

Im Verlauf der Beratungen gerieten die französischen Vertreter jedoch bald unter Zugzwang, da die anderen Delegationen mit deutlich präzisieren Vorstellungen zur Ausgestaltung des Gemeinsamen Marktes aufwarteten. Vor allem bei der Frage des Integrationsansatzes - horizontale oder sektorale Integration - und bei der Harmonisierung der Soziallasten traten schnell tiefgreifende Meinungsverschiedenheiten auf. ${ }^{21}$ Die Harmonisierung der Soziallasten lag der französischen Regierung besonders am Herzen, da sie die Schwäche des französischen Außenhandels auf zu hohe Produktionskosten zurückführte, die sie in erster Linie durch die „fortschrittliche“, d. h. ausgedehnte Sozialgesetzgebung in Frankreich verursacht sah. Ohne die Beseitigung dieses Wettbewerbsnachteils war die Teilnahme Frankreichs an einem europäischen Binnenmarkt für sie undenkbar. Um die Führung der Diskussion nicht vollständig aus den Händen zu verlieren, entschloß sich die französische Regierung, ihre Vorstellungen von einem Gemeinsamen Markt in einem Memorandum zusammenzufassen, das den Delegationsleitern am 14. Oktober 1955 übermittelt wurde. Im Eröffnungssatz des Memorandums findet sich dabei ein erster Hinweis auf die ordnungspolitische Orientierung, die Frankreich auf die neu zu schaffende Wirtschaftseinheit zu übertragen wünschte:

"L'objet d'un marché commun européen doit être une vaste zone de politique économique commune constituant une puissante unité de production et permettant une expansion continue, une stabilité accrue, un relèvement accéléré du niveau de vie. De telles conditions ne peuvent êtres obtenues que s'il est mis fin aux pratiques par lesquelles la concurrence est faussée entre les producteurs, s'il est établit une coopération des états en vue d'une politique monétaire, d'une politique de conjoncture et d'une politique d'expansion et de progrès social commune, si les états réunis dans cette Communauté adoptent vis-à-vis des pays tiers une politique commerciale concertée." ${ }^{22}$

${ }^{18}$ Vgl. MAE (1955), Instructions à la délégation, in: série DE-CE, Vol 612, S. 45; zur abwartenden Verhaltensweise der französischen Delegation und der unentschlossenen Haltung der französischen Regierung über die Teilnahme an der EWG vgl. von der Groeben, H. (1981), Zur Wirtschaftsordnung der Europäischen Gemeinschaft, S. 14, in: Integration 1/81, Beilage zur Europäischen Zeitung 1/81, S. 3-21

${ }^{19} \mathrm{Vgl}$. MAE, Instructions à la délégation, in: série DE-CE, Vol 612, S. 45 f

${ }^{20}$ ebenda

${ }^{21} \mathrm{Vgl}$. DGAEF, Note du 7 mai 1956: Histoire de la position française à la conférence de Messine et à la conférence permanente de Bruxelles, in: Documents Diplomatiques Français, Paris 1988, S. 726

${ }^{22}$ Mémorandum de la délégation française au comité intergouvernemental créé par la Conférence de Messine du 14.10.1955, S. 600, abgedruckt in: Documents diplomatiques Français, Paris 1988, Jg. 1955 , tome II, S. $660 \mathrm{ff}$. 
Im Mittelpunkt des französischen Interesses stand somit die Schaffung einer politisch aktiven und nach außen hin machtvollen Wirtschaftsgemeinschaft, deren innere Ordnung sich durch eine enge wirtschaftspolitische Zusammenarbeit der Mitgliedstaaten und „korrigierte“, für die Unternehmen gleiche Wettbewerbsbedingungen auszeichnen sollte.

Die angestrebten Korrekturen waren dabei jedoch nicht im Sinne gleicher Wettbewerbsregeln für alle Unternehmen zu verstehen, sondern im kompensatorischen Sinne. Für die durch höhere Soziallasten und - infolge der hohen Kolonial- und Militärausgaben - durch höhere Steuern stärker belasteten französischen Unternehmen war nach Meinung der französischen Regierung eine Wirtschaftsordnung notwendig, die dauerhafte, nicht von den Unternehmen zu verantwortende Wettbewerbsnachteile ausglich. Folgende Maßnahmen erachtete sie deshalb als notwendig:

1. Maßnahmen zur Egalisierung der Arbeitsbedingungen, die, wesentlich für ein „korrektes Funktionieren der Konkurrenz “23, in erster Linie die Angleichung der Arbeitszeiten sowie der nationalen Sozialgesetzgebungen auf dem höchsten Niveau sozialer Sicherheit in Europa (welches das französische war) vorsahen;

2. die Einrichtung eines Anpassungs- und Investitionsfonds, aus dessen Mittel Maßnahmen zur Angleichung der wirtschaftlichen Strukturen unterstützt werden sollten;

3. die Angleichung der Wettbewerbsregeln hinsichtlich der Kontrolle von Kartellen, Monopolen und Subventionen;

4. das Verbot von staatlichen Interventionen, außer zur Korrektur von „Verzerrungen“, zur Dämpfung von „Störungen“ sowie zur Beseitigung von Preisunterschieden, die sich „schädlich“ auf das Funktionieren des Marktes sowie auf das Wirtschaftswachstum auswirkten;

5. die schrittweise Senkung der Zölle um insgesamt dreißig Prozent während der ersten Stufe, wobei sich der Zollsatz auf den Durchschnitt von insgesamt zehn Produktkategorien beziehen sollte, innerhalb derer die Länder je nach Produkt unterschiedliche Zollsenkungen vornehmen konnten;

6. den Abbau mengenmäßiger Einfuhrkontingente nach den Bestimmungen der OEEC, welche einen nach nationalen Erfordernissen unterschiedlichen Restbestand an Importkontingenten erlaubten;

7. die Herstellung eines gemeinsamen Außentarifs während der ersten Stufe auf der Basis des gewogenen Mittels der bestehenden Außentarife;

8. die Errichtung einer eigenen Marktorganisation für Agrarprodukte, die aufgrund der besonderen Rahmenbedingungen dieses Wirtschaftssektors (familiäre Struktur der Betriebe, Klimaabhängigkeit der Produktion, etc.) nicht ohne weiteres einem anonymen Marktmechanismus unterworfen werden sollten;

9. den Beschluß von Schutzklauseln, die einem Mitgliedstaat für den Fall größerer Schwierigkeiten in einem Produktmarkt oder bei der Entwicklung seiner Zahlungs-

${ }^{23}$ „Il est essentiel, à la fois pour le fonctionnement correct de la concurrence et pour l'amélioration du niveau de vie des travailleurs, d'éliminer certaines disparités dans les conditions de travail existants aujourd'hui “, so das Memorandum vom 14.10.1955, a.a.O., S. 660 
bilanz erlauben sollten, ohne vorherige Genehmigung Handelsbeschränkungen in Form von Zöllen und Kontingenten wieder einzuführen;

10.die Errichtung eines „Magistrats“, bestehend aus gemeinsam bestimmten „kompetenten Persönlichkeiten“, der in enger Zusammenarbeit mit den zuständigen Ministern über die Einhaltung der Vertragsbestimmungen wachen, die Verwirklichung des Gemeinsamen Marktes „fördern“ und den Regierungen am Ende der ersten Etappe Vorschläge machen sollte, wie der Übergang zum Gemeinsamen Markt innerhalb der zehn folgenden Jahre vollendet werden könnte. ${ }^{24}$

Schon in den vorbereitenden Beratungen war somit erkennbar, daß die französische Regierung für weite Bereiche des Gemeinsamen Marktes Wettbewerbsausnahmen wünschte. Deutlich war vor allem das Bemühen, den befürchteten Anpassungsschock für die eigene Industrie durch wettbewerbsmildernde Maßnahmen wie finanzielle Anpassungshilfen, Rückzugsklauseln und flexible Zollsenkungen erträglich zu gestalten. Dennoch war das Memorandum insofern ein Fortschritt, als daß Frankreich Abstand von der sektoralen Integration genommen hatte, mit der es anfänglich noch eine zu weit gehende Integration zu verhindern suchte.

Es gelang der französischen Delegation allerdings nicht, sich mit diesen Forderungen durchzusetzen. Sie geriet mit ihren ordnungspolitischen Ansichten schnell in einen Dauerkonflikt vor allem mit der marktwirtschaftlich orientierten Bundesrepublik und mußte am Ende der Auseinandersetzungen schließlich in zentralen ordnungspolitischen Fragen nachgeben. ${ }^{25}$ Der wesentliche Grund dafür lag außerhalb der eigentlichen Streitfrage. Anfang November 1955 brach in Frankreich erneut eine Regierungskrise aus, die im Januar 1956 zu Neuwahlen und einem anschließenden Regierungswechsel führte. Der französischen Delegation fehlte dadurch in der Auseinandersetzung um die ordnungspolitische Ausgestaltung des Gemeinsamen Marktes über weite Strecken die notwendige politische Rückendeckung, zumal die neue Regierung nach ihrer Wahl Zeit zur Einarbeitung brauchte. Von daher blieb Frankreichs Einfluß auf den Inhalt des Abschlußberichts des Spaak-Komites insgesamt gering. ${ }^{26}$

Der „Spaak-Bericht" stellte im Gegensatz zu den französischen Forderungen doch ein vollständiges Integrationsprogramm dar, das alle Stufen des Übergangs zum Gemeinsamen Markt umfaßte. Der institutionelle Rahmen für die neue Binnenmarktorganisation orientierte sich weitgehend an dem der EGKS. Er sah starke Gemeinschaftsinstitutionen vor, mit weitaus mehr Kompetenzen, als der von Frankreich vorgeschlagene Magistrat. ${ }^{27}$ So sollten die von Frankreich geforderten Schutzklauseln nur nach Genehmigung durch die Kommission in Anspruch genommen werden dürfen. Ferner wurde die „Harmonisierung der Soziallasten“ nur global als wünschenswert angespro-

${ }^{24}$ Vgl. Memorandum vom 14. Oktober 1955, a.a.O., S. $660 \mathrm{f}$.

${ }^{25}$ Vgl. DGAEF, note du 7. Mai 1956, a.a.O., S. 726

${ }^{26}$ Vgl. Küsters (1982), a.a.O., S. 205 sowie S. 218-222

27 Vgl. die Darstellung des Spaak-Berichts bei Streiter, G. (1956), Informationen und Berichte, S. 8781, in EA, 20.4.1956, S. $8779 \mathrm{ff}$. 
chen. Außerdem sah der Spaak-Bericht hinsichtlich des Übergangs zur Zollunion die vollständige Beseitigung der Einfuhrkontingente vor. Der Außentarif hingegen sollte aufgrund des arithmetischen Mittels der nationalen Tarife bestimmt werden, statt, wie von Frankreich gefordert, nach dem gewogenen Mittel, das die besondere Berücksichtigung französischer Interessen erlaubt hätte. Bei der Rückführung der Binnenzölle plädierte der Spaak-Bericht überdies für eine einheitliche Behandlung aller Produkte, was ebenfalls französischen Vorstellungen widersprach. Insgesamt wies der SpaakBericht letztendlich eine weitaus stärkere marktwirtschaftliche Prägung auf als es Frankreich lieb sein konnte. Während er bei allen anderen Partnerstaaten auf Zustimmung stieß, war die französische Regierung gezwungen, ihre Position für die nachfolgenden Regierungsverhandlungen zu überdenken und neu aufzubauen.

\section{B.1.3 Die Vorbereitung der Regierungsverhandlungen}

Die im Januar 1956 neu gewählte französische Koalitionsregierung unter Führung des Sozialisten Guy Mollet nahm den Spaak-Bericht zunächst mit großer Zurückhaltung auf. Auch auf seiten der einflußreichen ,haute administration“, die traditionell auf die Weltmachtrolle Frankreichs fixiert war und der europäischen Integration grundsätzlich skeptisch gegenüberstand, existierten große Vorbehalte. ${ }^{28}$ Einer kleinen Anzahl junger europafreundlicher Beamter, die Anfang 1956 mit der neuen Regierung Mollet in entscheidende Positionen aufstiegen, gelang es in zäher Überzeugungsarbeit jedoch, der zögernden Staatsführung die Notwendigkeit einer weiteren Teilnahme Frankreichs am europäischen Integrationsprojekt zu verdeutlichen. ${ }^{29}$ Ihnen gemeinsam war die Einsicht, daß Frankreich sich der Fusion der europäischen Volkswirtschaften nicht verschließen konnte, wollte es nicht in einen unaufholbaren wirtschaftlichen Rückstand gegenüber den anderen europäischen Nationen geraten. Ihrem Einfluß auf die Formulierung der französischen Außenpolitik war es zu verdanken, daß wirtschaftliche gegenüber machtpolitischen Erwägungen zunehmend größere Berücksichtigung fanden. In einer ersten Bewertung des Spaak-Berichts wurde dementsprechend anerkannt, daß die Integrationsproblematik durchaus richtig analysiert worden war und Frankreich nur die Wahl blieb, sich für oder gegen eine weitere Teilnahme an der europäischen Einigung $\mathrm{zu}$ entscheiden. ${ }^{30}$ Dennoch blieben die bisherigen Vorbehalte gegen das Programm des Gemeinsamen Marktes weiter bestehen. Zum einen sah man auch innerhalb der neuen Regierung, daß die französische Wirtschaft mit ihren sozialen und wirtschaftlichen Strukturen für den Wettbewerb mit den anderen europäischen Volkswirtschaften nicht ausreichend vorbereitet war. ${ }^{31}$ Zum anderen bestanden weitreichen-

\footnotetext{
${ }^{28}$ Vgl. Küsters (1982), a.a.O., S. 105 und 107

${ }^{29}$ Vgl. Marjolin R. (1986), Le travail d'un vie, Paris, S. 283

${ }^{30}$ Vgl. DGAEF (1956), note du 21. avril, in: Documentation Diplomatique Français, Paris 1988, tome 1, S. 637

31 "Un marché commun n'est sans doutes pas compatible avec le maintien de l'équilibre économique et social de la France, compte tenu, d'une part des pressions démographiques différents entre les Six
} 
de Zweifel an der Fähigkeit der eigenen Unternehmerschaft, sich im internationalen Wettbewerb behaupten zu können:

"Le fait que l'économie française ne soit pas concurrentielle dans tous les secteurs résulte d'autres causes: manque d'intérêt des milieux économiques pour l'exportation, mauvaise organisation, coûtes du système de distribution, etc. Suffira-t-il de la pression exercée par le marché commun pour amener les milieux français intéressés à modifier leurs conceptions et leurs méthodes?"132

Die Antwort auf diese Frage fiel offenbar negativ aus, denn die französische Regierung entschloß sich, im Vorfeld der für den Mai 1956 geplanten Außenministerkonferenz von Venedig, auf der über die Ergebnisse des Spaak-Berichts verhandelt werden sollte, den Partnerstaaten in einem weiteren Memorandum erneut die französischen Vorstellungen zur Ausgestaltung der Wirtschaftsgemeinschaft darzulegen. ${ }^{33}$ Inhaltlich knüpfte dieses Memorandum an jenes vom Oktober 1955 an. Vom Umfang her wurde es jedoch beträchtlich erweitert und wesentlich präzisiert, so daß der stellvertretende französische Delegationsleiter, Robert Marjolin, im nachhinein zugab: "La liste des revendications et réserves françaises était interminable. La négociation du traité de Rome consistera à en faire tomber le plus grand nombre possible..." ${ }^{34}$

Auf der Konferenz von Venedig bekundete der neue Außenminister Pineau Frankreichs Bereitschaft zur Teilnahme am Gemeinsamen Markt. Gleichzeitig betonte er aber, daß grundsätzlich die Eigenart des jeweils nationalen Wirtschaftssystems zu berücksichtigen sei, "que celle-ci soit libérale ou non", und daß Frankreich sich häufiger gezwungen sehen werde, auf einen "certain dirigisme" zurückzugreifen. ${ }^{35}$ Diese Feststellung war wegweisend für die Ausarbeitung der Instruktionen an die Delegation. Diese bauten auf dem Memorandum vom 14. Oktober 1955 sowie einem Arbeitspapier, das schon als Grundlage für das Memorandum vom Mai 1956 verwendet worden war, auf. ${ }^{36}$ Die Delegation wurde angewiesen, sich in erster Linie für einen zügigen Abschluß der Verhandlungen zur Europäischen Atomgemeinschaft einzusetzen, der

et, d'autre part, de la diversité des structures économiques et des méthodes de production et de vente des pays en cause.", DGAEF (1956), a.a.O., S. 636

${ }^{32}$ DGAEF (1956), a.a.O., S. 636

${ }^{33}$ Vgl. Marjolin (1986), a.a.O., S. 283

${ }^{34}$ Vgl. Marjolin (1986), a.a.O., S. 286

${ }^{35}$ Vgl. o. V., Projet de procès-verbal de la conférence des ministres des affaires étrangères des états membres de la C.E.C.A. tenu à Venise les 29 et 30 mai 1956, in: Documents Diplomatiques Français, Paris 1988, tome 1, S. 919

${ }^{36} \mathrm{Vgl}$. MAE, Projet de directives pour la délégation française à la conférence de Bruxelles, série DECE, Vol. 612, S. 49.; Das Memorandum vom Mai, welches leider nicht zugänglich war, scheint nur eine im wesentlichen unveränderte Fassung des „Arbeitspapiers“ zu sein, da die bei Marjolin zitierten Ausschnitte zu den entscheidenden Forderungen Frankreichs wörtlich mit den entsprechenden Passagen im Arbeitspapier übereinstimmen, vgl. Marjolin (1986), a.a.O., S. 284 und 285 sowie das „Arbeitspapier“: MAE (1956), Projet de document de travail sur l'établissement d'un marché commun présenté par la délégation française, im folgenden als „Arbeitspapier“ angesprochen, série DE-CE, Vol. 612, S. 173-199 
aus Sicht der französischen Regierung höhere Bedeutung beigemessen wurde, als dem Gemeinsamen Markt. ${ }^{37}$ Dieser Linie stimmte auch die Mehrheit der Nationalversammlung zu, die auf Initiative Ministerpräsident Mollets, der sein Vorgehen in den Verhandlungen innenpolitisch abgesichert wissen wollte, ausführlich über das europäische Integrationsvorhaben debattierte. Die Debatte konzentrierte sich fast ausschließlich auf die Zukunft und die Vorteile der nuklearen Zusammenarbeit in Europa. Am Ende stimmten die Abgeordneten mit 332 zu 181 Stimmen für eine Teilnahme Frankreichs an weiteren europäischen Integrationsschritten. ${ }^{38}$ Die Regierung versicherte sich ferner der Rückendeckung der einflußreichen Berufsverbände von Industrie und Landwirtschaft, die weitgehend mit der vorsichtigen Haltung der Regierung übereinstimmten. ${ }^{39}$ Die nach Brüssel entsandte Delegation selbst war aus jungen europafreundlichen Beamten zusammengesetzt, die mit Guy Mollet die Rückendeckung eines ebenfalls europafreundlichen Ministerpräsidenten genossen. ${ }^{40}$ Auch wenn regierungsintern weiter Widerstände existierten ${ }^{41}$, hatte sie damit deutlich bessere Voraussetzungen, den französischen Ordnungsvorstellungen Geltung zu verschaffen, als es für die französische Delegation im Spaak-Komitee der Fall war.

\section{B.1.4 Die Positionen Frankreichs in den Regierungsverhandlungen B.1.4.1 Die Harmonisierung der Wettbewerbsbedingungen}

In der Verhandlungsposition der neuen französischen Regierung fand hinsichtlich des Ziels der Europäischen Wirtschaftsgemeinschaft eine Akzentverschiebung statt. Statt einer „vaste zone de politique économique“ strebte Frankreich nun eine „puissante unité de production" mit einer gemeinsamen Wirtschaftspolitik, die dem sozialen Fortschritt sowie einer ausgeglichenen Wirtschaftsentwicklung dienen sollte, an. ${ }^{42}$ In der stärkeren Betonung sozialer Aspekte zeigte sich die Handschrift der jetzt regierenden sozialistischen Partei. Sie behielt jedoch die grundsätzliche ordnungspolitische Orientierung der Vorgängerregierung bei. Hauptziel blieb eine Wirtschaftsordnung, die auf Egalisierung der Produktionsbedingungen durch Beseitigung „verfälschender“ Faktoren ausgerichtet war, unter denen den nicht harmonisierten Sozialgesetzgebungen weiterhin höchste Priorität zugeschrieben wurde. ${ }^{43}$ Der französische Vertreter in der

\footnotetext{
${ }^{37}$ MAE, Projet de directives pour la délégation française à la Conférence de Bruxelles, a.a.O., S. 48

${ }^{38} \mathrm{Vgl}$. Küsters (1982), a.a.O., S. 297

${ }^{39}$ Vgl. Marjolin (1986), a.a.O., S. 292 f.

${ }^{40}$ Vgl. Küsters (1982), a.a.O., S. 299

${ }^{41}$ Zur kritischen Haltung der hier angesprochenen Kreise vgl. das Kapitel 'lutte à Paris' bei Marjolin (1986), a.a.O., S. 294

42 "L'objet d'un marché commun européen doit être de créer une puissante unité de production soumise à une politique économique commune qui vise au relèvement du niveau de vie ainsi qu'au progrès social dans l'ensemble des pays participants, en assurant, dans chacun d'eux, l'expansion de la production, le plein emploi et l'élimination des déséquilibres qui pourraient se produire dans leurs économies et dans leurs balances de paiements"., MAE, Arbeitspapier, a.a.O., S. 173

${ }^{43} \mathrm{Vgl}$. MAE, Arbeitspapier, a.a.O., S. 173
} 
Arbeitsgruppe „Gemeinsamer Markt“, Jacques Donnedieu de Vabres, begründete dies kurze Zeit nach Abschuß der Römischen Verträge wie folgt:

"L'objectif général pour que fonctionne sainement le marché commun doit toujours être d'assurer une véritable égalité des conditions de concurrence entre les entreprises. Mais cette égalité dépend d'un grand nombre de facteurs: elle dépend des charges fiscales, des charges sociales, du prix de l'énergie, du prix des transports, du prix du crédit. Tous ces facteurs influent sur les conditions de concurrence parce que, suivant que les tarifs, les prélèvements et les coûts sont plus ou moins élevées dans les divers pays, des entreprises sont appelées à bénéficier d'avantages qui ne sont pas liés à leur activité propre et qui dépendent des conditions générales du milieu financier, économique et social dans lequel elles opèrent. ${ }^{44}$

Diese Stellungnahme konkretisierte das schon im „Arbeitspapier“ für das Memorandum vom Mai 1956 enthaltene Wettbewerbsverständnis der französischen Regierung. Im Arbeitspapier wurde gefordert, den Wettbewerb auf eine „gerechte Basis“ zu stellen. Alle „Diskriminierungen“, die das „,normale Spiel der Kräfte“ verfälschen könnten, sollten beseitigt werden. Sie würden letztlich zu Ungleichheiten führen, die sich unvermeidbar in den Endverkaufspreisen niederschlügen. ${ }^{45}$ Die befürchtete „Ungerechtigkeit“" des Wettbewerbs lag damit offenbar in der einfachen Tatsache begründet, daß innerhalb der Gemeinschaft unterschiedliche Preise für Inputfaktoren existierten. Auffällig bei den von Donnedieu de Vabres aufgezählten Produktionsfaktoren war, daß sie im damaligen Frankreich fast ausschließlich von verstaatlichten Unternehmen angeboten wurden. Ebenso waren die Sozialleistungen in Frankreich durch den Staat vorgeschrieben und nicht durch die Tarifpartner ausgehandelt. Das Bestehen auf einer vertraglich geregelten Angleichung dieser Kostenfaktoren zeigte, daß die französische Regierung zum einen nicht bereit war, die Staatsbetriebe schutzlos dem Wettbewerb auszusetzen. Zum anderen zog sie offenbar vor, die zu erwartenden Anpassungsprozesse im Rahmen einer politischen Koordination vorzunehmen, statt sie über die marktliche Arbitrage ablaufen zu lassen. Diese Zurückhaltung ist jedoch vor dem Hintergrund der sich 1956 rapide verschlechternden Wirtschaftslage in Frankreich zu sehen. Dem gleichen Motiv entsprach auch die französische Forderung, die Binnenzölle im Gemeinsamen Markt nur in dem Maß abzubauen, wie Fortschritte bei der Angleichung der Produktionsbedingungen erzielt würden. ${ }^{46}$

Der französischen Regierung ging es in erster Linie um eine weitgehende Abmilderung des Anpassungsschocks, der beim Öffnen der Grenzen zu erwarten war. Forderungen nach „gerechten“ und „,normalen“ Wettbewerbsbedingungen deuteten darauf hin, daß das französische Wettbewerbsverständnis maßgeblich von ethisch-normativen Motiven geprägt war. Die französische Regierung war von der Notwendigkeit derartiger Ein-

\footnotetext{
${ }^{44}$ Donnedieu de Vabres, J. (1957), Le marché commun, conférence prononcé le 17 juin 1957, Paris, S. 4

${ }^{45}$ „... pour que cette concurrence s'établisse sur des bases équitables, il convient que soient également éliminés des discriminations qui faussent le jeu normale du marché et les inégalités qui affectent la formation des prix de revient", vgl. MAE, Arbeitspapier, a.a.O., S. 176

${ }^{46}$ MAE, Arbeitspapier, a.a.O., S. 176
} 
griffe fest überzeugt und nicht bereit, die Wirtschaft der ,anonymen“ Koordination des Marktes zu überantworten. Von einer vertraglich geregelten Angleichung der Faktorpreise erhoffte sie sich letztlich auch egalisierte Investitionsbedingungen. ${ }^{47}$ Auf diesem Wege hätte sie einerseits eine weitgehende Nivellierung bestehender Standortvorteile erreicht und andererseits den nicht wettbewerbsfähigen Teil der französischen Wirtschaft vor europäischer Konkurrenz geschützt. Ebenfalls geschützt wäre damit auch ihre kostenträchtige Sozial-, Militär- und Wirtschaftspolitik, die sie unabhängig von den wirtschaftlichen Konsequenzen weiter hätte verfolgen können.

\section{B.1.4.2 Die Harmonisierung der Soziallasten}

Wie schon ihre Vorgängerin setzte auch die Regierung Mollet die Harmonisierung der Sozialbestimmungen an die erste Stelle ihres Forderungskataloges. Auch sie sah in den unterschiedlichen Sozialgesetzgebungen der Mitgliedstaaten den Hauptgrund für angebliche „Wettbewerbsverzerrungen“ und damit für die Wettbewerbsschwäche der französischen Wirtschaft. Ihr ging es allerdings auch um die Zustimmung der Arbeiter zum Gemeinsamen Markt, deren sozialer Besitzstand durch die europäische Integration nicht gefährdet werden durfte. ${ }^{48}$ Die Angleichung der Sozialbestimmungen sollte deshalb nur nach dem höchsten Niveau erfolgen. ${ }^{49}$ Dieses allerdings war, so Robert Marjolin, in weiten Kreisen der französischen Diplomatie nur die Vorstufe zur Forderung nach vollständiger Angleichung der Löhne und anderer Bestandteile der Produktionskosten. $^{50}$

Zur Harmonisierung der Soziallasten forderte Frankreich folgende Maßnahmen ${ }^{51}$ :

- die Herstellung der gleichen Bezahlung von Männern und Frauen innerhalb der ersten zwei Jahre nach Beginn des Binnenmarktes;

- die Angleichung des bezahlten Jahresurlaubs, der Wochenarbeitszeit sowie der Bezahlung von Überstunden während der ersten vier Jahre;

${ }^{47}$ Vgl. MAE, Arbeitspapier, a.a.O., S. 177

48 "A cet égard ... l'harmonisation des législations sociales revêt une importance particulière. En effet, non seulement les charges salariales et sociales ont une incidence déterminante sur les prix de revient, mais l'extension à tous les pays participants des mesures de progrès social introduites par certains d'entre eux rendra également plus apparent, aux yeux des travailleurs, le lien qui doit exister entre l'instauration du Marché Commun et le relèvement des niveaux de vie", Memorandum der französischen Regierung an die Teilnehmer der Konferenz von Venedig, zit. nach Marjolin (1986), a.a.O., S. 284; die Wahrung der sozialen Absicherung war ein erklärtes Ziel des sozialistischen Ministerpräsidenten, vgl. die Regierungserklärung Guy Mollets, S. 8649, abgedruckt in EA, 1955, S. $8648 \mathrm{ff}$.

${ }^{49}$ Vgl. MAE, Arbeitspapier, a.a.O., S. 178

${ }^{50} \mathrm{Vgl}$. Marjolin, a.a.O., S. 284

${ }^{51} \mathrm{Vgl}$. Ambassade de France en Belgique, note du 25.9.1956, in: MAE, série DE-CE, Vol 616-618, S. 2 
- die Angleichung der Sozialgesetzgebungen und des Lohnniveaus dergestalt, daß am Ende der Übergangsperiode alle auf die Lohnkosten einwirkenden Größen europaweit angeglichen wären. ${ }^{52}$

Für Frankreich hätte eine solche Regelung den Vorteil gehabt, als einziger Mitgliedsstaat keinerlei Anpassungsmaßnahmen vornehmen zu müssen. Es stieß mit seinem Ansinnen allerdings auf massiven Widerstand vor allem der deutschen Delegation, die sich aufgrund der bundesdeutschen Tarifautonomie nicht in der Lage sah, den französischen Forderungen zuzustimmen.

Die Auseinandersetzungen über die Harmonisierung der Soziallasten nahmen schnell grundsätzlichen Charakter an. Sie spalteten die Delegationen in ein dirigistisch und ein marktwirtschaftlich orientiertes Lager. Die Fronten verhärteten sich bald, so daß die Streitfrage schließlich auf die Ebene der Außenminister verlagert werden mußte. Eine für den 20. und 21. Oktober 1956 angesetzte Außenministerkonferenz in Paris scheiterte jedoch aufgrund der unversöhnlichen Gegensätze zwischen Deutschland und Frankreich. ${ }^{53}$ Damit steckte die Regierungskonferenz in einer ernsthaften Krise, so daß Paul Henri Spaak, der wieder die Verhandlungen leitete, ihr Scheitern nicht mehr ausschloß ${ }^{54}$ Eine Einigung ergab sich erst im Verlauf der „Suez-Krise“, die am 6. November 1956 mit dem Scheitern der französisch-britischen Militärintervention in Ägypten ihren Höhepunkt erreichte. Auf massiven diplomatischen Druck der USA und der UNO mußten Frankreich und Großbritannien ihre Kampfhandlungen nur zwei Tage nach deren Beginn wieder einstellen, während die Sowjetunion zeitgleich ungehindert den Ungarn-Aufstand blutig niederschlug. ${ }^{55}$ Frankreich blieb nichts anderes übrig, als endgültig den faktischen Verlust seiner Weltmachtrolle anzuerkennen sowie die Hegemonie der Supermächte in ihren jeweiligen Machtbereichen zu akzeptieren.

Die Niederlage am Suez-Kanal wurde innerhalb der französischen Regierung als schmerzliche außenpolitische Niederlage empfunden. ${ }^{56}$ Mit der europäischen Integration bot sich für Frankreich die letzte Möglichkeit, einen weiteren diplomatischen Gewichtsverlust zu vermeiden. ${ }^{57}$ Der französische Ministerpräsident, bisher sehr auf die Rückendeckung der Parteien und Verbände bedacht, setzte sich von diesem Zeitpunkt an entschlossen für einen zügigen und erfolgreichen Abschluß der Verhandlungen ein. $^{58}$

52, „... harmonisation progressive des régimes sociaux et des niveaux de salaires de telle façon qu'à la fin de la période transitoire les charges salariales globales soient équivalent dans les États membres", vgl. Note vom 25.9.1956, a.a.O., S. 2

${ }^{53}$ Vgl. MAE, bilan de la conférence des Ministres des Affaires Étrangères à Paris (20/21 octobre 1956), note du 25.10.1956, in: MAE, série DE-CE, Vol. 613, S. 428-436, S. 431

${ }^{54}$ Vgl. die Schilderung des Verhandlungsverlaufs bei Spaak, P.H. (1969), Combats inachevés, Brüssel, S. $92 \mathrm{ff}$.

${ }^{55} \mathrm{Vgl}$. Gerbet (1987), a.a.O., S. $95-97$

${ }^{56}$ Vgl. Marjolin (1986), a.a.O., S. 294

${ }^{57} \mathrm{Vgl}$. Gerbet (1987), a.a.O., S. 101

${ }^{58} \mathrm{Vgl}$. Marjolin (1986), a.a.O., S. 294 
Die Lösung für den deutsch-französischen Dissens ergab sich dadurch, daß Bundeskanzler Adenauer trotz aller internationalen Proteste an einem länger geplanten Treffen am 6. November 1956 mit Mollet festhielt. Beide Seiten nutzten die veränderte Lage, um sich bei der umstrittenen Anpassung der Soziallasten auf einen Formelkompromiß zu verständigen, der sich später in leicht abgewandelter Form als Zusatzprotokoll im EWG-Vertrag wiederfand: ${ }^{59}$

"Nach Ansicht der Mitgliedstaaten wird die Errichtung des Gemeinsamen Marktes am Ende der ersten Stufe Verhältnisse herbeiführen, unter denen die Grundlagen, bei deren Überschreitung Überstunden vergütet werden, sowie die durchschnittliche Höhe dieser Überstundenzuschläge in der Industrie den betreffenden Werten in Frankreich entsprechen werden, und zwar nach dem Durchschnitt des Jahres 1956." ${ }^{160}$

Sollte dieses nicht der Fall sein, wäre die Kommission gehalten, Frankreich zu ermächtigen, bestimmte Schutzmaßnahmen zur Unterstützung der betroffenen Industrien zu treffen. ${ }^{61}$ Faktisch ließ die französische Regierung damit von ihren wesentlichen Forderungen bei der Harmonisierung der Lohnnebenkosten ab. Da sich hinter dem Streit um die Anpassung der Soziallasten eigentlich die Grundsatzentscheidung über die interventionistische oder marktwirtschaftliche Ausrichtung des Binnenmarktes verbarg, erkannte Frankreich mit seinem Nachgeben die Dominanz des Wettbewerbsprinzips an. Freilich erfolgte dies nicht aufgrund eines schlagartigen Wandels der ordnungspolitischen Überzeugungen, sondern auf Druck außenpolitischer Ereignisse. Das französische Nachgeben in Fragen der Sozialpolitik hatte jedoch seinen Preis. Dafür, daß sich die Harmonisierung der Soziallasten im EWG-Vertrag nur noch in Absichtserklärungen niederschlug, erhielt Frankreich auf anderen Gebieten der Binnenmarktpolitik Kompensationen, die eine zu weitgehende Ausdehnung wettbewerblicher Regelungen verhinderten. ${ }^{62}$

\section{B.1.4.3 Interventionen und Schutzklauseln}

Für den Fall gravierender wirtschaftlicher Schwierigkeiten beanspruchte die französische Regierung, möglichst ungehindert über Eingriffsmöglichkeiten und -mittel verfügen zu können. Wenn sie auch im Memorandum vom 14. Oktober 1955 anerkannte, daß Interventionen grundsätzlich nicht mit dem Gemeinsamen Markt vereinbar seien, so leitete sie daraus keineswegs deren völliges Verbot $a b .{ }^{63}$ Vielmehr präsentierte sie

\footnotetext{
${ }^{59} \mathrm{Zu}$ den Begebenheiten dieser Begegnung und ihrer Auswirkung auf den weiteren Verhandlungsverlauf siehe Müller-Armack, A. (1971), Auf dem Weg nach Europa, S. 115 ff., Tübingen

${ }^{60} \mathrm{Vgl}$. EWG-Vertrag, Protokoll über bestimmte Vorschriften betreffend Frankreich, II. Entgelt für Überstunden (1)

${ }^{61}$ Vgl. EWG-Vertrag, Protokoll über bestimmte Vorschriften betreffend Frankreich, II. Entgelt für Überstunden (2)

${ }^{62}$ Vgl. Art. 117 bis 122 EWG-Vertrag zur Sozialpolitik

${ }^{63}$ Vgl. Memorandum vom 14.10.1955, a.a.O., S. 662
} 
in umständlicher Negativformulierung eine Aufzählung derjenigen Fälle, in denen Interventionen erlaubt sein müßten: "Toute procédure qui n'aurait pas pour objet de corriger des distorsions, d'amortir des perturbations ou de limiter des écarts de prix préjudiciables à l'expansion économique devrait être éliminée. ${ }^{.64}$ Unter dieser Prämisse konnte jede erdenkliche Wirtschaftslage als Ausnahmefall deklariert werden, was darauf hindeutet, daß die französische Regierung nicht ernsthaft gewillt war, sich klar definierten Interventionsrichtlinien zu unterwerfen. Vor allem während der Übergangsperiode erachtete sie das Recht zu Eingriffen als unerläßlich für den Fall, daß bestimmte Produktionen oder gar die gesamte Zahlungsbilanz in eine schwierige Lage gerieten. ${ }^{65}$ Grundsätzlich sollten die Mitgliedstaaten deshalb über die Möglichkeit verfügen, Ausgleichsmaßnahmen (mesures de compensation) und Schutzmaßnahmen (clauses de sauvegarde) treffen zu können.

Beide Maßnahmengruppen waren protektionistischen Charakters. Die "Ausgleichsmaßnahmen" umfaßten längerfristige direkte Eingriffe in den Preismechanismus:

„L'oeuvre d'harmonisation progressive des charges qui interviennent dans la formation des prix de revient exigera de longs délais ... Tant qu'elle ne sera pas achevée, des causes de disparité de prix subsisteront, qui rendront nécessaire l'introduction des mécanismes de compensation. Les pays qui auront à souffrir de l'existence d'une source de disparité de prix établiront les éléments du calcul de cette disparité et mettront en application les mécanismes de compensation correspondants. ${ }^{666}$

Welche konkreten Elemente der Preisbildung hinzugefügt werden sollten, darüber schwieg sich das „Arbeitspapier“ aus. Die „,ausgleichenden“ Eingriffe selbst bestanden in nicht näher genannten Maßnahmen zur Verlangsamung des Zollabbaus, die jedoch durch die Gemeinschaft zu genehmigen sein sollten. ${ }^{67}$

Die „Schutzmaßnahmen“ hatten mehr den Charakter einer wirtschaftspolitischen Notbremse für den Fall ungewöhnlich großer wirtschaftlicher Ungleichgewichte (,déséquilibres graves"). Fälle dieser Art waren aus französischer Sicht gegeben, wenn

- die Zahlungsbilanz ein Defizit erreichte, das eine bestimmte, vorher gemeinsam festgelegte Grenze überschritt;

- das Beschäftigungsniveau eine gewisse, in absolut geleisteten Arbeitsstunden zu bemessende Grenze unterschritt sowie wenn

- die Industrieproduktion eines Mitgliedstaates den Gemeinschaftsdurchschnitt um einen bestimmen Prozentsatz zu unterschreiten drohte. ${ }^{68}$

Für dringende Fälle bestand die französische Regierung auf das Recht, „automatisch“, d. h. ohne vorherige Genehmigung durch die Gemeinschaft, „geeignete“ Maßnahmen

${ }^{64}$ ebenda

${ }^{65} \mathrm{Vgl}$. Memorandum vom 14.10.1956, a.a.O., S. 663 sowie MAE, Arbeitspapier, a.a.O., S. 180

${ }^{66}$ MAE, Arbeitspapier, a.a.O., S. 180

${ }^{67}$ Vgl. MAE, Arbeitspapier, a.a.O., S. 180

${ }^{68}$ Vgl. MAE, Arbeitspapier, a.a.O., S. 181 
treffen zu können. ${ }^{69}$ „Geeignet“ in diesem Sinne waren die Anhebung von Zöllen, die Einführung von Importkontingenten sowie der Rückgriff auf andere außenwirtschaftspolitische Instrumente. ${ }^{70}$ Außerdem sollte ein in Schwierigkeiten geratener Mitgliedstaat Anspruch auf Unterstützung im Rahmen einer "action concertée" durch die Gemeinschaft haben. ${ }^{71}$ Für sich selbst beanspruchte die französische Regierung dabei noch eine weitere Ausnahme: Aufgrund seiner finanziellen Verpflichtungen als Kolonialmacht sollte Frankreich das Recht erhalten, Importsteuern sowie sein System der Exportförderung solange aufrechterhalten zu dürfen, bis die französische Handelsbilanz über eine ,hinreichend lange Zeit" wieder einen positiven Saldo auswies. ${ }^{72}$

Der französischen Regierung gelang es, diese Forderungen im Verhandlungsverlauf teilweise durchzusetzen. Als Gegenleistung für das Entgegenkommen bei der Harmonisierung der Soziallasten, wurde ihr zugestanden, Ausfuhrbeihilfen und Einfuhrabgaben solange beizubehalten, bis sich die Zahlungsbilanz über die Dauer eines Jahres im Gleichgewicht hielt und die Währungsreserven eine „befriedigende“ Höhe erreichten. ${ }^{73}$ Die Partnerstaaten kamen Frankreich ferner in der Ausgestaltung des Artikel 115 EWG-Vertrag (Maßnahmen zur Behebung von Schwierigkeiten) entgegen, der den Mitgliedstaaten im „Dringlichkeitsfall“ erlaubte, „selbst die erforderlichen Maßnahmen zu treffen", die allerdings im Nachhinein von der Gemeinschaft wieder aufgehoben werden konnten.

Weniger erfolgreich war die französische Regierung indessen bei der Ausgestaltung der Bestimmungen zur gemeinsamen Wettbewerbspolitik. Die französische Delegation wehrte sich dagegen, der Kommission auf diesem Sektor ein Verordnungsrecht zu übertragen. Sie wollte den Mitgliedsstaaten die Anwendung der Vorschriften zur Überwachung des Wettbewerbs belassen und der Kommission nur eine koordinierende Funktion zugestehen. ${ }^{74}$ Ebenfalls sollte die Beurteilung der Zulässigkeit von Beihilfen aus dem Zuständigkeitsbereich der Kommission herausgehalten werden. Deutschland und die Niederlande setzten am Ende jedoch durch, daß beides, die Umsetzung und Überwachung der gemeinschaftlichen Wettbewerbs- und Beihilfenpolitik, der Kommission übertragen wurde. ${ }^{75}$ Die Ausarbeitung konkreter Bestimmungen mußte aufgrund der Komplexität der Materie allerdings auf einen Zeitpunkt nach Abschluß des Vertrages verschoben werden.

${ }^{69}$ Vgl. MAE, Arbeitspapier, a.a.O., S. $180 \mathrm{f}$.

${ }^{70}$ Vgl. Memorandum vom 14.10.1955, a.a.O., S. 663

${ }^{71}$ Vgl. MAE, Arbeitspapier, a.a.O., S. 181

${ }^{72} \mathrm{Vgl}$. Ambassade de France en Belgique, note du 25.9.1956 concernant le mémorandum de la délégation française du 19.9.1956, in MAE, série DE-CE, Vol. 616-618, S. 2

${ }^{73}$ Vgl. EWG-Vertrag, Protokoll über bestimmte Vorschriften betreffend Frankreich, I. Abgaben und Beihilfen Abs. (1) bis (3)

${ }^{74}$ Vgl. Memorandum vom 14.10.1955, a.a.O., S. 661 f. sowie Küsters (1982), a.a.O., S. 368

${ }^{75}$ Vgl. Küsters (1982), a.a.O., S. 368 f.; zu den Verhandlungsergebnissen vgl. Art. 85, 86, 87, 91, 92 EWGV 


\section{B.1.4.4 Der Investitions- und Anpassungsfonds}

Schon im Memorandum vom Oktober 1955 forderte die französische Regierung die Einrichtung eines Investitions- und Anpassungsfonds (fonds de réadaptation et d'investissement) zur Angleichung der Wirtschaftsstrukturen im Gemeinsamen Markt. ${ }^{76} \mathrm{Im}$ „Arbeitspapier" wurde dessen Zielsetzung konkretisiert. Die Mittel dieses Fonds sollten weniger wettbewerbsfähigen Mitgliedstaaten zur Verfügung gestellt werden, um ihre Volkswirtschaften zu stärken:

"l'objectif étant que, sous réserve de la réalisation par chaque Gouvernement des efforts qu'il peut raisonnablement fournir les outillages productifs des divers pays membres, soient, à la fin de la période transitoire, suffisamment harmonisé en qualité et en quantité pour qu'une concurrence sans correctifs puisse, à ce moment, s'établir entre eux dans les conditions souhaitables d'équité et d'éfficaçité." 17

Über die Fondsmittel sollten Investitionen unterschiedlichster Art gefördert werden wie z. B.:

- Produktivinvestitionen in Mitgliedstaaten, die in diesem Bereich im Vergleich zu den anderen Gemeinschaftsmitgliedern nur ein „unzureichendes“ Niveau erreichten. In diesen Fällen sollte auf die Bereitstellung verbilligter Kreditmittel (à taux adéquat) zurückgegriffen werden können. Bei Infrastrukturinvestitionen sollten die Kosten sogar in vollem Umfang übernommen werden;

- Rationalisierungs- und Spezialisierungsinvestitionen, die zu einer verbesserten Arbeitsteilung zwischen den Unternehmen der Mitgliedstaaten führten sowie allgemein Investitionen, die den Unternehmen helfen würden, eine für den Gemeinsamen Markt hinreichende Dimension zu erreichen ${ }^{78}$;

- allgemeine Maßnahmen zur Anpassung und Umstellung der Unternehmen und Infrastruktur, die in direktem Zusammenhang mit der Öffnung der Grenzen stünden, sowie Maßnahmen zur Anpassung der Arbeitskräfte an die Erfordernisse des Gemeinsamen Marktes (Ausbildung, Umschulung, etc.). ${ }^{79}$

Die notwendigen Finanzmittel für den Investitions- und Anpassungsfonds sollten von den Mitgliedsstaaten entsprechend der Höhe ihres Nationaleinkommens bereitgestellt werden. ${ }^{80}$ Basis seiner Arbeit sollte eine umfassende Studie über den Modernitätsgrad der nationalen Produktivapparate und der nationalen Möglichkeiten zur Finanzierung notwendiger Anpassungsmaßnahmen sein. Ein zu bildendes Kollektivorgan sollte dabei rückstandsgefährdeten Ländern Vorschläge unterbreiten, wie deren materielle und finanzielle Modernisierungsprobleme gelöst werden könnten.

\footnotetext{
${ }^{76}$ Vgl. Memorandum vom 14. Oktober 1955, a.a.O., S. 661

${ }^{77}$ Vgl. MAE, Arbeitspapier, a.a.O., S. 196

${ }^{78}, \ldots$ investissements permettant de constituer des unités de production assez puissant pour faire face aux besoins d'un marché élargie", vgl. MAE, Arbeitspapier, a.a.O., S. 195

${ }^{79}$ Vgl. MAE, Arbeitspapier, a.a.O., S. 195

${ }^{80} \mathrm{Vgl}$. MAE, Arbeitspapier, a.a.O., S. 195
} 
Frankreich konnte sich mit diesen Vorstellungen nicht vollständig durchsetzen. Sein Anliegen fand insofern Berücksichtigung, als daß sich die Delegationen auf die Gründung eines Sozialfonds einigten, der die Ausbildung, Umschulung und Wiedereingliederung von Arbeitnehmern im Zuge der Integration unterstützen und den Mitgliedstaaten einen Teil ihrer finanziellen Aufwendungen zurückzuerstatten sollte. ${ }^{81}$ Außerdem wurde die Errichtung der Europäischen Investitionsbank beschlossen, die Unternehmen und Gebietskörperschaften in unterentwickelten Regionen sowie die betreffenden Mitgliedstaaten bei ihren Modernisierungsanstrengungen finanziell zu unterstützen hatte. ${ }^{82}$ Damit war zwar dem ursprünglichen Anliegen Frankreichs, die Entwicklungsstände und die Wettbewerbsfähigkeit der Volkswirtschaften im Rahmen einer gemeinsamen Politik zielgerichtet anzugleichen, nicht entsprochen. Immerhin eröffnete der getroffene Kompromiß Frankreich den Zugang zu Fremdmitteln, die es im Rahmen seines nationalen Modernisierungs- und Industrialisierungsprogramms einsetzen konnte, um den Abstand zur industriell mittlerweile führenden Bundesrepublik zu verkleinern. ${ }^{83}$

In Anbetracht der damaligen französischen Finanzkrise war dies ein nicht zu unterschätzender Verhandlungserfolg. Ordnungspolitisch betrachtet zeigte sich mit dem Engagement fur den Investitions- und Anpassungsfonds ein weiteres Mal die skeptische Haltung der französischen Regierung gegenüber dem freien Wettbewerb als Leitprinzip der Wirtschaftsentwicklung. Sie vertraute mehr auf die Leistungsfähigkeit politischer Koordinationsmechanismen und war erst dann bereit, die französische Wirtschaft dem europäischen Wettbewerb auszusetzen, wenn Unterschiede in der Wettbewerbsfähigkeit ausgeglichen waren, also erst dann, wenn sich die eigentlichen Wirkungen des Wettbewerbs erübrigt hätten.

\section{B.1.4.5 Die Koordination der Wirtschaftspolitik}

Das Bemühen um eine politisch koordinierte und kontrollierte Entwicklung der europäischen Volkswirtschaften prägte insbesondere die Vorstellungen der französischen Regierung von der allgemeinen wirtschaftspolitischen Zusammenarbeit in der Gemeinschaft. Ausgangspunkt für die französischen Überlegungen war die grundsätzliche Feststellung, daß der marktwirtschaftliche Wettbewerb allein keine zufriedenstellende wirtschaftliche Entwicklung herbeiführen könne:

"L'établissement des conditions normales de concurrence ne suffirait cependant pas, à lui seul, à assurer dans chacun des pays la réalisation du plein emploi, le maintien de la stabilité monétaire et l'élimination ou l'atténuation des déséquilibres conjoncturels. Il ne permet pas non plus de garantir un déve-

\footnotetext{
${ }^{81}$ Vgl. Art. 123 und 125 EWGV

${ }^{82} \mathrm{Vgl}$. Art. 129 und 130 EWGV

${ }^{83}$ Vgl. Küsters (1982), a.a.O., S. 378
} 
loppement harmonieux de toutes les régions économiques ... C'est aux États qu'il appartient de pratiquer la politique monétaire, la politique de conjoncture et la politique d'expansion appropriées ..." ${ }^{84}$

Die Notwendigkeit einer konzertierten europäischen Wirtschaftspolitik war somit von Beginn an zentraler Bestandteil der französischen Überlegungen zum Binnenmarkt. Innerhalb der Regierung war man sich dabei offenbar bewußt, daß unter den europäischen Partnern abweichende Vorstellungen über das erforderliche Maß an koordinierten wirtschaftspolitischen Eingriffen bestanden. Dementsprechend wies das „Arbeitspapier" explizit nicht nur auf deren Notwendigkeit, sondern auch auf die Schädlichkeit unterschiedlicher Wirtschaftspolitiken innerhalb des Gemeinsamen Marktes hin:

"L'orientation de la vie économique constitue un aspect essentiel des responsabilités qui incombent aux gouvernements ... La poursuite des politiques économiques divergentes dans chacun des pays membres faussait les conditions de la concurrence, multiplierait les raisons de recourir aux clauses de sauvegarde et entraverait le développement rationnel de l'activité économique. ${ }^{185}$

Um der Wirtschaftsentwicklung zu einer ,rationellen“ Entfaltung zu verhelfen, erachtete die französische Regierung die Verpflichtung der nationalen Politiken auf gemeinsame Ziele als notwendig, was wiederum die Errichtung intergouvernementaler Kooperationsorgane sowie gemeinschaftlicher Politikinstrumente erforderlich machte. ${ }^{86}$ Vorrangige Ziele der gemeinschaftlichen Wirtschaftspolitik aus französischer Sicht waren ein hinreichendes Wirtschaftswachstum, Vollbeschäftigung, stabile Währungsbeziehungen und eine ausgeglichene Zahlungsbilanz, wobei dem Wachstums- und Beschäftigungsziel eindeutige Priorität zukommen sollte. ${ }^{87}$ Als Rahmen für die Koordinierung der Wirtschaftspolitiken stellte man sich, so Robert Marjolin, eine Art „planification européenne“ vor. ${ }^{88} \mathrm{Im}$ „Arbeitspapier" selbst fällt zwar nicht der Begriff "planification", einzelne Passagen im Zusammenhang mit der Abstimmung der Wachstumspolitik lassen jedoch kein Zweifel, daß die französische Regierung tatsächlich an etwas wie einen europäischen Wirtschaftsplan gedacht haben muß:

„Une politique d'expansion ... implique des investissements qui, dans les industries de base, dans l'industrie chimique, dans de nombreuses branches des industries de transformation, reposent sur une conception précise des objectifs qui doivent être assignés à la production sur une période de plusieurs années. La convergence des diverses politiques économiques nationales ne peut donc être assurée qu'en rapprochant et harmonisant les objectifs nationaux de production". ${ }^{89}$

Auf gleiche Weise sollten die nationalen Bemühungen zur Sicherstellung der Vollbeschäftigung abgestimmt werden:

\footnotetext{
${ }^{84}$ Vgl. MAE, Arbeitspapier, a.a.O., S. 174

${ }^{85} \mathrm{Vgl}$. MAE, Arbeitspapier, a.a.O., S. 181

${ }^{86}$ ebenda

${ }^{87}$ Vgl. MAE, Arbeitspapier, a.a.O., S. 182

${ }^{88}$ Vgl. Marjolin (1986), a.a.O., S. 284

${ }^{89}$ MAE, Arbeitspapier, a.a.O., S. 174
} 
"À long terme, la poursuite de cet objectif nécessite la mise en oeuvre des politiques nationaux de développement et d'expansion économique, dans le cadre des plans ou programmes établis pour plusieurs années. A court terme elle suppose, en cas de crise conjoncturelle apparaissant dans un pays, un recours rapide aux divers mesures qui permettent d'accroître la demande intérieure: en outre, les États membres doivent apporter au pays en crise une aide concertée."

Wie in dieser Passage des „Arbeitspapiers“ ersichtlich, strebte Frankreich auch im Bereich der kurzfristigen Wirtschaftspolitik eine „Konzertierung“ an. Im Gegensatz zur langfristigen Koordination verlagerten sich die Eingriffe dabei auf die Seite der Nachfrage. Offensichtlich erhoffte man sich, über den Rückgriff auf Gemeinschaftsmittel ein konjunkturelles „fine-tuning“ realisieren zu können. Lang- und kurzfristige Koordination sollten außerdem, so das „Arbeitspapier“, durch die Harmonisierung der nationalen Gesetzgebungen auf den Gebieten der Fiskal-, Währungs-, Kredit- und Sozialpolitik ergänzt werden.

Es gelang Frankreich nicht, sich mit diesen Vorstellungen zur Koordination der Wirtschaftspolitik durchzusetzen. Zwar einigte man sich darauf, die Wahrung eines hohen Beschäftigungsstandes, der Preisstabilität und einer ausgeglichenen Zahlungsbilanz als gemeinsame Ziele der Wirtschaftspolitik festzulegen. ${ }^{91}$ Auch wurde die Konjunkturpolitik zu einer „Angelegenheit von gemeinsamem Interesse“ erhoben..$^{92}$ Insgesamt waren die wirtschaftspolitischen Auffassungen der Mitgliedstaaten jedoch zu unterschiedlich, als daß sie bereit waren, substantielle Kompetenzen in diesem Bereich abzugeben. ${ }^{93}$ Von französischer Seite wurden die Überlegungen des „Arbeitspapiers“ auch nicht mit letzter Kraft verfochten, da ihre Durchsetzung immer auch die nationale Souveränität eingeschränkt hätte. ${ }^{94}$ Klar zeigte sich indes, daß die französische Regierung versuchte, ihre wirtschaftspolitische Konzeption auf europäische Ebene zu übertragen. Mit der Fixierung auf das Wachstums- und Beschäftigungsziel fanden sich die beiden Hauptprobleme der nationalen Wirtschaftspolitik Frankreichs als Ziele einer gesamteuropäischen Wirtschaftspolitik wieder. Über die gemeinsame Zielvereinbarung, die Aufstellung von Entwicklungsplänen und -programmen und über konzertierte Aktionen bei Konjunkturkrisen hätte sich die französische Regierung die nachhaltige Unterstützung der Gemeinschaft bei der Entwicklung der rückständigen, eigenen Industrie gesichert. Dieser Versuch erhärtet letztlich die Vermutung, daß die französische Regierung im Gemeinsamen Markt primär ein Mittel zur Behebung nationaler Wirtschaftsprobleme sah und weniger das „Ferment“ der europäischen Integration, wie es bei den anderen Verhandlungspartnern der Fall war.

\footnotetext{
${ }^{90}$ Vgl. MAE, Arbeitspapier, a.a.O., S. 182

${ }^{91}$ Vgl. Art. 104 EWGV

${ }^{92}$ Vgl. Art. 103 EWGV

${ }^{93}$ Vgl. Küsters (1982), a.a.O., S. 369

${ }^{94}$ Vgl. Küsters (1982), a.a.O., S. 369 f.
} 


\section{B.1.4.6 Die Koordination der Währungspolitik}

Mit dem Abbau der Zollgrenzen wurde eine engere Zusammenarbeit auf dem monetären Sektor und damit auf dem Gebiet der Währungspolitik unumgänglich. Hinsichtlich der Durchführung des Kapitalverkehrs, des Ausgleichs der Zahlungsbilanzen sowie in bezug auf die Wechselkurspolitik mußte eine Einigung gefunden werden. Obwohl Frankreich sich im Memorandum vom Oktober 1955 wie auch im „Arbeitspapier“ für eine enge Koordination auf diesen Gebieten ausgesprochen hatte, bezog es in den Verhandlungen eine zurückhaltende Position. Die französische Geld- und Finanzpolitik befand sich im Verlauf des Jahres 1956 in einer schwierigen Situation. Die stark wachsenden Staatsausgaben vor allem für das militärische Engagement in Algerien und am Suez-Kanal erschwerten die Finanzierung des Haushaltsdefizits zunehmend und hatten die Währungsreserven nahezu aufgezehrt. Hinzu kam ein steigendes Defizit im Außenhandel, das unter anderem auf einen überbewerteten Franc zurückzuführen war. Die völlige Liberalisierung des Zahlungsverkehrs in dieser Situation hätte aus französischer Sicht nur zu einer weiteren Vergrößerung der Zahlungsbilanzprobleme geführt. Die französische Regierung stand einer solchen Maßnahme deshalb äußert reserviert gegenüber und nahm eine dementsprechend restriktive Haltung ein:

"... la France était profondément attachée ... au contrôle des changes. La liberté pour les mouvements de capitaux jouerait, pensait-on, au profit des spéculateurs, qui en profiteraient pour attaquer notre monnaie." 95

Im Falle der Liberalisierung des Kapitalverkehrs befürchtete die französische Regierung eine massive Kapitalflucht. ${ }^{96}$ Für den Gemeinsamen Markt forderte sie, den Regierungen die Entscheidung zu belassen, in welchem Maße sie den Kapitalverkehr freigaben. ${ }^{97}$ Im Laufe der Verhandlungen plädierte sie dafür, Kapitaltransfers nur in Zusammenhang mit produktiven Investitionen zuzulassen. ${ }^{98}$ Die anderen Delegationen gaben den französischen Vorbehalten im Verhandlungsverlauf nach. ${ }^{99}$ Am Ende wurde die Übereinkunft getroffen, den allgemeinen Zahlungsverkehr für Leistungen zu gestatten, die nach dem EWG-Vertrag liberalisiert waren, und weitere Liberalisierungen vorzunehmen, sobald die Wirtschaftslage und der Zustand der Zahlungsbilanz dies erlaubten. ${ }^{100}$ Die Möglichkeit, reine Kapitalgeschäfte durchzuführen, blieb dagegen auf ein - so Artikel 67 (1) EWGV- für das Funktionieren des Gemeinsamen Marktes „notwendiges" Maß beschränkt: "Inutile de dire que l'interprétation française fut plus restrictive que celle du Benelux et de l'Allemagne", so Robert Marjolin. ${ }^{101}$

\footnotetext{
${ }^{95}$ Vgl. Marjolin (1986), a.a.O., S. 297

${ }^{96}$ Vgl. Donnedieu de Vabres (1957), a.a.O., S. 11

${ }^{97}$ Vgl. MAE, Arbeitspapier, a.a.O., S. 184

${ }^{98}$ Vgl. Küsters (1982), a.a.O., S. 362

${ }^{99}$ Vgl Marjolin (1986), a.a.O., S. 297

${ }^{100} \mathrm{Vgl}$. Art. 106 (1) EWGV

${ }^{101}$ Vgl. Marjolin (1986), a.a.O., S. 298
} 
Auf dem Gebiet der Zahlungsbilanzpolitik zeigte Frankreich deutlich mehr Interesse an einer Zusammenarbeit. Hier regte es die Einsetzung eines Währungsausschusses an, der jedoch kein Organ der Gemeinschaft sein sollte, sondern ein Rat von Sachverständigen mit beratender Funktion. ${ }^{102}$ Seine Kompetenzen sollten neben der Beratung der Regierungen und der Kommission auch das Recht umfassen, Kredite aufzunehmen und über deren Verwendung zu disponieren. ${ }^{103}$ Frankreich sah den Ausgleich der Zahlungsbilanzsalden als Angelegenheit von gemeinsamem Interesse an. ${ }^{104} \mathrm{Im}$ Verlauf der Verhandlungen plädierte es sogar für eine Beistandspflicht der Mitgliedstaaten. ${ }^{105}$ Mit dieser Idee traf es jedoch auf wenig Zustimmung bei seinen Partnern, da sie zu offensichtlich im Zusammenhang mit den spezifisch französischen Zahlungsbilanzproblemen stand. Auf deutscher Seite wurden die französischen Vorschläge als direkter „Angriff“ auf die Währungsreserven der Bundesbank interpretiert. Außerdem war man grundsätzlich nicht bereit, sich auf währungspolitischem Gebiet zu konkreten Maßnahmen zu verpflichten, ohne daß zuvor im Bereich der Wirtschaftspolitik verbindliche Verpflichtungen zu einer stabilitätsorientierten Politik vereinbart wurden. ${ }^{106}$ Die Delegationen verständigten sich schließlich auf die Einsetzung eines Währungsausschusses mit dem Status eines beratenden Organs. ${ }^{107}$ Für den Fall gravierender Zahlungsbilanzdefizite wurde ferner bestimmt, der Kommission ein Vorschlagsrecht für Beistandsmaßnahmen einzuräumen, die der Rat mit qualifizierter Mehrheit beschließen können sollte. ${ }^{108}$

Im Bereich der Wechselkurspolitik sprach Frankreich sich grundsätzlich für feste Wechselkurse aus. Es wehrte sich dagegen, Disparitäten in der Entwicklung der europäischen Volkswirtschaften über Wechselkursanpassungen auszugleichen:

"L'élimination des disparités générales des prix peut théoriquement être obtenue par des ajustements de taux de change. Mais l'abaissement du taux de change signifie une réduction du niveau de vie de la population. Faire de ce moyen d'action la procédure normale d'élimination des disparités générales de prix à l'intérieur du marché commun aboutirait à rendre politiquement et socialement indésirable la réalisation de ce marché. L'atténuation progressive des disparités, ..., doit au contraire être recherché par l'harmonisation de plus en plus poussée des charges qui interviennent dans la formation des prix de revient." 109

Die französische Regierung ließ somit keinen Zweifel an ihrer prinzipiellen Ablehnung des Wechselkurses als Anpassungsinstrument. Die Identifizierung von Wechselkursniveau und volkswirtschaftlichem Wohlstand deutete vielmehr darauf hin, daß sie den Wechselkurs in erster Linie als Symbol nationalen Reichtums interpretierte. Allerdings war sein symbolischer Wert nicht so hoch, daß Frankreich der Vereinbarung unverän-

\footnotetext{
${ }^{102}$ Vgl. Küsters (1982), a.a.O., S. $370 \mathrm{f}$.

${ }^{103}$ Vgl. Küsters (1982), a.a.O., S. $370 \mathrm{f}$.

${ }^{104}$ Vgl. Donnedieu de Vabres (1957), a.a.O., S. 11

${ }^{105}$ Vgl. Küsters (1982), a.a.O. S. 372

${ }^{106}$ Vgl. Küsters (1982), a.a.O. S. 371

${ }^{107}$ Vgl. Art. 105 (2) EWGV

${ }^{108}$ Vgl. die Bestimmungen des Art. 108 EWGV

${ }^{109}$ Vgl. MAE, Arbeitspapier, a.a.O., S. 177
} 
derlicher Paritäten zustimmte, wie von den Benelux-Staaten vorgeschlagen. ${ }^{110} \mathrm{Da}$ in dieser Frage die Zurückhaltung bei allen Mitgliedstaaten überwog, einigte man sich, die Wechselkurspolitik ebenfalls als „Angelegenheit von gemeinsamem Interesse“ zu betrachten zu behandeln, ohne weitere konkrete Maßnahmen zu beschließen. ${ }^{11}$

Zusammenfassend läßt sich feststellen, daß die französische Regierung auf dem Währungssektor noch weit weniger als im Bereich der Realwirtschaft bereit war, Marktkräfte frei walten zu lassen. Die symbolische Bedeutung des Wechselkurses als Zeichen nationalen Wohlstands stand einer technisch-instrumentellen Auffassung des Wechselkurses als Marktpreis einer Währung entgegen und erlaubte nicht, den Wechselkurs als Instrument zum Ausgleich unterschiedlicher Wirtschaftsentwicklungen zwischen zwei Währungsräumen zu betrachten. Statt dessen politisierte Frankreich die Wechselkursfrage, indem es vorschlug, die Geldmarktmechnismen durch gemeinsam verwaltete Finanzierungsfazilitäten für Zahlungsbilanzdefizite und durch Kapitalverkehrskontrollen zu ersetzen. Die Gründe dafür waren nur zum Teil sachlicher Natur, d. h. in der prekären Situation der französischen Zahlungsbilanz und dem damaligen Devisenmangel begründet. Robert Marjolin zufolge spielten auch diffuse Ängste vor der Spekulation und unheilvollen ,puissances d'argent" eine Rolle in der französischen Währungspolitik. ${ }^{112} \mathrm{Zu}$ offensichtlich war allerdings der Versuch, das eigene Zahlungsbilanzdefizit durch Rückgriff auf die Währungsreserven der Partnerländer zu finanzieren. Diese waren keinesfalls gewillt, Frankreich über die Reichweite seiner eigenen Finanzierungsmöglichkeiten hinaus in seiner Ausgabenpolitik zu unterstützen. Ihre Zurückweisung der französischen Vorschläge war außerdem auf grundsätzliche Bedenken zurückzuführen, über die Fremdfinanzierung von Außenhandelsdefiziten die Inflation zu fördern und damit die Stabilität des Geldwertes zu unterminieren.

\section{B.1.4.7 Die Errichtung der Zollunion und Außenhandelspolitik}

Auch in Fragen der Zoll- und Außenhandelspolitik war die französische Haltung von Vorsicht gegenüber marktwirtschaftlichen Prinzipien geprägt. Schon im Memorandum vom Oktober 1955 hatte Frankreich den Abbau der Importkontingente nach den Regelungen der OEEC gefordert, die den Fortbestand von Restkontingenten für „sensible“ Produkte zuließen. ${ }^{113}$ Es gelang der französischen Regierung im Verhandlungsverlauf insofern ihre Vorbehalte geltend zu machen, als daß während der Übergangszeit Einfuhrbeschränkungen, die aufgrund der OEEC-Beschlüsse erlaubt waren,

\footnotetext{
${ }^{110}$ Vgl. Küsters (1982), a.a.O., S. 372

${ }^{111}$ Vgl. Art. 107 (1) EWGV

${ }^{112}$ Um den damaligen Ministerpräsidenten Mollet von der Notwendigkeit der Kontrolle des Kapitalverkehrs zu überzeugen, ließ Wirtschafts- und Finanzminister Ramadier ihm Note um Note zukommen, in denen er vor den unheilvollen „Geldmächten“ warnte, bis der Ministerpräsident in der Sache schließlich nachgab, vgl. Marjolin (1986), a.a.O., S. 297

${ }^{113} \mathrm{Vgl}$. Memorandum vom 14.10.1955, a.a.O., S. 662
} 
zunächst beibehalten werden durften. Bis zum Ende der Übergangsperiode mußten diese weitgehend, aber nicht vollständig beseitigt werden. ${ }^{114}$

Beim Abbau der Binnenzölle sprach sich die französische Regierung dafür aus, zunächst nur für die erste Stufe einen 30-prozentigen Abbau zu vereinbaren. ${ }^{115}$ Außerdem plädierte sie dafür, den Zollabbau nicht für alle Produkte einheitlich, sondern nur für zehn fest definierte Produktgruppen vorzunehmen. Auf diese Weise hätten „sensible“ Produkte durch Umschichtungen innerhalb einer Produktgruppe von Zollsenkungen ausgenommen werden können. Frankreich konnte sich mit seinen Vorbehalten teilweise durchsetzen: Im EWG-Vertrag wurde ein Verfahren für die schrittweise vollständige Reduktion der Binnenzölle bis zum Ende der Übergangsperiode vereinbart. Für die einzelnen Stufen wurden dabei Globalsätze festgelegt, die unterteilt waren in einen minimalen Satz, um den alle Zölle zu senken waren, sowie in eine zweite Komponente, innerhalb derer die einzelnen Zollsätze unterschiedlich gesenkt werden konnten, allerdings unter der Voraussetzung, daß insgesamt die Globalquote eingehalten wurde. ${ }^{116}$ Seine Zustimmung zu diesem Verfahren gab Frankreich jedoch nur für das Zugeständnis zu einer Schutzklausel, derzufolge die vereinbarte Zollsenkung in Ausnahmefällen ausgesetzt werden konnte. ${ }^{117}$ Eine entsprechende Regelung wurde in Form des Artikel 15 EWG-Vertrag festgelegt.

Den Übergang zu einem einheitlichen Außenzoll wollte Frankreich schon ab Beginn der ersten Stufe sichergestellt wissen. Seine Höhe sollte sich aus dem gewogenen Mittel der bestehenden Außentarife berechnen, womit Länder mit hohen Zöllen je nach Umfang ihrer Produktion mehr Einfluß auf den gemeinsamen Außentarif gehabt hätten, als Länder mit geringer Außenprotektion. Frankreich begründete diesen Modus wie folgt:

"Il devra être tenu compte du cas particulier des produits qui sont fabriqués dans certains pays participants et ne le sont pas dans d'autres: en général ces derniers pays n'ont en effet pas institué des droits à l'importation pour les produits en cause; une trop forte réduction des droits institués pour les pays producteurs pourrait provoquer l'élimination pure et simple de la production." 118

Der Umstand, daß eine derartige Regelung Nachteile infolge höherer Preise für importabhängige Mitgliedstaaten zur Folge gehabt hätte, spielte in den französischen Überlegungen keine Rolle. Im Gegenteil war die so indirekt eingeführte Präferenz für europäische Produkte aus französischer Sicht sogar erwünscht. ${ }^{119}$ Frankreich setzte sich außerdem dafür ein, während der Übergangszeit und auch nach dem Eintritt in die Endphase des Marktes, Änderungen und Aussetzungen des gemeinsamen Zollsatzes

\footnotetext{
${ }^{114}$ Vgl. die Artikel 30 bis 36 EWGV

${ }^{115} \mathrm{Vgl}$. Memorandum vom 14. 10.1955, a.a.O., S. 662

${ }^{116}$ Vgl. Art. 19 EWGV

${ }^{117}$ Vgl. Küsters (1982), a.a.O., S. 338

${ }^{118} \mathrm{Vgl}$. MAE, Arbeitspapier, a.a.O., S. 179

${ }^{119}$ Vgl. Küsters (1982), a.a.O., S. 344
} 
nur durch einstimmigen Beschluß der Mitgliedstaaten zuzulassen. ${ }^{120}$ Mit dem so erworbenen Vetorecht hätte es jede unliebsame Zollsenkung verhindern können. Es konnte sich allerdings auch mit diesen Vorstellungen nur teilweise durchsetzen. So wurde der gemeinsame Außentarif nach dem arithmetischen Mittel der bestehenden Zölle bestimmt. Seine Änderung bzw. Aussetzung sollte in der Übergangsperiode noch einstimmig, spätestens ein Jahr nach Eintritt in die Endphase des Gemeinsamen Marktes aber mit qualifizierter Mehrheit beschlossen werden. ${ }^{121}$

Da mit der Einführung eines gemeinsamen Außentarifs eine gemeinsame Handelspolitik gegenüber Drittländern erforderlich wurde, mußte schließlich noch eine Regelung für die Vertretungsfrage gefunden werden. Frankreich tendierte in dieser Frage dazu, die Definition der gemeinsamen Handelspolitik als eine intergouvernementale Angelegenheit zu betrachten und der Kommission nur ein Konsultationsrecht einzuräumen. Die Niederlande setzten sich für eine genau entgegengesetzte Regelung ein. Frankreich schlug darauf hin vor, der Kommission nach einstimmiger Mandatserteilung durch den Rat das Recht zur Verhandlungsführung zu übertragen. ${ }^{122}$ Am Ende einigte man sich auf ein kompliziertes Verfahren für die Verteilung der Kompetenzen zwischen Rat und Kommission, in dem beide Positionen Berücksichtigung fanden. ${ }^{123}$

Insgesamt gelang es der französischen Regierung damit auf dem Gebiet der Außenwirtschaft nur teilweise, ihre Vorstellungen durchzusetzen. Ihre Haltung in bezug auf die Öffnung der Märkte war von großer Vorsicht gekennzeichnet. Tendenziell versuchte sie, eine möglichst hohe Außenprotektion zu erhalten. Offensichtlich war sie dabei mehr auf den Schutz der entwicklungsbedürftigen französischen Wirtschaft fixiert, als auf die Förderung des inner- und außergemeinschaftlichen Handels, ganz zu schweigen von der bewußten Nutzung der Wettbewerbsimpulse, die aus der Öffnung von Märkten resuliteren, als Instrument zur Förderung der Wirtschaftsentwicklung.

\section{B.1.4.8 Die Koordination der Agrarpolitik}

Schon im Spaak-Komitee drängte die französische Regierung auf eine gesonderte Behandlung des Agrarsektors im Gemeinsamen Markt. Sie konnte sich damit jedoch nicht durchsetzen, da die Niederlande und Italien Ausnahmen für Agrargüter generell als unbegründet ansahen. ${ }^{124}$ In den Regierungsverhandlungen verfolgte die französische Regierung ihr Anliegen deshalb um so intensiver. ${ }^{125}$ Die Landwirtschaft war von hoher Bedeutung für die französischen Exporteinnahmen und beschäftigte ca. ein Viertel al-

${ }^{120}$ Vgl. Küsters (1982), a.a.O., S. 346

${ }^{121}$ Vgl. Art. 19 und 28 EWGV

${ }^{122}$ Vgl. Küsters (1982), a.a.O., S. 374

${ }^{123}$ Vgl. Art. 110-116 EWG-Vertrag

${ }^{124}$ Vgl. Küsters (1982), a.a.O., S. 174

${ }^{125}$ Vgl. Küsters (1982), a.a.O., S. 174 sowie die Darstellung des Verhandlungsverlaufs zur Frage der Integration der Landwirtschaft S. 347-358 
ler Erwerbsfähigen. Seit längerer Zeit litt allerdings auch dieser Sektor an einer sich stetig verschlechternden Ertragssituation, die vor allem die kleineren Betriebe zunehmend bedrohte. Die französische Regierung war daher vor allem an gesicherten $\mathrm{Ab}$ satzmöglichkeiten für Agrarexporte interessiert. ${ }^{126} \mathrm{Da}$ sie selbst nur auf schwachen Beinen stand, war sie gezwungen, sich eng an den Forderungen der landwirtschaftlichen Berufsverbände $\mathrm{zu}$ orientieren, die in der Nationalversammlung einen großen Rückhalt hatten. ${ }^{127}$ Regierungsintern sah man darüber hinaus in gesicherten Exportmöglichkeiten für französische Agrarüberschüsse eine gerechtfertigte Kompensation für die zu erwartenden großen Anpassungsbelastungen im Bereich der wenig wettbewerbsfähigen Industrie. ${ }^{128}$ Vor den europäischen Partnern jedoch begründete Frankreich die Notwendigkeit einer eigenständigen Marktorganisation für landwirtschaftliche Produkte mit den „besonderen“ Produktionsbedingungen in diesem Sektor, die eine grundsätzliche Wettbewerbsausnahme erforderten:

"... l'élargissement de la concurrence, insuffisant pour assurer la répartition la plus favorable des activités industrielles, l'est tout autant pour assurer celles des activités agricoles. La structure sociale à prédominance familiale de l'agriculture dans les pays participants, la nécessité primordiale d'une stabilité dans les approvisionnements, l'instabilité du marché qui tient à l'influence des conditions atmosphériques et la faible élasticité de la demande exigent une intervention publique étendue dans ce domaine." 129

Unmißverständlich kamen in dieser Feststellung noch einmal die generellen Zweifel der französischen Regierung an der Leistungsfähigkeit des Wettbewerbsprinzips zum Ausdruck. Die im Bereich der Landwirtschaft gewünschte „intervention publique“ bestand in einer besonderen Organisation der Produktmärkte. Deren wesentliches Merkmal sollte ein Preissystem mit garantierten, europaweit einheitlichen Mindestpreisen für jedes einzelne Produkt sein. Die Preise sollten dabei so festgelegt werden, daß sie die Produktion der Nachfrage entsprechend steuerten, gleichzeitig aber auch der landwirtschaftlichen Bevölkerung ein „hinreichendes“ Einkommen ermöglichten, das mit der Entwicklung in der Industrie mithalten konnte. ${ }^{130}$ Der französischen Regierung war dabei bewußt, daß ein solches Agrarpreisniveau üker dem des Weltmarktes liegen würde. Zusätzlich forderte sie deshalb eine gesonderte Protektion des europäischen Agrarmarktes. ${ }^{131}$

Die innere Absicherung der Preise erforderte aus Sicht der französischen Regierung ferner einen speziellen Interventionsmechanismus. Bei Unterschreiten der festgelegten

\footnotetext{
${ }^{126}$ Vgl. Donnedieu de Vabres, a. a. O., S. 6 f.

${ }^{127} \mathrm{Vgl}$. Küsters (1982), a.a.O., S. 348 f. sowie die Darstellungen bei Marjolin (1986), a.a.O., S. 292 f., der sich als stellvertretender Delegationsleiter vor den Verhandlungen mit den Berufsverbänden auseinandergesetzt hatte, um ihren Standpunkt in den Positionen genügend berücksichtigen zu können.

${ }^{128} \mathrm{Vgl}$. Marjolin (1986), a.a.O, S. $299 \mathrm{f}$.

${ }^{129}$ Vgl. MAE, Arbeitspapier, a.a.O., S. 174

${ }^{130} \mathrm{Vgl}$. Ambassade de France en Belgique, note du 30.10.1956, in: MAE: série DE-CE, Vol. 616-618, S. 60

${ }^{131}$ Vgl. Donnedieu de Vabres (1957), a.a.O., S. 6 f.
} 
Mindestpreise auf den jeweiligen Produktmärkten sollten die überschüssigen Mengen über Stützungskäufe aus dem Markt genommen werden, um sie später zu günstigeren Zeitpunkten wieder anzubieten oder zu exportieren. ${ }^{132}$ Außerdem sah Frankreich die Einführung des „Präferenzprinzips“ als unabdingbar an. Jeder Mitgliedstaat sollte seine Agrarimporte vorzugsweise aus Ländern der Gemeinschaft mit überschüssiger Produktion beziehen. Deshalb sollten die Partnerländer schon während der Übergangszeit langfristige bi- und multilaterale Handelsverträge untereinander schließen. ${ }^{133}$ Darüber hinaus sollte durch spezielle Programme der Absatz landwirtschaftlicher Produkte gefördert werden, so z. B. über die „Unterstützung“ des Verbrauchs wirtschaftlich schwacher Konsumenten oder durch gemeinsam finanzierte Ausbildungsprogramme für den Agrarsektor, um das notwendige Wissen für den Absatz von Agrarprodukten unter den Landwirten zu verbreiten. ${ }^{134}$

In bezug auf die außenwirtschaftliche Absicherung des Mindestpreissystems erachtete die französische Regierung eine wirksame Außenprotektion für die Gemeinschaft als notwendig. „Elle doit pouvoir disposer des instruments défensifs et offensifs, tels que le contingentement, le commerce d'état et l'aide à l'exportation ..." ${ }^{135}$ Die Exporthilfen sollten sich vor allem auf unverarbeitete Agrarprodukte erstrecken, wobei sich das Interesse Frankreichs in erster Linie auf die Getreide- (Weizen) und Zuckerproduktion konzentrierte. ${ }^{136}$ Notwendig aus Sicht der französischen Regierung war ferner eine gemeinsame aktive Exportpolitik, um den Absatz überschüssiger europäischer Agrarprodukte auf dem Weltmarkt sicherzustellen, wobei sie sich von der kumulierten Angebots- oder Nachfragemacht der Gemeinschaft eine vorteilhafte Verhandlungsposition erhoffte. ${ }^{137}$

Um möglichst bald in den Genuß dieser Vorteile zu kommen, bestand die französische Regierung darauf, schon während der ersten Stufe der Übergangszeit eine engere Koordination der nationalen Interventionsregime zu realisieren. Wie schon im Bereich der Industrie sollte dies im Rahmen von Plänen und Programmen geschehen:

"Pour ces grands secteurs de base, des programmes coordonnés s'étendant sur plusieurs années devront fixer les objectifs de production en fonction des besoins de consommation prévisible à l'intérieur du marché commun ainsi que des débouchés extérieurs. L'établissement et la réalisation concertée de ces programmes, assorties d'accords de spécialisation, permettront un ajustement graduel des productions et des besoins à des niveaux de prix déterminés, dont le maintien serait assuré par des mécanismes stabilisateurs." ${ }^{138}$

${ }^{132}$ Vgl. MAE, Arbeitspapier, a.a.O., S. 188

${ }^{133} \mathrm{Vgl}$. Ambassade de France en Belgique, Note du 15.10.1956, S. 39 in: MAE, série DE-CE, Vol. 616-618,

${ }^{134}$ ebenda, S. 40

${ }^{135}$ MAE, Arbeitspapier, a.a.O., S. 189

${ }^{136}$ Vgl. MAE, Arbeitspapier, a.a.O., S. 189 sowie Küsters (1982), a.a.O., S. 349

${ }^{137}$ Vgl. MAE, Arbeitspapier, a.a.O., S. 189

${ }^{138}$ MAE, Arbeitspapier, a.a.O., S. 188 
Zur Finanzierung der gemeinsamen Agrarpolitik schlug die französische Regierung die Errichtung eines Ausgleichs- und Garantiefonds vor. ${ }^{199}$ Dessen Mittel sollten zum einen aus regulären Beiträgen der Mitgliedstaaten stammen und zum anderen aus Ausgleichszahlungen derjenigen Länder, die trotz Präferenzprinzip Billigimporte aus Drittstaaten zuließen. Diese sollten die ersparte Differenz zwischen gezahltem günstigeren Einfuhrpreis und dem Marktpreis nach EG-Preisnorm an den Agrarfonds überweisen.

Frankreich präsentierte diese Forderungen am 9. Oktober $1956 .{ }^{140}$ Schon am 30. Oktober konnte es befriedigt feststellen, daß die wesentlichen Elemente von seinen Partnern im Grundsatz angenommen waren. ${ }^{141}$ In allen europäischen Ländern stand die Landwirtschaft vor einem schwierigen Strukturwandel und somit rechneten alle Regierungen damit, in der einen oder anderen Weise von gemeinschaftlichen Agrarregelungen zu profitieren. In Detailfragen allerdings bauten sich schnell große Schwierigkeiten auf, die dazu führten, daß im EWG-Vertrag nur die Grundsätze der Agrarmarktordnung vereinbart werden konnten. Ihre konkrete Erarbeitung wurde auf eine Konferenz nach Vertragsschluß verschoben. Im EWG-Vertrag verpflichteten sich die Mitgliedstaaten zur Stabilisierung der Einkommen der Landwirte durch Preisregelungen, Beihilfen sowie zu Interventionen zwecks Stabilisierung der Agrarpreise. ${ }^{142}$ Der Agrarsektor wurde von den allgemein vereinbarten Wettbewerbsregeln ausgenommen. Für Agrarimporte unter europäischem Preisniveau legten die Vertragspartner die Erhebung von Ausgleichsabgaben fest. ${ }^{143}$ Frankreich konnte damit seine agrarpolitischen Vorstellungen fast vollständig umgesetzt sehen. Erfolglos hingegen war das französische Bemühen, den künftigen Schutz der Landwirtschaft generell auf einem Niveau festzuschreiben, das nicht geringer sein durfte, als der schon bestehende Schutz in den Mitgliedstaaten. ${ }^{144}$

Vom 3. bis 11. Juli 1958 unternahmen die Mitgliedstaaten auf der Konferenz von Stresa den ersten Versuch, eine Basis für die gemeinsame Agrarmarktordnung zu finden. Auch nach der Übernahme der Staatsgeschäfte durch de Gaulle blieb die französische Position in Agrarfragen unverändert. In ihren Instruktionen wurde die französische Delegation angewiesen, die Ausarbeitung einer Bilanz anzustreben, um ein klares Bild der Überschüsse und Defizite der Gemeinschaft bei den einzelnen Agrarprodukten zu erhalten, sowie auf die Notwendigkeit einer gemeinsamen Expansionspolitik im Agrarsektor hinzuweisen. ${ }^{145}$ Außerdem sollten die französischen Delegierten auf die Harmonisierung der Produktionsbedingungen und Rechtsgrundlagen für die Handelspolitiken hinwirken, in Diskussionen über die Beziehungen der Gemeinschaft zu Drittländern

\footnotetext{
${ }^{139} \mathrm{Vgl}$. Ambassade de France, note du 15.10.1956, a.a.O., S. 40

140 ebenda

${ }^{141} \mathrm{Vgl}$. die Note der französischen Botschaft an das Außenministerium vom 30.10.1956, in MAE, série DE-CE, Vol. 641-645, S. $11 \mathrm{ff}$.

${ }^{142} \mathrm{Vgl}$. Art. 39 (1) b. und c. sowie Art. 40 (2) und (3) EWGV

${ }^{143} \mathrm{Vgl}$. Art. 42, 44 und $46 \mathrm{EWGV}$

${ }^{144}$ Vgl. Küsters (1982), a.a.O., S. 357

${ }^{145} \mathrm{Vgl}$. Instructions à la délégation française, in: MAE, série DE.CE, Vol. 647 oder 648, S. $23 \mathrm{ff}$.
} 
jedoch vorerst Zurückhaltung wahren. Der französische Agrarminister akzentuierte diese Schwerpunktsetzung in seiner Rede noch einmal, indem er

- auf die Wichtigkeit von klar definierten Produktionszielen hinwies, die aus einer Projektion der Verbrauchsentwicklung und der Exportentwicklung abzuleiten waren,

- ein umfassendes Preissystem forderte, das einerseits die Einkommensentwicklung in der Landwirtschaft zu berücksichtigen hätte, andererseits aber auch zur Erreichung der gesetzten Produktionsziele motivieren sollte und durch Interventionen zu stabilisieren war, sowie

- sich für gemeinsame mehrjährige Investitionsprogramme einsetzte, um den technischen Fortschritt vor allem bei der Ausrüstung der Betriebe zu unterstützen. ${ }^{146}$

Wie schon im EWG-Vertrag fanden sich auch in der Abschlußerklärung der Konferenz von Stresa viele dieser Forderungen wieder. Die Landwirtschaftsminister vereinbarten

- eine gemeinsame Agrarpolitik mit einheitlichem Preisniveau einzuführen, das einerseits eine rationelle Ausrichtung der Produktion ohne Überschüsse sowie die Steigerung der Produktivität ermöglichte, andererseits aber auch den Anschluß der Einkommensentwicklung in der Landwirtschaft an die allgemeine Entwicklung der Einkommen sicherstellte,

- die familiäre Struktur der Betriebe zu erhalten sowie die freigesetzten Arbeitnehmer beim Übergang in andere Wirtschaftssektoren zu unterstützen und

- den Übersee-Départements Frankreichs Hilfe bei der Entwicklung ihrer landwirtschaftlichen Produktion zukommen zu lassen. ${ }^{147}$

Mit diesem Ausgang der Konferenz konnte Frankreich erneut befriedigt feststellen, daß seine Kernforderungen zumindest in Form von Grundsatzformulierungen berücksichtigt waren. In die Gestaltung der Agrarmarktordnungen flossen damit Vorstellungen ein, die offenbar von der beliebigen Konstruierbarkeit von Wirtschaftsordnungen ausgingen. Neben der nachfragegerechten Versorgung mit Agrarerzeugnissen sollte der von Frankreich angestrebte Agrarmarktmechanismus noch die Einkommenssicherung der Produzenten auf einem politisch erwünschten Niveau gewährleisten, die Anpassung der Produktionsstruktur an den technischen Fortschritt unterstützen und den profitablen Absatz der französischen Agrarüberschüsse garantieren. Zur Sicherstellung seiner Funktionsfähigkeit wurde auf Marktzutrittsbeschränkungen, Interventionsmechanismen und eine exportorientierte Außenhandelspolitik zurückgegriffen. Die realen Auswirkungen solcher Maßnahmen auf die Funktionsweise einer marktwirtschaftlichen Ordnung, die der Agrarmarkt im Kern immer noch war, haben in den französischen Überlegungen keine Rolle gespielt. Die französische Agrarmarktkonzeption war somit ein reines Produkt ordnungspolitischen Konstruktivismus, der die Gestaltung

\footnotetext{
${ }^{146} \mathrm{Vgl}$. Ansprache des französischen Landwirtschaftsministers Roger Houdet auf der Konferenz von Stresa vom 4.7.1958, in: MAE, série DE.CE, Vol. 647 oder 648, S. 68 f.

${ }^{147} \mathrm{Vgl}$. Schlußerklärung der Konferenz von Stresa, in MAE, série DE.CE, Vol. 647 - 648, S 60
} 
von Marktbeziehungen in erster Linie als Problem der technischen Machbarkeit auffaßte.

\section{B.1.5 Die ordnungspolitische Orientierung der französischen Europapolitik wäh- rend der IV. Republik}

Die vorstehenden Abschnitte zeigen, daß Frankreich sich ursprünglich am Gemeinsamen Markt nicht um der europäischen Integration willen beteiligte, sondern um der Gefahr einer außenpolitischen Isolation auf europäischer wie internationaler Ebene zu entgehen. In den Verhandlungen äußerte sich die geringe Europabegeisterung Frankreichs in einer Haltung, die weitgehend auf den Erhalt der eigenen Souveränität bedacht war und von der Europäischen Wirtschaftsgemeinschaft vorrangig Unterstützung für die Modernisierung der eigenen Wirtschaft erwartete. Zu diesem Zweck strebte die französische Regierung schwache Gemeinschaftsinstitutionen an sowie die Errichtung einer Wirtschaftsordnung, die in erster Linie auf eine gemeinschaftlich koordinierte wirtschafts- und währungspolitische Gesamtsteuerung der Wirtschaftsentwicklung hinauslief.

Den marktwirtschaftlichen Wettbewerb als Instrument zur Koordination wirtschaftlicher Abläufe beurteilte die französische Regierung sehr skeptisch. Ihr Hauptanliegen war die Herstellung ,normaler" oder ,gerechter“" Wettbewerbsbedingungen, was darauf hindeutete, daß es in erster Linie bestimmte ethisch motivierte Normvorstellungen waren, die die französische Wettbewerbsauffassung leiteten. Der Idealzustand wirtschaftlichen Wettbewerbs zeichnete sich aus französischer Sicht durch harmonisierte Wettbewerbsbedingungen aus, wobei die Vorstellungen bis hin zur Sicherstellung identischer Faktorpreise reichten - ein utopischer Zustand letztlich, in dem sich jeder Wettbewerb unter den Volkswirtschaften erübrigt hätte. Besonders sensibel zeigte sich Frankreich dabei in sozialpolitischen Fragen. Grundsätzlich zog die französische Regierung vor, die Entwicklung von Wirtschaft und Währung politisch zu entscheiden und zu steuern. Als geeignetes Rahmenkonzept zur Strukturierung der anstehenden Probleme schwebte ihr die Planification vor wie sie im eigenen Land praktiziert wurde. Die dabei zu treffenden Entscheidungen sollten jedoch von den Regierungen selbst und nicht durch Gemeinschaftsorgane vorgenommen werden. Die französische Europapolitik war überdies stark auf die Wahrung der nationalen Souveränität fixiert und daher sehr zurückhaltend in allen Fragen, die auf den Transfer substantieller Kompetenzen hinausliefen.

Aus Sicht der Euckenschen Wettbewerbsordnung betrachtet stellten die französischen Ordnungsvorstellungen einen Fundamentalversto $\beta$ gegen das Grundprinzip eines funktionsfähigen Preismechanismus dar. Hinter der französischen Forderung nach „gerechten“ Wettbewerbsbedingungen verbarg sich im Grunde nichts weiter als der Versuch, über die politisch verabredete Angleichung der Faktorpreise die bestehenden Unterschiede in den nationalen Preisniveaus und damit in der Wettbewerbsfähigkeit 
einzuebnen. Besonders offen gestaltete sich dieser Verstoß im Bereich der Agrarpolitik, wo die Marktpreissteuerung offensichtlich als beliebig manipulierbares Instrument zur Verwirklichung wirtschaftspolitischer Wachstums- und Entwicklungsziele aufgefaßt wurde.

Die währungspolitische Haltung Frankreichs war geprägt durch dogmatisches Festhalten an festen Wechselkursen. Die französische Vorstellung von äußerer Geldwertstabilität war eine politisch dekretierte und nicht eine über die Geldmarktmechanismen eingespielte. Dementsprechend hatte die französische Regierung auch keine Bedenken, auf strenge Kapitalverkehrskontrollen sowie auf die Fremdfinanzierung von Zahlungsbilanzdefiziten als Instrumente der Geldpolitik zurückzugreifen. Stärker noch als auf den Gütermärkten sollte die Stabilität auf dem Währungssektor losgelöst von den Entwicklungen auf den Devisen- und Kapitalmärkten geregelt werden. Die Politisierung der Wechselkursstabilität ist vor allem auf die symbolische Überhöhung des Wechselkurses als Ausdruck nationalen Wohlstands zurückzuführen. Dies schloß von vornherein ein Verständnis des Wechselkurses als Preis einer Währung oder als Instrument zum Ausgleich der unterschiedlichen Wettbewerbsfähigkeit zweier Volkswirtschaften aus. Die von Frankreich gewünschte strikte Kontrolle des Kapitalverkehrs wie auch die gemeinschaftliche Defizitfinanzierung sprachen eher für eine der Geldwertstabilität abträglichen währungspolitischen Haltung.

Ebenfalls kritisch zu bewerten aus Sicht der Wettbewerbsordnung war die damalige französische Position hinsichtlich der Öffnung der Märkte. Mit einer Vielzahl von Initiativen dokumentierte die französische Regierung ihre Zurückhaltung in dieser Frage. Der nur teilweise angestrebte Abbau von Binnenzöllen und mengenmäßigen Handelsbeschränkungen, die Bemühungen Frankreichs um die Erhaltung des Zollschutzes für „sensible“ Produkte, das Pochen auf das Recht, in Dringlichkeitsfällen Handelsbeschränkungen wieder einführen zu dürfen oder das Bemühen um einen möglichst hohen gemeinsamen Außentarif zeigten, daß Frankreich mehr auf die Protektion der europäischen Wirtschaft und der französischen Unternehmen fixiert war als auf die Liberalisierung des Handels.

Die Sorge um das Wohl der eigenen Wirtschaft dominierte die französische Haltung auch in Fragen, in denen das ordnungspolitische Prinzip der Einheit von Gestaltungsmacht und Haftung berührt war. Mit sektoriellen Wirtschaftsplänen und einer antizyklischen Nachfragesteuerung sollte die Grundlage für ein stetiges Wachstum geschaffen werden. Über Finanzierungshilfen sollten Rationalisierungs-, Spezialisierungs- und Erweiterungsinvestitionen gefördert werden. Die Angleichung der Faktorpreise wiederum hätte die Standortunterschiede in der Wettbewerbsfähigkeit aufgehoben. Den Unternehmen hätten sich nach den französischen Ordnungsvorstellungen bei politisch opportunem Verhalten viele Handreichungen geboten, mit denen sich der Staat in ihre Planungs- und Investitionsaktivitäten eingeschaltet hätte. Die unternehmerische Haftung wäre durch diese Unterstützungsmaßnahmen herabgesetzt worden. Der Anreiz zur vorsichtigen Disposition des Unternehmenskapitals wäre reduziert, weil der Staat mit 
seinen Subventionen einen Teil des finanziellen Risikos bei Investitionen übernommen hätte. Auch dürfte der Wettbewerb sich teilweise vom Markt weg hin zum Wettbewerb um Subventionen verlagert haben, was auf längere Zeit eine Veränderung der Unternehmermentalität weg vom Pionierunternehmer, hin zum risikoaversen und innovationsscheuen „rent-seeking“ bewirkt hätte. Letztlich hätte die französische Regierung mit ihren Vorschlägen auf Dauer den Ansporn zu unternehmerischem Denken herabgesetzt und damit ihren eigenen Klagen über das mangelnde Geschäftsinteresse der Unternehmerschaft Vorschub geleistet.

In bezug auf das Prinzip der „Monopolkontrolle“ ließen die französischen Ordnungsvorstellungen nur wenig konkrete Tendenzen erkennen. Mit der finanziellen Förderung von Erweiterungsinvestitionen sollte das Entstehen von Großunternehmen gezielt gefördert werden. Allerdings ließen sich aus diesen Ergebnissen noch keine direkten Rückschlüsse auf den Umgang mit Monopolen ziehen. Kritisch an diesen Vorschlägen zu bewerten war jedoch der Versuch, die Bestimmung von Unternehmensgrößen politischen Erwägungen zu unterwerfen, statt ausschließlich marktlichen Erfordernissen zu folgen.

Eindeutig zu bewerten hingegen war die Haltung Frankreichs auf dem Gebiet der Einkommenspolitik. Mit intensivem Einsatz bemühte sich die französische Regierung, die Entlohnung des Produktionsfaktors Arbeit der Regelung über den Markt zu entziehen. Die Angleichung der indirekten Bestandteile der Arbeitskosten (bezahlter Urlaub, Arbeitszeit) wie auch direkter Lohnbestandteile (Überstundenbezahlung) war aus französischer Sicht Gegenstand der staatlichen Sozialpolitik und nicht der Marktkoordination. Durch die politische Festlegung wesentlicher Elemente der Entlohnung wäre die automatische Anpassung von Angebot und Nachfrage auf dem Arbeitsmarkt eingeschränkt worden. Unterhalb der vorgeschriebenen Minima hätte es keine Verhandlungen über die Bestandteile der Entlohnung mehr geben können. Nach Erreichen der Minimallöhne wäre der Lohn in seiner Funktion als Knappheitsanzeiger ausgefallen. Insgesamt hätten die von Frankreich geforderten Harmonisierungsmaßnahmen gegen die Forderung nach einer möglichst unverzerrten Primärverteilung der Einkommen über die Arbeitsmärkte verstoßen.

In bezug auf die Vorhersehbarkeit und Stetigkeit der Wirtschaftspolitik ließ sich bis zum Abschluß der Regierungsverhandlungen natürlich noch kein Erfahrungswert ermitteln. Dennoch deutete das Bemühen Frankreichs um eine planifizierende, die wirtschaftliche und konjunkturelle Entwicklung bestimmende Politik auf eine generelle Tendenz zur Politisierung des Wirtschaftslebens hin. In Anbetracht der Vielzahl der geforderten Interventionsmöglichkeiten hätten Veränderungen auf politischer Ebene ungehindert auf den Wirtschaftsablauf durchschlagen können. Der Kalkulierbarkeit wirtschaftlicher Entwicklungen im Sinne einer verstetigten Erwartungsbildung wäre eine solche Entwicklung abträglich gewesen. 
Die französischen Ordnungsvorstellungen waren damit offensichtlich auf eine interventionistische Wirtschaftsordnung ausgerichtet, in der Richtung und Ziel der wirtschaftlichen Entwicklung Gegenstand politischer Entscheidungen sein sollten. Die politisch gesetzten Ziele hätten durchaus Koordinationsspielräume für den marktwirtschaftlichen Wettbewerb gelassen, nur fand sich nirgends ein Hinweis darauf, ob und wo aus französischer Sicht Grenzen für politische Eingriffe in das Wirtschaftsgeschehen bestehen sollten. Im Verhandlungsprozeß unterlag Frankreich letztlich mit seiner Ordnungskonzeption. Die vereinbarte europäische Wettbewerbsordnung akzeptierte es nur widerstrebend und unter dem Druck seiner außenpolitischen Niederlagen. Wenn Frankreich in der ordnungspolitischen Grundsatzentscheidung auch unterlegen war, so gelang es ihm doch, zahlreiche interventionistische Marktausnahmen durchzusetzen. Den größten Erfolg konnte es mit der Marktausnahme für den Bereich der Landwirtschaft erringen. Hier geriet der Wettbewerb zu einer staatlich administrierten Veranstaltung, in der ein politisch manipulierter Preismechanismus zur gewünschten Wachstums- und Einkommensentwicklung führen sollte. Ohne Rücksicht auf die Funktionsfähigkeit dieser Konstruktion wurden wirtschaftliche und sozialpolitische Interessen mit Elementen der Wettbewerbsordnung kombiniert. Die Agrarmarktordnung war letztlich das Abbild der ordnungspolitischen Idealvorstellungen der französischen Regierung, deren Übertragung auf den Gemeinsamen Markt ihr jedoch verwehrt blieb. 


\section{B.2 Frankreichs Binnenmarktpolitik unter Charles de Gaulle (1958-1969)}

In die bis zum 29. April 1969 dauernde Amtszeit Charles de Gaulles fiel fast die gesamte Übergangsperiode zur Verwirklichung der Europäischen Wirtschaftsgemeinschaft. De Gaulle übernahm von seinen Vorgängern die Mitgliedschaft in einer EWG, deren ordnungspolitische Ausrichtung französischen Interessen in vielfältiger Weise zuwider lief. Außerdem erinnerte die EWG mit ihrem supranationalen Integrationsansatz sowie in ihrem institutionellen Aufbau stark an frühere Integrationsversuche auf wirtschaftlichem und militärischem Gebiet (EGKS, EVG), die de Gaulle persönlich zu ihrer Zeit vehement bekämpft hatte. ${ }^{1}$ Herausragende europapolitische Ereignisse in den sechziger Jahren waren die Ablehnung der Erweiterung des Binnenmarktes sowie die Krise von 1965 im Zusammenhang mit dem Übergang zur dritten Stufe des Übergangsprozesses, die beide maßgeblich von Frankreich mit verursacht wurden und die europäische Integration ab Mitte der sechziger Jahre in eine Phase lähmender Stagnation führten.

\section{B.2.1 Die europapolitische Konzeption \\ B.2.1.1 Die wirtschaftlichen Rahmenbedingungen}

Am 13. Mai 1958, nachdem noch drei weitere Regierungen der Guy Mollets gefolgt waren, führte die Algerienkrise zum endgültigen Zusammenbruch der IV. Republik. Charles de Gaulle, dem zum zweiten Mal in einer Krise die Regierungsgeschäfte übertragen wurden, reagierte auf die bestehenden Probleme, indem er eine Staatsreform durchsetzte, die zur Gründung der V. Republik führte. Es kam zur Ausarbeitung einer neuen Verfassung, in der die Kompetenzen der Regierung und vor allem des Staatspräsidenten zu Lasten der Nationalversammlung deutlich gestärkt wurden. Konnte in der IV. Republik die Regierung jederzeit durch wechselnde Mehrheiten in der Nationalversammlung gestürzt werden, so war es nach der Verfassung der V. Republik der Staatspräsident, der den Premierminister ernannte, den Vorsitz in Ministerratssitzungen führte und die Nationalversammlung, deren Kompetenzen im wesentlichen auf ihre gesetzgeberische Funktion zurückgeführt wurden, auflösen konnte. ${ }^{2}$ Außerdem wurde auf dem Gebiet der Außenpolitik dem Staatspräsidenten die Verhandlungsführung und der Abschluß von Verträgen übertragen. ${ }^{3}$ Somit wechselte die Außenpolitik und damit die Europapolitik Frankreichs in die neu geschaffene „domaine réservé“ des Präsidenten, die - im Gegensatz zur IV. Republik - dem Einfluß der Nationalversammlung weitgehend entzogen war. ${ }^{4}$

\footnotetext{
${ }^{1}$ Vgl. Jouve, E. (1965), Die Europa-Politik Frankreichs unter de Gaulle, S. 262, in: EA, Folge 7/1965, S. 261-274

${ }^{2}$ Zur institutionellen Neuordnung siehe Schütze, W. (1959), De Gaulle vor der Bewährungsprobe, S. 88 ff., in: EA, Folge 4/1959, S. 87-108

${ }^{3}$ Vgl. Titel VI, Art. 52 und 53 der Verfassung vom 4.10.1958

${ }^{4}$ Vgl. Grosser, A. (1986): Frankreich und seine Außenpolitik, München, S. 185
} 
Parallel zur Verfassungsreform griff de Gaulle in die krisenhafte Entwicklung der französischen Wirtschaft ein. Auf der Grundlage des Berichts einer Expertenkommission setzte er ein wirtschafts- und finanzpolitisches Sanierungsprogramm durch, das Frankreich über eine restriktive Wirtschafts- und Geldpolitik sowie marktwirtschaftliche Reformen zurück auf den Wachstumspfad brachte. Es umfaßte eine drastische Reduzierung der Subventionen und der Verwaltungsausgaben, den Abbau bestehender Marktzugangsbeschränkungen und zahlreicher Preisindexierungsmechanismen sowie eine Abwertung des Franc um 17,55 Prozent. ${ }^{5} \mathrm{Da}$ mit der Rückführung der Staatsausgaben und der Anpassung des Franc-Wechselkurses an die außenwirtschaftliche Realität die wesentlichen Hindernisse für das Wachstum der ansonsten entwicklungsbereiten französischen Wirtschaft beseitigt waren, führte dieses Reformprogramm umgehend zu einer Gesundung der wirtschaftlichen Lage. ${ }^{6}$ Bis in die Studentenunruhen von 1968 hinein erlebte Frankreich ein stabiles Wachstum, begleitet von einer entspannten Lage der Zahlungsbilanz und im Beschäftigungssektor. De Gaulle war somit in verhältnismäßig kurzer Zeit nach seiner Ernennung zum Staatspräsidenten von den wirtschaftlichen Schwierigkeiten befreit, die seine Vorgänger noch stark belastet hatten. Damit war Handlungsspielraum gewonnen, der ihm zur Realisierung seiner europapolitischen Vorstellungen zur Verfügung stand.

\section{B.2.1.2 Der Inhalt der europapolitischen Konzeption}

Charles de Gaulle folgte einer europapolitischen Konzeption, die nicht mit dem supranationalen Integrationskonzept der Römischen Verträge übereinstimmte, die auf die Überwindung der Nationalstaaten in Europa angelegt waren. ${ }^{7}$ De Gaulles Vorstellungen von einer Gemeinschaft der europäischen Staaten beruhten im Kern auf zwei Leitbildern, die nebeneinander existierten: Auf der "grandeur" Frankreichs und einer bestimmten Vorstellung von der Einheit Europas. ${ }^{8}$ Diese Dualität von Nationalstaat und Union führte ihn zwangsläufig zu einem Integrationsmodus, der mit dem Gedanken der Supranationalität kollidierte.

Grundlegend im politischen Denken de Gaulles war die Rolle der Nationen. Die Nation stellte für ihn in erster Linie einen kulturellen Begriff dar. ${ }^{9}$ Sie transzendierte in der Form des Nationalstaates alle Wesenszüge der menschlichen Gemeinschaft und verkörperte als Schöpfer und Verwalter der modernen Kultur das vollkommenste Pro-

\footnotetext{
${ }^{5}$ Vgl. Rueff, J. (1959), Bericht zur Finanzlage, in: Ordo, Band 11, S.3-67, hier: S. 26 ff sowie S. $37 \mathrm{ff}$.

${ }^{6}$ Vgl. Vesperini (1993), a.a.O., S. $12 \mathrm{ff}$.

${ }^{7}$ Vgl. Schütze, W. (1972), Frankreichs Außenpolitik im Wandel von de Gaulle zu Pompidou, S. 13, in: EA, Folge 1/1972,S. 11-20

${ }^{8}$ Vgl. Schomerus, J. (1963), De Gaulles Europa-Konzeption im Spiegel seiner Memoiren und Reden, S. 325, in: EA, Folge 9/1963, S. 323-332

9 ebenda
} 
dukt der menschlichen Geschichte. ${ }^{10}$ Sie war Ziel und Krönung aller Politik und stellte in Form des souveränen Nationalstaats die einzige Realität dar, die in der Geschichte wirklich zählte. ${ }^{11}$ Unverständlich war daher für de Gaulle der Gedanke, daß diese, in langwierigen, teilweise schmerzhaften Prozessen entstandenen Einheiten, die er als höchste Ausdrucksformen menschlichen Daseins betrachtete, auf einmal aufhören sollten zu existieren. ${ }^{12}$ Dementsprechend konnte das vereinte Europa nur ein Europa sein, das auf diesen Einheiten aufbaute und sie in sich weiter bestehen ließ, nicht aber ihre Auflösung anstrebte. De Gaulle strebte ein „Europa der Staaten“ an - Staaten, die, seiner Ansicht nach, aufgrund ihrer Seele, ihrer Geschichte, ihres Ruhmes und ihres Ehrgeizes zwar verschieden seien, letztlich aber die einzig wirklichen Autoritäten verkörperten. Nur sie verfügten über das Recht, Gesetze zu verabschieden bzw. über den Anspruch auf Gehorsam, und deshalb konnten nur sie die „Realitäten Europas“ darstellen, auf denen der europäische Einigungsprozeß aufzubauen war: ${ }^{13}$

„Es ist eine Schimäre, zu glauben, man könnte etwas Wirksames schaffen und daß die Völker etwas billigen, was außerhalb oder über dem Staat stehen würde. Gewiß trifft es zu, daß, bevor man das Europaproblem in seiner Gesamtheit behandelt hat, gewisse mehr oder weniger supranationale Einrichtungen geschaffen werden konnten. Diese Einrichtungen haben ihren technischen Wert, aber sie haben und können keine Autorität und politische Wirksamkeit besitzen. Solange nichts Ernstliches geschieht, funktionieren sie ohne viel Komplikationen, doch sobald ein dramatischer Umstand eintritt oder ein großes Problem zu lösen ist, stellt man fest, daß diese oder jene hohe Behörde auf die verschiedenen Nationen ohne Autorität ist und daß nur die Staaten über eine solche verfügen, ... ${ }^{\text {“14 }}$

Der supranationale Integrationsansatz der Römischen Verträge mußte somit für de Gaulle zwangsläufig zum Scheitern führen, weil es den Gemeinschaftsinstitutionen immer an der nötigen Autorität den Mitgliedstaaten gegenüber fehlen würde. Da Europa, so de Gaulle, nun einmal nicht über einen „Föderator“ verfüge, der ausreichend Macht, Kredit und Fähigkeiten habe, um die Nationen in eine neue Einheit zu integrieren, und es außerdem für ihn undenkbar war, daß die Völker sich Gesetzen unterwürfen, die von „ausländischen Abgeordneten“ verabschiedet würden, sah er die Gemeinschaft in einer unbefriedigenden „Zwittersituation“, von der er nicht glaubte, daß sie je

${ }^{10}$ Vgl. Ziebura, G. (1965), Ideologische Grundlagen der Außenpolitik de Gaulles, S. 278 f., in: EA, Folge 8/1965, S. 275-284

${ }^{11}$ ebenda

12 „A quelle profondeur d'illusion ou de parti pris faudrait-il plonger, en effet, pour croire que des nations européennes, forgés au long des siècles par ses efforts et des douleurs sans nombre, ayant chacune sa géographie, son histoire, sa langue, ses traditions, ses institutions, pourraient cesser d'être elles-mêmes ...?, de Gaulle, C. (1971), Mémoires d'espoir, Paris, S. 151; zu den Unterschieden im Verständnis des Nation-Begriffs zwischen Deutschland und Frankreich siehe Kolboom, I. (1985), Une certaine idée de la France ... Nachtrag zu einem deutsch-französischen Mißverständnis über Nation und Europa, Vortrag, gehalten am 13.6.1985 im Kolloquium „Deutsch-französische Beziehungen in der Krise" im HAUS-RISSEN, Hamburg

${ }^{13}$ Vgl. die Pressekonferenz de Gaulles vom 5.9.1960, D 304, abgedruckt in Auszügen in: EA, Folge 21/1960, D 297 - D 307

${ }^{14}$ ebenda 
lebendige dauerhafte Wirklichkeit werden konnte. ${ }^{15}$ So, wie die supranationale Integration im allgemeinen für ihn etwas Unsinniges darstellte und zwangsläufig zum Scheitern verurteilt war, da sie sich gegen die Natur der Dinge richtete ${ }^{16}$, so war es der Versuch, die europäischen Volkswirtschaften unter der Führung einer machtlosen Zentralbehörde zu integrieren, im besonderen. Da niemand eine „wichtige wirtschaftliche Maßnahme ergreifen kann, ohne einen politischen Akt zu vollziehen“, konnte es auch niemals eine „ausländische Technokratie“ bzw. „ein technokratischer vaterlandsloser niemandem verantwortlicher Aeropag "17 sein, der über das Schicksal der Nationen gebot, sondern nur die wahren Inhaber der Macht selbst: die Regierungen der Staaten. $^{18}$

De Gaulles Vision eines „Europa der Staaten“ lief deshalb auf eine Neuorientierung der 1957 beschlossenen Gemeinschaft hinaus. Er wollte es neu strukturieren und auf den „wahren“ machtpolitischen „Realitäten“ - den Mitgliedstaaten - aufbauen. Aus den drei Gemeinschaften EGKS, EWG, EAG sollte eine „politische Union“ entstehen, in der die verantwortlichen Regierungen alle wichtigen Fragen regelmäßig gemeinsam beraten und, wenn möglich, Probleme gemeinsam lösen sollten. ${ }^{19}$ De Gaulle wollte ein „concert des États“, in dem sich die Nationen durch „systematische Annäherung“ langsam aneinander gewöhnten, um so in Zukunft zu einer größeren Einheit zu finden. ${ }^{20}$ Diese sollte idealerweise die Form einer Konföderation annehmen, wäre damit jedoch eine Staatengemeinschaft geblieben und nicht die vollintegrierte Einheit, auf die der EWG-Vertrag ausgerichtet war. ${ }^{21}$

Die Neuorientierung der europäischen Integration war für de Gaulle nicht nur ein Akt der politischen Vernunft, sondern auch eine historische Notwendigkeit. Aufgrund der gemeinsamen historischen Erfahrung, des gemeinsamen christlichen Glaubens und der gleichen Lebens- und Denkweise gab es für ihn eine gewisse Verwandtschaft zwischen den Völkern Europas. ${ }^{22}$ Die gemeinsamen Ideale, die gemeinsame Kultur sowie der gemeinsame Beitrag zum Fortschritt der Menschheit, zu ihrer Zivilisation, so de Gaulle, hätten unter den europäischen Nationen ein Gefühl der Solidarität aufkommen

${ }^{15}$ Vgl. die Pressekonferenz de Gaulles vom 15.5.1962, D 332 f., abgedruckt in Auszügen in: EA, Folge 13/1962,D 330 - D 334; seine tiefe innere Abneigung gegen die Integration drückte er einleitend zu den vorstehenden Äußerungen aus: „,... und außerdem glaube ich nicht, daß Europa eine lebendige Wirklichkeit sein kann, wenn es nicht Frankreich mit seinen Franzosen, Deutschland mit seinen Deutschen und Italien mit seinen Italienern usw. umfaßt. Dante, Goethe, Chateaubriand gehören ganz Europa, gerade weil sie in erster Linie Italiener, Deutsche oder Franzose waren. Sie hätten Europa keinen großen Dienst erwiesen, wenn sie Staatenlose gewesen wären und in irgendeinem integrierten Esperanto oder Volapük geschrieben und gedacht hätten.“

${ }^{16} \mathrm{Vgl}$. Ziebura (1965), a.a.O., S. 280

${ }^{17}$ Ein Ausdruck, mit dem de Gaulle vor allem auf die Europäische Kommission zielte, vgl. die Pressekonferenz de Gaulles vom 9.9.1965, EA, Folge 1965, D 490

${ }^{18} \mathrm{Vgl}$. die Stellungnahme de Gaulles in seiner Pressekonferenz vom 15.5.1962, a.a.O., D 332

${ }^{19}$ Vgl. die Pressekonferenz vom 5.9.1960, a.a.O., D 304

${ }^{20}$ Vgl. de Gaulle (1971), a.a.O., S. 137

${ }^{21}$ Vgl. de Gaulle, Pressekonferenz vom 21.2.1966, EA, Folge 6/1966, D 146

${ }^{22}$ ebenda 
lassen, aus dem der natürliche Wunsch herrühre, sich zu vereinigen. ${ }^{23}$ In der gemeinsamen Kulturleistung der europäischen Staaten lag allerdings nicht nur die ,raison d'être“ Europas, sondern auch die Grundlage einer europäischen „Mission“: Als „foyer" der Zivilisation konnte Europa sich in einer von Kriegen geschüttelten und von zwei militärischen Supermächten beherrschten Welt unmöglich auf sich selbst zurückziehen. Vielmehr hätte es dem Frieden und dem Fortschritt der Menschheit zu dienen. ${ }^{24}$ Europa sollte der Welt wieder zu mehr Gleichgewicht verhelfen und mit seiner überlegenen politischen Erfahrung als Schiedsrichter zwischen dem atlantischen und sowjetischen Lager auftreten. ${ }^{25}$ Die Universalität seiner im Kern auf christlichen Werten beruhenden Zivilisationsmission ließ das Europa de Gaulles weit über den Rahmen der Sechsergemeinschaft hinausgehen. Natürlicherweise erstreckte es sich für ihn vom Atlantik bis an den Ural. ${ }^{26}$ Aufgrund der Realitäten der Nachkriegswelt war er jedoch gezwungen, seine Vision vorerst auf Westeuropa zu beschränken.

Um seine Mission erfüllen zu können, mußte dieses Europa für de Gaulle gleichberechtigt neben den Weltmächten bestehen. Aus seiner Sicht war es deshalb erforderlich, die Selbstbeschränkung auf die wirtschaftliche Zusammenarbeit aufzugeben und ein ,europäisches Europa“ zu begründen, das eine eigene, unabhängige Politik verfolgte. ${ }^{27}$ Diese Abgrenzung war für de Gaulle um so notwendiger, als daß er die Rolle Europas weniger von der militärischen Macht der Sowjetunion bedroht sah, als vielmehr von den wirtschaftlich übermächtigen USA, der unangefochtenen Führungsmacht des Westens, die Frankreich in den Konferenzen von Jalta und Potsdam von der Gestaltung der Nachkriegsordnung ausgeschlossen hatte und Europa dadurch zu banalisieren drohten, daß sie ein neues Gleichgewicht der Mächte zwischen den UdSSR, den USA und China anstrebten. ${ }^{28}$ Um dieser Gefahr $\mathrm{zu}$ entgehen, mußte das ,europäische" Europa sich wieder auf seine Souveränität konzentrieren, was notwendigerweise auch einen gewissen Abstand zum traditionell ,,atlantisch“ orientierten Großbritannien implizierte und das ,europäische Europa“ auf den Kontinent beschränkte. ${ }^{29}$

Unter den so verbleibenden kontinentaleuropäischen Nationen war es Frankreich, dem aus Sicht de Gaulles natürlicherweise die Führungsrolle zufallen mußte. Der Grund

\footnotetext{
${ }^{23}$ Vgl. Schomerus (1963), a.a.O., S. 325

${ }^{24}$ Vgl. de Gaulle (1971), a.a.O., S. 137

${ }^{25}$ Vgl. Ziebura (1965), a.a.O., S. 283

26 „Europa, Mutter der modernen Zivilisation, muß vom Atlantik bis zum Ural entstehen, in Eintracht zusammenarbeiten, um seine gewaltigen Hilfsmittel zu entwickeln und gemeinsam mit Amerika, seiner Tochter, die Rolle zu spielen, die ihm zukommt, um zwei Milliarden Menschen zu dem dringend notwendigen Fortschritt zu verhelfen“, Vgl. de Gaulle, Pressekonferenz vom 4.2.1965, Folge 4/1965, D 97

${ }^{27} \mathrm{Vgl}$. Pressekonferenz de Gaulles vom 23.7.1964, D 405, abgedruckt in Auszügen in: EA, Folge 16/1964, D 404 - D 410

${ }^{28}$ Das gespannte Verhältnis de Gaulles zu den Vereinigten Staaten sowie der als persönliche Demütigung erfahrene Ausschluß von den Konferenzen zur Gestaltung der Nachkriegsordnung finden sich ausführlich dargestellt bei Ziebura (1965), a.a.O., S. $278 \mathrm{ff}$.

${ }^{29}$ Vgl. de Gaulle (1971), a.a.O., S. 137
} 
dafür lag weniger darin, daß Italien und insbesondere die Bundesrepublik als Kriegsverlierer zu einer gewissen Zurückhaltung gezwungen waren. Frankreichs Führungsrolle ergab sich für de Gaulle vielmehr aus seiner Geschichte und Zivilisation, die aus seiner Sicht von beispielhaftem Wert für die Menschheit waren. ${ }^{30}$ Aus seinen Traditionen, aus seiner ,grandeur" heraus hatte Frankreich, so de Gaulle, schon seit Jahrhunderten die Gewohnheit angenommen, „Baumeister“ Europas zu sein. ${ }^{31}$ Die Berufung der französischen Nation zu Höherem leitete er aus seiner „certaine idée de la France“ $a b .{ }^{32}$ Aus ihr bestimmte sich die Sendung Frankreichs an den Rest der Welt, welche in dem ,universellen Zweck" bestand, die „Würde und den Fortschritt aller Menschen" zu wahren. Sie rechtfertigte gleichzeitig den Anspruch Frankreichs auf einen herausgehobenen Rang unter allen Nationen. ${ }^{33}$ Den Fortschritt der Menschen, das Ziel des „nationalen Strebens“ Frankreichs, verstand de Gaulle dabei global als Sammelbegriff für alle politisch herbeigeführten positiven Entwicklungen auf wirtschaftlichem, sozialem und bevölkerungspolitischem Gebiet sowie auf der Ebene der internationalen Politik. ${ }^{34}$ Die französischen Erfolge auf all diesen Ebenen, so de Gaulles Überzeugung, waren in der Geschichte ohne Präzedenzfall. Vor allem die unterdrückten Völker im europäischen Osten sowie die sich entwickelnden Staaten Lateinamerikas und Asiens würden in dem Selbstbewußtsein sowie in dem freien Willen, mit dem Frankreich sein Fortschrittsziel verfolge, immer wieder einen „Ansporn zum Mut und zur Vernunft“

${ }^{30}$ Zur ,grandeur“ Frankreichs bei de Gaulle siehe Schomerus (1963), a.a.O., S. 326 und Zibura (1965), a.a.O., S. $277 \mathrm{f}$.

31 „Le peuple français“, so de Gaulle in einem Gespräch mit Adenauer, „avait, pendant des siècles, pris l'habitude d'être le mastodonte de l'Europe et c'est le sentiment qu'il avait de sa grandeur, par conséquent de sa responsabilité, ...“, de Gaulle (1971), a.a.O., S. 143

${ }^{32}$ „Zeit meines Lebens begleitet mich eine bestimmte Vorstellung vom Wesen Frankreichs. Das Gefühl hat sie mir ebenso eingegeben wie der Verstand. Was in mir an Gemütskräften lebendig ist, sieht Frankreich wie eine Märchenprinzessin oder die Madonna an der Kirchenwand, berufen zu einem großartigen und außergewöhnlichen Schicksal. Mein Instinkt sagt mir, die Vorsehung habe Frankreich zu vollkommenen Erfolgen oder zu vorbildlichen Leiden erschaffen. Zu Zeiten, da Mittelmäßigkeit Frankreichs Tun und Lassen kennzeichnet, habe ich das Gefühl einer absurden Anomalie, die auf das Versagen der Franzosen zurückgehen muß, nicht auf den Genius des Vaterlandes ... Auch sagt mir mein Verstand, daß Frankreich nicht Frankreich ist, wenn es nicht an erster Stelle steht, daß nur großartige Unternehmungen den Hang unseres Volkes zur Zersplitterung auszugleichen vermögen und daß sich unser Land, so wie es nun einmal ist, unter anderen Ländern, so wie sie nun einmal sind, ein hohes Ziel setzen muß, wenn es nicht in tödliche Gefahr geraten will. Kurz, ich glaube, ohne Größe kann Frankreich nicht Frankreich sein“, de Gaulle, C., (1959), mémoires de guerre - L'appell, zit. n. Schomerus (1963), a.a.O., S. 326

${ }^{33}$ Vgl. de Gaulle (1971), a.a.O. S. 133

34 „Ein Volk wie das unsere müht sich nicht ab, schafft sich keine Stabilität und hilft nicht, den Frieden zu erhalten, um sich nur mit dem Erreichten zufrieden zu geben. Der Fortschritt ist heute Ziel unseres nationalen Strebens" so de Gaulle in seiner Neujahrsansprache für das Jahr 1963, D 52, abgedruckt in: EA, 2/1963, D 51 f. 
entdecken. ${ }^{35}$ Seine Beispielhaftigkeit zwinge Frankreich letztlich dazu, ,in der Welt eine eigene Rolle zu spielen" und auf seine Souveränität zu achten: ${ }^{36}$

„... eine fünfzehnhundertjährige Geschichte hat uns gelehrt, daß es nicht ohne Schwierigkeiten, ohne Risiken und ohne Kosten möglich ist, Frankreich zu sein. Aber wie eh und je halten wir auch heute an der Unabhängigkeit fest, zunächst, weil wir es so seit vielen Jahrhunderten gehalten haben, und ferner, weil wir auf Grund von mannigfaltigen Erfahrungen glauben, daß wir am besten beurteilen können, was wir zu tun haben, und schließlich, weil die Auslöschung Frankreichs für die ganze Welt ein Unglück wäre ${ }^{\text {c637 }}$.

Um der Welt dieses Unglück zu ersparen und Frankreich seiner „säkularen Berufung“ nachkommen zu lassen, die letztlich die Sache Europas und aller freien Länder der Welt sei, wurde die nationale Souveränität von de Gaulle in den Stand der Unantastbarkeit erhoben. ${ }^{38}$ Die hohe Bedeutung der französischen Zivilisationsmission, die de Gaulle letztlich auf Europa übertragen wollte, für die Menschheit, erforderte, daß Frankreich als Nation und Staat bestehen blieb: „... weil die Union Westeuropas - ... ein Hauptziel unseres außenpolitischen Wirkens ist, wollen wir nicht in ihr auf gehen. ${ }^{639}$

Stellt man diese Vision neben das Integrationsvorhaben der Römischen Verträge, so wird umgehend klar, daß der hier niedergelegte wirtschaftliche Integrationsversuch für de Gaulle viel zu kurz griff. Der EWG-Vertrag mit seiner Idee, die Integration der Volkswirtschaften zur Grundlage eines europäischen Einheitsstaats zu machen, litt aus seiner Sicht an einem kapitalen und irreparablen Geburtsfehler. Daß Frankreich unter de Gaulle dennoch nicht aus der EWG austrat, war hauptsächlich auf die wirtschaftlichen Vorteile zurückzuführen, die auch de Gaulle erkannte und die er für die entwicklungsbedürftige französische Industrie und die französische Landwirtschaft nutzen wollte. ${ }^{40}$ Der EWG-Vertrag hatte für ihn dementsprechend eher den Rang eines Handelsvertrages. ${ }^{41}$ Die notwendigerweise mit ihm verbundene Einbindung Frankreichs in die EWG betrachtete er als unabwendbare „marriage de raison“. ${ }^{42}$ Im wesentlichen bildete die Sechsergemeinschaft für de Gaulle eine geeignete Ausgangsbasis für seine ambitionierte europapolitische Konzeption. Unter der geistigen und moralischen Führung Frankreichs sollten die Mitgliedstaaten zu einem mächtigen „europäischen Europa" vereinigt werden, das zum Wohle der Menschheit einen gleichberechtigten

${ }^{35}$ So de Gaulle in einer Rede in Lyon am 28.9.1963, D 556, abgedruckt in Auszügen in: EA, Folge 22/1963, D $555 \mathrm{f}$.

${ }^{36}$ Vgl. die Rundfunk- und Fernsehansprache am 19.4.1963, D 281, abgedruckt in: EA, Folge 11/1963, D $281 \mathrm{f}$.

${ }^{37}$ de Gaulle in seiner Rede vom 28.9.1963, a.a.O., D 555

${ }^{38}$ Vgl. die Ausführungen zur Größe Frankreichs bei Schomerus (1963), a.a.O., S. 326

${ }^{39}$ So de Gaulle in seiner Rundfunk- und Fernsehansprache vom 19.4.1963, a.a.O., D 281

${ }^{40}$ Vgl. de Gaulle (1971), a.a.O., S. 128

${ }^{41}$ Vgl. Hirsch, E. (1988): Ainsi va la vie, Lausanne, S. 171

${ }^{42}$ Vgl. Jouve, E. (1975): Le Général de Gaulle et l'Europe, in: Joel Rideau et. al. (Hrsg.): La France et les Communautés Européenes, Paris, S. 49-62, hier: S. 61 
Rang neben den Hegemonialmächten der Nachkriegszeit beanspruchte, ohne dabei die Souveränität seiner Mitgliedstaaten anzutasten.

De Gaulle legte mit dieser Konzeption ein schlüssiges Konzept vor, dessen geistige Wurzeln, ausgehend von der geographischen Ausdehnung des ,europäischen Europas“, von seiner Zivilisationsmission sowie von der Fixierung de Gaulles auf die Rangordnung der Mächte, noch weitgehend in der europäischen Vorkriegsordnung ruhten. Die grundlegenden Bestandteile dieses Konzeptes, die Anschauungen de Gaulles von Nation, Zivilisation und Fortschritt, reichten sogar noch weiter bis ins 17. Jahrhundert zurück, d. h. in die Zeit der Aufklärung und des vorrevolutionären Frankreichs. ${ }^{43}$ De Gaulle übertrug diese Vorstellungen und insbesondere das Zivilisationsideal, welches er für sein eigenes Land definiert hatte, auf Europa, das damit praktisch zum verlängerten Arm des politischen Gestaltungswillens Frankreichs wurde. Europa war fester Bestandteil der Außenpolitik de Gaulles, die Gilbert Ziebura als leidenschaftlichen Versuch charakterisierte,

„,...die von der Kriegsallianz inaugurierte Ordnung durch eine andere, bessere, weil seiner Meinung nach den realen Erfordernissen des Friedens eher entsprechende Ordnung zu ersetzen, wobei unterstellt wird, daß dieses Ziel ohne Europa nicht erreichbar ist und daß Europa keinen besseren Anwalt seiner wahren Interessen finden kann als Frankreich. ${ }^{* 44}$

\section{B.2.1.3 Die Umsetzung der europapolitischen Konzeption}

Auf der Grundlage seiner Europakonzeption begann de Gaulle bald, die wiedergewonnene Handlungsfreiheit Frankreichs zu nutzen, um die politische Realität der Sechsergemeinschaft seinen Vorstellungen anzupassen. De Gaulle wollte sie zur Keimzelle einer neuen europäischen „Union“ machen, in der die politische Zusammenarbeit außer auf die Wirtschaft auch auf andere Gebiete ausgedehnt werden sollte:

"Diese Union der Sechs kann und muß eine der Grundmauern sein, auf denen erst das Gleichgewicht und dann die Zusammenarbeit und schließlich eines Tages vielleicht der Zusammenschluß (Union) ganz Europas aufgebaut werden, was unserem Kontinent die Möglichkeit verleihen würde, seine eigentlichen Probleme zu lösen, ..., und als Hauptwiege der Zivilisation einen Grad der materiellen und menschlichen Entwicklung zu erreichen, der seinen Fähigkeiten und Mitteln entspricht. Überdies wäre diese Union der Sechs, wenn sie zustande käme, schon jetzt ein aktives Element der Ordnung für den Fortschritt, das Einvernehmen, den Frieden aller Völker der Welt." ${ }^{45}$

Im Sommer 1960, vor dem Hintergrund wachsender Spannungen zwischen den USA und der UdSSR, kündigte Frankreich eine entsprechende Initiative zur Neuorganisation der europäischen Zusammenarbeit an. ${ }^{46}$ Ihr folgten Verhandlungen über die Errich-

\footnotetext{
${ }^{43}$ Vgl. Schomerus (1963), a.a.O., S. 324

${ }^{44}$ Vgl. Ziebura (1965), a.a.O., S. 283

${ }^{45}$ Pressekonferenz de Gaulles vom 21.2.1966, abgedruckt in: EA, Folge 6/1966, D 146

${ }^{46}$ „Contribuer à bâtir l'Europe occidentale en un groupement politique, économique, culturel et humain, organisé pour l'action, le progrès, la défense, c'est à quoi la France veut s'appliquer ... Sans
} 
tung einer „politischen Union“, in der die Staats- und Regierungschefs sowie die Außenminister regelmäßig gemeinsam über Fragen der Außen-, Wissenschafts-, Kulturund Verteidigungspolitik beraten und entscheiden sollten. ${ }^{47}$

Frankreich wollte auf diesem Wege die ungenügende „wirtschaftliche Konstruktion“ durch weitere politische Institutionen ergänzen, um die Europäische Wirtschaftsgemeinschaft zu einem „politischen Ganzen“" zu machen. ${ }^{48}$ Auf diese Weise versuchte es, die eingeschlagene Entwicklung in Richtung Supranationalität umzudrehen und die Gemeinschaft in die entgegengesetzte Richtung hin zu einer Konföderation zu bewegen, die das von de Gaulle präferierte Integrationsmodell darstellte. ${ }^{49}$ Unabhängig von der bestehenden Organisation sollten ein Rat der Staats- und Regierungschefs sowie weitere Ministerräte für Außen-, Kultur- und Wissenschaftspolitik geschaffen werden. Diese waren als Gremien gedacht, in denen die Regierungen sich daran gewöhnen sollten, politische Fragen gemeinsam zu behandeln und ihre Politik aufeinander abzustimmen, allerdings ohne irgend eine Seite dabei konkreten Zwängen zu unterwerfen. ${ }^{50}$ Die französische Initiative scheiterte jedoch im April 1962 nach über einjährigen Verhandlungen, weil die übrigen fünf Mitgliedstaaten, und unter diesen insbesondere die Niederlande, nicht hinnehmen wollten, daß mit einem Rat der Staats- und Regierungschefs außerhalb der EWG ein zweites wirtschaftspolitisches Entscheidungsgremium geschaffen würde, welches, oberhalb der bestehenden Institutionen angesiedelt, in der Lage war, mit seinen Entscheidungen den mühsam erreichten Integrationsstand wieder zu gefährden. ${ }^{51} \mathrm{Da}$ de Gaulle aber auf keinen Fall bereit war, die Kompetenz dieses höchsten Gremiums einzuschränken, kam es zu keiner Einigung. Die Verhandlungen wurden auf unbestimmte Zeit vertagt. Zur Enttäuschung des Generals blieb es vorerst bei dem vereinbarten supranationalen Integrationsmodus.

Frankreich blieb also zunächst nichts anderes übrig, als zur Kenntnis zu nehmen, daß seine Partner es vorzogen, den Aufbau des Gemeinsamen Marktes in Zusammenarbeit mit einer engagiert und betont selbständig auftretenden Kommission fortzusetzen. Der französische Versuch, die Basis der Zusammenarbeit auszudehnen und die abgegebenen Kompetenzen faktisch wieder auf die intergouvernementale Ebene zurückzuverla-

doute, aussi, faut-il que les nations qui s'associent ne cessent pas d'être elles-mêmes et que la voie suivie soit celle d'une coopération organisée des Etats, en attendant d'en venir, peut-être, à une imposante Confédération.“, de Gaulle (1971), a.a.O., S. 682 sowie die außenpolitische Erklärung der französischen Regierung vom 25.7.1960, abgedruckt in: EA, Folge 17/1960, D 235 - D 237

${ }^{47}$ Siehe die verschiedenen französischen Entwürfe für eine politische Union, abgedruckt in: EA, Folge 19/1964, D 466 ff.

${ }^{48}$ Vgl. Pressekonferenz de Gaulles am 15.5.1962, D 331, abgedruckt in Auszügen in: EA, Folge 13/1962, D 329 - D 333,

${ }^{49}$ Vgl. Pressekonferenz vom 9.9.1965, D 490, abgedruckt in Auszügen in: EA, Folge 19/1965, D 486 D 494

${ }^{50}$ ebenda

${ }^{51} \mathrm{Zu}$ den konkreten Differenzen zwischen Frankreich und den Fünf vgl. o. V., Vom FouchetAusschuß am 15.3.1962 angenommener Entwurf mit Alternativtexten für die Artikel, in denen keine Einigung erzielt wurde, in: EA, Folge 19/1964, D 467-D 485; zum Scheitern der Verhandlungen vgl. Jouve (1965), a.a.O., S. 270 
gern, war gescheitert. Frankreich konnte diese Situation solange akzeptieren, wie die wesentlichen Entscheidungen innerhalb der Gemeinschaft einstimmig zu fällen waren, es also mit seinem Veto jede unannehmbare Initiative blockieren konnte. Mit dem Übergang zur dritten Stufe, die am 1. Januar 1966 beginnen sollte, wäre allerdings der überwiegende Teil der Gemeinschaftsentscheidungen mit Mehrheitsbeschlüssen zu fällen gewesen. Da die Beschlüsse des Ministerrates laut EWG-Vertrag die Initiative der Kommission voraussetzten, wäre so der Einfluß dieser supranationalen Institution gewachsen, die de Gaulle seit ihrem Bestehen ein Dorn im Auge war. Er sah eine Bedrohung der Souveränität Frankreichs heraufziehen, da es in wichtigen Fragen hätte überstimmt werden können. ${ }^{52}$ Auch wäre der politische Führungsanspruch Frankreichs in der Gemeinschaft durch den faktischen Kompetenzzuwachs der Kommission in Frage gestellt worden.

Um dieses zu verhindern, nutzte Frankreich am 30 Juni 1965 die Gelegenheit, sich unter dem Vorwand einer nicht fristgerecht verabschiedeten Finanzierungsregelung für die gemeinsame Agrarpolitik aus den Gemeinschaftsinstitutionen zurückzuziehen und seine Mitarbeit im Ministerrat vorerst einzustellen. Erst als ihm sieben Monate später

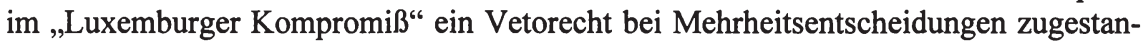
den wurde, erklärte es sich bereit, dem Übergang in die dritte Stufe der Übergangsphase zuzustimmen und seine Mitarbeit wieder aufzunehmen. Somit wendete sich die Krise der Gemeinschaft noch zum Guten. Frankreich konnte den Integrationsfortschritt zwar nicht in die von ihm gewünschte Richtung leiten, immerhin war es ihm jedoch gelungen, Europa auf dem Weg in die Supranationalität zu stoppen. Die anderen Mitgliedstaaten konnten indessen das Fortbestehen der Gemeinschaft verbuchen. Allerdings wirkte die unnachgiebige Haltung, mit der Frankreich seine Interessen durchgesetzt hatte, nach. In der zweiten Hälfte der sechziger Jahre erlosch unter den Mitgliedstaaten der Gemeinschaft jegliches Engagement für eine Vertiefung der Zusammenarbeit.

Neben der inhaltlichen und strukturellen Ausrichtung der Gemeinschaft war auch die Gestaltung ihrer Außenbeziehungen zwischen Frankreich und den anderen Mitgliedstaaten umstritten. Der EWG-Vertrag war hinsichtlich des Zutritts zum Gemeinsamen Markt grundsätzlich auf eine weitgehende Öffnung der Märkte ausgelegt. Nach Artikel 237 EWG-Vertrag sollte allen europäischen Staaten der Zutritt zum Binnenmarkt grundsätzlich offenstehen. In Artikel 18 EWG-Vertrag erklärte sich die Gemeinschaft darüber hinaus bereit, die Außenhandelsbeziehungen durch den Abbau der Zölle nach dem Prinzip der Gegenseitigkeit zu fördern. Einer ersten Prüfung wurden diese Bekenntnisse schon kurz nach der Gründung der Gemeinschaft ausgesetzt. Großbritannien schlug, als es wider Erwarten feststellen mußte, daß der erfolgreiche Abschluß des EWG-Vertrags bevorstand, die Errichtung einer Freihandelszone im Rahmen der OEEC vor. Es versuchte auf diese Weise, wirtschaftlich den Anschluß an den Binnenmarkt zu erhalten, ohne sich den Verpflichtungen aus dem Integrationsprozeß unter-

${ }^{52} \mathrm{Vgl}$. die ausführliche Kritik de Gaulles an der Kommission sowie seine Ablehnung von Mehrheitsentscheidungen auf der Pressekonferenz vom 9.9.1965, a.a.O., D $490 \mathrm{ff}$. 
werfen zu müssen. ${ }^{53}$ Dieser Vorschlag stieß innerhalb der OEEC und auch unter den zukünftigen Mitgliedstaaten der EWG auf allgemeines Interesse. Dementsprechend wurden am 13. Februar 1957 Verhandlungen mit dem Ziel aufgenommen, den Handel mit Industriegütern schrittweise von Zöllen und mengenmäßigen Beschränkungen zu befreien. ${ }^{54}$ Landwirtschaftliche Produkte hingegen sollten jedoch auf britischen Wunsch von den Handelsgesprächen ausgeschlossen bleiben.

Frankreich verhielt sich diesem Vorhaben gegenüber von Anfang an zurückhaltend, da es in dem britischen Vorschlag vornehmlich ein Störmanöver gegen den erfolgreichen Abschluß des EWG-Vertrages sah. ${ }^{55}$ Es bezog erst eindeutig Stellung als die Verhandlungen über die Freihandelszone nach einem erfolglosen ersten Jahr langsam Konturen annahmen. In einem Memorandum an die Fünf vom März 1958 forderte die französische Regierung, das Inkraftreten der Freihandelszone für mindestens drei Jahre aufzuschieben, um dem Gemeinsamen Markt Zeit zur Entwicklung zu geben. Ausserdem sollten in den Teilnehmerländern die Wettbewerbsbedingungen sowie die Wirtschaftspolitik zunächst harmonisiert werden. Darüber hinaus wollte Frankreich die Liberalisierung des Handelsverkehrs nur schrittweise und getrennt nach Wirtschaftsektoren zulassen. Von Großbritannien forderte es überdies die Aufgabe seiner privilegierten Stellung im Handel mit den Dominions. ${ }^{56}$

Diese Forderungen erschwerten den Fortschritt der Verhandlungen und wurden allseits als brüskierend empfunden. ${ }^{57}$ Als ihr Abschluß im Herbst 1958 dennoch erstmals in Sichtweite rückte ${ }^{58}$ erklärte der französische Regierungssprecher am 14. November 1958 überraschend, daß eine Freihandelszone für Frankreich unter den gegebenen Bedingungen immer noch nicht akzeptabel sei. ${ }^{59}$ Frankreich forderte zusätzlich einen gemeinsamen Außentarif, konkrete Überlegungen zur Gründung einer Wirtschaftsunion sowie die Einbeziehung der Landwirtschaft in die Verhandlungen, was jedoch, wie alle Regierungen wußten, nicht realisierbar war. Diese seitens de Gaulle bewußt inszenierte Provokation während laufender Verhandlungen - selbst die eigene Delegation war nicht informiert - führte zur sofortigen Unterbrechung durch Großbritannien. Ein vier Wochen später durchgeführter Versuch zur Wiederaufnahme der Gespräche verlief ergebnislos, so daß diese auf unbestimmt vertagt wurden. Damit war der erste Versuch, den Gemeinsamen Markt nach außen zu öffnen, auf französisches Betreiben hin gescheitert. De Gaulle fürchtete die Zerstörung des Gemeinsamen Marktes durch dessen

\footnotetext{
${ }^{53} \mathrm{Vgl}$. die Ausführungen zur britischen Haltung im Hinblick auf die EWG bei Küsters (1982), a.a.O., S. 280-293

${ }^{54}$ Vgl. Gerbet (1987), a.a.O., S. 123

${ }^{55}$ Vgl. Jouve, E. (1975), Le Général de Gaulle et l'Europe, in: Joël Rideau et. al. (Hrsg.): La France et les Communautés Euopéennes, Paris, S. 49-62, hier: S. 56

${ }^{56} \mathrm{Vgl}$. Gerbet (1987), a.a.O., S. $127 \mathrm{f}$.

${ }^{57}$ Vgl. Müller-Armack (1971), a.a.O., S. 210

${ }^{58}$ Vgl. Müller-Armack (1971), a.a.O., S. 216

${ }^{59}$ Vgl. Couve de Murville, M., (1971), Une politique étrangère, Paris., S. 43
} 
Integration in eine Freihandelszone. Er zog die Konsolidierung des Erreichten der Erweiterung des Binnenmarktes vor und konnte sich mit dieser Haltung durchsetzen. ${ }^{60}$

Nachdem sich die im Anschluß an die gescheiterten Bemühungen um die Freihandelszone auf OEEC-Ebene gegründete European-Free-Trade-Area (EFTA) bald als wenig vorteilhaft erwiesen hatte, ersuchte Großbritannien mit seinen EFTA-Partnern 1961 formal um Aufnahme in die Gemeinschaft. Noch im selben Jahr begannen die Beitrittsverhandlungen, die jedoch schon binnen kurzem über die aus den Verhandlungen über die europäische Freihandelszone bekannten Streitpunkte ins Stocken gerieten. $\mathrm{Zu}$ diesen Schwierigkeiten trug unter anderem der von Frankreich durchgesetzte umständliche Verhandlungsmodus bei, nach dem Großbritannien nicht mit der Kommission, sondern direkt mit den sechs Regierungen verhandeln mußte. Trotz dem rückte der Verhandlungserfolg Ende 1962 langsam in Sicht, so daß der britische Beitritt schon fast außer Frage stand ${ }^{61}$ als de Gaulle - erneut auch für die französische Delegation überraschend - völlig unerwartet am 14. Januar 1963 in einer Pressekonferenz den britischen Beitritt mit folgender Begründung als faktisch unmöglich erklärte:

„Großbritannien ist ein Inselstaat, ausgerichtet auf die See. Es ist durch seinen Handel, seine Märkte und seine Versorgung an die verschiedensten, oftmals weit entlegenen Länder gebunden. Es ist in erster Linie ein Industrie- und Handelsstaat, der nur wenig Landwirtschaft betreibt. Es besitzt in all seinem Tun Gewohnheiten und Traditionen, die sehr ausgeprägt und eigener Art sind. Kurzum, das Wesen, die Struktur und die Umstände, die Großbritannien eigen sind, unterscheiden es weitgehend von den kontinentalen Staaten ... Es müßte ein ganz anderer Gemeinsamer Markt in Erwägung gezogen werden. Aber dieser Markt zu Elf, dann zu Dreizehn und vielleicht auch zu Achtzehn würde sicherlich in keiner Weisen dem gleichen, den die Sechs aufgebaut haben ... Es ist vorauszusehen, daß der Zusammenhalt all dieser sehr zahlreichen und verschiedenartigen Mitglieder jenen Problemen nicht lange gewachsen wäre, und schließlich würde es dann zu einem Koloß von atlantischer Gemeinschaft in amerikanischer Abhängigkeit und unter amerikanischer Führung kommen, der die Europagemeinschaft aufsaugen würde. Das ist eine Hypothese, die in den Augen gewisser Leute durchaus richtig sein mag, aber es ist nicht das, was Frankreich gewollt hat und will, nämlich eine ausgesprochen europäische Konstruktion." ${ }^{62}$

Klar erkennbar waren es geostrategische Überlegungen, die de Gaulle die Markterweiterung ablehnen ließen. Er reagierte mit dieser Erklärung auf die damalige politische Annäherung zwischen den USA und Großbritannien in Fragen der Atomrüstung sowie auf die Politik des „grand design“ des US-Präsidenten Kennedy, der im Juli 1962 in einer aufsehenerregenden Rede den Vorschlag zur Gründung einer „atlantischen Gemeinschaft" der freien europäischen Staaten und der USA gemacht hatte. De Gaulle allerdings sah darin eine Bedrohung seiner europapolitischen Konzeption und vor allem der Führungsrolle Frankreichs auf dem Kontinent. ${ }^{63}$ Nachdem

${ }^{60} \mathrm{Vgl}$. Gerbet (1987), a.a.O., S. $129 \mathrm{f}$.

${ }^{61}$ Vgl. Gerbet, P. (1983), La construction de l'Europe, S. $298 \mathrm{f}$.

${ }^{62}$ Vgl. Pressekonferenz de Gaulles am 14.1.1963, D 89, abgedruckt in: EA, Folge 4/1963, D 87-90

${ }^{63}$ Vgl. de la Serre, F. (1975), La France et l'élargissement des Communautés Européennes: La candidature britannique, in: Joël Rideau: La France et les Communautés Européennes, Paris, S. 743- 
die französische Initiative zur politischen Einigung Europas erfolglos war, konnte eine um Großbritannien erweiterte Gemeinschaft $\mathrm{zu}$ nichts anderem führen als $\mathrm{zu}$ einem „protectorat américain“64. Mit dem „brutalen Abbruch“ der Verhandlungen erreichte Frankreich zwar, daß die von ihm befürchtete Gefahr gebannt war, allerdings um den Preis seiner vorläufigen innergemeinschaftlichen Isolation und des weitgehenden Stillstands des Integrationsprozesses für den Rest des Jahres $1963 .{ }^{65}$

Aus französischer Sicht war dieser Preis indessen nicht zu hoch. In welchem Maße Frankreich die Erweiterung der Gemeinschaft als Bedrohung empfand ließ sich vier Jahre später erkennen als Großbritannien, nach einem erneuten Regierungswechsel, ein zweites Beitrittsgesuch an die Gemeinschaft richtete. Dieses wurde von de Gaulle erneut zurückgewiesen, diesmal allerdings schon fünf Tage nach seiner Überreichung. Wieder auf einer Pressekonferenz verkündete er, daß Großbritannien die für einen Beitritt notwendigen wirtschaftlichen und politischen Umwandlungen immer noch nicht vollzogen habe. ${ }^{66}$ Sechs Monate später, auf einer weiteren Pressekonferenz, begründete er die endgültige Ablehnung des britischen Beitritts damit, daß

"... wollte man ihn dennoch durchsetzten, würde das offensichtlich den Zerfall einer Gemeinschaft bedeuten, die nach Regeln aufgebaut wurde und funktioniert, welche eine so monumentale Ausnahme nicht vertragen ... Damit Europa der immensen Macht der Vereinigten Staaten die Waage zu halten vermag, darf man es nicht schwächen, sondern muß im Gegenteil die Bedingungen und Regeln der Gemeinschaft verstärken ... Somit hängt alles nicht etwa von Verhandlungen $a b$, die für die Sechs einen Marsch in die Selbstaufgabe darstellen würden, der den Tod ihrer Gemeinschaft zur Folge hätte, ..."67

Erneut erhob de Gaulle den britischen Beitritt zur Existenzfrage für die Gemeinschaft, die aus seiner Sicht mit der Erweiterung um Großbritannien unvermeidlich in die Gefahr amerikanischer Abhängigkeit geraten würde. Dementsprechend lehnte Frankreich im Ministerrat die Aufnahme von Verhandlungen mit Großbritannien ab, womit dieses Thema ein weiteres Mal auf unbestimmte Zeit vertagt wurde. ${ }^{68}$ Bis Ende 1967 hatte es damit in drei Fällen, jeweils gegen den Willen seiner Partner, die Erweiterung des Ge-

774, hier S. 743 f.; sowie von der Groeben, H., (1982), Aufbaujahre der Europäischen Gemeinschaft, Baden-Baden, S. 186

${ }^{64}$ So de Gaulle in einer Pressekonferenz am 23.7.1964, abgedruckt in de Gaulle (1971), a.a.O., S. 886

${ }^{65}$ Seitens der Fünf nahm man Frankreich die dogmatische Verfechtung des engen Integrationstyps übel und mußte ohnmächtig zur Kenntnis nehmen, daß seine Begeisterung für Europa offenbar an der Barriere des gemeinsamen Außentarifs endete, so der deutsche Delegationsleiter Alfred Müller-Armack, der für sich persönlich nach dieser enttäuschenden Erfahrung seinen Rückzug aus der Politik beschloß. Vgl. Müller-Armack (1971), a.a.O., S. 226

${ }^{66}$ Vgl. Pressekonferenz de Gaulles vom 16.5.1967, abgedruckt in: EA, Folge 11/1967, D. 249-D 253, hier D 253

${ }^{67}$ Vgl. Pressekonferenz de Gaulles vom 27.11.1967, abgedruckt in: EA, Folge 24/1967, D 553-D 561, hier $560 \mathrm{f}$.

${ }^{68}$ Vgl. Erklärung des französischen Regierungssprechers, Georges Gorse, vom 20. Dezember 1967 zu den Ergebnissen der Tagung des Rats der Europäischen Gemeinschaft am 18. und 19. Dezember (Auszüge), in: EA, Folge 2/1968, D $44 \mathrm{f}$. 
meinsamen Marktes verhindert. Eine Wende in der französischen Haltung zur Beitrittsfrage trat allerdings Anfang 1969 ein als Frankreich im Verlauf der Wirtschafts- und Sozialkrise des Vorjahres erstmalig wieder auf die Hilfe seiner Partner angewiesen war. In Erkenntnis dieser Abhängigkeit überlegte de Gaulle, die französischen Außenbeziehungen neu zu ordnen. Im Zuge der sogenannten „Soames"-Affäre wurde bekannt, daß de Gaulle geneigt war, zwischen Frankreich, der Bundesrepublik Deutschland, Großbritannien und den USA eine besondere Ebene der politischen Zusammenarbeit aufzubauen. Für Großbritannien war dabei ein privilegierter Status im Verhältnis zur Gemeinschaft vorgesehen, was jedoch von britischer Seite empört zurückgewiesen wurde. $^{69}$

Zusammenfassend bleibt festzuhalten, daß de Gaulle nicht zögerte, seine europapolitische Konzeption in die Praxis umzusetzen. Noch in seinem ersten Amtsjahr wehrte Frankreich die Öffnung der frisch gegründeten Gemeinschaft ab, um sie vor störenden äußeren Einflüssen zu bewahren. Nur anderthalb Jahre später ging die französische Europapolitik dazu über, die politische Zusammenarbeit der Mitgliedstaaten inhaltlich und strukturell neu zu definieren, um die Gemeinschaft in eine Politische Union nach französischen Vorstellungen zu überführen. Kurze Zeit später zeigte sich mit der erstmaligen Ablehnung des britischen Beitritts, daß Frankreich über ein klares geostrategisches Konzept für die Ausgestaltung der gemeinschaftlichen Außenbeziehungen verfügte. Mit nachhaltigem Engagement bemühte sich die französische Europapolitik in den sechziger Jahren, die europapolitische Konzeption de Gaulles Wirklichkeit werden zu lassen und die Gemeinschaft auf globaler Ebene zu einem einflußreichen politischen Faktor neben den herrschenden Supermächten zu machen. Ökonomische Aspekte spielten in den französischen Überlegungen keine Rolle. Frankreich kam es unter de Gaulle in erster Linie auf die Konsolidierung der Europäischen Wirtschaftsgemeinschaft an, um sie zu einer eigenständigen politischen Einheit unter französischer Führung auszubauen.

\section{B.2.2 Die Wirtschaftspolitik B.2.2.1 Der Übergang zur Zollunion}

Nach dem Scheitern der Verhandlungen um eine Freihandelszone auf OEEC-Ebene begann die französische Regierung, sich um die innere Stabilisierung der EWG zu bemühen. Angesichts der in Frankreich wie auch in den Partnerstaaten unerwartet günstigen Wirtschaftsentwicklung sah man die Möglichkeit gegeben, mit der vorgezogenen Einführung eines gemeinsamen Außentarifs sowie einer zusätzlichen Senkung der Binnenzölle die Entschlossenheit der Sechsergemeinschaft zur Fortführung ihres Projekts zu demonstrieren. Auf französischer Seite erhoffte man sich außerdem eine ent-

${ }^{69}$ Die britische Regierung ließ im Rahmen einer Indiskretion an die Öffentlichkeit kommen, daß de Gaulle dem britischen Botschafter Christopher Soames entsprechende Überlegungen anvertraut hatte. 
mutigende Wirkung auf weitere „Zersetzungsversuche“ von dritter Seite. ${ }^{70}$ Im November 1959 wandte sich die französische Regierung mit dem "Wormser-Plan"71 an ihre Partner, in dem sie die folgenden Maßnahmen vorschlug:

a) die Beschleunigung des innergemeinschaftlichen Zollabbaus entweder durch eine außerplanmäßige zusätzliche Senkung der Zölle am 1. Januar 1960 oder durch die Erhöhung der laut EWG-Vertrag für den 1. Juli 1960 vorgesehenen Zollsenkung von zehn auf zwanzig Prozent und

b) die Annäherung der Außenzölle vom 1. Januar 1962 auf den 1. Juli 1960 vorzuziehen, und zwar so, daß die nationalen Außenzölle um 5/8 der insgesamt vereinbarten dreißig Prozent angeglichen würden.

Von diesen beiden Maßnahmen war es jedoch die zügige Errichtung des gemeinsamen Außentarifs, an der man französischerseits am meisten interessiert war. ${ }^{72}$ Mit seiner vorgezogenen Einführung verband man neben der demotivierenden Außenwirkung auf die Europapolitik gewisser Drittstaaten die Hoffnung, eine „Gemeinschaftspräferenz“ für Importprodukte zu begründen. Insbesondere in Niedrigzolländern wie der Bundesrepublik und den Niederlanden, die bei vielen Importgütern keine Zölle erhoben, hätten sich Importe aus Drittländern verteuert, was tendenziell französischen Exporten zugute gekommen wäre. ${ }^{73}$ Die zusätzliche Senkung der Binnenzölle hingegen wurde vor dem Hintergrund der wirtschaftlichen Wiederbelebung als vertretbar angesehen, zumal sie die Irreversibilität des Integrationsprozesses unterstrich.

Da gleichzeitig von belgischer Seite eine ähnliche Initiative vorlag, beauftragte der Ministerrat die Kommission, alle Möglichkeiten zur Beschleunigung der Zollunion zu prüfen und ein eigenes Konzept vorzuschlagen. Die Kommission legte ihren Beschleunigungsplan im März 1960 vor. Er ging jedoch weit über die ursprünglichen Vorstellungen Frankreichs hinaus. Der Kommissionsplan sah vor:

- die im innereuropäischen Handel mit Industrieerzeugnissen noch bestehenden Einfuhrkontingente bis Ende 1961 vollständig abzubauen,

- die Binnenzölle während der ersten Stufe um fünfzig statt um dreißig Prozent abzubauen, wobei die am 1. Juli 1960 und am 31. Dezember 1961 vorzunehmenden Zollsenkungen von jeweils zehn Prozent auf zwanzig Prozent erhöht werden sollten,

- die im Außenhandel mit Drittländern auf vergleichbarem Entwicklungsniveau bestehenden Importkontingente bis Ende 1961 unter der Bedingung der Gegenseitigkeit abzubauen sowie

\footnotetext{
${ }^{70}$ Vgl. MAE, Histoire de l'accélération du Traité de Rome, S. 49, série DE.CE, Vol. 616., S. 45-49

${ }^{71} \mathrm{Vgl}$. die verschiedenen Beschleunigungsvorschläge in: EA 13-14/1960 S. 169 ff. sowie die Darstellungen bei Welter, N., (1961), Die Konsolidierung der europäischen Wirtschaftsgemeinschaft, S. 64 EA, Folge 3/1961, S. $63 \mathrm{ff}$.

${ }^{72} \mathrm{Vgl}$. MAE, Histoire de l'accélération du Traité de Rome, a.a.O., S. 45

${ }^{73}$ Vgl. MAE, Histoire de l'accélération du Traité de Rome, a.a.O., S. 48
} 
- die Einführung eines gemeinsamen Außentarifs auf den 1. Juli 1960 vorzuziehen und diesen dabei gleichzeitig um 20 Prozent herabzusetzen. ${ }^{74}$

Seitens der französische Regierung stießen diese Vorschläge generell auf ein positives Echo, doch boten die Bestimmungen zum Außentarif und vor allem ihre Übertragung auf den Agrarmarkt Anlaß zu Kritik. Eine interne Analyse kam zu folgender Bewertung der Kommissionsvorschläge:

a. Die undifferenzierte Ausdehnung der Beschleunigungsvorschläge auf Industrie- und Agrarprodukte war inakzeptabel. Vor allem war eine Senkung des Außentarifs für Agrarprodukte unannehmbar, während die beschleunigte Senkung der Binnenzölle und die vorgezogene Einrichtung eines gemeinsamen Außentarifs für beide Bereiche befürwortet wurde.

b. Eine faktische Senkung der Außentarife für alle Produkte sollte auf jeden Fall verhindert werden.

c. Allenfalls einer Senkung im Sinne einer niedrigeren Kalkulationsbasis für die Annäherung der Außentarife konnte zugestimmt werden. Für die Hochzolländer würde dies zwar eine größere Anpassungslast bedeuten, andererseits wäre jedoch der gute Wille, die europäische Einigung voranzutreiben, unterstrichen.

d. Im übrigen sei es angebracht, sich liberal zu zeigen, ohne allerdings weitergehende Verpflichtungen einzugehen, da für die auf GATT-Ebene anstehenden Verhandlungen mit Drittländern (Dillon-Runde) noch genügend Verhandlungsspielraum verbleiben müsse. $^{75}$

In der folgenden Ministerratssitzung zur Beschleunigung der Übergangsphase am 12. Mai 1960 stieß Frankreich mit seinen Vorbehalten auf ein positives Echo. Seine vorsichtige Haltung auf dem Gebiet der Agrarzölle wurde von verschiedenen Mitgliedstaaten geteilt. Insgesamt konnte Frankreich seine Positionen am Ende der Diskussionen insofern berücksichtigt sehen, als daß die Mitgliedstaaten sich darauf einigten,

a. zum 1. Juli 1960 die Binnenzölle um zwanzig statt, wie ursprünglich vorgesehen, um zehn Prozent zu senken,

b. die erste Angleichung der Außentarife auf den 31. Dezember 1960 so vorzuziehen, daß sie zwar auf einer um zwanzig Prozent niedrigeren Kalkulationsgrundlage stattfand, ohne damit jedoch zu einer faktischen Senkung des Außentarifs zu führen,

c. für landwirtschaftliche Erzeugnisse die Binnenzölle bei nichtliberalisierten Produkten um zusätzliche fünf Prozent zu senken sowie die bestehenden Globalkontingente beschleunigt abzubauen, die Außenzölle jedoch unangetastet zu lassen,

${ }^{74} \mathrm{Vgl}$. Welter (1961), a.a.O., S. 65

${ }^{75}$ Vgl. Welter (1961), a.a.O., S. 65 
d. bis zum 30. Juni 1961 über eine zusätzliche Zollsenkung von zehn Prozent am Jahresende $\mathrm{zu}$ beschließen. ${ }^{76}$

Frankreich hatte somit seine Ziele hinsichtlich des Außenzolls sowie der Landwirtschaft erreicht. Die Gemeinschaft konstituierte sich, wie von der französischen Regierung erhofft, ein Jahr früher als geplant als außenwirtschaftliche Einheit, ohne daß das Niveau ihrer Außenprotektion gesenkt wurde.

Die Entwicklung der Gemeinschaft zur Zollunion sollte im kommenden Jahr allerdings hinter den französischen Erwartungen zurückbleiben. Vor allem auf dem für Frankreich so wichtigen Agrarsektor kam die Ausarbeitung einer gemeinsamen Politik und der entsprechenden Marktregelungen nur schleppend voran. Unbefriedigt über diesen Verlauf, entschloß sich die französische Regierung, ihre Zustimmung zu der zweiten zusätzlichen Zollsenkung, über die im Sommer 1961 abgestimmt werden sollte, nicht ohne Gegenleistung zu geben, auch wenn, so ihre Analyse, aus wirtschaftlicher Sicht nichts gegen diese Maßnahme sprach. ${ }^{77}$ Im Ministerrat erklärte Frankreichs Außenminister Maurice Couve de Murville den Kollegen sein Bedauern über die ungenügenden Fortschritte der Gemeinschaft auf dem Agrarsektor. Dies würde einerseits die Zustimmung Frankreichs zum Übergang zur zweiten Stufe vorerst unmöglich machen und andererseits - aufgrund der immer noch unklaren Perspektive für die europäische Landwirtschaft - die Überlegungen hinsichtlich einer zusätzlichen zehnprozentigen Zollsenkung auf eine unkalkulierbare Basis stellen, was zwangsläufig zu ihrer Verschiebung führen müsse. ${ }^{78}$ Der französische Außenminister stellte somit ein Junktim zwischen der Beschleunigung der Zollunion und dem Übergang zur zweiten Stufe auf der einen Seite und der Errichtung der für Frankreich so wichtigen Agrarmarktordnungen auf der anderen Seite her.

Der Gemeinschaft bescherte dies einen verhandlungsintensiven Herbst, da der Übergang zur zweiten Stufe einstimmig zu beschließen war. Zusätzlich gebildete Arbeitsgruppen intensivierten die schon laufenden Beratungen, um eine Einigung über die von Frankreich geforderte Errichtung der Marktordnungen für die einzelnen Agrarprodukte zu erreichen. Im wesentlichen ging es dabei um die Einführung eines einheitlichen Preisniveaus sowie eines gemeinschaftlichen Interventionsmechanismus zu dessen Stabilisierung, die außerdem noch durch die Erhebung von Einfuhrabgaben sowie durch eine gemeinschaftliche Organisation zur Vermarktung der Agrarüberschüsse zu ergänzen waren. Die Verhandlungen gingen im Dezember 1961 in sogenannte „Marathonsitzungen“ über, in denen erst am 14.1.1962, also vierzehn Tage nach dem

${ }^{76}$ Vgl. Beschluß des Ministerrats der Europäischen Wirtschaftsgemeinschaft vom 12.5.1960 über die beschleunigte Verwirklichung der Vertragsziele, D 176 und D 178, abgedruckt in: EA, Folge 1314/1960, D 176 - D 179

${ }^{77}$ Vgl. die Note vom 1.7.1961 zu den taktischen Überlegungen seitens des Außenministeriums in: MEF, Fonds 9, Vol. 20, B 17.682

${ }^{78}$ Vgl. den Auszug aus dem Sitzungsprotokoll der 50. Sitzung des Ministerrats, MEF, Fonds 9, Vol. 20, B 17.682 
vertraglich vorgesehenen Übergang zur zweiten Stufe, eine vorläufige Einigung erreicht werden konnte. Für die Finanzierungsprobleme der gemeinsamen Agrarpolitik konnte nur eine provisorische Regelung gefunden werden, die bis zum 30. Juni 1965 durch eine endgültige zu ersetzen war.

Mit seiner hartnäckigen Haltung in den Agrarverhandlungen verfolgte Frankreich nicht nur die Befriedigung seiner Interessen auf landwirtschaftlichem Gebiet. Die französische Regierung beabsichtigte daneben, die Gemeinschaft schnellstmöglich als zolltechnische Einheit zu konsolidieren. Sie war vor allem an deren geschlossenem Auftreten in den internationalen Verhandlungen zur Liberalisierung des Handels interessiert. Diese begannen Anfang der sechziger Jahre im Rahmen der OECD mit der „Dillon-Runde“ und sollten später im Rahmen des GATT mit der Kennedy-Runde fortgeführt werden. Außerdem wollte Frankreich möglichst noch vor dem Beginn der Beitrittsverhandlungen mit Großbritannien im Herbst 1961 die Zollfragen auf landwirtschaftlichem Gebiet entschieden wissen, um es mit einer einheitlichen Haltung der Sechs konfrontieren zu können. Nachdem die Dillon-Runde schon 1962 allerdings mit bescheidenden Zollsenkungen endete und im Januar 1963 die Beitrittsverhandlungen mit Großbritannien scheiterten, war es bis 1967 die Kennedy-Runde, auf die sich die französischen Bemühungen im Rahmen der europäischen Außenwirtschaftspolitik konzentrierten.

Kennedys Initiative stand im Zusammenhang mit seinen Bemühungen, vor dem Hintergrund der sich zuspitzenden militärischen Spannungen zwischen den USA und der UdSSR (Kuba-Krise) einen atlantisch-europäischen Block zu bilden, der von de Gaulle jedoch generell abgelehnt wurde. Der französische Staatspräsident sah darin nichts anderes als einen weiteren Versuch der USA, Europa in vollständige Abhängigkeit zu bringen. ${ }^{79} \mathrm{Da}$ alle anderen Staaten dem US-Vorschlag jedoch positiv gegenüberstanden, beschloß man im Rahmen des GATT, Verhandlungen aufzunehmen. Ausgangspunkt der Gespräche war Kennedys Vorschlag, weltweit die Zölle für alle Güter um fünfzig Prozent zu senken. Um für diese Verhandlungen, die im Mai 1964 beginnen sollten, gut vorbereitet zu sein, sah Frankreich den zügigen Abschluß der innergemeinschaftlichen Agrarverhandlungen als notwendig an. Zur Beschleunigung der immer noch zäh verlaufenden Folgeverhandlungen zum ersten Agrarmarathon verschärfte es seinen Verhandlungsstil bis hin zu latenten Austrittsdrohungen, ohne damit allerdings zum erwünschten Ergebnis zu gelangen. ${ }^{80}$ Die Spannungen im Ringen um die Agrarprobleme übertrugen sich auf die Gespräche zur Abstimmung der Gemeinschaftsposi-

\footnotetext{
${ }^{79}$ Vgl. Couve de Murville (1971), a.a.O., S. 101-103 sowie Gerbet (1983), a.a.O., S. 303

${ }^{80}$ „Doch es soll niemand an der Festigkeit unserer Entschlossenheit zweifeln. Wenn die grundlegenden Interessen der Nation in Frage gestellt sind und die Regierung glaubt, daß die in der Agrarpolitik aufgetretenen Schwierigkeiten solche grundlegenden Interessen ... in Frage stellen, muß man wohl feststellen, daß das Maß voll ist. Wir sind bereit, die Zukunft offen zu halten, und wir hoffen, daß sie günstiger sein wird, aber wir sind nicht bereit, die Trümpfe Frankreichs aus der Hand zu geben" so Außenminister Couve de Murville in seiner Rede vom 3.11.1964 vor der Nationalversammlung, D 615, abgedruckt in: EA, Folge 23/1964, D 608 D 617
} 
tion in den GATT-Verhandlungen. Frankreich strebte in diesen im Gegensatz zur Bundesrepublik nur eine moderate Senkung der Zollsätze an und wollte diese auch nur auf Industriegüter angewandt wissen. ${ }^{81}$ Die Ausnahme der Landwirtschaft begründete es mit den Unwägbarkeiten, die aus der angeblichen Unfähigkeit der Gemeinschaft zu einer gemeinsamen Agrarpolitik herrührten. Außerdem würden zu hohe Zollsenkungen, so der französische Außenminister, die europäische Wirtschaft im Verhältnis zu den hoch leistungsfähigen USA unnötig schwächen:

„... die Schwierigkeiten, auf welche der Versuch der politischen Zusammenarbeit der sechs Länder stößt, berechtigen zu der Annahme, daß der Tag noch nicht gekommen ist, an dem in einem festgefügten Gemeinsamen Markt jene großen europäischen Unternehmen zustande kommen würden, die in der Lage wären, der Konkurrenz der Riesenunternehmen, wie sie die wichtigsten Betriebe der Vereinigten Staaten sind, gleichberechtigt zu begegnen. Deshalb scheint eine starke Senkung des gemeinsamen Außenhandelstarifs unter solchen Umständen unbestreitbare Risiken zu enthalten. ${ }^{“ 82}$

Über die innereuropäischen Schwierigkeiten bei der Definition einer gemeinsamen Verhandlungsposition legten sich die im Verlauf der Jahre 1964/65 aufkommenden Meinungsverschiedenheiten über die Rolle der Europäischen Kommission, die ihren Höhepunkt mit dem Auszug Frankreichs aus dem Ministerrat am 1. Juli 1965 erreichten. Damit war jede Ausarbeitung eines gemeinschaftlichen Standpunktes vorerst verhindert und dementsprechend die Kennedy-Runde blockiert. Erst im Juli 1966, also zwei Jahre nach Beginn der Kennedy-Runde, gelang es der Gemeinschaft erstmals, mit eigenen Verhandlungsvorschlägen aufzuwarten. ${ }^{83}$ Diese öffneten dann den Weg für einen vergleichsweise zügigen Abschluß der GATT-Handelsgespräche: Am 15. Mai 1967 wurde eine durchschnittliche Senkung der Außenzölle um 35 Prozent vereinbart, die allerdings von zahlreichen Ausnahmen, insbesondere für Agrarprodukte, durchsetzt war. ${ }^{84}$

Abschließend betrachtet war die französische Haltung in Fragen der Zoll- und Außenwirtschaftspolitik in der Ära de Gaulle sehr zurückhaltend und von einem latenten Protektionismus gekennzeichnet. Wie schon bei der Erweiterung der Gemeinschaft kam es Frankreich auch in Fragen der Handelspolitik auf die zügige außenwirtschaftliche Absicherung Europas an, so daß beide Politikbereiche als komplementär betrachtet werden konnten. Wehrte Frankreich im Rahmen seiner Außenpolitik alle Beitrittsgesuche Dritter ab, um seinen Führungsanspruch in Europa zu verteidigen, so versuchte es mittels der Zollpolitik, und hier besonders mit seinen Bemühungen um die forcierte Errichtung eines gemeinsamen Außenzolls, die Gemeinschaft als souveräne Wirtschaftseinheit zu konstituieren und zu stabilisieren. Den Außenzoll benutzte die französische Regierung dabei als operatives und verhandlungstaktisches Instrument zum Schutz der europäischen Wirtschaft vor übermächtiger Konkurrenz. Der Binnenzoll hingegen wurde ausschließlich als taktisches Druckmittel benutzt, mit dem Frank-

\footnotetext{
${ }^{81}$ Vgl. de Carmoy, G. (1967), Les politiques étrangères de la France 1944-1966, Paris, S. 462

${ }^{82}$ Siehe die Rede Couve de Murvilles vom 3.11.1964, a.a.O., D 615

${ }^{83}$ Vgl. de Carmoy (1967), a.a.O., S. 463

${ }^{84} \mathrm{Vgl}$. Gerbet (1983), a.a.O., S. 314
} 
reich Integrationsfortschritte behinderte, um wirtschaftliche Vorteile auf dem Agrarsektor einzuhandeln. Zusammenfassend läßt sich somit feststellen, daß die Zollpolitik von französischer Seite in erster Linie im restriktiven Sinne als Instrument zur machtpolitisch motivierten Abgrenzung eines Wirtschaftsraums benutzt wurde und nicht im wirtschaftlichen Sinne als Mittel zur Entwicklung des Binnenmarktes. Die Haltung Frankreichs in der europäischen Zollpolitik konnte direkt aus den Motiven der europapolitischen Konzeption de Gaulles abgeleitet werden. Die gemeinschaftliche Außenwirtschaftspolitik stellte für die französische Europapolitik ein Mittel dar, um eine Basis zu schaffen, von der aus die Gemeinschaft später ihre eigene internationale Politik betreiben konnte. Insgesamt war Frankreich mit seiner Politik maßgeblich daran beteiligt, daß die Öffnung des Gemeinsamen Marktes am Ende der sechziger Jahre weit hinter dem zurückgeblieben war, was angesichts der günstigen Wirtschaftslage sowie der positiven Einstellung der französischen Partner zur Erweiterung der Gemeinschaft eigentlich möglich gewesen wäre.

\section{B.2.2.2 Die Landwirtschaftspolitik}

In Folge der Konferenz von Stresa, auf der die Mitgliedstaaten erstmals ihre nationalen Agrarmarktregelungen miteinander konfrontierten, wurde die Europäische Kommission mit der weiteren Ausarbeitung von konkreten Vorschlägen für eine gemeinsame Agrarmarktordnung beauftragt. Aufgrund divergierender Auffassungen der Mitgliedstaaten in Detailfragen zogen sich diese Vorarbeiten ergebnislos über fast zwei Jahre hin. Intern stellte die französische Regierung im Mai 1960 enttäuscht fest, daß entgegen den Bestimmungen des Römischen Vertrages bislang nur wenige langfristige Handelsverträge zwischen den Mitgliedstaaten geschlossen worden waren und daß die Partnerstaaten häufig Vertragsbestimmungen, wie z. B. die zehnprozentige Zollsenkung vom 1. Januar 1959, nicht einhielten oder alle Vertragsausnahmen in Anspruch nahmen, um die Protektion ihrer Märkte aufrecht zu erhalten. ${ }^{85}$ Derart enttäuscht über den Integrationsstand auf diesem Sektor, lehnte sie die Ausdehnung der Anfang 1960 allgemein diskutierten Beschleunigung des Zollabbaus auf den Agrarsektor ab. In den entsprechenden Verhandlungen konnte Frankreich die zusätzliche Senkung der Binnenzölle für Agrarprodukte auf 5 Prozent begrenzen und die Senkung des gemeinsamen Außentarifs für Agrarprodukte gänzlich verhindern, wobei dem Agrarministerium selbst diese Maßnahmen noch zu weit gingen. ${ }^{86}$

Nachdem Anfang 1960 ein vorläufiger Kommissionsvorschlag scheiterte und die Kommission den Termin zur erneuten Vorlage von Vorschlägen nicht mehr einhalten

\footnotetext{
${ }^{85} \mathrm{Vgl}$. note du 9.5.1960 in: MAE, série DE.CE, Vol. 650, S. 25 f. sowie den Brief des französischen Delegationsmitglieds für die Ministerratssitzung vom 12.5.1960 an seinen Gesprächspartner auf deutscher Seite, von Scherpenberg, in dem unmißverständlich die Enttäuschung Frankreichs über das Verhalten der Partnerländer zum Ausdruck gebracht sowie auf den wachsenden Druck seitens der französischen Landwirte hingewiesen wird, MAE, série DE.CE, Vol 650, ohne Seitenangabe

${ }^{86} \mathrm{Vgl}$. den Briefwechsel des Premier- und Agrarministers in MAE, série DE.CE, Vol. 650,S. $35 \mathrm{f}$.
} 
konnte, beschloß der Ministerrat am 12. Mai des Jahres einen Zeitplan, nach dem die weiteren Arbeiten zur Errichtung der gemeinsamen Agrarpolitik abzulaufen hätten. ${ }^{87}$ Bald darauf begannen die von Frankreich lang ersehnten Verhandlungen über die Ausgestaltung der ersten Marktorganisationen. Bei der Ausarbeitung ihrer Verhandlungsposition für die einzelnen Marktordnungen orientierte sich die französische Regierung wieder eng an den Forderungen der landwirtschaftlichen Berufsverbände, die zum Teil explizit in die Instruktionen der Delegation übernommen wurden. ${ }^{88}$ In den Instruktionen der Delegation für die Getreidemarktorganisation wurde so z. B. vor dem Hintergrund der jüngsten Produktionsentwicklung die von der Kommission angestrebte Stabilisierung der Produktion auf dem Niveau von 1960 pauschal als unrealistisch und nicht akzeptabel abgelehnt und statt dessen unabhängig vom Umfang der Produktion die Festlegung von Einheitspreisen auf einem Niveau gefordert, um so den Landwirten eine rentable Produktion zu ermöglichen. Im Rahmen der Ausfuhrbeihilfen gingen die französischen Forderungen so weit, daß den Exporteuren von der Gemeinschaft nicht nur die Differenz zwischen europäischem Preisniveau und Weltmarktpreis, sondern zusätzlich noch die Transportkosten und Kosten für Vertragsabschlüsse erstattet werden sollten. ${ }^{89}$ Bei der Festlegung der Interventionspreise bestand man hingegen auf Mindestpreisen, die mindestens dem Preisniveau Frankreichs zu entsprechen hätten. Um die Landwirte im Fall von stabilisierenden Eingriffen der Gemeinschaftsmechanismen nicht mit übermäßig hohen Transportkosten zu belasten, sollte außerdem auf ein hinreichend enges Netz von Interventions- und Vorratsstellen bestanden werden. ${ }^{90}$

Als wichtig erachtete die französische Regierung außerdem, daß die Fortschritte bei der innergemeinschaftlichen Angleichung der Preise parallel zum Aufbau einer gemeinschaftlichen Handelspolitik gegenüber Drittländern erfolgten. ${ }^{91}$ In deren Rahmen wiederum sei, so die Instruktionen, auf Einfuhrabgaben zu bestehen, die Importe aus Drittstaaten wirksam verhinderten, um so den Absatz französischer Überschüsse im Binnenmarkt zu unterstützen. ${ }^{92}$ Aus gleichem Grunde sollte sich die Delegation prinzipiell gegen den Abbau von Einfuhrkontingenten für Importe aus Drittländern wenden:

${ }^{87}$ Vgl. den Beschluß des Ministerrats vom 12.5.1960, a.a.O., D 176; zu den Schwierigkeiten unter den Mitgliedstaaten siehe Welter, N. (1960), Agrarpolitik in der Europäischen Wirtschaftsgemeinschaft, S. 25 f., in: EA, Folge 1-2/1960, S. 25-36

${ }^{88} \mathrm{Vgl}$. die explizite Bezugnahme auf die Forderungen der interessierten Verbände in den Instruktionen und vorbereitenden Arbeiten für die Verhandlungen zu den einzelnen Marktordnungen, in MAE, série DE.CE, Vol. 653, S. 53 ff. (Getreide), S. 72 ff. (Obst und Gemüse), S. 78 ff. (Fleisch und Eier), S. $87 \mathrm{ff}$. (Milchprodukte) sowie S.93 ff. (Zucker)

${ }^{89} \mathrm{Vgl}$. projet d'instruction pour la délégation française au comité spécial en vue de la discussion des propositions de la Commission concernant la politique céréalière commune, $\mathrm{S}$. $56 \mathrm{ff}$, in MAE, série DE.CE, Vol. 653, S. 53-70

${ }^{90}$ Aufgrund der bestehenden, aus französischer Sicht hohen Getreideimporte aus Drittländern sowie „beunruhigender" Entwicklungen auf dem Weltmarkt wurden häufige Interventionen als wahrscheinlich unterstellt, vgl. die Instruktionen für die Getreidemarktorganisation, a.a.O., S. 60

${ }^{91} \mathrm{Vgl}$. das projet d'instruction für den gemeinsamen Getreidemarkt, in MAE, a.a.O., S. 62

${ }^{92}$ ebenda, S. $61 \mathrm{ff}$. 
„... 1'abandon du contingentement des importations de la C.E.E. marque un pas très dangereux dans le sens du libéralisme." ${ }^{\text {"93 }}$

Außer diesen offensichtlich ideologisch begründeten Vorbehalten sprachen taktische Überlegungen für die Beibehaltung bestehender Kontingente. Sie sollten für die bevorstehenden Verhandlungen im Rahmen der Dillon-Runde als Verhandlungsmasse verwendet werden. ${ }^{94}$ Ergänzt wurden diese Forderungen schließlich durch die Anweisung, die Europäische Kommission nochmals zu Vorschlägen aufzufordern, die den Abschluß langfristiger Handelsverträge für Agrarprodukte zwischen den Mitgliedsländern während der Übergangszeit verpflichtend machten. ${ }^{95}$

Vergleichbare Forderungen fanden sich auch in den Instruktionen der Delegationen für die anderen Arbeitsgruppen (Milchprodukte, Zucker, Fleisch und Eier, Obst und Gemüse). Da alle Mitgliedstaaten ähnlich vorbereitet waren, gestalteten sich die Verhandlungen von Beginn an schwierig. Die Schwierigkeiten nahmen nochmals zu als von französischer Seite zusätzlich gefordert wurde, die Kosten der europäischen Agrarpolitik schon während der Übergangsperiode gemeinsam zu tragen, wobei diese nicht durch die Landwirte z. B. in Form einer Steuer finanziert werden sollten, sondern aus Einfuhrabgaben für Importe aus Drittländern, die nach Errichtung der gemeinschaftlichen Marktordnungen immer noch getätigt würden. ${ }^{96}$ Frankreich betrachtete es als natürliches Recht der Gemeinschaft, nach Einführung der gemeinsamen Politik Agrareinfuhren mit prohibitiven Zöllen zu belegen, um den Absatz der innereuropäischen Produktion zu garantieren. ${ }^{97}$ Sollte es in den Mitgliedstaaten dennoch zu Einfuhren kommen, so sollte über die auf ihnen erhobenen und in einem Gemeinschaftsfonds gesammelten Abgaben der Export der im Binnenmarkt nicht absetzbaren europäischen Überschüsse finanziert werden, indem der Fonds den Exporteuren die Differenz zwischen dem niedrigeren Weltmarktpreis und dem Preisniveau innerhalb der Gemeinschaft erstattete.

Ihren Forderungen verlieh die französische Regierung Nachdruck, indem sie Mitte 1961 ihre Zustimmung zum Übergang zur zweiten Stufe an konkrete Verhandlungserfolge auf agrarpolitischem Gebiet band. Ein alle Seiten zufriedenstellender Kompromiß konnte erst nach Verstreichen der gesetzten Frist im Januar 1962 erreicht werden. Dieser sah die Errichtung der ersten Marktordnungen vor, reichte aber auf dem Gebiet der Finanzierung der gemeinsamen Agrarpolitik nur zu einer provisorischen Regelung. Nach dieser mußten zunächst die Mitgliedstaaten weiter für die Kosten aufkommen. Bis zum 30. Juni 1965 wurde jedoch vereinbart, eine endgültige Finanzierungsregelung zu finden.

\footnotetext{
${ }^{93} \mathrm{Vgl}$. das projet d'instruction für den gemeinsamen Getreidemarkt, in MAE, a.a.O., S. 60

94 ebenda

${ }^{95} \mathrm{Vgl}$. das projet d'instruction für den gemeinsamen Getreidemarkt, in MAE, a.a.O., S. $63 \mathrm{f}$.

${ }^{96}$ Vgl. Delorme, H. (1975), La France et le Marché Commun agricole, S. 619, in: Joël Rideau et. al. (Hrsg.), La France et les Communautés Européennes, Paris, S. 609-634

${ }^{97} \mathrm{Vgl}$. die Stellungnahme de Gaulles in der Pressekonferenz vom 14.1.1963, a.a.O., D 88
} 
In den Verhandlungen zur Festlegung der Preise bemühte sich Frankreich zunächst um ein, relativ betrachtet, niedriges Niveau, was aufgrund der im europäischen Vergleich günstigen landwirtschaftlichen Produktionsbedingungen und den daraus resultierenden niedrigeren französischen Agrarpreisen problemlos möglich war. Auch strebte die französische Regierung ursprünglich eine differenzierte Struktur des Preissystems an, so $d a ß$ über die Preise ein gewisser Einfluß auf die Produktionsentscheidungen der Landwirte ausgeübt werden konnte. Frankreich stie $\beta$ mit diesen Bemühungen aber von Beginn an auf zum Teil erbitterten Widerstand der Partner, die weniger günstige Produktionsvoraussetzungen hatten. ${ }^{98}$ Dementsprechend rückte bald der zügige Fortschritt der Verhandlungen an die Spitze der französischen Prioritäten und verdrängte damit das Ziel eines funktionierenden Agrarpreissystems. Um ihre Forderungen durchzusetzen, ging die französische Regierung bis hin zu latenten Austrittsdrohungen, die spätestens nach dem Scheitern der britischen Beitrittsverhandlungen ihre Wirkung nicht mehr verfehlten. ${ }^{99}$ Sie wurden schließlich am 30. Juni 1965 im Rahmen der „Politik des leeren Stuhls" sogar im Ansatz verwirklicht, als Frankreich unter dem Vorwand, daß die Finanzierungsregelung für die gemeinsame Agrarpolitik nicht rechtzeitig in Kraft gesetzt worden war, seine Mitarbeit im Ministerrat der Gemeinschaft unterbrach. Wenn die Defizite in der Agrarpolitik auch nicht der wahre Grund für diese Entscheidung waren - Frankreich nahm seine Mitarbeit sieben Monate später wieder auf, als ihm ein Vetorecht bei Mehrheitsentscheidungen zugesichert wurde - so zeigte die Tatsache, daß Agrarprobleme für die französische Regierung hinreichend Gewicht hatten, um als Vorwand zu dienen, unter dem es die Gemeinschaft in ihre bis dahin schwerste Krise stürzte, den hohen Rang agrarpolitischer Interessen innerhalb der damaligen Europapolitik Frankreichs. Bei der Festsetzung der Agrarpreise führte der von Frankreich erzeugte Druck zu einem hohen Preisniveau. Viele Mitgliedstaaten stimmten diesem bereitwillig zu, nur um zu Abschlüssen zu kommen und den Integrationsprozeß nicht weiter zu gefährden. Von deutscher Seite wurden hohe Agrarpreise aus Rücksicht auf die eigene Landwirtschaft sogar bewußt gefordert.

Am Ende jedoch wendete sich der Verhandlungsstil der französischen Regierung gegen ihre eigenen Interessen. Die von Frankreich verursachte Stagnation der europäischen Integration führte dazu, daß eine Finanzierungslösung für die europäische Agrarpolitik auch zum Ende der Amtszeit de Gaulles noch nicht gefunden werden konnte. Die französische Regierung sah sich damit einer europäischen Agrarpolitik gegenüber, die sie ursprünglich nicht gewollt hatte. Zwar konnte sie mit der Realisierung eines Mindestpreissystems, der Errichtung einer wirksamen Außenprotektion und des Ausgleichs- und Garantiefonds einige wichtige Forderungen im Grundsatz verwirklicht sehen. Das hohe Niveau der Preisgarantien führte jedoch schnell zu einer kostspieligen Überproduktion und zu verkrusteten und unrentablen Produktionsstrukturen sowie zu einem Kompetenzzuwachs der geschmähten Europäischen Kommission,

\footnotetext{
${ }^{98}$ Vgl. Delorme (1975), a.a.O., S. 615

${ }^{99}$ Vgl. Gerbet (1983), a.a.O., S. 255-258
} 
so daß das Agrarproblem am Ende der sechziger Jahre aus französischer Sicht nur unbefriedigend gelöst war. ${ }^{100}$

Ordnungspolitisch betrachtet knüpfte die agrarpolitische Konzeption Frankreichs unter de Gaulle unmittelbar an die seiner Vorgänger an. Wie diese versuchte man, über besondere Marktordnungen gleichzeitig die Einkommen der Landwirte zu sichern, den Wirtschaftssektor an den technischen Fortschritt anzupassen und den profitablen Absatz der eigenen Agrarüberschüsse zu sichern. Faktisch führte dieser ordnungspolitische Ansatz dazu, daß der Agrarsektor vollständig aus dem Geltungsbereich der Wettbewerbsordnung, wie sie für den Binnenmarkt vorgesehen war, herausfiel. Frankreich hielt damit an seiner Konzeption fest, über die Gestaltung der Wirtschaftsordnung bestimmte sozial-, struktur- und außenhandelspolitische Zielvorstellungen zu realisieren, und dies trotz der schon früh sichtbaren Mängel und Fehlfunktionen der EGAgrarmarktordnungen.

$\mathrm{Da}$ ordnungspolitische Bedenken in der agrarpolitischen Konzeption Frankreichs keinerlei Niederschlag fanden, lag hauptsächlich daran, daß für de Gaulle die Agrarproblematik eine eigenständige Dimension besaß. Er begriff Frankreich als einen Agrarund Industriestaat. ${ }^{101}$ Die französische Landwirtschaft sah er als einen bedeutenden Wirtschaftssektor, der mit seinen zwei Millionen Betrieben immer noch ein Fünftel aller Erwerbstätigen beschäftigte und vor der schwierigen Aufgabe stand, sich vom Niveau einer auf Selbstversorgung angelegten nationalen Landwirtschaft zu einer international wettbewerbsfähigen Agrarindustrie zu entwickeln. ${ }^{102}$ Dieser tiefgreifende Strukturwandel war aufgrund der hohen Bedeutung der Landwirtschaft für das Wohlergehen der Nation und der Verdienste der Landbevölkerung um die Erfolge Frankreichs für de Gaulle ein eminent nationales Anliegen. ${ }^{103}$ Um ein soziales Drama zu verhindern, aber auch, um Frankreich zu einer wettbewerbsfähigen Landwirtschaft zu verhelfen, war die Nation verpflichtet, diesen Anpassungsprozeß zu gestalten. Wissend um die Entwicklungserfordernisse im „Zeitalter der Maschine“, so de Gaulle, das jetzt

\footnotetext{
${ }^{100}$ Vgl. Gerbet (1983), a.a.O., S. 259

101 Vgl. Pressekonferenz des französischen Staatspräsidenten Charles de Gaulle vom 31.1.1964, D 150, abgedruckt in: EA, Folge 5/1964, D 143-154

${ }^{102}$ Zur problematischen Ausgangslage und den Entwicklungszwängen für die Landwirtschaft vgl. die ausführliche Behandlung dieses Sektors im Abschnitt „L'économie“ der Memoiren de Gaulles, de Gaulle (1971), a.a.O., S. 126-129

103 „Comment, étant que je suis, ne serais-je pas ému et socieux en voyant s'estomper cette société campagnarde ... cette France millénaire, que sa nature, son activité, son génie, avaient faite essentiellement rurale? ... c'est la campagne qui demeurait la source de la vie, la mère de la population, la base des institutions, le recours de la patrie ... Comment ne pas comprendre que les paysans français ont d'instincte le sentiment d'être, en somme, la France elle-même et que la colossale mutuation qui diminue leur volume social et leur rôle économique suscite inévitablement leur inquiétude et leur mélancolie? ... Comment laisser la profession agricole errer, par le temps qui court, sans la formation technique, l'organisation des transactions, l'aide rationnelle du crédit, indispensables à la concurrence? Comment résoudre sans drame ce problème gigantesque et émminement national, à moins que la collectivité tout entière ne le prenne à son compte?", vgl. de Gaulle (1971), a.a.O, S. 126 f.
} 
auch die Landwirtschaft erfaßt habe, müsse der Staat sicherstellen, daß die „richtigen“ Strukturen eingenommen würden. Zum einen waren größere Betriebe notwendig, die den Übergang zu einer stückkostenminimalen Produktion ermöglichten, ${ }^{104}$ zum anderen aber auch ein Preisniveau, das gleichzeitig den Einkommensbedürfnissen der Landwirte und den Finanzierungsmöglichkeiten des Staates zu entsprechen hatte. ${ }^{105}$ Der Staat hatte für de Gaulle natürlicherweise eine Verantwortung für die Kostenseite der Produktion wie auch für die Einkommen den Landwirte, denen auf diese Weise die wirtschaftliche Verantwortung für die Strukturanpassung ihres Sektors in weiten Teilen abgenommen wurde.

Da dieser Anpassungsprozeß, für den de Gaulle die Dauer einer Generation unterstellte, aufgrund der zunehmenden Überschußproduktion Frankreichs und der Verschärfung des internationalen Preiswettbewerbs nicht mehr im nationalen Rahmen zu bewältigen war, bot sich mit dem Gemeinsamen Markt eine glänzende Möglichkeit zur Lösung des Problems, denn in diesem bestand noch Bedarf für Agrarprodukte, die Frankreich im Überschuß produzierte:

"Je dois dire que si, reprenant nos affaires en main, j'ai adopté d'emblée le Marché Commun, c'est en raison de notre condition de pays agricole aussi bien que du progrès à imposer à notre industrie. Certes, je ne me dissimule pas que, pour faire effectivement entrer l'agriculture dans la Communauté, nous devrons agir vigoureusement auprès de nos partenaires dont en cette matière les intérêts ne sont pas les nôtres. Mais je tiens qu'il y a là, pour la France, une condition sine qua non de sa participation." ${ }^{106}$

Dieses klare Bekenntnis zeigt, daß der gemeinsame Agrarmarkt für de Gaulle in erster Linie ein Mittel zur Befriedigung der nationalen Interessen Frankreichs darstellte und weniger ein Instrument zur Förderung der europäischen Integration. Das Engagement, mit dem die französische Politik auf seine Errichtung drängte, verdeutlicht ferner den hohen Stellenwert, den das nationale Interesse in seiner Europapolitik einnahm und damit zugleich die relativ geringe innere Verpflichtung, die Frankreich gegenüber dem Integrationsvorhaben der Sechs empfand. Ebenfalls ersichtlich wurde in diesem $\mathrm{Zu}$ sammenhang das große Vertrauen der französischen Politik in den wirtschaftlichen Sachverstand des Staates, was im Agrarsektor dazu führte, einen ganzen Wirtschaftsbereich nahezu geschlossen dem marktwirtschaftlichen Wettbewerb zu entziehen. Am Ende waren es außenwirtschaftliche Interessen und einkommenspolitische Zielsetzungen, die in der französischen Agrarpolitik alle ordnungspolitischen Überlegungen

104 "Il s'agit, en somme, d'aider à s'agrandir, à modifier leur structure, à adapter leur production, les exploitations qui sont économiquement valables et d'amener à se joindre à d'autres celles qui ne le sont pas faute d'une dimension suffisante. Il s'agit d'obtenir que le cultivateur produise les denrées qu'il faut et les envoie à la vente présentées comme il faut, au cours qu'il faut, là et quand il faut.", de Gaulle (1971), a.a.O., S. 127

105 "Il nous faut donc exporter et, dans un monde où les surplus agricoles sont offerts en masse, nous devons le faire, malgré tout, à des prix qui répondent aux besoins de nos producteurs, à moins que l'État leur fournisse des subventions telles qu'elles écraseraient ses finances.", de Gaulle (1971), a.a.O., S. 128

${ }^{106}$ de Gaulle (1971), a.a.O., S. 128 
dominierten und zu einer Wirtschaftsordnung führten, die voll auf die staatliche Regelungskompetenz vertraute.

\section{B.2.2.3 Die Koordinierung der Wirtschaftspolitik}

Schon im ersten Jahr ihres Bestehens bemühte sich die Europäische Wirtschaftsgemeinschaft um eine engere Koordinierung der Wirtschaftspolitik. Die erste Initiative wurde von deutscher Seite vorgelegt und betraf die Bildung eines Konjunkturausschusses. Dessen Hauptaufgabe sollte die Koordination der Wachstumspolitiken sein. Im Konjunkturausschuß sollten die dazu notwendigen Studien und Empfehlungen ausgearbeitet werden. Weiter war ein Konjunkturfonds vorgesehen, der aus eigenen Mitteln antizyklisch die Wachstumsentwicklung beeinflussen und stabilisieren sollte. Frankreich reagierte positiv auf diese Initiative und erklärte sich bereit, die aufgeworfene Frage näher zu untersuchen, ohne allerdings in dem konkret vorgeschlagenen Konjunkturfonds einen Bestandteil von großer Notwendigkeit zu sehen. ${ }^{107}$

In den ersten Beratungen gelang es der Europäischen Kommission, die Initiative zu übernehmen und ihre eigenen Vorstellungen zur Grundlage der weiteren Beratungen zu machen. Ihre Vorstellungen wichen insofern von der deutschen Konzeption ab, als daß der Konjunkturausschuß nicht mehr über eigene Mittel zur Stabilisierung des Konjunkturverlaufs verfügen sollte, sondern die Einhaltung eines ,code de bon conduit" zu überwachen hatte. Da diese Konzeption nur in geringem Maße zur Verlagerung von Kompetenzen auf supranationale Ebene geführt hätte, vermochte sie in weitaus größerem Umfang die Zustimmung der französischen Regierung zu erwecken. Sie bemängelte am Kommissionsvorschlag aber, daß es kaum möglich sein werde, über die Bestimmung abstrakter Kriterien im „code“ der jeweiligen Situation der einzelnen Volkswirtschaften gerecht $\mathrm{zu}$ werden. ${ }^{108}$ Außerdem bestand die französische Regierung darauf, daß der Konjunkturausschuß eine Einrichtung zu sein habe, die sowohl der Kommission als auch dem Rat unterstehe, denn die Ausschußmitglieder seien schließlich Repräsentanten der Mitgliedstaaten und nicht unabhängige Experten. ${ }^{109}$ Aufgrund der insgesamt stark voneinander abweichenden konjunkturpolitischen Auffassungen der Mitgliedstaaten einigte man sich schließlich auf einen Minimalkompromiß: Am 9. März 1960 beschloß der Ministerrat die Einsetzung eines Konjunkturausschusses, der ausschließlich beratende Funktion hatte, faktisch also keinerlei Einflußmöglichkeiten auf das konjunkturpolitische Verhalten der Mitgliedstaaten besaß.

Wenig zufrieden mit diesem Ergebnis, wagte die Kommission zwei Jahre später mit ihrem „Aktionsprogramm für die zweite Stufe“ einen erneuten Versuch zur Intensivierung der wirtschaftspolitischen Zusammenarbeit, der weit über den Anlauf zur Koordi-

\footnotetext{
${ }^{107}$ Vgl. MAE, Brief des Finanzministers an den Premierminister vom 13.6.1959, S. 123 f., in: série DE.CE, Vol. 680 , S. 122-124

${ }^{108} \mathrm{Vgl}$. MEF, note pour le ministre, 30.6.1960, Fonds 9, Vol. 20, B 25.343

${ }^{109}$ ebenda sowie MAE, note (ohne Datum), S. 162 ff., in: série DE.CE, Vol. 680, S. 161-165
} 
nierung der Konjunkturpolitiken hinausging. Sie schlug vor, über eine enge Koordination der im EWG-Vertrag benannten Wirtschaftspolitiken die Entwicklung der Gemeinschaft in Richtung einer Wirtschaftsunion fortzusetzen:

„Was noch zu verwirklichen ist, ist die fortschreitende Fusion der nationalen Wirtschaftspolitiken in eine gemeinsame kurzfristige und langfristige Politik. Diese Politik soll eine möglichst rasche Expansion, Stabilität und eine Milderung der Konjunkturschwankungen und der nationalen und regionalen Ungleichgewichte sichern. Sie umfaßt notwendigerweise die gemeinschaftliche Fixierung von langfristigen Zielen ... Es wird eine Union zwischen den Mitgliedstaaten geschaffen auf dem eminent politischen Gebiet der Wirtschaft oder genauer: auf dem Gebiet der staatlichen Einflußnahme auf die Wirtschaft, d. h. der Wirtschaftspolitik."“110

Ausgehend von der Feststellung, daß eine „moderne freiheitliche Wirtschaftsordnung nicht bestehen kann ohne eine ständige Präsenz des Staates in der Wirtschaft" “111, drängte die Kommission, die Abstimmung der nationalen Entwicklungspläne für die Wirtschaft im Rahmen sogenannter gemeinschaftlicher „Programme“ vorzunehmen. Auf der Basis von Berechnungen der Expansionsmöglichkeiten sollten die Politiken der Mitgliedstaaten und der Europäischen Wirtschaftsgemeinschaft auf eine „möglichst vollständige Ausnutzung der produktiven Möglichkeiten der Gemeinschaft" abgestimmt werden, ohne dabei inflationäre Spannungen zu verursachen. ${ }^{112}$ Notwendig war diese Koordination vor allem deshalb, so die Kommission, weil

a. viele Investitionen auf Bedürfnissen beruhten, deren Notwendigkeit, wie im Fall von Infrastrukturmaßnahmen, vom Markt gar nicht wahrgenommen würde, da sich die wirtschaftlichen Ergebnisse erst nach langer Zeit bemerkbar machten,

b. weil sie ein unerläßliches Instrument zur rationellen Verteilung der begrenzten Mittel der öffentlichen Hand war,

c. weil sie eine notwendige Richtschnur für nationalen Wirtschaftspläne darstellte, zu denen immer mehr Mitgliedstaaten übergingen, da mit der Öffnung der Volkswirtschaften die Außenwelt zunehmend unsicher geworden wäre,

d. weil so die Einkommenspolitik besser den Wachstumsmöglichkeiten des Produktionsapparates angepaßt werden könnte, ohne dabei das Ziel einer gerechten Einkommensverteilung aus den Augen zu verlieren,

e. weil damit die schon vergemeinschafteten Politiken auf dem Agrar-, Verkehrs- und Energiesektor sowie die Regionalpolitik optimal in eine Gesamtperspektive eingeordnet werden könnten und

f. weil sie ein Mittel darstellte, den Wettbewerb dort wiederherzustellen, wo er durch Kartelle und den Mißbrauch beherrschender Stellungen verhindert war. ${ }^{113}$

${ }^{110}$ Memorandum der EWG-Kommission vom 24.10.1962 über das Aktionsprogramm der Gemeinschaft für die zweite Stufe, D 65, abgedruckt in Auszügen in: EA, Folge 3/1963, D 63 - D 68

"II Memorandum der Kommission vom 24.10.1962, a.a.O., D 64

${ }^{112}$ Vgl. Memorandum der Kommission vom 24.10.1962, a.a.O., D 67

${ }^{113} \mathrm{Vgl}$. Memorandum der Kommission vom 24.10.1962, a.a.O., D $67 \mathrm{f}$. 
Hinter der technischen Konzeption der „Programmierung“ verbarg sich ein Koordinationsregime nach dem Vorbild der französischen Planification. Inspiriert waren die Vorstellungen der Kommission von Robert Marjolin, als EG-Kommissar zuständig für Wirtschaftspolitik. Marjolin hatte in den Regierungsverhandlungen zu den Römischen Verträgen stellvertretend die französische Delegation geleitet und in der Nachkriegszeit unter Jean Monnet die französische Planification mit aufgebaut. ${ }^{114}$ Kurz nach Überreichung des Memorandums an die Mitgliedstaaten präzisierte er in einem Kolloquium zur „wirtschaftlichen Programmierung“ deren Zielsetzung noch einmal dahingehend, daß sie ein Mittel sei, um den „Zusammenhang der staatlichen Eingriffe auf wirtschaftlichem Gebiet“" und „die für alle Einzelentscheidungen notwendige Markttransparenz" zu gewährleisten ${ }^{115}$ :

„Dem einzelnen sind die mit seiner Wahl verbundenen Vorteile und Risiken kenntlich zu machen und die Entscheidungen zu empfehlen, die als angemessen und wünschenswert erscheinen “ ${ }^{\text {“116. }}$.

Dieser Präzisierung ließ Marjolin seine Vorstellungen über das Prozedere der Programmerstellung folgen, welches im wesentlichen dem der Planification, wie sie damals in Frankreich praktiziert wurde, entsprach. ${ }^{117}$ Wie in dieser sollten in einem ersten Schritt allgemeine Projektionen über die langfristige Wirtschaftsentwicklung in den Mitgliedsländern und auf Gemeinschaftsebene erstellt werden, die im wesentlichen auf einer Prognose der Hauptdeterminanten des Wachstums beruhten (Nachfrage nach Arbeitskräften, Entwicklung des Bruttosozialprodukts, der Investitionen und des AuBenbeitrags). Nach der Feststellung der Wachstumsmöglichkeiten war dann in einem zweiten Schritt die Detailplanung für die einzelnen Wirtschaftssektoren vorzunehmen. Auf der Grundlage eines als wahrscheinlich unterstellten Szenarios der zukünftigen Wirtschaftsentwicklung mit konkreten Vorgaben für die anzustrebenden volkswirtschaftlichen Kenngrößen wären danach die Investitions-, Produktions- und Verbrauchsplanungen von privater und öffentlicher Seite in einem schrittweisen Prozeß solange miteinander zu konfrontieren gewesen, bis schließlich eine in bezug auf das vorher festgelegte Wachstumsziel konsistente Gesamtplanung aller Wirtschaftsbereiche erreicht gewesen wäre. Eine zusätzliche dritte Etappe hätte nach den Vorstellungen Marjolins außerdem darin bestehen können, die „Finanzierungsmöglichkeiten der für die Durchführung des gewünschten Gesamtwachstums erforderlichen Investitionen“" zu untersuchen. ${ }^{118}$

\footnotetext{
${ }^{114}$ Vgl. Kleps, K. (1966), Langfristige Wirtschaftspolitik in Westeuropa, Freiburg, S. 433

${ }^{115}$ Vgl. Bericht des Vizepräsidenten der EWG-Kommission, Robert Marjolin, für das Kolloquium "Wirtschaftliche Programmierung" in Rom am 30. 11.1962, D 73, abgedruckt in: EA, Folge 3/1963, D 68-D 78

116 ebenda

${ }^{117}$ Einen guten Überblick über die französische Planifikation zu Beginn der sechziger Jahre bieten: Tholl, G. (1965), Die französische Planification - ein Vorbild? in: Ordo, Band 15/16, S. 197-274; Hetman, F. (1963), Wirtschaftsplanung in Frankreich, in: Konjunkturpolitik, 9. Jg., S. 29-50 sowie Massé, P. (1964), Les principes de la planification française, in: Weltwirtschaftliches Archiv, Bd. 92, Heft 1, S. 113-140

${ }^{118} \mathrm{Vgl}$. Bericht des Vizepräsidenten der Kommission vom 30.11.1962, a.a.O., D 76
} 
Insgesamt schwebte Marjolin eine zentralisierte und staatlich geleitete Investitionsplanung auf europäischer Ebene vor, in der private wie öffentliche Wirtschaftspläne in einem konsensuellen und zugleich rationalen Verhandlungsprozeß auf ein vorgegebenes Wachstumsziel hin abgestimmt werden sollten. Dieser Prozeß sah die Beteiligung der Interessenvertretungen von Arbeitnehmern und Arbeitgebern vor, jedoch weniger, um ihnen einen gewissen Einfluß auf die Ausgestaltung des Gesamtplanes zu verschaffen, sondern vielmehr, um „den Unternehmern und den einzelnen sozialen Gruppen einen Gesamtüberblick auf die wirtschaftliche Entwicklung Europas sowie auf ihre eigene Rolle bei einer freiwilligen Mitarbeit aller an einer optimalen Entwicklung der Gemeinschaft zu ermöglichen" ${ }^{\text {119 }}$. Dies zeigt, daß es der Kommission bei der Programmierung der europäischen Wirtschaft hauptsächlich darum ging, Arbeitnehmern und Unternehmern Einsicht in die Sachzwänge und Möglichkeiten einer optimalen Wirtschaftsentwicklung zu vermitteln. Über die Konfrontation ihrer Einzelinteressen im Verlauf des Planungsprozesses konnten sie sich ein Bild über das zukünftige Marktergebnis machen, und sie würden irrational handeln, wenn sie von den gemeinsam im Plan festgelegten Maßnahmen, die den optimalen Weg zur Realisierung der theoretisch ermittelten maximalen Wachstumsmöglichkeiten darstellten, abweichen würden. Selbst wenn, wie Robert Marjolin wiederholt betonte, die Programme insgesamt nur einen indikativen Charakter haben sollten, hätte schon das Verfahren zu ihrer Erstellung die Folgeplanungen der Privatwirtschaft nicht unbeeinflußt gelassen. Auf staatliche Initiative - und nicht nur auf ihre eigene - wären alle beteiligten Wirtschaftssubjekte zu einer systematischen Reflexion ihrer zukünftigen Aktivitäten angehalten worden. Für viele wäre dies nicht ohne eine Vorabinformation über die Entwicklung der staatlichen Nachfrage möglich gewesen. Über deren Dosierung bot sich für die Wirtschaftspolitik die Möglichkeit, Rahmendaten für die Planung der nichtstaatlichen Wirtschaftseinheiten zu setzen und damit den Wirtschaftsablauf im Sinne politisch gewünschter Zielvorgaben zu beeinflussen.

Seitens der französischen Regierung wurden die Ideen der Kommission zur „Programmierung“ der europäischen Wirtschaftspolitik positiv aufgenommen. In einer ersten interministeriellen Besprechung des Memorandums, drei Wochen nach seiner Übermittlung, trafen die Kommissionsvorschläge auf Zustimmung, da

a. die Programmierung der von Frankreich seit längerem angestrebten Harmonisierung der Wettbewerbsbedingungen entgegenkam,

b. die Programmierung die in den kommenden Verhandlungen der Gemeinschaft mit Drittstaaten erforderliche engere Abstimmung der Wirtschaftspolitik veranlasse und

c. die Programmierung auf europäischer Ebene ein notwendiges Komplement für die Planung auf nationaler Ebene darstellte. ${ }^{120}$

${ }^{119}$ Bericht des Vizepräsidenten der Kommission vom 30.11.1962, a.a.O., D 78

${ }^{120} \mathrm{Vgl}$. MEF, Protokoll der Sitzung des Comité Interministériel pour les Questions Économiques Européennes vom 9.11.1962, in: Fonds 9, Vol. 20, B 17.684 
Nach außen fanden diese Überzeugungen ihren Ausdruck in der Einleitung zum 4. Plan (1961-1965), in der Pierre Massé, Commissaire du Plan und Theoretiker der Planification, auf die Verpflichtung Frankreichs hinwies, auf europäischer Ebene der französischen Plankonzeption zum Durchbruch zu verhelfen. ${ }^{121}$ Im Namen der Regierung vertrat Jean de Lipkowski, Staatssekretär im Außenministerium und Vertrauter de Gaulles, die Überzeugung, daß auf europäischer Ebene eine gemeinsame Wirtschaftsplanung unabdingbar sei:

"Ein weiteres Problem, das Frankreich besonders am Herzen liegt, ist das einer europäischen Planung. Frankreich selbst hat ein anpassungsfähiges Plansystem entwickelt, auf das es nicht verzichten wird. Es erscheint logisch, den französischen Plan eines Tages in einen europäischen Plan einzuordnen. Frankreich ist der Ansicht, daß sich ein solcher Plan in Zukunft als unerläßlich für Europa erweisen wird. "122

Dieser Wunsch, den französischen Plan eines Tages als Koordinationsinstrument auf europäischer Ebene wiederzufinden, ging letztlich auch mit den ordnungspolitischen Vorstellungen de Gaulles konform. Er sah zwar einerseits im europäischen Wettbewerb ein nützliches Erziehungsinstrument, um der noch entwicklungsbedürftigen französischen Wirtschaft zur Steigerung ihrer Leistungsfähigkeit zu verhelfen. ${ }^{23}$ Auch erkannte er durchaus die Verdienste des „kapitalistischen“ Wirtschaftssystems um die Steigerung der Produktivität an. ${ }^{124}$ Zugleich war er andererseits von der moralischen Verwerflichkeit einer rein marktwirtschaftlichen Wirtschaftsweise überzeugt:

„Cependant, depuis longtemps, je suis convaincu qu'il manque à la société mécanique moderne un ressort humain qui assure son équilibre. Le système social qui relègue le travailleur - fût-il convenablement rémunéré - au rang d'instrument et d'engrenage est, suivant moi, en contradiction avec la nature de notre espèce, voire avec l'esprit d'une saine productivité ... le fait est qu'il porte en lui même les motifs d'une insatisfaction massive et perpétuelle. Il est vrai que des palliatifs atténuent les excès du régime fondé sur le <<laissez faire, laisser passer $\gg$, mais ils ne guérissent pas son infirmité morale. “125

121 "D'autres nations commencent à pressentir que l'institution rapide de la liberté des échanges peut créer des problèmes, si elle n'est accompagné de la mise en oeuvre d'une politique commune ayant pour contenu réel sous un nom ou un autre, les premiers rudiments d'un plan. Certes, la disposition d'esprit de nos partenaires est un fait que seule la persuasion ou l'expérience changera. Mais persuader nous incombe. Nous y parviendrons d'autant mieux que nous exprimerons plus clairement notre conception du plan et que, sans en sacrifier l'essentiel, nous nous garderons à infléchir vers des modalités de nature à en éloigner nos interlocuteurs.", siehe: Commissariat générale du plan (1961), Introduction et vue d'ensemble sur le IVme plan, Paris 27.10.1961, S. 5

122 de Lipkowski, J. (1963): Das deutsch-französische Gespräch über die Zukunft der EWG, in: EA, Folge 12/1963, S. 451-456, hier S. 456

${ }^{123}$ „Il s'agit de la compétition internationale, parce que c'est le levier qui peut soulever le monde de nos entreprises, les contraindre à la productivité, les amener à s'assembler, les entraîner à la lutte au-dehors: d'où ma résolution de pratiquer le Marché commun...", so de Gaulle in seinen Memoiren, siehe de Gaulle (1971), a.a.O., S. 110

${ }^{124}$ Vgl. de Gaulle (1971), a.a.O., S. 111

${ }^{125}$ ebenda 
Aufgrund dieser moralischen Defizite und der Unangepaßtheit an die menschliche Natur - Mängel, die für de Gaulle im übrigen auch den Kommunismus kennzeichneten - schloß der französische Staatspräsident auf die Notwendigkeit einer den Erfordernissen der "Zivilisation“ besser angepaßten Wirtschaftsordnung. In dieser sollten die menschlichen Beziehungen idealerweise so gestaltet sein, daß jeder an den Ergebnissen seines Unternehmens in dem Maß partizipierte wie er zu ihnen beitrug. ${ }^{126} \mathrm{Um}$ sich selbst nicht „der zügellosen Willkür eines liberalen Kapitalismus“ auszuliefern, hätte Frankreich sich entschlossen, so de Gaulle, sein Schicksal in die Hand zu nehmen und seinen „Fortschritt zu lenken ... um den größten Ertrag, die größte Kontinuität und die größte Gerechtigkeit zu erzielen “'127. Man wollte zwar den ,individuellen und kollektiven Unternehmergeist" frei gewähren lassen, müsse der „Wirtschaft aber durch staatliche Maßnahmen die Richtung weisen, um den Fortschritt der Nation auf allen Gebieten zu gewährleisten “'128.

„Chez nous, la tâche de l'État consiste donc ... à conduire son évolution. Pourtant, bien que la liberté reste un levier essentiel de l'oeuvre économique, celle-ci n'en est pas moins collective, commande directement le destin national et engage à tout instant les rapports sociaux. Cela implique donc une impulsion, une harmonisation, des règles, qui ne sauraient procéder que de l'État. Bref il y faut le dirigisme ... En fait, il s'agit tout d'abord d'arrêter le Plan, c'est-à-dire de déterminer les objectifs à atteindre, le rythme à suivre, les conditions à observer par l'économie du pays, et de fixer à l'État luimême l'effort financier à fournir, les domaines du développement dans lesquels il doit intervenir, les mesures à prendre en conséquence par ses décrets, ses lois et ses budgets. ${ }^{\text {"129 }}$

Für de Gaulle resultierte die Notwendigkeit zur Planung des Wirtschaftsablaufs somit direkt aus der staatlichen Verantwortung für den Fortschritt der Nation. ${ }^{130}$ Dieser konnte der Staat nur gerecht werden, wenn er die grundsätzlich freien Wirtschaftssubjekte einem gewissen Dirigismus unterwarf, welcher seinen konkreten Ausdruck im Plan fand. Der Plan war also das Mittel, um die Wirtschaft in die staatlichen Bemühungen im Hinblick auf den Fortschritt der Nation zu integrieren. Er hatte der Wirtschaft die Ziele vorzugeben und die Voraussetzungen furr die Mitarbeit aller am gemeinsamen Vorhaben sicherzustellen, während im Gegenzug die Erfüllung des Planes für de Gaulle eine „glühende Verpflichtung“ der gesamten Nation darstellte. ${ }^{131}$

Wenn am Ende die Ansichten der französischen Regierung zur Lenkung der Wirtschaft mit denen der Europäischen Kommission übereinstimmten, so übersah sie indessen

126 „Condamnant l'un et l'autre de ces régimes opposés, je crois donc que tout commande à notre civilisation d'en construire un nouveau, qui règle les rapports humains de telle sorte que chacun participe directement aux résultats de l'entreprise à laquelle il apporte son effort et revête la dignité d'être, pour sa part, responsable de la marche de l'oeuvre collective dont dépend son destin“, ebenda

${ }^{127}$ So de Gaulle in der Pressekonferenz vom 4.2.1965, a.a.O., D 88

128 ebenda

${ }^{129}$ de Gaulle (1971), a.a.O., S. $121 \mathrm{f}$.

${ }^{130}$ Zum Fortschritt als Ziel des nationalen Strebens Frankreichs vgl. die Neujahrsansprache de Gaulles vom 31.12.1962, abgedruckt in: EA, Folge 2/1963, D 52

${ }^{131}$ Vgl. de Gaulle (1971), a.a.O., S. 110 
nicht die Vorbehalte auf seiten ihrer Partner und unter diesen vor allem nicht die Widerstände auf deutscher Seite. Schon in der ersten interministeriellen Besprechung der Kommissionsvorschläge stellte man fest, daß diese abseits der französischen Zustimmung bei anderen Staaten auf Ablehnung stoßen dürften. Auch Jean de Lipkowski bekannte im Anschluß an seine Befürwortung der „Programmierung“, daß Frankreich sich nur schwer vorstellen könne, „wie ein System der nationalen Planung mit einem integralen europäischen Liberalismus in Einklang gebracht werden kann, wie er besonders von Herrn Erhard vertreten wird. “132

Die Unterschiede in der ordnungspolitischen Auffassung zwischen der Kommission und der Bundesrepublik traten auch prompt öffentlich zutage. Auf dem Kolloquium von Rom, wo Marjolin die Vorstellungen der Kommission zur mittelfristigen Programmierung darlegte, kam es zu ernsthaften Auseinandersetzungen zwischen dem Kommissionspräsidenten Walter Hallstein und dem Bundeswirtschaftsminister Ludwig Erhard, in deren Folge die Kommission sich zu einer Überarbeitung ihres Aktionsprogramms gezwungen sah, um der „Programmierung“ im Ministerrat überhaupt noch eine Chance zu geben. In einem weiteren Memorandum vom 25. Juli 1963 nahm sie ihre Position insoweit zurück, als daß die mittelfristige Programmierung nur noch eine reine Projektionsfunktion im Sinne einer Orientierungshilfe für Politik und Wirtschaft haben sollte. ${ }^{133}$ Die sich anschließenden Diskussionen endeten am 15. April 1964 im Beschluß des Ministerrates, einen „Ausschuß für mittelfristige Wirtschaftspolitik" einzusetzen. Dieser sollte hauptsächlich beratend tätig sein und eine Projektion der Wirtschaftsentwicklung in der Gemeinschaft für die kommenden fünf Jahre aufstellen, für die man immerhin noch den Namen „Programm“ beibehalten hatte. Mit der Annahme eines solchen Programms, so der Beschluß, gäben die Mitgliedstaaten ihrer Absicht Ausdruck, "auf dem vom Programm erfaßten Gebiet entsprechend den darin vorgesehenen Leitgedanken zu handeln"134. Auf den Charakter einer reinen Absichtsbekundung reduziert, fristeten die mittelfristigen Programme jedoch vom ersten Tag an ein Schattendasein, ohne jemals tatsächlich Einfluß auf die Wirtschaftspolitik der Mitgliedstaaten genommen zu haben. ${ }^{135}$ Sie wurden aber dennoch bis 1985 weiter aufgestellt, um dann, mit dem Beschluß zur Vollendung des Binnenmarktes im Rahmen der Einheitlichen Europäischen Akte, endgültig aufgegeben zu werden.

Wenn die mittelfristige Programmierung insgesamt kaum Einfluß auf die Wirtschaftsabläufe im Gemeinsamen Markt hatte, so entsprach die ihr zugrundeliegende interventionistische Ordnungskonzeption den Überzeugungen der französischen Regierung. In diesen stellte der Markt das Forum dar, in dem die Wirtschaftssubjekte ihre Einzelin-

${ }^{132}$ de Lipkowski (1963), a.a.O., S. 456

${ }^{133} \mathrm{Vgl}$. Empfehlungen der EWG-Kommission zur mittelfristigen Wirtschaftspolitik in der Europäischen Wirtschaftsgemeinschaft an den EWG-Ministerrat vom 25.7.1963, in: EA: Folge18/1963, D $452-455$

${ }^{134} \mathrm{Vgl}$. Beschluß des Rats der EWG vom 15.4.1964 über die Einsetzung eines Ausschusses für mittelfristige Wirtschaftspolitik, in: EA, Folge 15/1964, D $391 \mathrm{f}$.

135 Vgl. Cambus, C. (1994): Perspective, planification et programmation dans l'Europe du Marché Unique, in: Journal Officiel de la République Française, No. 13, 18.6.1994, S. 55-104, S. 96 
teressen verfolgen und koordinieren können sollten, solange das Allgemeininteresse nicht berührt war. Die Marktkoordination hatte allerdings aus französischer Sicht den grundlegenden Nachteil, wie der französische Plankommissar Massé erläuterte, daß sie nur bei kurzfristigen Entscheidungen zu optimalen Koordinationsergebnissen führen würde, bei denen die Wirtschaftssubjekte schnell und klar die Auswirkungen ihrer Handlungen überschauen könnten, wie z. B. bei Preisentscheidungen oder Investitionen mit kurzer Amortisationsdauer. ${ }^{136}$ Die Unfähigkeit der Märkte, langfristige Entscheidungen „korrekt“ zu orientieren, machte die zentrale Planung des Wirtschaftsablaufes erforderlich. ${ }^{137}$ Dies war natürlich eine Aufgabe für den Staat als Vertreter des allgemeinen Interesses. Er entsprach seiner Verpflichtung, indem er die Vertreter aller Wirtschaftsbereiche an einen Tisch holte, wo sie unter seinem „wohlwollenden Auge $^{\text {‘1 } 138}$ ihre Planungen in ein langfristiges, auf die gemeinsame Zukunft ausgerichtetes gesamtwirtschaftliches Konzept integrierten. Die vom Staat gelenkte Gemeinschaftsplanung war somit das ideale Mittel um die marktlichen „Koordinationsmängel“ zu überwinden. ${ }^{139}$

Der Plan war aus französischer Sicht ein notwendiges Instrument zur Konzertierung des Wirtschaftslebens, das alle Parteien um das gemeinsame Ziel einer optimalen Wirtschaftsentwicklung herum scharen und ihnen den Weg zu mehr Wachstum weisen sollte. Wenn er dabei formal keinen zwingenden Charakter hatte, so lag die primäre Funktion des Plans darin, auf subtile Weise das Planungs- und Entscheidungsverhalten der Wirtschaftssubjekte in die politisch gewünschte Richtung zu lenken. Subtil zum einen, weil auf gesamtwirtschaftlicher Ebene ein Planungsprozeß angeregt wurde, der ohne staatliche Initiative nie stattgefunden hätte. Subtil zum anderen, weil mit diesem Planungsprozeß ein Forum geschaffen wurde, in dem der Staat als erster seine Entwicklungsabsichten verkünden konnte. Zumindest hätte er für die von ihm abhängigen privaten Wirtschaftseinheiten die Eingangsdaten ihrer Planung gesetzt und damit ihre zukünftige wirtschaftliche Aktivität in seinem Sinne beeinflußt. Subtil aber auch drittens, weil Wirtschaftssubjekte über alle Wirtschaftsbereiche hinweg zu einer Art Vorkoordination ihres Handelns bewegt und so in einen kollektiven Handlungszusammenhang eingebunden worden wären, der Beeinflussungsmöglichkeiten bot wie sie auf freien Märkten nicht bestanden. Der Plan war ein konsensorientiertes, auf rationalen Überlegungen beruhendes Koordinierungsinstrument, das die individuellen Planungen mit dem Allgemeininteresse der Nation in Übereinstimmung zu bringen suchte. Der rationale Diskurs aller Wirtschaftssubjekte unter staatlicher Führung war aus französischer Sicht das optimale Koordinationsverfahren im Bereich des Wirtschaftlichen und damit zugleich Ausdruck höchster wirtschaftspolitischer Vernunft. In diesem Sinne stellte er das Äquivalent zur ,prästabilierten Harmonie“ dar, die im Rahmen der libe-

\footnotetext{
${ }^{136}$ Vgl. Massé (1964), a.a.O., S. 127

137 ebenda

138 „Il est à l'avantage mutuel que la confrontation des prévisions et des décisions du secteur privé s'effectue suivant une procédure publique <<sous l'oeil bienveillant, mais attentif, des gouverne-

139 ments $\gg$ ", Massé (1964), a.a.O., S. 129

ebenda
} 
ralen Wirtschaftstheorie auf freien Märkten als optimales Koordinationsergebnis angesehen wird. Jeder, der abweichend von den im Plan festgelegten Vorgaben handelte, hätte sich nach französischer Ordnungslogik den Vorwurf gefallen lassen müssen, irrational zu handeln. Der Plan bot aus französischer Sicht das beste Mittel, politischen Zielen Eingang in die Pläne der Unternehmen zu verschaffen, und dies in einem Maß, das in einer Wettbewerbsordnung nie möglich gewesen wäre.

Wie sich in diesen Betrachtungen zeigt, wurden Wirtschaft und Staat bzw. Wirtschaft und Politik im Frankreich de Gaulles als untrennbar verbundene Bestandteile einer politischen Gesamtkonzeption verstanden, die sich dem Bemühen verschrieben hatte, nicht nur die französische Nation, sondern Europa und über die Europäische Gemeinschaft die Welt auf dem Weg des gesellschaftlichen Fortschritts voranzubringen. In der französischen Befürwortung der „mittelfristigen Programmierung“ zeigte sich, daß Frankreich diese Ordnungskonzeption grundsätzlich auf europäische Ebene zu übertragen gewillt war. Im Zusammenhang mit der praktischen Realisierung dieses Vorhabens zeigte sich darüber hinaus wie wirksam die Entsendung engagierter Spitzenbeamter, in diesem Fall die von Robert Marjolin, an die Schaltstellen der Gemeinschaftsinstitutionen für die Umsetzung bestimmter ordnungspolitischer Zielvorstellungen sein konnte. $\mathrm{Da}$ Frankreich die Einführung der Programmierung auf europäischer Ebene letztendlich nicht nachhaltig vorantrieb, lag in erster Linie an der realistischen Einschätzung der Widerstände gegen dieses Konzept. Hinzu traten praktische Mängel der Planification insbesondere im Bereich der Prognose, die mit der Öffnung der französischen Volkswirtschaft zunehmend sichtbar wurden und dazu führten, daß die Wirtschaftspläne nach und nach nur noch indikativen Charakter erhielten. Die Loslösung vom Wirtschaftsplan als Koordinierungsinstrument bedeute indessen, wie die nachfolgenden Ausführungen zeigen, nicht die Aufgabe des dahinterstehenden interventionistischen Ordnungswollens.

\section{B.2.2.4 Die Industriepolitik}

Ihre Bemühungen, die Wirtschaftsentwicklung verstärkter politischer Lenkung zu unterwerfen, verfolge die französische Regierung seit Mitte der sechziger Jahre in neuer Form. Mit gezielten Ansätzen zur Förderung der wirtschaftsnahen technologischen Forschung sowie der Bereitstellung besonderer Rahmenbedingungen für die Unternehmensentwicklung sollten die Grundlagen für eine gemeinschaftliche Industriepolitik gelegt werden. Ihren Ursprung hatten diese Bemühungen in der zunehmenden Besorgnis der französischen Regierung über die Expansion amerikanischer Großunternehmen, die seit Anfang der sechziger Jahre unaufhaltsam in den Binnenmarkt drängten. Ihr wirtschaftlicher Erfolg in Bereichen der Spitzentechnologie, wie z. B. der Nuklearindustrie, dem Luftfahrzeugbau oder der Informationstechnologie, war unübersehbar, ohne das Europa etwas Vergleichbares entgegenzusetzen hatte. 
Der französische Wirtschafts- und Finanzminister Valéry Giscard d'Estaing trug dementsprechende Sorgen erstmals in einer Ministerratssitzung im März 1963 vor, in der er darauf aufmerksam machte, daß in Europa mittlerweile ganze Branchen in Gefahr seien, von US-Unternehmen dominiert zu werden. Weniger problematisch seien dabei wirkliche Direktinvestitionen vor Ort, die neue Unternehmen entstehen ließen, als vielmehr Versuche von amerikanischer Seite, über ein finanzielles Engagement Eigentumsanteile an europäischen Unternehmen zu erwerben. ${ }^{140}$ Das Problem bestünde vor allem in den großen Finanzreserven der amerikanischen Unternehmen, die zum Teil den Umsatz ganzer Branchen in Europa überstiegen. Dieses, so Giscard d'Estaing, bedrohte zum einen den Wettbewerb im Gemeinsamen Markt, da es den amerikanischen Unternehmen mit ihren Finanzmitteln leicht möglich sei, wirtschaftliche Verluste ihrer Neuerwerbungen weitaus länger zu finanzieren, als es deren Einnahmen sonst je erlaubt haben würden. Zum anderen bestünde die Gefahr, daß sich die Entscheidungen vieler Unternehmen in kürzerer Zeit in einem ,auswärtigen Rahmen“ vollziehen würden - eine diplomatische Formulierung dafür, daß durch die Expansion amerikanischer Unternehmen die nationale Souveränität französischerseits als gefährdet betrachtet wurde. ${ }^{141} \mathrm{Da}$ dieses Problem eine europäische Dimension hätte, forderte Giscard d'Estaing vom Ministerrat eine Debatte über geeignete Gegenmaßnahmen und schlug als eine solche gezielte Kapitalverkehrsbeschränkungen vor. Allerdings vermochte er nicht, seine Kollegen zu überzeugen, die die Besorgnis Frankreichs in bezug auf amerikanische Direktinvestitionen nicht teilten.

Die französische Regierung reagierte daher im Alleingang, indem sie die für Devisenausländer bestehenden Beschränkungen des Erwerbs von börsennotierten Unternehmensanteilen auf Beteiligungsgeschäfte ausdehnte. Der Kommission gegenüber, die darin einen Verstoß gegen die Rechtsbestimmungen zur Liberalisierung des Kapitalverkehrs sah und sich anschickte, Frankreich mit rechtlichen Mitteln zu drohen, begründete die französische Regierung die Zulässigkeit dieser Maßnahme mit einer restriktiven, buchstabengetreuen Auslegung des EWG-Vertrages, so daß die Kommission im Verlauf des Jahres 1964 ihre Gegenwehr aufgab. ${ }^{142}$ Frankreichs Reaktion gegen die als bedrohlich empfundenen amerikanischen Übernahmeversuche ging sogar noch weiter. Überzeugt davon, daß die Innovationsfähigkeit der französischen Unternehmen nicht ausreichen würde, um im internationalen Wettbewerb überleben zu können, ging die französische Regierung zu einer durchgreifenden Umstrukturierung der nationalen Industrielandschaft über. In allen als wichtig erachteten Bereichen wirkte sie auf die Entstehung von ein oder zwei führenden Großunternehmen hin. Auf dem Gebiet der Informationstechnologie führte diese Politik zum ,plan calcul“, der aufgestellt wurde, als im Rahmen eines militärischen Beschaffungsvorhabens feststellt wurde, daß die erforderlichen Großrechner nur in den USA erhältlich waren. Die französische Regie-

\footnotetext{
${ }^{140}$ Vgl. die Protokolle der Ministerratssitzungen vom 25. und 26.3.1963, in MEF, Fonds 9, Vol. 20, B 17.738 , Projet de procès verbal

141 ,... décisions et actions s'inscrivent dans un cadre extérieur", so die Formulierung Giscard d' Estaings im Sitzungsprotokoll, ebenda

${ }^{142} \mathrm{Vgl}$. Note vom 24.10.1964, in MEF, Fonds 9, Vol. 20, B 17.735
} 
rung untersagte daraufhin deren Beschaffung und bewegte zwei einheimische Unternehmen (Computer Bull und Honeywell) zur Fusion, so daß die französische Unabhängigkeit auf diesem Wirtschaftssektor wiederhergestellt war. ${ }^{143}$

Um der amerikanischen Konkurrenz jedoch noch schlagkräftiger entgegentreten zu können, wandte sich die französische Regierung im April 1965 mit dem Vorschlag einer gemeinsamen Politik auf dem Gebiet der Forschung und Technologie erneut an die europäischen Partner. ${ }^{144}$ Vor dem Hintergrund der hohen Forschungsaufwendungen der USA und der UdSSR sowie der seit Jahren zu beobachtenden Abwanderung führender Wissenschaftler aus Europa (,brain drain“) schlug sie vor, die gemeinsamen Forschungskapazitäten zusammenzulegen und rationell zu nutzen, um die Wettbewerbsfähigkeit der europäischen Industrie zu erhalten. ${ }^{145}$ Statt weiter im nationalen Rahmen nebeneinander her zu arbeiten und dabei Doppelarbeit zu verrichten, sollte Europa wieder zu seiner historischen Verpflichtung zurückkehren, wissenschaftliche Spitzenleistungen hervorzubringen:

"...la Communauté économique européenne, en raison de la solidarité économique grandissante de ses membres, de la spécificité de ses objectifs, en raison aussi de la traditionnelle vocation de l'Europe à fournir à la science mondiale des chercheurs et des savants de grand renom, se doit de fournir en matière de recherche scientifique un effort plus ample et plus systématique qui soit à la mesure de ses ambitions." ${ }^{146}$

Als erste konkrete Maßnahme sollte nach dem Willen der französischen Regierung eine gemeinsame Bestandsaufnahme der gegenwärtigen Forschungsbemühungen in allen Mitgliedstaaten durchgeführt werden, die auf zwei Fragen eine Antwort zu geben hatte:

1. auf die Art und den Mittelansatz der gegenwärtigen Forschungsaktivitäten in den Mitgliedstaaten, um so einen Überblick über die Schwerpunkte und die Prioritäten der nationalen Forschungsvorhaben zu erhalten und die Bereiche identifizieren zu können, in denen Doppelarbeit geleistet würde. Dazu sollten öffentliche wie private Forschungsaktivitäten erfaßt werden, selbst wenn bei letzteren die Erhebung von Informationen auf Schwierigkeiten stoßen würde.

2. In einer zweiten Studie sollten die Forschungsbereiche identifiziert werden, in denen die europäische Industrie im Vergleich zu Drittländern weniger aktiv war, sowie jene Wirtschaftsbereiche, deren Zukunft in außergewöhnlich hohem Maße vom wissenschaftlichen und technischen Fortschritt abhängen würde. ${ }^{147}$

\footnotetext{
${ }^{143}$ Vgl. de Carmoy (1967), a.a.O., S. 465

${ }^{144}$ Note du gouvernement français du 4.3.1965, S. 17 ff., in G. Caty (Hrsg.), L'Europe technologique, Paris 1970, S. 17-20

145 "Il s'agirait essentiellement de renforcer, par l'utilisation rationnelle des ressources intellectuelles de chaque État membre, la capacité concurrentielle des industries de la Communauté, et notamment dans les secteurs où le progrès scientifique est le plus rapide ..." ebenda, $S .18 \mathrm{f}$.

${ }^{146}$ ebenda, S. 18

${ }^{147}$ ebenda, S. $19 \mathrm{f}$.
} 
Auf dieser Grundlage sollte anschließend in einem dritten Schritt eine gemeinsame Forschungspolitik konzipiert werden, die, um den wirtschaftlichen Erfolg sicherzustellen, noch durch eine gemeinsame Politik auf dem Gebiet der Investitionen zu ergänzen war:

"Une attitude libérale à l'égard des pays-tiers appelle nécessairement un effort des pays membres de la Communauté économique européenne en vue de pratiquer une politique d'investissement qui permette à l'industrie communautaire de demeurer concurrentielle, notamment à l'égard des industries de certains grands pays qui reçoivent des pouvoirs publics une aide considérable, en particulier sous forme de contrats de recherche." ${ }^{148}$

Konkret ging es Frankreich also im Rahmen dieser Investitionen um die finanzielle Förderung der industriellen Forschung, die es durch das im EWG-Vertrag festgelegte Verbot staatlicher Beihilfen nach Artikel 92 und 93 behindert sah. Zur Beseitigung etwaiger Hindernisse forderte die französische Regierung die Kommission auf, „Kenntnis zu nehmen, von dem Zustand der Dinge“, wenn sie, wie vom Vertrag vorgesehen, staatliche Forschungsbeihilfen auf ihre Zulässigkeit prüfe ${ }^{149}$ - ein Hinweis, hinter dem sich unausgesprochen die Forderung verbarg, Subventionen im Rahmen der Forschungsförderung zuzulassen.

Mit dieser Note konterkarierte die französische Regierung die gemeinschaftlichen Koordinationsbemühungen auf wirtschaftspolitischem Gebiet noch bevor das erste „mittelfristige Programm“ verabschiedet wurde. Sie zeigte damit, daß sie in Fragen von nationalem Interesse die intergouvernementale Koordinierung der nationalen Wirtschaftspolitiken vorzog. Die im Juli 1965 von Frankreich provozierte Krise brachte die eigene Initiative allerdings zum Erliegen, was die französische Regierung von ihrem industriepolitischen Anliegen jedoch nicht abbringen sollte. Frankreich wurde auch in den Folgejahren nicht müde, auf die Gefahren einer technischen Unterlegenheit hinzuweisen. De Gaulle persönlich reihte sich in diese Bemühungen ein, indem er die Notwendigkeit gemeinsamer Forschungsanstrengungen mit der Bedrohung durch das ,atlantische" Hegemonialstreben der USA in Verbindung brachte. ${ }^{150}$ Im Oktober 1967 konnte Frankreich schließlich den ersten Erfolg verbuchen: Der Ministerrat beschloß die Einsetzung einer „Arbeitsgruppe Forschungspolitik“, die auf französisches Drängen nicht der Kommission, sondern dem Ministerrat unterstand. ${ }^{151}$ Sie wurde unter

${ }^{148}$ Note du gouvernement français (1965), a.a.O., S. 19 f.

149 "À cet égard, il est souhaitable que la Commission tienne compte de cet état des choses lorsqu'il lui incombe d'examiner, au titre des articles 92 et 93 du Traité de Rome, les initiatives prises par les États membres pour instituer des formes nouvelles d'aide à la recherche", Note du gouvernement français (1965), a.a.O., S. 20

150 „Vielleicht ist die Stärkung des europäischen Geistes auch auf die Bedrohung zurückzuführen, die der Expansionsdrang der Amerikaner auf technologischem Gebiet für die Sechs darstellt", so de Gaulle in seiner Pressekonferenz vom 16.5.1967, a.a.O., D 250

$151 \mathrm{Vgl}$. Touscoz, J. (1975), La France et la politique technologique des Communautés Européennes“, S. 639 f., in: Joël Rideau et. al. (Hrsg.), La France et les Communautés Européennes, Paris, S. $635-642$ 
dem Namen „PREST“152 dem Ausschuß für Mittelfristige Wirtschaftspolitik angegliedert und erhielt den Auftrag, eine Studie zu den von Frankreich zwei Jahre zuvor aufgeworfenen Fragen auszuarbeiten. ${ }^{153}$

Die Arbeiten von PREST kamen unter der allgemeinen innergemeinschaftlichen Lethargie Ende der sechziger Jahre jedoch nur langsam voran. Aus diesem Grund schlug die französische Regierung in einem „Programm zur Stärkung der EWG“ im November 1968 die Straffung des Zeitplanes für PREST vor. ${ }^{154}$ Außerdem regte sie an, die gemeinsame Forschungs- und Technologiepolitik von Anfang an für Drittstaaten offenzuhalten. Dies mag auf den ersten Blick als Widerspruch erscheinen, da so potentiell dem „Atlantismus“ Tür und Tor zur Schwächung der europäischen Wettbewerbsfähigkeit geöffnet wurden - doch praktizierte Frankreich in seiner nationalen Forschungspolitik auf der Ebene von Projekten wie der „Concorde“ und der „European Space Agency" schon seit längerem die Zusammenarbeit mit Großbritannien, und so reihte sich dieser Vorschlag nahtlos in das französische Bemühen um eine europäische Forschungsförderung ein. Ergänzt wurde es um einen weiteren Vorschlag zur Lockerung der nach französischer Meinung zu eng gefaßten europäischen Wettbewerbsregeln. Um endlich auch in Europa Großunternehmen amerikanischen Zuschnitts entstehen zu lassen, regte Frankreich die „Festlegung eines Regimes, das die Fusionen zwischen Unternehmen des Gemeinsamen Marktes erleichtern würde“, an. ${ }^{155}$ Konkret ging es der französischen Regierung um eine Revision der Artikel 85 und 86 EWGV sowie der Verordnung Nr. 17, in der sie die größten Hindernisse für die aus ihrer Sicht erforderliche gemeinsame Politik auf dem Gebiet der Unternehmenszusammenschlüsse sah. In diplomatischem Ton formulierte sie ihre Forderung:

"Die Bestimmungen des Vertrages und die des Reglements Nr. 17 über die Übereinkommen hätten diese Entwicklung (bisherige Unternehmenszusammenschlüsse, Anm. d. Verf.) jedoch behindern können, wenn die Kommission nicht die erfreuliche Initiative ergriffen hätte, die einen und die anderen so auszulegen, daß daraus kein solcher Nachteil entsteht. Es wäre aber vorteilhaft, daß der Rat darüber eine Debatte ansetzt, um im Einvernehmen mit der Kommission die Haltung genauer festzulegen, welche die Gemeinschaft auf einem für ihre Zukunft so wichtigen Gebiet einnehmen sollte." 156

Ergänzend drängte Frankreich auf die forcierte Ausarbeitung des Statuts einer „Europäischen Handelsgesellschaft“ - einer in allen Mitgliedstaaten gültigen einheitlichen Rechtsform für Unternehmen, mit der die juristischen Voraussetzungen für Unternehmenszusammenschlüsse auf europäischer Ebene geschaffen werden sollten. Mit diesem Vorstoß kurz vor dem Ende der Amtszeit de Gaulles vermochte die französische Regierung allerdings auch nicht mehr den Lauf der Dinge zu wenden. Die sich zu

\footnotetext{
${ }^{152}$ Die Abkürzung für „Groupe de travail de la Politique de la Recherche Scientifique et Technique“

${ }^{153} \mathrm{Vgl}$. Mandat du groupe de travail "politique de la recherche scientifique et technique" de la CEE, abgedruckt in: Gilbert Caty (1969): L'Europe Technologique, Paris, S. 20 f.

154 Vgl. Programm der französischen Regierung zur Stärkung der EWG vom 5. November 1968, D 614, in: EA, Folge, 24/1968, D 612-615

${ }^{155}$ Vgl. Programm zur Stärkung (1968), a.a.O., D 614

${ }^{156}$ Vgl. Programm zur Stärkung (1968), a.a.O., D 614
} 
dieser Zeit verschärfenden Währungsprobleme sollten bald das Interesse der Mitgliedstaaten auf andere Fragen lenken und die Industriepolitik vorerst von der Tagesordnung der Gemeinschaft verdrängen.

Aus ordnungspolitischer Sicht zeigte sich, daß sich in der französischen Initiative zu einer europäischen Industriepolitik jenes Bemühen um die langfristige Orientierung der Wirtschaftsentwicklung fortsetzte, das zuvor schon die französische Haltung zur „Programmierung“ der europäischen Wirtschaftspolitik geprägt hatte: Wieder war es der Staat, der sich um die „korrekte“ Ausrichtung der langfristigen Entwicklungspläne bemühte; wieder waren es seine Finanzmittel, mit denen er auf der Ebene der Unternehmen angesetzt hätte, um ihre Entscheidungen in die gewünschte Richtung zu lenken, und wieder handelte es sich um einen Versuch, die Lösung jener Wirtschaftsprobleme auf gesamteuropäische Ebene zu verlagern, bei denen die nationalen Mittel nicht mehr hinreichten. Beim Rückstand im Bereich der Forschung handelte es sich aus französischer Sicht um ein eminent nationales Problem - immerhin war die Unabhängigkeit der Nation berührt -, weshalb es Sache der Regierungen war, eine Lösung zu finden und Abhilfe zu schaffen. Erforderlich war dazu die intergouvernementale Kooperation, die sich im Falle der gemeinsamen Industriepolitik nicht mehr auf die gesamte Wirtschaft, sondern nur auf bestimmte Schlüsselindustrien erstrecken sollte. Bezeichnend für den ordnungspolitischen Ansatz der französischen Regierung war die Überzeugung, daß eine der Hauptursachen für die mangelnde Wettbewerbsfähigkeit der europäischen Industrie in den Wettbewerbsregeln des EWG-Vertrags lag. Der Mangel an technologischer Wettbewerbsfähigkeit wurde aus französischer Sicht als Mangel der Marktkoordination gedeutet, der die Notwendigkeit staatlicher Intervention begründete. $\mathrm{Da}$ es für Frankreich bei der Industriepolitik um mehr ging als ausschließlich wirtschaftliche Sachfragen, war an den wiederholten Verweisen auf die USA erkennbar, deren „,bedrohliche“ Wirtschaftskraft Ursprung und Richtmaß aller industriepolitischen Bemühungen Frankreichs war. Machtpolitische und wirtschaftspolitische Erwägungen traten in der industriepolitischen Konzeption Frankreichs untrennbar zusammen.

\section{B.2.3 Die Währungspolitik \\ B.2.3.1 Die währungspolitische Ausgangssituation}

Die Währungsangelegenheiten der Europäischen Gemeinschaft wurden in den sechziger Jahren noch auf der Basis des Abkommens von Bretton-Woods aus dem Jahre 1944 geregelt. ${ }^{157}$ Die Wechselkurse der einzelnen Währungen waren über ihren Kurs

${ }^{157}$ Nach Artikel 107 (1) EWG-Vertrag war vereinbart, die Politik auf dem Gebiet der Wechselkurse als eine Angelegenheit von gemeinsamem Interesses zu betrachten. Auf informeller Ebene wurden zwar regelmäßige quartalsweise Treffen der Finanzminister durchgeführt, in denen diese aktuelle währungspolitische Entwicklungen besprachen, doch fanden diese bewußt außerhalb des Gemeinschaftsrahmens statt. Nach Artikel 105 EWG-Vertrag wurde außerdem ein Währungsausschuß eingesetzt, der jedoch hauptsächlich beratende Funktion hatte. 
zum US-Dollar definiert, dessen Wert wiederum durch seine Goldparität bestimmt wurde, die seit 1944 unverändert bei 35 Dollar pro Feinunze Gold lag. Damit entstand ein Paritätengitter, daß seine Stabilität dadurch erhielt, daß die USA sich verpflichteten, jederzeit Dollars zu dem festgelegten Kurs in Gold zurückzutauschen, während die anderen Teilnehmer die Verpflichtung hatten, den Wert ihrer Währungen zum Dollar zu verteidigen, wobei ihnen eine minimale Schwankungsbreite von $+/$ - zwei Prozent zugestanden wurde. Ergänzt wurde diese Konstruktion durch das Europäische Währungsabkommen (EWA) von $1957 .{ }^{158}$ Dieses regelte den monatlichen Ausgleich der Devisenbestände und legte fest, daß auftretende Salden ausschließlich in Dollar zu begleichen waren. Um die Wechselkursschwankungen auf ein Minimum zu beschränken, sah das EWA eine Reduzierung der Schwankungsbreite um den offiziellen Dollarkurs auf 1,5 Prozent vor, was die maximal mögliche Abweichung der Wechselkurse untereinander auf drei Prozent beschränkte.

Den europäischen Staaten boten diese beiden Abkommen eine geregelte Grundlage zur Abwicklung ihres Zahlungsverkehrs. Ihr währungspolitischer Spielraum war allerdings im wesentlichen auf die Höhe ihrer Dollar- und Goldreserven begrenzt. Im Gegensatz dazu profitierten die USA von der Sonderrolle des Dollars, der als einzige Währung zugleich auch als Devisenreserve akzeptiert wurde. Ihnen öfneten sich damit bei Zahlungsbilanzdefiziten theoretisch unbegrenzte Finanzierungsmöglichkeiten. Sie waren im Falle eines übermäßigen Abflusses von Devisen- und Währungsreserven im Gegensatz zu den europäischen Staaten nicht zu währungs- oder wirtschaftspolitischen Anpassungsmaßnahmen gezwungen.

Die asymmetrisch verteilten Anpassungslasten zwischen den Mitgliedstaaten im internationalen Währungssystem machten sich erstmals Ende der fünfziger Jahre bemerkbar als die amerikanischen Ausgaben im Ausland die Einnahmen überstiegen. Die zur Stabilisierung ihrer Wechselkurse verpflichteten europäischen Zentralbanken mußten zunehmend in eigener Währung intervenieren, um den wachsenden Dollarumlauf zu kompensieren. Ab Anfang der sechziger Jahre kam es in allen Mitgliedstaaten der Gemeinschaft zu einem spürbaren Anstieg der Inflationsraten. Da der weltweite Dollarumlauf seit Ende des zweiten Weltkrieges um das Fünffache zugenommen hatte, während die Goldreserven der USA stetig abnahmen, war es auch nicht mehr problemlos möglich, die akkumulierten Dollarbestände der Zentralbanken einfach in Gold zurückzutauschen.

\section{B.2.3.2 Das „Collective Reserve Units“-Konzept Giscard d'Estaings}

Frankreich sah sich 1963 erstmals gezwungen, auf die Beschleunigung des Preisanstiegs zu reagieren. Es verabschiedete einen ,plan de stabilisation“, der neben Maß-

${ }^{158}$ Zum Europäischen Währungsabkommen vgl. Schleiminger, G. (1956), Das Europäische Währungsabkommen von 1955 und einige neuere währungspolitische Entwicklungen, Diskussionsbeiträge des Instituts für Weltwirtschaft an der Christian-Albrechts-Universität Kiel, Kiel 
nahmen zur Begrenzung des Geldmengenwachstums auch die Verhängung eines generellen Preisstopps vorsah. ${ }^{159}$ Die französische Regierung kritisierte darauf hin erstmals massiv die amerikanische Zahlungsbilanzpolitik, der sie die Hauptursache für diese erforderlich gewordene Korrektur zuschrieb. ${ }^{160}$ Um die negativen Auswirkungen der amerikanischen Zahlungsbilanzpolitik wirkungsvoll zu begrenzen, schlug der französische Wirtschafts- und Finanzminister Valéry Giscard d'Estaing 1964 erstmals eine Reform des internationalen Währungssystems vor.

Giscard d'Estaings Reformkonzept sah vor, die Schaffung neuer Liquidität international zu kontrollieren und über künstliche Reservewährungseinheiten zu steuern. Grundsätzlich mußte ein neues stabiles Währungssystem aus seiner Sicht den Interessen aller beteiligten Staaten im gleichen Maße dienen und durfte keiner Währung einen Sonderstatus gewähren. Idealerweise sollte es die Weltwirtschaft mit hinreichender Liquidität so versorgen, daß es weder zu Wachstumsbehinderungen noch zu einer Inflation kam. Außerdem mußte es klare und wirksame Anpassungsmechanismen für den Fall vorsehen, daß ein Mitgliedstaat in ein Zahlungsbilanzungleichgewicht geriet. ${ }^{161}$

Konkret schlug Giscard d'Estaing auf der Versammlung des Internationalen Währungsfonds (IWF) am 9. September 1964 vor, daß die großen Staaten sich zunächst „feierlich verpflichten“" sollten, ihre Zahlungsbilanzdefizite wieder in Gold zu begleichen. Auch sollte die Finanzierung von Maßnahmen zur Überwindung struktureller Defizite wieder im Rahmen der Fazilitäten der Abkommen von Bretton-Woods und des EWA's vorgenommen werden. Vor der Schaffung weiterer Liquidität sollte das internationale Währungssystem durchgreifend erneuert werden. Dabei war der Saldenausgleich zwischen den Zentralbanken aller Länder grundsätzlich auf Zahlungen in Gold umzustellen. ${ }^{162}$ Als Währungsreserven sollten nur noch Gold und vom Gold „abgeleitete“ zusätzliche Reserven gehalten werden dürfen. Außerdem war vorgesehen, die Devisenhaltung der Zentralbanken auf das zur Abwicklung des internationalen Zahlungsverkehrs notwendige Maß zu beschränken. Der Abbau überschüssiger Währungsreserven sollte durch das Einstellen ihrer Verzinsung sowie durch die vorgezogene Rückzahlung ehemaliger Finanzierungshilfen beschleunigt werden. Am Ende des Reformprozesses sollten schließlich alle Währungen in Gold konvertibel sein.

Das wesentlich Neue an diesem Reformvorschlag war der Mechanismus zur Schaffung neuer Liquidität. Sie sollte nicht mehr in direkter Abhängigkeit von den physisch vorhandenen Goldreserven und dem jährlichen Zuwachs der weltweiten Goldproduktion stehen, sondern über die kontrollierte Emission künstlicher, vom Gold abgeleiteter $\mathrm{Li}$ quidität in Form von „Collective Reserve Units“ (CRU) erfolgen. Zentral für Giscard

\footnotetext{
${ }^{159}$ Zum ,plan de stabilisation“ vgl. Vesperini (1993), a.a.O., S. 26-31

${ }^{160}$ Kritik zu diesen beiden Punkten äußerte der französische Wirtschafts- und Finanzminister Valéry Giscard d'Estaing auf den Jahresversammlungen des Internationalen Währungsfonds in Washington am 1.10.1963 und am 9.9.1964 in Tokio

${ }^{161}$ So Giscard d'Estaing am 11.2.1965 in einer Rede im maison du Droit der Université de Paris

${ }^{162} \mathrm{Zu}$ den Vorschlägen vgl. die Reden Valéry Giscard d'Estaings vom 9.9.1964 und vom 11.2.1965
} 
d'Estaing war dabei, daß die Geldschöpfung nicht mehr in Reaktion auf kurzfristig auftretende Zahlungsschwierigkeiten einzelner Staaten vorgenommen wurde. Vielmehr sollte der weltweite Bedarf an neuen Reserven antizipativ anhand objektiver statistischer Indikatoren ermittelt werden. ${ }^{163} \mathrm{Um}$ dabei den Vorrang des weltwirtschaftlichen Gesamtinteresses vor nationalen Eigeninteressen sicherzustellen, sollte neue Liquidität nur auf einstimmigem Beschluß aller Staaten geschaffen werden. ${ }^{164}$ Einmal beschlossen, waren die neu geschaffenen CRU's gegen die Hinterlegung nationaler Währung entsprechend der internationalen Verteilung der Goldvorräte an die Zentralbanken abzugeben. Auf diese Weise wären, so Giscard d'Estaing, die internationalen Kontrollerfordernisse und das Souveränitätsbedürfnis der Mitgliedstaaten, die über die erhaltenen Gelder frei verfügen können sollten, optimal aufeinander abgestimmt.

Giscard d'Estaing verfolgte mit seinem CRU-Konzept zwei Ziele. Zunächst ging es ihm darum, in Währungsfragen die politische Gleichberechtigung Europas mit den USA zu erlangen. Dazu war die Asymmetrie bei der Verteilung der Anpassungslasten im internationalen Währungssystem zu überwinden. Darüber hinaus ging es ihm langfristig um die Neuordnung der internationalen Währungsbeziehungen nach einem aus seiner Sicht überlegenen Ordnungssystem. Danach sollte die Schaffung zusätzlicher Reserven vorausschauend und in Abhängigkeit „objektiv“ erkannter gesamtwirtschaftlicher Notwendigkeiten erfolgen. Er selbst sah das Problem des Zahlungsbilanzausgleichs in erster Linie als ein technisches Problem der effizienten Verteilung (,rédistribution“) vorhandener Geldmittel an und weniger als eines der Schaffung neuer Reserven, die, im Übermaß geschaffen, nur die Anpassungsanstrengungen der Defizitländer herabsetzen und $\mathrm{zu}$ inflationären Entwicklungen führen würden. ${ }^{165}$ Unklar im CRU-Konzept blieben jedoch die Vorstellungen des französischen Finanzministers über die Anpassungsprozesse, welche eine defizitäre Zahlungsbilanz wieder ins Gleichgewicht zurückfuihren sollten. Dies war um so verwunderlicher, da er selbst in seinen Kriterien für ein optimales Währungssystem auf die Notwendigkeit klar definierter Anpassungszwänge hingewiesen hatte. Wohl war mit der „feierlichen Erklärung" zum Ausgleich der Zahlungsbilanzdefizite in Gold und über die Einstimmigkeitsregel bei der Schaffung neuer Währungsreserven ein gewisser Schutz gegen die unbegrenzte Schaffung übermäßiger Liquidität vorhanden. Waren neu geschaffene Währungsreserven jedoch erst einmal zugeteilt, so hätten sie den Mitgliedstaaten ohne weitere Auflagen zur Verfügung gestanden. Auch das CRU-Konzept befaßte sich somit nur mit den Modalitäten der Geldmengenausweitung, die es in letzter Konsequenz einem politischen Beschluß unterwarf, statt sie an sachliche Kriterien zu binden. Defizitländern wären neue Finanzierungsmittel nach politischer Opportunität zur Verfügung gestellt worden, ohne daß sie von vornherein mit konkreten Stabilisierungszwängen z. B. im Sinne einer restriktiven Geld- oder Fiskalpolitik konfrontiert worden wären. Damit umging letztlich auch das CRU-Konzept den delikaten Teil notwendiger

${ }^{163}$ Vgl. Drouin, P. (1965), Die Währungspolitik Frankreichs, in: EA, Folge 22, S. 853-860, hier S. 857

${ }^{164} \mathrm{Vgl}$. die Rede Valéry Giscard d'Estaings am 15.6.1965 vor dem Institut d'Études Bancaires et Financières

${ }^{165}$ Vgl. Rede Giscard d'Estaings vom 15.6.1965 
stabilitätspolitischer Anpassungsprozesse, ohne einen substantiellen Fortschritt gegenüber dem damaligen internationalen Währungssystem darzustellen. Immerhin hätte es allen Währungen einen einheitlichen Status und den Staaten währungspolitisch die Gleichberechtigung mit den USA beschert.

Als Ersatz fur die fehlenden konkreten Stabilisierungsmechanismen formulierte Giscard d'Estaing verschiedene allgemeine Grundsätze, die bei der Ausweitung der Geldmenge beachtet werden sollten. So war prinzipiell der Verwendungszweck der neuen Mittel von entscheidender Bedeutung:

„... il ne faut pas apprécier le montant des liquidités mondiales à un instant donné sans apprécier en même temps l'utilité des transactions qu'elles servent à financier. J'ai dit tout à l'heure que ces liquidités servaient au règlement des opérations commerciales et aussi des opérations financières. Si l'on estimait par exemple que celles-ci atteignaient en elles-mêmes un montant trop élevé, il y aurait quelque illogisme à fonder un jugement sur le montant souhaitable des liquidités mondiales en considérant ces transactions financières comme une donnée intangible. On peut estimer qu'il convient de décourager certains opérations de cette nature, au lieu de chercher à en faciliter le financement. “166

Giscard d'Estaing unterschied den Zweck der Mittelverwendung, wenn er auf die unterschiedliche Bedeutung der Finanzierung von Handels- und Kapitaltransaktionen hinwies. Klar gab er zu erkennen, daß es ihm bei der Schaffung neuer Liquidität vor allem um die Förderung des Handels ging, während Kapitalgeschäfte nach Erreichen eines bestimmten, als „zu hoch“ bewerteten Umfanges nicht mehr unantastbar sein sollten und dementsprechend zu „entmutigen“ gewesen wären. Diese offenkundige Geringschätzung von Finanzgeschäften kam auch in Giscard d'Estaings Ablehnung der damals diskutierten Goldpreiserhöhung zum Ausdruck. Diese sollte vor allem deshalb nicht stattfinden dürfen, weil sie einseitig die Guthaben von Ländern mit Goldreserven erhöht hätte, während der Betrag von Verbindlichkeiten konstant geblieben wäre. Eine solche Entwicklung, so Giscard d'Estaing, hätte nicht nur ein Nachlassen der Bemühungen zum Ausgleich der Zahlungsbilanz zur Folge gehabt, sondern auch zu moralisch zweifelhaften Geschäften geführt:

„Enfin, la hausse du prix de l'or, la hausse massive du prix de l'or apporterait à tous ceux qui ont choisi de ne pas participer normalement à la vie financière internationale une prime sur les conséquences morales de laquelle il convient malgré tout de s'interroger ${ }^{\text {c167 }}$.

Mit diesem Hinweis auf moralisch fragwürdige Gewinne waren offenbar die Spekulationsgewinne gemeint, zu denen ein flexibler Goldpreis natürlicherweise Anlaß gegeben hätte. Eine ähnliche Haltung prägte auch Giscard d'Estaings Auffassung von Devisen, deren Wert - ihr Wechselkurs also - für ihn keinen Marktpreis darstellte, sondern auf politischer Übereinkunft zu beruhen hatte. Währungen sollten keine Handelsware sein, und dementsprechend verbot es sich auch, zwischen den Zentralbanken Zinsen zu nehmen:

\footnotetext{
${ }^{166}$ Vgl. die Rede Giscard d'Estaings vom 15.6.1965

${ }^{167}$ ebenda
} 
„... les avoirs monétaires des banques centrales n'ont qu'une valeur conventionnelle. Ces avoirs ne sont pas des marchandises, le prix auquel ils sont échangés est un prix convenu ... il faut adopter, concernant la nature des réserves possédées, une attitude unique ... celui-ci doit s'étendre à tout et il faut donc mettre fin à la rémunération des avoirs détenus par les banques centrales, qu'est un élément de perversion du système ${ }^{\text {“168 }}$.

Diese moralische Entrüstung des französischen Wirtschafts- und Finanzministers über die Zinserhebung (,perversion“) schloß sich nahtlos an seine technische Perspektive der Währungsproblematik an. Giscard d'Estaing sah Währungen offenbar ausschließlich in ihrer Funktion als Zahlungsmittel im Handelsverkehr, die den Wirtschaftssubjekten für ihre Transaktionen nach objektiven Kriterien und vor allem nach politischen Erwägungen bereitzustellen waren. Ihre Hauptfunktion war auf die Ermöglichung des Güteraustausches beschränkt, was implizierte, daß Währungen selbst möglichst nicht zum Handelsobjekt werden sollten. Diese Perspektive entzog den gesamten Geldkreislauf den Marktgesetzlichkeiten und hätte ihn unter die Kontrolle staatlicher bzw. politischer Instanzen gestellt, die über die Instrumente der Geld- und Kreditpolitik einen wirksamen Hebel zur Steuerung der Gesamtwirtschaft erhalten hätten. Giscard d'Estaings Vorstellungen von der Mechanik eines reformierten internationalen Währungssystems kollidierten allerdings mit denen Staatspräsident de Gaulles, der sich in Währungsfragen statt von seinem Finanzminister von Jacques Rueff, dem Vater der Reformen von 1958, beraten ließ. De Gaulle folgte Rueffs Empfehlung, zum Goldstandard zurückzukehren. Da dieses Konzept zur Ordnung der internationalen Währungsbeziehungen auf einer völlig anderen Logik als das CRU-Konzept beruhte, kam es im Verlauf des Jahres 1965 zu Spannungen zwischen dem Präsidenten und dem Finanzminister, die Anfang 1966 zum vorläufigen Ausscheiden Giscard d'Estaings aus dem Amt führten.

\section{B.2.3.3 De Gaulle und die Rückkehr zum Goldstandard}

Der französische Staatspräsident schaltete sich 1965 persönlich in die währungspolitische Diskussion ein, nachdem die Spannungen im internationalen Währungssystem aufgrund des unverändert wachsenden Zahlungsbilanzdefizits der USA stetig zunahmen. Auf einer Pressekonferenz am 4. Februar 1965 stellte er fest, daß sich die Verteilung der Goldreserven mittlerweile grundlegend verändert habe und deshalb eine Anpassung des internationalen Währungssystems unumgänglich geworden sei. ${ }^{169}$ Das Goldmonopol der USA, welches ursprünglich die Ausnahmestellung des Dollars begründet hatte, bestünde nicht mehr und damit sei sein Status als einzige Reservewährung nicht mehr gerechtfertigt. Außerdem würden die USA die Sonderstellung des Dollars mißbrauchen, indem sie zur Bezahlung ihrer Auslandsausgaben nach Belieben Dollars in Umlauf setzten. Dies wäre ihnen nur möglich, weil sie nicht wie alle anderen Staaten ihre Defizite in Gold entgelten müßten, das als einzige Währungsreserve

\footnotetext{
168 ebenda

${ }^{169}$ Vgl. Pressekonferenz des französischen Staatspräsidenten vom 4.2.1965, in: EA, Folge 4/1965, D 87-D 97, hier D 91
} 
einen reellen Wert besäße. ${ }^{170}$ Diese einzigartige Möglichkeit, ,gegenüber dem Ausland Schulden zu machen, die sie nichts kosten“, führe in Europa zur Inflation und begünstige in ungerechtfertigter Weise amerikanische Direktinvestitionen in Europa, „was wiederum in gewissen Ländern eine Art Enteignung des einen oder anderen Unternehmens" zur Folge hätte. ${ }^{171}$

Um diese „Enteignung“ zu verhindern, hatte Frankreich schon 1963 im Rahmen seiner Industriepolitik gezielte Kapitalverkehrsbeschränkungen eingeführt. Zur wirksamen Beseitigung der Mißstände sah de Gaulle jedoch eine umfassende Neuordnung der internationalen Währungsbeziehungen als notwendig an. Sein Reformansatz beruhte dabei nicht auf dem CRU-Konzept seines Finanzministers, sondern auf dem Goldstandard, der von 1873 bis 1914 Europa eine durchgehende Währungsstabilität beschert hatte:

„Wir halten es für notwendig, daß der internationale Handelsaustausch wie vor den großen Weltkriegen auf eine unanfechtbare Grundlage gestellt wird, die nicht den Stempel eines einzelnen Landes trägt. Welche Grundlage soll das nun sein? In Wahrheit kann man sich kein anderes Kriterium, keinen anderen Standard als das Gold vorstellen. “172

Mit dem Vorschlag zur Wiedereinführung des Goldstandards griff de Gaulle auf ein ehemals erfolgreiches Währungssystem zurück. Alle Währungen wären danach über ihren Goldpreis zu definieren gewesen und über ihre Goldparitäten konvertibel. Wie damals sollten, so de Gaulle, die Salden der Zahlungsbilanz wieder ausschließlich durch den Austausch von Edelmetallen ausgeglichen werden. ${ }^{173}$ Mit dem Goldstandard wäre allerdings auch ein rigides währungspolitisches Regime eingeführt worden, das den Spielraum eines jeden Landes strikt an den Umfang seiner Goldreserven gebunden hätte. Für die USA hätte dies eine unverzügliche Revision ihrer Währungspolitik zur Folge gehabt. Um dieser Forderung auf internationaler Ebene mehr Gewicht zu verleihen, beschwörte de Gaulle die Solidarität der Sechs:

„Schließlich wäre es Sache der sechs Staaten, die auf dem Wege zu sein scheinen, eine westeuropäische Wirtschaftsgemeinschaft zu verwirklichen, untereinander jenes feste System auszuarbeiten und ihm nach außen Gültigkeit zu verschaffen, das dem gesunden Menschenverstand und der wiedererstarkenden wirtschaftlichen und finanziellen Macht unseres alten Kontinents entspricht. “174

Die Unterstützung des alten Kontinents blieb de Gaulle jedoch versagt, da Frankreich kurze Zeit nach dieser Aufforderung mit seiner „Politik des leeren Stuhls“ vorerst jede weitere Zusammenarbeit unmöglich gemacht hatte. Um ihrer währungspolitischen Initiative Nachdruck zu verleihen, ging die französische Regierung dazu über, ihren Saldenausgleich konsequent in Gold durchzuführen. Sie tauschte einen bedeutenden

\footnotetext{
${ }^{170}$ Vgl. de Gaulle, Pressekonferenz vom 4.2.1965, a.a.O., D 91

${ }^{171}$ Vgl. de Gaulle, Pressekonferenz vom 4.2.1965, a.a.O., D 91

${ }^{172}$ Vgl. de Gaulle, Pressekonferenz vom 4.2.1965, a.a.O., D $91 \mathrm{f}$.

${ }^{173}$ Vgl. de Gaulle, Pressekonferenz vom 4.2.1965, a.a.O., D 92

${ }^{174}$ de Gaulle, Pressekonferenz vom 4.2.1965, a.a.O., D 92
} 
Teil ihrer Dollarreserven in Gold zurück, womit die angeschlagenen Goldreserven der USA weiter reduziert und die schwindende Stabilität des internationalen Währungssystems zusätzlich unterminiert wurde.

Mit der Rückkehr zum Goldstandard wäre ein System fester Wechselkurse in Kraft getreten, das im Gegensatz zum CRU-Konzept den Anpassungsmechanismus klar definiert und zur Stabilisierung auf den Marktmechanismus zurückgegriffen hätte. Im Goldstandard war jede Regierung verpflichtet, den Wechselkurs ihrer Währung konstant zu halten. Beim Abweichen des Devisenmarktkurses von der offiziellen Parität wäre ein Defizitland gezwungen gewesen, mit kurzfristigen Maßnahmen wie z. B. einer Erhöhung des Diskontsatzes, eine positive Zinstreppe herzustellen, um einen bedrohlichen Abfluß seiner Goldreserven zu vermeiden. Handelte es sich um ein außergewöhnlich hohes Zahlungsbilanzdefizit, so hätte ein gewisser Deflationsdruck ausgeübt werden müssen, um die Wettbewerbsfähigkeit der Volkswirtschaft nachhaltig zu erhöhen und die Exporteinnahmen wieder zum Steigen zu bringen.

Gerade in diesem systematisch angelegten Zwang zur Deflationspolitik lag ein Problem, das schon in der Ära de Gaulle die Rückkehr zum Goldstandard illusorisch erscheinen ließ. Unabdingbare Voraussetzung für einen deflationären Anpassungsproze $\beta$ war, daß die Preise und vor allem die Löhne flexibel waren, was insbesondere bei unveränderten Wechselkursen ihre Beweglichkeit nach unten erforderte. Ferner wäre eine restriktive Geld- und Fiskalpolitik notwendig gewesen, die im Falle von Rezessionen darauf verzichtet hätte, öffentliche und private Investitionen über die Ausweitung der Geldmenge zu finanzieren. ${ }^{175}$

Diese Bedingungen hätte selbst Frankreich zum damaligen Zeitpunkt nicht mehr erfüllen können und wollen. Im Rahmen der Pläne zur Industrialisierung des Landes waren die staatliche Förderung von öffentlichen und privaten Investitionen wie auch staatliche Eingriffe zur Stabilisierung der Nachfrage üblich geworden, die allesamt mit einem Wachstum der Geldmenge einhergingen. Die 1968 ausbrechende Wirtschaftsund Sozialkrise, die nach langen Streiks zu massiven Lohnsteigerungen führte, zeigte außerdem, daß eine Senkung der Löhne faktisch unmöglich war. Frankreich wäre selbst nicht in der Lage gewesen, die erforderliche Disziplin des Goldstandards aufzubringen, was den Vorschlag de Gaulles von vornherein unrealistisch machte. ${ }^{176}$ Dies galt um so mehr, weil der damalige Goldpreis von 35 Dollar pro Feinunze aus dem Jahre 1934 datierte und nicht die Verfünffachung des Dollarumlaufs sowie die Abnahme der US-Goldreserven seit dem Ende des zweiten Weltkrieges berücksichtigte. Die Rückkehr zum Goldstandard hätte die USA zahlungsbilanzpolitisch in eine unan-

${ }^{175} \mathrm{Zu}$ den Funktionserfordernissen des Goldstandards und der Unmöglichkeit einer Rückkehr vgl. Lutz, F.-A., (1958), Das Problem der internationalen Währungsordnung, in: Ordo, Band 10, S. 133-147, hier S. $138 \mathrm{ff}$.

${ }^{176}$ Vgl. Fabra, P. (1985), La politique monétaire internationale du Président Giscard d'Estaing, in: Samy Cohen und Marie.-Claude. Smouts (Hrsg.), La politique extérieure de Valéry Giscard d'Estaing, Paris, S. 138-150, hier: S. 145 
nehmbare Position gebracht. ${ }^{177}$ Außerdem war grundsätzlich fraglich, inwieweit das Souveränitätsbedürfnis Frankreichs es jemals erlaubt hätte, sich den anonymen Anpassungszwängen eines Systems zu unterwerfen, dessen Funktionsfähigkeit die Abwesenheit politisch motivierter Interventionen voraussetzte.

Derart kritische Überlegungen wurden innerhalb der französischen Regierung nicht angestellt, denn auch in den kommenden Jahren hielt Frankreich an seiner goldfundierten Währungspolitik fest. Um sie nachhaltig nach außen vertreten zu können, war ein von ihr überzeugter Finanzminister erforderlich, was auf Giscard d'Estaing nicht zutraf. Sein CRU-Konzept beruhte im Vergleich zum Goldstandard auf einer völlig anderen Anpassungslogik. Weder sah es selbständig handelnde Währungsbehörden vor, die unabhängig von politischen Einflüssen ihre stabilisierenden Eingriffe aufgrund der Entwicklungen auf den Geldmärkten vornahmen, noch sollte die zirkulierende Geldmenge ausschließlich an die physisch vorhandene Goldmenge gebunden sein. Statt dessen wäre die Geldversorgung auf politischer Ebene entschieden und über die Schaffung künstlicher Währungsreserven sichergestellt worden. Während im Fall von Zahlungsbilanzdefiziten der Goldstandard die Anpassungslasten grundsätzlich symmetrisch zwischen Überschuß- und Defizitländern verteilte und die Behebung von Zahlungsbilanzungleichgewichten ohne zusätzliche Geldschöpfung vorsah, war das CRU-Konzept asymmetrisch zugunsten der Defizitländer ausgerichtet. Es verlagerte das Problem auf die politische Ebene, wo dann zu entscheiden gewesen wäre, ob es sich bei diesem Defizit um das Problem eines einzelnen Landes oder um ein allgemeines Finanzierungsproblem handelte, das die Emission zusätzlicher Liquidität erforderte. Letzteres setzte zwar einen einstimmigen Entschluß voraus, doch hätte sich das Abstimmungsverhalten der Defizitländer grundsätzlich durch Verhandlungsstrategien wie z. B. „package deals" beeinflussen lassen, so daß die Tendenz zur Finanzierung von Zahlungsbilanzdefiziten durch internationale Geldschöpfung nicht auszuschließen war. ${ }^{178}$ Diese unterschiedlichen Ansichten über die Anpassungsmechanismen und die Verteilung der Anpassungslasten in den jeweiligen Reformkonzepten begründeten letztlich grundlegende währungspolitische Widersprüche, die das vorläufige Ausscheiden Giscard d'Estaings aus der französischen Finanzpolitik unausweichlich machten.

\section{B.2.3.4 Der Goldkrieg und die Verteidigung des Franc}

Nachdem die Trennung von Giscard d'Estaing unvermeidlich geworden war, übernahm Michel Debré die Verteidigung der Währungspolitik de Gaulles. Frankreich versuchte weiter, eine Reform des internationalen Währungssystems zu erreichen, in der die Währungen eng an das Gold gebunden waren. Es wehrte sich dementsprechend auch gegen die zunehmend diskutierte Schaffung künstlicher Liquidität in Form von Sonderziehungsrechten (SZR) zur vorübergehenden Finanzierung von Zahlungsbilanz-

${ }^{177}$ Vgl. Lutz, C. (1976), Währungsordnung und Außenpolitik, S. 472, in: EA, Folge 14/1976, S. $469-478$

${ }^{178}$ Vgl. Fabra (1985), a.a.O., S. 147 
defiziten. Diese wollte es nur dann zulassen, wenn „wichtige“ Mitglieder des IWF vorher ihre Zahlungsbilanz sanierten und die neu geschaffenen Fazilitäten als wirkliche Kredite konstruiert würden, die nicht automatisch bereitständen, nicht transferierbar wären und außerdem zurückgezahlt werden müßten. ${ }^{179}$ Um Entscheidungsdruck zu erzeugen, brachte Frankreich wiederholt die Möglichkeit einer Erhöhung des Goldpreises ins Gespräch, die ebenfalls neue Finanzierungsmittel geschaffen hätte. Bei seinen Partnern stieß dieser Vorschlag jedoch nicht auf ein positives Echo. ${ }^{180} \mathrm{Um}$ den Druck auf die USA zu erhöhen, zog Frankreich sich im Juni 1967 aus dem Goldpool zurück, der durch laufende Marktinterventionen den Goldpreis auf dem vereinbarten Niveau von 35 Dollar pro Feinunze stabilisierte. Doch auch mit dieser provozierenden Haltung vermochte Frankreich letztlich nicht die dominante Position der USA im IWF zu unterminieren. Die US-Regierung konterte im Regelfall erfolgreich, indem sie auf ihre Militärausgaben zur Verteidigung ihrer europäischen Verbündeten verwies, die sie im Falle einer restriktiveren Finanzpolitik hätte beschneiden müssen. Den europäischen NATO-Mitgliedern blieb angesichts der gespannten sicherheitspolitischen Lage in der zweiten Hälfte der sechziger Jahre (Prager-Frühling 1968) nichts anderes als sich der amerikanischen Währungspolitik zu beugen. ${ }^{181}$

Am 1. April 1968 wurde auf der Konferenz des Weltwährungsfonds in Stockholm die Einführung der Sonderziehungsrechte beschlossen. Frankreich stimmte als einziges Mitglied des „Zehnerklubs" nicht zu, da es in diesem neuen Reservemedium nur ein weiteres Mittel sah, das den USA die Fortführung ihrer defizitären Geld- und Haushaltspolitik ermöglichte. ${ }^{182}$ Dieses Verhalten Frankreichs war um so brüskierender, als daß zwei Wochen zuvor, am 17. März 1968, der Goldpool im Verlauf einer massiven Goldspekulation auseinandergebrochen war und die USA aufgrund der diese Spekulation begleitenden Flucht aus dem Dollar dringender denn je auf die SZR zum Ausgleich ihres sprunghaft gestiegenen Defizits bei den laufenden Zahlungen angewiesen waren. $\mathrm{Zu}$ Beginn der Konferenz versuchte der französische Finanzminister vergebens noch einmal, die Diskussion abzulenken, indem er auf die Möglichkeit einer Erhöhung des Goldpreises verwies und noch einmal darauf hindeutete, daß vor der Schaffung der SZR die Ursachen der gegenwärtigen Probleme analysiert werden müßten. Seine Ansprache stieß bei seinen mittlerweile entschlossenen Kollegen jedoch nur noch auf

${ }^{179}$ Vgl. Lecerf, J. (1975), La Communauté en péril, Paris, S. 112 f.

${ }^{180}$ Diese Idee wurde vom währungspolitischen Berater de Gaulles, Jacques Rueff, schon 1965 vertreten und Michel Debré schloß eine Erhöhung des Goldpreises in einem Interview zwei Jahre später ebenfalls nicht aus, vgl. Drouin (1965), a.a.O., S. 858 und das Interview Debrés vom 8.1.1967, D 399, abgedruckt in: EA, Folge 17/1967, D 397 - D 400

${ }^{181}$ Die USA begründeten ihr Zahlungsbilanzdefizit $u$. a. durch ihre hohen Militärausgaben für die Sicherheit Westeuropas und drohten den Europäern auf ihre Forderung zur Reduzierung des Defizits mit dem Abzug ihrer militärischen Kräfte. Vor allem auf die Bundesrepublik machte diese Drohung großen Eindruck als im Verlauf der Ereignisse in der CSSR die militärischen Spannungen weiter zunahmen. vgl. Lecerf (1975), a.a.O., S. $114 \mathrm{f}$.

${ }^{182}$ Vgl. Fabra, P. (1968), M. Debré refuse de signer l'accord de Stockholm sur les <droits de tirage spéciaux>, Le Monde, 1.4.1968, S. 1 und 19 
Schweigen. ${ }^{183}$ Das sich anschließende Abstimmungsergebnis war für Frankreich in zweierlei Hinsicht ein Rückschlag. Nicht nur, daß es den Entschluß zur Schaffung der SZR hinnehmen mußte - des weiteren wurde noch der Übergang zum gespaltenen Goldmarkt beschlossen. Auf diesem sollten die Zentralbanken weiter ihren Zahlungsausgleich in Gold zum Preis von 35 Dollar pro Feinunze vornehmen, während für den kommerziellen Goldhandel der Preis freigegeben wurde. Frankreich hatte sich somit durch sein Abstimmungsverhalten nicht nur völlig isoliert, sondern mit seiner Währungspolitik auch die Demonetisierung des Goldes provoziert, das seiner währungspolitischen Konzeption nach eigentlich den Stabilitätsanker im internationalen Währungssystem bilden sollte.

Trotz dieser Rückschläge hielt Finanzminister Debré entschlossen an der bisherigen Währungspolitik Frankreichs fest. Seiner Meinung nach konnte aufgrund der mittlerweile erreichten Dimension der internationalen Währungskrise nicht mehr weiter nur nach „technischen“ Lösungen gesucht werden. Das Ausmaß der Krise machte es aus seiner Sicht grundsätzlich unmöglich, sie von ihren politischen Aspekten zu trennen:

„Jedes große Problem ist politisch und muß politisch sein. Das internationale Währungssystem ist das Ergebnis einer Reihe von sowohl politischen als auch wirtschaftlichen Umständen, und seine Wirkungsweise wird von bestimmten Konzeptionen bestimmt, die ebenfalls sowohl politischer als auch wirtschaftlicher Art sind.“184

Wenn Frankreich sich mit seiner Kritik an der Zahlungsbilanzpolitik der USA wie auch an der Konstruktion des internationalen Währungssystems durchaus zutreffend an den sachlichen Realitäten orientierte, so deutete seine Isolation im internationalen Währungssystem an, daß es die Realität auf dem Gebiet des politisch Machbaren verkannt hatte. ${ }^{185}$ Anfang 1968 ließ sich feststellen, daß Giscard d'Estaing mit seinem CRU-Konzept der Entwicklung deutlich näher stand und sich mit Sicherheit leichter an die tatsächlichen Verhältnisse hätte anpassen können, als es der provokanten und die Desintegration des internationalen Währungssystems beschleunigenden Währungspolitik de Gaulles und Debrés je möglich war. Die Fixierung der französischen Währungspolitik auf die Goldbindung der Währungen kann als Ausdruck eines strikten Stabilitätsstrebens gedeutet werden, das unter den gegebenen Umständen illusorisch war und aufgrund seiner Realitätsferne keine optimale Lösung im Sinne der Geldwertstabilität darstellte. Frankreich mußte tatenlos zusehen, wie eine schleichende „Demonetisierung des Goldes" infolge der Spaltung des Goldmarktes um sich griff, da, nach dem Ansteigen des Goldpreises auf dem freien Markt, die Zentralbanken immer weniger geneigt waren, ihre Defizite in Gold zu unterbewerteten Preisen auszugleichen und dementsprechend verstärkt auf ihre reichlichen Dollarguthaben und SZR zurückgriffen. Insgesamt läßt sich also feststellen, daß die währungspolitische Haltung Frankreichs nicht nur in sich widersprüchlich, sondern zusätzlich auch dem eigenen Ziel der

${ }^{183}$ ebenda, S. 19

${ }^{184}$ Interview vom 8.1.1967, a.a.O., D 400

${ }^{185}$ Vgl. Bordo, M., Simard, D., White, E. (1994), France and the Bretton-Woods International Monetary System: 1960 to 1968, S. 23, Nber Working Paper Series, No. 4642 
Geldwertstabilität abträglich war. Indem die französische Regierung die politischen Machtverhältnisse nicht zur Kenntnis nahm, isolierte sie sich selbst und vergab so die Möglichkeit, an der politischen Führung innerhalb des internationalen Währungssystems teilzuhaben und sich konstruktiv für die Stabilisierung der Währungsbeziehungen einzusetzen.

Mit dem Beginn der Studentenunruhen im Mai 1968 brach der provokanten und in die Vergangenheit gerichteten Währungspolitik de Gaulles jedoch die Grundlage weg. Infolge der schlagartig ausbrechenden gesellschaftspolitischen Krise kam es in Frankreich zu Streiks, an denen sich über die Dauer von vier Wochen bis zu fünfzig Prozent aller Arbeitnehmer beteiligten. Das Ergebnis waren ein Rückgang der Inlandsproduktion um drei Prozent sowie eine durchschnittliche Anhebung der Löhne um zehn bis fünfzehn Prozent. Diese einschneidenden Veränderungen machten sich umgehend im Außenhandel und im Geld- und Finanzsektor bemerkbar. ${ }^{186}$ Die Lohnsteigerungen verteuerten die Produktion, so daß schlagartig die Exporte sanken, während gleichzeitig durch die zusätzliche Kaufkraft die Importnachfrage anstieg. Die Folge waren ein rasch zunehmendes Defizit im Außenhandel sowie ein Zunehmen der Inflation, die, angeheizt durch Stabilisierungseingriffe der Regierung in Form von verbilligten Krediten zur Exportförderung und Programmen zur Stabilisierung der Nachfrage, rasch in eine Kapitalflucht aus dem Franc umschlugen. Nach kurzer Zeit stand Frankreich vor einem immensen Defizit im auswärtigen Zahlungsverkehr, das seine Währungsreserven in kurzer Zeit vollständig aufzuzehren drohte. Als in der zweiten Hälfte des Jahres 1968 auch verschärfte Kapitalverkehrsbeschränkungen diese Entwicklung nicht zu bremsen vermochten, brach eine Abwertungsspekulation gegen den Franc aus, die schließlich eine umfangreiche politische Reaktion unumgänglich machte. ${ }^{187}$

Intern versuchte die französische Regierung, den Anstieg der Inflation und des Außenhandelsdefizits zu bremsen, indem sie - ohne gemäß Artikel 103 bzw. 107 EWGVertrag vorher die Kommission und die Partnerstaaten zu konsultieren - wieder Preiskontrollen, Steuererhöhungen und Importabgaben einführte, was allerdings nicht hinreichte, um das Vertrauen der Kapitalmärkte in den Franc wieder herzustellen. ${ }^{188}$ Der Druck auf den Franc wie auch die Flucht in die Mark nahmen schließlich in einem Maße zu, daß sich die Zehnergruppe im November 1968 veranlaßt sah, nach einer dauerhaften Lösung zu suchen. Die in diesem Zusammenhang diskutierte Möglichkeit einer Abwertung des Franc wurde zwar schon im Vorfeld der Verhandlungen von de Gaulle als „schlimmste Absurdität“ verworfen, sie blieb aber dennoch weiter im Gespräch und wurde letztlich als ungeschriebener Bestandteil eines in mühsamer Kleinar-

${ }^{186} \mathrm{Zu}$ den wirtschaftlichen Folgen der Mai-Unruhen siehe Versperini (1993), a.a.O., S. 45-48

${ }^{187}$ Frankreich verlor vom Beginn des Jahres 1968 bis in den November des Jahres 60 Prozent seiner Währungsreserven, vgl. Mathieu, G., „Le gouvernement va renforcer son programme d'austerité et lutter contre la hausse des prix", Le Monde vom 23.11.1968, S. 1

${ }^{188} \mathrm{Zu}$ den Stabilisierungsmaßnahmen der französischen Regierung und ihren Ergebnissen vgl. Vesperini (1993), a.a.O., S. 48-74 
beit ausgehandelten Kompromisses übernommen. ${ }^{189}$ Die Finanzminister einigten sich am 25. November 1968 darauf, gemeinsam gegen die Spekulation vorzugehen und Frankreich zwei Milliarden Dollar in SZR zur Finanzierung seines Zahlungsbilanzdefizits zur Verfügung zu stellen, während Frankreich sich im Gegenzug verpflichtete, seine Stabilisierungsbemühungen fortzusetzen. ${ }^{190}$ Außerdem verpflichtete sich die Bundesrepublik, über Maßnahmen zur Importförderung sowie über die Einführung einer Ausfuhrabgabe ihren Überschuß im Außenhandel abzubauen. Von Frankreich wurde indessen inoffiziell die Abwertung des Franc in einer Höhe von ca. zehn Prozent erwartet. ${ }^{191}$ De Gaulle persönlich wischte dieses Verhandlungsergebnis jedoch einen Tag später vom Tisch als er im Verlauf einer Kabinettssitzung entschied, den Franc nicht abzuwerten.

Innerhalb der französischen Regierung wurde die Wechselkursanpassung des Franc als Frage von politischem Prestige aufgefaßt. Man kam schließlich zu dem Ergebnis, daß es zwecklos sei, einseitig den Franc abzuwerten, wenn es nicht gleichzeitig zu einer Aufwertung der unterbewerteten D-Mark käme. Ohne Korrektur des D-Mark-Kurses würde letztlich weiter Anlaß für eine Aufwertungsspekulation bestehen und sich nichts an der Flucht aus dem Franc ändern. Überdies, und dies scheint, so Vesperini, der ausschlaggebende Grund gewesen zu sein, war de Gaulle persönlich davon überzeugt, daß Frankreich die Krise aus eigenen Kräften heraus überwinden konnte. ${ }^{192}$ Diese Vermutung entspricht zumindest der offiziellen Begründung des Beschlusses, den Franc nicht abzuwerten, in der de Gaulle darauf verwies, daß Frankreichs Wirtschaft durch das Stabilisierungsprogramm der Regierung bereits wieder Tritt gefaßt habe und nur durch eine „verabscheuenswürdige“ (odieuse) Spekulation daran gehindert würde, ihr Gleichgewicht wieder zu erreichen. ${ }^{193}$

Die Mißstände auf dem Währungssektor würden allerdings, so de Gaulle, dank der „Spannkraft“ des französischen Volkes sowie der vorhandenen eigenen Reserven und

${ }^{189}$ de Gaulle äußerte sich im Verlauf der Sitzung des französischen Ministerrats vom 13.11.1968, in der ein neues Finanzierungsprogramm zur Stabilisierung der wirtschaftlichen Entwicklung vorgelegt wurde, wie folgt: „Depuis le début de 1968, l'expansion a été significative, même si elle a été stoppée par les événements de mai-juin. Ensuite on a noté une reprise intéressante qui n'était pas due seulement à l'aide gouvernementale. Il est donc nécessaire d'adapter au mieux les mesures prises afin qu'elles ne se retournent pas contre la monnaie: accepter la dévaluation serait la pire absurdité qui soit“, siehe Le Monde, 14.11.1968, S. 32

${ }^{190} \mathrm{Vgl}$. „Le communiqué de la conférence des Dix“, Le Monde vom 24.11.1968, S. 2

${ }^{191}$ Die Abwertung des Franc war kein Bestandteil des Kommuniqués der Konferenz. Le Monde zufolge ging man jedoch fest von ihrer Durchführung aus, so daß sich die Diskussion am Tag nach dem Verhandlungsabschluß nur noch um den Abwertungssatz drehte. Vgl. dazu die Berichterstattung in Le Monde, ebenda, S. 1

${ }^{192}$ Vgl. Vesperini (1993), a.a.O., S. 64

193 „Mais jusqu'à ce qu'il l'ait retrouvé (l'équilibre, Anm. d. Verf.), rien ne peut empêcher qu'il y ait, au-dedans et au-dehors, nombre des gens qui suspendent la confiance qu'ils avaient en lui et tâchent de faire passer leurs intérêts à eux avant l'intérêt public. Naturellement, c'est la monnaie nationale qui risque alors de faire les frais de cette odieuse spéculation."Ansprache de Gaulles im Anschluß an die Ministerratssitzung vom 25.11.1968, abgedruckt in Le Monde, 26.11.1968, S. 2 
der internationalen Finanzierungsmöglichkeiten den wirtschaftlichen Aufschwung Frankreichs nicht verhindern können. Außerdem würden die unvermeidbar negativen Erfahrungen mit der gegenwärtigen Währungsordnung bald den Tag bringen, an dem es ein „vernünftiges“ und ausgewogenes System gäbe, das die Länder vor plötzlichen und ,absurden“ Spekulationsbewegungen auf den Finanzmärkten schützen würde. ${ }^{194}$

„Bref, nous avons, en toute vérité, pour le présent et pour l'avenir, tout ce qu'il faut pour achever le rétablissement commencé et repasser en tête du peloton. C'est pourquoi, tout bien pesé, j'ai, avec le gouvernement, décidé que nous devons achever de nous reprendre sans recourir à la dévaluation. “195

De Gaulles Eingreifen in die Abwertungsdiskussion zeigte, welch hohe politische Bedeutung er der Wechselkursfrage beimaß. Seine beißende Kritik an Spekulationsgeschäften zeigte ferner, daß moralische Kriterien, wie schon für Giscard d'Estaing, so auch für ihn eine wichtige Rolle in währungspolitischen Fragen spielten. Ihre Bewertung als „absurd“ und „verabscheuenswürdig“" wirft allerdings die Frage auf, inwieweit de Gaulle ihr Zustandekommen überhaupt mit realwirtschaftlichen Hintergründen in Zusammenhang gesehen hat. Die Kapitaleigner reagierten mit ihrer Flucht in die Mark auf den real vorliegenden schlagartigen Verlust an Wettbewerbsfähigkeit, den die französische Wirtschaft durch die Ereignisse vom Mai 1968 erlitten hatte, und handelten damit ökonomisch rational. De Gaulle interpretierte die Spekulation jedoch von vornherein als gegen das öffentliche Interesse gerichtet, das für ihn in der unantastbaren Stabilität des Wechselkurses lag - eine Bewertung, die realwirtschaftlichen Handlungszwängen in monetären Fragen nur einen nachgeordneten Rang zuwies. Dementsprechend ging die Sichtweise des Wechselkurses bei de Gaulle über eine sachliche Beurteilung weit hinaus. Er setzte dessen Stabilität nicht nur mit dem öffentlichen Interesse gleich, sondern sah ihn direkt in symbolischer Verbindung mit dem Wollen und dem Streben der französischen Nation:

„Il s'agit de la monnaie, critère de la santé économique et condition du crédit, dont la solidité garantie et attire l'épargne, encourage l'esprit d'entreprise, contribue à la paix sociale, procure l'influence internationale, mais dont l'affaiblissement déchaîne l'inflation et le gaspillage, étouffe l'essor, suscite le trouble, compromet l'indépendance; je donnerai à la France un franc modèle, dont la parité ne changera pas aussi longtemps que je serai là ..." ${ }^{196}$

Bei der Stabilität des Franc-Kurses handelte es sich für de Gaulle um ein Dogma, dessen Begründung neben wirtschaftlichen Überlegungen vor allem auf die internationale Rolle Frankreichs und seine Unabhängigkeit zurückzuführen war. Der Wechselkurs war Ausdruck der Größe und der Macht der Nation und damit einer ausschließlich auf die monetäre Sachrationalität fixierten Perspektive entzogen. Mit welch hohem Preis dieser Dogmatismus zu bezahlen war, zeigten die anschließenden währungspolitischen Entscheidungen Frankreichs. Nach der verweigerten Abwertung verschärfte es noch-

\footnotetext{
194 ebenda

${ }^{195}$ Ansprache de Gaulles im Anschluß an die Ministerratssitzung vom 25.11.1968, abgedruckt in Le Monde, 26.11.1968, S. 2

${ }^{196}$ de Gaulle (1971), a.a.O., S. 110
} 
mals seine Kapitalverkehrskontrollen und nahm die nötigen Mittel zum Ausgleich seines Zahlungsbilanzdefizits ausgerechnet bei den USA im Rahmen eines Swap-Kredits der Federal Reserve Bank auf. Mit dem Rückgriff auf die Währungsreserven des ärgsten Widersachers stellte de Gaulle die französische Währungspolitik vollends auf den Kopf, so daß sich am Ende seiner Amtszeit die Frage stellte, worin ihre eigentliche Orientierung überhaupt bestand.

Feststellbar ist, daß sowohl der Ansatz Giscard d'Estaings als auch der de Gaulles darauf ausgerichtet waren, die internationalen Währungsbeziehungen auf eine stabile Grundlage zu stellen, beide sich jedoch in ihren Anpassungsmechanismen unterschieden. Während Giscard mit seinem CRU-Konzept dem nahekam, was 1968 später auf internationaler Ebene mit den SZR entschieden wurde, strebte de Gaulle mehr oder weniger ernsthaft die Rückkehr zu einer Währungsordnung an, deren Funktionsvoraussetzungen längst nicht mehr gegeben waren. Beiden Ansätzen war das Streben nach Politisierung von Währungsfragen gemein: Im CRU-Konzept wurde es offen in der Liquiditätssteuerung propagiert, bei der die Entscheidungen den Regierungen und nicht sachkompetenten Institutionen überlassen werden sollten, wohingegen in der Währungspolitik de Gaulles seine persönlichen Ausführungen über die Rolle der Währungen wie auch die Äußerungen Michel Debrés keinen Zweifel daran ließen, daß Währungsprobleme in erster Linie politische Probleme darstellten. Diese Orientierung der französischen Währungspolitik wirft grundsätzliche Fragen auf, da sie sich überhaupt nicht mit der von Frankreich propagierten Rückkehr zum Goldstandard vertrug, der ein Währungssystem bezeichnete, das gerade politische Eingriffe ausschloß. Dies legt den Eindruck nahe, daß es sich bei dem französischen Vorschlag eher um eine bewußte Provokation der USA, denn um die ernsthaft angestrebte Zielstruktur eines reformierten internationalen Währungssystems handelte. ${ }^{197}$ Die Währungspolitik de Gaulles wie auch die Giscard d'Estaings räumten zwar unterschiedlich, aber nachdrücklich der Wahrung der nationalen Souveränität einen hohen Rang ein: Das CRU-Konzept ließ bewußt den Mitgliedstaaten freie Hand bei der Verwendung zugeteilter Währungsreserven und verzichtete vollständig auf zwingende Vorschriften zur Beseitigung von Zahlungsbilanzdefiziten, während für de Gaulle die Stärke der Währung selbst integraler Bestandteil der nationalen Unabhängigkeit war und der Wechselkurs aus diesem Grund nicht verändert werden durfte.

Beide Konzepte charakterisierte dennoch ein gewisses Bemühen um Objektivität und damit um ökonomische Rationalität in dem Sinne, daß die in ihnen angestrebten Veränderungen zumindest vom Anspruch her auf sachlichen Grundlagen beruhen sollten. So sah das CRU-Konzept Indikatoren vor, mittels derer ein weltweiter Liquiditätsbedarf objektiv zu ermitteln war, bevor über die Emission zusätzlicher Liquidität politisch zu entscheiden gewesen wäre. Der Goldstandard umriß dagegen ein Konzept, in dem währungspolitische Entscheidungen primär auf tatsächlichen Entwicklungen am Geldmarkt und damit auf objektiven ökonomischen Gegebenheiten basierten.

${ }^{197}$ Ein Eindruck, den auch Bordo et. al. teilen, vgl. Bordo (1994), a.a.O., S. 23 
Daß diese „objektiv“ ermittelten Erkenntnisse allerdings bestenfalls indikativen Charakter gehabt hätten und nicht automatisch bestimmte währungspolitische Entscheidungen präjudizieren sollten, lag an der Dominanz außermonetärer Erwägungen in der französischen Währungspolitik wie z. B. der moralischen Qualität von Kapitalbewegungen, am Souveränitätsbedürfnis oder am wie auch immer definierten „Allgemeininteresse“. Ihr hoher Stellenwert zeigte sich noch einmal deutlich in dem Appell de Gaulles an das französische Volk anläßlich der von ihm verhinderten Abwertung des Franc, als er die Stabilität der nationalen Währung zur Schicksalsfrage der Nation erhob:

„Françaises, Français, ce qui se passe pour notre monnaie nous prouve, une fois de plus, que la vie est un combat, que le succès coute l'effort, que le salut exige le victoire. $\mathrm{Si}$, comme nous le pouvons et comme nous le devons, nous gagnons celle-ci en y participant tous ensemble, alors nous serons en mesure de mener à bien, comme il le faut, les transformations, les réformes, les progrès, qui feront de nous, à coup sûr, un grand peuple exemplaire des temps modernes. Car, à travers nos épreuves, quelles qu'elles soient et quelles qu'elles doivent être, voilà le but national.

Vive la République! Vive la France! ${ }^{198}$

\section{B.2.4 Die ordnungspolitische Orientierung der französischen Binnenmarktpolitik unter Charles de Gaulle}

Nach elf Jahren französischer Binnenmarktpolitik unter de Gaulle ist zunächst festzuhalten, daß sich die anfänglichen Befürchtungen hinsichtlich des weiteren Verbleibs Frankreichs in der Gemeinschaft schnell als gegenstandslos herausgestellt hatten. Auch wenn die für den Binnenmarkt vereinbarte Wettbewerbsordnung französischen Vorstellungen nicht entsprach, so arrangierte sich die französische Politik doch recht schnell mit den Gegebenheiten. Dies hielt sie allerdings nicht davon ab, im Rahmen verschiedener Sektorpolitiken den Versuch zu wagen, die Wirtschaftsordnung des Gemeinsamen Marktes schrittweise ihren Ordnungsvorstellungen anzupassen. Ihren Ursprung hatten diese Versuche allerdings nicht in bestimmten wirtschaftspolitischen Überzeugungen, sondern in der europapolitischen Konzeption de Gaulles. Diese legte Europa auf eine gemeinsame und eigenständige Politik auf der Ebene der neuen Hegemonialmächte fest, war sich aber der Tatsache bewußt, daß es zur effektiven internationalen Einflußnahme politischer Macht bedurfte, die ihrerseits wiederum ohne eine starke Wirtschaft nicht denkbar war.

Die europapolitische Konzeption de Gaulles bestach im Gegensatz zur Europapolitik der IV. Republik durch ihre Klarheit und ihre innere Geschlossenheit. Sie war darauf ausgerichtet, Europa in eine politische Union souveräner Staaten umzuwandeln und diese auf der Ebene der Supermächte als gleichberechtigten Mitspieler unter französischer Führung zu etablieren. Von dort aus sollte Europa seine politische Mission erfüllen, die nach de Gaulle darin bestand, der Welt Frieden, Fortschritt und Zivilisation

${ }^{198}$ de Gaulle (1968), texte intégral de l'allocution radio-diffusée du général de Gaulle, Le Monde, 26.11.1968, S. 2 
zu bringen. Bei genauerem Hinsehen entpuppte sich diese Mission allerdings als die ins Europäische gewandte Version der französischen Zivilisationsmission, aus der heraus de Gaulle letztlich den französischen Führungsanspruch in Europa ableitete. Da diese Vision vom Fortbestehen der Nationen als wahren Trägern und letztem Ursprung politischen Willens ausging, mußte sie zwangsläufig mit dem supranationalen Integrationsansatz der Römischen Verträge in Konflikt geraten, welche auf die Gründung eines europäischen Einheitsstaates angelegt waren. De Gaulle akzeptierte die Sechsergemeinschaft dennoch, da sie mit wirtschaftlichen Vorteilen für das eigene Land verbunden war und eine geeignete Basis zur Errichtung der von ihm angestrebten politischen Ordnung in Europa darstellte.

Die Umsetzung seiner europapolitischen Konzeption war letzten Endes die Verlängerung einer Strategie, die de Gaulle schon im Zusammenhang mit dem nationalen Einigungswerk formuliert hatte:

„Si l'oeuvre nationale que j'entreprends exige l'adhésion des esprits, elle implique évidemment que le pays en ait les moyens... enfin, ce qu'il vaut au sens physique du terme et, par conséquent, ce qu'il pèse par rapport aux autres, telles sont les bases sur lesquelles se fondent nécessairement la puissance, l'influence, la grandeur, aussi bien que ce degré relatif de bien-être et de sécurité que pour un peuple ici-bas, on est convenu d'appeler le bonheur. Ce fut vrai de tous temps. Ce l'est aujourd'hui plus que jamais, parce que tout individu est constamment en proie au désir de posséder les biens nouveaux créés par l'époque moderne; ... parce que la rapidité et l'étendu de l'information font que chaque homme et chaque peuple peuvent à tout instant comparer ce qu'ils ont relativement à leurs semblables. ${ }^{\text {“199 }}$

Die Wirtschaft stellte für de Gaulle die materielle Basis des politischen Einflusses und der Macht eines Staatswesens dar. Ihre Entwicklung war natürliches Anliegen und integraler Bestandteil der allgemeinen Politik einer Nation. Aufgrund ihrer existentiellen Bedeutung für die Lebensfähigkeit eines Staatswesens konnte die Wirtschaft niemals politikfreier Bestandteil des gesellschaftlichen Lebens sein. Für de Gaulle war es undenkbar, ja sogar „absurd“, die wirtschaftliche Entwicklung nur den „Zufälligkeiten“ des Marktmechanismus unterwerfen zu wollen, zumal ein ungezügelter Wettbewerb aus seiner Sicht nicht von einem unzivilisierten, moralisch korrupten Kapitalismus zu trennen war. Die Wirtschaftspolitik stellte für de Gaulle einen Politikbereich dar, der seine Vorgaben aus übergeordneten gesellschaftspolitischen und geostrategischen Zielsetzungen erhielt. Macht- bzw. geopolitische Erwägungen überlagerten das wirtschaftspolitische Denken Frankreichs insbesondere dann, wenn es auf die mangelnde Wettbewerbsfähigkeit der europäischen Wirtschaft im Vergleich zu den USA fixiert war. Für de Gaulle stand außer Zweifel, daß Defizite auf diesem Gebiet am besten durch lenkende Eingriffe des Staates in den Ausbau der Wirtschaftsstrukturen zu beseitigen waren.

Ordnungspolitisch betrachtet setzte sich unter de Gaulle damit die schon bei seinen Vorgängern festgestellte Tendenz zur Politisierung der Wirtschaftsstruktur und des

${ }^{199}$ So de Gaulle in seinen Memoiren einleitend zur Wirtschaft, de Gaulle (1971), a.a.O., S. 107 
Wirtschaftsablaufs fort. Ziel der französischen Binnenmarktpolitik war und blieb es, auf europäischer Ebene politischen Einfluß auf die Wirtschaftsentwicklung zu gewinnen. Die dabei verfolgten realwirtschaftlichen Ordnungsvorstellungen widersprachen in mehrfacher Hinsicht den Euckenschen Prinzipien der Wettbewerbsordnung. So waren die Initiativen auf der Ebene der Außenwirtschaftspolitik nicht mit dem Grundsatz der Öffnung der Märkte in Übereinstimmung zu bringen. Frankreich verfolgte das Ziel, die EWG schnellstmöglich in eine geschlossene und nach außen selbständig auftretende politische Einheit zu überführen. Dazu wehrte es drei Anläufe zur Erweiterung des Gemeinsamen Marktes ab, bei denen mit Großbritannien ein Land aufgenommen worden wäre, das ihm überdies den politischen Führungsanspruch innerhalb der EG streitig hätte machen können. Ferner strebte Frankreich eine nachhaltige Absicherung des Agrarmarktes gegen Importe, die Verschärfung von Kapitalverkehrskontrollen sowie die Überwachung von Direktinvestitionen an. Zusammen mit seinem durchgängigen Bestehen auf einen zügig eingeführten und hinreichend hohen Außenzoll kann Frankreich auf dem Gebiet der gemeinschaftlichen Außenwirtschaftspolitik durchweg eine protektionistische Haltung unterstellt werden.

Mitte der sechziger Jahre entstand mit der europäischen Industriepolitik ein weiteres Betätigungsfeld, auf dem Frankreich versuchte, seine Ordnungsvorstellungen umzusetzen. Hatte es zuvor noch das Bemühen der Kommission für gut geheißen, die Wirtschaftsentwicklung im Binnenmarkt über einen planifikatorischen Gesamtansatz politisch zu koordinieren und zu steuern, so ging die französische Regierung mit der Forderung nach einer europäischen Industriepolitik dazu über, dieses Vorhaben im Rahmen sektorspezifischer Politikansätze weiter zu verfolgen. Im Bereich der Forschungspolitik ging es Frankreich darum, die Gemeinschaft auf eine einheitliche Politik zur Steigerung der industriellen Wettbewerbsfähigkeit festzulegen. Konkret schlugen sich diese Bemühungen in der Forderung nach Subventionen für Forschungsprojekte sowie nach einer gezielten Politik zur Förderung von Großunternehmen nieder. Letzteres würde im Sinne der Wettbewerbsordnung einen Verstoß gegen das „Prinzip der Monopolkontrolle“ darstellen. Die Zahlung von Forschungssubventionen käme einer staatlichen Beteiligung am unternehmerischen Risiko gleich und hätte somit dem Prinzip der Einheit von Gestaltungsmacht und wirtschaftlicher Haftung widersprochen. Insgesamt wäre eine gemeinschaftliche Industriepolitik nach französischen Vorstellungen auf die strategische Ausrichtung der Wirtschaftsentwicklung hinausgelaufen und hätte aufgrund der damit einhergehenden unbegrenzten politischen Gestaltungsmöglichkeiten einen grundlegenden Verstoß gegen die Forderung nach Stetigkeit und Vorhersehbarkeit der Wirtschaftspolitik nach sich gezogen.

Neben der Industriepolitik entwickelte sich ab Mitte der sechziger Jahre die Währungspolitik zum zweiten Schwerpunkt der ordnungspolitischen Gestaltungsbemühungen Frankreichs. Die währungspolitische Konzeption Frankreichs folgte keiner einheitlichen Auffassung darüber, wie die innere und äußere Geldwertstabilität gewahrt werden sollte. Finanzminister und Staatspräsident verfolgten völlig unterschiedliche Politikansätze. Wie schon während der Regierungsverhandlungen zum EWG-Vertrag 
hielt die französische Währungspolitik auch unter de Gaulle dogmatisch an festen Wechselkursen fest und ließ sich dabei in all ihren Bemühungen um die Stabilisierung der internationalen Währungsbeziehungen mehr von allgemein politischen Erwägungen als von ökonomischen Überzeugungen leiten. So blieb es bei der Auffassung des Wechselkurses als Symbol nationaler Stärke und Unabhängigkeit. Dies hinderte Frankreich daran, ihn als Instrument zum Ausgleich divergierender realwirtschaftlicher und monetärer Entwicklungen zu akzeptieren. Auch spielten moralische Kategorien eine entscheidende Rolle in der französischen Währungspolitik, was sich beim Finanzminister wie beim Staatspräsidenten in abwertenden Urteilen über die Natur von Finanzund Spekulationsgeschäften niederschlug. Überhaupt schienen reine Geldgeschäfte von moralisch zweifelhafter Natur zu sein und die Geldpolitik primär die Aufgabe zu haben, sich auf die Ermöglichung realer Warengeschäfte zu beschränken. Insgesamt blieb Frankreich dabei, eine strenge Kontrolle der Geld- und Devisenmärkte zu fordern und monetäre Stabilität primär über politische Intervention statt über eine den Finanzmärkten angepaßte Währungspolitik erreichen zu wollen. Der Freiheit von Angebot und Nachfrage auf den Finanzmärkten stand die französische Währungspolitik extrem skeptisch gegenüber. Alle Zweifel und Vorurteile gegenüber der Marktkoordination verdichteten sich im Urteil über die Natur von Spekulationsgeschäften zu purer Hilflosigkeit. Hier mußte die französische Währungspolitik auf ethische Argumente zurückgreifen, um dem eigenen, ökonomisch fragwürdigem Handeln noch einen Sinn zu geben. Dadurch wurde sichtbar, daß die französische Währungspolitik eine äußerst schwache theoretische Fundierung besaß.

Die französischen Ordnungsvorstellungen waren in ihren monetären wie realwirtschaftlichen Aspekten kaum mit den Erfordernissen einer wettbewerblich ausgerichteten Wirtschaftsordnung in Übereinstimmung zu bringen. Allen Bereichen der französischen Wirtschafts- und Währungspolitik auf europäischer Ebene war das Bemühen um „Re-Politisierung“ der vereinbarten Koordinationsmechanismen gemeinsam. Das Ziel der französischen Politik war dabei nicht die Abschaffung der Marktkoordination des EWG-Vertrages, sondern die Wiederherstellung des mit Eintritt in die EWG verlorengegangenen staatlichen Einflusses vor allem auf die langfristige Wirtschaftsentwicklung. Als ordnungspolitische Idealkonzeption der französischen Binnenmarktpolitik „en miniature“ kann die Landwirtschaftspolitik betrachtet werden. Hier hatte Frankreich nachdrücklich und erfolgreich darauf hingewirkt, den Preismechanismus politischen Allokations- und Verteilungszielen gleichzeitig zu unterwerfen. Frankreich schwebte letztlich ein diskretionärer Interventionismus vor, der nicht mehr, wie noch bei den Vorgängern de Gaulles, rein passiv zum Schutz der Volkswirtschaft vor einer übermächtigen Konkurrenz gedacht war, sondern aktiv und antizipativ die strategische Orientierung der langfristigen Wirtschaftsentwicklung nach politischen Zielvorgaben sicherstellen sollte.

Das geringe Vertrauen der französischen Binnenmarktpolitik in die Marktkoordination deutet auf ein großes Mißtrauen in die Fähigkeit der Wirtschaftssubjekte hin, ihre wirtschaftlichen Probleme selbständig und dezentral befriedigend lösen zu können. Bei de 
Gaulle, der, so Johanna Schomerus, ,aus seinen Wurzeln in der französischen Vergangenheit seine illusionslos pessimistische Welt- und Menschenkenntnis" ${ }^{200}$ bezog, führten diese Zweifel direkt zum Staat, der die Menschen auf dem Pfad des zivilisatorischen Fortschritts zu führen hatte und dementsprechend nicht nur die Pflicht, sondern auch das Recht besaß, bei „Fehlentwicklungen“ direkt in die Wirtschaft einzugreifen. Seine Perspektive von Staat und Wirtschaft war stark von seiner militärischen Vergangenheit beeinflußt. Er, für den der Krieg immer noch „Vater aller Dinge“ war $^{201}$, sah die Wirtschaft in erster Linie als Machtbasis für die innere und äußere Politik eines Staates an. Das tägliche Wirtschaftsgeschehen selbst erschien ihm als nie endenwollende kriegerische Auseinandersetzung im Kampf um materielle Vorteile. Diese Vorstellungswelt verhinderte schon im Ansatz eine Wirtschaftspolitik, die sich auf rein sachliche Gegebenheiten der Güterproduktion und des Gütertausches reduzieren ließ. Was das Wesen der Wirtschaft für ihn wirklich ausmachte, brachte de Gaulle zum Abschluß des Kapitels „L'économie“ in seinen „mémoirs d'espoir“ noch einmal offen zum Ausdruck:

„Pourtant, aux prises avec les réalités matérielles et humaines, dans un domaine où tout n'est qu'âpreté, où rien ne se trouve acquis une bonne fois et sans retour, où, quoi que l'on obtienne, personne ne s'en contente à beaucoup près, je vérifie chaque jour que l'économie, comme la vie, est un combat au long duquel il n'y pas de victoire qui soit décidément gagnée. Même le jour d'un Austerlitz, le soleil n'y vient pas illuminer le champ de bataille.“202

\footnotetext{
${ }^{200} \mathrm{Vgl}$. Schomerus (1963), a.a.O., S. 324

${ }^{201} \mathrm{Vgl}$. de Gaulle auf seiner Pressekonferenz vom 4.2.1965, a.a.O., D 92

${ }^{202}$ de Gaulle (1971), a.a.O., S. $130 \mathrm{f}$
} 


\section{B.3 Frankreichs Binnenmarktpolitik unter Georges Pompidou 1969-1974}

Die Europapolitik in der nicht einmal fünf volle Jahre dauernden Amtszeit Georges Pompidous war durch eine hohe Ereignisdichte gekennzeichnet. Noch im Jahr 1969 entschlossen sich die Partnerstaaten auf französische Initiative, die Stagnation des europäischen Integrationsprozesses zu überwinden. Höhepunkte der Europapolitik waren der Beschluß zur Gründung einer Wirtschafts- und Währungsunion sowie der erfolgreiche Abschluß der Beitrittsverhandlungen mit Großbritannien, Irland und Dänemark. $\mathrm{Ab}$ Mitte 1971 wurden die Integrationsbemühungen jedoch zunehmend durch Währungsunruhen überlagert, die im März 1973 schließlich den vollständigen Zusammenbruch des Währungssystems von Bretton-Woods zur Folge hatten. Die im Herbst 1973 eintretende Ölkrise brachte mit sich, daß der 1972 gegründete Europäische Wechselkursverbund, der schon kurz nach seiner Gründung wichtige Mitglieder verloren hatte, auch Frankreich verlieren sollte. Mit Georges Pompidou führte in dieser Zeit ein ausgebildeter Literaturwissenschaftler die Staatsgeschäfte, der als Bankier und von 1962 bis 1968 als Premierminister unter de Gaulle bereits Erfahrungen in Wirtschaft und Politik gesammelt hatte.

\section{B.3.1 Die europapolitische Konzeption B.3.1.1 Die wirtschaftlichen Rahmenbedingungen}

Nach der verweigerten Abwertung des Franc im November 1968 geriet die französische Wirtschaft - vor dem Hintergrund einer in Frankreich intensiv geführten Diskussion um die "amerikanische Herausforderung" und des wirtschaftlichen Aufstiegs der Bundesrepublik - zunehmend in Schwierigkeiten. Um den Anschluß nicht zu verlieren, verkündete Staatspräsident Pompidou in der ersten Pressekonferenz nach seiner Wahl, die Entwicklung der französischen Wirtschaft und insbesondere der Industrie wiederbeleben zu wollen. Sein oberstes Ziel war, Frankreich zu einem "wirklichen Industrieland" zu machen. ${ }^{1} \mathrm{Zu}$ beseitigen seien, so Jacques Chaban-Delmas, der neue Premierminister, die strukturelle Rückständigkeit der französischen Wirtschaft, die vor allem darin bestünde, daß der Anteil der Industrie an der wirtschaftlichen Gesamttätigkeit zu gering war. ${ }^{2}$ Pompidou selbst befand in seinem programmatischen Buch "Le noeud gordien", daß Frankreichs Wirtschaft zu zergliedert sei. ${ }^{3}$ Dementsprechend ging es vor allem darum,

„der französischen Wirtschaft internationale Dimensionen zu geben. Und das heißt wohlgemerkt zunächst: Europa. Wie auch immer die europäischen Konstruktionen in Zukunft aussehen mögen, die französischen Unternehmen sollten entweder aus eigener Kraft oder in den meisten Fällen durch Zusammenschluß mit anderen europäischen Unternehmen oder auch mit außereuropäischen Unterneh-

${ }^{1}$ Vgl. Pressekonferenz Pompidous vom 10.7.1969, abgedruckt in La Politique Étrangère de la France, 2. Sem. 1969, S. 46

${ }^{2}$ Vgl. Regierungserklärung des französischen Premierministers vom 26.6.1969, D 388, abgedruckt in Auszügen in: EA, Folge 16/1969, D 385 - D 389

${ }^{3}$ Vgl. Pompidou, G. (1974), Le noeud gordien, Paris, S. 124 
men eine internationale Dimension erlangen und so den Wettbewerb aufnehmen, nicht nur innerhalb unserer Grenzen oder derjenigen der Sechs, sondern auf allen Märkten der Welt." ${ }^{4}$

Die Wirtschaftspolitik Frankreichs hatte vor allem die Stärkung der französischen Wettbewerbsfähigkeit zum Ziel. Ihr zentraler Bestandteil war die Industriepolitik, der sich Pompidou im Verlauf seiner Amtszeit häufig persönlich widmete und die sich neben der Außenpolitik zur zweiten "domaine réservé" des Präsidenten entwickelte. ${ }^{5}$ Als konkretes Ziel setzte er sich die Verdoppelung der industriellen Produktion im Verlauf der kommenden zehn Jahre. ${ }^{6}$ Wichtig in diesem Zusammenhang war ihm, den Abstand zur wirtschaftlich führenden Bundesrepublik zu verringern. Bis zum Ende seines "septenats" sollte ihre Leistungsfähigkeit übertroffen und Frankreich wirtschaftlich die Nummer eins in Europa werden.?

Diese Ambitionen konfligierten Mitte 1969 jedoch mit der tatsächlichen Wirtschaftslage Frankreichs. Die Reformmaßnahmen der französischen Regierung im Anschluß an die verweigerte Abwertung vom November 1968 hatten sich als erfolglos erwiesen. ${ }^{8}$ Die fortbestehende wirtschaftliche Unsicherheit wurde durch die unklaren politischen Verhältnisse nach dem plötzlichen Abtritt de Gaulles verstärkt, so daß das seit 1968 wieder bestehende Defizit in der Zahlungsbilanz deutlich zunahm. Die Deckung der Importe durch die Exporte fiel auf 82 Prozent zurück, was auf die infolge der hohen Lohnzuwächse stark gestiegene Inlandsnachfrage zurückzuführen war. ${ }^{9}$ Dieser Umstand und eine Mitte 1969 erneut auflebende Abwertungsspekulation gegen den Franc führten zu weiteren empfindlichen Verlusten an Währungsreserven. ${ }^{10}$ Die Inflation begann spürbar zuzunehmen. Im Vergleich zur Bundesrepublik wuchs die Differenz auf 5,7 Prozent an, so daß sich die französische Regierung schließlich zu einschneidenden Gegenmaßnahmen gezwungen sah. ${ }^{11}$

Ähnlich wie 11 Jahre zuvor unter Charles de Gaulle griff sie erneut auf eine massive Abwertung des Franc und ein begleitendes Austeritätsprogramm zurück, um in möglichst kurzer Frist die Binnennachfrage einzudämmen und die Wettbewerbsfähigkeit der französischen Exportwirtschaft wiederherzustellen. Die Abwertung des Franc im August 1969 in Höhe von 11,11 Prozent, die im Oktober noch durch eine Aufwertung der DM um 9,3 Prozent ergänzt wurde, führte schlagartig zu einer Wiederbelebung des französischen Exports. ${ }^{12}$ Ein neuer "plan de redressement", der u. a. einen befristeten

${ }^{4}$ Pompidou in der Pressekonferenz vom 10.7.1969, abgedruckt in Auszügen in: EA, D 395, Folge 16/1969, D 390 - D 395

${ }^{5}$ So der industriepolitische Berater Pompidous, Bernard Esambert, vgl. Esambert (1994), Pompidou, capitaine d'industries, Paris, S. 10

${ }^{6}$ Vgl. Pressekonferenz Pompidous am 2.7.1970, abgedruckt in: PE, S. 27, 2. Sem. S. 27-33

${ }^{7}$ So Pompidou in einem vertraulichen Gespräch mit dem Sprecher des Elysee-Palasts, Leo Hamon, vgl. Esambert (1994), a.a.O., S. 260

${ }^{8}$ Zum Scheitern des Reformprogramms siehe Vesperini (1993), a.a.O., S. 62-73

${ }^{9}$ Vgl. INSEE (1989), a.a.O., S. 91

${ }^{10}$ Vgl. OECD (1970), Economic survey, France, S. 5

${ }^{11}$ Vgl. Vesperini (1993), a.a.O., S. 83

${ }^{12}$ Zum "plan de redressement" und seinen Auswirkungen siehe Vesperini (1993), a.a.O., S. $75 \mathrm{ff}$. 
Preisstopp, Maßnahmen zur Krediteindämmung und eine Erhöhung der Einkommensund Mehrwertsteuer vorsah, vermochte in kurzer Zeit, den Binnenkonsum auf das gewünschte Niveau zurückzuführen. Dementsprechend war schon im vierten Quartal 1969 die Bilanz der laufenden Zahlungen wieder nahezu ausgeglichen. ${ }^{13}$ Ab 1970 konnte Frankreich im europäischen Vergleich sogar die höchsten Zuwachsraten beim Bruttosozialprodukt und im Export verzeichnen. ${ }^{14}$ Nach kurzer Zeit hatte sich die französische Regierung somit den Sachzwängen einer defizitären Zahlungsbilanzsituation entledigt und wirtschaftspolitischen Handlungsspielraum zurückgewonnen.

Im Verlauf der kommenden Jahre verfolgte die französische Wirtschaftspolitik ihren Expansionskurs weiter. Den Schwerpunkt bildete die Industriepolitik, die sich in erster Linie auf den Strukturwandel im Bereich der Hochtechnologie konzentrierte und die Ausrichtung der französischen Industrie auf den Weltmarkt forcierte. Frankreich setzte alles daran, um wieder zu einer positiven Handelsbilanz zu gelangen. Überschüsse im Außenhandel, so Valéry Giscard d'Estaing, der 1969 als Wirtschafts- und Finanzminister wieder in die Regierung zurückgekehrt war, seien dem Rang der französischen Nation angemessen ebenso wie die Rolle eines Kapitalexporteurs, die moderne Industriestaaten normalerweise einzunehmen hätten. ${ }^{15}$ Dem drohenden Rückgang der Exportnachfrage infolge der Währungsturbulenzen zu Beginn der siebziger Jahre trat die französische Regierung ab Mitte 1970 mit einem Stabilisierungsprogramm entgegen. Dieses enthielt gezielte Maßnahmen zur Beschränkung der Preissteigerungen (contrats anti-hausse) sowie eine gelockerte Fiskalpolitik zur Stimulierung der Nachfrage und führte schon nach kurzer Zeit zu den erhofften Erfolgen. Zunehmend schwieriger hingegen gestaltete sich die Inflationsbekämpfung. Eingebettet in eine weltweite Beschleunigung des Preisauftriebs erlebte Frankreich aufgrund des nach den Streiks von 1968 garantierten Kaufkraftausgleichs jährliche Lohnsteigerungen von über 10 Prozent, die deutlich über dem europäischen Durchschnitt lagen. ${ }^{16}$ Mit einer verschärften Preisüberwachung sowie einer überdurchschnittlichen Anhebung des Zinsniveaus gelang es jedoch bis Mitte 1973, den Inflationsunterschied moderat zu halten, ohne das

${ }^{13} \mathrm{Vgl}$. OECD (1970,), a.a.O., S. 28

${ }^{14} \mathrm{Vgl}$. Vesperini (1993), a.a.O., S. 84 f. sowie OECD, Economic Surveys, laufende Jahrgänge ab 1969

15 "Aussi bien, l'objectif n'est-il pas seulement de rétablir l'équilibre du commerce extérieur de la France: il est, en réaltié, de dégager un excédent permanent dans ses échanges. La France doit passer, non pas seulement du déficit à l'équilibre, mais du déficit à l'excédent... pour pouvoir être exportatrice de capitaux. Telle est bien la situation normale d'un pays industrialisé, que de porter au dehors ses propres capacités économiques, au lieu de se contenter d'accueillir celles des autres. La Politique que nous avons à conduire n'est donc pas une politique de circonstance, pour la fin de l'année 1969. C'est une politique à long terme, dont l'objet est de dégager l'une des ambitions nationales de la France: devenir à son tour, comme ses grands voisins, un pays qui soit - de façon permanente - excédentaire quant à son commerce extérieur", Exposé Giscard d'Estaings vor dem "congrès des conseillers du commerce extérieur" vom 12.9.1969, auszugsweise abgedruckt in: PE, S. 662 . Sem., S. $66 \mathrm{ff}$.

${ }^{16}$ Vgl. Vesperini (1993), a.a.O., S. 112 
Wirtschaftswachstum, welches bis Mitte 1974 deutlich über 5 Prozent lag, zu beeinträchtigen. ${ }^{17}$

Der Erfolg dieser Politik endete abrupt im Herbst 1973 mit dem Ausbruch der Ölkrise. Die plötzliche Vervierfachung des Erdölpreises führte aufgrund der unelastischen Nachfrage und der hohen Erdölabhängigkeit Frankreichs zu Preissteigerungen und einer erneut defizitären Außenhandelsbilanz. ${ }^{18}$ Durch den automatischen Inflationsausgleich kam es außerdem zu einem verstärkten Anstieg der Löhne, der einen zusätzlichen Inflationsimpuls auslöste. Mit einem Anstieg der Preise um bis zu 17 Prozent erlebte Frankreich 1973 schließlich eine der höchsten Inflationsraten in Europa ${ }^{19}$ Auf das Wirtschaftswachstum schlug diese abrupte Verschlechterung ökonomischer Grunddaten allerdings erst Mitte 1974 durch. Im europäischen Vergleich wurde Frankreich damit deutlich später von der Wirtschaftskrise getroffen. ${ }^{20}$ Insgesamt konnte es zwischen 1969 und 1974 eine ausgeglichene Zahlungsbilanz und sowie ein beständiges Wachstum realisieren. Wie schon unter de Gaulle waren es auch unter Georges Pompidou radikale wirtschaftspolitische Einschnitte, mit denen die französische Wirtschaft nach anfänglichen Schwierigkeiten rasch wieder auf Expansionskurs gebracht wurde. Die Inflation blieb allerdings ein Dauerproblem, das dem Wachstum jedoch kaum Schaden zufügte. Durch die rasche Lösung der meisten ökonomischen Probleme hatte sich Georges Pompidou schon bald nach seinem Amtsantritt den nötigen Freiraum verschafft, um auf dem Gebiet der Europapolitik unbehindert von nationalen wirtschaftlichen Sachzwängen agieren zu können.

\section{B.3.1.2 Der Inhalt der europapolitischen Konzeption}

Die europapolitischen Vorstellungen Georges Pompidous waren stark geprägt durch seine 24-jährige Zusammenarbeit mit Charles de Gaulle. Noch vor seiner Wahl versprach er, sich auf dem Gebiet der Außenpolitik der Lehren zu erinnern, die er von seinem Vorgänger erhalten hatte. Dementsprechend erhob er die Wahrung der Interessen, der Unabhängigkeit sowie der "Würde" Frankreichs zum Hauptziel seiner Außenpolitik. ${ }^{21}$ Wie de Gaulle, so betrachtete auch Pompidou die Außenpolitik als "domaine

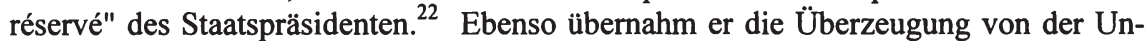
veränderbarkeit der Nationen, deren Interessen für ihn die prima causa aller Außenpo-

\footnotetext{
${ }^{17} \mathrm{Vgl}$. OECD Economic Survey, France, laufende Jahrgänge

$1872,5 \%$ seines Energieverbrauchs wurden in Erdöl gedeckt, vgl. Grosser (1986), a.a.O., S. 312

${ }^{19}$ Vgl. Vesperini (1993), a.a.O., S. 130

${ }^{20}$ Zur Stabilisierungspolitik der französischen Regierung und ihren Resultaten siehe Vesperini (1993), a.a.O., S. $91-128$

21 "En tout cas, je vous promets que je me rapellerai des grandes leçons que j'ai reçu en ce domaine du général de Gaulle", so Pompidou in seinem letzten Fernsehauftritt vor der Wahl, Le Monde vom 15.6.1969, "Les déclarations de M. Pompidou", S. 3

${ }^{22}$ Vgl. Ménudier H. (1973), Französische Außenpolitik nach den Wahlen vom März 1973, S. 452, in: EA, Folge 13/1973, S. 453-460 sowie Grosser (1986), a.a.O., S. 286
} 
litik darstellten. ${ }^{23}$ Der Hauptunterschied zu de Gaulle lag in der Art der Verteidigung französischer Interessen, die pragmatischer erfolgte, ohne dabei jedoch an Nachhaltigkeit einzubüßen. ${ }^{24}$

Frankreich war für Pompidou nur als starkes, einflußreiches Frankreich denkbar, dessen Unabhängigkeit und Einfluß auf seiner wirtschaftlichen Macht beruhten und dessen "grandeur" bzw. Rang unter den Nationen in seinen Verdiensten um die abendländische Kultur und Zivilisation begründet war. Wenn er auch öffentlich eingestand, daß Frankreich nicht mehr den Rang einer Großmacht hatte ${ }^{25}$, so war es für ihn um so mehr die Kulturleistung, die Frankreich auszeichnete und die dem Literaturwissenschaftler Pompidou besonders am Herzen gelegen haben dürfte:

"Enfin, et précisément parce que nous sommes sans doute un des pays qui ont toujours attaché le plus de prix aux problèmes intellectuels et moraux et aujourd'hui à ceux que pose à notre civilisation le progrès scientifique et technique, nous avons, en effet, la prétention de définir un art de vivre et une conception de la société moderne dont la valeur s'étende au-delà de nos frontières. N'est-il pas vrai que le retentissement de ce qui se passe à Paris est sans commune mesure avec notre production d'acier ou avec notre puissance nucléaire? On l'a vu, encore, en Mai 1968, dans un sens comme dans l'autre. Pour tout dire, nous croyons aux valeurs spirituelles et nous pensons n'en être dépourvus." ${ }^{26}$

In dem Grad seiner Überzeugtheit von der zivilisatorischen Sendung des eigenen Landes sowie dessen internationaler Bedeutung stand Pompidou somit de Gaulle in nichts nach. So vertrat auch er die Auffassung, daß die wirtschaftliche Leistungsfähigkeit zwar keine hinreichende, wohl aber eine notwendige Voraussetzung dafür war, dieser Sendung weltweit Geltung zu verschaffen. ${ }^{27}$ Dementsprechend lehnte Pompidou jede Nachlässigkeit in dem Vorhaben ab, Frankreich zu einer führenden Industriemacht zu machen. ${ }^{28}$ In diesem Bemühen spielte Europa für Frankreich eine zentrale Rolle, wie auch Frankreich für Europa von zentraler Bedeutung war. Zum einen, so Pompidou, konnte Frankreich seinen weltweiten Rang nur bewahren und ausbauen, wenn es sich mit den europäischen Staaten vereinigte. ${ }^{29}$ Zum anderen war ein starkes Frankreich die

${ }^{23}$ Vgl. Grosser (1986), a.a.O., S. 286

${ }^{24}$ Vgl. Fontaine, A., "La Politique Étrangère de M. Pompidou", Le Monde vom 3.2.1970, S. 2

${ }^{25}$ Ansprache vor dem National Press Club, Washington, 24.2.1970, abgedruckt in: PE, S. 58, 1. Sem 1970 , S. 57-63

${ }^{26}$ So Pompidou in seiner Pressekonferenz im "National Press Club" in Washington am 24.2.1970, a.a.O., S. 58

27 "Nous savons l'importance de la puissance économique. C'est pourquoi nous avons entrepris un grand effort de modernisation et d'industrialisation qui sera, dans les années à venir, le principal souci de mon gouvernement. Mais il faut comprendre que pour nous la richesse économique n'est pas un but en soi, qu'elle n'a d'autre intérêt que de servir l'homme, de lui permettre de développer sa personnalité en se libérant des contraintes de la misère et des soucis lincinants du lendemain", ebenda

28 "Rien, je l'avoue, ne m'est plus pénible que les appels à la médiocrité, à l'abaissement qu'on baptise sagesse, ... Que l'on veuille tout transformer, voire tout bouleverser, conquérir le pouvoir, ... que ce soit pour proposer à la France un avenir de grandeur et non de soumission!" so Pompidou in einem Interview mit dem Time-Magazine im Februar 1970, zit. n. Esambert (1994), a.a.O., S. 24 f.

${ }^{29}$ So Pompidou in einer Fernsehansprache am 11.4.1972 anläßlich des Referendums über die Erweiterung der EWG, abgedruckt in: PE, S. 138, 1. Sem. 1972 
unbedingte Voraussetzung dafür, daß Europa sein Gleichgewicht sowie seine Unabhängigkeit erhalten konnte und "überall Zutritt fände" ${ }^{\prime 30}$. Frankreich und Europa standen für Pompidou in wechselseitiger Abhängigkeit, wobei er die Frage, wer in diesem Verhältnis wen mehr prägte, klar zugunsten Frankreichs beantwortete.

Wie schon de Gaulle, so strebte Georges Pompidou ein "unabhängiges" und „europäisches Europa“ an, das seine Entscheidungen unbeeinflußt von Drittmächten traf und eine eigenständige internationale Politik verfolgte. ${ }^{31}$ Die Unabhängigkeit Europas war in erster Linie auf die USA bezogen, denen er unterstellte, mit ihrer Währungs- und Verteidigungspolitik einen zu großen Einfluß auf die europäische Politik auszuüben ${ }^{32}$ und Europa dominieren zu wollen. ${ }^{33}$ Pompidou blieb der Vorstellung de Gaulles von einem "Europa der Staaten" treu. Auch sein Europa war das der souveränen Staaten, die Schritt für Schritt ihre Politik harmonisierten und mit realistischem Augenmaß bei der Integration fortschreiten sollten. Dies brachte er in dem geflügelten Wort "L'Europe se fera dans le respect de la personnalité des États qui en feront partie ou ne se fera pas ${ }^{\prime 34}$ zum Ausdruck. Damit war klar, daß Frankreich auch unter Pompidou jeden Fortschritt der europäischen Integration in Richtung Supranationalität ablehnte und entschlossen bekämpfen würde.

Im Gegensatz zu de Gaulle war das "europäische Europa" Pompidous allerdings nicht mehr auf die "Schiedsrichter"-Rolle zwischen den beiden Supermächten festgelegt. ${ }^{35}$ Dem primären Ziel der Unabhängigkeit verpflichtet, sollte es vielmehr erst einmal alles daran setzen, "es selbst zu sein", um danach seine Beziehungen zu Drittmächten neu zu bestimmen. ${ }^{36}$ In einer Zeit, in der überall neue große Staatengebilde wie die USA, die UdSSR, Brasilien, China und Indien entstünden, so Pompidou, müsse man ein neues Europa "bauen" (construire), um zu verhindern, daß die westeuropäischen Staaten endgültig in der Bedeutungslosigkeit versinken würden. ${ }^{37} \mathrm{Ihr}$ Zusammenschluß lag aufgrund ihrer gemeinsamen Lebensform, Geographie, ihrer Auffassung von Demokratie sowie "evidenter wirtschaftlicher und politischer Interessen" nahe. Wenn es auch in der Vergangenheit „Probleme“ zwischen einzelnen Mitgliedstaaten gegeben hätte, so müsse es in Zukunft darum gehen, so Pompidou, die gemeinsame "Tradition einer christli-

${ }^{30} \mathrm{Vgl}$. Ansprache Pompidous in Straßburg vom 27.6.1970, abgedruckt in: Le Monde vom 30.6.1970, S. 3

${ }^{31}$ So Pompidou in einem Interview mit BBC am 17.5.1971, abgedruckt in: PE, S. 170, 1. Sem. 1970

32 "... l'Europe indépendante se définit essentiellement par rapport aux États-Unis ... Il s'agit simplement de se distinguer afin d'affirmer une personnalité européenne, ..." so Pompidou in einem Interview mit EPOCA vom 9.2.1972, abgedruckt in: PE, S. 97, 1. Sem. 1972

${ }^{33}$ Zur kritischen Haltung Pompidous gegenüber den USA siehe Grosser (1986), a.a.O., S. 308-314 sowie Cousté, P.-B. (1974), Pompidou et l'Europe, Paris, S. $57 \mathrm{ff}$.

${ }^{34}$ Ansprache Pompidous am 27.6.1970 in Straßburg, a.a.O., zurückgehend auf die bekannt gewordene Bemerkung Rueffs: "L'Europe se fera par la monnaie ou ne se fera pas".

${ }^{35} \mathrm{Vgl}$. das BBC-Interview Pompidous vom 17.5.1971, a.a.O, S 171 sowie Cousté (1974), a.a.O., S. 78

${ }^{36}$ Vgl. das BBC-Interview Pompidous vom 17.5.1971, a.a.O., S. 171

${ }^{37}$ Vgl. die Pressekonferenz Pompidous vom 16.3.1972, D 335, abgedruckt in: EA, Folge 14/1972, D 334 - D 337 
chen und rationalistischen Zivilisation" zu bewahren. ${ }^{38}$ Europas "raison d'être" lag für ihn in seiner Kulturleistung und deren Bewahrenswürdigkeit, wenn er feststellte: "... es gibt einen europäischen Menschen, es gibt eine europäische Zivilisation, und es geht darum, sie zu erhalten und anzupassen an die Entwicklung der Welt" ${ }^{39}$. Diese Kulturleistung sah Pompidou nicht nur als ein passives Gut an, sondern, wie im Falle Frankreichs, als Ursprung einer europäischen „Mission“. Die "rôle mondial" Europas bestand in der Verpflichtung, seinen gesellschaftlichen Werten international Geltung zu verschaffen:

„Se retrouver pour participer à une grande oeuvre commune qui est la construction d'une Europe groupant des nations décidées à concilier la sauvegarde de leurs identités propres avec les contraintes d'une action communautaire. Représentant une puissance économique comparable à celle des plus grands, ayant par leur situation géographique et la parenté de leurs civilisations des intérêts politiques et humains en grande partie communs, gardant de leur passé un égal souci d'aide aux pays en voie de développement, ..., les nations d'Europe occidentale trouveraient dans leur cohésion organisée le moyen de rendre à l'Europe la maîtrise de son destin et un rôle mondiale à mesure de ses capacités. Plus encore peut-être, notre association nous permettrait-elle de retrouver une conception proprement européenne de la civilisation, je veux dire une conception qui assure la primauté de l'homme. ${ }^{640}$

Die Bewahrung der europäischen Zivilisation lag Pompidou um so mehr am Herzen, als er in der Krise der modernen Gesellschaften nach 1968 weitgehend eine Reaktion auf die Unzulänglichkeiten der herrschenden Gesellschaftssysteme sowjetischen und amerikanischen Typs sah. Während Ersteres den Menschen insgesamt unterdrücke, so Pompidou, versuchte man seitens der USA, durch einen puren "Materialismus" im Sinne von Güterüberfluß die menschlichen Bedürfnisse zu befriedigen, was seiner Auffassung nach jedoch weder dem menschlichen Streben entsprach noch hinreichend war, um den Menschen die notwendige Sinnstiftung vermitteln zu können. ${ }^{41}$ Worum es ihm ging, war die Vermittlung von Werten, auf denen Gesellschaften aufgebaut werden konnten. Auf diesem Gebiet waren Europa und Frankreich mit ihrer alten Zivilisation, ihren Traditionen und Erfahrungen prädestiniert, einen wichtigen Beitrag zu leisten. ${ }^{42}$ Überzeugt davon, daß Frankreich und Europa eine gewichtige Rolle zu spielen hätten $^{43}$, wies Pompidou immer wieder darauf hin, wie wichtig es war, sich von den USA zu unterscheiden. Im Streit um die Amtssprache der Gemeinschaft ging er dabei so weit, Französisch als offizielle Amtssprache zu fordern, um den Unterschied zu den USA klar zu markieren, denn Englisch sei mittlerweile mehr die Sprache der USA als die Großbritanniens. ${ }^{44}$

${ }^{38}$ Vgl. Pressekonferenz vom 16.3.1972, a.a.O., D 337

${ }^{39}$ ebenda

${ }^{40}$ Ansprache Pompidous anläßlich eines Essens zu Ehren Edward Heaths am 20.5.1971, in: Pompidou (1975), a.a.O., S. 123

${ }^{41}$ Vgl. Pompidou (1974), a.a.O., S. 177

42 ebenda, S. 178 und 181

${ }^{43}$ ebenda, S. 175

44 "... l'anglais, maintenant, beaucoup plus que la langue de l'Angleterre, c'est la langue des ÉtatsUnis et que, par conséquent, garder une place privilégiée au français comme langue de travail de la Communauté, c'est une façon de se distinguer des États-Unis - je dis se distinguer, je ne dis pas se couper des États-Unis - et je crois que, pour l'Europe, se distinguer des États-Unis est essentiel. Il 
Das so von Pompidou definierte Zivilisationsanliegen Europas war letztlich identisch mit dem Frankreichs. Beide hatten eine zivilisatorische Mission, die es zu verbreiten galt. Völlig unzureichend hingegen war für Pompidou eine Europäische Gemeinschaft, die sich nur auf rein wirtschaftliche Aspekte beschränkte. ${ }^{45}$ In einer von militärischen Supermächten beherrschten Welt war ein dem Humanismus verpflichtetes Europa für Pompidou eine vermittelnde Kraft, die dem Frieden und dem Ausgleich der Völker zu dienen hatte. ${ }^{46}$ Frankreich ging es letztlich auch unter Pompidou um ein machtvolles, starkes Europa, das auf globaler Ebene eine eigene Rolle spielen sollte. In dieser Vision blieb Europa das Mittel zur Verwirklichung französischer Kulturwerte, als das es schon de Gaulle definiert hatte. Von vornherein schloß diese Sichtweise aus, daß Frankreich in Europa aufging oder auch nur ansatzweise bereit war, seine nationale Identität aufzugeben. ${ }^{47}$

"L'Europe, compte tenue de son histoire, suppose le maintien de la personnalité des nations qui la composent; c'est en cela que la France entend lui imprimer sa <<marque〉> ... Mais l'Europe c'est aussi une entreprise où les difficultés ne manqueront pas, surtout si l'on veut, comme le gouvernement français, que l'Europe soit un ensemble puissant, indépendant, retrouvant dans le monde le rôle qui fut le sien. La France ne revendique pas le monopole de cette volonté européenne mais elle espère en donner l'exemple. ${ }^{48}$

Zusammenfassend betrachtet handelte es sich bei den Vorstellungen Pompidous von Europa und der Rolle Frankreichs in selbigem im wesentlichen um eine Fortführung der europapolitischen Konzeption de Gaulles. Wesentliche Elemente wie das Fortbestehen der Nationen, die Unabhängigkeit Europas, seine zivilisatorische Sendung sowie das kritische Verhältnis zu den USA hatte Pompidou unverändert übernommen. Europa stellte auch für ihn im wesentlichen ein vergrößertes Abbild der französischen Nation dar, die wiederum aufgrund ihrer Vorbildhaftigkeit eine besondere Rolle in Europa beanspruchte. Frankreich sollte weiter die geistige Führung wahrnehmen und als starkes Frankreich das Gleichgewicht in Europa und durch Europa in der Welt wahren. Einziger Unterschied zu de Gaulle war der größere Realitätsbezug, der sich in der Anerkennung des endgültigen Verlusts der Großmachtrolle Frankreichs und Europas so-

faut que l'Europe soit elle-même; or, elle a trop de liens et trop d'attaches avec les États-Unis pour qu'il ne soit pas nécessaire, d'abord, de marquer cette distinction", so Pompidou am 18.5.1971 in einem Interview mit dem belgischen Fernsehen, abgedruckt in: PE, S. 175, 1. Sem., S. $172 \mathrm{ff}$.

45 "... l'Europe ne doit pas être une communauté des marchands. Elle doit être conçu et réalisée au service des hommes...", so Pompidou in seiner Ansprache zur Eröffnung des Pariser Gipfels am 19.10.1972, abgedruckt in: LE MONDE, 20.10.1972, S. 2

${ }^{46}$ So Pompidou in einem Fernsehinterview am 14.10.1965, vgl. Cousté (1974), a.a.O., S. 9.

Zur Rolle Europas in der Welt aus französischer Sicht siehe auch die umfangreiche Stellungnahme Außenminister Schumanns in seiner Ansprache vor der UN-Vollversammlung am 24.9.1969, S. 75 ff., abgedruckt in: PE, 2. Sem 1969, S. 75-81

47 ,...une entreprise sans précédent par laquelle des États indépendants ont choisi d'aller vers l'unité sans sacrifier leur diversité afin de rendre à notre continent un rôle correspondant à ses capacités économiques, intellectuelles et humaines", so Pompidou in einer Ansprache anläßlich eines Staatsbesuchs in Belgien am 24.5.1971, S. 186, abgedruckt in: PE, 1. Sem. 1971, S. 184-186

${ }^{48}$ So Pompidou in einem Interview mit TIMES am 12.5.1972, abgedruckt in: PE, S. 158, 1. Sem. 1972 , S. $156 \mathrm{ff}$. 
wie im Wegfall der Parole des Europas "vom Atlantik bis zum Ural" ausdrückte. Die nüchternere Sichtweise Pompidous ließ sich in der Betonung der „Notwendigkeit“ Europas für die Industrialisierung Frankreichs sowie zur Verhinderung des drohenden Bedeutungsverlusts der westeuropäischen Nationen erkennen. Unter Georges Pompidou erhielt die französische Europapolitik eine stärker pragmatische Orientierung, die schon in der konstruktivistischen Formulierung, Europa "bauen" zu wollen, durchschien, ihren klarsten Ausdruck jedoch im Bild der Vernunftehe erhielt, derzufolge Europa einer Heirat entsprach, die nicht aus Liebe, sondern - was unausgesprochen damit gesagt war - primär aufgrund zweckrationaler Erwägungen geschlossen worden sei ${ }^{49}$ Inhaltlich war die europapolitische Konzeption Pompidous damit nicht weniger ambitioniert als die seines Vorgängers, einzig die Anerkennung der realen Machtverhältnisse versprach eine gewisse Zurückhaltung in der Umsetzung ihrer Inhalte.

\section{B.3.1.3 Die Umsetzung der europapolitischen Konzeption}

Ende der sechziger Jahre stand die Europapolitik im Zeichen der immer noch offenen Agrarfinanzierung, der ebenso ungeklärten Gemeinschaftsfinanzierung sowie einer allgemeinen Orientierungslosigkeit über die Zukunft der darniederliegenden Gemeinschaft. Überzeugt von der Notwendigkeit Europas, räumte Pompidou der Europapolitik schon in seiner ersten Pressekonferenz als Staatspräsident einen bedeutenden Platz ein. Um den Integrationsprozeß aus seiner Stagnation herauszureißen und den für 1970 avisierten Übergang zur Endstufe der Wirtschaftsgemeinschaft sicherzustellen, trat der französische Präsident mit einer umfassenden Initiative an die Öffentlichkeit. Medienwirksam warb er für einen neuen Anlauf zur Fortsetzung der europäischen Einigung, den er mit dem Bild des „Triptychons“ umschrieb. Danach sollte die Europäische Gemeinschaft zunächst „,vollendet“ werden, indem die Finanzierungsfragen endgültig geregelt würden, um dann in einem zweiten Schritt „vertieft“ zu werden, was durch eine engere Koordination der politischen Zusammenarbeit auf den Gebieten der Forschungs-, Währungs- und Energiepolitik sowie durch regelmäßige Treffen der höchsten Repräsentanten der Mitgliedstaaten geschehen sollte. Als dritter und letzter Schritt war schließlich an ihre Erweiterung gedacht, womit Pompidou den immer noch bestehenden britischen Beitrittsantrag von 1967 wieder in die Diskussion brachte. ${ }^{50} \mathrm{Da}$ mit dieser Aufzählung eine zwingende Reihenfolge verbunden war, wurde schnell klar, daß Frankreich für seine Zustimmung in der Beitrittsfrage Zugeständnisse bei der Agrarfinanzierung einhandeln wollte.

Pompidous Initiative traf auf seiten der Mitgliedstaaten auf positive Resonanz. Schon am 1. Dezember 1969 kamen die Staats- und Regierungschefs in Den Haag zu einem

\footnotetext{
49 "Pour moi, l'Europe, c'est un mariage entre États, un mariage à six ou dix, mais l'amour n'en est pas la base", so Pompidou in der Zeitschrift "Réalités", abgedruckt in Auszügen in: Le Monde vom 31.05.1970, S. 27

${ }^{50}$ Vgl. die Pressekonferenz Pompidous vom 10.7.1969, D 393, abgedruckt in: EA, 16/1969, D 390 D 395
} 
Gipfeltreffen zusammen, auf dem neben der Erweiterung der Gemeinschaft und der Regelung der Agrar- und Gemeinschaftsfinanzierung die Gründung einer Wirtschaftsund Währungsunion beschlossen wurde. ${ }^{51}$ Es schlossen sich die Berufung des „Werner"- und des „Davignon“-Ausschusses an, von denen der erste Vorschläge zur Gründung der Wirtschafts- und Währungsunion und der zweite Vorschläge zur Vertiefung der Zusammenarbeit auf außenpolitischem Gebiet ausarbeiten sollte. Ferner wurde mit der Erweiterung der Gemeinschaft die Aufnahme von Beitrittsverhandlungen mit Großbritannien und anderen EFTA-Staaten beschlossen.

Da diese sich plötzlich entfaltende Integrationsdynamik weit über das ursprüngliche Nahziel Pompidous hinausging, begann er ab Mitte 1970, seine Vorstellungen zum Aussehen Europas zu präzisieren. In einer Pressekonferenz am 2. Juli 1970 warnte Pompidou vor überstürzten Schritten auf dem Weg zur europäischen Einigung. Statt über imaginäre Endzustände nachzudenken, sollten besser konkrete Schritte für die nahe Zukunft überlegt werden. Die zukünftige politische Kooperation der westeuropäischen Staaten würde von dem abhängen, so Pompidou, was man ,politische Zusammenarbeit" nenne, wobei Frankreich schon immer Anhänger regelmäßiger Zusammenkünfte der Regierungen gewesen sei, mit dem Ziel, ihre Politiken auf allen Gebieten soweit wie möglich zu harmonisieren oder sogar $\mathrm{zu}$ vereinheitlichen. Hinsichtlich einer politischen Zusammenarbeit bemerkte er:

„Il y aura une politique européenne le jour où il y aura, à tout le moins, une Confédération Européenne, et, pour ma part, je crois possible et souhaitable de parvenir à une Confédération Européenne, mais je crois que le meilleur moyen de la tuer, c'est de vouloir brûler les étapes“. ${ }^{52}$

Mit der Rückbesinnung auf die Konföderation als institutionellen Rahmen für das gemeinsame Europa knüpfte Pompidou an die schon von de Gaulle propagierte intergouvernementale Zusammenarbeit als Muster der politischen Kooperation an, was faktisch wiederum eine klare Absage an die supranationale Integration darstellte. Dementsprechend lehnte er auch alle Diskussionen über eine Politische Union als möglichen Endzustand der Gemeinschaft, die vor allem innerhalb des Werner-Komitees geführt wurden, als „völlig illusorisch“ ab. Bestehende Interessendivergenzen der europäischen Mächte und die immer noch schwerwiegende Vergangenheit würden letztlich mit sich bringen, daß vorerst viel „Geduld“ und „Glaube“ zur Realisierung Europas notwendig seien. ${ }^{53}$ Pompidou verfolgte die Strategie de Gaulles weiter, nach der sich die Staaten schrittweise auf immer zahlreicheren Politikgebieten an die Zusammenarbeit gewöhnen sollten, um dann eines Tages, nach hinreichender Annäherung, zu einer einheitlichen Politik zu gelangen. ${ }^{54}$ Auf institutioneller Ebene hatte dies zur Folge, daß man französischerseits weiter auf den Ministerrat als zentrales Element der europäischen Institutionen baute. Die Zusammenarbeit in diesem Gremium verglich der fran-

\footnotetext{
${ }^{51}$ Vgl. das Kommuniqué dieser Konferenz, D 44, abgedruckt in: EA, 2/1970, D 42 - D 44

52 ebenda

53 ebenda

${ }^{54}$ ebenda
} 
zösische Präsident mit der innerhalb einer Koalitionsregierung, die natürlicherweise auseinanderbreche, wenn ein Koalitionsmitglied in „vitalen Fragen“ zu befürchten hätte, überstimmt zu werden. ${ }^{55}$ Mit dieser Feststellung plädierte Pompidou unausgesprochen für das weitere Festhalten am Einstimmigkeitsprinzip nach dem Luxemburger Kompromiß. Er stellte damit ferner unmißverständlich klar, daß er weiter an der Konzeption de Gaulles einer politischen Zusammenarbeit auf der Basis wohlkalkulierter nationaler Interessen festzuhalten gedachte. ${ }^{56}$

Derart disponiert lehnte Frankreich den Vorschlag des Werner-Berichts ab, die beschlossene Wirtschafts- und Währungsunion mit zentralen wirtschafts- und währungspolitischen Entscheidungsgremien zu versehen. Auf französische Zustimmung traf indessen die vom Davignon-Ausschuß vorgeschlagene engere Abstimmung der Regierungen auf dem Gebiet der Außenpolitik in Form von Konsultationen und unregelmässigen Treffen der Staats- und Regierungschefs. Auf letztere griff Frankreich erstmals zurück als sich im Verlauf der Jahre 1971 und 1972 das Fehlen einer engen währungspolitischen Koordination unter den europäischen Partnern bemerkbar machte. Auf Initiative des französischen Präsidenten trafen im Oktober 1972 die Staats- und Regierungschefs zusammen, um auf intergouvernementaler Ebene über die Fortführung der Integration und die Abstimmung der europäischen Währungspolitik zu beraten. Frankreich ging auf dieser Konferenz so weit, entgegen seiner ursprünglichen Zurückhaltung die Gründung einer Politischen Union vorzuschlagen, allerdings ohne ihr Aussehen näher zu bestimmen. ${ }^{57}$ Tatsächlich wurde sogar die Gründung einer Europäischen Union beschlossen. Über ihre Ziele und zeitliche Vorgaben im Hinblick auf ihre Verwirklichung wurden jedoch keine Angaben gemacht. Pompidou selbst definierte sie im September 1973 unklar näher als einen Zusammenschluß mit dem Ziel, die Zusammenarbeit über den Bereich des Wirtschaftlichen hinaus auszudehnen. Eine solche Union würde aber erst dann entstehen, wenn es eine harmonisierte allgemeine europäische Politik gäbe. ${ }^{58}$ Die Unklarheit der französischen Vorstellungen zur Politischen Union ging mit der Erfolglosigkeit dieser Idee einher. Erfolglos verlief auch die französische Initiative zur Ernennung von Europaministern sowie zur Bildung eines ständigen Sekretariats. Letzteres wurde französischerseits verworfen, als sich Paris nicht als Amtssitz durchsetzen ließ.

Ein weiteres Betätigungsfeld der französischen Europapolitik war die Erweiterung der Gemeinschaft. Mit der Formel „Vollendung-Vertiefung-Erweiterung“ stellte Frankreich bereits konkrete Bedingungen für seine Zustimmung in der Erweiterungsfrage.

${ }^{55}$ Vgl. die Pressekonferenz Pompidous vom 21.1.1971, S. 53, abgedruckt in Auszügen in: PE, 1. Sem. 1971, S. 52-56

56 Über die französische Konzeption der konkreten politischen Zusammenarbeit siehe Berger, R. (1971), Vor der Wiedergeburt Europas à la Wiener Kongreß ?, in: EA, Folge 19/1971, S. 665-672

${ }^{57}$ Vgl. die Ansprache Pompidous anläßlich der Eröffnung des Pariser Gipfels am 19.10.1972, S. 108, abgedruckt in: PE, 2. Sem 1972, S. 104-108

58 „Il n'y aura véritablement d'union européenne que le jour où il y aura une politique européenne“, so Pompidou in seiner Pressekonferenz vom 27.9.1973, S. 116, abgedruckt in Auszügen in: PE, 2. Sem. 1973, S. 115-122 
Diese waren mit dem 1969 erreichten Kompromiß bei der Agrarfinanzierung und der Anfang 1971 beschlossenen währungspolitischen Zusammenarbeit erfüllt. Der „Handel“", wie Pompidou später selbst zugab, in dem Frankreich die erwünschten Zusagen bei der Agrarfinanzierung und Währungsunion gegen die Aufgabe seiner Vorbehalte in der Erweiterungsfrage bekam, konnte somit vollzogen werden. ${ }^{59}$ Frankreich war an ihm jedoch nicht nur aus konkreten Tauschinteressen interessiert. Die französische Europapolitik war zunehmend über das wachsende Gewicht der wirtschaftlich aufstrebenden Bundesrepublik beunruhigt. Diese hatte durch die neue Ostpolitik Willy Brandts international erheblich an Bedeutung gewonnen und drohte, Frankreichs politische Rolle in Europa empfindlich zu unterminieren ${ }^{60}$ Die französische Haltung in der Erweiterungsfrage stand somit von Beginn an im Zeichen machtpolitischer Proporzüberlegungen. Mit der Aufnahme des politisch gewichtigen und wirtschaftlich potenten Großbritanniens bot sich aus französischer Sicht die Chance, den Bedeutungszuwachs der Bundesrepublik zu relativieren. ${ }^{61}$

Die Beitrittsverhandlungen gerieten 1971 in ihre entscheidende Phase, nachdem Frankreich zunächst die Verhandlungen über die Wirtschafts- und Währungsunion in die gewünschte Richtung gelenkt hatte. Pompidou hatte vorher betont, daß Frankreich eine Erweiterung nur akzeptieren würde, wenn diese zur Stärkung der Gemeinschaft führte. ${ }^{62}$ Um Sicherheit in dieser Frage zu erhalten, wurde im Frühjahr 1971 der britische Premierminister nach Paris eingeladen. Gesprächsgegenstand waren weniger wirtschaftliche Einzelfragen, sondern vor allem das „wirkliche Problem" des britischen Beitritts: die europapolitische Konzeption Großbritanniens. ${ }^{63}$ Pompidou unterstellte wie schon de Gaulle den Briten grundsätzlich die Neigung, die Europäische Gemeinschaft in einer Freihandelszone auflösen zu wollen. ${ }^{64} \mathrm{Er}$ fand jedoch während dieses Treffens schnell Übereinstimmung mit Heath in den für Frankreich wichtigen Fragen wie der Anerkennung des Präferenzgrundsatzes für den Agrarmarkt, der Beibehaltung der Einstimmigkeitsregel in Fragen nationalen Interesses, der Aufgabe des Status des Pfundes als Reservewährung für bestimmte arabische Staaten sowie allgemein hinsichtlich der zukünftigen politischen Rolle Europas. ${ }^{65}$ Das wesentliche am britischen

${ }^{59}$ Den „Handel“ zwischen Erweiterung und Fortschritt in der Agrarpolitik hätte er den Partnern auf der Konferenz von Den Haag dargelegt, so Pompidou in seinem Fernsehinterview vom 23.6.1971, abgedruckt in Auszügen in: EA,D 341, Folge 14/1971, D 340 - D 342

${ }^{60} \mathrm{Vgl}$. Loch, T. M. (1969), Ausgangspositionen für die europäische Gipfelkonferenz in Den Haag, S. 708, in: EA, Folge 20/1969, S. 707-716; zu der Befürchtung Frankreichs, in Osteuropa marginalisiert zu werden, siehe Grosser (1986), a.a.O., S. 302 f.

${ }^{61}$ Wahrscheinlich“, so Alfred Grosser „wäre es nicht zur Öffnung gegenüber Großbritannien gekommen, wenn man in Paris den deutschen Machtzuwachs innerhalb Europas nicht als bedrohlich empfunden hätte.“, vgl. Grosser (1986), a.a.O., S. 300

${ }^{62} \mathrm{Vgl}$. die Ansprache Pompidous im Commonwealth-Club in San Francisco vom 27.2.1970, abgedruckt in: PE, S. 74,1. Sem, S. 73-76

${ }^{63}$ So Pompidou in einem Interview mit der britischen Tageszeitung TIMES drei Tage vor dem Besuch Heaths, a.a.O., S. 169

${ }^{64}$ So Pompidou ein Jahr später in einem Interview mit der TIMES am 12.5.1971, abgedruckt in: PE, S. 159,1 . Sem., S. 156-162

${ }^{65}$ Siehe das Fernsehinterview Pompidous vom 23.6.1971, a.a.O., D 341 sowie das Kommuniqué der beiden Staatschefs vom 21.5.1971, D 276 f., abgedruckt in: EA, Folge 12/1971 
Beitritt zu Europa war für Pompidou nicht der Zuwachs an Wirtschaftskraft, sondern die britische Kulturleistung, die Europa helfen würde, zu seiner eigenen Gesellschaftsform zurückzufinden:

"Mais, avant tout, je pense que l'apport sera intellectuel, culturel. Il faut bien que nous arrivions, les uns et les autres, à retrouver une civilisation européenne, qui a existé dans le passé. Même à l'époque où nous nous battions les uns contre les autres, et c'est dans cet effort pour définir un mode de vie européen et une civilisation européenne que la Grande-Bretagne sera la plus précieuse ..." ${ }^{66}$

Der britische Beitritt reihte sich somit nahtlos in Pompidous Vision eines „Europe européenne" ein. Die Stärkung der Gemeinschaft durch ihre Erweiterung würde ihr, so Pompidou kurz vor Abschluß der Verhandlungen, eine größere Verantwortung gegenüber Resteuropa und der Welt sowie die materielle Basis zur Wahrnehmung der damit verbundenen Aufgaben bringen. ${ }^{67}$

Den erfolgreichen Verlauf der Verhandlungen gedachte Pompidou im Sinne seines politischen Ansehens und seiner Autorität zu nutzen. Er ließ die Ratifizierung der Beitrittsverträge durch das französische Volk direkt vornehmen, statt, wie bisher üblich, durch die Nationalversammlung. Infolge der mittlerweile zurückgegangenen Europabegeisterung nahmen jedoch nur 60 Prozent der Wahlberechtigten an der Abstimmung teil, von denen wiederum nur zwei Drittel dem Beitritt zustimmten ${ }^{68}$ Diese taktische Niederlage sowie die spätestens nach der Pfundkrise Mitte 1972 offensichtlichen Schwierigkeiten der Europäer, sich auf eine einheitliche Währungspolitik zu einigen, ließen auch auf seiten des französischen Präsidenten das Interesse an der Europapolitik sinken. ${ }^{69}$ Die Ernüchterung Frankreichs sollte noch wachsen, nachdem am 1. April 1974, einen Tag vor dem Tod Pompidous, die neu gewählte britische Regierung eine Neuverhandlung ihres finanziellen Beitrages zum Gemeinschaftshaushalt forderte - ein Problem, dessen Lösung erst zehn Jahre später gefunden werden sollte, das bis dahin jedoch noch für große Spannungen zwischen den Mitgliedstaaten sorgen sollte.

In der Erweiterungsdebatte Anfangs der siebziger Jahre zeigte sich erneut, daß Frankreich den Gemeinsamen Markt in erster Linie als wirtschaftspolitische Einheit mit auBenpolitisch nutzbarem Gewicht wahrnahm. Es waren vornehmlich geostrategische und nicht ökonomische Erwägungen, die die französische Haltung in der Erweiterungsfrage leiteten. Frankreich suchte einen neuen Partner, um seine europapolitische Konzeption unter den veränderten Rahmenbedingungen Anfang der siebziger Jahre realisieren zu können. Vor dem Hintergrund einer sich zunehmend emanzipierenden Bundesrepublik wandelte sich Großbritannien mit seinem traditionellen Streben nach Bewahrung seiner Eigenart gegenüber dem Kontinent von einer Gefahr für die französische europapolitische Konzeption zu einer Voraussetzung für deren Verwirklichung.

\footnotetext{
${ }^{66}$ So Pompidou im Interview mit der TIMES am 17.5.1971, a.a.O., S. 171

${ }^{67} \mathrm{Vgl}$. das Interview Pompidous mit EPOCA vom 9.2.1972, a.a.O., S. 96

${ }^{68} \mathrm{Zu}$ den Überlegungen Pompidous zum Referendum und seinem Verlauf siehe Grosser (1986), a.a.O., S. 298

${ }^{69}$ ebenda
} 
Trotz der Erfolglosigkeit seiner Initiativen blieb Frankreich auch im Jahr 1973 den Grundsätzen seiner Europapolitik treu. Als sich im Herbst 1973 während des JomKippur-Kriegs und der schlagartigen Erhöhung der Erdölpreise erneut das Fehlen einer eingespielten politischen Zusammenarbeit in der Gemeinschaft bemerkbar machte, war es wieder die französische Regierung, die zu einem gemeinsamen Vorgehen drängte. In einem offenen Brief an seine Kollegen monierte der französische Präsident, daß die Beendigung des Jom-Kippur-Krieges ohne jegliche Mitwirkung Europas allein durch die beiden Supermächte herbeigeführt wurde, obwohl Europa über historische Bindungen und wirtschaftliche Interessen in dieser Region verfügte ${ }^{70}$ : "Aus diesem und vielen anderen Gründen ... scheint es mir unerläßlich, daß wir den Beweis und die Probe sowohl der Festigkeit des europäischen Gebäudes als auch seiner Fähigkeit, zur Regelung der Weltprobleme beizutragen, leisten. ${ }^{71}$ Als Mittel dazu schlug er zum wiederholten Mal die Vereinbarung regelmäßiger Treffen der Staats- und Regierungschefs vor, auf denen sie ihre Haltungen miteinander konfrontieren und aufeinander abstimmen sollten. Die erste Zusammenkunft dieser Art sollte nach dem Willen des französischen Präsidenten noch im Jahr 1973 stattfinden. ${ }^{72}$ Die anderen Mitgliedstaaten kamen Frankreich insoweit entgegen, als sie im Dezember 1973 auf dem Gipfel von Kopenhagen zwar nicht die dauerhafte Einrichtung eines solchen Gremiums beschlossen, wohl aber einer gemeinsamen Erklärung über die „Identität Europas“ zustimmten, die auf einem französischen Entwurf beruhte. Ausgehend von der französischen These einer gemeinsamen Zivilisation mit unterschiedlichen nationalen Kulturen, die es zu erhalten gelte, gaben die Mitgliedstaaten ihrer Absicht Ausdruck, enger zu kooperieren und zunehmend mit gemeinsamer Stimme sprechen zu wollen, wobei gegenüber den USA betont wurde, die Beziehungen freundschaftlich auf der Basis der Gleichheit fortzusetzen. ${ }^{73}$ An letzterem lag Frankreich besonders viel, da es sich und Europa durch neue außenpolitische Initiativen der USA wie der "Atlantikcharta" Außenminister Kissingers, der amerikanischen Forderung nach einer neuen Welthandelskonferenz sowie dem Vorschlag zur Gründung einer Weltenergieagentur einer gewissen Bevormundung ausgesetzt sah. ${ }^{74}$ Die Bereitwilligkeit seiner europäischen Partner zu einer engen Kooperation mit den USA durchkreuzte allerdings die Linie Frankreichs, so daß Anfang 1974, am Ende der Amtszeit Pompidous, das „europäische Europa“ trotz aller Bemühungen Frankreichs weitgehend noch dem des Jahres 1969 glich.

Die Umsetzung der europapolitischen Konzeption Pompidous war somit in erster Linie durch das intensive, aber vergebliche Bemühen gekennzeichnet, die Politik der Mitgliedstaaten schrittweise zu vereinheitlichen. Er folgte weiter der Konzeption de Gaulles von einem "europäischen Europa", von dessen Aussehen er konkrete Vorstellungen hatte. Nach innen schwebte ihm dabei eine zunehmend intensivere Konzertati-

${ }^{70} \mathrm{Vgl}$. das Schreiben Pompidous an die Regierungschefs der anderen Mitgliedstaaten der Gemeinschaft vom 31.10.1973, abgedruckt in Auszügen in: EA, D 29, Folge 2/1974, D $28 \mathrm{ff}$.

${ }^{71}$ ebenda

72 ebenda sowie Pompidou in seiner Pressekonferenz vom 27.9.1973, a.a.O., S. 116

${ }^{73}$ Vgl. die Déclaration sur l'Identité Européenne“", abgedruckt in: Le Monde vom 15.12.1973, S. 2

${ }^{74} \mathrm{Zu}$ den Schwierigkeiten im Verhältnis USA-Frankreich in dieser Zeit siehe, Cousté (1974), S. $55 \mathrm{ff}$. sowie S. $67 \mathrm{ff}$. 
on der nationalen Politiken auf immer mehr Sachgebieten vor, bei der jedoch die nationale Unabhängigkeit weiter zu respektieren war. Nach außen hingegen sollte Gemeinschaft sich zu einer politisch handlungsfähigen Einheit entwickeln, die sich durch ein gemeinsames Auftreten gegenüber Drittstaaten auszeichnete, in der aber die Staatsund Regierungschefs das letzte Wort hatten. In diesen Vorstellungen setzte sich das französische Bestreben fort, die Europäische Wirtschaftsgemeinschaft zu einer Politischen Union auszubauen. Die französische Europapolitik folgte dabei konkreten geostrategischen Überlegungen im Hinblick auf die Rolle Europas auf globaler Ebene. Dies wurde insbesondere im Zusammenhang mit der Erweiterung der Gemeinschaft und der französischen Kritik an ihrem mangelnden Willen zu außenpolitischem Engagement deutlich. Hervorzuheben ist die Flexibilität, mit der sich die französische Europapolitik an die veränderten politischen und wirtschaftlichen Rahmenbedingungen der siebziger Jahre anpaßte. Angefangen mit der „relance“ des europäischen Einigungsprozesses durch den Gipfel von Den Haag, über den Beschluß der Währungsunion und die Integration Großbritanniens in die Gemeinschaft bis hin zum Vorschlag einer Politischen Union war Frankreich in der nicht einmal fünf Jahre dauernden Amtszeit Pompidous die treibende Kraft der europäischen Politik. Der relativ geringe Erfolg der französischen Initiativen ließ allerdings erkennen, daß sie offensichtlich den anderen Mitgliedstaaten zu weit gingen. Festzuhalten bleibt, daß es französischerseits nicht an Versuchen zur Umsetzung der eigenen europapolitischen Konzeption gemangelt hat. $\mathrm{Ob}$ und inwieweit sich diese auf die ordnungspolitische Ausrichtung der französischen Binnenmarktpolitik niedergeschlagen haben, sollen die folgenden Ausführungen zeigen.

\section{B.3.2 Die Wirtschafts- und Währungsunion}

Das herausragende Ereignis der Europapolitik zu Beginn der siebziger Jahre war die Absicht der Mitgliedstaaten, die bestehende Wirtschaftsgemeinschaft zu einer Wirtschafts- und Währungsunion weiterzuentwickeln. Der Entschluß der Staats- und Regierungschefs am 2. Dezember 1969, die Gemeinschaft in eine Wirtschafts- und Währungsunion zu überführen, entsprang ihrer Überzeugung, dem Integrationsproze $ß$ einen neuen Impuls geben zu müssen. Der Hauptanstoß kam dabei von den fünf Partnern Frankreichs, die nach der Stagnation der vorangegangenen Jahre auf einen wirklichen Schritt nach vorn hofften. Sie waren am ersten Tag des Gipfels von Den Haag von den bescheidenen Ambitionen des französischen Staatspräsidenten insbesondere hinsichtlich der institutionellen Fortentwicklung der Gemeinschaft enttäuscht. ${ }^{75}$ Pompidou, am Erfolg der auf seine Initiative hin einberufenen Konferenz interessiert, präzisierte daraufhin am zweiten Konferenztag seine Vorstellungen zur Intensivierung der Zusammenarbeit auf dem Gebiet der Währungs-, Wirtschafts-, Technologie- und Sozialpolitik, allerdings ohne diesem Ansinnen einen festen institutionellen Überbau zu verlei-

\footnotetext{
${ }^{75}$ Vgl. Le Monde vom 3.12.969, S. 2
} 
hen. ${ }^{76}$ Die Staats- und Regierungschefs einigten sich schließlich darauf, das Memorandum der Europäischen Kommission vom 12. Februar 1969 (Barre-Memorandum), dem die französische Regierung schon im Vorfeld der Konferenz zugestimmt hatte, zur Grundlage der weiteren Zusammenarbeit zu machen. ${ }^{77}$

Ziel dieses Memorandums war die Erhöhung der „Konvergenz der nationalen Orientierungsdaten im Bereich der mittelfristigen Wirtschaftspolitik“. Erreicht werden sollte diese über eine „ausreichende Kohärenz der kurzfristigen Wirtschaftspolitik“ sowie durch einen „Mechanismus für monetäre Zusammenarbeit “ ${ }^{78}$ Hauptinstrument zur engeren Koordinierung der Wirtschaftspolitik sollten eine bessere „Synchronisierung der einzelstaatlichen Programme" sowie systematische Konsultationen der Regierungen der Mitgliedstaaten sein. Diese Konsultationen sollten sich auch auf die nationalen Haushaltsplanungen erstrecken und durch ein "System von Warnindikatoren“ zur Überwachung der Konjunkturentwicklung ergänzt werden. ${ }^{79}$ Der Mechanismus für die monetäre Zusammenarbeit sah darüber hinaus die Schaffung von zwei neuen Beistandsfazilitäten vor. Die kurzfristige Fazilität sollte Mitgliedstaaten in Zahlungsbilanzschwierigkeiten Mittel bis zu einer bestimmten Höhe ohne Vorkonsultationen bis zu drei Monaten zur Verfügung stellen. Der mittelfristige Beistand hingegen sah vor, Ländern mit größeren Zahlungsproblemen Kredite unter bestimmten Auflagen über eine längere Frist zur Verfügung zu stellen. ${ }^{80}$

Frankreich stimmte diesen Vorschlägen nicht nur zu, sondern ging auf dem Gipfel von Den Haag sogar noch über darüber hinaus. So sprach der französische Finanzminister schon vor dem Gipfel davon, eine europäische Referenzeinheit für innergemeinschaftliche monetäre Transaktionen zu schaffen und einen Teil der Währungsreserven zusammenzulegen. ${ }^{81}$ Auf der Konferenz der Staats- und Regierungschefs schlug Pompidou zusätzlich die gemeinsame Inanspruchnahme der Sonderziehungsrechte der Mitgliedstaaten vor sowie gegenüber dem Internationalen Währungsfonds „unter allen Umständen eine gemeinsame Haltung einzunehmen“. Darüber hinaus forderte er die Einführung von Vorkonsultationen und die Bestimmung eines einzigen Sprechers, der die europäischen Mitgliedstaaten in internationalen Gremien vertreten sollte. ${ }^{82}$

In ihrer Abschlußerklärung verkündeten die Staats- und Regierungschefs ihren Entschluß, die zukünftige Gestaltung der wirtschafts- und währungspolitischen Zusam-

\footnotetext{
${ }^{76}$ Vgl. die Verlautbarung über die Erklärungen Pompidous am 2.12.1969, abgedruckt in: EA, Folge 2/1970, D $40 \mathrm{ff}$.

${ }^{77}$ Vgl. die Antwort Giscard d'Estaings am 28.11.1969 auf die Anfrage eines Abgeordneten zur europäischen Währungskooperation, S. 132 f., abgedruckt in: PE, 2. Sem. 1969, S. 131-133

${ }^{78} \mathrm{Vgl}$. Memorandum der Kommission der Europäischen Gemeinschaft an den Rat vom 12. Februar 1969 über die Koordinierung der Wirtschaftspolitik und die Zusammenarbeit in Währungsfragen innerhalb der Gemeinschaft, EA, D 166 ff, Folge 7/1969, D 163-D 174,

${ }^{79}$ ebenda, S. $170 \mathrm{f}$.

${ }^{80}$ ebenda, S. $171 \mathrm{ff}$.

${ }^{81} \mathrm{Vgl}$. die Antwort Giscard d'Estaings auf eine Abgeordnetenanfrage vom 28.11.1969, a.a.O., S. 133

${ }^{82}$ Vgl. die Ansprache Pompidous vom 2.12.1969, a.a.O., D 41
} 
menarbeit einer Expertengruppe zur weiteren Prüfung zu übertragen. Diese sollte ausgehend vom Barre-Memorandum im Laufe des Jahres 1970 einen Stufenplan zur Errichtung einer Wirtschafts- und Währungsunion vorlegen. ${ }^{83}$ Die Expertengruppe wurde am 6. März 1970 vom Ministerrat eingesetzt und der Führung des luxemburgischen Ministerpräsidenten Pierre Werner anvertraut.

In der Zwischenzeit hatten sich die Regierungen Belgiens, Luxemburgs, der Bundesrepublik sowie die Europäische Kommission mit eigenen Plänen in die Diskussion um die Wirtschafts- und Währungsunion eingeschaltet. ${ }^{84}$ Frankreich indessen hielt sich zunächst zurück. ${ }^{85}$ Erst in einer Ministerratssitzung Ende Mai 1970, anläßlich der Diskussion des Zwischenberichts der Werner-Gruppe, trat es mit eigenen Vorschlägen an die Öffentlichkeit. Wirtschafts- und Finanzminister Giscard d'Estaing sprach sich für die Schaffung eines europäischen Fonds zur Stabilisierung der Wechselkurse aus. $\mathrm{Zu}$ sätzlich forderte er eine Reduzierung der Schwankungsbreiten der europäischen Währungen untereinander. Beide Vorschläge waren Elemente der französischen Strategie eines „deuxième pôle monétaire“ zur Stabilisierung des internationalen Währungssystems. Europa sollte über ein Paritätengitter fester Wechselkurse einen Gegenpol zum Dollar bilden, der aus französischer Sicht aufgrund der laxen Zahlungsbilanzpolitik der USA nicht mehr als Grundlage stabiler internationaler Währungsbeziehungen geeignet war. ${ }^{86}$ Mit dieser Strategie versuchte Frankreich, eine eigenständige europäische Währungspolitik ins Leben zu rufen, mittels derer der Einfluß der USA auf die internationalen Währungsbeziehungen verringert werden sollte. ${ }^{87}$ In diesem Zusammenhang betonte der französische Finanzminister noch einmal seine ablehnende Haltung im Hinblick auf Überlegungen innerhalb des IWF, das Wechselkursregime zu lockern, da nur feste Wechselkurse in der Lage wären, geordnete Verhältnisse im Welthandel zu gewährleisten. $^{88}$

Mit dieser Stellungnahme trat der Konflikt zwischen „Monetaristen“ und „Ökonomisten" an die Öffentlichkeit, der bis dahin die Diskussionen innerhalb des Werner-Komitees beherrscht hatte. Die Fraktion der Monetaristen, die, unter der Führung Frankreichs stehend, noch Belgien und Luxemburg umfaßte, sprach sich dafür aus, die Wirtschafts- und Währungsunion primär über währungspolitische Maßnahmen herbeizuführen. Über systematisch angelegte monetäre Sachzwänge wie der Verengung der Schwankungsbreiten der europäischen Währungen und deren Verteidigung

${ }^{83}$ Vgl. Kommuniqué der Konferenz der Staats- und Regierungschefs der Mitgliedstaaten der Europäischen Gemeinschaften in Den Haag am 1. und 2. Dezember 1969, D 44, EA, Folge 2/1970, D $42-45$

${ }^{84}$ Eine Übersicht über diese Pläne findet sich bei Willgerodt et. al. (1972), Wege und Irrwege zur europäischen Währungsunion, Freiburg, S. 77-99

${ }^{85}$ Vgl. o. V., „À Venise, les ministres des finances des Six décident de s'opposer à toute modification des marges de fluctuation entre les monnaies européennes“, Le Monde vom 2.6.1970, S. 25

${ }^{86}$ Vgl. o. V., „M. Giscard d'Estaing: il est souhaitable de créer un second pôle monétaire en Europe“, Le Monde vom 30.5.1970, S. 22

${ }^{87}$ Vgl. o. V., „MM Schiller et Giscard d'Estaing s'opposent sur l'opportunité de la création d'un Fonds européen de régularisation des changes", Le Monde vom 31.5.1970, S. 21

${ }^{88}$ ebenda 
über eine gemeinsame Währungspolitik sollte ein allgemeiner Konvergenzzwang auch für die Wirtschaftspolitik der einzelnen Mitgliedstaaten erzeugt werden. Auf diese Weise hofften die Monetaristen, quasi automatisch zu einer einheitlichen Gesamtpolitik der Gemeinschaft zu gelangen, ohne dabei die Souveränität der einzelnen Staaten antasten zu müssen. ${ }^{89}$ Zur konsequenten Verringerung der Bandbreiten und deren Verteidigung bedurfte es aus französischer Sicht abgestimmter Interventionen, für die eigens ein gemeinsamer Reserve- oder Devisenausgleichsfonds geschaffen werden sollte. ${ }^{90}$ Dieser stellte aus Sicht des französischen Wirtschafts- und Finanzministers ein unverzichtbares Komplement dar und war das eigentliche Kernelement der monetaristischen Integrationsstrategie. ${ }^{91}$

Dem monetaristischem Integrationsansatz widersprachen die unter deutscher Führung stehenden „Ökonomisten“, zu denen noch Italien und die Niederlande zählten. Ihrer Meinung nach setzte die Entwicklung zu einer Wirtschafts- und Währungsunion zunächst die Überwindung der Strukturunterschiede zwischen den einzelnen Volkswirtschaften sowie die Harmonisierung der Wirtschaftspolitiken voraus, bevor in einem letzten Schritt zu einer endgültigen Festlegung der Wechselkurse übergegangen werden konnte. ${ }^{92}$ Über die Angleichung der wirtschaftlichen Strukturen sollte zunächst die Anpassung der Verhaltensweisen der Wirtschaftssubjekte sowie der wirtschaftspolitischen Zielpräferenzen herbeigeführt werden. Eine zu frühe währungspolitische Bindung ohne vorherige wirtschaftspolitische Harmonisierung war aus Sicht der „Ökonomisten" mit der ständigen Gefahr des Auseinanderbrechens der Währungsunion verbunden..$^{93}$ Außerdem befürchteten sie, daß über die Mechanismen zur gemeinschaftlichen Behebung der Zahlungsbilanzdefizite stabilitätsorientierte Länder übermäßig zu deren Finanzierung herangezogen werden könnten. Insbesondere auf seiten der Bundesrepublik bestand die Befürchtung, die Währungsreserven der Bundesbank der verfehlten Wirtschaftspolitik von Defizitländern opfern zu müssen.

Hinter diesen integrationspolitischen Ansätzen standen letztlich zwei diametral entgegengesetzte wirtschaftspolitische Auffassungen. Während die Ökonomisten das Stabilitätsziel in den Mittelpunkt ihrer Überlegungen stellten, das die Vereinheitlichung wirtschaftspolitischer Ziele und Instrumente voraussetzte, bevor einschneidende währungspolitische Konsequenzen zugelassen wurden, ging es den Monetaristen primär um die sofortige Vereinheitlichung der Währungspolitik, über die eine strukturelle und wirtschaftspolitische Anpassung quasi mechanisch herbeigeführt werden sollte. ${ }^{94}$ Die Konsequenz der monetaristischen Perspektive wäre jedoch eine Zwangsharmonisierung auf konjunkturellem Durchschnittsniveau gewesen. Für die Defizitländer hätte

${ }^{89}$ Zur Position der Monetaristen siehe Tietmeyer, H. (1971), Europäische Wirtschafts- und Währungsunion - eine politische Herausforderung, in: EA, S. 413-415, Folge 12/1971, S. 409-420

${ }^{90}$ Vgl. o.V., "MM. Schiller et Giscard d'Estaing...", a.a.O., S. 21

${ }^{91}$ Vgl. o.V., „A Venise, les ministres des finances des Six décident s'opposer à toute modification des marges de fluctuation entre les monnaies européennes", Le Monde 2.6.1970, S. 25

${ }^{92}$ Zur Position der Ökonomisten vgl. Tietmeyer, H. (1971), a.a.O., S. 413-415

${ }^{93} \mathrm{Vgl}$. Tietmeyer (1971), a.a.O., S. 414

${ }^{94}$ ebenda 
dies den Vorteil gehabt, bei der Finanzierung ihrer Zahlungsbilanzdefizite auf Gemeinschaftshilfen zurückgreifen zu können. Ohne zwingende wirtschafts- und finanzpolitische Vorgaben wäre es möglich gewesen, hohe Preissteigerungsraten ungehindert auf stabilere Volkswirtschaften zu übertragen, ohne dabei die eigenen wirtschaftlichen Schwächen direkt offenlegen zu müssen. ${ }^{95}$ Die Anpassungslast wäre so teilweise vom Verursacher genommen und durch Vergemeinschaftung gemildert worden. Allerdings wäre so auch der Konvergenzzwang herabgesetzt, der eigentlich nach monetaristischer Logik zur Behebung der strukturellen bzw. wirtschaftspolitischen Divergenzen führen sollte, was letztlich einem Widerspruch in der Argumentation der Monetaristen gleichkam.

Diese Bedenken setzten sich jedoch weder in Frankreich noch im Werner-Komitee durch. Letzteres legte im Oktober 1970 seinen Abschlußbericht vor, der den stufenweisen Übergang zu einer Wirtschafts- und Währungsunion bis 1980 vorsah. Ferner beinhaltete der Werner-Bericht einen umfangreichen Maßnahmenkatalog, der alle wesentlichen Forderungen der Monetaristen wie auch der Ökonomisten umfaßte. Als Endziel schwebte der Arbeitsgruppe eine Union vor, die durch einen völlig freien Güter-, Dienstleistungs-, Personen- und Kapitalverkehr gekennzeichnet war. Die Währungen der Mitgliedstaaten sollten in ein Paritätengitter mit irreversibel festen Wechselkursen eingebunden werden, welches, so der Werner-Bericht, logischerweise später zu einer gemeinsamen Währung führen mußte. Um den dauerhaften Zusammenhalt der Union sicherzustellen, wurde außerdem der Transfer aller „für die Verwirklichung eines gesamtwirtschaftlichen Gleichgewichts" entscheidenden wirtschafts- und währungspolitischen Kompetenzen auf Gemeinschaftsebene als notwendig erachtet. ${ }^{96}$

Der „monetaristische“ Einschlag des Werner-Berichts zeigte sich in den Maßnahmen für die erste Stufe. Auf währungspolitischem Gebiet sollte schon zu Beginn des Übergangsprozesses mit der schrittweisen Herabsetzung der Bandbreiten sowie ihrer Verteidigung durch gemeinschaftlich abgestimmte Interventionen begonnen werden. Des weiteren sollte die Gemeinschaft international eine einheitliche Währungspolitik vertreten und in internationalen Gremien mit einer Stimme sprechen. Die Koordination der Wirtschaftspolitik hingegen sollte über regelmäßige Konsultationen der Wirtschaftsminister sowie über ein "System von Gemeinschaftsindikatoren“ erfolgen. Letzteres war zur Überwachung der Konjunkturentwicklung gedacht und sollte den Mitgliedstaaten „Empfehlungen zur Orientierung der Wirtschaftspolitik“ in „detaillierter Form" geben. ${ }^{97}$ Diese Form der wirtschafts- und währungspolitischen Zusammenarbeit würde letztlich, so der Werner-Bericht, das „Ferment für die Entwicklung der politischen Union" darstellen, ohne die eine Wirtschafts- und Wäh-

\footnotetext{
${ }^{95}$ ebenda

${ }^{96}$ Vgl. Bericht einer vom Rat der Europäischen Gemeinschaften eingesetzten Arbeitsgruppe an Rat und Kommission über die stufenweise Verwirklichung der Wirtschafts- und Währungsunion in der Gemeinschaft vom 8.10.1970 (Werner-Bericht), D 532, abgedruckt in: EA, Folge 22/1970, D 531 D 546

${ }^{97}$ Vgl. Werner-Bericht, a.a.O., D $536 \mathrm{ff}$.
} 
rungsunion auf Dauer nicht bestehen könne. ${ }^{98}$ Als notwendige institutionelle Ergänzung wurde die Schaffung eines unabhängigen „wirtschaftspolitischen Entscheidungsgremiums" vorgeschlagen, das die Konjunkturpolitik und die nationalen Haushaltspolitiken koordinieren sollte, sowie die Errichtung eines ,gemeinschaftlichen Zentralbanksystems" nach dem Vorbild des Federal Reserve Systems, dem die währungspolitischen Entscheidungen über Liquidität, Zinssätze und die Kreditpolitik obliegen sollten. ${ }^{99}$

Die französische Regierung nahm den Werner-Bericht zurückhaltend auf, obwohl der französische Vertreter in der Expertengruppe ihm zugestimmt hatte. Außenminister Maurice Schumann verkündete schon kurz nach der Übergabe des Berichtes, daß dieser nicht die Meinung der jeweiligen Regierungen darstelle und daß die französische Regierung ihre Haltung erst nach einer eingehenden Prüfung bekannt geben werde. ${ }^{100}$ Schnell wurde klar, daß ihr der Werner-Bericht in seinen wirtschafts- und währungspolitischen Konsequenzen sowie in seinen zeitlichen Vorgaben zu weit ging. ${ }^{101}$ Schon im Juli 1970 hatte Georges Pompidou einzelne Elemente des Zwischenberichts des Werner-Komitees wie den Hinweis auf die einheitliche Währung abgelehnt und erklärt, daß es auf währungspolitischem Gebiet vorerst nur um eine schrittweise Annäherung sowie um ein gemeinsames Auftreten gegenüber den USA gehen könne. ${ }^{102}$ Nach der Veröffentlichung des Werner-Berichts konzentrierte sich seine Kritik vor allem auf die institutionellen Aspekte. Insbesondere die Konzentration wirtschafts- und währungspolitischer Kompetenzen in den vorgeschlagenen Gemeinschaftsinstitutionen wurde von Frankreich abgelehnt. Pompidou war der Auffassung, daß institutionelle Probleme zweckmäßigerweise erst im Augenblick der Erweiterung der Gemeinschaft angeschnitten werden könnten. ${ }^{103}$ Außenminister Schumann ergänzte diese Kritik, indem er feststellte, daß Frankreich keine „querelle théologique“ über imaginäre Endzustände einer Europäischen Wirtschafts- und Währungsunion wünsche, sondern bevorzuge, am Ende der ersten Stufe die erreichten Resultate zunächst zu beurteilen, um von dieser Basis aus die Integration fortzusetzen. ${ }^{104}$ Primär ginge darum, ein Element der Ordnung in die internationalen Währungsbeziehungen einzuführen, und es sei nichts weiter als trügerisch, für etwas, das noch zehn Jahre entfernt wäre, juristisch verbindliche Abreden treffen zu wollen. ${ }^{105}$ Letzte Unklarheiten über die französische Position

\footnotetext{
${ }^{98}$ Vgl. Werner-Bericht, a.a.O., D 532

${ }^{99}$ Vgl. Werner-Bericht, a.a.O., D $534 \mathrm{f}$.

100 Vgl. Lemaitre, P., „M. Schumann: une seule période transitoire pour les anglais“, Le Monde 28.10.1970, S. 34

${ }^{101}$ Vgl. Drouin, P., „Europe, monnaie et souveraineté“, Le Monde 24.11.1970, S. 1 und 4

102 „Ce qu'il faut, c'est d'une part, que les nations européennes, à commencer par la France, essayent ensemble de créer, non pas une monnaie unique - nous en sommes loin - mais un ensemble monétaire, une certaine union monétaire qui fasse que les pays européens puissent en quelque sorte équilibrer par leur masse économique le dollar.", so Pompidou in seiner Pressekonferenz am 2.7.1970, a.a.O., S. 31

${ }^{103} \mathrm{Vgl}$. die Verlautbarung über die Rede Pompidous vom 2.1.2.1969, a.a.O., D 42

${ }^{104}$ Vgl. die Rede Schumanns vor dem Senat vom 30.11.1970, S. 199, abgedruckt in: PE, 2. Sem. 1970, S. $197-204$

105 ebenda
} 
beseitigte Pompidou in seiner Pressekonferenz vom 21. Januar 1971, in der er ausführlich die von Frankreich angestrebte Form der Zusammenarbeit zwischen den Mitgliedstaaten darlegte. Diese umschrieb er mit dem Bild einer Koalitionsregierung, die notwendigerweise auseinanderbreche, wenn ein Mitglied in Fragen von vitalem Interesse überstimmt werde. Mit diesem Vergleich hatte er unmißverständlich klargestellt, daß Frankreich auch weiterhin nur zu einer Gemeinschaftspolitik auf der Basis intergouvernementaler Zusammenarbeit bereit war. Allen Hoffnungen auf eine institutionelle Verselbständigung des europäischen Einigungsprozesses war damit erneut ein vorläufiges Ende bereitet.

Frankreich weigerte sich, den Werner-Bericht als Grundlage der zu errichtenden Wirtschafts- und Währungsunion anzuerkennen. Die folgenden zwei Ministerratssitzungen im November und Dezember 1970, in denen über das weitere Vorgehen in dieser Sache debattiert wurde, verliefen aufgrund des Streits über die institutionelle Ausgestaltung der Union ergebnislos. ${ }^{106}$ Erst in der Ministerratssitzung vom 9. Februar 1971 konnte man sich auf einen Kompromiß einigen, der die restriktive Haltung Frankreichs hinreichend berücksichtigte, in wichtigen institutionellen und politischen Fragen aber weit hinter dem Werner-Bericht zurück blieb. ${ }^{107}$ Wohl wurde die Stufenfolge des Zeitplans bis 1980 und die Definition des Endzustandes der Wirtschafts- und Währungsunion übernommen, zu den politischen Konsequenzen der wirtschaftlichen Integration sowie zur Ausgestaltung der zweiten und dritten Stufe fehlten jedoch präzise Aussagen. ${ }^{108}$ Auf institutioneller Ebene wurde zwar noch von einem gemeinschaftlichen Zentralbankensystem sowie von Organen gesprochen, die die erforderlichen Befugnisse zur Führung der Union erhalten sollten. Diese Ausführungen blieben im weiteren jedoch unbestimmt wie auch die Ausführungen zur Kontrolle der Gemeinschaftspolitik durch das Europäische Parlament. ${ }^{109}$

Konkreter indessen waren die Bestimmungen zur gemeinsamen Währungspolitik. Beschlossen wurde, in Währungsbeziehungen zu Drittländern schrittweise einen gemeinsamen Standpunkt einzunehmen sowie von keiner Vorschrift Gebrauch zu machen, die zu einer Auflockerung des internationalen Wechselkurssystems führen würde. Durch abgestimmte Aktionen gegenüber dem Dollar sollten die Wechselkursschwankungen zwischen den Gemeinschaftswährungen versuchsweise innerhalb engerer Bandbreiten gehalten werden. Die dabei gemachten Erfahrungen sollten als Grundlage für Interventionen in Gemeinschaftswährungen sowie für eine weitere Verringerung der Bandbreiten dienen. Bis zum 30. Juni 1972 war ferner ein Bericht über die Errichtung, die Aufgaben und die Satzung eines „Europäischen Fonds für Währungspolitische Zu-

\footnotetext{
${ }^{106} \mathrm{Vgl}$. Fabra, P., „Les Six n'ont pu s'entendre sur les institutions de l'union économique et monétaire", Le Monde 16.12.1970, S. 1 und 38

${ }^{107} \mathrm{Vgl}$. Tietmeyer (1971), a.a.O., S. $418 \mathrm{f}$.

${ }^{108} \mathrm{Vgl}$. Entschließung des Rates der Europäischen Gemeinschaften und der Vertreter der Regierungen der Mitgliedstaaten vom 9.2.1971 über die stufenweise Verwirklichung der Wirtschafts- und Währungsunion, abgedruckt in: EA, Folge 6 (1971), D $140 \mathrm{ff}$.

${ }^{109} \mathrm{Vgl}$. Ratsentscheidung vom 9.2.1971, a.a.O., D $140 \mathrm{f}$.
} 
sammenarbeit" (EFWZ) vorzulegen. ${ }^{110}$ Frankreich konnte mit diesen Bestimmungen seine Kernforderungen als durchgesetzt betrachten. Einzig die Befristung der Geltungsdauer dieser Bestimmungen bis zum Übergang zur zweiten Stufe oder auf maximal fünf Jahre, die auf deutsches Drängen aufgenommen wurde, mußte akzeptiert werden. Seitens der Ökonomisten versuchte man so, einen Rest an Parallelität von wirtschafts- und währungspolitischer Entwicklung sicherzustellen, was im Verhältnis zu den Konzessionen an Frankreich jedoch nur einen geringen Erfolg darstellte. ${ }^{111}$

Die Ratsentscheidung, zusammen mit dem ebenfalls am 9. Februar 1971 beschlossenen mittelfristigen Beistandsmechanismus, hatte zur Folge, daß Frankreich wesentliche Elemente der monetaristischen Integrationskonzeption und seiner europapolitischen Zielsetzung als verwirklicht ansehen konnte. Hartnäckiges Verhandeln bescherte ihm eineinhalb Jahre nach der "relance" des Integrationsprozesses ein Europa, dessen Entwicklung sich in Richtung des „Europe européenne“ fortsetzte, ohne daß es zu substantiellen Eingriffen in die Souveränität der Mitgliedstaaten kam. Auch kam der beschlossene Ansatz zur Fortführung der Integration den bisherigen ordnungspolitischen Vorstellungen Frankreichs entgegen. Die gemeinschaftliche Fixierung von Wechselkursen und deren konzertierte Verteidigung über gemeinsame Interventionen hätten die Währungsentwicklung weitgehend zum Gegenstand der politischen Zusammenarbeit gemacht. Insgesamt wäre es damit zu einer umfassenden Politisierung des gesamteuropäischen Wirtschaftsprozesses gekommen wie sie von Frankreich schon seit Beginn der europäischen Einigung angestrebt wurde.

\section{B. 3.3 Die Wirtschaftspolitik B.3.3.1 Die Industriepolitik}

Parallel zur Ankündigung, Frankreich zu einem modernen Industriestaat zu machen, setzte sich die französische Regierung im Rahmen ihrer Forderung nach „Vertiefung“ der Gemeinschaft für eine europäische Industriepolitik ein. Beides stand für Präsident Pompidou in enger Verbindung, da sein Vorhaben, der französischen Industrie „internationale Dimensionen“ zu geben, vor allem auf die Vergrößerung der Unternehmenseinheiten abzielte, die wiederum vorzugsweise durch Kooperationen und Fusionen auf europäischer Ebene erreicht werden sollte. ${ }^{112}$ Was in der französischen Europapolitik unter dem Siegel „Vertiefung“ firmierte, war von Anfang an auch Bestandteil der nationalen Strategie zur Industrieförderung. Im Gegensatz zu dem vagen industriepolitischen Konzept unter de Gaulle sprach die französische Regierung unter Pompidou erstmals klar von einer „europäischen Industriepolitik“:

\footnotetext{
${ }^{110}$ Vgl. Ratsentschließung vom 9.2.1971, a.a.O., D 143

111 Vgl. Scharrer, H.-E. (1973), Europäische Wirtschafts- und Währungsunion - Pragmatismus ohne politisches Konzept, in Scharrer, H. E. und Wessels, W. (Hrsg.), Europäische Wirtschaftspolitik Programm und Realität, Bonn, S. 81-158, S. 98

112 Vgl. Pompidous Ausführungen auf der Pressekonferenz vom 10.7.1969, a.a.O., S. 46
} 
"Das Eigentümliche jedes gemeinschaftlichen Lebens ist - durch seine innere Logik -, entweder zur Verkümmerung verdammt oder aber zur Vertiefung bestimmt zu sein. Schon der Erfolg der "ersten Generation" wirft die Probleme der "zweiten Generation" auf. Man kann keinen wirklichen gemeinsamen Industriemarkt in der Gemeinschaft schaffen, ohne die Ungleichheit der Produktions- und Verkaufsbedingungen zu verringern. Sie werden uns also nicht nur hinsichtlich der Koordinierung und Harmonisierung der Wirtschaftspolitiken in ihrer ganzen Vielfältigkeit aufgeschlossen sehen, sondern uns immer bemüht finden, eine wirkliche Industriepolitik in der Gemeinschaft festzulegen und in die Tat umzusetzen."“113

Die Definition dessen, was konkret unter einer solchen Politik zu verstehen war, blieb die französische Regierung zunächst jedoch schuldig. Im nationalen Rahmen ging es dem Präsidenten bei der „Industriepolitik“ vorrangig darum, den Strukturwandel bzw. die „notwendigen Veränderungen“" in Sektoren wie der Landwirtschaft, des Handels und - aus Sicht Pompidous von besonderer Bedeutung - im Bereich des Sozialen sicherzustellen. ${ }^{114}$ Um eine "solide Basis" für die nationale Unabhängigkeit zu haben, waren für ihn eine starke (puissante) Wirtschaft und insbesondere eine leistungsfähige Industrie unabdingbar. ${ }^{115}$ Außenminister Schumann betonte im Zusammenhang mit der von Frankreich gewünschten europäischen „Industriepolitik“ die Notwendigkeit eines „wirklichen gemeinsamen Industriemarkts“, der die Reduzierung der Unterschiede in den Produktions- und Verkaufsbedingungen voraussetzte - eine Formel, die Frankreich schon in den Verhandlungen zu den Römischen Verträgen benutzt hatte. Dazu waren die Wirtschaftspolitik eng zu koordinieren und zu harmonisieren, Unternehmenszusammenlegungen zu fördern sowie die wissenschaftliche Forschung zu unterstützen. ${ }^{116}$ Jean Bernard Esambert, industriepolitischer Berater Pompidous, definierte „Industriepolitik“ indessen über ihre Inhalte. Als Hauptbestandteile betrachtete er die Wettbewerbspolitik im Sinne der Förderung von Unternehmensfusionen, die Handelspolitik, die Investitionspolitik im Sinne einer expansiven europäischen Investitionsstrategie in Drittländern, die Bildungspolitik sowie die Forschungspolitik. ${ }^{117}$ Die Heterogenität dieser Definitionsansätze zeigte, daß sich hinter der französischen Auffassung von "Industriepolitik“ kein fest umrissenes Konzept verbarg. Vielmehr schien alles, was mit der Bewältigung von Strukturwandel und einer verbesserten industriellen Wettbewerbsfähigkeit zu tun hatte, Industriepolitik zu sein.

Bei der Industriepolitik ging es aus französischer Sicht in erster Linie darum, die Wirtschaftsentwicklung stärker an politischen Zielvorgaben auszurichten. Das Hauptziel lag im Zuwachs an Wirtschaftskraft, der zur Absicherung der für Frankreich so bedeutsamen Unabhängigkeit notwendig war. Die von Frankreich geforderte europäische Industriepolitik begründete Außenminister Schumann mit der Notwendigkeit, den „Rang“ Europas in der Welt verteidigen zu müssen. ${ }^{118}$ Staatspräsident Pompidou wies

${ }^{113}$ Rede Außenminister Schumanns im Rat der EG am 22.7.1969, a.a.O., D 421

${ }_{114}^{114} \mathrm{Vgl}$. Pompidous Ausführungen auf der Pressekonferenz vom 10.7.1969, a.a.O., S. 46

${ }^{115}$ ebenda, S. 45

${ }^{116}$ Vgl. die Rede Schumanns vom 4.11.1969, a.a.O., S. 112

${ }_{117}^{117}$ Vgl. Esambert (1994), a.a.O., S. 45

118 „Il s'agissait d'une part de donner à la Communauté les moyens de la politique industrielle et technologique qui seule peut lui permettre de tenir son rang, demain, à la pointe des nations avancées, 
auf den aus seiner Sicht bestehenden direkten Zusammenhang zwischen politischer Selbständigkeit und industrieller Leistungsfähigkeit hin, der, mit Blick auf die wirtschaftlich führenden USA, eine intensivere wirtschaftspolitische Zusammenarbeit der europäischen Partner zwingend erforderlich machte:

"Nous mesurons également chaque jour la nécessité dans laquelle se trouve l'Europe de se doter d'une politique cohérente dans les différentes domaines qui touchent à l'économie, qu'il s'agisse de l'énergie, des transports, du droit des sociétés, des industries de pointe... Seuls des progrès dans tous ces domaines permettront à l'Europe de se doter d'une puissance industrielle, scientifique et technique qui la mette à parité avec les États Unis d'Amérique et lui donne les moyens de son indépendance. C'est par un effort constant et quotidien, non par des déclarations d'intention, fussent-elles fracassantes, que l'on construira vraiment l'Europe et qu'on lui permettra ainsi d'accéder à la personnalité politique"119.

Die europäische Industriepolitik als Mittel der europäischen Unabhängigkeit war in ihrer Konzeption dem nachempfunden, was Frankreich auf nationaler Ebene praktizierte. Ihre Letztbegründung war politischer Machtgewinn, der wiederum der Erreichung höherer Ziele diente, welche im Falle Frankreichs, so Bernard Esambert, direkt mit der Verbreitung seiner zivilisatorischen Sendung zusammenhingen. ${ }^{120}$ Das persönliche Engagement Pompidous, der die Industriepolitik neben der Außenpolitik als seine zweite „domaine réservé" betrachtete, zeigte den zentralen Stellenwert dieses Politikbereichs, in dem gesellschaftspolitisches Wollen und wirtschaftspolitisches Können in eine direkte Verbindung gebracht wurden.

Auf die mit der Industriepolitik unmittelbar verbundene Frage nach dem Verhältnis von staatlicher Intervention und marktlicher Koordination hatte Georges Pompidou schon als Premierminister eine ausführliche Antwort gegeben. Den Wettbewerb stufte er grundsätzlich als ein „gesundes Phänomen“ ein, wie er im Juni 1964 in einem Gespräch mit Unternehmern bekannte. Er wirke wie ein Medikament, das, gut dosiert, eine kräftigende Wirkung habe, in Überdosen jedoch gefährlich sei. ${ }^{121}$ Der Staat sollte sich nach Möglichkeit mit Interventionen in Wirtschaftsabläufe zurückhalten und aktiv geführten Privatunternehmen das Feld überlassen. ${ }^{122}$ Als Vertreter des Allgemeininteresses (intérêt générale) hatte er jedoch selbstverständlich Vorrang in allen Fragen und darüber hinaus die Aufgabe, die Bürger gegen das „Recht des Stärkeren“ bzw. das „,des

et d'autre part, de développer, entre les Six, l'union économique et monétaire qui est le prolongement et le complément de l'union douanière.", so Außenminister Schumann in seiner Rede vom 30.11.1970, a.a.O., S. 196

${ }^{119}$ Interview Pompidous mit EPOCA vom 9.2.1972, a.a.O., S. 97

120 „Conserver dans la société internationale la spécificité de notre influence implique la définition d'une stratégie industrielle ... C'est par le développement de son industrie que la France confortera sa capacité d'agir dans le monde, l'indépendance de ses vues, l'influence de sa culture", so Esambert in: ders. (1994), a.a.O., S. 23f.

${ }^{121} \mathrm{Vgl}$. das Gespräch Pompidous mit den Chefs von 19 französischer Großunternehmen in: EXPANSION, No. 458 vom 20.6.1964, zit. n. TEXTES et NOTES, vom 11.7.1964, S. 6

${ }^{122} \mathrm{Vgl}$. Pompidou (1974), a.a.O., S. 139 f. 
Dschungels“ zu schützen. ${ }^{123}$ Übertragen auf den Bereich der Wirtschaft erwuchs ihm daraus die Pflicht, aktiv zu sein und ihre Entwicklung zu orientieren: „, il faut insister sur le rôle actif et déterminant de l'Etat qui ne peut s'en remettre au jeu des lois économiques“. ${ }^{124}$ Die Hauptaufgaben des Staates lagen für Pompidou in der Festlegung der „großen Perspektiven“ sowie in der „Ausrichtung der Aktivitäten“: „Je crois enfin que c'est à lui seul, qu'il revient d'établir l'équilibre entre expansion nécéssaire et la stabilité non moins nécéssaire “125. Das dem Staat natürlich gegebene Recht zu Eingriffen in den Wirtschaftsablauf brachte mit sich, daß er dabei bestimmten Sektoren Priorität einräumen mußte. Aus Sicht des damaligen Premierministers Pompidou lag das Interventionsrecht des Staates überdies allgemein in seiner sozialen Verantwortung sowie in seiner Verantwortung als ,erster Patron“ begründet. Diese Feststellungen zeigen, daß Pompidou schon unter de Gaulle im Hinblick auf die Lenkung des Wirtschaftsablaufs ein klarer Verfechter interventionistischer Vorstellungen war.

Das geeignete Mittel zur Wahrnehmung der wirtschaftspolitischen Kompetenzen des Staates sah Pompidou ebenfalls wie de Gaulle in der Planification. ${ }^{126}$ Sie hatte als indikatives Steuerungsinstrument zu dienen, das den Wirtschaftssubjekten Vertrauen in die zukünftige Entwicklung einflößen sollte. ${ }^{127}$ Die Hauptfunktion der Planification, so Pompidou, lag in der Bestimmung der Prioritäten staatlichen Handelns, in der Ordnung seiner Investitionen sowie in der Steuerung des sektoralen Strukturwandels. ${ }^{128}$ All diese Aktivitäten könnten nur durch eine aktiv orientierende Planung effizient koordiniert und durchgeführt werden. Von einer Übertragung der Planification auf europäische Ebene allerdings sah man in Frankreich nach dem Debakel um die ,mittelfristige Programmierung" der europäischen Wirtschaft ab. Allenfalls im Vorschlag, über regelmäßige Treffen der Finanzminister die "Expansion unserer Wirtschaft" und die „Harmonisierung unserer Wachstumsraten" sicherzustellen, den Pompidou im Dezember 1969 auf der Konferenz von Den Haag machte, ließ sich noch ein gewisses Nachwirken planifikatorischer Vorstellungen erkennen. ${ }^{129}$ Die von Frankreich favorisierte europäische Industriepolitik ließ sich jedoch bei genauerem Hinsehen als sektorale Fortführung planifikatorischer Ordnungsvorstellungen auffassen, die auf die Gemeinschaft übertragen werden sollten.

$123, \ldots . . l^{\prime} E t a t$ n'est, dans un pays démocratique, rien d'autre que l'émanation de l'ensemble de ces citoyens contre la loi du plus fort, celle de la jungle où, précisément, il n'y a pas d'Etat", so Pompidou in seiner Neujahrsansprache am 1.1.1971, zit. n. Cousté (1974), a.a.O., S. 27

${ }^{124}$ Gespräch mit 19 Unternehmensführern vom 20.6.1964, a.a.O., S. 27

${ }^{125}$ ebenda, S. 29

126 „Pompidou ne méprisait pas la planification“, so Esambert (1994), a.a.O., S. 25

127 "Le Plan doit être volontariste. Il faut donner une impression de volonté, de progrès, d'expansion, que les Français aient l'impression qu'on les entraîne, qu'on les pousse en avant ... Mais il faut éviter des objectifs trop précis dans le détail, ouvrir l'éventail, fixer les directions, les axes de l'action, les volontés, montrer les nécessités. La tonalité du VI ${ }^{\mathrm{e}}$ Plan doit être celle d'une volonté optimiste de progrès“, so Pompidou in einer Ministerratssitzung zur Verabschiedung des VI. Plans, zit. n. Esambert (1994), a.a.O., S. 56 f.

${ }^{128}$ Pompidou (1974), a.a.O., S. 128-131

${ }^{129}$ Vgl. die Ansprache Pompidous vom 2.12.1969, a.a.O., D 41 
Trotz aller Bemühungen des Staates, die Wirtschaftsentwicklung „richtig“ zu orientieren, war, so Pompidou, der Privatinitiative ein weites Feld einzuräumen: „Son action doit permettre de conjuger les bienfaits d'une planification souple et des initiatives in-

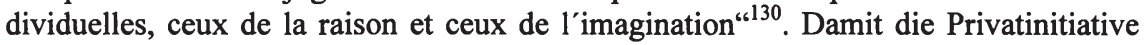
ihre Vorteile voll entfalten könne, sollten die Unternehmensführer mutig nach vorn schauen (,voir grand!“), die Wettbewerbsfähigkeit anstreben, permanent innovieren, nach rationaler Führung und Vergrößerung streben sowie die Auslandsmärkte zu erobern suchen. Während die Rolle des Staates für die Wirtschaft eine herausragende war (capitale), sei die der privaten Initiative die wesentliche. ${ }^{131}$ Die Grenzen unternehmerischer Initiative zog Pompidou, indem er auf die Verantwortung der Unternehmer dem Allgemeininteresse gegenüber hinwies. ${ }^{132}$ Seine Auffassung von der Privatinitiative relativierte er zusätzlich, indem er feststellte, daß die Privatinitiative für die Dynamik der Wirtschaft zu sorgen hätte, während es dem Staat obliege, die Leitlinien der Entwicklung zu bestimmen und diese zu kontrollieren:

„Mais je considère qu'il a intérêt à ramener dès que possible son rôle au minimum qui est de définir la ligne générale et de contrôler l'évolution. Quant au dynamisme, nous l'attendons et sommes en droit de l'attendre de l'initiative privée. Nous l'attendons surtout des chefs d'entreprise. J'ajoute que l'action de $\mathrm{l}^{\prime}$ Etat est toujours prête à épauler et à étayer le dynamisme, et non à l'enrayer“"133 .

Durch die Vorgabe der Richtung und die Kontrolle des Fortschritts war es letztlich doch der Staat, der die Koordination der Wirtschaftsabläufe bestimmte bzw. zu intervenieren hatte, wenn ihm Richtung und Geschwindigkeit der Wirtschaftsentwicklung nicht paßten. Als Hüter des Allgemeininteresses residierte er oberhalb des Theaters der Wirtschaft, in das einzugreifen war, wenn die Akteure dem Spielplan nicht folgten. Seine herausgehobene Position verlieh ihm dazu alle Rechte und die Industriepolitik die Mittel. Frankreichs nationale Industriepolitik unter Pompidou zeugte von reichhaltigen interventionistischen Lenkungsbemühungen, was die Fusion von Großunternehmen sowie industrielle Großprojekte anging. ${ }^{134}$ Auf europäischer Ebene fanden sich entsprechende Ansätze schon im ersten Appell Pompidous zur Vertiefung der Gemeinschaft, den er kurz nach seiner Wahl zum Staatspräsidenten an die Mitgliedstaaten richtete:

"...nous souhaitons, précisément parce que nous croyons que l'Europe doit être une réalité, que l'on approfondisse la notion européenne, c'est-à-dire qu'on fasse progresser la Communauté, pour en faire une véritable Communauté. A l'heure actuelle, il n'y a en réalié qu'une union douanière d'une part, et une communauté agricole assez difficile à faire fonctionner d'autre part. Il est de très nombreux domaines dans lesquels des progrès importants pourraient être réalisés, que ce soit techniques, scientifiques, qu'il s'agisse d'énergie, de transports, du droit des sociétés - ce qui est très important - ou en-

${ }^{130}$ Gespräch mit Unternehmensführern vom 20.6.1964, a.a.O., S. 29

131 ebenda

132 „Il faut que les Chefs des grandes entreprises comprennent que si l'Etat considère l'entreprise privée comme utile à l'intérêt général, en contrepartie eux ne doivent pas perdre de vue cet intérêt", Pompidou (1974), a.a.O., S. 143

${ }^{133}$ Gespräch mit 19 Unternehmensführern vom 20.6 1964, a.a.O., S. 36

${ }^{134}$ Detailliert beschrieben bei Esambert (1994) 
core de la politique financière et monétaire. Je trouverais mille autres domaines où il faudrait avancer très sérieusement si l'on voulait aboutir à une véritable communauté économique, c'est -à-dire à un ensemble économique qui forme véritablement un tout" ${ }^{\prime 135}$.

Diese umfassende Aufzählung von Aktionsfeldern wurde von Außenminister Schumann in seiner ersten Ansprache im Ministerrat, in der er die neue französische Europapolitik erläuterte, unter dem Begriff "europäische Industriepolitik" zusammengefaßt und später durch weitere Konkretisierungen ergänzt. In diesem Zusammenhang sprach er die Kooperation in der Nuklearforschung und auf dem Gebiet der Informationstechnologie an, die auch eine Zusammenarbeit mit Drittländern nicht ausschließen sollte. Des weiteren wies er auf die Notwendigkeit hin, finanzielle und juristische Hindernisse für die Fusion von Unternehmen sowie technische Hindernisse für den Warenaustausch zu beseitigen. ${ }^{136}$

Auf der Konferenz von Den Haag nahm Staatspräsident Pompidou diese Vorschläge noch einmal auf und erklärte, daß man eine Übersicht aller nationalen industriepolitischen Aktivitäten erstellen müsse, um durch politische Entscheidungen zu schnellen Entschlüssen auf Unternehmensebene zu kommen, statt endlos Zeit mit Expertendiskussionen $\mathrm{zu}$ verlieren. ${ }^{137}$ Wie schon mit seinen industriepolitischen Vorschlägen von 1965 und 1968 versuchte Frankreich erneut, seine Partner zu einem pragmatischen Vorgehen im Bereich der Wirtschaftsförderung zu bewegen. Wieder sollte, ausgehend von einer Gesamtübersicht der nationalen Anstrengungen und einer darauf aufbauenden Koordination der nationalen Fördermaßnahmen, unverzüglich zu politischen Entscheidungen auf europäischer Ebene übergegangen werden, um die Weichen für die zukünftige Wirtschaftsentwicklung zu stellen.

In diesem Zusammenhang forderte Staatspräsident Pompidou außerdem, die Sozialpolitik der Mitgliedstaaten besser abzustimmen. Wie gut dreizehn Jahre zuvor in den Verhandlungen zum EWG-Vertrag versuchte Frankreich abermals eine direkte Verbindung von Wachstums- und Sozialpolitik auf europäischer Ebene herzustellen. Konkret sprach der französische Präsident dabei die Reform des Europäischen Sozialfonds an, der bislang ein Schattendasein als Mittel zur Umverteilung von Geldern für die Berufsausbildung fristete. ${ }^{138}$ Das Ergebnis all dieser Bemühungen blieb jedoch zunächst mager. ${ }^{139}$ Im Kommuniqué der Konferenz von Den Haag "bekräftigten" die Sechs "ihren Willen" zur Intensivierung der Zusammenarbeit in der Hochtechnologiefor-

\footnotetext{
${ }^{135}$ Pompidou auf der Pressekonferenz vom 10.7.1969, a.a.O., S. 42

${ }^{136}$ Vgl. die Ansprachen Schumanns vor dem Ministerrat vom 22.7.1969, a.a.O., D 421 sowie die Rede vor der Nationalversammlung vom 4.11.1969, a.a.O., S. 112

${ }^{137}$ Ansprache Pompidous vom 2.12.1969, a.a.O., D 41

${ }^{138}$ ebenda

${ }^{139} \mathrm{Vgl}$. Lemaitre, P., "Les propositions françaises de coopération industrielle et scientifique", in: Le Monde, 4.12.1969, S. 2
} 
schung und gaben ihrer Ansicht Ausdruck, daß sie eine Reform des Sozialfonds im Rahmen einer weitgehenden Abstimmung der Sozialpolitik "für angebracht" hielten. ${ }^{140}$

Angesichts dieses enttäuschenden Ergebnisses verstärkte die französische Regierung ihre Bemühungen, indem sie sich am 20. März 1970 mit einem Memorandum zur Industriepolitik an die Partnerstaaten wandte. Darin forderte sie, die Voraussetzungen für die Einführung einer "wirklichen Industriepolitik" auf europäischer Ebene zu schaffen. ${ }^{141}$ Es folgte ein vollständiger Überblick über die aus französischer Sicht als notwendig erachteten Maßnahmen, die neben der Sozial- zusätzlich noch die Währungspolitik umfaßten. Außerdem wurde die Realisierung konkreter Projekte mit Symbolfunktion gefordert, die als Zukunftsträger und "Schlüssel" einer "wirklichen Unabhängigkeit" Europas dienen sollten: ${ }^{142}$

"Vor allem aber auf den Gebieten der Wachstumsindustrien, also in den zukunftsweisenden Bereichen, braucht Europa echte Symbole in Form von gemeinschaftlichen Unternehmungen. Ein Schnellbrüter mit 1000 Megawatt, ein Riesen-Elektronenrechner, eine Isotopentrennanlage, welche die beiden Techniken der Gasdiffusion und des Gaszentrifugenverfahrens vereinigt: das sind die Leitbilder, die wir der Generation vorschlagen müssen, welche auf das Jahr 2000 zugeht und es erleben wird." 143

Weiter wurde auf die Notwendigkeit einer gemeinsamen Politik auf dem Steuersektor hingewiesen, die Konzertierung bei der Vergabe öffentlicher Aufträge vorgeschlagen, die Förderung von Unternehmenszusammenlegungen gefordert sowie allgemein eine gemeinsame Investitionspolitik empfohlen. ${ }^{144}$ Letztere sollte die Ansiedlung europäischer Unternehmen im Ausland sowie eine gemeinsame Haltung gegenüber ausländischen Investitionen innerhalb Europas umfassen. Von Direktinvestitionen in der Gemeinschaft schien aus französischer Sicht immer noch eine gewisse Bedrohung auszugehen. Die Begründung der restriktiven Haltung Frankreichs in dieser Frage ließ sich Äußerungen Staatspräsident Pompidous entnehmen, auf dessen persönliches Eingreifen im Februar 1970 die Übernahme des französischen Technologiekonzerns JeumontSchneider durch das amerikanische Unternehmen Westinghouse unterbunden wurde. Er erklärte seine Entscheidung mit der hohen Bedeutung der Spitzentechnologie für den gerade angelaufenen und überlebensnotwendigen Transformationsproze $\beta$ der französischen Industrie:

"L'Etat ne peut donc pas s'en désintéresser. Il doit aider et inciter à la concentration et il doit, dans cette période de mutation, protéger. C'est pourquoi, nous sommes entièrement ouverts à

${ }^{140} \mathrm{Vgl}$. Kommuniqué der Konferenz von Den Haag, a.a.O., D $42 \mathrm{f}$.

${ }^{141}$ Das Memorandum vom 20.3.1970 ist leider nicht öffentlich zugänglich. Die Angaben zu seinen Inhalten sind den Äußerungen Außenminister Schumanns nach seiner Hinterlegung entnommen, Vgl. dazu die Stellungnahmen Schumanns zur europäischen Industriepolitik in seinen Reden vom 28.4.1970, a.a.O., D 255, vom 30.11.1970, a.a.O., S. 196 sowie vom 23.6.1970, a.a.O., S. 191

${ }^{142}$ Vgl. die Rede Schumanns vom 23.6.1970 vor der Nationalversammlung, abgedruckt in: PE, S. 191, 2. Sem., S. $187 \mathrm{ff}$

${ }^{143}$ Rede Schumanns am 28.4.1970, a.a.O., D 255

${ }^{144} \mathrm{Vgl}$. dazu die Stellungnahmen Schumanns zur europäischen Industriepolitik in seinen Reden vom 28.4.1970, a.a.O., D 255, vom 30.11.1970, a.a.O., S. 196 sowie vom 23.6.1970, a.a.O., S. 191 
l'implantation en France d'affaires américaines, mais nous adoptons une attitude sélective devant les prises de contrôle d'affaires françaises par des groupes étrangers, quels qu'ils soient... nous cherchons à ce que ce genre d'opérations ne contrarie pas les concentrations préalables, purement nationales et nous tenons enfin à ce que ces prises de contrôle, lorsqu'elles ont lieu, s'accompagent d'un enrichissement réel de notre économie, notamment sur le plan de la recherche et de la prospection du marché européen tout entier. C'est dans cet esprit que j'ai été conduit à m'opposer à l'achat par Westinghouse de Jeumont-Schneider..."145.

Diese Stellungnahme zeigte, daß Direktinvestitionen nach französischer Auffassung weiter unmittelbar mit Souveränitätsüberlegungen verbunden waren. Die Identität dieser Stellungnahme Pompidous mit der 1963 von Giscard d'Estaing geforderten gemeinschaftlichen Kontrolle von Direktinvestitionen legt die Vermutung nahe, daß die sieben Jahre später von Frankreich geforderte gemeinschaftliche Investitionspolitik kaum anders ausgesehen hätte, zumal sich eine starke europäische Industriemacht aus französischer Sicht in erster Linie immer noch durch ihre Unabhängigkeit von den USA auszeichnete.

Das französische Memorandum zur Industriepolitik blieb am Ende ein erfolgloser Vorstoß. Nachdem die Kommission fast zeitgleich ein eigenes, inhaltlich ähnliches Memorandum zur Industriepolitik vorgelegt hatte, wurde eine Arbeitsgruppe eingesetzt, die konkrete Möglichkeiten einer intensiveren industriepolitischen Zusammenarbeit auf europäischer Ebene eruieren sollte. Ihr Elan erlahmte jedoch schon im Verlauf des Jahres 1971, da die liberale Haltung der deutschen Seite nicht mit einer interventionistischen Konzeption zu vereinbaren war, wie sie Frankreich auf dem Gebiet der Industriepolitik vertrat. ${ }^{146}$ Pompidou wiederholte auf dem Gipfel von Paris deshalb noch einmal die französischen Forderungen zur europäischen Industriepolitik. ${ }^{147}$ Schließlich einigte man sich darauf, auf dem Sektor der Wissenschafts- und Technologiepolitik bis zum 1. Januar 1974 ein Arbeitsprogramm zu verabschieden. Die praktischen Ergebnisse dieses Beschlusses waren jedoch bescheiden. Der neu gegründete Ausschuß für wissenschaftliche und technologische Forschung, der die nationalen Politiken analysieren und Empfehlungen aussprechen sollte, konnte aufgrund von Meinungsverschiedenheiten zwischen den Mitgliedstaaten nicht eindeutig dem Rat oder der Kommission zugeordnet werden. Seine Kompetenzen bei der Vorbereitung von Ratsentscheidungen blieben unklar, was sich negativ auf seine Handlungsfähigkeit auswirkte. ${ }^{148}$

Ursache für dieses Problem war das französische Bemühen in der entscheidenden Ministerratssitzung im November 1973, die Europäische Kommission aus der Definition gemeinsamer industriepolitischer Aktionen herauszuhalten. Frankreich zog in diesem

${ }^{145}$ Ansprache Pompidous auf einem Essen zu seinen Ehren am 2.3.1970, abgedruckt in: PE, S. 85, 1. Sem., S. 83-86; ebenso auf der Pressekonferenz im NATIONAL PRESS CLUB am 24.2.1970, a.a.O., S. 62

${ }^{146}$ Vgl. Gerbet, P. (1971), Les communautés européennes après La Haye, S. 314, in Revue Française de Science Politique, vol. 21, no. 6, sowie Esambert (1994), a.a.O, S. 156

${ }^{147} \mathrm{Vgl}$. die Ausführungen Pompidous in seiner Rede vom 19.10.1972, a.a.O., S. 106

${ }^{148}$ Vgl. Menniken, J.-B., Das Aktionsprogramm der Europäischen Gemeinschaften für die Wissenschafts- und Technologiepolitik, S. 399, in: EA, Folge 10/1974, S. 335-344 
Bereich weiter vor, auf konkrete Einzelaktionen zu bauen, die nur von interessierten Mitgliedstaaten durchgeführt und von den Regierungen selbst auf intergouvernementaler Ebene koordiniert werden sollten. Im diesem Sinne versuchte es auch zu verhindern, daß die Technologiepolitik über Artikel 235 und 236 EWGV in den Rang einer offiziellen Gemeinschaftspolitik erhoben wurde, womit sie der ausschließlichen $\mathrm{Zu}$ ständigkeit der Mitgliedstaaten entzogen worden wäre. ${ }^{149}$

Zusammenfassend betrachtet zielte die von Frankreich angestrebte europäische Industriepolitik in erster Linie auf die Schaffung eines machtvollen und souveränen Europas, das aufgrund seiner Wirtschaftskraft zu einer unabhängigen Politik fähig sein sollte. Gleichzeitig achtete Frankreich darauf, seine eigene Unabhängigkeit zu wahren, indem es verhinderte, daß die Industriepolitik formal zu einer Gemeinschaftspolitik wurde, die dann möglicherweise Mehrheitsentscheidungen und dem Einfluß der Europäischen Kommission ausgesetzt gewesen wäre. Die konkreten Vorschläge auf dem Sektor der Technologiepolitik sowie zur direkten Unternehmens- und Investitionsförderung verdeutlichen, daß es sich bei der von Frankreich gewünschten Industriepolitik um eine interventionistische Konzeption handelte, bei der es vor allem darum ging, durch selektive Förderung gezielt ausgesuchter Wirtschaftssektoren die Gesamtentwicklung in eine politisch gewünschte Richtung zu lenken. Ordnungspolitisch betrachtet stand der französische Politikentwurf zur bewußten Gestaltung der Wirtschaftsentwicklung im Widerspruch zu den Erfordernissen einer Wettbewerbsordnung. Dementsprechend scheiterte er zunächst am Widerstand liberal gesinnter Mitgliedstaaten.

\section{B.3.3.2 Die Sozialpolitik}

Eng angelehnt an die industriepolitischen Bemühungen Frankreichs waren jene auf dem Gebiet der Sozialpolitik. Nach einem zögerlichen Anlauf auf dem Gipfel von Den Haag machte Staatspräsident Pompidou die gemeinsame Sozialpolitik im Oktober 1972 zu einem Schwerpunkt des Gipfels von Paris. Auf diesem stellte er grundsätzlich fest, daß wirtschaftlicher Fortschritt ohne sozialen Fortschritt sinnlos sei. Im Hinblick auf die Europäische Gemeinschaft forderte er, daß diese mehr sein müsse, als nur eine "Gemeinschaft der Kaufleute". Europa trage auch soziale Verantwortung und müsse von daher ein "Modell des sozialen Fortschritts" sein, das "im Dienste des Menschen" zu stehen habe. ${ }^{150}$ Frankreich legte diesbezüglich konkrete Vorschläge vor, die den Staats- und Regierungschefs von Premierminister Pierre Messmer erläutert wurden. Da die sozialen Effekte des Wirtschaftswachstums, so Messmer, oft nicht in hinreichendem Maß berücksichtigt würden, müßten in Zukunft das Wachstum "humanisiert", seine Früchte "gerechter" verteilt und die Arbeitsbedingungen verbessert werden. ${ }^{151}$

${ }^{149}$ Vgl. Touscoz (1975), a.a.O., S. $635 \mathrm{ff}$.

${ }^{150}$ Vgl. die Ansprache Pompidous vom 19.10.1970, a.a.O., S. 106 und 107

${ }^{151}$ Elles s'inspirent toutes de notre volonté d'humaniser la croissance économique, de promouvoir une plus juste répartition de ses fruits, d'améliorer les conditions de travail et d'existence, et de passer 
$\mathrm{Zu}$ diesem Zweck sollte die Gemeinschaft eine gemeinsame Vollbeschäftigungs- und Berufsbildungspolitik sowie eine gemeinsame Politik zur Verbesserung der Arbeitsbedingungen anstreben, damit für jeden Bürger eine seinen Fähigkeiten optimal angepaßte Beschäftigung gefunden werden konnte. Da der soziale Fortschritt über die Sozialabgaben allerdings auch die Wirtschaftsentwicklung belasten würde, sollten im Sinne einer gleichen Belastung aller europäischen Volkswirtschaften die Bedingungen der Beschäftigung angeglichen werden:

"Il s'agit, en effet, de ne pas briser la nécessaire égalité devant la concurrence ... il est du devoir des pouvoirs publics de créer des conditions propices à ce changement par des actions d'information, de recherche, par l'encouragement d'expériences fructueuses et par l'organisation d'une concertation des partenaires sociaux sur les problèmes d'organisation du travail." ${ }^{152}$

Um also keine Volkswirtschaft für ihre soziale Fortschrittlichkeit zu bestrafen, drängte die französische Regierung auf eine Vereinheitlichung der Sozialpolitik. Sie nahm damit eine Forderung wieder auf, die Frankreich schon in den Regierungsverhandlungen 1956 in den Mittelpunkt seiner Ordnungskonzeption für den Binnenmarkt gestellt hatte und an der die Verhandlungen damals fast gescheitert wären. Die danach günstig verlaufende Wirtschaftsentwicklung hatte die Sozialpolitik auf europäischer Ebene zwischenzeitlich in den Hintergrund treten lassen. Mit dem Auftreten erster wirtschaftlicher Schwierigkeiten Anfang der siebziger Jahre rückten jedoch das Problem der Arbeitslosigkeit und mit ihr die Sozialpolitik wieder stärker in das Bewußtsein der französischen Politik. Zur Annäherung der in den Mitgliedstaaten betriebenen Sozialpolitik schlug Frankreich die Errichtung einer europaweiten "Konzertation" der Sozialpartner vor. Die "Konkurrenz" sei, so Premierminister Messmer, als Leitprinzip des Gemeinsamen Marktes kein Ziel an sich, sondern in erster Linie ein Anreizmechanismus, dessen Auswirkungen über eine konzertierte Beteiligung der Sozialpartner an der Wirtschafts- und Sozialpolitik überwacht werden müßten. ${ }^{153} \mathrm{Zu}$ diesem Zweck sollten deshalb auf Branchenebene paritätisch besetzte Komitees gegründet werden und in den sozialen Dialog treten. Ferner schlug Frankreich vor, eine Gesellschaft zur Verbesserung der Arbeitsbedingungen sowie ein europäisches Institut für Sozialstudien ins Leben zu rufen. Wie allerdings schon die Initiativen zur Forschungs- und Technologiepolitik, so stieß auch die französische Initiative einer europäischen Sozialpolitik insbesondere bei den liberal gesinnten Mitgliedstaaten auf starke Vorbehalte. Sie endete schließlich in einem sozialpolitischen Aktionsprogramm, das Anfang 1974 verabschiedet wurde und die Gründung eines europäischen Berufsbildungszentrums sowie Maßnahmen zur Verbesserung des Schutzes und der Hygiene am Arbeitsplatz vorsah. Des weiteren wurden Maßnahmen zur Förderung der Integration von Gastarbeitern

ainsi progressivement d'une civilisation de la quantité à une civilisation de la qualité", so Premierminister Messmer in seiner Ansprache auf dem Gipfel von Paris am 19.10.1972, abgedruckt in: PE, S. 109,2. Sem., S. 108-111

${ }_{152}^{152}$ Ansprache Messmers vom 19.10.1972, a.a.O., S. 109

${ }^{153}$ Ansprache Messmers vom 19.10.1972, a.a.O., S. 110 
sowie der betrieblichen Mitbestimmung vereinbart. ${ }^{154}$ Insgesamt blieb es jedoch weitgehend bei Absichtserklärungen. Substantielle Fortschritte vor allem hinsichtlich der von Frankreich geforderten Beschäftigungspolitik und des sozialen Dialoges gab es nicht.

Charakteristisch für den französischen Vorstoß war, daß er nicht etwa mit dem Schutz der Arbeitnehmerinteressen begründet, sondern aus übergeordneten, abstrakten sozialphilosophischen Sollvorstellungen abgeleitet war. Der Hinweis auf die soziale Verantwortung Europas bzw. die Forderung nach einer Europäischen Gemeinschaft, die als soziales Modell den Menschen zu dienen hatte, zeigten dies deutlich. Die sozialpolitische Initiative der französischen Regierung stand in direkter Beziehung mit jenen Zivilisationsidealen, die auch die europapolitische Konzeption Pompidous leiteten. Diese sollten durch eine europäische Sozialpolitik auf das Wirtschaftsleben in allen Staaten des Binnenmarktes übertragen werden. Wie schon in den Regierungsverhandlungen 1956 versuchte Frankreich, sich über eine politisch dekretierte, zwangsweise Vereinheitlichung der Sozialbestimmungen den wirtschaftlichen Folgen seiner „fortschrittlichen“ Politik zu entziehen. Dem gleichen Zweck diente auch die Konzertation der Sozialpartner, die in erster Linie die Unterstützung der Wachstumsziele der Politik durch die Arbeitnehmer und Unternehmer sicherstellen sollte. Die französische Regierung war sich offenbar der Unverträglichkeit ihres sozialpolitischen Konzepts mit den Gesetzen der Wettbewerbswirtschaft, die sozialen Fortschritt nur in Abhängigkeit von dem zu verteilenden Sozialprodukt sowie von der Kräfteverteilung unter den Markteilnehmern erlaubte, bewußt. Mit der Forderung nach Harmonisierung der Sozialbestimmungen sollte ein offener "Wettbewerb der Sozialsysteme" vermieden werden - erfolglos jedoch, da sich die Partner Frankreichs auf dem Gebiet der Sozialpolitik offensichtlich nicht für eine grundsätzliche Abkehr vom Wettbewerbsprinzip entscheiden konnten.

\section{B.3.3.3 Die Außenwirtschaftspolitik}

Wie die Sozialpolitik, so waren auch die Handels- und Energiepolitik direkt in die französischen Bemühungen um eine aktive Politik zur Stärkung des Wachstums und der europäischen Wettbewerbsfähigkeit eingebunden. Beide Politikbereiche waren aus französischer Sicht in besonderer Weise von der Politik der USA Europa gegenüber betroffen. Frankreich, auf die nationale und europäische Unabhängigkeit bedacht, nahm grundsätzlichen Anstoß an den amerikanischen Bemühungen Anfang der siebziger Jahre, die politischen und wirtschaftlichen Beziehungen im westlichen Bündnis neu zu definieren. Die USA sahen sich nach der Erweiterung der Gemeinschaft einer ebenbürtigen Wirtschaftsmacht gegenüber, die sich innerhalb der NATO jedoch nicht zu gleichen Teilen an den Lasten der sicherheitspolitischen Verantwortung beteiligte. $\mathrm{Da}$ die USA weltweite Verantwortung, die EG-Mitgliedstaaten aber nur regionale Ver-

${ }^{154}$ Vgl. Lagrave, M. (1975), La France et la politique sociale, S. 606 f., in: Joel Rideau et. al. (Hrsg.), La France et les Communautés Européennes, Paris, S. 599-697 
antwortlichkeiten zu tragen hätten, schlug US-Außenminister Kissinger im April 1973 eine neue „Atlantik-Charta“ vor. Ziel dieser Charta war, die politische Zusammenarbeit der Westmächte auf allen Gebieten der Politik besser abzustimmen und zu vertiefen. ${ }^{155}$ Auf französischer Seite wurde die amerikanische Initiative jedoch als Angriff auf die europäische Selbständigkeit interpretiert. Dieser Dissens schlug weitgehend ungefiltert auf die Vorbereitung der für 1973 avisierten Zollverhandlungen im GATT durch.

Ein Kommissionsvorschlag zur Haltung der Staaten der Europäischen Gemeinschaft in den GATT-Verhandlungen vom April 1973 wurde von Außenminister Michel Jobert schroff in allen wesentlichen Punkten zurückgewiesen, weil er aus französischer Sicht europäische Interessen nicht deutlich genug betonte. Auf der Ministerratssitzung vom 15. Mai 1973 forderte er, grundsätzlich herauszustellen, daß nicht Europa, die erste Handelsmacht der Welt, um. Verhandlungen nachgesucht habe und es dementsprechend auch nicht als Bittsteller auftreten werde. ${ }^{156}$ Ferner sollte die Gemeinschaft unterstreichen, daß die Verhandlungen nicht zum Zweck haben könnten, das Handelsdefizit einer einzigen Nation - womit die USA gemeint waren - zu korrigieren, sondern daß im Gegenteil auf ein Gleichgewicht bei den Zugeständnissen und den Vorteilen zu achten sei. Außerdem wollte Frankreich klargestellt wissen, daß es in den Verhandlungen nicht um den vollständigen Abbau der Zollschranken gehen könne, da dies nur die Schutzlosigkeit und die Auflösung der EG in einer Freihandelszone zur Folge haben würde. ${ }^{157}$ Vielmehr sollte die Europäische Gemeinschaft auf eine feierliche Bekräftigung des gemeinsamen Außentarifs bestehen:

"Le seul objectif que nous pouvons rechercher sur le plan tarifaire, dans cette négociation, c'est $l^{\prime}$ harmonisation des tarifs. Encore faut-il nous assurer ... que nous avons les mêmes vues quant aux méthodes permettant d'atteindre ce but. On peut envisager, et nous les écartons bien entendu, des modalités d'harmonisation qui reviendrait en fait, à une élimination des tarifs. Il faut au contraire, donner à nos experts - qui auront également à se prononcer sur la question délicate de l'évaluation de la <<protection effective>> - mandat de définir une méthode permettant d'obtenir une harmonisation des tarifs telle que le tarif extérieur commun puisse rester suffisamment élevé. “158

Die Gemeinschaft sollte sich nach französischem Willen also das Recht der Zollerhebung nicht vorenthalten lassen und sich auch nicht, wie die Kommission in einer Auflistung vorgeschlagen hatte, vorzeitig zur Aufgabe nicht-tarifärer Handelshemmnisse verpflichten, sondern gerade bei letzteren entsprechend einer globalen Analyse sektorweise vorgehen und ihre Interessen entschlossen verteidigen. Ebenso fehlte dem französischen Außenminister der Hinweis auf die Währungspolitik und hier insbesondere darauf, daß die USA seit August 1971 immer noch nicht zur Konvertibilität des Dollars

\footnotetext{
${ }^{155}$ Vgl. die Rede Kissingers vom 23.4.1973 auf dem Jahresessen von ASSOCIATED PRESS in New York, abgedruckt in: EA, D 221, Folge 10/1973, D 220 - D 225

156 Vgl. die Erklärung Joberts vom 15.5.1973 im Ministerrat, abgedruckt in: PE, S. 143, 1. Sem., S. $142-145$

157 ebenda

158 ebenda
} 
zurückgekehrt waren. Außerdem forderte Frankreich eine klare Ablehnung des USVorschlages, Zölle bis zum Ausgleich ihrer Handelsbilanz erheben zu dürfen sowie eine eindeutige Erklärung, daß die europäische Agrarpolitik in keiner Weise zur Disposition stünde. ${ }^{159}$ Der französische Wirtschafts- und Finanzminister schloß sich diesen Forderungen kurze Zeit später an, indem er zusätzlich darauf hinwies, daß für einen erfolgreichen Verhandlungsverlauf eine neue Weltwährungsordnung mit stabilen Wechselkursen Voraussetzung sei. Am 12. September 1973, auf der Eröffnungsveranstaltung der GATT-Verhandlungen in Tokyo, konkretisierte er noch einmal die agrarpolitischen Vorbehalte Frankreichs, indem er die Einrichtung einer weltweiten Agrarmarktordnung für die einzelnen Produkte nach EG-Muster vorschlug. ${ }^{160} \mathrm{Da}$ die Einkünfte der Landwirte nicht erratischen Preisschwankungen preisgegeben werden dürften, sollte zur Stabilisierung der Preise ein Eingriffsmechanismus mit eigenen Lagern (Buffer-Stocks) geschaffen werden.

In handelspolitischen Fragen legte Frankreich somit eine provokante Haltung an den Tag, mit dem Ziel, die Gemeinschaft zu einer selbstbewußten Politik im Sinne eines unabhängigen „europäischen Europa“ zu bewegen. Ein weiteres Mal dominierte damit eine Perspektive, die schon unter de Gaulle die französische Binnenmarktpolitik geprägt hatte. Die gemeinsame Handelspolitik wurde von Frankreich auch unter Pompidou als Mittel begriffen, den Binnenmarkt als eigenständigen Wirtschaftsraum zu festigen und ihn je nach politischer Opportunität entweder abzuschotten oder zu öffnen. Ordnungspolitische Erwägungen im Hinblick auf die Gestaltung der Außenwirtschaftsbeziehungen waren von machtpolitischen Motiven dominiert. In der provokanten Haltung, mit der die französische Regierung ihre Forderungen vor allem den USA gegenüber vortrug, zeigte sich, wie überzeugt sie von der Richtigkeit ihrer Politik war.

Das kritische Verhältnis zu den USA in Handelsfragen sollte seinen Höhepunkt jedoch erst im Verlauf der im Herbst 1973 ausbrechenden Ölkrise erreichen. Die arabischen Ölstaaten hatten in Reaktion auf das Engagement der Supermächte im Jom-KippurKrieg den Ölpreis innerhalb kurzer Zeit auf das Vierfache erhöht und gleichzeitig die Ölförderung gedrosselt. Um die plötzlich auftretenden Schwierigkeiten bei der Energieversorgung zu beseitigen, luden die USA im November 1973 die wichtigsten westlichen Industrieländer zu einer Konferenz ein. Der französische Präsident indessen hatte sich zuvor schon in einem Brief an die europäischen Staats- und Regierungschefs beschwert, daß Europa den Superstaaten die Regelung des Nah-Ost-Konfliktes allein überlassen hatte. Er beschwor im Vorfeld der Energiekonferenz die europäische Identität und forderte, daß Europa zumindest in dieser Frage eine eigene Politik vertreten müsse. ${ }^{161}$ Im Gegensatz zu den USA schlug Frankreich deshalb als europäische Lö-

${ }^{159}$ ebenda, S. 144

160 Vgl. die Ansprache Giscard d'Estaings bei der Eröffnung der GATT-Konferenz in Tokyo am 12.9.1973, abgedruckt in: PE, S. 87, 2. Sem. S. 86-88

${ }^{161}$ Vgl. den eindringlichen Aufruf Pompidous zu mehr europäischem Engagement in seinem Schreiben an Staats- und Regierungschefs der EG vom 31.10.1973, abgedruckt in: EA, Folge 2/1974, D $28 \mathrm{f}$. 
sung der Ölkrise die Einberufung einer Weltenergiekonferenz unter dem Dach der UNO vor, auf der nicht nur die Industriestaaten, sondern alle interessierten Parteien vertreten sein sollten. Ölproduzenten und Ölkonsumenten sollten zusammengebracht werden und gemeinsam nach einer Lösung suchen, wobei unter den Konsumenten neben den Industrieländern auch die Länder der Dritten Welt eine eigene Stimme haben sollten. ${ }^{162}$ Den europäischen Partnern legte Frankreich zusätzlich noch die Aufnahme eines eigenständigen euro-arabischen Dialogs nahe.

Im Gegensatz zum amerikanischen Ansatz der Interessenverteidigung und -konfrontation setzte Frankreich in Fragen der Energieversorgung nicht auf die Bündelung der Nachfragemacht, sondern auf eine konsensorientierte Lösung mittels globaler Konzertation:

"Qu'il s'agisse du gaz, du pétrole, de l'énergie nucléaire, il faut que la détermination européenne apparaisse sans tarder, dans ce domaine, comme elle est apparue dans d'autres. Il faut ... que les sources d'énergie soient multiples, que les prix soient coordonnés, le marché organisé, la recherche encouragée, qu'il y ait en tout moins de caprice, moins d'incertitude, plus détermination et en somme plus d'Europe." 163

Letztlich ging es Frankreich um eine eigenständige europäische Energiepolitik mit dem Ziel einer vollständigen Neuordnung der Weltenergiemärkte. Wichtig aus ordnungspolitischer Sicht in diesem Zusammenhang war, daß die angestrebte Überwindung der Energieknappheit politisch herbeigeführt werden sollte. Nicht die Marktkräfte, sondern die politisch bestimmte Preissetzung und "Organisation" der Märkte waren die Instrumente, mit denen Frankreich die Überwindung des Energieproblems erreichen wollte.

Zu Frankreichs Enttäuschung schlossen sich die europäischen Partner, trotz verbaler Unterstützung der französischen Vorschläge, den USA an, deren Einladung zur Konferenz der wichtigsten Ölkonsumenten sie im Februar 1974 folgten. Im Gegensatz zu Frankreich unterstützten sie auch die Gründung einer internationalen Energieagentur der wichtigsten Verbraucherstaaten, die Frankreich strikt ablehnte. Die französischen Vertreter isolierten sich im Konferenzverlauf vollständig mit ihrer restriktiven Position und unterzeichneten dementsprechend auch nicht das abschließende Kommuniqué. ${ }^{164}$ Außenminister Jobert machte seiner Enttäuschung über die europäischen Kollegen nach seiner Rückkehr Luft, indem er vor der Nationalversammlung ankündigte, seine Kollegen auf der nächsten Ministerratssitzung mit "Guten Tag, ihr Verräter" begrüßen zu wollen. ${ }^{165}$ Letzten Endes jedoch verliefen die amerikanischen wie auch die franzö-

${ }^{162}$ Zur französischen Haltung siehe die Rede Joberts vor der Nationalversammlung am 12.11.1973, abgedruckt in: PE, S. 183, 2. Sem., S. 178 ff. sowie vor dem Senat am 30.11.1973, abgedruckt in: PE, 214 f., 2. Sem., S. 212 ff.

${ }^{163} \mathrm{Vgl}$. die Rede Joberts vom 12.11.1973, a.a.O., S. 183

${ }^{164} \mathrm{Vgl}$. die Rede Joberts vor den anwesenden Ministern vom 11.2.1974 auf der Konferenz von Washington sowie das Kommuniqué vom 13.2.1974, daß ausdrücklich die Punkte ausweist, denen Frankreich nicht zustimmte, abgedruckt in: PE, S. 82 ff., 1. Sem. 1974

${ }^{165}$ Er war im übrigen bewußt von Pompidou als Vertreter Frankreichs entsandt, da ihm Wirtschaftsund Finanzminister Giscard d'Estaing zu konziliant erschien, vgl. Grosser (1986), a.a.O., S. 313 
sischen Lösungsversuche im Sande, da alle Staaten in bilateralen Verträgen und Bemühungen frei nach dem Motto: "Rette sich wer kann" ihr Heil suchten. ${ }^{166}$ Das französische Engagement für eine eigenständige europäische Energiepolitik fügte dem komplexen Verhältnis Frankreichs zu den USA somit nur eine weitere Facette hinzu. Es lieferte allerdings auch ein weiteres Indiz für seine Präferenz, die Lösung schwieriger Wirtschaftslagen im Rahmen politischer Kooperation und Interventionen zu suchen, statt sich auf die Marktkoordination zu verlassen. Das Vertrauen auf die Organisierbarkeit der Energie- und Rohstoffmärkte unterstrich noch einmal den konstruktivistischen Charakter der französischen Außenwirtschaftspolitik, in der Frankreich, ordnungspolitisch betrachtet, ungebrochen an seinem bisherigen interventionistischen Kurs festhielt.

\section{B.3.3.4 Zusammenfassung}

Zusammenfassend betrachtet läßt sich feststellen, daß alle französischen Vorstöße auf dem Gebiet der Industrie-, Sozial- und Außenhandelspolitik sowie im Rahmen der Erweiterung der Gemeinschaft Teile einer Gesamtkonzeption darstellten, die auf die bewußte politische Gestaltung der wirtschaftlichen Entwicklung bzw. des Wachstums ausgerichtet war. Im Mittelpunkt dieser Konzeption stand die Industriepolitik. Ihr fiel die Aufgabe zu, die Wirtschaftsbranchen zu bestimmen, die das Wachstum zukünftig tragen sollten, sowie die notwendigen allgemeinen und sachlichen Voraussetzungen zu schaffen, damit der angestrebte Erfolg auch erreicht würde. Die Palette der wirtschaftspolitischen Eingriffe reichte von der Fusionsförderung über die Unterstützung prestigeträchtiger Großprojekte bis hin zur Subvention der industriellen Forschung und Entwicklung.

Der Sozialpolitik fiel die Aufgabe zu, die Sozialpartner, d. h. Arbeitnehmer und Unternehmer um die wachstumspolitischen Bemühungen der Regierungen zu scharen und sie in diese einzubinden. Die „Humanisierung“ des Wachstums, die „gerechte“ Verteilung des Produktionsergebnisses sowie eine europäische Vollbeschäftigungs- und Berufsbildungspolitik waren das Angebot an die Arbeitnehmer, an einem gemeinschaftsweiten Dialog der Sozialpartner teilzunehmen. Die Bereitschaft der Arbeitgeber zur Teilnahme am sozialen Dialog sollte mit der Vereinheitlichung der Sozialbedingungen, um Verzerrungen der Wettbewerbsbedingungen durch unterschiedlich hohe Sozialabgaben zu verhindern, erreicht werden. Beide Seiten wären im sozialen Dialog mit den politischen Wachstumsplänen der Regierungen bekannt gemacht worden und hätten im Rahmen einer staatlich überwachten Vorkoordination ihrer grundlegenden Interessen die wesentlichen Konflikte ausräumen können, die sonst etwa im Rahmen von Arbeitskämpfen die politischen Wachstumsbemühungen hätten gefährden können. Insofern entsprach der soziale Dialog der Anhörung der Sozialpartner wie sie im Verlauf der Planification stattfand, nur, daß nicht Produktionsziele an erster Stelle der Ge-

$\overline{{ }^{166} \text { Vgl. Grosser (1986), a.a.O., S. } 312}$ 
sprächsinhalte standen, sondern die am Allgemeininteresse orientierte Aussöhnung der jeweiligen Gruppeninteressen. Für Frankreich hätte ein europäischer sozialer Dialog im übrigen den Vorteil gehabt, die aufgrund des schwachen Organisierungsgrades der Arbeitnehmer und Arbeitgeber nur schwer steuerbaren Arbeitskämpfe auf nationaler Ebene besser verhindern zu können. Oberhalb der nationalen Strukturen wäre mit dem europäischen sozialen Dialog eine weitere Gesprächsebene etabliert worden, die die französischen Tarifpartner $\mathrm{zu}$ einer besseren internen Organisation und Abstimmung gezwungen hätte. Als Nebeneffekt hätte der europäische soziale Dialog es der französischen Regierung somit erleichtert, die Tarifpartner auch auf nationaler Ebene besser in die politischen Bemühungen zur Gestaltung des Wachstums zu integrieren.

Die Absicherung der gemeinschaftlichen Wachstumspolitik nach außen suchte die französische Regierung durch ihre Haltung in der Erweiterung der Gemeinschaft sowie durch eine europäische Handelspolitik zu erreichen. Die Öffnung des Gemeinsamen Marktes für Großbritannien, Irland und Dänemark folgte in erster Linie einem taktischen Machtkalkül, um den politischen Einfluß Frankreichs innerhalb der Gemeinschaft gegen eine zunehmend selbstbewußtere Bundesrepublik zu verteidigen. Zur Durchsetzung seiner ordnungspolitischen Ansichten war dies insofern von Vorteil, da Frankreich in der Vergangenheit häufig auf deutschen Widerstand getroffen und nicht selten daran gescheitert war. In Fragen der Außenwirtschaftspolitik ermunterte Frankreich die Gemeinschaft, ihre Wachstumsbemühungen aktiv nach außen zu vertreten. Ungeschminkt vorgetragen wurde dieses Ansinnen in Fragen der Agrarpolitik, die grundsätzlich der Liberalisierung des Welthandels entzogen bleiben sollte. Ebenfalls unmißverständlich forderte Frankreich den Rückgriff die Zollpolitik, wobei dem AuBentarif weiter zentrale Bedeutung beigemessen wurde. Die Bereitschaft, über eine Harmonisierung der Außenzölle sprechen zu wollen, nicht aber über deren Abschaffung, zeigte die grundsätzliche Zurückhaltung Frankreichs gegenüber einer Liberalisierung des Handels an sich. Die selbstbewußte Haltung, mit der diese Forderungen insbesondere gegenüber den USA vorgetragen wurden, verdeutlichte einmal mehr, daß die französische Haltung in außenwirtschaftlichen Fragen primär von geopolitischen und weniger von wirtschaftlichen Motiven getragen wurde. Die französische Energiepolitik war dabei ein Spezialfall, in dem alle ordnungspolitischen Zielvorstellungen Frankreichs noch einmal in nahezu reiner Form zum Ausdruck kamen, sei es im Bemühen, alle betroffenen Interessengruppen zu einer politisch moderierten Verhandlungslösung bewegen, die Märkte neu „organisieren“ oder die Energiepreise politisch festlegen und koordinieren zu wollen.

Ordnungspolitisch betrachtet strebte Frankreich unter Pompidou mit seinen Entwürfen einer europäischen Industrie-, Sozial- und Außenwirtschaftspolitik die Übertragung einer interventionistischen Wirtschaftspolitik auf die Gemeinschaft an. Die wirtschaftspolitische Zusammenarbeit auf europäischer Ebene sollte bewußt auf die aktive Förderung der Wettbewerbsfähigkeit und damit auf die Stärkung der europäischen Wirtschaftsmacht ausgerichtet werden. Das dirigistische Ordnungswollen der französischen Regierung war letztlich tief verwurzelt in einer bestimmten, grundsätzlichen 
Auffassung des Verhältnisses von Staat und Wirtschaft wie sie exemplarisch in den Äußerungen des Staatspräsidenten zum Ausdruck kam. Eine zivilisierte Gesellschaft, für die Frankreich auf nationaler wie europäischer Ebene kämpfte, vertrug sich nicht mit dem „Gesetz des Dschungels“ und „dem Recht des Stärkeren“, die französischerseits immer wieder mit einer freien Marktwirtschaft assoziiert wurden. Statt dessen sollten die „Früchte des Wachstums“ gerecht verteilt und das Wachstum „human" und sozialverträglich gestaltet werden. Stärker noch als unter de Gaulle schien die französische Binnenmarktpolitik unter Pompidou von Zweifeln an der Koordinationsfähigkeit des Marktmechanismus durchdrungen und von der politischen Gestaltbarkeit der Wirtschaftsentwicklung überzeugt zu sein. Im gleichen $\mathrm{Ma}$ fand sich die Binnenmarktpolitik der alles dominierenden europapolitischen Konzeption des Präsidenten untergeordnet, was dazu führte, daß die europäische Wirtschaftspolitik Frankreichs auch unter Pompidou in erster Linie Machtpolitik blieb.

\section{B.3.4 Die Währungspolitik \\ B.3.4.1 Europa als währungspolitische Einheit}

Die währungspolitische Isolation Frankreichs im letzten Jahr der Ära de Gaulle überwand die neue Regierung relativ schnell. Im August 1969 wertete sie einseitig den Franc ab und kurz darauf beantragte sie die Zuteilung von Sonderziehungsrechten, womit Frankreich die Blockade dieser neuen Institution endgültig aufgab. Mit der Rückkehr Valéry Giscard d'Estaings in das Amt des Wirtschafts- und Finanzministers knüpfte Frankreich wieder an die von ihm unter de Gaulle verfolgte währungspolitische Linie an. Er begrüßte am 1. Oktober 1969 auf der Jahresversammlung des IWF und der BIZ die Einführung der SZR, in denen er die Leitidee seines CRU-Konzepts aus dem Jahre 1964 umgesetzt sah. ${ }^{167}$ Als Hauptursache der Instabilität des Weltwährungssystems kritisierte er die schwachen Bemühungen einiger Mitgliedstaaten im Kampf gegen die Inflation sowie bei der Bereinigung ihrer Zahlungsbilanzdefizite. Vordringlich für die Stabilität im IWF war seiner Meinung nach, die Mittel des IWF wieder an den Umfang der internationalen Realtransaktionen anzupassen. Im Sinne einer flexiblen und dem internationalen Bedarf angepaßten Liquiditätsversorgung sollte den SZR neben dem Gold der Rang einer zweiten Währungsreserve zuerkannt werden, wie es das CRU-Konzept schon 1964 vorgesehen hatte. ${ }^{168}$ Dreh- und Angelpunkt des von Frankreich gewünschten Währungssystems war und blieb das Gold. Das internationale Währungssystem, so der französische Wirtschafts- und Finanzminister einen Tag nach der Jahresversammlung 1969 des IWF kategorisch, benötige einen "objektiven" Wertmaßstab, den nichts anderes als das Gold darstellen könne. ${ }^{169}$

${ }^{167}$ Vgl. die Ansprache Giscard d'Estaings auf der Jahresversammlung der Gouverneure der BIZ und des IWF am 1.10.1069, abgedruckt in: PE, S. 89, 2. Sem. S. $87 \mathrm{ff}$.

${ }^{168}$ ebenda, S. $88 \mathrm{f}$.

${ }^{169}$ So Giscard d'Estaing am 2.10.1969 in einem Interview mit dem NOUVEAU JOURNAL, abgedruckt in: PE, S. 91, 2. Sem., S. 91 f. 
Georges Pompidou begründete diese Haltung wenig später als naturgegeben: "La France, les Français ont toujours aimé l'or" ${ }^{170}$.

Diese Feststellung, zusammen mit dem Engagement für eine herausgehobene Rolle der goldfundierten SZR, zeigte, daß Frankreich den Faden in der Währungspolitik dort wieder aufnahm, wo Giscard d'Estaing ihn 1966 aus der Hand gegeben hatte. Dementsprechend blieb es bei der französischen Kritik am Euro-Dollar-Markt, der zwischenzeitlich stetig an Volumen und damit an Bedeutung gewonnen hatte. Seine "unbegrenzte " und "unkontrollierte" Entwicklung würde sich, so Giscard d'Estaing, einer "rationalen Bewertung" entziehen, was für die europäischen Volkswirtschaften "sehr schädlich" wäre. ${ }^{171}$ Des weiteren wandte sich der französische Finanzminister entschieden gegen alle Überlegungen, das bestehende Festkurssystem aufzuweichen, womit er auf erste Expertendiskussionen über die Flexibilisierung der Wechselkurse innerhalb des IWF abstellte. Das System fester Wechselkurse sei aufgrund der schmerzhaften Erfahrungen der Zwischenkriegszeit entstanden und habe zu einer bemerkenswerten Ausdehnung des internationalen Handels nach dem Krieg geführt. ${ }^{172}$ Für Länder mit ernsthaften außenwirtschaftlichen Problemen böte es im Fall fundamentaler Ungleichgewichte hinreichend Anpassungsmöglichkeiten, um den "wahren" Wert ihres Geldes neu zu bestimmen. ${ }^{173}$ Alles, was die Festigkeit der Paritäten zu ruinieren drohte, wie z. B. die Einführung neuer Finanzierungsfazilitäten oder eine Auflockerung der Schwankungsbreiten, würde die monetäre Landschaft einer Veränderung ins „Heimtückische“ aussetzen und im übrigen die Funktionsfähigkeit des EGBinnenmarktes gefährden, womit der von festen Paritäten abhängende Agrarpreismechanismus angesprochen war. ${ }^{174}$ Keinesfalls sollte von einer Flexibilisierung der Wechselkurse eine einfache Lösung der gegenwärtigen Probleme im Hinblick auf die Stabilisierung der internationalen Währungsbeziehungen nach Art eines "LSDmonétaire" erwartet werden.

Neben seiner internationalen Währungspolitik verfolgte Frankreich auf europäischer Ebene eine zweite Linie. Auf der Konferenz von Den Haag machte es das BarreMemorandum zum Ausgangspunkt seiner Politik. Ziel der neuen französischen Regierung war die Herbeiführung einer einheitlichen Währungspolitik der Gemeinschaft, damit diese es in den internationalen Gremien von ihrem Gewicht her mit den alles beherrschenden USA aufnehmen konnte. ${ }^{175}$ Aus dem Barre-Memorandum übernahm

${ }^{170}$ So Georges Pompidou in seiner Pressekonferenz vom 24.2.1970, a.a.O., S. 61. Zur Fixierung Pompidous auf die Rolle des Goldes als Stabilitätsanker des internationalen Währungssystems siehe seine ausführlichen Stellungnahmen zur Reform des internationalen Währungssystems während seiner USA-Reise Anfang 1970 in den Pressekonferenzen vom 24.2.1970, a.a.O., S. 61 f., vom 27.2.1970, a.a.O., S. 74 und in der Ansprache vom 2.3.1970, a.a.O., S 86

${ }^{171}$ Vgl. das Interview Giscard d'Estaings vom 2.10.1969, a.a.O., S. 91 f. sowie das Interview Giscard d'Estaings am 25.9.1969 mit EUROPE No. 1, abgedruckt in: PE, S. 82 f., 2. Sem., S. 81 ff.

172 ebenda, S. 89

173 ebenda

174 ebenda, S. $89 \mathrm{f}$.

${ }^{175}$ So Pompidou in seiner Ansprache vom 2.12.1969 auf dem Gipfel von Den Haag, a.a.O., D 41 
Frankreich die Idee, über stetig zu reduzierende Bandbreiten zwischen den europäischen Währungen zu einer engeren währungs- und wirtschaftspolitischen Kooperation zu gelangen. Die vereinbarten Wechselkurse sollten über einen gemeinschaftlichen Interventionsmechanismus verteidigt werden. Des weiteren unterstützte die französische Regierung den Vorschlag des Memorandums, einen kurzfristigen und einen mittelfristigen Währungsbeistand einzurichten sowie die SZR gemeinsam zu verwalten. ${ }^{176}$ Die anderen Mitgliedsstaaten gaben diesen Vorschlägen jedoch nur insofern nach, als daß im Kommuniqué des Gipfeltreffens von Den Haag vorerst nur die Prüfung eines gemeinsamen Reservefonds vereinbart wurde. ${ }^{177}$

Die französische Währungspolitik mündete im Verlauf des Jahres 1970 in die Strategie des „deuxième pôle monétaire“ und schuf damit das Lager der „Monetaristen“, das sich, unter französischer Führung stehend, im Verlauf der Verhandlungen über die Wirtschafts- und Währungsunion mit seinen Positionen weitgehend durchsetzen konnte. In diesem Zeitraum konkretisierte die französische Regierung weitere Elemente ihrer währungspolitischen Strategie. So brachte Pompidou während einer USAReise im Frühjahr 1970 unumwunden zum Ausdruck, daß es bei der Vereinheitlichung der europäischen Währungspolitik in erster Linie darum ging, ob Europa als Währungsblock zu einer zweiten Säule des internationalen Währungssystems werden könne oder nicht. ${ }^{178}$ Im Juli des Jahres ergänzte er diese Aussage dahingehend, daß es vor allem auf die Bildung einer „gewissen Währungsunion" ankomme, die durch ihr Eigengewicht die Bewegungen des zunehmend inflationsgeschüttelten Dollars auszugleichen vermochte und sich durch ihren gemeinsamen Widerstand gegenüber allen Versuchen zur Erweiterung der Bandbreiten bzw. zum Übergang zu flexiblen Wechselkursen auszeichnete. ${ }^{179}$ Giscard d'Estaing konkretisierte in diesem Sinne die französische Kritik am Euro-Dollar-Markt, dessen wachsender Einfluß seiner Meinung nach nur den schleichenden Verfall des internationalen Währungssystems demonstrierte. Auf der Jahresversammlung der Gouverneure des IWF und der BIZ im Herbst 1970 forderte er, „Ordnung“ in diesen nicht organisierten und unüberwachten Markt zu bringen. ${ }^{180}$ Außerdem lehnte er ab, flexible Wechselkurse als Instrument zur Behebung von Zahlungsbilanzproblemen zu akzeptieren. ${ }^{181}$ Jede Ausweitung der Wechselkursflexibilität würde unweigerlich die Verteidigung gegen inflationäre Entwicklungen schwächen. Außerdem würden Länder mit stabiler Preisentwicklung über die Inflation eine relative Aufwertung gegenüber schwächeren Währungen erfahren und so Anpassungslasten übernehmen, die nach französischem Verständnis grundsätzlich von den Inflationsverursachern zu tragen waren. ${ }^{182}$ Des weiteren sei an die Länder der Dritten Welt zu denken, die auf feste Wechselkursen angewiesen wären, da ihnen ob ihrer be-

\footnotetext{
${ }^{176}$ ebenda

${ }^{177} \mathrm{Vgl}$. Kommuniqué der Konferenz von Den Haag, a.a.O., D 44

${ }^{178}$ Vgl. die Pressekonferenz vom 27.2.1970, a.a.O., S. 74

${ }^{179}$ Vgl. die Pressekonferenz vom 2.7.1970, a.a.O., S. 31

180 So Giscard d'Estaing auf der Jahresversammlung der Gouverneure der BIZ und des IWF vom 22.9.1970, abgedruckt in: PE, S. 71, 2. Sem., S. 70 ff.

${ }^{181}$ ebenda, S. 72

182 ebenda
} 
schränkten Mittel jeglicher Schutz gegen die Folgen fluktuierender Paritäten fehle. Das Motto der internationalen Währungspolitik müsse deshalb, so Giscard d'Estaing, „das Minimum an Flexibilität, das Maximum an Stabilität" lauten. ${ }^{183}$

Dies galt um so mehr, als man sich, so Giscard d'Estaing weiter, vor der Illusion zu hüten habe, die Wirtschaft als eine abstrakte Welt zu begreifen, in der sich die Gleichgewichte entsprechend einer kybernetischen Mechanik problemlos von selbst einstellten bzw. in der sich Zahlungsbilanzungleichgewichte über flexible Wechselkurse und künstlich geschaffene Liquidität ohne Schwierigkeiten beseitigen ließen. Seiner Meinung nach erforderten alle Bemühungen zur Stabilisierung der internationalen Währungsbeziehungen ein „intelligent“ (lucidement) organisiertes Vorgehen durch die Verantwortlichen, das auf nationaler Ebene wiederum couragiert von den Sozialpartnern zu unterstützen war. ${ }^{184}$ Bezogen auf das „offensichtlich überlegene" System fester Wechselkurse - nach französischer Meinung am besten verkörpert durch einen goldfundierten „Monometallismus“ ${ }^{185}$ - bestand die intelligente Organisation in der richtigen Handhabung der SZR. Diese stellten aus Sicht des französischen Wirtschaftsund Finanzministers das optimale Mittel zur Lösung des eigentlichen Hauptproblems des internationalen Währungssystems, der rationalen Liquiditätsversorgung, dar. ${ }^{186}$

Derart disponiert wurde die französische Währungspolitik Ende April 1971 mit einer ersten massiven Spekulationswelle konfrontiert. Im Zuge einer Aufwertungsspekulation erreichte die Kapitalflucht aus dem Dollar in die Mark ungeahnte Höhen. Am 28. April beschlo $ß$ der Ministerrat vereinbarungsgemäß die erste Bandbreitenverengung für die europäischen Währungen von $+/-0,75$ Prozent auf $+/$ - 0,6 Prozent, die zum 15. Juni 1971 in Kraft treten sollte. Beunruhigt über die Spekulationsbewegungen legte der deutsche Finanzminister jedoch schon kurze Zeit später seinen Kollegen nahe, über ein Blockfloating das beschlossene Arrangement gegenüber dem Dollar zu verteidigen, was von französischer Seite jedoch energisch ablehnt wurde. ${ }^{187}$ Einzig eine Erhöhung des Goldpreises sei akzeptabel, so der französische Wirtschafts- und Finanzminister ${ }^{18}$ - eine Forderung, die von ihrer Wirkung her einer Abwertung des Dollars gleichkam und, einmal in die Presse gekommen, die Flucht aus dem Dollar nochmals verstärkte. ${ }^{189}$ Als sich zwei Wochen später die Zentralbanken unter dem übermäßigen Dollarzustrom zur Aussetzung des Devisengeschäfts gezwungen sahen, führte der Dissens zwischen Frankreich und Deutschland über eine adäquate währungspolitische Reaktion zum offenen Bruch. Uneinig über eine gemeinsame Reaktion der Gemeinschaft gaben

\footnotetext{
${ }^{183}$ ebenda, S. 73

${ }^{184}$ ebenda, S. 74

185 ebenda

186 Vgl. den Artikel Giscard d'Estaings in: L'ÉCONOMIE, abgedruckt in: PE, S. 131, 1. Sem, S. $131 \mathrm{ff}$.

187 "V. Giscard d'Estaing est vigoureusement opposé à cette idée", Lecerf, J., (1975), La communauté en péril, Paris, S. 286

${ }^{188}$ Vgl. Lemaitre, P., Les ministres des finances des Six ont axé leurs discussions sur le dollar, Le Monde, 28.4.1971, S. 35

${ }^{189} \mathrm{Vgl}$. Lecerf (1975), a.a.O., S. 286
} 
die Bundesrepublik und wenig später auch die Niederlande ihre Währungen frei, während Frankreich weiter jede Lockerung der vereinbarten Paritäten kategorisch ablehnte. ${ }^{190}$ Die französische Regierung unterbrach ihre Mitarbeit in der Expertengruppe zur Verwirklichung der Währungsunion, da sie diese Arbeiten bei zwei floatenden Währungen als zwecklos ansah. Diesen Schritt wollte Giscard d'Estaing jedoch nicht als eine neue "Politik des leeren Stuhls" verstanden wissen, sondern als logische Konsequenz der Ereignisse, bei der Frankreich nur dem "bon sens" folgen würde. ${ }^{191}$

Die französische Regierung begründete ihre Ablehnung des Blockfloatings damit, daß es eine verschleierte Form der Aufwertung der europäischen Währungen darstellte, die wiederum eine versteckte Form des Inflationsimports aus den USA wäre. ${ }^{192}$ Ein Inflationsimport war jedoch, so Giscard d'Estaing, aus "politischen" und "philosophischen" Gründen abzulehnen, da er unweigerlich mit einem geringeren Wirtschaftswachstum und einem Beschäftigungsrückgang bezahlt werden müsse. ${ }^{193}$ Als geeignete Reaktion der Gemeinschaft schlug Frankreich statt dessen eine konzertierte Aktion gegen den freien Kapitalverkehr vor, der aus französischer Sicht das eigentliche Problem darstellte. ${ }^{194}$ Dieses wurde wiederum von der Bundesrepublik abgelehnt. Frankreich blieb somit nur noch, so der französische Wirtschafts- und Finanzminister im nachhinein, ein einseitiges Reagieren der Mitgliedstaaten bezüglich der veränderten Agrarpreisrelationen sowie die allgemeine Billigung des Übergangs zu flexiblen Wechselkursen zu verhindern. ${ }^{195}$ Giscard d'Estaing betonte noch einmal, daß die Anpassungslasten bei der Behebung dieser Krise ausschließlich von dem verursachenden Defizitland, den USA also, zu tragen wären. Zur Stabilisierung des internationalen Währungssystems forderte er erneut, bei der globalen Liquiditätsversorgung zur konditionierten Emission von SZR überzugehen und die Euro-Dollar-Märkte stärker gemeinsam zu überwachen. ${ }^{196}$ Letzteres wäre um so mehr geboten, als im Verlauf dieser Krise kurzfristige Kapitalbewegungen erstmals total unabhängig von der Entwicklung der laufenden Zahlungen vorgenommen worden seien. ${ }^{197}$ Dieses wertete Giscard d'Estaing als logische Konsequenz der "irrationalen" Liquiditätsversorgung im internationalen Wäh-

${ }^{190}$ Vgl. Lemaitre, P., Vingt heures de débat pour laisser au gouvernement allemand les mains libres", Le Monde, 11.5.1971, S. 5

${ }^{191}$ Vgl. das Interview Giscard d'Estaings am 11.5.1971, abgedruckt in: PE, S. 159, 1. Sem, S. 159 f. sowie $0 . V$., Les experts françaises ne participeront pas aux débats sur l'union monétaire, Le Monde 12.5.1971, S. 1

${ }^{192}$ Vgl. o.V., M. Giscard d'Estaing: il faut défendre l'économie française contre la vague d'inflation, Le Monde 14.5.1971, S. 3

193 Vgl. die Erklärungen Giscard d'Estaings vor der französischen Nationalversammlung vom 12.5.1971, abgedruckt in: PE, S. $164 \mathrm{f}$.

194 ebenda, S. 164

${ }^{195}$ ebenda, S. 165. Auf französisches Drängen wies die gemeinsame Erklärung der EG-Finanzminister nur "Verständnis" für den Übergang zu flexiblen Wechselkursen aus, ohne dieser Maßnahme zuzustimmen. Ebenso wurde explizit auf die Unverträglichkeit des Floatings mit den Gemeinschaftsbeschlüssen hingewiesen. Vgl. die Entschließung des Ministerrates vom 9.5.1971 zur monetären Situation, abgedruckt in: EA, D 419, Folge 18/1971

${ }^{196}$ Vgl. die Erklärungen Giscard d'Estaings vom 12.5.1971, a.a.O., S. 166

${ }^{197}$ Vgl. die Ansprache Giscard d'Estaings vor dem Ministerrat der OECD am 7.6.1971, abgedruckt in: PE, S. 220, 1. Sem, S. $218 \mathrm{ff}$. 
rungssystem, das aufgrund seiner institutionellen Ausgestaltung zwangsläufig zu einer kumulativen Inflation und einer siegreichen Spekulation führen müsse. ${ }^{198}$

Dieser Haltung blieb Frankreich auch im August 1971 treu, als die USA aufgrund einer erneuten Abwertungsspekulation und eines drastischen Verlusts an Währungsgold die Konvertibilität ihrer Währung sowohl in Gold als auch in Devisen aufhoben und gleichzeitig Außenhandelsrestriktionen zur Stabilisierung ihrer defizitären Zahlungsbilanz, die unter anderem einen zehnprozentigen Importzoll umfaßten, verhängten. Auf der nachfolgenden EWG-Ministerratssitzung lehnte der französische Wirtschafts- und Finanzminister erneut energisch die von deutscher Seite geforderte Anpassung der Paritäten $\mathrm{ab}$ und betonte noch einmal seine Verbundenheit mit dem Prinzip fester Wechselkurse, die über den Goldwert der einzelnen Währungen zu definieren waren. ${ }^{199} \mathrm{Au}-$ ßerdem forderte Giscard d'Estaing, sich nicht dem Ziel der Amerikaner zu beugen, eine Aufwertung der europäischen Währungen zuzulassen, die letztlich nur der Wettbewerbsfähigkeit Europas schaden würde. ${ }^{200}$ Noch einmal bestand er darauf, daß die USA als Verursacher der Währungskrise allein die Anpassungslasten beim Zahlungsbilanzausgleich zu tragen hätten. ${ }^{201}$ Frankreich hielt indessen weiter an der Bekämpfung der Spekulation durch Beschränkung des Kapitalverkehrs fest und schlug am 19. August zusätzlich vor, einen gespaltenen Devisenmarkt einzurichten:

"Um nicht den Wert der Währungen in einer von Spekulationsbewegungen erfaßten Welt durch die ungewissen Gesetze von Angebot und Nachfrage bestimmen zu lassen, soll der Zugang zu den Devisenmärkten gemäß den Regeln des Internationalen Währungsfonds für Transaktionen aufgrund von Warengeschäften reserviert werden. Daneben sollen Märkte eingerichtet werden, auf denen die Devisen für die anderen Auslandsgeschäfte gehandelt werden." 202

Mit dieser Maßnahme hoffte die französische Regierung, zumindest die Realtransaktionen den Folgen der Spekulation zu entziehen, um so die Wettbewerbsfähigkeit der Unternehmen binnen- wie außenwirtschaftlich abzusichern. ${ }^{203}$ Wie jedoch schon im Mai des Jahres, prallten im Ministerrat die unvereinbaren währungspolitischen Standpunkte Deutschlands und Frankreichs aufeinander. ${ }^{204}$ Auch dieser Vorstoß der franzö-

\footnotetext{
198 ebenda, S. 219

199 Vgl. o. V., Un affrontement assez vif oppose à Bruxelles M. Giscard d'Estaing à M. Schiller, Le Monde, 20.8.1971, S. 1 sowie die Erklärung des Generalsekretärs beim französischen Präsidialamt, Michel Jobert, am 18. August 1971 über die Haltung Frankreichs zur währungspolitischen Lage, in: EA, Folge 18/1971, D $430 \mathrm{f}$.

${ }^{200}$ Vgl. Interview mit Giscard vom 30.8.1971, a.a.O., S. 82

201 " ... unser Außenhandel ist im Gleichgewicht, unser Preisniveau ist wettbewerbsfähig. Wir sehen nicht ein, warum wir die Parität ändern sollen, bloß weil die Amerikaner Schwierigkeiten mit ihrer Wirtschaft und Währung haben" so Giscard d'Estaing in einem Interview im SPIEGEL, "Schiller ist ziemlich doktrinär", DER SPIEGEL, 30.8.1971, No, 36, S. 82

${ }^{202} \mathrm{Vgl}$. Erklärung vom 18.August, a.a.O., D 431

${ }^{203}$ So Giscard am 2.9.1971 vor der commission des finances der französichen Nationalversammlung, vgl. o.V. "M. Giscard d'Estaing affirme sa volonté de maintenir la parité actuelle du franc et de lutter contre l'inflation sans nuire à la croissance et à l'emploi", Le Monde, 4.9.1971, S. 22

${ }^{204}$ Vgl. o. V., "Un affrontement assez vif oppose à Bruxelles M. Giscard d'Estaing et M. Schiller", Le Monde vom 20.8.1971, S. 1
} 
sischen Regierung und damit die Ministerratssitzung endeten erneut in einem Mißerfolg. ${ }^{205}$ Frankreich führte den gespaltenen Devisenmarkt ein, während andere Mitgliedstaaten ihre Währungen weiter floaten ließen. Mangels einer entschlossenen Gegenreaktion wurde der faktische Zerfall der Grundlagen des Nachkriegswährungssystems von allen Seiten hingenommen.

Zusammenfassend läßt sich zum Zeitpunkt des faktischen Endes des Gold-DollarStandards feststellen, daß Frankreich trotz aller Probleme weiter ungebrochen auf der Beibehaltung eines internationalen Festkurssystems auf Goldbasis bestand. Mit der Definition der Währungen in Gold wollte es die Anpassungsmechanik des Goldstandards erhalten, die, um die Wirtschaftsentwicklung nicht den Zufälligkeiten der Goldproduktion zu unterwerfen, durch eine besondere Liquiditätssteuerung ergänzt werden sollte. In der „rationalen“ Handhabung dieser Liquiditätssteuerung steckte nach französischer Meinung das Hauptproblem der internationalen Währungspolitik. Unter Rückgriff auf das CRU-Konzept Giscard d'Estaings strebte Frankreich die Instrumentalisierung der SZR als zentrales Mittel der internationalen Geldversorgung an. Aufbauend auf einem von Fachleuten "objektiv" ermittelten globalen Liquiditätsbedarf sollte im Rahmen einer internationalen währungspolitischen Konzertation über die Emission zusätzlicher Mittel entschieden werden. Letzten Endes ging es Frankreich um die Errichtung eines politisch kontrollierten Festkurssystems, daß sich zwar an die rigide Anpassungssystematik des erfolgreichen Goldstandards anlehnte, in dem aber unerträgliche Härten wie auch unerwünschte Entwicklungen durch eine politische Feinsteuerung ausgeglichen werden sollten. Wie schon auf wirtschaftspolitischer Ebene, so strebte Frankreich auch im Bereich der monetären Außenwirtschaft eine politische Kontrolle der Entwicklung an. Wie eng Außenwirtschaft und Währung dabei für die französische Regierung zusammenhingen, ließ sich an ihrer Furcht vor Aufwertungen gegenüber dem Dollar und dem damit verbundenen Verlust an Wettbewerbsfähigkeit ablesen sowie daran, daß sie die Ausweitung der Geldmenge immer eng an die Entwicklung der Realtransaktionen zu binden wünschte.

Um seine währungspolitischen Vorstellungen innerhalb des US-dominierten internationalen Währungssystems durchzusetzen, verfolgte Frankreich auf europäischer Ebene eine komplementäre Strategie. Über die sukzessive Verengung der Bandbreiten zwischen den europäischen Währungen versuchte es, eine währungspolitische Einheit zu erreichen, die von ihrem wirtschaftlichen und politischen Gewicht her den USA, welche sich den Systemzwängen des internationalen Währungssystems zunehmend entzogen, wirkungsvoll entgegenzutreten vermochte. Das währungspolitisch geeinte Europa wollte es in den Kreuzzug gegen die internationale Spekulation einbinden. Mit geeinter Kraft sollte der von den nationalen Währungsbehörden unabhängige EuroDollar-Markt wieder unter Kontrolle gebracht und so die vollständige politische Kontrolle über die Entwicklung der internationalen Währungsbeziehungen zurückgewonnen werden.

${ }^{205}$ Vgl. Erklärung des Vizepräsidenten der Kommission der Europäischen Gemeinschaften, Raymond Barre, am 20. August 1971 zur Tagung des Rats, in: EA, Folge 18/1971, D 434 
Dieses Kontrollstreben war aus ordnungspolitischer Sicht allerdings kaum mit dem Grundsatz der Geldwertstabilität zu vereinbaren. Da sich die währungspolitische Haltung Frankreichs im wesentlichen am CRU-Konzept Giscard d'Estaings orientierte, kann auf die vorstehend daran geübte Kritik verwiesen werden, die sich hauptsächlich auf den Primat der Politik im Hinblick auf die Liquiditätssteuerung konzentrierte. Ein weiterer Kritikpunkt in diesem Zusammenhang war die Abstützung auf die Anpassungsmechanik des Goldstandards, der die volle Preiselastizität, den Verzicht auf eine Sterilisierungspolitik sowie die uneingeschränkte Freiheit von Handels- und Kapitalverkehr voraussetzte und damit Bedingungen stellte, die sich von vornherein nicht mit politischen Eingriffen vertrugen und die zu erfüllen die Mitgliedstaaten schon länger nicht mehr in der Lage waren. Die französische Währungspolitik und mit ihr die monetaristische Integrationskonzeption des "deuxième pôle monétaire" stellten selbst eine Gefahr für die von Frankreich eigentlich angestrebte Geldwertstabilität dar. Zu kritisieren in dieser Hinsicht war vor allem das Streben nach einer Gemeinschaftsfinanzierung von Zahlungsbilanzdefiziten, das zwangsläufig eine Abschwächung der Anpassungszwänge für Defizitländer mit sich gebracht und zu einer allgemeinen Stabilitätsorientierung der Wirtschafts- und Währungspolitik auf Durchschnittsniveau geführt hätte.

Kritikwürdig im Sinne der Geldwertstabilität war ferner der von Frankreich vorgeschlagene Übergang zu einem gespaltenen Devisenmarkt. In der bewußten Herbeiführung unterschiedlicher Wechselkurse für Waren- und Kapitaltransaktionen fand die Abneigung gegen Geldgeschäfte aus Spekulationsmotiven ihren Ausdruck, die auf der Annahme beruhte, daß kurzfristige, "schlechte" Kapitalbewegungen von langfristigen, durch Leistungsgeschäfte induzierte, "guten" Kapitalbewegungen getrennt werden konnten. ${ }^{206}$ Folgt man den Untersuchungen von Hasse et. al., so ist die unausgesprochene Annahme der eindeutigen Trennbarkeit des kurzfristigen vom langfristigen Kapitalverkehr sowie die Annahme einer nicht bestehenden Interdependenz zwischen beiden weder ökonomisch noch statistisch haltbar. ${ }^{207}$ Ein gespaltener Devisenmarkt hätte Leistungstransaktionen mit zusätzlichem Verwaltungsaufwand belastet, dadurch Wirtschaftsabläufe verzögert und Kaufleute letztlich zu "Befehlsempfängern" degradiert. ${ }^{208}$ Hinzu kommt, daß der Kapitalverkehr außerdem regelmäßig in Grenzfällen mit juristischen Unsicherheiten konfrontiert gewesen wäre, die sich wiederum lähmend auf die zugrundeliegenden Realtransaktionen ausgewirkt hätten. Darüber hinaus hätte die Spaltung der Devisenmärkte auf gesamteuropäischer Ebene den Integrationsprozeß hin zur Wirtschafts- und Währungsunion verlangsamt und damit letztlich den Zielen der monetaristischen Integrationskonzeption widersprochen. ${ }^{209}$

\footnotetext{
${ }^{206}$ Vgl. Hasse, R. et. al. (1975), Außenwirtschaftliche Absicherung zwischen Markt und Interventionismus, Frankfurt/M., S. 52 f.

207 Vgl. Hasse et. al. (1975), a.a.O., S. 53-61

${ }^{208}$ ebenda, S. 61

${ }^{209} \mathrm{Zu}$ den administrativen Erfordernissen der Durchsetzung eines gespaltenen Devisenmarktes sowie den Folgen siehe Hasse (1975), a.a.O., S. 51-79
} 
Insgesamt stand das Stabilitätsbemühen Frankreichs auf währungspolitischem Gebiet den eigenen Zielen und Interessen entgegen. Wie schon auf dem Gebiet der Wirtschaftspolitik strebte Frankreich auch im monetären Bereich eine politisch kontrollierte Entwicklung der zentralen Aggregatgrößen an. Währungsexperten und Politiker waren die dominierenden Agenten, welche nach französischen Vorstellungen die Stabilität des Geldwertes herbeiführen und erhalten sollten, ohne dabei ,autonomen“ Marktmechanismen Spielraum und Einfluß zu gewähren. Die Überlegenheit der konzertierten Zusammenarbeit von Experten und Politikern der Marktkoordination gegenüber drückte sich aus französischer Sicht vor allem in der ihnen unterstellten Fähigkeit zur "objektiven" Ermittlung des weltweiten Liquiditätsbedarfs und der darauf aufbauenden "rationalen" Liquiditätssteuerung aus. Das Vertrauen in das überlegene Wissen der geldpolitischen Akteure resultierte zumindest beim französischen Wirtschafts- und Finanzminister aus der grundsätzlichen Überzeugung, daß die Wirtschaft von der politischen Ebene aus steuerbar war. Auf die Frage, ob er dabei bestimmten grundlegenden Überzeugungen folge, antwortete er in einem Interview im August 1971:

„Ja, das ist wirklich eine merkwürdige Sache. Ich würde mich selbst als einen Neoliberalen bezeichnen. Ich bin für eine durchdachte Marktwirtschaft, in der der Wettbewerb der Unternehmen zu wirtschaftlichen Anpassungen führt. Und ich bin für eine quantifizierende Wirtschaftspolitik, soweit es die volkswirtschaftlichen Größen betrifft. Denn ich behaupte, daß die wichtigsten Größen, seien sie nun monetärer oder budgetärer Art, quantitativ vorausgeschätzt und mengenmäßig beeinflußt sein müssen. “210

An gleicher Stelle bekannte sich Giscard d'Estaing ferner zur Legitimität des wirtschaftspolitischen Ziels, Exportüberschüsse zu erwirtschaften und diese zu verteidigen, solange dabei nicht mit ,unlauteren“ Mitteln gearbeitet würde. Dieses wäre für Frankreich um so wichtiger, da wirtschaftliche Macht letztlich politische Macht sei und Frankreich seine politische Macht mit wirtschaftlicher Macht unterlegen müsse, um in Europa das „Gleichgewicht“ zu wahren. ${ }^{211}$ Diese Überzeugungen waren identisch mit den ordnungspolitischen Ansichten Staatspräsident Pompidous, die ebenfalls auf ein wirtschaftlich leistungsfähiges und damit politisch machtvolles und unabhängiges Europa abzielten. Frankreichs Währungspolitik fußte somit auf einem Ansatz, der letztlich nichts zu tun hatte mit einer unabhängigen, allein der Preisstabilität verpflichteten Geldpolitik.

\section{B.3.4.2 Der Übergang zum Paritätengitter}

Ein starres Festhalten an den konfligierenden Standpunkten der streitenden Mitgliedstaaten hätte unweigerlich das Ende jeglicher europäischer Integrationsbemühen be-

${ }^{210}$ Giscard d'Estaing im Interview mit DER SPIEGEL, a.a.O., S. 86

211 ebenda. Auf die Frage, ob er glaube, daß sich wirtschaftliche Macht automatisch in politische Macht umsetze, antwortete Giscard d'Estaing: "Wirtschaftliche Macht ist politische Macht." (Hervorhebung im Original) 
deutet und außerdem das Funktionieren des Agrarmarktes bedroht, an dem Frankreich besonders viel lag. ${ }^{212}$ Frankreich und die Bundesrepublik waren von daher gezwungen, ihre dogmatischen Haltungen früher oder später aufzugeben. Ein Kompromiß gelang auf der Ministerratssitzung am 13. September 1971, auf der die sechs Finanzminister übereinkamen, grundsätzlich feste Paritäten zu vereinbaren, die jedoch „realistisch“ zu seien hätten. ${ }^{213}$ Ferner wurde beschlossen, ein Realignment der Paritäten im internationalen Währungssystem anzustreben, bei dem die Anpassungslasten dem Anpassungsvermögen der Volkswirtschaften entsprechen sollten. Außerdem sprachen sich die Minister für gemeinsame Maßnahmen zur Entmutigung spekulativer Kapitalbewegungen aus, wobei in erster Linie an eine Erweiterung der Bandbreiten gedacht war. Ferner sollte die Schaffung zusätzlicher Liquidität wieder über Gold abgesichert und in zunehmenden Maße über Ziehungen von SZR realisiert werden, bei gleichzeitiger Reduzierung der Bedeutung nationaler Währungen als Reserveinstrument. Direkt an die USA gewandt forderten die Sechs die Beseitigung der im August 1971 von den USA errichteten Handelshemmnisse. Mit der Einigung auf die neue Formel der "festen, aber anpassungsfähigen" Wechselkurse umgingen die Europäer das währungspolitische Patt. Frankreich verabschiedete sich von der Doktrin der unantastbaren Paritäten, während die Bundesrepublik Abstand vom Blockfloating nahm. Die Begeisterung französischerseits über diesen Kompromiß war jedoch gering, da man, wie Giscard d'Estaing feststellte, auf eine Periode geringeren Wachstums zugehe. ${ }^{214}$ Er forderte daher, daß der Franc bei einem Realignment nicht aufgewertet werden dürfe. ${ }^{215}$ Die Zustimmung Frankreichs zu diesem Kompromiß wurde durch die Tatsache erleichtert, daß die Partnerstaaten ihm hinsichtlich der französischen Kernforderungen nach einer schärferen Kontrolle des Kapitalverkehrs und in bezug auf die Rolle des Goldes, der SZR und des Dollars entgegenkamen.

Mit der Überwindung der alten Frontstellung war das Tor zur vorläufigen Lösung der Währungskrise aufgestoßen, die schließlich mit dem Smithsonian Agreement im Dezember 1971 erreicht wurde. Frankreich war an diesem Erfolg insofern beteiligt, als der französische Staatspräsident während eines Treffens mit dem amerikanischen Präsidenten am 14. Dezember 1971 auf den Azoren die grundsätzliche Zustimmung der USA zu einem Realignment erreichte. Vier Tage später, am 18. Dezember, wurden die Paritäten neu bewertet: Der Dollar wertete um 7,9 Prozent ab, während die DM um 4,6 Prozent, der Gulden, der belgische und französische Franc jeweils um 2,76 Prozent aufwerteten. Die Schwankungsbreiten wurden auf 2,25 Prozent ober- und unterhalb

\footnotetext{
${ }^{212}$ Vgl. Pressekonferenz des französischen Staatspräsidenten vom 23.9.1971, a.a.O., D 510 sowie die Rede Außenminister Schumanns vor der Nationalversammlung am 3.11.1971, in: EA, Folge 24, D 563

${ }^{213} \mathrm{Vgl}$. Kommuniqué der Ministerratssitzung vom 13.9.1971, abgedruckt in Auszügen in: Le Monde, "Le communiqué de Bruxelles", 15.9.1971, S. 34

${ }^{214}$ So Giscard d'Estaing in seiner Ansprache auf der Jahresversammlung der Gouverneure des IWF und der BIZ am 28.9.1971, abgedruckt in: PE, S. 140, 2. Sem. S. $139 \mathrm{ff}$.

${ }^{215}$ So die Äußerungen des französischen Finanzministers nach der Ministerratssitzung vom 13.9.1971, vgl. o. V., "Les Six proposent un réalignement des monnaies", Le Monde vom 15.9.1971, S. 34
} 
der offiziellen Wechselkurse erweitert und der Goldpreis von 35 auf 38 Dollar pro Feinunze erhöht. Die USA versprachen außerdem, ihre Handelsbeschränkungen aufzuheben. Die Wiedereinführung der Goldkonvertibilität des Dollars blieb jedoch ungelöst, da der neue offizielle Goldpreis immer noch deutlich unter dem Marktpreis lag und ein goldkonvertibler Dollar die Goldreserven der USA weiter reduziert hätte. Die Goldkonvertibilität sollte auch in den folgenden Jahren nicht wieder eingeführt werden. Das internationale Währungssystem war damit seines ureigensten Wesensmerkmals und damit seiner Stabilitätsgarantie beraubt: dem jederzeit gültigen Umtauschversprechen des Dollars in Gold. Mit dem Smithonian Agreement mutierte der GoldDollar-Standard von 1944 faktisch zu einem reinen Dollar-Standard. Die überraschend hohe Abwertung des Dollars entsprang einer geschickten Verhandlungsstrategie der USA. Sie waren entschlossen, sich von der Golddeckung des Dollars zu befreien und zögerten eine Verhandlungslösung solange hinaus, bis die Europäer ihnen mit einem Blockfloating und massiven Kapitalverkehrsbeschränkungen drohten. ${ }^{216}$ Erst in diesem Moment bekannten sie ihre Bereitschaft zur Abwertung des Dollars, dann jedoch in einem Maße, das die Europäer und vor allem Frankreich vorher nie akzeptiert hätten. $^{217}$

Die französische Regierung wertete diese Vereinbarung dennoch als einen Erfolg und sah ihre Position bestätigt. Die abtrünnigen Währungen waren wieder in das Festkurssystem zurückgekehrt, "... le seul susceptible de favoriser la croissance des échanges internationaux, c'est-à-dire le développement économique" ${ }^{118}$. Aus französischer Sicht war dieses Währungsabkommen jedoch keine generelle Lösung, zumal das Problem der Konvertibilität des Dollars und der erweiterten Margen noch bestand. Immerhin war man zufrieden, daß die Wettbewerbsfähigkeit Frankreichs faktisch nicht beeinträchtigt wurde. Zumindest fiel die Abwertung des Dollars gegenüber dem Franc im Vergleich zur D-Mark geringer aus. Den gespaltenen Devisenmarkt und die nationalen Kapitalverkehrskontrollen allerdings wollte die französische Regierung solange weiter aufrechterhalten, bis die Güter- und Kapitaltransaktionen in Länder mit nicht konvertierbaren Währungen wieder einander entsprechen würden. Im neuen Kompromiß konnte die französische Währungspolitik letztlich wesentliche Teile ihrer Positionen noch einmal als gerettet betrachten.

Auf europäischer Ebene bedeutete die erweiterte Schwankungsbreite von insgesamt 4,5 Prozent bei kreuzweiser Ausnutzung der Schwankungsbreiten im Zeitverlauf eine maximale Abweichung der Paritäten von 9 Prozent. Dieser Umstand bedrohte den so mühsam ausgehandelten Agrarpreismechanismus und erforderte daher eine Reaktion der Gemeinschaft. Die französische Regierung drängte auf eine Reduktion der Band-

${ }^{216}$ Geschehen auf der Konferenz der Zehner-Gruppe am 1.12.1971 in Rom. Eine detaillierte Beschreibung des Tagungsablaufs bei Hellmann, R. (1977), La guerre des monnaies, Paris, S. 9-12

${ }^{217}$ So die Beurteilung von Lutz (1976), a.a.O., S. 474

${ }^{218}$ So Giscard d'Estaing am 21.12.1971 vor dem Wirtschafts- und Sozialrat über die Beschlüsse von Washington, abgedruckt in: PE, S. 315, 2. Sem. S. 315 ff. 
breiten innerhalb der Gemeinschaft und auf nochmals verschärfte Restriktionen für den Kapitalverkehr. ${ }^{219}$ Zur Reduzierung der Rolle des Dollars als Währungsreserve sollten außerdem die Interventionen der europäischen Zentralbanken zukünftig in europäischen Währungen erfolgen, welche damit vergleichbar dem Dollar in den Stand von Währungsreserven erhoben worden wären. ${ }^{220}$ Konkrete Vorschläge diesbezüglich wurden den Partnern im März des Jahres 1972 zugeleitet. ${ }^{221}$

Ende März beschloß der Ministerrat die Errichtung eines innereuropäischen Wechselkursverbundes. Er forderte die Zentralbanken auf, spätestens bis zum 1. Juli 1972 die Schwankungsbreiten der Mitgliedswährungen auf insgesamt 2,25 Prozent zu verringern. ${ }^{222}$ Durch eine beidseitige Interventionsverpflichtung in Gemeinschaftswährungen sollten die Wechselkurse stabilisiert werden. Auf diese Weise entstand das Gemeinschaftsband, für das sich schnell der Name "Schlange" fand. Nur wenn eine Währung die obere oder untere Grenze des „Tunnels“, d. h. der maximal erlaubten Abweichung zur Dollarparität erreichte, waren Interventionen in Dollar erlaubt. Parallel zur Errichtung des Europäischen Wechselkursverbundes verabschiedete der Ministerrat die "Richtlinie zur Regulierung der internationalen Finanzströme und zur Neutralisierung ihrer unerwünschten Wirkungen auf die binnenwirtschaftliche Liquidität"223. Fast drei Jahre nach Antritt der neuen Regierung konnte Frankreich endlich sein währungspolitisches Kernanliegen als realisiert ansehen. Ein Regime fester Wechselkurse war installiert, dessen Funktionsfähigkeit mit Kapitalverkehrskontrollen abgesichert und Europa wieder auf monetaristischen Integrationskurs zurückgebracht.

Hinsichtlich der Koordination der Wirtschafts- und Währungspolitik hielt sich das neue Arrangement allerdings ähnlich zurück wie zuvor schon die Ratsentscheidung vom 9. Februar 1971. Auch im Europäischen Wechselkursverbund war nur eine Intensivierung der Konsultationen vorgesehen, was sich bei der im Frühjahr 1972 wieder anziehenden Inflation schnell als Problem erweisen sollte. Die offiziellen Paritäten, die keine Gleichgewichtskurse widerspiegelten, konnten nur mühsam mit Interventionen, gespaltenen Devisenmärkten und Kapitalverkehrskontrollen verteidigt werden. ${ }^{224}$

${ }^{219}$ Konkret sollten Zinszahlungen an Devisenausländer, Auslandskredite inländischer Unternehmen sowie die Auslandspositionen der Banken im restriktiven Sinne beeinflußt werden, vgl. die Erklärungen Giscard d'Estaings vor dem Finanzausschuß der Nationalversammlung vom 27.1.1972, abgedruckt in: PE, S. 79, 1. Sem., S. $78 \mathrm{ff}$.

220 ebenda

${ }^{221}$ Vgl. die Rede Giscard d'Estaings vor der Nationalversammlung am 22.1.1974, abgedruckt in: PE, S. 41,1 . Sem., S. $39 \mathrm{ff}$.

${ }^{222}$ Vgl. Entschließung des Rates der Europäischen Gemeinschaften und der Vertreter der Mitgliedstaaten vom 21.3.1972 betreffend die stufenweise Verwirklichung der Wirtschafts- und Währungsunion, D 339, abgedruckt in: EA, Folge 14, D 337-D 339

${ }^{223} \mathrm{Vgl}$. Amtsblatt der Europäischen Gemeinschaften, 15. Jg., Nr. L 91 vom 18. April 1972, S. 13 f.

${ }^{224}$ Vgl. Hasse, R. (1979), Der Europäische Wechselkursverbund - Entwicklung und Erfahrungen mit einem internationalen Multiwährungsinterventionsstandard bei festen und flexiblen Wechselkursen, Gutachten erstellt im Auftrag des Bundesministers für Wirtschaft, S. 16 sowie Hellmann (1977), a.a.O., S. 24 
Schon drei Monate nach ihrer Gründung verlor die „Schlange“ das Vertrauen der Märkte. Im Verlauf der Pfund-Krise vom Sommer 1972 erlagen Großbritannien und Dänemark im Zuge einer Spekulationswelle den rigiden Systemzwängen des Europäischen Wechselkursverbundes und sahen sich zum Austritt gezwungen. Die Monetaristen mußten zum zweiten Mal in kurzer Folge erkennen, daß politisch gesetzte monetäre Sachzwänge allein offenbar nicht ausreichten, um die Partnerstaaten zu einer hinreichend engen wirtschafts- und währungspolitischen Koordination sowie zur notwendigen Stabilitätsdisziplin zu bewegen.

Trotz dieses Rückschlags blieb die „Schlange“ für die französische Währungspolitik weiter von zentraler Bedeutung. Mit ihr bot sich nach dem Rückschlag von 1971 ein zweites Mal die Chance zur Realisierung des „deuxième pôle monétaire“. Die monetäre Eigenständigkeit Europas versuchte Frankreich zu stärken, indem es seinen Partnern eine weitere Intensivierung der Zusammenarbeit bei der Durchführung von Zentralbankinterventionen und bei der Inflationsbekämpfung vorschlug. Hinsichtlich eines gemeinsamen Vorgehens gegen die weltweit sich beschleunigende Inflation - die in Frankreich ab 1972 schneller anstieg als in der Bundesrepublik - regte Giscard d'Estaing eine „konzertierte Aktion“ der Gemeinschaft an. ${ }^{225}$ Konkret forderte er, sofort die Arbeitsgruppe zur Koordination der kurzfristigen Wirtschafts- und Währungspolitik mit der Prüfung der Preisentwicklung in den Mitgliedsstaaten sowie mit der Erarbeitung eines Vorschlages zum gemeinsamen Vorgehen gegen den Preisanstieg zu beauftragen. Eine optimale Strategie zur Bekämpfung der Inflation sollte sich dabei vornehmlich auf die gemeinsame Kontrolle der Preis- und vor allem der Lohnentwicklung konzentrieren, was aus französischer Sicht zusätzlich die Einbindung der Sozialpartner erforderlich machte. ${ }^{226}$ Der von Frankreich grundsätzlich gewünschte soziale Dialog auf europäischer Ebene hatte somit auch währungspolitische Relevanz, indem er als Transmissionsriemen funktionierte, der die Tarifpolitik der Sozialpartner direkt mit den Zielen der europäischen Geldpolitik verband. Auf welche konkreten Maßnahmen die weitere Zusammenarbeit bei der Kontrolle der Preisentwicklung hinauslaufen sollte, blieb französischerseits allerdings unklar. Auf nationaler Ebene war die französische Regierung zu dieser Zeit gerade dazu übergegangen, mit Preisstops und vertraglichen Preisregulierungen (contrats anti-hausse) die Inflation zu bekämpfen. Es ist davon auszugehen, daß die französische Regierung im Falle eines positiven Echos seitens der Partnerstaaten angestrebt hätte, diese Maßnahmen auf europäische Ebene zu übertragen.

Was die französische Regierung im Zusammenhang mit der gemeinschaftlichen Inflationsbekämpfung strikt ablehnte, war eine restriktive Geldpolitik. Aufgrund der Ergebnisse aktueller Studien, die bewiesen hätten, daß die Zunahme des Wirtschaftswachs-

${ }^{225} \mathrm{Vgl}$. den Brief des französischen Finanzministers an seine Kollegen vom 1.9.1972, abgedruckt in: PE, S. 66

${ }^{226}$ ebenda, S. 63 sowie Fabra, P., "Et si la vieille théorie était juste ...", Le Monde vom 1.11.1972, S. 1 und 24 
tums mit dem der Geldmenge einhergehe, fühlte sich der französische Wirtschafts- und Finanzminister in seiner Auffassung bestätigt, daß die Lehre von der "Neutralität des Geldes" nicht stimme. ${ }^{227}$ Um die Wirtschaftsentwicklung nicht abzuwürgen, war eine restriktive Geldmengenpolitik zu vermeiden. Da die französische Regierung infolge der Währungsunruhen mittelfristig eine Verlangsamung des Wachstums befürchtete, ging sie wieder zu einer lockereren Geldpolitik über. Die europäischen Partnerstaaten forderte sie auf, die Steuerung der Inflationsbekämpfung nicht ausschließlich von der Kostenseite, sondern zunehmend wieder von der Nachfrageseite her vorzunehmen. ${ }^{228}$ Mit dieser keynesianisch inspirierten makroökonomischen Politik blieb Giscard d'Estaing seiner Philosophie von der Steuerbarkeit der Volkswirtschaft über die bewußte Beeinflussung zentraler gesamtwirtschaftlicher Kenngrößen treu. Seiner Selbsteinschätzung als neoliberaler Ökonom dürfte er damit jedoch kaum genügt haben. Die europäischen Kollegen vermochte der Politikentwurf des französischen Wirtschafts- und Finanzministers nicht zu überzeugen. Am 31. Oktober 1973 verabschiedete der Ministerrat eine Entschließung zum Kampf gegen die Inflation, derzufolge sich die Mitgliedstaaten um die Begrenzung der Preissteigerungsrate auf maximal 4 Prozent "bemühen" wollten. Statt der von Frankreich gewünschten präzisen Maßnahmen enthielt sie sonst nur Absichtserklärungen hinsichtlich der Begrenzung der Staatsausgaben und des Geldmengenwachstums. ${ }^{29}$ Ihre Auswirkungen auf die Preisentwicklung blieben denn auch, wie die zweistelligen Inflationsraten des Jahres 1973 zeigten, eher begrenzt. ${ }^{230}$

Der zweite währungspolitische Schwerpunkt der französischen Regierung auf europäischer Ebene betraf die Intensivierung der Zusammenarbeit zur Verteidigung der Paritäten innerhalb der verengten Bandbreiten. Zu diesem Zweck hatte sie bereits 1969 vorgeschlagen, die Währungsreserven der Mitgliedstaaten innerhalb eines gemeinsamen Fonds zu poolen. Die Gründung des Europäischen Fonds für Währungspolitische Zusammenarbeit (EFWZ) noch während der ersten Phase des Übergangs zur Währungsunion war am 11. September 1972 beschlossen worden. ${ }^{231}$ Auf dem Pariser Gipfel im Oktober 1972 forderte Frankreich jedoch schon seine beschleunigte Errichtung sowie die Erhöhung des Umfangs seiner Beistandsfazilitäten und die gemeinsame Verwaltung eines zunehmend größeren Teils der nationalen Währungsreserven. ${ }^{232}$ Zentralbanken und Regierungen sollten alles tun, um Europa zu einer "Zone der Stabi-

\footnotetext{
${ }^{227}$ Vgl. Fabra, P., "Et si la vieille théorie était juste ...", Le Monde vom 1.11.1972, S. 1 und 24

${ }^{228}$ So in seinem Schreiben an die Finanzminister vor der Ministerratssitzung vom 11. September, vgl. o. V., "Les pays européens divergent sur la façon de lutter contre l'inflation et sur les réformes monétaires à entreprendre", Le Monde vom 9.9.1972, S. 30

${ }^{229} \mathrm{Vgl}$. die Entschließung des Ministerrates der EG zur Inflationsbekämpfung vom 31.10.1973, abgedruckt in: PE, 2. Sem., S. $120 \mathrm{ff}$.

${ }^{230}$ Zum Verlauf der gemeinsamen Maßnahmen und ihrem geringen Erfolg siehe Nürk, R. (1993), Die Koordinierung der Konjunkturpolitik in der Europäischen Gemeinschaft, Baden-Baden, S. 117-121

${ }^{231} \mathrm{Vgl}$. die Erklärungen des Ministerrats vom 11. und 12.9.1972, abgedruckt in: EA, Folge 19/1972, D $470 \mathrm{f}$.

${ }^{232}$ Vgl. die Rede Pompidous vom 19.10.1972, a.a.O., S. 104 f.
} 
lität und des Wachstums" zu machen, so Pompidou ${ }^{233}$, der damit die Währungspolitik in eine direkte Verbindung mit den politisch angestrebten Wachstumszielen brachte. Die Poolung von Interventionsmitteln sowie die vereinbarten symmetrischen Interventionen hätten jedoch allenfalls kurzfristig zur Stabilisierung der Wechselkurse führen können. Über die Erweiterung der Interventionsmittel und die Verteilung der Interventionslasten auf zwei Zentralbanken wäre überdies der Zwang zu einer stabilitätsorientierten Politik herabgesetzt worden. Bei der damals offensichtlich geringen Neigung der Regierungen, ihre Wirtschaftspolitik externen Sachzwängen zu unterwerfen, hätten Defizitländer die Milderung der Stabilitätszwänge wahrscheinlich eher zur Fortführung ihrer bisherigen Politik benutzt. Folgt man Bofingers Analyse von Systemen fester Wechselkurse, so entsprach das von Frankreich präferierte Arrangement mit seinen massiven Interventionsmitteln dem "Kompromiß- Paritätengitter-Standard", der in dieser Ausgestaltung von seinem stabilisierenden Effekt her stark zum "inflationären $\mathrm{Pa}$ ritätengitter-Standard" tendierte und damit dem Festkurssystem mit dem geringsten Inflationsschutz entsprach. ${ }^{234}$

Zusätzlich destabilisierend hätte außerdem noch eine Erhöhung des Goldpreises gewirkt, die Staatspräsident Pompidou im Oktober 1972 mit seinem Vorschlag, den damaligen Goldpreis der aktuellen Entwicklung anzupassen, in die Diskussion brachte. ${ }^{235}$ Dem Interzentralbankenpreis von 38 Dollar stand mittlerweile ein Marktpreis von bis zu 170 Dollar pro Feinunze Gold gegenüber, was bereits zur völligen Suspendierung des Goldes im Saldenausgleich zwischen den Zentralbanken geführt hatte. Durch die Anpassung des Interzentralbankenpreises wäre es zur Wiedereinführung des Goldes als Währungsreserve im Zahlungsverkehr der Zentralbanken gekommen. Neue Liquidität wäre so geschaffen, die den damaligen Überhang an internationaler Liquidität noch einmal vergrößert hätte. Mit diesem Vorschlag konterkarierte Frankreich somit ein weiteres Mal sein erklärtes Bemühen um die Geldwertstabilität.

Inkonsistenz prägte auch die französischen Vorstöße zur Reform des internationalen Währungssystems. Die neu gewonnene währungspolitische Einheit Europas, deren maßgebliches Charakteristikum aus französischer Sicht in der Nutzung ihrer eigenen Währungen für Interventionen bestand, nutzte die französische Regierung noch im Monat ihrer Entstehung zur Neuordnung des Verhältnisses Europa - USA. Innerhalb des internationalen Währungssystems, so Giscard d'Estaing in einer Rede vor amerikanischen Geschäftsleuten am 3. März 1972, müsse entschlossen zur Verteidigung der neu festgelegten Paritäten übergegangen werden. Grundsätzliche Voraussetzung dazu war seiner Meinung nach eine Gestaltung des Kapitalverkehrs derart, daß langfristige, investitionstragende Transaktion ermöglicht würden, während destabilisierende, kurz-

233 ebenda

${ }^{234} \mathrm{Vgl}$. Bofinger (1991), Festkurssystem und geldpolitische Koordination, Baden-Baden, S. $160 \mathrm{f}$. und S. 165

${ }^{235}$ Vgl. die Rede Pompidous am 19.10.1972, a.a.O., S. 105 
fristige Kapitalbewegungen zu unterbinden seien. ${ }^{236}$ Als mittlerweile weltgrößter Reservenhalter müßte Europa in Zukunft die USA beim Tragen der Lasten der Konvertibilität unterstützen. Frankreich ging damit unausgesprochen von seiner Forderung ab, den USA die Lasten der Beseitigung ihres Zahlungsbilanzdefizits allein aufzubürden. Das neue Verhältnis zwischen Europa und den USA sollte ein "Parallelismus" sein, in dem keiner den anderen als "zone de tirage" für die Erzielung von Überschüssen betrachtete. ${ }^{237}$ Handelsbilanzüberschüsse im europäisch-amerikanischen Verhältnis sollten nur in dem Umfang geduldet werden, wie sie zum Kapitalexport, zu dem die beiden "Zonen" als führende Industrieblöcke der dritten Welt gegenüber verpflichtet wären, notwendig waren. ${ }^{238}$ Der amerikanisch-europäische Außenhandel erschien somit aus französischer Sicht ein weiteres Mal als originär politische Größe und nicht als Arbitrageergebnis, das sich aufgrund von komparativen Kostenvorteilen auf den Warenmärkten von selbst einstellte.

Auf der Jahresversammlung der Gouverneure des IWF und der BIZ im September 1972 mündeten diese Vorschläge in ein neues Reformprogramm zur Konsolidierung des internationalen Währungssystems, dessen Verwirklichung der französische Wirtschafts- und Finanzminister bis zur Jahresversammlung 1973 forderte. Ausgehend vom Leitgedanken des Parallelismus wurde nun die "Symmetrie" zur zentralen Forderung Frankreichs in bezug auf die Neugestaltung der internationalen Währungsbeziehungen:

"Symétrique, car nous traitons d'un sujet qui affecte l'ensemble des relations internationales et même ... l'essentiel de ces relations, dès lors qu'elles sont devenues pacifiques. La symétrie des droits et des devoirs dans le domaine monétaire est l'équivalent de l'indépendance sur le plan politique. Aussi devrons-nous veiller à assurer cette symétrie dans nos conclusions: symétrie entre les devoirs d'ajustement des pays en déficit et ceux en excédent, symétrie entre les efforts demandés aux grands pays dont la monnaie est accepté par les autres et ceux qui doivent faire appel au crédit international, symétrie dans le respect des intérêts des pays industrialisés et ceux des nations en voie de développement, enfin cette symétrie, la plus difficile sans doute à atteindre, et qui consiste à se tenir à égale distance de l'inflation et de la déflation." ${ }^{239}$

Bei der Symmetrie handelte es sich um ein umfassendes, den Bereich der Währungspolitik weit transzendierendes Meta-Prinzip, dessen universelle Gültigkeit offenbar allein schon hinreichend war, um ihm die währungspolitischen Beziehungen, die französischerseits wiederum als bedeutender Bestandteil staatlicher Außenbeziehungen

236 "Or, la préoccupation de ceux qui s'efforcent de maintenir un système monétaire international organisé, c'est de faire que les sorties de capitaux à long terme puissent s'effectuer dans les conditions satisfaisantes dès lors qu'ils sont porteurs d'investissements. Par contre, les mouvements déstabilisateurs de capitaux doivent faire l'objet d'une réflexion des banques centrales", so Giscard d'Estaing in einer Konferenz vor amerikanischen Geschäftsleuten am 3.3.1972, abgedruckt in: PE, S. 110,1 . Sem., S. $106 \mathrm{ff}$.

${ }^{237}$ ebenda, S. 112

${ }^{238}$ ebenda

${ }^{239}$ Ansprache Giscard d'Estaings auf der Jahresversammlung des IWF und der BIZ am 26.9.1972, abgedruckt in: PE, S. 83, 2. Sem, S. 83 ff. 
wahrgenommen wurden, zu unterwerfen. Sachliche Bedenken im Hinblick auf die Geldwertstabilität nahmen aus dieser Sichtweise nur eine nachgeordnete Rolle ein. Die Identifizierung der monetären Außenbeziehungen mit der für Frankreich so wichtigen ,indépendance" deutete erneut darauf hin, daß die Währungspolitik aus Sicht der französischen Regierung integraler Bestandteil ihres machtpolitisch und geostrategisch inspirierten Ordnungswollens war, das primär die Gleichberechtigung Europas im Verhältnis zu den USA zum Ziel hatte. Dem Primat der Außenpolitik untergeordnet, mußte sich die französische Währungspolitik am Ende unweigerlich ihrer Sachrationalität beraubt finden.

Die Tendenz zur stärkeren Politisierung der internationalen Währungsbeziehungen prägte auch das von Frankreich vorgeschlagene Konzept zu ihrer Stabilisierung. Zur dauerhaften Sicherstellung der Funktionsfähigkeit eines internationalen Paritätengitters, das im Kern auf den in Gold definierten SZR basieren sollte, schlug der französische Wirtschafts- und Finanzminister ein Prozedere in drei Phasen vor. In Phase eins sollten die allgemeine Funktionsfähigkeit gestärkt sowie Maßnahmen zur finanziellen Unterstützung der Entwicklungsländer getroffen werden. ${ }^{240}$ Wichtig in diesem $\mathrm{Zu}$ sammenhang war Giscard d'Estaing die Vermeidung zweierlei Fehlverhaltens:

"Le changement de parité ne doit pas être conçu comme un substitut aux politiques internes de rétablissement de l'équilibre extérieur. D'autre part, les modifications de parités ne doivent pas être commandées par des critères d'application automatique. Il ne faut pas tenter d'accomplir par des procédures formelles ce qui doit résulter du jeu même des règles monétaires internationales: c'est l'état des règlements entre banques centrales qui doit fournir les principales incitations aux changements de parités dans un sens ou dans l'autre." 241

Kapitaler Fehler aus französischer Sicht waren somit zum einen, den Wechselkurs als wirtschaftspolitisches Anpassungsinstrument zu nutzen, und zum anderen, eine regelgebundene Währungspolitik zu verfolgen. Mit letzterem wurde auf ein Mittel der Stabilisierung verzichtet, denn bei adaptiver Erwartungsbildung seitens der Wirtschaftssubjekte sind Regeln üblicherweise als Mittel zur Stabilisierung des Geldwerts zu sehen. Frankreich zog statt dessen diskretionäre Regelungen durch die Währungsbehörden vor, die damals fast alle von den jeweiligen Regierungen abhängig waren. Damit wäre der währungspolitische Durchgriff bis in letzte währungstechnische Einzelheiten und über diesen eine direkte Einbindung der Geld- und Währungspolitik in die allgemeinpolitischen Bemühungen zur Gestaltung der Wirtschaftsentwicklung ermöglicht worden.

In Phase zwei sollte das internationale Währungssystem zur vollständigen Konvertibilität aller Währungen übergehen, was für den Dollar den endgültigen Verlust des Status als offizielle Währungsreserve bedeutet hätte. Ferner, wesentlich für die Europäer, sollte über Kapitalverkehrskontrollen die "übermäßige" Akkumulation von Währungs-

${ }^{240}$ ebenda, S. 84
${ }^{241}$ ebenda, S. 85 
reserven verhindert werden. ${ }^{242}$ Phase drei sollte schließlich zur Einführung der SZR als neuem Währungsmaßstab führen. Sie sollten allerdings immer noch in Gold definiert werden und nicht, wie neuerdings von den USA gefordert, als abstrakte Währungseinheit. ${ }^{243}$ Phase zwei und drei beinhalteten damit altbekannte Forderungen Frankreichs. Die Anfang 1973 ausbrechenden Währungstumulte nahmen den französischen Reformvorschlägen jedoch jegliche Chance auf Realisierung.

Zusammenfassend betrachtet war die währungspolitische Haltung Frankreichs in der Zeit um das Smithsonian Agreement herum durch den Übergang zur Akzeptanz einer gewissen Wechselkursflexibilität sowie durch die neue Forderung nach symmetrischer Lastenverteilung in den Währungsbeziehungen gekennzeichnet. Die Anerkennung einer gewissen Flexibilität der Wechselkurse war jedoch nicht als Parteinahme zugunsten einer mehr marktorientierten Währungspolitik zu verstehen. Sie wurde zwangsweise akzeptiert und führte ebenso zwangsweise zur Forderung nach symmetrischer Verteilung der Anpassungslasten bei der Wechselkursstabilisierung bzw. beim Zahlungsbilanzausgleich. Über symmetrisch verteilte Anpassungslasten versuchte die französische Währungspolitik, die mit der Flexibilisierung der Wechselkurse verlorengegangenen politischen Einflußmöglichkeiten auf die monetäre Entwicklung zurückzugewinnen. Klarer noch als in der Zeit bis zum August 1971 trat nach der Flexibilisierung des internationalen Währungssystems zutage, daß die französische Regierung die Währungspolitik als ein aktives Instrument zur politischen Gestaltung der Wirtschaftsentwicklung betrachtete, das im engen Zusammenhang mit der Außenhandels- und Wachstumspolitik stand. Ihre Bemühungen um die Geldwertstabilität waren deshalb primär auf die Fixierung der Wechselkurse ausgerichtet, die sie unabhängig von der Wirtschaftsentwicklung über gemeinschaftliche Eingriffe stabilisiert sehen wollte. In der Tat stimmte dann das Postulat Giscard d'Estaings, daß die Symmetrie bei der Verteilung der Anpassungslasten das Pendant der politischen Unabhängigkeit sei. Letztere war offensichtlich das alles überragende Motiv, dem sich auch die Währungspolitik unterzuordnen hatte. Das ungebremste Gestaltungsstreben einer wachstumsorientierten Politik, die auf die Stärkung der Wirtschaftskraft ausgerichtet war, um darüber hinausreichende außenpolitische Ziele zu verwirklichen, und sich zur Lenkung der Wirtschaftsentwicklung verpflichtet und befähigt fühlte, vertrug sich grundsätzlich nicht mit dem Wirken freier Marktkräfte, gleich ob auf monetärer oder realwirtschaftlicher Ebene. Die erst nach vergeblichem Widerstand akzeptierte Flexibilisierung des internationalen Währungssystems mußte zwangsläufig zum Ruf nach Interventionen zur Stabilisierung der Wechselkurse führen. Die „natürliche“ Nachrangigkeit stabilitätspolitischer Erwägungen in der französischen Währungspolitik war somit eine logische Folge.

\footnotetext{
${ }^{242}$ Vgl. die Ansprache Giscard d'Estaings vom 26.9.1972, a.a.O., S. $85 \mathrm{f}$.

${ }^{243}$ Vgl. die Ansprache Giscard d'Estaings vom 26.9.1972, a.a.O., S. 86
} 


\section{B.3.4.3 Der Übergang zum Währungskorb und zum Floating}

Die Rettung des Systems fester Wechselkurse beherrschte die Haltung Frankreichs auch in der Währungskrise vom Februar/März 1973. Die französische Regierung sah in dieser Entwicklung nichts weiter als die Bestätigung ihrer These von der Schädlichkeit flexibler Wechselkurse bei unkontrollierten Kapitalmärkten. Wohl konnte sie noch während der ersten Dollarkrise im Februar mit Befriedigung zur Kenntnis nehmen, daß statt des von Deutschland befürworteten Blockfloatings eine zehnprozentige Abwertung des Dollars beschlossen wurde, die, so Giscard d'Estaing, zwar einen "wirtschaftlichen Mißerfolg" für die USA darstellte, in diesem Fall aber unvermeidbar war. ${ }^{244}$ Als jedoch nur drei Wochen danach unter einem erneuten Überangebot von Devisen die Märkte geschlossen werden mußten, brach die Unterstützung für das Festkurssystem vollends zusammen. Vergeblich appellierte der französische Wirtschaftsund Finanzminister, die neu festgelegten Paritäten zu verteidigen, die seiner Meinung nach durchweg den Realitäten entsprachen. Er wandte sich gegen das von Deutschland und den Niederlanden befürwortete gemeinsame Floating, da dieses unweigerlich eine Aufwertung der europäischen Währungen mit sich bringen würde. ${ }^{245}$

Auf internationaler Ebene blieb dieser Appell jedoch ohne Echo. Das internationale Festkurssystem brach vollends zusammen. Nur auf europäischer Ebene spielten feste Wechselkurse noch eine Rolle. Zwischenzeitlich nutzte Italien die Währungsturbulenzen, um die „Schlange“ zu verlassen, in die es zehn Monate zuvor nur unter der großzügigen Ausnahmegenehmigung hineingelockt werden konnte, als einziges Land seine Interventionen jederzeit in Dollar durchführen zu dürfen.

In den Augen der französischen Regierung manifestierte sich im Zusammenbruch des Systems von Bretton-Woods ein weiteres Mal das Versagen der ,irrationalen“ Marktkräfte, die in einem nicht organisierten Umfeld zu große Freiheiten vorgefunden hätten und dementsprechend leicht ihre zerstörende Wirkung freisetzen konnten. ${ }^{246} \mathrm{Ihr}$ angeblich irrationales Verhalten zeigte sich, so Giscard d'Estaing drei Monate später, vor allem in der paradoxen andauernden Schwäche des Dollars, der trotz einer offensichtlichen Gesundung der US-Wirtschaft sowie der amerikanischen Zahlungsbilanz weiter

${ }^{244}$ Seine Interpretation von Abwertungen gab Giscard d'Estaing in einem Fernsehinterview klar zu erkennen: "Ich möchte noch etwas zum Thema dieser Abwertung sagen: nämlich daß man das Problem in seiner wirklichen Bedeutung sehen muß. Eine Abwertung, das ist kein Erfolg, und vor allem ist es kein Erfolg für das Land, das sie vornimmt. Als wir 1969 den Franc abwerteten, haben wir das getan, weil es notwendig war, aber wir haben niemals so getan, als sei es ein Erfolg. Zwei Abwertungen innerhalb von 14 Monaten, das ist auch für die Vereinigten Staaten, die erste Wirtschaftsmacht der Welt, ein Mißerfolg - man muß es wohl so nennen -, ein wirtschaftlicher Mißerfolg, wohlgemerkt. Aber was zählt, ist schließlich das, was spürbar wird", Fernsehinterview Valéry Giscard d'Estaings anläßlich der währungspolitischen Situation vom 13.2.1973, D 165, in: EA, Folge 7/1973, D 164-D 166

${ }^{245} \mathrm{Vgl}$. Lemaitre, P., "Les Neufs ont reporté leur décision à dimanche prochain", Le Monde vom 6.3.1973, S. 42

${ }^{246}$ So die Analyse Giscard d'Estaings in einer Kabinettssitzung der französischen Regierung am 6.6.1973, abgedruckt in: PE, S. 210 f., 1. Sem. 
an Wert verlor. ${ }^{247}$ Ein rationales Verhalten der Devisenmärkte hätte nach der Neubestimmung „realistischer" Dollarkurse im Februar zu einer Beruhigung der Wechselkursentwicklung führen müssen. ${ }^{248}$ Seiner Meinung nach vermochte das internationale Währungssystem wegen der zu großen Flexibilität und der fortbestehenden Spekulation nicht mehr standzuhalten:

„Une trop grande flexibilité, l'expérience le démontre, ne pourrait que compromettre la coopération mondiale, car les comportements des marchés des changes sont, et demeuront, profondément irrationnels, c'est à dire sensibles à des événements de toutes natures qui peuvent se produire ici ou là dans nos pays qui s'éloignent d'une appréciation objective des situations économiques. Ces derniers jours ont permis de vérifier ce que nous avons affirmé à plusieurs reprises: la fixation de la valeur des monnaies ne peut pas être laissée, dans un monde incertain, au seul jeu de l'offre et de la demande. Il n'existe pas dans ce domaine de vérité stable du marché.“ 249

Das grundsätzlich irrationale Verhalten der Märkte bestand für Giscard d'Estaing in ihrer Unfähigkeit, zu einer "appréciation objective des situations économiques" zu gelangen. Liberalisierte Devisenmärkte schienen ihm grundsätzlich nicht die Fähigkeit zu rationalen Entscheidungen zu besitzen, die in diesem Fall im Vertrauen auf die politisch gesetzten "realistischen" Wechselkurse bestanden hätte. Ob dieser unterstellten Unfähigkeit der Märkte, die Währungsgeschicke selbsttätig „rational“ zu koordinieren, mußten kompetentere Stellen diese Aufgabe übernehmen, nämlich die Politiker und ihre Fachleute in den Währungsbehörden. ${ }^{250}$

Die Währungskrise war für Giscard d'Estaing die logische Konsequenz der Abwesenheit jeglicher Währungsordnung: "Comme sur tout marché non organisé la réalisation permanente de l'équilibre de l'offre et de la demande sur le marché des changes par le mécanisme des prix produit des variations de cours brutales et sans lien avec l'équilibre des balances des paiements sur la moyenne période ${ }^{\text {‘251. }}$. Als im Juni und Juli des Jahres 1973 der Dollar trotz sonst positiver Entwicklung der US-Wirtschaft nochmals stark an Wert verlor, fühlte sich der französische Wirtschafts- und Finanzminister erneut bestätigt und sprach, angesichts der allgemeinen Untätigkeit der Währungsbehörden, sogar von einer "totalen Irrationalität" der Entwicklung und von einem Schritt

${ }^{247}$ ebenda, S. 211

${ }^{248}$ Vgl. die Erklärung Giscard d'Estaings einen Tag später, am 7.6.1973 vor dem Ministerrat der OECD, abgedruckt in: PE, S. 157, 1. Sem., S. 156 ff.; "La persistance d'une certaine agitation, que nous observons, doit être pour nous un sujet de méditation. Elle apporte, me semble-t-il, la démonstration claire qu'il n'est pas réaliste de vouloir confier le soin de fixer le taux de change aux seules lois de marchés, dont on supposerait le comportement national. Je souhaite que cette leçon, évidente à l'heure actuelle, soit entendu.", so Giscard d'Estaing weiter, ebenda, S. 157

249 ebenda, S. 158

250 "Le ministre y voit la preuve de l'echec des théories favorables à une flexibilité des changes. Le simple jeu des marchés économiques, pense-t-il, ne peut régler raisonnablement les mouvements des monnaies. Il faut donc que ce soient les autorités politiques et monétaires qui régularisent le marché et défendent leur monnaie", so die Verlautbarung des Regierungssprechers über die Äußerungen Giscard d'Estaings in der Kabinettssitzung vom 6.6.1973, a.a.O., S. 210

${ }^{251}$ So Giscard d'Estaing am 27.7.1973 in einem Interview mit der TIMES, abgedruckt in: PE, S. 70, 2. Sem., S. $70 \mathrm{ff}$. 
zurück in "Anarchie und Unverantwortlichkeit"252. Das offensichtlich fehlende Engagement auf internationaler Ebene zur Rückkehr zu festen Paritäten hielt ihn nicht davon ab, erneut selbige zu fordern, da sie in seinen Augen nicht nur Abbild einer "guten" Organisation des internationalen Währungssystems waren, sondern allgemein die Voraussetzung für "zufriedenstellend" verlaufende Anpassungsprozesse. ${ }^{253}$

Das Vehikel für die folgenden französischen Versuche zur Wiederherstellung einer stabilen internationalen Währungsordnung war zum wiederholten Male Europa: "L'Europe a pour ambition de définir, pour elle-même, un modèle d'expansion et de stabilité", so der neue Außenminister Jobert im Juni in der französischen Nationalversammlung. ${ }^{254}$ In seiner Vorbildrolle hatte es aus französischer Sicht die Aufgabe, der Welt zu einer stabilen und funktionsfähigen Währungs- und Handelsordnung zu verhelfen - selbstverständlich auf der Basis strikter Gleichberechtigung zwischen den Staaten. ${ }^{255}$ Giscard d'Estaing ging sogar noch weiter, indem er die Handelspolitik direkt mit den Bemühungen um die Stabilisierung des internationalen Währungssystems zu verbinden versuchte. In einer Anhörung durch den Finanzausschuß der Nationalversammlung stellte er ein Junktim zwischen der Aufnahme der Welthandelskonferenz und der Wiederherstellung geordneter Währungsverhältnisse her, da die Rückkehr zu festen Wechselkursen seiner Meinung nach eine wesentliche Voraussetzung furr einen funktionierenden Welthandel darstellte. ${ }^{256}$ Die französischen Verhandlungspartner ließen sich auf diese Forderung jedoch nicht ein.

Resignierend fügte sich Frankreich den Fakten, um einer Isolierung im Internationalen Währungsfonds zu entgehen. Auf der Jahreskonferenz der Gouverneure des IWF und der BIZ am 25. September 1973 trug der französische Wirtschafts- und Finanzminister zwar erneut die Forderung nach der Rückkehr zu festen Paritäten vor. Im Mittelpunkt des zu reformierenden internationalen Währungssystems sollten auch weiter die SZR stehen, die alle Geldfunktionen wahrzunehmen hätten und deren Einführung bis Juli 1974 abgeschlossen sein sollte. Neu an der französischen Position war jedoch, daß die SZR erstmals nicht mehr in Gold, sondern als abstrakte Währungseinheit definiert werden sollten, womit man sich einem amerikanischen Vorschlag anpaßte. ${ }^{257}$ Staatspräsident Pompidou begründete diesen Wechsel vom Gold-SZR-Standard zu einem

${ }^{252}$ ebenda, S. 71

253 "La nécessité de <<tenir >> les taux de change - une fois ceux-ci établis à un niveau réaliste (ce qui était le cas en février dernier) est non seulement une règle de bonne organisation du système monétaire international et de coopération entre les nations, elle est aussi la condition d'un fonctionnement satisfaisant du processus d'ajustement", ebenda

${ }^{254}$ Rede Joberts vor der Nationalversammlung vom 19.6.1973, abgedruckt in: PE, S. 175, 1. Sem., S. $170 \mathrm{ff}$.

${ }^{255}$ ebenda

${ }^{256}$ Vgl. das Kommuniqué über die Anhörung des Wirtschafts- und Finanzministers durch den Finanzausschuß der Nationalversammlung vom 6.7.1973, abgedruckt in: PE, S. 46 f., 2. Sem., S. 45 ff. sowie die Äußerungen Giscard d'Estaings vom 7.6.1973 vor dem Ministerrat der OECD, abgedruckt in: PE, S. 159, 1. Sem., S. 156-161

257 Vgl. die Ansprache Giscard d'Estaings auf der Jahreskonferenz der Gouverneure des IWF und der BIZ vom 25.9.1973, abgedruckt in: PE, S. 109 ff, 2. Sem., S. $107 \mathrm{ff}$. 
reinen Währungskorb-Standard damit, daß gewisse IWF-Mitglieder nicht mehr bereit waren, Gold als Währungsreserve zu akzeptieren, was vor allem für die USA zutraf, und daß Frankreich sich ob seiner relativen Bedeutung im internationalen Währungssystem den herrschenden Verhältnissen nicht entziehen konnte. ${ }^{258}$

Die neue Haltung Frankreichs beruhte somit nicht auf neuen theoretischen Einsichten, sondern auf rein praktischen Überlegungen. ${ }^{259}$ Die Überwindung zu diesem Schritt war allerdings für Giscard d'Estaing größer als für Pompidou. Kurz vor der Jahreskonferenz wurde noch in einer unter seiner persönlichen Leitung entstandenen Studie des französischen Finanzministeriums das Währungskorbkonzept auf Grundlage der SZR verworfen. ${ }^{260}$ In bezug auf die Geldwertstabilität war diesem Ergebnis durchaus zuzustimmen, da ein Währungskorbstandard grundsätzlich voraussetzt, daß die Mehrheit der Mitglieder eine stabilitätsorientierte Wirtschafts- und Währungspolitik betreibt. Sind die Währungen außerdem im Verhältnis zu einer Einheit definiert, die selbst nur das gewichtete Mittel unterschiedlich stabiler Teilnehmerwährungen darstellt, führt dies letztlich nur zu einer Stabilitätsorientierung auf Durchschnittsniveau.

Das Währungskorbkonzept bot keine Garantie für Geldwertstabilität, entsprach aber mit der in ihm angelegten Tendenz zur Politisierung der Währungsangelegenheiten voll und ganz den Prinzipien der französischen Währungspolitik, so daß die Zustimmung zu dem amerikanischen Vorschlag letztlich leicht fiel. Die Kritik, daß es stabilitätsorientierte Länder bei Anpassungsvorgängen tendenziell stärker belaste, entsprach überdies den abermals gewandelten französischen Vorstellungen von der Verteilung der Anpassungslasten. Starkwährungsländer sollten danach durchaus ihren Anteil an den anfallenden Anpassungslasten übernehmen, statt Währungsreserven im Übermaß anzuhäufen. Georges Pompidou betonte in diesem Sinne auf einer Pressekonferenz am 27. September 1973 die Notwendigkeit der Symmetrie der Pflichten von Überschußund Defizitländern bei der Beseitigung von Zahlungsbilanzungleichgewichten, auf die bei der notwendigen Reform des internationalen Währungssystems unbedingt zu achten sei:

„.... mais il va de soi qu'il faut que les déficits permanents de balance commerciale soient sanctionnés, et il va de soi aussi, dusse-je étonner, qu'un excès dans l'accroissement des réserves doit également être surveillé et faire l'objet éventuellement de mesures prudentes, difficiles à mettre au point, mais tout de même doit faire l'objet de mesures, car nous sommes dans un monde où la rivalité économique a pour bonne part, remplacé la rivalité militaire et dire qu'ainsi on punira ceux qui travaillent mieux et qui sont mieux organisé ne m'impressionne pas, car ceux qui faisaient la guerre, ceux qui attaquaient, à moins d'être des fous, étaient des gens qui avaient une organisation militaire meilleure, de meilleures armées et de bonnes chances de gagner aussi, n'est-ce pas?

\footnotetext{
${ }^{258}$ Vgl. die Pressekonferenz Pompidous vom 27.9.73, a.a.O., S. $118 \mathrm{f}$.

${ }^{259}$ ebenda

${ }^{260}$ Vgl. Fabra (1985), a.a.O., S. 148

${ }^{261}$ Vgl. Pompidou auf der Pressekonferenz vom 27.9.1973, a.a.O., S. 120
} 
Pompidou - offenbar um den wirtschaftlichen Frieden besorgt - sah in der Verhinderung neu ausbrechender Konflikte hinreichend Anlaß, um die Verpflichtung von Überschußländern zur Übernahme von Anpassungslasten beim Zahlungsbilanzausgleich zu rechtfertigen. $\mathrm{Da} ß$ eine derartige Belastung wirtschaftlich erfolgreicher Länder und deren Wirtschaftseinheiten letztlich entmutigend auf jegliches intensive Streben nach wirtschaftlichem Erfolg und Geldwertstabilität wirken mußte, war ein offener Widerspruch zu Pompidous eigenen Überzeugungen hinsichtlich der Förderung und Motivation der Wirtschaft wie er sie im Zusammenhang mit der Industriepolitik dargestellt hatte. $\mathrm{Da}$ den Staatspräsidenten dieser Aspekt jedoch „nicht beeindruckte“, läßt wiederum darauf schließen, daß er im Zweifel dazu neigte, politischen Notwendigkeiten den Vorrang vor ökonomischen Erfordernissen einzuräumen. An gleicher Stelle bekannte er sich jedenfalls zu der Überzeugung Giscard d'Estaings, die Freiheit der Finanzmärkte zu beschränken, um die Stabilität des internationalen Währungssystems sicherzustellen und um den Konflikt zwischen reichen und armen Nationen nicht eskalieren zu lassen. Dadurch sollte das internationale Währungssystem seiner wahren Funktion zugeführt werden, den internationalen Handel zu fördern. ${ }^{262}$ Ein weiteres Mal zeigte sich damit, daß die Währungspolitik aus französischer Sicht mehr politischen Opportunitäten und der Außenwirtschaft verpflichtet war als der Geldwertstabilität an sich.

Die zunehmende Enttäuschung Frankreichs über die stagnierende Entwicklung innerhalb des internationalen Währungssystems erreichte im Verlauf der Ölkrise 1973/74 ihren Höhepunkt als der Dollar durch die schlagartige Verteuerung des Öls wieder zu einer gefragten Währung wurde und innerhalb kurzer Zeit fast seine ursprüngliche $\mathrm{Pa}$ rität erreichte. Frankreich erlitt durch seine schlagartig angestiegenen Ausgaben für Ölimporte einen herben Verlust an Währungsreserven, der sich ab Januar 1974 nochmals verschärfte, als der Franc innerhalb der „Schlange“ unter Abwertungsdruck geriet. Die französische Regierung entschloß sich darauf hin kurzfristig, die „Schlange“ für sechs Monate zu verlassen und zum Floating überzugehen. ${ }^{263}$ Diese 180 -GradWendung in der eigenen Währungspolitik fand auf Initiative des Staatspräsidenten und gegen den Willen Giscard d'Estaings statt. ${ }^{264}$ Giscard d'Estaing, der seine währungspolitische Position zum zweiten Mal durch eine Intervention des Staatspräsidenten kompromittiert sehen mußte, blieb in Anbetracht seiner Absicht, Pompidou im Amt zu folgen, nichts weiter übrig, als sich diesem Entschluß zu beugen. ${ }^{265}$

\footnotetext{
262 „Nous ne pouvons pas avoir ce que nous refusions sur le plan intérieur sur le plan international, 'c'est-à-dire une liberté totale dans laquelle les gros écrasent automatiquement les faibles, les riches écrasent les pauvres. Il faut que chacun soit discipliné, et il faut que s'il ne s'auto-discipline pas, on l'incite à se discipliner, par des mesures prudents, je le répète. Au total, un système monétaire international doit permettre de faciliter les échanges, doit assurer une stabilité générale et ne pas être inflationniste, il ne doit pas être non plus à l'excès concurrentiel et capitaliste, car nous retrouverions l'éternel duel entre les pays riches et pauvres, nous arriverions fatalement à une catastrophe mondial", ebenda

${ }^{263}$ Ein Überblick über die Einzelheiten dieser Maßnahmen findet sich bei Hasse (1979), a.a.O., S. 41

${ }^{264} \mathrm{Vgl}$. Hellmann (1977), a.a.O., S. 69

${ }^{265}$ Vgl. Hellmann (1977), a.a.O., S. 70 f.
} 
Er verteidigte diesen Schritt dementsprechend vor der Nation als Maßnahme zur Rettung der französischen Währungsreserven vor der Spekulation sowie mit der zurückgewonnenen wirtschaftspolitischen Handlungsfreiheit für Frankreich. ${ }^{266}$ Als weitere Motive führte er neben der mittlerweile wieder defizitären Zahlungsbilanz die hoffnungslosen Anläufe zur Reform des internationalen Währungssystems sowie den Umstand an, daß die „Schlange“ sowieso nur noch in beschränktem Maße bestanden habe und in ihrer Konstruktion den brutalen Schocks nicht mehr gewachsen gewesen sei. ${ }^{267}$ Staatspräsident Pompidou griff diese Argumente zwei Tage später in einer Ansprache in Poitiers nochmals auf, in der er darauf hinwies, daß es letztlich darum ging, Frankreichs wirtschafts- und währungspolitische Handlungsfreiheit zu bewahren und die eigenen Reserven vor Verschwendung zu schützen. ${ }^{268}$ Wie schon vor ihm Giscard d'Estaing betonte der Staatspräsident, daß der Übergang zum Floating nicht die Aufgabe der währungspolitischen Überzeugungen Frankreichs bedeute und daß trotz aller widrigen Erfahrungen man weiter an ihnen festhalten und zur gegebenen Zeit auf sie zurückkommen werde:

„À l'heure actuelle d'abord, il n'y a pas d'espoir de réforme monétaire générale à court terme et, par conséquent, nous maintenons entièrement nos thèses, nous les défendrons le moment venu, mais nous sommes bien obligés de constater qu'aujourd'hui, nous nous bornerons à crier dans le désert.“269

Offensichtlich enttäuscht und sich dem Druck der Ereignisse fügend akzeptierte Frankreich am Ende der Amtszeit Pompidous widerwillig flexible Wechselkurse als einzig realisierbares währungspolitisches Arrangement auf internationaler Ebene. Nachdem seine Irrationalismus-Schelte bei den währungspolitisch liberal orientierten Partnern keine Resonanz gefunden hatte, versuchte Frankreich über das Einschwenken auf die amerikanisch inspirierte Währungskorbkonzeption vom Festkurssystem noch zu retten, was möglich war. Die überwältigende Macht der internationalen Geldströme und der sie erzeugenden Ereignisse bereiteten den französischen Träumen von ihrer Kontrollierbarkeit jedoch ein jähes Ende. Mit diesen Träumen scheiterte vorerst auch die Vorstellung von der politischen Steuerbarkeit der internationalen Währungsbeziehungen und damit zunächst auch die Möglichkeit, sie expansiven außenwirtschaftlichen Ambitionen unterzuordnen.

\section{B.3.4.4 Zusammenfassung}

Nach intensivem Engagement fand sich die französische Währungspolitik am Ende der Ära Pompidou vor einem Scherbenhaufen wieder. Der Integrationsstand der interna-

${ }^{266}$ Vgl. Rundfunk- und Fernsehansprache Valéry Giscard d'Estaings vom 19.1.1974 zu den von der Regierung getroffenen währungspolitischen Maßnahmen, D 179, abgedruckt in Auszügen in: EA, Folge 8/1974, D $178 \mathrm{f}$.

${ }^{267}$ Vgl. die Ansprache Giscard d'Estaings vor der Nationalversammlung am 22.1.1974, abgedruckt in: PE, S. 40 und 41,1 . Sem., S. $39 \mathrm{ff}$.

${ }^{268}$ Vgl. die Rede Pompidous in Poitiers vom 24.1.1974, abgedruckt in: PE, S. 51, 1. Sem., S. $46 \mathrm{ff}$

${ }^{269}$ ebenda 
tionalen Währungsbeziehungen lag weit hinter dem zu Beginn der Amtszeit Pompidous zurück. Wie zum Ende der Amtszeit de Gaulles hatte Frankreich sich mit seiner Währungspolitik erneut isoliert. Alle französischen Bemühungen zur Stabilisierung des stetig und unübersehbar zu flexiblen Wechselkursen tendierenden internationalen Währungssystems blieben ebenso erfolglos wie die von Frankreich maßgeblich mitgestaltete „Schlange“, die als politisches und wirtschaftliches Integrationsvehikel letzten Endes vollständig gescheitert war. ${ }^{270}$ Die französische Währungspolitik stellte den verzweifelten Versuch dar, mit allen Mitteln und gegen alle Widerstände die sich in der Auflösung befindlichen Festkurssysteme zu retten. Frankreich verschrieb sich dazu allen möglichen Erscheinungsformen von Währungssystemen, beginnend mit dem goldfundierten Leitwährungsstandard, über den Paritätengitter-Standard bis hin zum Währungskorb-Standard. Ohne den unterschiedlichen theoretischen und praktischen Implikationen dieser Arrangements zuviel Aufmerksamkeit zu schenken, korrespondierte die jeweilige Wahl in erster Linie mit dem Nachlassen der stabilitätspolitischen Bemühungen auf internationaler Ebene. Je geringer die internationale Bereitschaft zur Unterstützung fester Wechselkurse war, desto lockerer wurde das währungspolitische Arrangement, für das Frankreich plädierte. Angesichts der Ergebnisse dieser Politik sowie ihrer Widersprüchlichkeit im Hinblick auf das Ziel der Geldwertstabilität drängt sich der Eindruck einer gewissen Theorielosigkeit der damaligen französischen Währungspolitik auf.

Allen währungspolitischen Initiativen Frankreichs gemeinsam war die Perspektive, daß der Wechselkurs natürlicherweise ein Instrument zur Absicherung einer expansiven Außenwirtschaftspolitik ist und daß der Währungssektor von politischer Seite aus kontrolliert und gesteuert werden muß. Die von Frankreich angestrebte Institutionalisierung fester Paritäten und ihre Beherrschung im internationalen währungspolitischen Konsens hätten die Abkopplung der Wechselkurse von ihren realwirtschaftlichen $\mathrm{Be}-$ stimmungsfaktoren zur Folge gehabt. Französischerseits wurde diese Entwicklung als legitime Fortsetzung des französischen Unabhängigkeitsstrebens auf wirtschafts- und währungspolitischem Gebiet verstanden. Seine ambitionierte nationale Wirtschaftspolitik sowie die nicht weniger ehrgeizige Binnenmarktpolitik Frankreichs wären über die gemeinschaftliche Garantie fester Wechselkurse währungspolitisch nicht nur abgesichert worden, über die breitere Ressourcenbasis bei den Interventionsmitteln hätten sich sogar wirtschaftspolitische Handlungsspielräume eröffnet, die weit über die Reichweite der nationalen Währungsreserven hinausreichten.

$\mathrm{Da}$ in einer derartigen Währungspolitik frei wirkende Marktkräfte nur stören konnten, lag auf der Hand. Die Rufe nach Begrenzung freier Kapitalbewegungen sowie die den Märkten unterstellte Irrationalität deuten auf die tiefsitzende Skepsis der französischen Währungspolitik gegenüber der Leistungsfähigkeit der Marktkoordination hin. Rationalität der Geldmarktakteure bestand im Akzeptieren der politisch gesetzten Rahmenbedingungen. Ihre offensichtlich nicht gegebene Neigung dazu machte die

${ }^{270}$ Vgl. Lutz, C. (1974), Nachruf auf die europäische Währungsschlange, S. 290, in: EA, Folge 9/1974, S. $285-290$ 
"Organisation" der Märkte erforderlich. Auf diesem Weg sollten alle Störgrößen ausgeschaltet werden, so daß am Ende Real- und Kapitaltransaktionen befreit von spekulativen Einflüssen einander entsprachen. Derart gezähmte, ausschließlich auf die Finanzierung von Realtransaktionen ausgerichtete Kapitalmärkte wären am Ende einer Währungspolitik entgegengekommen, die zwar vordergründig auf die Stabilität des Geldwerts fixiert schien, in letzter Konsequenz jedoch nur Instrument zur Durchsetzung einer expansiven interventionistischen Wirtschaftspolitik war. Die währungspolitische Konzeption Frankreichs war zentraler Bestandteil eines gesamtpolitischen Konzepts, das von einem engagierten, über das Wirtschaftliche hinausgehenden Gestaltungswillen beseelt war, dessen Spielraum jedoch direkt vom Ausmaß der tatsächlichen wirtschaftlichen Macht abhing. Monetäre Sachrationalität spielte in der französischen Währungspolitik somit von Anfang an nur eine untergeordnete Rolle.

\section{B.3.5 Die ordnungspolitische Haltung Frankreichs unter Georges Pompidou}

Mit dem Tod Georges Pompidous am 2. April 1974 endete eine fast fünfjährige Periode der französischen Europapolitik, die ordnungspolitisch betrachtet von hoher Aktivität geprägt war. Frankreich hatte unter de Gaulle den europäischen Einigungsprozeß zum Stehen gebracht. Es hat ihn unter Georges Pompidou wieder aus seiner Stagnation befreit und mit einer Vielzahl von Initiativen voranzutreiben versucht. Das wiedererwachte europapolitische Engagement Frankreichs beruhte auf einem Perspektivenwechsel unter Pompidou, der Europa nicht mehr wie de Gaulle als eine Möglichkeit, sondern, infolge einer realistischeren Einschätzung des politischen Gewichts der einzelnen Mitgliedstaaten und der eigenen Nation, als eine Notwendigkeit betrachtete. ${ }^{271}$ Alle wesentlichen Elemente der europapolitischen Konzeption de Gaulles sowie die sich daraus ergebenden Ordnungsvorstellungen wurden ansonsten von Pompidou übernommen. Europa blieb danach weiter ein Bündnis unabhängiger Staaten, das zu einer eigenständigen und von den USA unabhängigen Politik finden sollte. Frankreich ging es weiterhin um die Schaffung eines machtvollen und international einflußreichen politischen Blocks, der sich innerhalb wie außerhalb seiner Grenzen der Vertretung bestimmter gesellschaftspolitischer Zielvorstellungen widmen sollte. Diese waren identisch mit der spezifisch französischen Auffassung von Zivilisation, was zur Folge hatte, daß Frankreich die politische Führungsrolle in Europa beanspruchte und die Europäische Gemeinschaft primär als Vehikel zur Verbreitung französischer Gesellschaftsideale betrachtete. Das französische Verhältnis zur europäischen Integration blieb auch unter Pompidou ein eher zweckrationales, was unter anderem im nachhaltigen Bestehen Frankreichs auf seine nationale Unabhängigkeit zum Ausdruck kam.

Voraussetzung für die erfolgreiche Umsetzung dieser Konzeption war politische Macht, die sich aus französischer Sicht unmittelbar aus der wirtschaftlichen Leistungsfähigkeit eines Staatswesens ergab. Dementsprechend strebte die französische Bin-

${ }^{271}$ Vgl. Cousté (1974), a.a.O., S. 3 
nenmarktpolitik unter Pompidou in erster Linie die Stärkung der europäischen Wirtschaft an. Um das Erreichen dieser Zielsetzung nicht dem Zufall oder gar den Zufälligkeiten sich frei entwickelnder Märkte zu überlassen, galt es, die politische Kontrolle und Steuerung der Wirtschaftsentwicklung sicherzustellen. Hauptanliegen der französischen Binnenmarktpolitik war dementsprechend die Errichtung bzw. Vertiefung der wirtschafts- und währungspolitischen Zusammenarbeit in der Gemeinschaft. Die französischen Vorstöße im Rahmen der Industriepolitik wie auch in der Währungspolitik liefen alle darauf hinaus, Mittel und Möglichkeiten der politischen Einflußnahme zur Orientierung der Wirtschaftsentwicklung auf europäischer Ebene zu institutionalisieren. Dies hätte deren Politisierung zur Folge gehabt und aufgrund des angenommenen „irrationalen“ Verhaltens der Märkte zu einer weitreichenden Suspendierung marktwirtschaftlicher Steuerungsmechanismen geführt. Mit den Grundsätzen einer Wettbewerbsordnung war ein solches Vorhaben jedoch kaum zu vereinbaren. Dementsprechend umfangreich fielen die Verstöße der französischen Binnenmarktpolitik gegen ihre Prinzipien aus.

So wäre die unbehinderte Funktion des Preismechanismus durch die französischen Vorschläge im Rahmen der Handelspolitik, durch den Vorschlag eines internationalen Agrarpreismechanismus sowie in der Energiepolitik durch die Forderung nach "Organisation" der Preise und Märkte beeinträchtigt worden.

Die französische Währungspolitik war nicht primär auf die Herbeiführung der Geldwertstabilität mittels automatischer und politisch unabhängiger Anpassungsmechanismen ausgerichtet. Währungspolitik wurde französischerseits vor allem in direktem $\mathrm{Zu}$ sammenhang mit außenwirtschaftlichen Zielen gesehen, für deren Verwirklichung feste Wechselkurse als unbedingte Voraussetzung angesehen wurden. Grundsätzlich ging die französische Politik davon aus, daß stabile Wechselkurse das Ergebnis international koordinierter politischer Absprachen zu sein hätten. Prägend für die französische Währungspolitik unter Pompidou war die Überzeugung, daß politisch dekretierte Wechselkurse an sich das Vermögen hätten, die notwendigen Sachzwänge für eine stabilitätsorientierte Wirtschaftspolitik zu schaffen, obwohl Frankreich selbst, wie im Rahmen seiner industriepolitischen Initiativen ersichtlich, nie bereit war, sich die eigene wirtschaftspolitische Handlungsfreiheit nehmen zu lassen. Insofern setzte die französische Politik auf monetärer Ebene das Ergebnis einfach voraus, ohne sich ernsthaft um die realwirtschaftlichen Voraussetzungen für seine erfolgreiche Verwirklichung zu kümmern. Alle von Frankreich vorgeschlagenen geld- und währungspolitischen Arrangements hätten unter den gegebenen Bedingungen Anfang der siebziger Jahre kaum zu einer Stabilisierung der Wechselkurse beitragen können. Frankreich selbst hätte Schwierigkeiten gehabt, die stabilitätspolitischen Voraussetzungen seiner währungspolitischen Konzeption zu erfüllen. Über die in den französischen Vorschlägen durchgängig angelegte Tendenz zur Vergemeinschaftung von Anpassungslasten hätten Länder mit defizitärer Zahlungsbilanz ihre Wirtschaftspolitik länger durchhalten können. Länder mit stabiler Wirtschaftsentwicklung wären dazu herangezogen worden, die Erhaltung des Status Quo zu finanzieren. Der Zusammenbruch des Währungssystems von 
Bretton-Woods und der schleichende Zerfall der „Schlange“ belegten, daß die Partner Frankreichs damals nicht den notwendigen Willen und auch nicht die Disziplin gehabt hätten, um zu einer französischen Vorstellungen entsprechenden Stabilisierung der Wechselkurse beizutragen. Für die französische Währungspolitik schien dies indessen nicht von ausschlaggebender Bedeutung. Sie hielt bis zum Ende der Amtszeit Pompidous unerschütterlich an ihrer eigentlichen Doktrin fest: Hauptziel war und blieb, die Kontrolle und Gestaltung der monetären Entwicklung in die Hände der politischen Entscheidungsträger zurückzuverlagern. Mit dieser Zielsetzung führte Frankreich die monetären Ordnungsvorstellungen fort, die schon unter de Gaulle die französische Währungspolitik gekennzeichnet hatten. Sichtbar wurde diese Kontinuität nicht nur in der vehementen Ablehnung flexibler Wechselkurse, sondern auch im unerschütterlichen Festhalten an der Golddeckung der Währungen, von dem Frankreich erst abließ, als die vollständige Auflösung des internationalen Währungssystems unmittelbar bevorstand und nicht mehr zu verhindern war.

Die Öffnung des Binnenmarktes war ebenfalls kein originäres Ziel der französischen Binnenmarktpolitik. Wohl war sie bereit, in bestimmten wohldefinierten Grenzen die Außenprotektion des Binnenmarktes herabzusetzen. Unumwunden brachte die französische Regierung aber zum Ausdruck, daß sie Zölle weiter als probates Instrument zur Absicherung des Gemeinsamen Marktes erachtete. Ebenfalls wollte sie sich nicht von der protektionistischen EG-Agrarpolitik trennen. Auch die Erweiterung des Binnenmarktes durch die Aufnahme neuer Mitgliedstaaten wurde nicht unter wirtschaftlichen Gesichtspunkten bewertet, sondern ausschließlich aus politischer Sicht entschieden. Die französische Außenwirtschaftspolitik war weiterhin in erster Linie der außenwirtschaftlichen Absicherung der Gemeinschaft sowie ihrer Ausformung zu einem selbständigen handelspolitischen Block verpflichtet. Sie stand in direktem Zusammenhang mit der europapolitischen Konzeption Pompidous, die auf die Errichtung einer international handlungsfähigen und machtvollen politischen Einheit ausgerichtet war und die EG nicht als eine wirtschaftliche Marktorganisation betrachtete, die es aus ökonomischen Überlegungen heraus vorrangig zu öffnen und zu vergrößern galt. Mit dieser Orientierung setzte die französische Binnenmarktpolitik auch auf außenwirtschaftlichem Gebiet den Kurs fort, den Frankreich schon unter de Gaulle eingeschlagen hatte.

Die Intention der von Frankreich angestrebten Industriepolitik war, die Orientierung der Wirtschaftsentwicklung nach strategischen, vom Staat erkannten Notwendigkeiten auszurichten. Sie konzentrierte sich dazu vorzugsweise auf die Förderung von Unternehmen aus dem Bereich der Hochtechnologie. Um die politische Einflußnahme auf deren Entwicklung sicherzustellen, sollten Forschung und Entwicklung im Bereich der Industrie nicht einfach freien Märkten überlassen werden. Frankreich drängte auf wirtschaftspolitische Eingriffe zur Stimulation von Investitionen, zur Förderung der industriellen Forschung und Entwicklung sowie auf eine Politik zur Unternehmenskonzentration. Die dabei bewußt angestrebte Bildung großer Unternehmenseinheiten widersprach, ordnungspolitisch betrachtet, jedoch dem "Grundsatz der Monopolkontrolle". Die finanzielle Förderung der industriellen Forschung über Subventionen 
wäre darüber hinaus mit der staatlichen Übernahme unternehmerischer Risiken verbunden gewesen, was aus Sicht der Wettbewerbsordnung einen Verstoß gegen das Prinzip der Einheit von Gestaltungsmacht und Haftung bedeutet hätte. Auch im Bereich der Industriepolitik hielt die französische Europapolitik an den interventionistischen Bemühungen zur bewußten Gestaltung der Wirtschaftsentwicklung fest, die Frankreich schon unter de Gaulle auf Europa zu übertragen versucht hatte.

Problematisch aus Sicht der Wettbewerbsordnung gestaltete sich auch die von Frankreich gewünschte Sozialpolitik. Ihr zentrales Merkmal war das Bemühen, die Regelung der Beziehungen von Arbeitnehmer und Arbeitgeber in einen formal institutionalisierten sozialen Dialog zu verlagern, an dem nach französischer Auffassung immer auch der Staat beteiligt gewesen wäre. Damit wären die politischen Einflußmöglichkeiten auf die Ausgestaltung der Arbeitsbeziehungen erhöht und die Arbeitsmärkte ihrer Koordinationsfunktion beraubt worden. Dies gilt um so mehr, angesichts der französischen Forderung, im sozialen Dialog ein europaweit einheitliches Niveau der Sozialleistungen herbeizuführen. Ordnungspolitisch betrachtet widersprach der sozialpolitische Ansatz Frankreichs daher der Forderung nach einer marktneutralen Sozialpolitik. Da letztlich alle Bereiche der von Frankreich vertretenen Wirtschafts- und Währungspolitik grundsätzlich einen größeren politischen Einfluß auf die Entwicklung von Wirtschaft und Währung zum Ziel hatten, konnte die französische Binnenmarktpolitk überdies auch nicht der Forderung nach Stetigkeit und Vorhersehbarkeit der Wirtschaftspolitik genügen.

Wie unter de Gaulle, so verfolgte die französische Europapolitik auch unter Georges Pompidou einen ordnungspolitischen Ansatz, der insgesamt nicht mit einer marktwirtschaftlich orientierten Wirtschaftsordnung zu vereinbaren war. Die französische Binnenmarktpolitik beruhte weiter auf einer interventionistischen Grundüberzeugung. Weder der Staatspräsident noch der Wirtschafts- und Finanzminister zweifelten an der Berufung des Staates, die Entwicklung auf wirtschaftlichem Gebiet lenken zu müssen, noch an der Fähigkeit der Akteure in Politik und Verwaltung, den selbst erteilten Lenkungsauftrag erfolgreich bewältigen zu können. Sie konnten es auch nicht, da sie überzeugt waren, daß wirtschaftliche Stärke eine unabdingbare Voraussetzung für politische Macht und den internationalen Einfluß eines Staates darstellten, welche es auf nationaler wie europäischer Ebene zu mehren galt. Wirtschaftlicher Stärke und politischer Macht bedurfte es, um die eigentliche Mission Frankreichs und Europas zu verwirklichen, die darin bestand, bestimmte französische Zivilisationsvorstellungen gegen den Einfluß übermächtiger Hegemonialmächte und insbesondere der USA nicht nur zu bewahren, sondern in der Welt zu verbreiten.

Ordnungspolitisch hielt die französische Binnenmarktpolitik unter Georges Pompidou an ihrer bisherigen interventionistischen Orientierung fest. Sie kann damit als Fortsetzung derer de Gaulles und dessen Vorgänger zu Zeiten der IV. Republik gesehen werden. Im Vergleich zu diesen verfolgte Frankreich unter Georges Pompidou jedoch einen umfassenderen und konsistenteren Ordnungsansatz. Mit der Industrie-, Sozial- und 
Außenwirtschaftspolitik versuchte Frankreich auf drei Wegen parallel, die Gemeinschaft zu einer einheitlichen und bewußten Politik zur Stärkung der wirtschaftlichen Wettbewerbsfähigkeit zu bewegen. Dem gleichen Ziel sollte nach französischem Willen auch die gemeinschaftliche Währungspolitik dienen. Klarer als zuvor wurden die europäische Wirtschafts- und Währungspolitik dabei als Mittel zur Realisierung gesellschaftspolitischer Ambitionen begriffen und zu einem geschlossenen makroökonomischen Gesamtkonzept weiterentwickelt, das aufgrund der fehlenden Trennung von Wirtschaft und Politik jedoch zwangsläufig mit den Prinzipien einer marktwirtschaftlich ausgerichteten Wettbewerbsordnung kollidieren mußte. 


\section{B.4 Frankreichs Binnenmarktpolitik unter Valéry Giscard d'Estaing 1974 - 1981}

Valéry Giscard d'Estaing übernahm die Führung der Staatsgeschäfte zu einem Zeitpunkt als die erste Ölkrise und die sie begleitende internationale Wirtschaftskrise ihren Höhepunkt erreichten. In seine Präsidentschaft fiel auch die zweite Ölkrise der Jahre 1979/80, so daß in dieser Regierungsperiode die französische Wirtschaft mit weitaus stärkeren externen Schocks zu kämpfen hatte als es in der Amtszeit der Vorgänger Giscard d'Estaings der Fall war. Auf das außen- und europapolitische Engagement Frankreichs hatte dies jedoch keinen Einfluß. Schwerpunkt der französischen Außenund insbesondere Außenwirtschaftspolitik waren die Sicherung der internationalen Rohstoffversorgung sowie die Lösung der Währungsprobleme in der Folge des $\mathrm{Zu}$ sammenbruchs des Währungssystems von Bretton-Woods. Auf europäischer Ebene standen die Institutionalisierung regelmäßiger Treffen der Staats- und Regierungschefs und die Fortführung des Europäischen Wechselkursverbundes an erster Stelle der politischen Tagesordnung. Der europäische Einigungsprozeß blieb nicht unbeeinflußt von den Entwicklungen auf internationaler Ebene. Da die Regierungen im Zuge der internationalen Wirtschaftskrise erstmals wieder mit einer ernsthaften Rezession zu kämpfen hatten, konzentrierten sie ihre Anstrengungen vornehmlich auf die Lösung nationaler Probleme. Die europäische Integration verlor dementsprechend im Verlauf der siebziger Jahre erneut stetig an Dynamik.

\section{B.4.1 Die europapolitische Konzeption B.4.1.1 Die wirtschaftlichen Rahmenbedingungen}

Die Wirtschaftskrisen der siebziger Jahre hatten keinen dämpfenden Einfluß auf die wirtschaftspolitischen Ambitionen des dritten Präsidenten der V. Republik. Giscard $d$ 'Estaing strebte wie seine Vorgänger einen herausgehobenen Platz der französischen Wirtschaft unter den führenden Industrienationen an, um die notwendigen Voraussetzungen zum Erhalt der nationalen Unabhängigkeit sicherzustellen. Wie schon zuvor für Georges Pompidou wählte er die Bundesrepublik zum Maßstab, deren Industrieproduktion die französische Wirtschaft bis 1985 überholt haben sollte. ${ }^{1}$ Diesem Ziel stellten sich jedoch in der zweiten Jahreshälfte 1974 ein auf 0,4 Prozent gesunkenes Wachstum der Inlandsproduktion entgegen, verbunden mit einer auf siebzehn Prozent angestiegenen Inflationsrate und einem zunehmenden Außenhandelsdefizit. ${ }^{2}$ Anfang 1975, auf dem Höhepunkt der Ölkrise, kam es sogar zu einem Rückgang des Inlandsprodukts um 0,9 Prozent sowie der Exporte um 1,9 Prozent, so daß sich die Regierung zu einschneidenden Gegenmaßnahmen gezwungen sah.

Über eine restriktive Geld- und Budgetpolitik wurden im Rahmen des „Plan Fourcade“ ab 1974 eine Rückführung der Inflation im Jahr 1975 auf sechs bis sieben Prozent und

\footnotetext{
${ }^{1}$ Vgl. Giscard d'Estaing, V. (1977), Französische Demokratie, Ulm, S. 145

${ }^{2}$ Zur Wirtschaftslage Frankreichs im Jahr 1974 siehe Vesperini (1993), a.a.O., S. 147 - 157
} 
die Beseitigung des Außenhandelsdefizits angestrebt. ${ }^{3}$ Zur nachhaltigen Dämpfung des Preisauftriebs wurde ein Gesetz über eine „Konjunkturabgabe“ vorbereitet, um die Unternehmen dazu zu bewegen, Produktivitätsfortschritte nicht vollständig in Gewinnund Lohnsteigerungen umzusetzen. ${ }^{4}$ Von dem Differenzbetrag ihres Umsatzes, abzüglich der Kosten aller Inputfaktoren außer den Löhnen und des entnommenen Gewinns, sollte ein Anteil von 33.3 Prozent der Nationalbank überwiesen und nach einer bestimmten Zeit nur für investive Ausgaben wieder ausgezahlt werden. Je höher die Preissteigerungen durch Gewinnentnahmen und Lohnzuwächse, so der Leitgedanke dieses Projekts, um so höher die Konjunkturabgabe. Um jedoch exportorientierte Unternehmen nicht übermäßig zu belasten, waren gewisse Ausnahmen vorgesehen. Außerdem sollten die Berechnungsgrundlagen durch verschiedene Korrekturgrößen dem gewünschten Wachstum sowie einer als tolerierbar angesehenen Preissteigerung angepaßt werden. Über diesen massiven Eingriff in die Freiheit der unternehmerischen Preissetzung wollte die Regierung den Geldumlauf erheblich reduzieren sowie die Investitionsquote und damit längerfristig das Wachstum anregen. Proteste der französischen Unternehmen wie auch Zweifel innerhalb der Regierung an den Auswirkungen dieses komplexen Instruments auf die französische Wettbewerbsfähigkeit führten jedoch dazu, daß Ende 1975, als die Inflationsrate die Zehnprozentmarke wieder unterschritt, auf eine Ratifizierung des Gesetzentwurfs verzichtet wurde.

Zur deutlichen Verlangsamung des Preisanstiegs im Jahr 1975 trugen verschiedene Maßnahmen bei. So wurden die Preiskontrollen im Rahmen der ,programmation des prix“ wieder verschärft, die Staatsausgaben eingefroren und die Erdölimporte auf neunzig Prozent der Vorjahreseinfuhr beschränkt. Frankreich konnte im Anschluß an diese Maßnahmen bald einen substantiellen Rückgang der Importe verzeichnen. Ende 1975 erreichten der Außenhandel und der Staatshaushalt sogar einen leichten Überschuß. Als negatives Ergebnis blieben jedoch ein nahezu stagnierendes Wachstum und ein Anstieg der Arbeitslosigkeit zu verzeichnen. Die Erwerbslosenrate stieg um fast fünfzig Prozent von 624.000 Erwerbslosen im IV. Quartal 1974 auf 924.000 im IV. Quartal 1975. ${ }^{5}$ Beiden Entwicklungen versuchte die Regierung auf Intervention des Präsidenten mit einer Lockerung der Budget- und Geldpolitik zu begegnen. ${ }^{6}$ Diese Politik war insofern erfolgreich, als daß sich das Wachstum des Bruttoinlandsprodukts im ersten Semester 1976 wieder auf real 3,1 Prozent erhöhte und die Zunahme der Arbeitslosigkeit gestoppt werden konnte. ${ }^{7}$ Außerdem gelang es, den Außenwert des Franc so zu stabilisieren, daß er im Juli $1975 \mathrm{zu}$ seinem alten Kurs wieder in die „Schlange“ zurückkehren konnte.

\footnotetext{
${ }^{3} \mathrm{Vgl}$. die Pressekonferenz Giscard d'Estaings vom 24.10.1974, abgedruckt in: EA, Folge 23, D 560

ff. bzw. o. V.: La France a la capacité de faire face aux difficultés actuelles, S. 4, Le Monde vom 26.10 .1974$, S. $1 \mathrm{ff}$.

${ }^{4}$ Zur Konjunkturabgabe vgl. Vesperini (1993), a.a.O., S. 140-144

${ }^{5}$ Vgl. OECD (1990), Main Economic Indicators 1969 - 1988, Paris, S. 333

${ }^{6}$ Vgl. Lerch, W. (1983), Das Experiment Barre, Köln, S. 159

${ }^{7}$ Vgl. Vesperini (1993), a.a.O., S. 170
} 
Dieser Erfolg war jedoch nur von kurzer Dauer. Die gelockerte Geld- und Budgetpolitik ließen die Konsumnachfrage und in deren Folge die Importe deutlich schneller ansteigen als die Exporte. Das Ergebnis war ein neues Außenhandelsdefizit Ende 1976, bei dem der Import Frankreichs nur noch zu 90,6 Prozent durch Exporte gedeckt war. ${ }^{8}$ Die Inflation beschleunigte sich von 8,7 Prozent im dritten Trimester 1975 auf 9,5 Prozent im selben Zeitraum des Folgejahres. Diese Verschlechterung der ökonomischen Grunddaten führte dazu, daß der überbewertete Franc erneut in den Sog einer Abwertungsspekulation geriet, die Frankreich im März 1976 zwang, ein zweites Mal die „Schlange“ zu verlassen. ${ }^{9}$ Auch die Bemühungen Premierminister Barres, der, nach einem Zerwürfnis Premierminister Chiracs mit dem Präsidenten, ersterem im Amt folgte und mittels einer marktwirtschaftlich orientierten Politik die Inflation und das Außenhandelsdefizit $\mathrm{zu}$ bekämpfen gedachte, brachten keine meßbaren Erfolge. ${ }^{10} \mathrm{Er}$ versuchte, im Rahmen des „Experiment Barres“ über eine langfristig angelegte restriktive Geldpolitik die innere und äußere Geldwertstabilität zu sichern. Weitere Maßnahmen, wie die Aufgabe von Preiskontrollen und eine intensive Außenhandelsdiplomatie, an der sich auch der Präsident persönlich beteiligte, sollten die französische Wirtschaft international wettbewerbsfähiger machen und den Außenhandel zurück ins Gleichgewicht bringen. ${ }^{11}$ Innenpolitische Widerstände gegen diese stärkere Hinwendung zur Marktwirtschaft sowie der unerwartet auftretende zweite Ölschock von 1979 und die Unterminierung der eigenen Politik durch viele widersprüchliche Einzelmaßnahmen versagten dem „Experiment Barre“ am Ende den Erfolg. Zwar konnte der Wechselkurs des Franc zur D-Mark ab 1978 stabil gehalten werden. Die Inflation jedoch, die 1977 und 1978 nochmals unter zehn Prozent sank, stieg bis 1980 auf 13,6 Prozent. ${ }^{12}$ Das reale Wachstum fiel von Werten oberhalb 3 Prozent in den Jahren 1977 bis 1979 auf 1,6 Prozent im Jahr $1980 .{ }^{13}$ Die Außenhandelsbilanz fand nur 1978 noch einmal ins Gleichgewicht zurück, um dann bis 1981 zunehmend größere Defizite aufzuweisen, während sich die Anzahl der Erwerbslosen von 1976 bis Mitte 1981 auf fast 1,8 Millionen Erwerbslose verdoppelte. ${ }^{14}$

Valéry Giscard d'Estaing hatte mit dieser Bilanz nicht nur seine wirtschaftspolitischen Ziele verfehlt. Er war nach de Gaulle und Pompidou der erste Präsident, dem es nicht gelang, sich mit einem Austeritätsprogramm von den im Zeitpunkt der Amtsübernahme existierenden wirtschaftlichen Schwierigkeiten kurzfristig und dauerhaft zu befrei-

\footnotetext{
${ }^{8}$ Vgl. Vesperini (1993), a.a.O., S. 167

${ }^{9}$ Vgl. Vesperini (1993), a.a.O., S. 173

${ }^{10} \mathrm{Zu}$ den Maßnahmen des Reformprogramm Barres siehe Lerch (1983), a.a.O., S. $138 \mathrm{ff}$., zu den Ergebnissen vgl. Lerch (1983), a.a.O., S. 393 ff. sowie Vesperini (1993), a.a.O., S. 165 ff.

" $\mathrm{Zu}$ den intensiven Bemühungen der französischen Regierung, den Export durch gezieltes Engagement auf diplomatischer Ebene zu fördern, und zu den bescheidenen Erfolgen dabei vgl. Lacorne, D. (1985), La Politique de promotion des exportations ou le Colbertisme dans les moyens en vue du libéralisme comme fin, S. 167-170, in: Samy Cohen und Marie-Claude Smouts (Hrsg.): La politique extérieure de Valéry Giscard d'Estaing, Paris, S. 151-172

${ }^{12} \mathrm{Vgl}$. Vesperini (1993), a.a.O., S. 202

${ }^{13}$ Vgl. Vesperini (1993), a.a.O., S. 203 und 208

${ }^{14}$ Vgl. OECD (1990), a.a.O., S. 333 und 349
} 
en und sich so wieder freie Hand für seine Außenpolitik zu verschaffen. Zwar entsprach die französische Entwicklung bei der Inflation und im Außenhandel auf OECDEbene dem Durchschnitt, doch konnte Frankreich nie die Erfolge der Bundesrepublik erreichen, die auf beiden Gebieten über alle Jahre hinweg die besseren Ergebnisse erzielte und dementsprechend auf wirtschaftspolitischem Gebiet in Europa Maßstäbe setzte. Die zaghaften Versuche der französischen Wirtschaftspolitik, sich von einer anfänglich stark interventionistischen Wirtschaftspolitik hin zu einer mehr liberalistischen Konzeption zu bewegen, wurden durch die geringe Popularität dieser Maßnahmen in Frankreich, aber auch durch eine ungünstige internationale Wirtschaftsentwicklung vereitelt. Aufgrund der eigenen wirtschaftlichen Probleme sowie im Schatten einer wirtschaftlich erfolgreicheren Bundesrepublik unterlag die französische Europapolitik in der Amtszeit Valéry Giscard d'Estaings weitaus größeren ökonomischen Sachzwängen, als es zu Zeiten de Gaulles und Pompidous der Fall gewesen war. Dies bescherte ihr zwangsläufig einen geringeren Gestaltungsspielraum.

\section{B.4.1.2 Der Inhalt der europapolitischen Konzeption}

Valéry Giscard d'Estaing entwarf seine Außenpolitik vor dem düsteren Hintergrund einer krisengeschüttelten Welt: "Le monde est malheureux. Il est malheureux parce qu'il ne sait pas où il va et parce qu'il devine que, s'il le savait, ce serait pour découvrir qu'il va à la catastrophe" ${ }^{15}$. Die Bevölkerungsexplosion in der dritten Welt, die sich häufenden Hungerkatastrophen, begrenzte Vorräte an Rohstoffen und Energieträgern sowie die Ölpreiserhöhungen des Vorjahres führten ihn zur Überzeugung, daß diese Krise dauerhaft sei. ${ }^{16}$ Im Gegensatz zu den Jahren zuvor würde deshalb die weitere Entwicklung diskontinuierlich und instabil verlaufen. Für die globale Außenpolitik resultierte daraus die Notwendigkeit, so der neu gewählte französische Präsident, das "Unvorhersehbare" beherrschen zu müssen (gérer l'imprévisible) ${ }^{17}$. Die wachsende Verflechtung der Volkswirtschaften bei gleichzeitiger Begrenztheit der Ressourcen brachte aus seiner Sicht mit sich, daß diese Aufgabe nur im Rahmen einer weltweiten Kooperation zu lösen sei. Dementsprechend verschrieb Valéry Giscard d'Estaing seine Außenpolitik der globalen Konzertierung, um zusammen mit den anderen Staaten im Konsens nach Lösungen für die gemeinsamen Wirtschaftsprobleme zu suchen. ${ }^{18}$

Vor allem Europa war nach Ansicht Valéry Giscard d'Estaings direkt von der allgemeinen Krise betroffen. Seiner Meinung nach drohte ihm aufgrund des relativen Rückgangs der europäischen Bevölkerung und der jüngsten Rohstoffverteuerung die materielle Verarmung. Der französische Präsident erwartete in den kommenden Jahren einen gewissen "Abstieg", den er als eine Art Revanche des Schicksals für den euro-

\footnotetext{
${ }^{15}$ Pressekonferenz Giscard d'Estaings vom 24.10.1974, abgedruckt in: LE MONDE vom 26.10.1974, S. 2

${ }^{16}$ ebenda

${ }^{17}$ ebenda

${ }^{18}$ ebenda
} 
päischen Aufstieg im 19. Jahrhundert deutete. Das Eintreten dieser düsteren Zukunftsprognose konnte seiner Meinung nach jedoch durch die "Organisation der Europäischen Einheit" verhindert werden. ${ }^{19}$ Die Herbeiführung der europäischen Einheit war für den französischen Präsidenten allerdings auch aus anderen Gründen erforderlich. Wie schon seine Vorgänger, so war auch Giscard d'Estaing davon überzeugt, daß ein geeintes Europa einen wichtigen Beitrag zum Ausgleich zwischen den Staaten der Welt zu leisten habe. ${ }^{20}$ Nach Meinung des neuen französischen Außenministers Sauvagnargues würden vor allem die Völker der Dritten Welt auf Europa schauen und seine Unterstützung bei der Lösung ihrer Probleme erwarten. ${ }^{21}$ Ähnlich äußerte sich Premierminister Chirac, für den die finale Zweckbestimmung Europas in seiner Außenwirkung als vorbildliches Gesellschaftsmodell lag:

"Dans le monde, enfin, combien de nations attendent, de l' Europe qu' elle leur apporte l' inspiration de son exemple, le fruit de son expérience et le concours de son aide. $\mathrm{L}^{\prime}$ union de $\mathrm{l}^{\prime}$ Europe représente $l^{\prime}$ un des plus grands desseins de ce siècle tourmenté. $C^{\prime}$ est la responsabilité des dirigeants et des peuples européens de faire en sorte que cette espérance devienne réalité. Cette responsabilité, le gouvernement français entend en assumer toute sa part. La construction de l'Europe est une tache nécessaire." 22

Sein Nachfolger Raymond Barre faßte diese Haltung etwas allgemeiner, indem er auf die Ausstrahlung Europas verwies, dessen Staaten sich vereinigen müßten, "s'ils veulent maintenir $\mathrm{l}^{\prime}$ exceptionnel foyer de civilisation, de progrès social et de démocratie qui est l'Europe" ${ }^{\prime 23}$. Präsident Giscard d'Estaing schloß sich dieser Perspektive an, indem er die Wichtigkeit der "Organisation" Europas damit begründete, daß es von der Größe seiner Wirtschaft und seiner Bevölkerung her den beiden Supermächten ebenbürtig sei und es deshalb darum ginge, den Rang der europäischen Kultur zu bewahren: "...pour maintenir à la tête du progrès humain la manière de vivre, des principes politiques et sociaux, la civilisation et la spiritualité occidentale" ${ }^{24}$. Wie schon für de Gaulle und Pompidou definierte sich Europa somit auch für den dritten Präsidenten in erster Linie über seine originäre Kulturleistung.

Auch bei der formalen Ausgestaltung dieses Europas gab es unter Giscard d'Estaing kaum Abweichungen zu den Vorstellungen seiner Vorgänger. Es blieb bei der Forde-

${ }^{19}$ ebenda

20 "L'équilibre du monde a besoin de l'union de l'Europe", so Giscard d'Estaing in einer Rede am 9.5.1975, PE, S. 160, 1. Sem., S. 159 f.

${ }^{21}$ Vgl. die Erklärung Außenminister Sauvagnargues vor dem außenpolitischen Ausschuß der Nationalversammlung vom 27.6.1975, abgedruckt in: PE, S. 230, 1. Sem., S. $223 \mathrm{ff}$.

${ }^{22} \mathrm{Vgl}$. die Rede Chiracs am 10.6.1975 vor dem französischen Senat, abgedruckt in: PE, S. 207, 1. Sem., S. $196 \mathrm{ff}$.

${ }^{23} \mathrm{Vgl}$. die Ansprache Barres vor der Nationalversammlung vom 5.10.1976, abgedruckt in: PE, S. 55, 2. Sem., S. $55 \mathrm{ff}$.

${ }^{24}$ Vgl. die Rede Giscard d'Estaings vom 15.51979 in Hoerdt (Elsaß) 
rung nach einem "europäischen Europa" ${ }^{25}$. Dieses sollte ein politisch aktives, selbständiges Europa sein, das, so Außenminister Sauvagnargues, als zweite Entscheidungsund Initiativkraft der westlichen Wertegemeinschaft erlauben sollte, fest auf zwei Beinen zu stehen. ${ }^{26}$ Die Rolle Europas blieb damit in den Augen der französischen Regierung die einer zweiten, von den USA unabhängigen Führungsmacht in der westlichen Welt. ${ }^{27}$ Auch bei den Vorstellungen zur institutionellen Ausgestaltung Europas wich man nicht von der bisher geforderten Konföderation ab. Giscard d'Estaing begründete dies zum einen damit, daß in Europa keinem Staat ein bestimmter Kurs gegen seinen Willen aufgezwungen werden dürfe. Zum anderen würde ein föderatives Europa durch die Heterogenität der nationalen Temperamente und Traditionen gehemmt und wäre deshalb als monolithischer, aber handlungsschwacher Block einem zu großen Einfluß der USA ausgesetzt. ${ }^{28}$ Frankreich blieb damit auch unter Valéry Giscard d'Estaing bei seiner Forderung nach einem politisch selbständigen Europa, das sich aus unabhängigen Staaten zusammensetzten sollte. Das Interesse der französischen Europapolitik galt weiter der Schaffung einer politischen Einheit, die über eine schrittweise Annäherung der Politik souverän bleibender Mitgliedstaaten erreicht werden sollte. Frankreich hielt damit weiter unausgesprochen an seiner bisherigen Ablehnung der supranationalen Integration fest.

Die "Organisation" eines solchen Europas war für Valéry Giscard d'Estaing eines der wichtigsten Ziele der französischen Außenpolitik, deren Ausgestaltung auch er als eine der vornehmsten persönlichen Aufgaben des französischen Staatspräsidenten betrachtete. ${ }^{29}$ Oberstes Ziel seiner Außenpolitik blieb jedoch der Erhalt der Unabhängigkeit Frankreichs. Vor dem düsteren Hintergrund der Globalisierung, die für den französischen Präsidenten in erster Linie durch den Übergang von einer "civilisation de groupe" zu einer "civilisation mondiale" gekennzeichnet war, mußten Antworten auf grundlegende Fragen der Menschheit gefunden werden. ${ }^{30}$ Valéry Giscard d'Estaing reagierte auf diese Herausforderung mit dem Entwurf einer "mondialistischen" Außenpolitik, die vor allem eine Politik der Aussöhnung sein sollte. Frankreich als "ami de

${ }^{25}$ Vgl. die Stellungnahmen Außenminister Sauvagnargues am 24.9.1974 vor der UNO, abgedruckt in: PE, S. 89,2. Sem., S. 89 ff.; sowie am 19.11.1974 vor dem Sénat, abgedruckt in: PE, S. 190, 2. Sem., S. 189 ff; und am 19.1.1975, abgedruckt in: PE, S. 51, 1. Sem., S. $51 \mathrm{ff}$.

${ }^{26}$ Vgl. die Erklärung Außenminister Sauvagnargues vor der Nationalversammlung vom 27.6.1975, S. 230 und 231, PE, 1. Sem., S. $223 \mathrm{ff}$.

${ }^{27}$ Vgl. die Rede Chiracs vom 5.6.1974, a.a.O., S. 160

${ }^{28}$ Vgl. die Pressekonferenz Giscard d'Estaings vom 21.11.1978, abgedruckt in: EA, D 687, Folge 24/1978, D $671 \mathrm{ff}$.

${ }^{29}$ "Je suis le vrai ministre des affaires étrangères", so Giscard d'Estaing zu einem hohen Beamten des Außen-ministeriums zu Beginn seiner Amtszeit, zit. n. Cohen, S., La politique extérieure de la France de 1974 à 1981: Un seul homme? Un homme seul?, S. 26, in: Samy Cohen; Marie-Claude Smouts (Hrsg.): La politique extérieure de Valéry Giscard d'Estaing, Paris, S. 18-38; zum Stil Giscard d'Estaings in der Außenpolitik siehe auch Grosser (1986), a.a.O., S. 319

${ }^{30} \mathrm{Vgl}$. die Ansprache Giscard d'Estaings am 20.12.1974 in: EN DIRECT DE L'ÉLYSÉE, abgedruckt in: PE, S. 313, 2. Sem., S. 301 ff. sowie die Pressekonferenz Giscard d'Éstaings vom 24.10.1974, a.a.O., S. 2 
tout le monde" ${ }^{31}$ sollte dabei die Rolle eines "agent actif de la coopération internationale" übernehmen. ${ }^{32}$ Aufgrund seiner Geschichte und seines hervorragenden Beitrags zur Zivilisation hatte Frankreich dazu nicht nur die Verpflichtung, sondern, so der französische Staatspräsident, auch die Berufung:

"Als Vaterland universell anerkannter Ideen, als Schauplatz der größten politischen Revolutionen in neuerer Zeit, als Land, das seine Sprache und Kultur in die Welt hinausgesandt hat, wird sich das demokratische Frankreich nicht in sich zurückziehen. Er wird ein ideenreicher und geachteter Partner der Welt unserer Tage bleiben, seine Züge, sein Gesicht unversehrt bewahren, aber imstande sein, seinen Geist und sein Herz den großen Veränderungen und der neuen Solidarität zu öffnen, welche die heutige Menschheit zusammenschließt." ${ }^{33}$

Frankreich blieb somit auch für Giscard d'Estaing das Land der beispielhaften Kulturleistung ${ }^{34}$, das es schon für de Gaulle war. In seiner Vorbildhaftigkeit lag auch für den dritten Präsidenten der französischen Republik die Rechtfertigung, bei der "Organisation" Europas die Führungsrolle für Frankreich zu beanspruchen. ${ }^{35}$ Klarer noch als seine Vorgänger stellte Giscard d'Estaing dabei die Identität der europäischen und der französischen Zivilisationsmission heraus:

„L'Europe, c'est aussi l'espérance. L'espérance que les valeurs humaines de la vieille Europe, que notre façon de travailler et de vivre ne seront pas submergées, écrasées par la puissance et le nombre, dans le monde en mouvement. L'espérance que la France, active et généreuse, regardant loin et

31 "Un Chef d'Etat doit transformer et conduire la société qui lui a confié sa responsabilité. Sur le plan de la politique étrangère, pour moi, je crois que nous passons, et je l'ai dit et écrit, comme vous le savez, d'une civilisation de groupe à une civilisation mondialiste. Je le crois profondément, c'est-àdire que déjà les problèmes sont des problèmes de l'espèce humaine. Donc la politique étrangère, c'est d'essayer de trouver les règles, d'essayer de trouver des solutions qui permettront de traiter les problèmes de l'espèce: problèmes de la survie de l'espèce, la paix, la pollution, ainsi la suite, le problèmes du développement et du progrès de l'espèce. Ce qui fait que, nécessairement, la politique étrangère de la France, pour moi, à l'heure actuelle, sera une politique mondialiste et de conciliation ... C'est pourquoi on peut dire: vous êtes l'ami de tout le monde ... Effectivement, je crois que notre rôle, notre type d'action, c'est d'être un facteur de conciliation chaque fois que c'est possible et chaque fois que l'indépendance de notre position nous en donne les moyens", ebenda

${ }^{32} \mathrm{Vgl}$. die Pressekonferenz Giscard d'Estaings vom 16.12.1974, abgedruckt in: PE, S. 288, 2. Sem, S. $288 \mathrm{ff}$.

${ }^{33}$ Giscard d'Estaing (1977), a.a.O., S. 189

34 "Die Definition Frankreichs, das ist, das Beste zu sein", so Giscard d'Estaing, zit. n. Grosser (1986), a.a.O., S. 324

35 "Nous autres Français ne sont pas doués pour jouer les traînards. Le génie de la France la porte à se placer en tête de ceux qui défendent des idées neuves et généreuses. L'esprit de 1789, celui des droits de l'homme, celui des lointaines croisades, habite toujours le peuple français. Mais c'est aussi l'intérêt de la France de conduire l'organisation de l'Europe. ... En étant à la tête de l'organisation européenne, nous pouvons l'orienter vers des solutions conformes à nos vues...C'est ce que la France continuera à faire dans l'avenir. Car c'est son rôle. Quand on est à la tête, on conduit. Quand on est à la traîne, on subit. C'est pourquoi la vocation et l'intérêt de la France sont de conduire, avec nos partenaires, l'organisation de l'Europe.", Rede vom 15.5.1979, a.a.O., S. 6 
voyant grand, pourra jouer dans cette Europe rajeunie le rôle qui revient à son génie et à sa brillante histoire." ${ }^{36}$

Damit blieb die schon von Charles de Gaulle definierte "grandeur" Frankreichs auch unter Valéry Giscard d'Estaing weiter die Letztbegründung für die französische Führungsrolle in Europa. Für das nur noch ein Prozent der Weltbevölkerung zählende Frankreich war Europa nach Meinung des Präsidenten allerdings auch die einzig verbleibende Möglichkeit, auch zukünftig eine "grande nation" zu sein. ${ }^{37}$ Frankreich und Europa standen, wie schon für Georges Pompidou, so auch für Valéry Giscard d'Estaing in wechselseitiger funktionaler Abhängigkeit. Der Führungsanspruch beim Ausbau Europas, seine Begründung in der "grandeur" Frankreichs sowie die Vision von Europa als Zivilisationsmodell für den Rest der Welt zeigten, daß auch der europapolitische Ansatz Giscard d'Estaings im wesentlichen eine Fortführung der Europapolitik Charles de Gaulles darstellte. ${ }^{38}$ Europa hatte keine andere Mission als Frankreich selbst. Dementsprechend blieb es Multiplikator französischer Zivilisationsideen und damit des französischen Einflusses in der Welt. ${ }^{39}$ Der sich Mitte der siebziger Jahre ausweitende Nord-Süd-Konflikt war das neue Betätigungsfeld, auf dem Frankreich nicht abseits stehen wollte. Eine erfolgreiche Außenpolitik setzte jedoch politische Macht voraus, weshalb Frankreich sich weiter um ein politisch geeintes und einflußreiches Europa bemühte, dessen "Organisation" Giscard d'Estaing zu seinem primären europapolitischen Ziel erhob. ${ }^{40}$

\section{B.4.1.3 Die Umsetzung der europapolitischen Konzeption}

Ganz im Stil seiner Vorgänger begann auch Giscard d'Estaing die Umsetzung seiner europapolitischen Konzeption mit einer Initiative zur "relance européenne". Schon im September 1974 lud der neue Präsident seine Amtskollegen zu einem informellen Arbeitsessen nach Paris, auf dem er seine europapolitischen Vorstellungen darlegte. Am 24. Oktober wurde die Öffentlichkeit im Rahmen einer großen Pressekonferenz informiert. Am neunten und zehnten Dezember 1974 fand auf Einladung Frankreichs in Paris die erste regelmäßige Sitzung der Staats- und Regierungschefs der Gemeinschaft statt. Damit war der Grundstein für die Gründung des Europäischen Rates gelegt, der wenn auch noch nicht vertraglich als offizielles Organ der Gemeinschaft bestätigt -

\footnotetext{
${ }^{36}$ Vgl. Rede vom 15.5.1979, a.a.O., S. 10 sowie die Rede Giscard d'Estaings zum 150. Geburtstag der École Centrale am 15.11.1979

${ }^{37}$ Eine Äußerung Giscard d'Estaings im Vorfeld der Wahlen zum Europäischen Parlament 1979, vgl. Hargrove C. (1986), Valéry Giscard d'Estaing, in: Politique Étrangère, S. 125, No. 1, printemps 1986, 51. Jg., S. 115 ff.

${ }^{38}$ Vgl. Smouts, M.-C.; Cohen, S. (1985), Cohérence et contradictions d'un septenat, S. 16, in: ders., La Politique Extérieure de Valéry Giscard d'Estaing, Paris, S. 13-17

${ }^{39} \mathrm{Vgl}$. de la Serre, F. (1985), L'Europe communautaire entre le mondialisme et l'entente francoallemande, S. 87, in: Samy Cohen und Marie-Claude Smouts (Hrsg.), La Politique Extérieure de Valéry Giscard d'Estaing, Paris, S. 86-109

${ }^{40}$ Vgl. Giscard d'Estaing (1977), a.a.O., S. 185
} 
zukünftig die Leitlinien der Europapolitik festlegen sollte. Seine Errichtung ging auf eine französische Initiative noch aus der Amtszeit Georges Pompidous im Zusammenhang mit der Nahost-Krise (Herbst 1973) zurück. ${ }^{41}$ Nach vierzehn Jahren vergeblichen Bemühens hatte Frankreich damit die seit 1960 geforderte Einrichtung eines obersten Beschlußorgans auf Ebene der Staats- und Regierungschefs, welches das Kernelement der französischen Strategie für ein politisch handlungsfähiges Europa bildete, erreicht. ${ }^{42}$ Die Vertiefung der politischen Zusammenarbeit in der Gemeinschaft auf diesem Wege versprach aus Sicht der neuen französischen Regierung den größten Erfolg, um die Gemeinschaft ihrer wirklichen Bestimmung näher zu bringen, sich zu einer Politischen Union $\mathrm{zu}$ entwickeln, die in der Lage war, ihre Interessen weltweit nachdrücklich und erfolgreich durchzusetzen. ${ }^{43}$ Valéry Giscard d'Estaing erwartete von häufigen persönlichen Treffen der obersten Entscheidungsträger Europas einen entscheidenden Impuls für die weitere Entwicklung der Gemeinschaft hin zu einer wirklichen politischen Einheit. ${ }^{44}$ Er sah in regelmäßigen Zusammenkünften der höchsten Repräsentanten der Mitgliedstaaten ein geeignetes Instrument, um die Nationen an eine engere Zusammenarbeit zu gewöhnen, sowie ein Mittel, um die politische Einheit Europas eindrucksvoll nach außen zu dokumentieren. Die Regelung außenpolitischer Probleme im direkten persönlichen Kontakt entsprach allerdings auch der persönlichen Präferenz Giscard d'Estaings, der grundsätzlich von der überlegenen Effizienz persönlicher Kontakte der Staats- und Regierungschefs als Mittel der Diplomatie überzeugt war. ${ }^{45}$

Weitere Bestandteile der französischen Strategie zur Herstellung der politischen Einheit Europas waren die Direktwahl des Europäischen Parlaments sowie die Begrenzung des übermäßigen Gebrauchs der Einstimmigkeitsregel, in der Außenminister Sauvagnargues einen Hauptgrund für das Erlahmen der Gemeinschaftsaktivität sah. ${ }^{46}$ Dies war allerdings nicht als Fürsprache für den generellen Übergang zu Mehrheitsabstimmungen zu verstehen. Frankreich ging es vielmehr darum, klar jene Gebiete $\mathrm{zu}$ bestimmen, auf denen nach der Mehrheitsregel abgestimmt werden sollte, um die Entscheidungsabläufe in der EG effizienter zu gestalten. Auf keinen Fall beabsichtigt war ein zusätzlicher Transfer von Souveränitätsrechten. ${ }^{47}$ Beide Forderungen wurden auf

${ }^{41}$ Vgl. das Schreiben Pompidous an die Regierungschefs der anderen Mitgliedstaaten der Gemeinschaft vom 31.10.1973, abgedruckt in Auszügen in: EA, D 29, Folge 2/1974, D $28 \mathrm{ff}$. sowie die Ausführungen Pompidous in seiner Pressekonferenz vom 27.9.1973, a.a.O., S. 116

${ }^{42} \mathrm{Vgl}$. Delarue, M., "Une autre <<dîner privé>> des Neuf aurait lieu à l'Élysée en novembre", LE MONDE vom 1.7.1974, S. 2

${ }^{43} \mathrm{Vgl}$. die ausführliche Schilderung der europapolitischen Ziele Frankreichs in der Erklärung AuBenminister Sauvagnargues zur französischen Außenpolitik vor der Nationalversammlung vom 27.6.1975, a.a.O., S. 229

44 Vgl. die Erklärung Giscard d'Estaings im Anschluß an den ersten Europäischen Rat vom 10.12.1974, abgedruckt in: PE, S. 257, 2. Sem., S. 254 ff.

${ }^{45}$ Vgl. Cohen (1986), a.a.O., S. 25

${ }^{46} \mathrm{Vgl}$. die Rede Außenminister Sauvagnargues vom 6.11.1974 vor der Nationalversammlung, abgedruckt in: PE, S. 163, 2. Sem., S. $160 \mathrm{ff}$.

${ }^{47} \mathrm{Vgl}$. die Rede Außenminister Sauvagnargues vor dem Sénat am 19.11.1974, abgedruckt in: PE, S. 192 und 193, 2. Sem., S. $189 \mathrm{ff}$. 
dem Gipfel von Paris angenommen, so daß Frankreich Ende 1974 die erneute „relance européenne" im wesentlichen als verwirklicht betrachten konnte. Wie seinen Vorgängern, so war es auch Valéry Giscard d'Estaing gelungen, den europäischen Einigungsprozeß mit einem erfolgreichen Coup wiederzubeleben und ihn damit ein Stück weiter in die von Frankreich gewünschte Richtung zu bewegen.

Dieser Impuls war jedoch nur von kurzer Dauer. Außer der Tatsache, daß es in Europa auf institutioneller Ebene ein zusätzliches Organ gab, änderte sich in den folgenden Jahren nichts an der im Prinzip schon seit den Währungsunruhen von 1971 zu beobachtenden Stagnation des Integrationsprozesses. In seinem Bericht zur Lage der Gemeinschaft stellte der belgische Ministerpräsident Tindemanns Ende 1975 fest, daß die europäische Idee in der Krise steckte und die Öffentlichkeit die Verbindung zu ihr verloren habe. ${ }^{48}$ Unter den Belastungen der Weltwirtschaftskrise hätten sich die Staaten als zu schwach erwiesen, das Leitbild der europäischen Einigung weiter mit Leben zu erfüllen. Angesichts der Gefahr eines völligen Zerfalls der Gemeinschaft forderte der Tindemanns-Bericht eine Neudefinition des europäischen Einigungswerkes. ${ }^{49}$ Die französische Europapolitik vermochte nicht, sich diesem Ansinnen wirksam anzunehmen. Sie verlor deutlich an Initiativkraft, als Anfang 1976 infolge grundlegender Meinungsverschiedenheiten zwischen Präsident und Premierminister das Kabinett Chirac auseinanderbrach. Die zunehmend schwieriger werdende Wirtschaftslage zwang die nachfolgende Regierung unter Raymond Barre, sich zunächst primär auf nationale Probleme $\mathrm{zu}$ konzentrieren. Auch gab es koalitionsinterne Abstimmungsschwierigkeiten mit der europakritischen gaullistischen Fraktion, die nachhaltige Initiativen Frankreichs auf europäischer Ebene von vornherein verhinderte. Giscard d'Estaing blieb Mitte 1976 nur, zur Kenntnis zu nehmen, daß Europa in der Weltpolitik immer noch keine „Realität“ geworden war, sowie eine neue Debatte über die "Organisation" Europas und seine internationale Rolle zu fordern. ${ }^{50}$ In einer Rede vor den Angehörigen des britischen Ober- und Unterhauses am 23. März 1976 forderte er Großbritannien auf, gemeinsam mit Frankreich Europa zu mehr politischer Präsenz auf internationaler Ebene zu verhelfen. Immerhin hätten beide Nationen aus Gewohnheit ein Interesse an den großen Problemen der Menschheit sowie enge Verbindungen in alle Teile der Welt, die sie natürlicherweise zur Stärkung der politischen Einheit Europas bewegen müßten. ${ }^{51} \mathrm{Zu}$ seiner Enttäuschung verhallte auch dieser Appell ungehört. Die Europäische Gemeinschaft blieb außenpolitisch zunächst, trotz dreimaliger Treffen ihrer Staats- und Regierungschefs im Jahr, ein Staatenbund ohne das von Frankreich gewünschte internationale Gewicht.

\footnotetext{
${ }^{48} \mathrm{Vgl}$. das Schreiben des belgischen Ministerpräsidenten an seine Kollegen im Europäischen Rat vom 29.12.1975,D $55 \mathrm{ff}$, in: EA, Folge 3/1976, D $53 \mathrm{ff}$.

${ }^{49}$ ebenda

${ }^{50} \mathrm{Vgl}$. die Ansprache Giscard d'Estaings vom 23.3.1976 im House of Lords vor den Mitgliedern beider Kammern, S. 176 f., PE, 1. Sem., S. 175 ff.

${ }^{51}$ ebenda, S. 177
} 
Auch die nach vielen Schwierigkeiten für den 10. Juni 1979 festgelegte erste Direktwahl des Europäischen Parlaments vermochte den faktischen Stillstand des Integrationsprozesses nicht zu verdecken. In Frankreich selbst war dieses Ereignis seitens der Gaullisten, die eine Einschränkung der französischen Unabhängigkeit befürchteten, heftig umstritten. Giscard d'Estaing formulierte dementsprechend vorsichtig, daß Frankreich zwar der Direktwahl des Europäischen Parlaments zustimme, nicht jedoch einer Ausdehnung seiner Kompetenzen. ${ }^{52}$ Eine solche sollte erst in Erwägung gezogen werden, wenn sich Europa zu einer wirklichen Konföderation entwickelt habe. Bis dahin würde die Direktwahl des Europäischen Parlaments mehr den Charakter einer „Umfrage“ bei den Bürgern als den einer echten Wahl tragen. ${ }^{53}$

Eine gewisse Dynamik erfuhr der europäische Integrationsprozeß immerhin durch die Beitrittsanträge Griechenlands, Spaniens und Portugals, denen man, nachdem sie sich Mitte der siebziger Jahre zu Demokratien entwickelt hatten, die Aufnahme in die Gemeinschaft nicht länger verweigern konnte. Die französische Regierung stimmte dieser Erweiterung der Gemeinschaft und damit des Binnenmarktes mit dem Hintergedanken zu, auf diese Weise das Gravitätszentrum Europas wieder mehr nach Süden zu verlagern und Frankreich so wieder mehr in den Mittelpunkt des Geschehens zu rücken. ${ }^{54}$ Der französische Präsident sah Frankreich aufgrund gemeinsamer lateinischer Traditionen als natürlichen Verbündeten der neuen südeuropäischen Demokratien. Ihren Beitritt begrüßte er im Sinne eines Ausgleichs zwischen den Demokratien anglo-amerikanischen und lateinischen Typs in der Gemeinschaft. ${ }^{55}$ Als lateinische Bruderstaaten und natürliche Verbündete paßten sie ideal in sein Konzept eines politisch geeinten Europas:

"ma thèse est la suivante: l'organisation de l'Europe est une organisation politique. C'est l'organisation d'un continent qui a en commun une histoire, une civilisation, un mode de vie, une fraternité dans les relations humaines. Il n'est pas possible d'exclure de l'organisation de ce continent des pays qui en font partie de toute évidence et depuis l'origine. ${ }^{\text {"56 }}$

Wie schon bei den ersten Erweiterungsbemühungen stand für Frankreich auch bei der zweiten Erweiterung der Gemeinschaft die Kompatibilität der Bewerber mit den Zielen der französischen Europapolitik im Vordergrund. Wirtschaftliche Gründe spielten erneut nur eine nachgeordnete Rolle. Sie eigneten sich allenfalls dazu, den Verlauf der Beitrittsverhandlungen zu verzögern, wie z. B. im Zuge massiver Proteste südfranzösischer Landwirte gegen spanische Billigimporte. Auch trugen innerfranzösische Besorgnisse über die niedrigen Löhne der spanischen Landwirtschafts- und Industriearbeiter dazu bei, daß Frankreich den Verlauf der Beitrittsverhandlungen mit Spanien

\footnotetext{
${ }^{52}$ Vgl. die Pressekonferenz Giscard d'Estaings am 21.11.1978, a.a.O., S. 87

53 ebenda

${ }^{54}$ Vgl. Gerbet (1983), a.a.O., S. 389 sowie de la Serre (1985), a.a.O., S. 104 f.

${ }^{55}$ So Giscard d'Estaing während eines Staatsbesuchs in Spanien am 29.6.1978 in einer Ansprache vor dem spanischen Senat, abgedruckt in, PE, S. 107, 1. Sem.

${ }^{56}$ Vgl. die Pressekonferenz Giscard d'Estaings vom 21.11.1978, abgedruckt in: PE, S. 86, 2. Sem., S. $82 \mathrm{ff}$.
} 
verzögerte. $^{57}$ Während sich für Griechenland noch 1979 eine Lösung finden ließ, dauerten die Verhandlungen mit Spanien und Portugal noch weitere fünf Jahre bis 1984.

Die Umsetzung der europapolitischen Konzeption Valéry Giscard d'Estaings war am Ende seiner Amtszeit, gemessen an ihren ursprünglichen Zielen, von geringem Erfolg gekrönt. Die umfangreiche Reforminitiative zu Beginn seiner Amtszeit sorgte zwar für einen gelungenen Auftakt, doch vermochte Frankreich in den folgenden Jahren nicht, dem europäischen Einigungsprozeß weiter nachhaltig Impulse zu verleihen. Unter dem Eindruck der internationalen Wirtschaftskrise fand sich kaum Unterstützung für die europapolitischen Ambitionen der französischen Regierung. Auch fehlte Frankreich wegen seiner innen- und wirtschaftspolitischen Probleme die Kraft, seine Vision eines politisch aktiven und international handlungsfähigen Europas energisch weiter zu verfolgen. Wie groß die persönliche Enttäuschung Giscard d'Estaings über dieses Ergebnis gewesen sein muß, läßt sich allerdings erst ermessen, wenn man die enge Verzahnung seiner europapolitischen Konzeption mit der von ihm maßgeblich geprägten „mondialistischen“ Außenpolitik näher betrachtet. Als Erfolg bleibt festzuhalten, daß Frankreich unter Giscard d'Estaing die seit 1960 geforderte Einrichtung regelmäßiger Zusammentreffen der Staats- und Regierungschefs gelang. Auch wenn damit noch keine neue Institution oberhalb des Ministerrats entstand, so wurde faktisch die Grundlage für die Vertiefung der intergouvernementalen Zusammenarbeit in der Gemeinschaft gelegt. Für den europäischen Einigungsprozeß bedeutete dies einen weiteren Schritt in Richtung der von Frankreich seit jeher bevorzugten Konföderation der Mitgliedstaaten. In diesem Sinne war der absolut betrachtet geringe Erfolg der Europapolitik Giscard d'Estaings langfristiger Natur. Seine Auswirkungen sollten sich erst später entfalten.

\section{B.4.2 Die Wirtschaftspolitik}

Im Mittelpunkt der mondialistischen Außenpolitik Giscard d'Estaings stand die Errichtung einer neuen Weltwirtschaftsordnung (nouvel ordre économique). Der europäische Binnenmarkt wäre Teil dieser neuen Wirtschaftsordnung gewesen und Frankreich erwartete von seinen europäischen Partnern aktive Unterstützung bei ihrem Aufbau. Ausgangspunkt der Überlegungen Valéry Giscard d'Estaings war sein pessimistisches Szenario der zukünftigen Wirtschaftsentwicklung. Bei zunehmender Interdependenz der Volkswirtschaften sah er die Gefahr einer dauerhaften Krise, der sich keine Nation entziehen können würde. ${ }^{58}$ Notwendig war deshalb die „mondialistische“ Außenpolitik, deren Hauptanliegen darin lag, im Rahmen einer weltweiten Kooperation nach gemeinsamen Lösungen für die aktuellen Wirtschaftsprobleme zu suchen. ${ }^{59}$ Aus Sicht des französischen Staatspräsidenten stellte sich die Rohstoff- und Energiekrise als

\footnotetext{
${ }^{57}$ Vgl. Lecerf (1984), La communauté face à la crise, S. 334 und 335, Paris

${ }^{58}$ Vgl. die Pressekonferenz Giscard d'Estaings am 24.10.1974, a.a.O., S. 2

59 "... c'est ensuite une politique mondialiste, parce que je suis convaincu, à l'heure actuelle, que les problèmes qui se posent, en réalité, à l'échelle mondiale et qu'il faut donc prendre la perspective et la dimension mondiale dans la recherche des solutions“, ebenda
} 
Binnenkrise der Staatengemeinschaft dar, die eine konsensorientierte Lösung im Rahmen einer globalen „Konzertation“ aller betroffenen Staaten erforderte. ${ }^{60}$

Die wirtschaftliche Lage der Welt sah Giscard d'Estaing durch drei grundlegende Ungleichgewichte bedroht: durch die Inflation, die er auf soziologische Veränderungen zurückführte, durch das instabile Weltwährungssystem, das an einer übermäßigen Ausdehnung der Geldmenge litt, sowie durch die "brutale" Anhebung der Energiepreise, die er auf die Verknappung der Ressourcen zurückführte. ${ }^{61}$ Alle drei Probleme waren seiner Meinung nach getrennt zu behandeln, da sie unterschiedliche Ursachen hätten. Ein Lösungsansatz im Sinne des "Allgemeininteresses" (intérêt commun) der betroffenen Länder legte seiner Meinung nach nahe, gemeinsam eine "objektive" Analyse (examen objective du problème) vorzunehmen, in der die legitimen Interessen der beteiligten Länder gebührend Berücksichtigung finden sollten. Für die Entwicklungsländer, als deren Sprecher Frankreich sich verstand ${ }^{62}$, war das die Bekämpfung ihrer Armut, für die Industrieländer die Überwindung ihrer wirtschaftlichen Stagnation und für die Rohstoffproduzenten, insbesondere für die OPEC-Staaten, die Maximierung ihrer Exporteinnahmen. Eine langfristig stabile Lösung setzte nach Ansicht des französischen Staatspräsidenten eine positive Entwicklung der Weltwirtschaft voraus. Nur so sei ein hinreichender Verbrauch an Rohstoffen sicherzustellen, der wiederum die Voraussetzung für hinreichende Einnahmen der Rohstoffländer darstellte bzw. dafür, die notwendigen Mittel zur Finanzierung von Unterstützungsmaßnahmen für die dritte Welt zu erwirtschaften. Alle Länder müßten deshalb ein gemeinsames Interesse an der Lösung der Weltwirtschaftskrise haben und dazu ihren Beitrag leisten.

Konkret schlug der französische Präsident deshalb im Oktober 1974 die Einberufung einer Weltkonferenz vor, in der Vertreter der Erdölförderländer, der Industriestaaten sowie der Entwicklungsländer sich zunächst zwei Themen widmen sollten. Zum einen war die Frage zu klären, über welche Maßnahmen die Weltwirtschaft wieder angekurbelt werden konnte und zum anderen waren Garantien für die Einnahmen rohstoffproduzierender Länder auszuhandeln. Als geeignetes Instrument zur Lösung dieser Probleme lancierte Frankreich die Indexierung der Rohstoffpreise, deren Entwicklung an bestimmte volkswirtschaftliche Kenngrößen gebunden werden sollte. ${ }^{63}$

Die Weltwirtschaftskonferenz, ursprünglich schon von Georges Pompidou im Januar 1974 zur Lösung der Weltenergieprobleme vorgeschlagen ${ }^{64}$, sollte nach französischem Willen möglichst Anfang 1975 beginnen. Von den Europäern forderte der französische Präsident auf dieser Konferenz, als Einheit aufzutreten und mit einer Stimme zu sprechen. Außerdem erwartete Frankreich die Unterstützung seiner Partner im euroarabischen Dialog, einer französischen Initiative aus dem November 1973 zur Sicher-

\footnotetext{
${ }^{60}$ ebenda

${ }^{61}$ ebenda

${ }^{62}$ Vgl. die Rede Chiracs vom 10.6.1975, a.a.O., S. 205

${ }^{63}$ ebenda, S. 3

${ }^{64} \mathrm{Vgl}$. die Rede Pompidous in Poitiers am 24.1.1974, a.a.O., S. 52
} 
stellung der europäischen Energieversorgung. ${ }^{65}$ Tatsächlich kam es im Juli 1974 zu einem Treffen zwischen Vertretern der Gemeinschaft und denen von vier ölproduzierenden Ländern. Das geringe Interesse der europäischen Partner Frankreichs an einer separaten Energiepolitik, Uneinigkeit in der Palästina-Frage sowie nicht zu vereinbarende Positionen der Gemeinschaftsvertreter und der Ölländer in Fragen der Energieversorgung führten jedoch schnell zum Scheitern dieser Initiative. ${ }^{66}$

Trotz dieses Mißerfolges verfolgte Frankreich seine Idee einer Weltkonferenz zur Lösung der Wirtschaftsprobleme weiter. Valéry Giscard d'Estaing rückte zunehmend den Gedanken in den Vordergrund, daß es auf der Konferenz nicht nur um die Rohstoffversorgung gehen dürfe, sondern grundsätzlich eine neue globale Wirtschaftsordnung erforderlich sei, um die Weltwirtschaft zukünftig vor „brutalen“ Schocks zu bewahren. ${ }^{67}$ Diese neue Wirtschaftsordnung sollte so angelegt sein, daß der Welthandel, die Geldmärkte und die Verteilung der Einkünfte wieder ins Gleichgewicht zurückfänden. Zum Ausgleich des Welthandels sah der Präsident zum einen die Regulierung der Rohstoffpreise und zum anderen eine Garantie der Einnahmen der rohstoffexportierenden Länder als unabdingbare Voraussetzungen an. ${ }^{68}$ Für einzelne Produkte insbesondere aus Entwicklungsländern sollten dabei Abkommen über die Ober- und Untergrenzen der Marktpreise geschlossen werden. Die Preise selbst wiederum sollten über einen Eingriffsmechanismus mit Zwischenlagern verteidigt werden. ${ }^{69}$ Ferner erachtete der französische Präsident Importgarantien der Industrieländer sowie einen Fonds als notwendig, dessen Mittel zur Stabilisierung der Exporteinnahmen besonders bedürftiger Entwicklungsländer dienen sollten. Außerdem sollte diesen Staaten über allgemeine Zollpräferenzen (préférences généralisées) beim Export ihrer Industriegüter geholfen werden. Zum Ausgleich der Wirtschaftstätigkeit sollte die neue Weltwirtschaftsordnung ferner so angelegt sein, daß sie den Technologieexport sowie Auslandsinvestitionen förderte. Die Forderung nach Ausgleich der Geldmärkte hingegen zielte auf die Stabilisierung der Wechselkurse und die Kontrolle des Kapitalverkehrs, während der Ausgleich der Einkommen eine gerechtere Verteilung der Entwicklungshilfe sowie der Lasten für ihre Erbringung umfaßte.

Auf der Tagesordnung der Konferenz zur Neuordnung der Weltwirtschaft hatten nach französischem Willen dementsprechend die Energie- und Rohstoffversorgung, die Entwicklungshilfe sowie finanzielle und monetäre Aspekte im Vordergrund zu stehen. Um zu einer Lösung im Konsens zu gelangen, forderte der französische Präsident, daß die Teilnehmer nicht weiter in einer puren Eigennutzorientierung verharren dürften, sondern mit Gemeinsinn und vor allem mit Rücksicht auf die Entwicklungsländer ihre Interessen vertreten sollten. Grundsätzlich war zwar die Souveränität der Nationen zu

\footnotetext{
${ }^{65}$ So Außenminister Sauvagnargues in einem Interview mit FRANCE-INTER am 19.1.1975, abgedruckt in: PE, S. 55,1. Sem., S. 51 ff.

${ }^{66}$ Vgl. de la Serre (1985), a.a.O., S. 99

${ }^{67} \mathrm{Vgl}$. die Rede Giscard d'Estaings vom 28.10.1975 vor der ÉCOLE POLYTECHNIQUE

${ }^{68}$ ebenda

${ }^{69}$ ebenda
} 
wahren, doch durfte das Verhandlungsergebnis auf keinen Fall auf einen Sieg einer Gruppe über die andere hinauslaufen. Vielmehr hätte, so der französische Präsident, die Neuregelung der Weltwirtschaftsordnung zu einem „Sieg der Menschheit über sich selbst“ zu führen, weil es dabei letzten Endes um die Neuordnung der wirtschaftlichen Grundlagen der Menschheit insgesamt ginge. ${ }^{70}$

Was sich außenpolitisch als groß angelegter Versuch der globalen Aussöhnung darstellte, war ordnungspolitisch betrachtet der Versuch, eine dauerhafte Lösung globaler Wirtschaftsprobleme außerhalb der Marktmechanismen herbeizuführen. Überzeugt von der Überlegenheit der politischen Koordination, glaubte die französische Regierung, das allokative Optimum besser im Rahmen einer konsensorientierten globalen Koordination erreichen zu können. Aus französischer Sicht ging es darum, Märkte zu „organisieren“, den Koordinationsspielraum des Preismechanismus auf politisch definierte Grenzen zurückzuführen und dieses Reglement auf möglichst viele Produkte zu übertragen. ${ }^{71}$ Dabei sollte das freie Spiel der Preise nicht grundsätzlich unterbunden werden. Vorrangig jedoch war aus Sicht der französischen Regierung, "exzessive" Preisbewegungen zu unterbinden und durch Interventionen „gerechte“ Preise für Rohstoffe und andere Produkte der dritten Welt sicherzustellen. ${ }^{72}$ Ziel dieser Eingriffe waren somit eine effektive Kontrolle der Marktkoordination sowie die Realisierung eines politisch als angemessen beurteilten Verteilungsergebnisses.

Neben einem Zuwachs an "Gerechtigkeit" ging es dem französischen Präsidenten bei der Einschränkung des freien Spiels der Preise außerdem um mehr "Rationalität“ in den internationalen Wirtschaftsbeziehungen, die sich für ihn in einer besser geordneten Preisentwicklung ausdrückte und die er als Voraussetzung für eine übersichtlichere und besser vorhersehbare Wirtschaftsentwicklung ansah. ${ }^{73}$

"Il faut aussi rechercher une évolution plus ordonnée des prix des produits faisant l'objet des échanges internationaux significatifs, qu'ils s'agissent de produits bruts ou industrialisés. Cette recherche implique nullement le refus des revalorisations justifiées, soit par l'ajustement de l'offre à la demande, soit par l'augmentations des coûts, soit par des exigences sociales ou politiques légitimes. Ce qu'on doit éliminer, ce sont les fluctuations erratiques ou contradictoires, les variations à la hausse ou à la baisse trop marquées ou trop brutale, susceptibles de perturber durablement les marchés, ou les secteurs productifs, au détriment des producteurs comme des consommateurs. ${ }^{174}$

An dieser Stelle zeigte sich, daß die Preissetzung für den französischen Präsidenten kein autonomer Akt der Wirtschaftssubjekte war, dem er, auf gesamtwirtschaftlicher

\footnotetext{
${ }^{70}$ ebenda

${ }^{71}$ Vgl. die Rede Außenminister Sauvagnargues im Ministerrat der OECD vom 28.5.1975, abgedruckt in: PE, S.185,1. Sem., S. 183 ff.

${ }^{72}$ Vgl. die Rede des Wirtschafts- und Finanzministers Fourcade am 2.9.1975 auf der Jahreshauptversammlung des IWF und der BIZ, abgedruckt in: PE, S. 67, 2. Sem., S. $64 \mathrm{ff}$.

${ }^{73}$ Vgl. die Ansprache Giscard d'Estaings zur Eröffnung der Konferenz über die internationale wirtschaftliche Zusammenarbeit am 16.12.1975, abgedruckt in: PE, S. 195, 2. Sem., S. 195 f.

${ }^{74}$ ebenda
} 
Ebene unbehindert vorgenommen, zutraute, zur vollen Entfaltung der ökonomischen Rationalität und damit gesamtwirtschaftlich zum allokativen Optimum zu führen. Vielmehr waren in der Preisbildung höhere Interessen als nur die der unmittelbar Betroffenen zu berücksichtigen, wenn sie gleichzeitig mit Rücksicht auf die Entwicklung des Welthandels und die Einkommensverteilung unter den Nationen zu erfolgen hatte. Die Tatsache, daß Frankreich über direkte Eingriffe, statt über die Gestaltung wirtschaftlicher Rahmenbedingungen, den Preismechanismus in die gewünschte Richtung zu beeinflussen suchte, deutete darauf hin, daß auch unter dem vermeintlichen "Neoliberalen" Giscard d'Estaing ein grundsätzliches Mißtrauen gegenüber dem Marktmechanismus die ordnungspolitische Orientierung der französischen Politik beherrschte.

Die Rechtfertigung für "korrigierende" Eingriffe in den Marktmechanismus führte der französische Präsident auf das „Allgemeininteresse“ zurück, welches Frankreich als Industriestaat, natürlicher Alliierter der Entwicklungsländer und „champion de l'humanité" zu vertreten habe. Im Vollvertrauen auf die Fähigkeit der Wirtschaftspolitik, Märkte und damit die Wirtschaftsentwicklung lenken zu können, zu der sich Giscard d'Estaing schon im Sommer 1971 bekannt hatte ${ }^{75}$, strebte Frankreich die Institutionalisierung einer den Marktmechanismus überlagernden politischen Koordination an, die sich am Vorbild der europäischen Agrarmarktordnung orientierte. Die Rechtfertigung gerade dieser ordnungspolitischen Richtungswahl kann allerdings kaum auf wirtschaftlichen Überlegungen beruht haben. Die Funktionsmängel des EGAgrarmechanismus waren schon seit mehreren Jahren bekannt und nichts deutete darauf hin, daß seine Übertragung auf globale Ebene zu besseren Ergebnissen führen würde. Im französischen Entwurf der neuen Weltwirtschaftsordnung dominierten letztlich idealistische Erwägungen. Forderungen wie die nach „gerechten Preisen“ sowie das Ziel, eine Wirtschaftsordnung zu schaffen, die einen Sieg der Menschheit über sich selbst darstellte, zeigten, daß die französische Initiative in erster Linie rein ethischen Motiven und nicht einer bestimmten wirtschaftlichen Ordnungslogik folgte. ${ }^{76}$

In dieser Hinsicht stimmte die neue Weltwirtschaftsordnung mit jenen Ordnungsvorstellungen überein, die Valéry Giscard d'Estaing schon seiner nationalen Wirtschaftspolitik vorangestellt hatte. Ihr Ausgangspunkt war die Feststellung, daß die Wirtschaft im Dienst des Menschen zu stehen habe. ${ }^{77}$ Damit die Gesellschaft ihre Entwicklung bewußt lenken könne, müsse, so der französische Präsident, zunächst ein mittel- und langfristiger Gesamtüberblick geschaffen werden, der den wirkungsvollen Einsatz der Werkzeuge zur Beeinflussung der Wirtschaftsentwicklung ermögliche. In Frankreich geschehe dies im Rahmen der "planification“, die, so Giscard d'Estaing, sicherstelle, daß die Meinung aller für das wirtschaftliche und soziale Leben Verantwortlichen be-

${ }^{75}$ Vgl. sein Bekenntnis zur Lenkbarkeit der Wirtschaft im Interview mit DER SPIEGEL vom 31.8.1971, a.a.O., S. 86

${ }^{76}$ Vgl. Zorgibe, C., Frankreich und die "neue Weltwirtschaftsordnung", S. 545, EA Folge 16/1976, S. $539 \mathrm{ff}$.

${ }^{77}$ Vgl. Giscard d'Estaing (1977), a.a.O., S. 133 
rücksichtigt und auf diese Weise eine demokratische Orientierung der Wirtschaftsentwicklung stattfinden werde. Eine „fortschrittliche Gesellschaft“ konnte nach Ansicht des französischen Präsidenten ihre Lenkung nicht allein nur dem Markt anvertrauen. Die von ihm skizzierte Wirtschaftsordnung hatte seiner Meinung nach den Vorteil, daß die Mechanismen des Markts und des Wettbewerbs den Unternehmen erlaubten, elementare Entscheidungen selbst zu treffen, während parallel dazu die Konzertation der Sozialpartner auf politischer Ebene die notwendigen Ergänzungen und Korrekturen herbeiführen werde. ${ }^{78}$

Wesentliche Elemente dieses Ordnungsentwurfs prägten letztlich auch den französischen Ansatz zur Neuordnung der Weltwirtschaft. Dies galt vor allem für die obligatorische Konsultation der Sozialpartner sowie für die aus dem Allgemeininteresse legitimierten, von vornherein als notwendig erachteten staatlichen Interventionen zur Korrektur der Marktergebnisse. Die wirtschaftlichen Ordnungsvorstellungen Giscard d'Estaings hatten ihren Ausgangspunkt in seiner Auffassung von einer „fortschrittlichen“ Gesellschaft und nicht in ökonomischen Prinzipien. Die Dominanz gesellschaftspolitischer Sollvorstellungen ließ ihn Entwicklungen wie z. B. die zunehmende weltweite Verflechtung der Volkswirtschaften vornehmlich auf ihre sozialen Implikationen reduzieren. Dementsprechend war die Globalisierung für den französischen Präsidenten primär Ausdruck für den weltweiten Übergang von einer „civilisation de groupe“ zu einer „civilisation mondiale“, den es im Sinne des Allgemeininteresses in geordnete Bahnen zu überführen galt, und nicht das Ergebnis wirtschaftlicher Entwicklungsprozesse.

Der praktische Erfolg der französischen Initiative zur Neuordnung der Weltwirtschaft war jedoch nur ein begrenzter. Die europäischen Partner, auf deren Unterstützung Frankreich baute, beschlossen, nachdem die erste Vorbereitungskonferenz zum Weltwirtschaftsgipfel fehlschlug, von weiteren Bemühungen abzusehen. Frankreich indessen setzte sich über diesen Beschluß hinweg. In aller Deutlichkeit forderte Außenminister Sauvagnargues am 27. Juni 1975 vor der Nationalversammlung noch einmal, daß Europa endlich in der internationalen Politik als geschlossene Einheit mit einer gemeinsamen Haltung auftreten müsse und dieser seinem wirtschaftlichen Gewicht entsprechend Geltung zu verschaffen hätte. ${ }^{79}$ In bezug auf die Zusammenarbeit mit den arabischen und afrikanischen Ländern galt dies um so mehr, da aus der europäischen Kolonialgeschichte heraus Beziehungen bestünden, die der Gemeinschaft eine privilegierte Rolle sicherten. ${ }^{80}$ Nach intensivem diplomatischen Engagement erreichte Frank-

${ }^{78}$ „Eine fortgeschrittene Gesellschaft kann ihre Lenkung nicht allein dem Wettbewerb oder allein dem Markt anvertrauen; um sich selbst bewußt und wirksam zu lenken, muß sie es den Mechanismen des Marktes überlassen, die Grundfunktion der Wirtschaft zu regeln, die sie sodann korrigieren und ergänzen kann.“, so Giscard d'Estaing (1977), a.a.O., S. 136

${ }^{79}$ Vgl. die Rede Sauvagnargues am 27.6.1976, a.a.O., S. 230

80 "Je dirai en deuxième lieu que la France et la Communauté européenne ont un rôle à jouer en raison des liens qu'elles ont su maintenir ou créer avec le Tiers-Monde comme cela a été démontré par la négociation et la conclusion de la Convention de Lomé", ebenda, S. 232 
reich am 16. Dezember 1975 die Eröffnung der „Konferenz für die internationale wirtschaftliche Zusammenarbeit“, die bald als „Nord-Süd-Dialog“ firmierte. Sie endete jedoch nach eineinhalb Jahren im Juni 1977 mit einem ernüchternden Schlußkommuniqué, in dem, neben Absichtsbekundungen zur Unterstützung der Entwicklungsländer sowie zur Förderung einer geregelten wirtschaftlichen Kooperation, klar zum Ausdruck kam, daß die Konferenzteilnehmer zu keiner Einigung über die Stabilisierung der Rohstoff- und Energiepreise gekommen waren und sich auch nicht über einen weltweiten Konsultationsmechanismus einigen konnten. ${ }^{81}$ Zurückzuführen war dieses, den ursprünglichen Intentionen Frankreichs zuwiderlaufende Ergebnis dem Kopräsidenten des Ausschusses für Entwicklungsfragen, Edmond Wellenstein, zufolge, zum einen auf die unübersehbare Heterogenität der Einzelinteressen der beteiligten Nationen und zum anderen auf die Sorge der Industrieländer, unter dem Druck der Ereignisse in einen Prozeß hineingezogen zu werden, der das normale Funktionieren der bisherigen Weltwirtschaftsordnung zerstören würde. ${ }^{82}$ Darüber hinaus existierten auf seiten der Entwicklungsländer Zweifel an der Glaubwürdigkeit der gastgebenden französischen Regierung. Die unter Giscard d'Estaing intensiv betriebene französische Außenwirtschaftsdiplomatie konterkarierte die von ihm selbst geforderte Gemeinwohlorientierung aller Teilnehmerstaaten am Nord-Süd-Dialog. ${ }^{83}$ Frankreichs Versuch, sich zum Sprecher der Dritten Welt zu erheben, war überdies nur sehr schwer von seinem Eigeninteresse zu trennen, sich selbst den Zugang zu existenznotwendigen Ressourcen für seine Wirtschaft zu sichern. ${ }^{84}$ Darüber hinaus kollidierte die französische Forderung, den Entwicklungsländern Einkommensgarantien zuzugestehen, mit der Weigerung Frankreichs, garantierte Mindestpreise für Rohstoffe und Energieträger festzulegen. ${ }^{85}$ Gemessen an den ursprünglichen Vorstellungen Frankreichs war die Nord-Süd-Konferenz ein Mißerfolg. Im Verlauf der zweiten Hälfte der Amtszeit Valéry Giscard d'Estaings sah die französische Diplomatie dementsprechend von weiteren Versuchen zur Neuordnung der Weltwirtschaftsbeziehungen ab. Statt des globalen Dialogs zog Frankreich fortan vor, im Rahmen des „Trilogue" separate, privilegierte Beziehungen zu den arabischen und afrikanischen Staaten auf bilateraler Ebene aufzubauen. ${ }^{86}$ Dabei vertrat es seine außenwirtschaftlichen Interessen in direkten Verhandlungen, in die sich, wenn es dem Export französischer Produkte half, häufig auch der Präsident persönlich einschaltete.

${ }^{81} \mathrm{Vgl}$. Schlußbericht der Konferenz über die internationale wirtschaftliche Zusammenarbeit vom 2.6.1977, in: EA, D 495 ff., Folge 17/1977, D 493 ff.

${ }^{82}$ Vgl. Wellenstein, E.-P. (1977), Der Pariser "Nord-Süd-Dialog", in: EA, S. 563, Folge 17/1977, S. $561 \mathrm{ff}$.

${ }^{83}$ Vgl. Grosser (1986), a.a.O., S. 325 f.; Lacorne (1985), a.a.O., S. 160 ff.; Zorgibe (1976), a.a.O., S. 545

${ }^{84} \mathrm{Vgl}$. Grosser (1986), a.a.O., S. 325 f.

${ }^{85} \mathrm{Vgl}$. Zorgibe (1976), a.a.O., S. 542

${ }^{86}$ Vgl. Grosser (1986), a.a.O., S. 325 f. 


\section{B.4.3 Die Währungspolitik}

Neben der "Organisation" der Märkte spielte auch die Reform des internationalen Währungssystems eine herausgehobene Rolle in den französischen Bemühungen um die Neuordnung der Weltwirtschaft. ${ }^{87}$ Bevor Frankreich jedoch auf internationaler Ebene initiativ wurde, wendete es sich zunächst mit einem umfangreichen Programm zur Reform des Europäischen Wechselkursverbundes an seine europäischen Partner. Zur Behebung der schlechten Wirtschaftslage sei es notwendig, so Wirtschafts- und Finanzminister Fourcade im Ministerrat am 16. September 1974, daß Europa reagiere. Bis zum Ende des Jahres sollte die Gemeinschaft über den Ausbau ihrer Finanzierungsmechanismen und über die Akzentuierung ihres internationalen Gewichts zur Gesundung der Weltwirtschaftsordnung und des internationalen Währungssystems entscheiden. ${ }^{88}$ Wie schon bei der neuen Weltwirtschaftsordnung sollte es auch bei der Reform der europäischen Währungsordnung nicht in erster Linie um ausgefeilte, technisch perfektionierte Modelle gehen, sondern um die Suche nach pragmatischen und wirksamen Lösungen. Aus französischer Sicht bedurfte es dazu folgender Maßnahmen $^{89}$ :

- Ausgabe einer Gemeinschaftsanleihe: Europa sollte nach französischen Vorstellungen eine seinem wirtschaftlichen Gewicht entsprechende herausgehobene Rolle beim Recycling der Petrodollars spielen und diese zur Stützung seines Wirtschaftswachstums nutzen. Zu diesem Zweck sollte die EG einen Kredit in Höhe von zwei Milliarden Europäischen Rechnungseinheiten (ERE) direkt bei den Ölförderländern aufnehmen.

- Einführung einer neuen Europäischen Rechnungseinheit: Da das Gold seine ursprüngliche Funktion im internationalen Währungssystem verloren hatte und viele Mitglieder im EWV ihre Währungen floaten ließen, sah die französische Regierung die Neudefinition der bisher in Gold definierten ERE als zwingend notwendig an. Die neue ERE sollte nach französischen Vorstellungen als Währungskorb angelegt sein, in dem die Gewichtsverteilung nach den Anteilen der einzelnen Währungen am kurzfristigen Währungsbeistand zu bemessen war. Von ihrer Funktion her sollte die neue Währungseinheit vor allem als Recheneinheit im innereuropäischen Zahlungsverkehr der Zentralbanken verwendet werden.

87 "Organisation des marchés, accroisement de l'aide en faveur des plus défavorisés, ces deux premiers éléments doivent, pour être efficaces, s'intégrer dans un système monétaire plus stable", so Wirtschafts- und Finanzminister Fourcade am 2.9.1975 auf der Jahrestagung des IWF und der BIZ, a.a.O., S. 68

88 "C'est à l'action qu'il faut passer sans tarder. Il importe à la fois de renforcer, en les adaptant, les mécanismes financiers intracommunautaires et de donner à l'Europe le rôle qui doit être le sien dans la remise en ordre de l'économie mondiale et du système monétaire international", so Fourcade in einer Mitteilung an den Ministerrat am 16.9.1974, abgedruckt in: PE, S. 79, 2. Sem., S. $79 \mathrm{ff}$.

${ }^{89}$ ebenda, S. $79 \mathrm{ff}$. 
- Anpassung des europäischen Währungssystems: Im reformierten EWV sollten die Wechselkurse im Verhältnis zur neuen ERE definiert werden. Um die Zentralkurse, die regelmäßig zu überprüfen waren, sollten die Währungen innerhalb geringer Grenzen schwanken dürfen. Zur Verteidigung der Bandbreiten sollte die Zusammenarbeit der Zentralbanken intensiviert und der kurz- und mittelfristige Beistand um zehn Milliarden ERE erweitert werden. Langfristig sollten diese Interventionsmittel aus dem Europäischen Fonds für Währungspolitische $\mathrm{Zu}$ sammenarbeit (EFWZ) stammen, dem dazu schrittweise mehr eigene Mittel zu übereignen waren. Nach außen hin sollten die Währungen der Gemeinschaft ferner ein gemeinsames Niveau gegenüber dem Dollar einnehmen und dieses im Rahmen einer währungspolitischen Kooperation mit den USA gemeinsam und dauerhaft einhalten. Für Nichtmitglieder wurde schließlich noch die Errichtung einer ,structure d'accueil“" vorgeschlagen: Um ihnen die Rückkehr oder den Verbleib in der „Schlange“ zu ermöglichen, sollten in Ausnahmefällen die Schwankungsbreiten veränderbar sein und zeitweise überschritten werden dürfen.

- Eine engere Zusammenarbeit bei der Überwachung der Euro-Dollar-Märkte: Um die im Zuge der wirtschaftlichen Ungleichgewichte entstandenen Zahlungsströme besser überwachen zu können, sollten die Währungsbehörden bei der Kontrolle des Kapitalverkehrs enger zusammenarbeiten. Dies erforderte aus französischer Sicht, die erforderlichen Reglements zu harmonisieren und zu präzisieren.

Mit diesen Reformvorschlägen machte Frankreich jene Forderungen zum Gegenstand seiner europäischen Währungspolitik, die es schon im Herbst 1973 auf internationaler Ebene gestellt hatte. Auch Europa sollte sich jetzt aktiv in das Recycling der Petrodollars einschalten und seine internen Währungsbeziehungen auf der Basis des Währungskorbkonzepts neu ordnen. Hinter dem französischen Reformansatz zur Stärkung der „solidarité et personnalité européenne ${ }^{“ 90}$ verbargen sich jene währungspolitischen Überzeugungen, die Giscard d'Estaing als Wirtschafts- und Finanzminister schon unter Georges Pompidou entwickelt hatte. ${ }^{91}$ Über die Poolung der Währungsreserven, den Aufbau umfangreicher Beistandsmechanismen, den Übergang zum Währungskorbkonzept sowie mit dem Versuch, Außenstehenden den Beitritt zum gemeinsamen Währungssystem möglichst leicht zu machen, strebte Frankreich eine möglichst weitgehende Vergemeinschaftung der europäischen Währungspolitik an, die es als Voraussetzung für eine durchsetzungsfähige Währungspolitik Europas auf internationaler Ebene betrachtete.

Der enge Zusammenhang der währungspolitischen Bemühungen Frankreichs auf europäischer und internationaler Ebene wurde nochmals auf der Jahrestagung 1974 des IWF und der BIZ deutlich. Wirtschafts- und Finanzminister Fourcade forderte die Partnerstaaten erneut auf, sich stärker um das Recycling der Petrodollars zu bemühen

\footnotetext{
${ }^{90}$ Vgl. „Les propositions de M. Fourcarde“, Le Monde vom 18.9.1974, S. 6

${ }^{91}$ Vgl. Hasse (1979), a.a.O., S. 66-68
} 
und den Anteil der Ölländer an den Einlagen des IWF zu erhöhen. ${ }^{92}$ Darüber hinaus sprach er sich zum wiederholten Mal für die Demonetisierung des Währungsgoldes und eine umfangreichere Entwicklungshilfe aus. Außerdem wies Fourcade auf die aus französischer Sicht immer noch bestehende Notwendigkeit einer Reform des internationalen Währungssystems hin, die den Erfordernissen der "Stabilität", "Modernität", "Gleichheit" und "Solidarität" zu genügen hatte. ${ }^{93}$ Mit der „Stabilität" war die Rückkehr zu festen Wechselkursen angesprochen, die Frankreich weiter als unabdingbar für die Erholung des Welthandels und der Weltwirtschaft ansah. Alle Währungen sollten zu einem System mit klaren Regeln für die Konvertibilität sowie mit „wirksamen“ Kapitalverkehrskontrollen zurückkehren, da unkontrollierte Kapitalströme immer wieder einzelne Länder in Schwierigkeiten gebracht hätten. Hinter der Forderung nach "Modernität" hingegen verbarg sich das Ziel, die SZR endgültig in den Mittelpunkt des internationalen Währungssystems zu stellen und damit den Währungskorbstandard als Instrument zur Festlegung der Wechselkurse durchzusetzen. Die französischerseits ferner als notwendig erachtete "Gleichheit" zielte auf die bekannte Forderung Frankreichs nach "Symmetrie" der Pflichten von Defizit- und Überschußländern bei der Beseitigung von Zahlungsbilanzdefiziten:

"Il lui (la France, Anm. d. Verf.) parait souhaitable que l'ajustement des balances de paiements soit recherché en coopération, entre créditeurs et débiteurs, dans une perspective de symétrie des efforts et non de manière trop automatique, ce qui introduirait un élément de rigidité insupportable à la longue. De même que les déficits persistants doivent être éliminés par des politiques de redressement, de même les excédents structurels doivent être corrigés par des mesures appropriées. ${ }^{194}$

Frankreich hielt somit weiter an seiner Überzeugung fest, daß auch Überschußländer einen Beitrag zu einer international gleichgewichtigen Wirtschaftsentwicklung zu leisten hätten. Der Übergang zum Währungskorbstandard war nur die konsequente Fortsetzung dieser Haltung auf währungspolitischer Ebene, da dieser von seiner Konstruktion her ermöglichte, daß ein Starkwährungsland z. B. im Fall einer Aufwertungsspekulation allein an die Interventionsgrenzen gedrückt werden konnte, ohne daß sich eine zweite Währung notwendigerweise am unteren Interventionspunkt einfinden müßte wie es bislang im Paritätengitter der „Schlange“ der Fall war. Die bei bilateral fixierten Wechselkursen implizite alleinige Verpflichtung des Schwachwährungslandes zur Übernahme der Anpassungslast sei ungerecht, so Minister Fourcade im Mai 1975, da es manchmal auch am Starkwährungsland liegen könne, wenn seine Währung zum Spekulationsobjekt würde und andere Währungen damit ohne eigenes Zutun in einen Aufwertungssog hineingezogen würden. ${ }^{95}$ Die französische Forderung nach "Gleichheit" stellte somit primär einen Schutz gegen den Zwang zur Anpassung an die Wirtschafts- und Währungspolitik von Hartwährungsländern dar, hinter dem sich wie-

\footnotetext{
${ }^{92}$ Vgl. die Rede Fourcades vom 1.10.1974, abgedruckt in: PE, S. 108

${ }^{93}$ ebenda, S. $109 \mathrm{f}$.

${ }^{94}$ ebenda, S. 110

${ }^{95}$ Vgl. Lemaitre, P.: „M. Fourcade préconise de limiter les fluctuations du dollar par rapport au <serpent>"Le Monde vom 22.5.1975, S. 39
} 
derum das starke Bedürfnis Frankreichs nach wirtschaftspolitischer Unabhängigkeit verbarg. Die Forderung nach mehr "Solidarität" schließlich betraf den finanziellen Beistand für die Länder der Dritten Welt, die in einem reformierten internationalen Währungssystem nicht marginalisiert werden sollten.

Die französischen Reformprojekte auf europäischer wie internationaler Ebene waren inhaltlich aus einem "Guß" und stellten das monetäre Komplement der „mondialistischen“ Außenpolitik Frankreichs dar. Diese war auf stabile Wechselkurse als unabdingbare Voraussetzung fur die angestrebte politische Lenkung der neu zu "organisierenden" Märkte angewiesen. Wie schon die wirtschaftspolitische, so lief auch die währungspolitische Komponente dieser Strategie auf die allumfassende Politisierung der relevanten Wirtschaftsbereiche, hier also der Devisen- und Kapitalmärkte, hinaus. Diese Tendenz an sich sowie die Fixierung der französischen Währungspolitik auf das Währungskorbkonzept und umfangreiche Beistands- und Konzertierungsmechanismen waren indessen kaum mit der von Frankreich angestrebten Geldwertstabilität vereinbar. Die von Frankreich außerdem noch geforderte Freisetzung der bis dato blockierten Goldreserven der Zentralbanken und des IWF im Rahmen der "Banalisierung" des Goldes hätte ferner einen zusätzlichen Liquiditätsimpuls ausgelöst und so die Geldwertstabilität weiter beeinträchtigt. Die französische Regierung sah dies jedoch nicht so. Wirtschafts- und Finanzminister Fourcade hielt weiter an der Überzeugung fest, daß die herrschende Inflation vor allem dem Floating und der Desorganisation des internationalen Währungssystems zuzuschreiben war. Das Floating hätte Unsicherheit in die Wirtschaftsabläufe gebracht und so das Wachstum behindert. Die Desorganisation des internationalen Währungssystems hingegen machte er für die hohe Bewegungsfreiheit des Kapitals verantwortlich, die spekulative Kapitalzuflüsse ermöglichte und so zur Beschleunigung der Preissteigerung beigetragen hätte. ${ }^{96}$ Das Stabilitätsverständnis der französischen Währungspolitik setzte demnach mehr auf direkte Überwachung und Lenkung der Akteure durch währungspolitische Autoritäten denn auf deren Steuerung und Kontrolle durch die Märkte.

Mit dieser währungspolitischen Strategie, die im Kern weiterhin monetaristischen Charakters war, die wirtschaftliche und politische Konvergenz also über die Verpflichtung zur Einhaltung fester Wechselkurse erzwingen wollte, traf Frankreich in Europa jedoch erneut auf den Widerstand der „Ökonomisten“. Wenn Frankreich diese in bezug auf die Banalisierung des Goldes im Dezember 1974 noch zur Zustimmung zu bewegen vermochte ${ }^{97}$, so scheiterten seine Vorschläge zur Reform des EWV aufgrund ihrer „monetaristischen" Ausrichtung sowohl im Europäischen Rat als auch im Ministerrat am Widerstand vor allem der deutschen Seite. ${ }^{98}$ Frankreich blieb somit vorerst nichts anderes übrig, als im Juli $1975 \mathrm{zu}$ den alten Bedingungen in die „Schlange“ zurückzukehren. Durch hartnäckiges Insistieren erreichte es immerhin eine Verlängerung der

\footnotetext{
${ }^{96}$ Vgl. die Rede Fourcades vor dem OECD-Ministerrat vom 29.5.1975, a.a.O., S. 189

${ }^{97} \mathrm{Vgl}$. das Interview Giscard d'Estaings vom 16.12.1974, a.a.O., S. 290

${ }^{98}$ Vgl. Lemaitre, P., Les propositions monétaires de la France sont accueillies avec scepticisme à Bruxelles, Le Monde vom 18.9.1974, S. 1 und 6
} 
Kreditfristen des sehr kurzfristigen Währungsbeistandes von einem auf drei Monate sowie eine Veränderung der Interventionsmodi, die jetzt auch Interventionen in Dollar zuließen und auf den vorgeschriebenen Goldanteil beim Saldenausgleich ganz verzichteten. ${ }^{99}$ Außerdem konnte Frankreich erfolgreich die Aufnahme der Schweiz in die „Schlange" verhindern, was es zum einen mit deren Nichtmitgliedschaft in der Gemeinschaft begründete und zum anderen damit, daß die „Schlange“ nicht zu einem Hartwährungsklub verkommen dürfe. ${ }^{100} \mathrm{Im}$ Vergleich zu seinen ursprünglichen Reformabsichten nahmen sich diese Erfolge jedoch eher gering aus.

Wie auf europäischer Ebene, so hielt Frankreich auch auf internationaler Ebene an seinen bisherigen monetären Ordnungsvorstellungen fest. Überzeugt davon, daß es eigentlich nicht der schlagartige Anstieg der Ölpreise, sondern der Verfall der internationalen Währungsordnung war, der die Weltwirtschaftskrise verursacht hatte, stellte der französische Präsident fest: „Ce que le monde appelle la crise du capitalisme est en réalité une crise monétaire ${ }^{\text {" }} 101$. So, wie es die internationalen Wirtschaftsbeziehungen durch die „Organisation“ der Märkte neu ordnen wollte, strebte Frankreich auch die Behebung der Krise in den internationalen Währungsbeziehungen über eine Neuorganisation an. Die dazu notwendige Kooperation sollte in diesem Fall jedoch auf die maßgeblichen großen Industrieländer beschränkt bleiben. Deren Staats- und Regierungschefs lud der französische Präsident zu einem separaten Gipfeltreffen ein, das nur einen Monat vor dem Beginn der Nord-Süd-Konferenz stattfand. Ziel dieses Gipfels sollte das gemeinsame Nachdenken über die globale wirtschaftspolitische Verantwortung der westlichen Industrienationen sein, ohne dabei in konkrete Verhandlungen über bestimmte Fragen zu treten. ${ }^{102}$ Auf der Jahrestagung des IWF und der BIZ am 2. September 1975 ließ der französische Wirtschafts- und Finanzminister allerdings durchblicken, daß das eigentliche Hauptthema der Konferenz die Schaffung einer „stabilen“ und „gerechten“ Weltwährungsordnung sein werde. Insbesondere das Floa-

${ }^{99}$ Auf den Ministerratssitzungen vom 18.3.1975 und 20.5.1975 setzte Frankreich sich erneut für die Einführung der Rechnungseinheit und für seine Reforminitiative ein, vgl. Lemaitre, P.: „Les ministres des finances des Neufs traiteront le 18 mars de la création d'une unité de compte européenne“, Le Monde vom 19.2.1975, S. 34; ders.: „M. Fourcade préconise ...“, Le Monde 22.5.1975, S. 39; Vgl. Fabra, P.: „L'entrée du franc dans le <serpent>“, Le Monde vom 11.7.1975, S. 25; Vgl. Hasse (1979), a.a.O., S. $68 \mathrm{f}$.

${ }^{100}$ Der französische Wirtschafts- und Finanzminister Fourcade erklärte schon im Mai 1975 offen seine Ablehnung einer Aufnahme des Schweizer Franken in den EWV mit der Begründung, daß dieser prioritär der Wiederherstellung einer gemeinschaftlichen Währungspolitik der Neun zu dienen hätte und dementsprechend nicht zu einem außergemeinschaftlichen Club von Starkwährungsländern verkommen dürfte, vgl. die Berichterstattung zur entsprechenden Ministerratssitzung vom 20. Mai 1975 in Le Monde vom 22.5.1975, S. 39 sowie von der Sitzung vom 17. November in Le Monde vom 19.11.1975, S. 35. Zum endgültigen Scheitern der Beitrittsbemühungen der Schweiz auf der Ministerratssitzung im Dezember 1975 und der Rolle Frankreichs in diesem Prozeß siehe Hellmann, R. (1977), La guerre des monnaies, Paris, S. 79-84

${ }^{101} \mathrm{Vgl}$. Fabra, P., La lutte contre la récession passe par une solution monétaire estime M. Giscard d'Estaing, Le Monde vom 9.7.1975, S. 24

${ }^{102} \mathrm{Vgl}$. Giscard d'Estaing in einem Interview mit dem FIGARO am 12.11.1975, a.a.O., abgedruckt in: PE, S. 150 
ting und die unkontrollierte Schaffung neuer Liquidität sollten im Mittelpunkt der Beratungen stehen, da sie nach Meinung der französischen Regierung schädliche Auswirkung auf die Entwicklung eines geordneten Außenhandels sowie auf die Aufstellung "rationaler" Investitionsprogramme hätten. ${ }^{103}$ Um die Konferenz jedoch nicht mit allzu hohen Erwartungen zu belasten, präzisierte Präsident Giscard d'Estaing diese Forderung noch an gleicher Stelle: Worauf es seiner Meinung nach ankam, war die Realisierung eines Minimums an Stabilität, das, wie das erfolgreiche Beispiel der EG gezeigt hätte, auch möglich sei. ${ }^{104}$

Im wesentlichen ging es Frankreich darum, praktische Schritte in der währungspolitischen Zusammenarbeit anzuregen, um zumindest die gröbsten Spannungen zwischen den "Schlangenwährungen“ und dem Dollar sowie dem Gold zu verhindern. ${ }^{105}$ Unzufrieden mit den ausbleibenden Fortschritten bei den Konsultationen innerhalb des internationalen Währungssystems, versuchte Frankreich, mit dem Gipfeltreffen der führenden Industrienationen außerhalb der bestehenden Institutionen zu Fortschritten zu gelangen. Es war insofern erfolgreich, als daß es im November 1975 auf Schloß Rambouillet tatsächlich zu dem gewünschten Treffen kam. In schwierigen Verhandlungen gelang es der französischen Regierung, eine Abschlußerklärung zu erreichen, in der die Teilnehmer ihre Absicht zur Zusammenarbeit im Sinne einer größeren wirtschaftlichen und monetären Stabilität bekundeten. ${ }^{106}$ Konkret beschloß man sogar ein „konzertiertes“ Vorgehen der Währungsbehörden zur Eindämmung „erratischer" Schwankungen der Wechselkurse. Diesem Beschluß ging allerdings ein zuvor zwischen Frankreich und den USA ausgehandeltes Geheimabkommen vorweg. In diesem erklärten die hinsichtlich fester Wechselkurse sehr zögerlichen USA ihre Bereitschaft ${ }^{107}$, sich an gemeinsamen Stabilisierungsbemühungen zu beteiligen, während Frankreich im Gegenzug der Reform des IWF-Statuts zustimmen und auf weitere Forderungen nach einem internationalen Festkurssystem verzichten wollte. ${ }^{108}$ Am Ende des Treffens von Rambouillet einigten sich die Staats- und Regierungschefs darauf, daß die Zentralbanken ihre Interventionen auf der Grundlage der Einrichtungen des Baseler Abkommens täglich abstimmen, die stellvertretenden Finanzminister in wöchentlichen Gesprächen die verbleibenden offenen Fragen regeln sowie die Finanzminister in dreimonatigen Zusammenkünften die gemeinsame Geldpolitik festlegen sollten. Damit war es Giscard d'Estaing gelungen, zumindest bei der Bekämpfung „erratischer" Schwankungen die Währungspolitik der USA wieder mit der Westeuropas zu verbinden. Außerdem hatte er erfolgreich den Grundstein für die G-7 Gipfel-

${ }^{103} \mathrm{Vgl}$. die Rede Fourcades auf der Jahrestagung des IWF und der BIZ vom 2.9.1975, a.a.O., S. 66 ff. sowie das Interview Giscard d'Estaings im FIGARO vom 12.11.1975, abgedruckt in: PE, S. 150

104 ebenda

${ }^{105}$ Vgl. Fabra, P.: „<Sommet> difficile à Rambouillet“, Le Monde vom 16.11.1975, S. 19

${ }^{106}$ Vgl. o. V.: „La <<déclaration de Rambouillet>>, in Le Monde vom 19.11.1975, S. 34

107 Außenminister Kissinger erklärte noch am 11.11.1975, daß das beste Währungssystem darin bestünde, daß jedes Land sein eigenes Währungsregime wählte, vgl. Fabra in Le Monde vom $16.11 .1975, \mathrm{~S} 19$

$108 \mathrm{Vgl}$. Lemaitre, P.: „Dans six mois on pourra apprécier les résultats de l'accord franco-américain estime M. Jean-Pierre Fourcade“, Le Monde vom 19.11.1975, S. 35 
treffen gelegt, einem zweiten Konzertationsgremium, in dem wie im Europäischen Rat die höchsten Regierungsvertreter regelmäßig zusammentrafen, um über Möglichkeiten einer gemeinsamen Politik zu beraten und ihre persönlichen Standpunkte auszutauschen.

Allerdings blieben die Erklärung von Rambouillet und die nachfolgenden Beschlüsse weit hinter den ursprünglichen Vorstellungen des französischen Präsidenten zurück. Idealerweise hätten danach zur Entmutigung der Spekulation Zielzonen für den ECU, den Dollar und den Yen vereinbart werden sollen, die bei Annäherung der Marktkurse an die Zentralwerte zunehmend zu verkleinern gewesen wären. ${ }^{109}$ Die Umsetzung dieses Vorhabens sollte über eine gemeinsame Geldmengenpolitik sowie über abgestimmte Interventionen erfolgen. Die vereinbarten Schwankungsbreiten wie auch der Umfang der Interventionsmittel waren nach französischen Vorstellungen dabei geheim zu halten. Außerdem sollten im Laufe der Zeit die Bandbreiten laufend verkleinert und über zunehmend umfangreichere Interventionen verteidigt werden.

Diese auf Geheimhaltung und umfangreiche Interventionen vertrauende währungspolitische Idealkonzeption des französischen Präsidenten, die davon ausging, bestimmte Zielvorstellungen zur Not auch gegen die Geldmärkte durchsetzen zu können, vermochte Frankreichs Partner jedoch nicht zu überzeugen. Vor dem Hintergrund der damaligen Geldpolitik und der Zahlungsbilanzprobleme einzelner Länder dürfte sie der Geldwertstabilität eher abträglich gewesen sein, da die Bereitstellung umfangreicher Interventionsmittel zur Herabsetzung der Stabilitätsdisziplin geführt hätte. Dieser Effekt wäre durch die faktische Ausschaltung der Märkte noch vergrößert worden, da die geringste Lücke in der Geheimhaltung unweigerlich zu plötzlichen und massiven Kapitalbewegungen geführt und damit jeder geordneten Geldpolitik die Grundlagen entzogen hätte. Ein weiterer Widerspruch im französischen Bemühen um stabile Wechselkurse bestand darin, daß Frankreich, um die Zustimmung der USA zu gemeinsamen Interventionen zu erreichen, sich ihnen gegenüber verpflichtete, bei der im Januar 1976 vorgesehenen Reform des Statuts des IWF nicht länger auf die Rückkehr zu einem internationalen Festkurssystem zu bestehen. ${ }^{110}$ Dieses Nachgeben im Grundsatz wurde der französischen Regierung jedoch nur mit wenig konkreten Zugeständnissen entgolten. In der Erklärung von Rambouillet erhielt Frankreich nur ein vages Versprechen der USA zur Stabilisierung der Währungsbeziehungen, bei dem weder konkrete Zielwerte für die Wechselkurse definiert wurden noch der Begriff „erratische Schwankungen" eine eindeutige inhaltliche Festlegung erhielt.

Der faktische Erfolg der französischen Währungspolitik blieb dementsprechend gering. Trotz des Kompromisses von Rambouillet hielten die USA und Frankreich weiterhin

${ }^{109}$ Dieser Vorschlag wurde, so Paul Fabra, von Michel Poniatiowski, einem Vertrauten Giscard d'Estaings, im Vorfeld der Konferenz von Rambouillet in der Presse lanciert, siehe Fabra (1985), a.a.O., S 141-143

${ }^{110}$ Vgl. Fabra, P.: „Pour un dollar plus stable“, Le Monde vom 19.11.1975, S. 35 
an abweichenden Interpretationen der Interventionsnotwendigkeit fest. ${ }^{111}$ Im Januar 1976 schließlich mußte Frankreich die faktische Legalisierung flexibler Wechselkurse durch das geänderte IWF-Statut hinnehmen, ohne daß die SZR als neuer Anker des internationalen Währungssystems institutionalisiert wurden. Da die gaullistische Fraktion in der Regierungskoalition diesen Widerspruch zur bisherigen französischen Politik fester Wechselkurse nicht duldete, verweigerte sie gemeinsam mit der Opposition erfolgreich die Ratifizierung des neuen Statuts durch die französische Nationalversammlung. ${ }^{112}$ Als außerdem der Rücktritt des Kabinetts Chirac und ein sich abzeichnender Erfolg der sozialistischen Opposition in den Kommunalwahlen eine Spekulation gegen den Franc auslösten, mußte Frankreich im März 1976 die „Schlange“ zum zweiten Mal verlassen. Vergeblich hatte die französische Regierung zuvor noch versucht, ihre Partner zu einem Realignment und einer Erweiterung der Bandbreiten sowie zu einer Vereinfachung der Rückzahlungsbedingungen für Mittel aus dem gemeinsamen Währungsbeistand zu bewegen. ${ }^{113}$ Die Mitgliedstaaten waren allenfalls zu einer einseitigen Abwertung des Franc bereit, die die französische Regierung mit Blick auf die noch laufenden Kommunalwahlen wiederum ablehnte. ${ }^{114}$ Mit diesem zweiten Austritt aus der ,Schlange“ scheiterte endgültig der französische Versuch, die europäische währungspolitische Zusammenarbeit von innen heraus zu reformieren und über politisch gesetzte monetäre Sachzwänge die Partnerstaaten zu einer engeren Zusammenarbeit zu bewegen. Das gleiche Los ereilte ein Jahr später die französischen Bemühungen zur Stabilisierung der internationalen Währungsbeziehungen. Als Mitte 1977 der Dollar unter massiven Abwertungsdruck geriet und die Zentralbanken sich sukzessive aus den gemeinsamen Interventionen zu seiner Stützung zurückzogen, verlor auch das lockere Arrangement von Rambouillet seine Wirksamkeit, so daß ab diesem Zeitpunkt die westliche Welt währungs- und wirtschaftspolitisch "führungslos" war.

Der Überwindung dieser Führungslosigkeit und der damit verbundenen Gefahr der Desintegration Europas - die „Schlange“ war mittlerweile auf einen DM-zentrierten Hartwährungsklub zusammengeschrumpft, der seine Politik außerhalb der Gemeinschaftsinstitutionen betrieb - diente die Initiative des damaligen EG-Kommissionspräsidenten Roy Jenkins zur Gründung des Europäischen Währungssystem (EWS), deren Umsetzung alsbald vom deutschen Bundeskanzler Helmut Schmidt tatkräftig

${ }^{111}$ Während Vertreter der USA weiter betonten, daß langfristige Entwicklungen auf den Kapitalmärkten nicht durch Interventionen aufzuhalten seien und im übrigen im Fall von Meinungsunterschieden vor allem die Bewahrung der nationalen Handlungsfreiheit vorrangig sei, hob die französische Seite vor allem die bilaterale Pflicht zur Konzertation und Verhinderung übermäßiger Wechselkursausschläge hervor, vgl. Hellmann (1977), a.a.O., S. 142

112 Vgl. Renard, F.: „La France et le Fonds Monétaire - l'hostilité du R.P.R. et de la gauche aux accords de Jamaïque n'a pas faibli“, Le Monde vom 8.4.1978, S. 1 und 38

${ }^{113}$ Vgl. Fabra, P., „La sortie du <serpent> entraîne pour le franc une dépréciation de près de 4,5 \%“, Le Monde vom 16.3.1976, S. 1

${ }^{114}$ Vgl. Hasse (1979), a.a.O., S. 82 sowie Hellmann (1977), a.a.O., S. 91 f. 
vorangetrieben wurde. ${ }^{115}$ Frankreich war an der Entstehung des EWS insofern maßgeblich beteiligt, als daß der deutsche Bundeskanzler seine Aktivitäten in enger Abstimmung mit dem französischen Präsidenten betrieb. Ausschlaggebend für das französische Interesse war vor allem die Perspektive, innerhalb eines stabilen Währungsgebiets den wachsenden wirtschaftlichen Abstand zur Bundesrepublik verringern zu können. Außerdem ließ sich das unpopuläre Stabilisierungsprogramm der Regierung Barre unter Hinweis auf die systemimmanenten Disziplinierungszwänge des EWS einer marktwirtschaftlichen Sachzwängen kritisch gegenüberstehenden Bevölkerung besser vermitteln. ${ }^{116}$ Darüber hinaus begründete der französische Präsident die Notwendigkeit des EWS damit, daß die USA und Japan als Hauptkonkurrenten auf den Weltmärkten geschlossene Währungsgebiete wären, während Europa seinen Binnenhandel und damit seine Wirtschaftsentwicklung den Risiken einer instabilen Währungsordnung mit frei schwankenden Wechselkursen und unkontrollierten Kapitalströmen aussetze. ${ }^{117}$ Um die krisengeschüttelte Wirtschaft Europas im Inneren wie auch nach außen hin zu stärken, war aus französischer Sicht die Einbeziehung aller Mitgliedstaaten der Gemeinschaft in eine monetäre Einheit unabdingbar. Dazu bedurfte es jedoch einer anderen Konstruktion als die der „Schlange“, die Frankreich als Referenzmodell ablehnte, da sie nur als DM-Zone funktionierte und damit aus französischer Sicht nicht den Bedürfnissen wirtschaftlich schwächerer Mitgliedstaaten gerecht würde. ${ }^{118}$

Erneut forderte die französische Regierung ein System fester, aber anpassungsfähiger Wechselkurse, das als Währungskorbstandard mit umfangreichen Interventionsmitteln zur Verteidigung der festgelegten Wechselkurse konzipiert sein sollte. ${ }^{119}$ Die Attraktivität der Währungskorbkonzeption lag für Frankreich weiter darin begründet, daß diese es ermöglichte, starke Währungen an die Interventionsgrenzen kommen zu lassen, ohne schwächere notwendigerweise an den Devisenverkaufspunkt zu drücken. Sie bot außerdem den Vorteil, Paritätsänderungen aufgrund der unübersichtlichen Beziehungen der Währungen untereinander relativ undramatisch durchführen zu können, da nicht mehr direkt im Verhältnis zu einer anderen Währung auf- oder abgewertet werden mußte. ${ }^{120}$ Zur Steuerung der notwendigen Interventionen schwebte Valéry Giscard d'Estaing ein komplexes System von Abweichungsschwellen vor, die, definiert auf der

${ }^{115}$ Zur Motivationsanalyse der Gründungsstaaten siehe Ludlow, P. (1982), The making of the European Monetary System, London, S. $37 \mathrm{ff}$.

${ }^{116}$ Vgl. Ludlow (1982), a.a.O., S. 33

117 Vgl. die Pressekonferenz Giscard d'Estaings nach dem Europäischen Rat von Kopenhagen am 8.4.1978, abgedruckt in: PE, S. 21, 2. Sem., S. 18 ff.; die Pressekonferenz Giscard d'Estaings während seines Spanienbesuchs am 30.6.1978, a.a.O., S. 111 sowie Ludlows Schilderungen der Ratssitzung von Kopenhagen in: Ludlow (1982), a.a.O., S. 91

${ }^{118}$ Vgl. die Pressekonferenz Giscard d'Estaings während seines Spanienbesuchs am 30.6.1978, a.a.O., S. 111 und die Äußerungen des französischen Notenbankpräsidenten Clappier in: Ludlow (1982), a.a.O., S. 161

${ }^{119} \mathrm{Zu}$ den französischen Positionen auf dem Gipfel in Bremen im Juli 1978 siehe Lemaitre, P., Le sommet de Brême - Paris espère que les Neuf definiront les grandes options du nouveau système de stabilisation monétaire européen, Le Monde vom 6.7.1978, S. 26

${ }^{120}$ Vgl. Ludlow (1982), a.a.O., S. 102 sowie S. 161 
Grundlage bestimmter statistischer Indikatoren, einmal ausgelöst, die Währungsbehörden $\mathrm{zu}$ abgestuften Eingriffen in die Geldmärkte veranlassen sollten. ${ }^{121}$ Des weiteren sollten der zeitweilige Austritt aus dem Interventionsmechanismus in Krisensituationen möglich sein sowie anfänglich erweiterte Bandbreiten für Neumitglieder festgelegt werden, um ihnen den Beitritt bzw. die Rückkehr in das gemeinsame Währungssystem zu erleichtern.

Mit diesem abermaligen Versuch Frankreichs, seine Reformvorschläge von 1974 umzusetzen, traf die französische Regierung erneut auf Ablehnung vor allem seitens der Bundesrepublik. Diese bevorzugte eine Konstruktion ähnlich der des EWV und konnte sich hinsichtlich der Rolle des Währungskorbkonzeptes in einem auf belgisches $\mathrm{Be}$ mühen hin gefundenen Kompromiß weitgehend durchsetzen. Diesem Kompromiß zufolge wurden die Leitkurse der Währungen zwar im Verhältnis zum ECU definiert, für die Verpflichtungen zur Intervention waren aber paritätisch festgelegte Leitkurse ausschlaggebend. Zur Feinsteuerung der Interventionen übernahm man das Konzept des "Abweichungsindikators", der ausgelöst werden sollte, wenn eine Währung um mehr als 75 Prozent von ihrem ECU-Leitkurs abwich. Vergeblich bemühte sich Frankreich darum, im Falle seiner Auslösung das betroffene Land zur Durchführung bestimmter Maßnahmen zu verpflichten. Aufgrund des erfolgreichen Widerstands des Bundesbankpräsidenten legte der Ratsbeschluß zur Gründung des EWS den betroffenen Staaten nach Auslösung des Indikators nur Korrekturmaßnahmen nahe ${ }^{122}$ Giscard d'Estaing bewertete seine Einführung dennoch als einen großen Erfolg ${ }^{123}$, da er ermögliche, im Falle eines Aufwertungssoges z. B. der DM die Bundesrepublik zu verpflichten, eine Stabilisierung der Wechselkurse wieder herbeizuführen. ${ }^{124}$ Sechs Jahre später indessen stellte die Bundesbank fest, daß der Abweichungsindikator die in ihn gesetzten Hoffnungen nicht erfüllt hatte. Durch seine Konstruktion bedingt reagierte er häufig erst nach Erreichen der bilateralen Interventionspunkte, so daß die einseitige Übernahme der Interventions- und Anpassungslast durch das Defizitland weiter die Regel blieb. Außerdem wurde seitens der Mitgliedstaaten in seiner Auslösung „nur selten eine Aufforderung zu konkreten wirtschafts- und währungspolitischen Gegenmaßnahmen gesehen “125. Am Ende hatte sich faktisch das Paritätengitter mit seinen Sachzwängen im EWS durchgesetzt. Frankreich rückte von seiner Forderung nach einem währungskorbgestützten Interventionsmechanismus erst nach längerem Zögern ab. Im Verhandlungsverlauf gab es damit der Erkenntnis nach, daß seine technische

${ }^{121}$ Vgl. Fabra (1985), a.a.O., S. 150

122 „Überschreitet eine Währung ihre „Abweichungsschwelle“, so besteht eine Vermutung, daß die betreffenden Behörden diese Situation durch angemessene Maßnahmen korrigieren werden, ...", so die Formulierung der Entschließung des Europäischen Rates vom 5.12.1978 über die Errichtung des EWS, D 126, abgedruckt in: EA, Folge 5/1979, D 124-D 129; zu der Auseinandersetzung zwischen dem französischen und dem deutschen Notenbankpräsidenten siehe Ludlow (1982), a.a.O., S. 232

${ }^{123}$ Vgl. Fabra, P.: „Version amélioré du <serpent>?“, Le Monde vom 7.12.1978, S. 4

${ }^{124}$ Vgl. Pressekonferenz vom 21.11.1978, a.a.O., D. 691

${ }^{125} \mathrm{Vgl}$. Deutsche Bundesbank (1986), Internationale Organisationen und Abkommen im Bereich von Währung und Wirtschaft, Frankfurt/M., Sonderdruck Nr. 3, S. 272 
Umsetzung sehr kompliziert war. ${ }^{126}$ Darüber hinaus lag der Währungskorbanteil der an der DM orientierten Hartwährungsländer über fünfzig Prozent, so daß diese als Währungsblock betrachtet zumindest faktisch nicht mehr die Interventionsschwelle erreichen konnten. Dies bedeutete, daß die Interventionslast trotz allem weiter vollständig bei den Schwachwährungsländern lag, was eigentlich dem französischen Verständnis von „Symmetrie“ entgegenstand. Immerhin gelang es Frankreich, die deutsche Delegation auf einen gemeinschaftlichen Beistandsmechanismus mit einem Volumen von 25 Milliarden ECU festzulegen, indem es seine Auslegung eines Thesenpapiers zur Reform des EFWZ durchsetzten konnte. ${ }^{127}$ Des weiteren konnte es mit der vereinbarten Möglichkeit zu zeitweilig erweiterten Bandbreiten sowie mit der Verlängerung der Frist zum Saldenausgleich in der sehr kurzfristigen Fazilität auf 45 Tage weitere Kernforderungen verwirklichen. ${ }^{128}$ Formal betrachtet fanden sich somit viele der von Frankreich gewünschten Konstruktionsmerkmale im EWS wieder. Im Kern jedoch blieb es bei der von deutscher Seite aus angestrebten Fortsetzung des EWV. Dem französischen Präsidenten trug dieses Nachgeben Frankreichs von britischer Seite den Vorwurf ein, als "the chancelors brilliant second" vor Deutschland kapituliert zu haben. ${ }^{129}$ Entschädigt wurde Frankreich jedoch damit, ohne Kotau vor der D-Mark in das EWS zurückgekehrt zu sein. Das EWS selbst wurde aufgrund seiner Konstruktionsmerkmale zu einer echten Gemeinschaftsinstitution, in der sich durch den Zutritt neuer Mitglieder das relative Gewicht der Bundesrepublik verringert hatte. Ferner brachte das EWS einen höheren Grad an währungspolitischer Konvergenz, der eine spätere Rückkehr zu einer gemeinschaftlichen Währungspolitik im Sinne der „Monetaristen“ nicht ausschloß, und schließlich kam die französische Regierung in den Genuß des Vorteils, über die Stabilitätserfordernisse des EWS die Belastungen der stabilitätsorientierten Wirtschafts- und Haushaltspolitik Premierminister Barres der französischen Wählerschaft gegenüber leichter rechtfertigen zu können. Ohne somit die maßgeblichen Charakteristika des EWS bestimmt zu haben, profitierte Frankreich dennoch in vielerlei Hinsicht von seiner Gründung.

Die Bilanz der französischen Währungspolitik unter Valéry Giscard d'Estaing fällt hinsichtlich ihres faktischen Erfolges sowie aus Sicht der Geldwertstabilität dennoch negativ aus. Vom Standpunkt des reinen Erfolges her ist festzustellen, daß bis 1977

${ }^{126}$ Vgl. Ludlow (1982), a.a.O., S. 162

${ }^{127}$ Das Kommuniqué des Europäischen Rats vom Juli 1978 in Bremen legte undeutlich formuliert als Anfangsbestand an ECUs die Hinterlegung von Gold und Dollars in Höhe von ,... z. B. 20 Prozent der üblichen Reserve der Zentralbanken der Mitgliedsländer und eines vergleichbaren Betrages von Währungen der Mitgliedsländer" fest, eine Bestimmung die sich konkret auf $25 \mathrm{Mrd}$. ECU bezifferte, von der Bundesrepublik im Sinne von „bis zu 25 Mrd. ECU“ interpretiert wurde. Frankreich verstand dies jedoch als Richtwert und setzte sich mit seiner Auslegung im Verlauf der Verhandlungen schließlich durch, vgl. Schlußfolgerungen des Europäischen Rates in Bremen vom 7.7.1978, D 462, abgedruckt in: EA, Folge 16/1978, D 457- D 462 sowie Kloten, N. (1980), „Das Europäische Währungssystem“, S. 115 , in: EA, Folge 4/1980, S. 111-122 wie auch Ludlow (1982), a.a.O., S. 241

${ }^{128}$ Vgl. Anlage 1 zur Entschließung des Europäischen Rates vom 5.12.1978, a.a.O., D 125 und D 126

${ }^{129} \mathrm{Vgl}$. Ludlow (1982), a.a.O., S. 162 
alle Bemühungen Frankreichs zur Institutionalisierung einer auf feste Wechselkurse ausgerichteten europäischen und internationalen währungspolitischen Zusammenarbeit gescheitert waren. Auf beiden Ebenen hatte es versucht, in möglichst großem Rahmen seine Partner in Festkurssysteme einzubinden, um sie so zu einer gemeinsamen Währungspolitik zu bewegen, die französischerseits wiederum als Voraussetzung für eine gemeinsame Wirtschaftspolitik und für die Durchsetzung einer einheitlichen Wirtschaftsordnung betrachtet wurde. Die von Frankreich gewünschten institutionellen Arrangements hätten mit der Einführung des Währungskorbstandards, den umfangreichen Beistands- und Konzertierungsmechanismen und einer strengen gemeinsamen Kapitalverkehrsüberwachung den Durchgriff der Währungspolitik bis in die letzten Einzelheiten der internationalen und europäischen Währungsbeziehungen ermöglicht. Den Geldmärkten hingegen sollte über die Geheimhaltung währungspolitischer Entscheidungen und über Kapitalverkehrskontrollen jegliche Störmöglichkeit entzogen werden. Vergeblich war die Suche nach einem theoretisch fundierten Hintergrund für diese Politik: "Cette croyance dans la toute-puissance de la technocratie", so Paul Fabra, langjähriger Wirtschaftsjournalist bei Le Monde, ,se substitue à la recherche d'une doctrine" ${ }^{130}$. Der pragmatische Ansatz der französischen Währungspolitik entsprang ihrer Abneigung, sich einer expliziten Regelbindung oder einer bestimmten theoretischen Fundierung zu verschreiben und sich so ihrer Gestaltungsmöglichkeiten zu begeben. Diese Haltung führte hinsichtlich der Geldwertstabilität wiederholt zu inneren Widersprüchen, in denen letztlich die Ursache für die geringe Überzeugungskraft der monetären Ordnungsvorstellungen Frankreichs zu suchen sein dürfte. ${ }^{131}$

Ordnungspolitisch ist die französische Währungspolitik unter Giscard d'Estaing als die Fortsetzung dessen zu betrachten, was sie schon unter Georges Pompidou war: Ein engagierter Versuch, über die bewußte Manipulation zentraler währungspolitischer Determinanten die Voraussetzung für die politische Steuerung der Wirtschaftsentwicklung herzustellen. Ihre Bewertung aus stabilitätspolitischer Sicht erfolgte schon im Abschnitt B.3. und soll deshalb an dieser Stelle nicht wiederholt werden. Das Urteil war, was die Erfordernisse der Geldwertstabilität angeht, negativ. Daran änderte auch die bereitwillige Rückkehr Frankreichs in das als Paritätengitter funktionierende EWS, das zumindest von seiner stabilitätspolitischen Disziplin her den französischen Vorschlägen überlegen war, nichts. Frankreich trat ihm letztlich auch nicht aus ordnungspolitisch gewandelten, sondern vornehmlich aus politisch-taktischen Motiven bei, unter denen das Bestreben, der wirtschaftlich führenden Bundesrepublik das Feld nicht allein zu überlassen, dominierte. Seine Rückkehr in das EWS kann letztlich als "dritter" Versuch einer Rückkehr in die „Schlange“ gewertet werden, ohne daß sich damit das französische Verständnis von Geldwertstabilität geändert hätte oder auch nur Anzeichen für eine grundlegende ordnungspolitische Neuorientierung Frankreichs zu verzeichnen gewesen wären.

${ }^{130}$ Fabra (1985), a.a.O., S. 141

131 ebenda, S. 143 


\section{B.4.4 Die ordnungspolitische Orientierung der französischen Binnenmarktpolitik unter Valéry Giscard d'Estaing}

Frankreichs Europapolitik fand sich unter Giscard d'Estaing eingebettet in das außenpolitische Leitkonzept des „Mondialismus“. Sie war damit Teil eines groß angelegten und von Frankreich moderierten „Aussöhnungsversuchs“, der auf globaler Ebene zu einer dauerhaften und konsensorientierten Lösung der weltweiten Wirtschaftskrise der siebziger Jahre führen sollte. Ideell beruhte die europapolitische Konzeption Valéry Giscard d'Estaings auf der zuvor von Charles de Gaulle formulierten und von Georges Pompidou übernommenen Zielvorstellung eines politisch aktiven „europäischen“ Europas. Dessen Mission bestand in der Verbreitung europäischer Zivilisationsideale, die bei genauerem Hinsehen jedoch identisch mit denen Frankreichs waren. Die historischen Verdienste der eigenen Nation um den zivilisatorischen Fortschritt rechtfertigten auch für Giscard d'Estaing den Anspruch Frankreichs auf eine führende Rolle beim Aufbau und der Ausgestaltung Europas. Inhaltlich waren in der europapolitischen Konzeption Valéry Giscard d'Estaings keine Neuerungen im Vergleich zu seinen Vorgängern zu erkennen. Charakteristisch für seine Amtszeit war jedoch, daß im Verlauf der Umsetzung des Mondialismus klarer als zuvor der Zusammenhang von gesellschaftspolitischen Idealen und den Leitprinzipien zur Ordnung der Wirtschaft in der französischen Politik hervortrat.

Das Hauptproblem der Staatengemeinschaft in den siebziger Jahren bestand aus französischer Sicht darin, die Weltwirtschaftsordnung von einer „unorganisierten“ Marktkoordination in einen Zustand zu überführen, in dem durch politische Interventionen der Wirtschaftsprozeß so beeinflußt werden konnte, daß die „,berechtigten“ Interessen aller Länder im gleichen Maße berücksichtigt würden. Zu diesem Zweck schlug Frankreich eine „neue Weltwirtschaftsordnung“ vor, deren Realisation die Berücksichtigung des „Allgemeininteresses“ besser gewährleisten sollte. Die französische Regierung unterstellte, zu wissen, was das „Allgemeininteresse“ sei und fühlte sich berufen, das französische Gesellschaftsideal auf die Welt zu übertragen. Da sie die weltweite Wirtschaftskrise als Binnenkrise der Staatengemeinschaft wahrnahm, war zu ihrer Überwindung die Errichtung einer Art „Weltinnenpolitik“ notwendig. Bei dieser ging es aus französischer Sicht vornehmlich darum, die erforderlichen Mechanismen für eine friedliche Vermittlung zwischen den berechtigten, aber konfligierenden Einzelinteressen der Nationen zu institutionalisieren.

Die angestrebte Aussöhnung aller Einzelinteressen sollte im Rahmen politischer Verhandlungen erfolgen. Frankreich strebte damit ein Ordnungskonzept an, daß sich nicht mit den Grundsätzen der wettbewerblichen Marktkoordination vertrug. Der Marktmechanismus entsprach von vornherein nicht den Harmonieidealen des französischen Präsidenten und war somit von Anfang an kein hinreichendes Instrument zur Koordination der Wirtschaftsabläufe. Er ließ sich darüber hinaus nicht mit den Vorstellungen Valéry Giscard d'Estaings von einer "fortschrittlichen“ Zivilisation vereinbaren. Frankreich stand mit seinem Ordnungsentwurf für die Wirtschaft im Binnenmarkt so- 
wie für die gemeinschaftliche Wirtschafts- und Währungspolitik letztlich allein unter den Mitgliedstaaten. Der Glaube an die Omnipotenz der Politik und an die Möglichkeit, über politische Verhandlungen für jedes Problem zur besten aller denkbaren Lösungen zu gelangen, fehlte auf seiten der anderen europäischen Regierungen. Die global angelegten ordnungspolitischen Reformbemühungen des französischen Präsidenten scheiterten daher sämtlich alle und dies auf monetärem wie realwirtschaftlichem Gebiet.

Die ordnungspolitische Orientierung der französischen Außen- und Europapolitik konnte von dem vermittelnden Grundanliegen des Mondialismus nicht unberührt bleiben. Die aus dem „Allgemeininteresse“ heraus notwendige Berücksichtigung aller Einzelinteressen führte zum Entwurf einer interventionistischen „,neuen Weltwirtschaftsordnung", die mit ihren Konsultationsmechanismen und den vorgesehenen Eingriffen in den Preismechanismus viele Ähnlichkeiten mit der „Planification“ aufwies. Auf die von Frankreich vorgeschlagenen Mechanismen zur Stabilisierung der Einnahmen der Entwicklungsländer aus dem Erdöl- und Rohstoffexport läßt sich die gesamte ordnungspolitische Kritik im Sinne der Wettbewerbsordnung anwenden, die vorstehend schon an der EG-Agrarpolitik geübt wurde. Die EG-Agrarmarktordnung stand damit im Prinzip erneut Modell für den Ordnungsentwurf, den Frankreich auf Europa und die Welt übertragen wollte. Wie die EG-Agrarpolitik, so wäre auch die von Frankreich gewollte ,neue Weltwirtschaftsordnung“ in keiner Weise mit einer Wettbewerbsordnung in Übereinstimmung zu bringen gewesen. Der flagranteste Verstoß bestand in der politisch verabredeten Setzung von Mindestpreisen. Dies hätte die Marktpreisbildung in ihrer allokativen Steuerungsfunktion wesentlich eingeschränkt. Überdies wäre den Produzenten die Haftung für ihre Produktionsentscheidungen weitgehend abgenommen worden, wenn sie in jedem Fall mit der Abnahme ihrer Produkte sowie mit einem Mindestgewinn rechnen konnten. Eine diskretionäre Wirtschaftspolitik nach französischen Vorstellungen hätte es den Wirtschaftssubjekten darüber hinaus erschwert, angesichts der massiven Eingriffe in das Wirtschaftsgeschehen zu erahnen, wie die Politik auf veränderte Wirtschaftslagen reagieren würde. Damit war auch gegen den ordnungspolitischen Grundsatz der Stetigkeit und Vorhersehbarkeit der Wirtschaftspolitik verstoßen. Diese Verstöße gegen die Grundprinzipien einer wettbewerbswirtschaftlichen Ordnung hatten ihren Ursprung letztlich in dem ursprünglichen Ansinnen Frankreichs, die weltweite Wirtschaftsentwicklung von politischer Ebene aus steuern und kontrollieren sowie über Eingriffe in den Preismechanismus konkrete Entwicklungsziele und eine bestimmte Verteilung der Einkommen gleichzeitig erreichen zu wollen.

Da Frankreich auf dem Gebiet der Währungspolitik unter Valéry Giscard d'Estaing auf Konzepte zurückgriff, die es schon zuvor auf europäischer wie auf internationaler Ebene propagiert hatte, läßt sich auch hier die Kritik kurz fassen. Im Kern blieb es bei dem Versuch, die Partnerstaaten zur Rückkehr zu festen Wechselkursen zu bewegen und die internationalen Währungsbeziehungen so zu gestalten, daß sie sich optimal in die Bemühungen zur „Organisation“ der Märkte im Rahmen der „,neuen Weltwirtschaftsordnung" integrierten. Frankreich versuchte hier ein institutionelles Arrange- 
ment zu installieren, das die Dominanz des politischen Gestaltungswillens sicherstellen sollte, notfalls sogar gegen die Geldmärkte. Auch hier lehnte die französische Regierung ab, sich den Ergebnissen der anonymen Marktkoordination zu unterwerfen oder gar unabhängigen Institutionen die Wahrung der Geldwertstabilität anzuvertrauen. Ihr Verständnis von Geldwertstabilität war kein absolutes, sondern ein am politisch gewünschten Verlauf der Wirtschaftsentwicklung orientiertes. Da diese währungspolitische Konzeption inhaltlich im wesentlichen identisch war mit jener, die Frankreich zuvor schon unter Georges Pompidou verfolgte, erübrigt sich eine erneute ordnungspolitische Bewertung.

Am Ende bleibt festzuhalten, daß die ordnungspolitische Haltung Frankreichs unter Valéry Giscard d'Estaing sich kaum von der seiner Vorgänger unterschied. Deutlicher als bei diesen jedoch trat die enge Verbindung von wirtschaftlichen und politischen Ordnungsvorstellungen hervor. Die Dominanz des Politischen resultierte aus dem Bestreben, im Sinne des „Allgemeininteresses“, das zu kennen den Politikern stillschweigend unterstellt wurde, zwischen divergierenden wirtschaftlichen Interessen vermitteln zu wollen. Da das Ordnungsbestreben der französischen Politik im Kern auf diskretionäre Aussöhnung statt auf Autoregulation setzte, hatte ein marktwirtschaftlicher Lösungsansatz in der Europapolitik Valéry Giscard d'Estaings von vornherein bestenfalls nur einen nachgeordneten Platz. 


\section{B.5 Frankreichs Binnenmarktpolitik unter François Mitterrand 1981-1992}

Wie bei seinen Vorgängern, so fiel auch die Amtsübernahme François Mitterrands im Jahr 1981 in eine wirtschaftliche Rezession. Im Gegensatz zu Großbritannien und den USA, die ebenfalls mit wirtschaftlichen Schwierigkeiten zu kämpfen hatten, optierte Frankreich nicht für eine angebotsorientierte, sondern für eine konsequent nachfrageorientierte Wirtschaftspolitik. Dieses Experiment mußte jedoch mangels wirtschaftlicher Erfolge und eines sich verschärfenden gesamtwirtschaftlichen Ungleichgewichts nach nur zwei Jahren abgebrochen werden. Es folgte eine über Jahre hinweg dauernde schrittweise Annäherung an die allgemein in Europa praktizierte Stabilitätspolitik. Auf außenpolitischer Ebene hingegen waren die hervorragenden Ereignisse für Frankreich und Europa die schrittweise Auflösung des Warschauer Paktes sowie die deutsche Wiedervereinigung. Die Auflösung der bipolaren Weltordnung nahm Europa und den USA den gemeinsamen militärischen Gegner. Die bisherige französische Politik eines eigenständigen, den Supermächten ebenbürtigen Europas bedurfte der Neudefinition, da nur noch eine Weltmacht übrig geblieben war. Mit Deutschland wuchs währenddessen innerhalb der Gemeinschaft eine neue Einheit heran, die allein aufgrund ihrer Größe nicht mehr ignoriert bzw. auf die alte, von einer gewissen Pflicht zur Zurückhaltung geprägten Rolle reduziert werden konnte. In diesem neu strukturierten globalen Kräftefeld galt es, die Rolle Europas und Frankreichs neu zu definieren und eine geeignete gemeinschaftliche Wirtschafts- und Währungspolitik zu finden.

\section{B.5.1 Die europapolitische Konzeption \\ B.5.1.1 Die wirtschaftlichen Rahmenbedingungen}

François Mitterrand übernahm seine Amtsgeschäfte in einer schwierigen Wirtschaftslage: 1981 zählte Frankreich 1,75 Millionen Arbeitslose, das Wachstum des Bruttoinlandsprodukts ging auf 1,2 Prozent zurück, während die Inflation auf 13,4 Prozent stieg und der Außenhandel ein wachsendes Defizit aufwies. ${ }^{1}$ Die französische Wirtschaft fand sich eingebettet in eine rezessive Weltwirtschaftsentwicklung, die von den Folgen des zweiten Ölschocks von 1979 und einer bis Mitte der achtziger Jahre währenden Dollar-Hausse geprägt war. Wenig Hilfe bot die Mitgliedschaft in der Europäischen Gemeinschaft, die keinen Konsens zur gemeinsamen Krisenbekämpfung zu finden vermochte. Im Gegensatz zu den USA, Großbritannien und der Bundesrepublik, die zu Beginn der achtziger Jahre auf eine angebotsorientierte Wirtschaftspolitik umgeschwenkt waren, versuchte der neue sozialistische Präsident Mitterrand, mit einer nachfrageorientierten Politik Frankreich im Alleingang zum Wiederaufschwung zu verhelfen:

"J'ai choisi, avec d'autres, de placer la France à la pointe des nations industrielles initiatrices d'un nouveau type de développement, fondé sur une meilleure et sur une plus juste organisation des rela-

${ }^{1}$ Vgl. Vesperini (1993), a.a.O., S. 402 ff. Datenanhang 
tions sociales, sur une meilleure utilisation de nos ressources, sur une meilleure répartition de nos revenues et du temps de travail" ${ }^{2}$.

Mit einer „Strategie des sozialen Wachstums“ beabsichtigte die sozialistische Regierung, die Krise zu beheben. Ihrer Meinung nach hatte sich der Kapitalismus angesichts der weltweiten Rezession als unfähig erwiesen, die wirtschaftlichen Probleme der Staaten zufriedenstellend zu lösen. ${ }^{3}$ Im Mittelpunkt der neuen französischen Wirtschaftspolitik standen die Stimulierung des Wachstums sowie die Bekämpfung der Arbeitslosigkeit. Mehr Wachstum sollte in erster Linie durch die Stärkung der Nachfrage der Unternehmen, des Staates und der privaten Haushalte entstehen. ${ }^{4}$ Zur Förderung des Konsums der Haushalte wurden der gesetzliche Minimallohn sowie die Mindestrenten deutlich erhöht. Die staatliche Nachfrage wurde hauptsächlich über die Ausweitung der öffentlichen Infrastrukturinvestitionen ausgedehnt. Zur direkten Bekämpfung der Arbeitslosigkeit wurden außerdem 170.000 neue Arbeitsplätze im öffentlichen Dienst geschaffen, das Rentenalter gesenkt, eine Vorruhestandsregelung eingeführt, die Wochenarbeitszeit reduziert sowie eine Höchstgrenze für die jährlichen Überstunden festgelegt. Mit der Wiedereinführung von Preiskontrollen sollte außerdem die Inflation gesenkt werden. Neu eingefuhrte Kapitalverkehrskontrollen sollten die Währungsreserven schützen und eine Abwertung des Franc zur Beseitigung des Außenhandelsdefizits beitragen. Grundsätzlich kehrte die neue Regierung damit zu einer interventionistischen Wirtschaftspolitik zurück, von der sich die Regierung Barre zuvor schrittweise und unter großen Mühen gelöst hatte.

Darüber hinaus verstaatlichte die neue Regierung jene Unternehmen, denen sie strategische Bedeutung für die Wirtschaftsentwicklung zusprach. "Schnellstens" sei die Bewegungsfreiheit und Konkurrenzfähigkeit der französischen Wirtschaft wiederherzustellen, so Premierminister Mauroy in seiner Regierungserklärung, da die Durchdringung des französischen Marktes mit ausländischen Erzeugnissen mittlerweile "beunruhigende Ausmaße" angenommen hätte. Ziel der neuen Wirtschaftspolitik für Frankreich war deshalb, die "Beherrschung seines Produktionsapparates " wiederzuerlangen. ${ }^{5}$ Im Rahmen eines "plan intérimaire" wurden fünf Großunternehmen der Stahl-, Elektronik-, Automobil- und Werkzeugmaschinenindustrie sowie fast der gesamte Bankensektor verstaatlicht. In jedem strategisch wichtigen Wirtschaftsbereich strebte die neue Regierung den Aufbau vollständiger „Produktions“- bzw. „Wertschöpfungsketten" an. Frankreich wollte auf diesem Weg den Anschluß an die führenden Industrienationen zurückgewinnen. Ein ausgedehnter und starker "secteur public" sollte der Volkswirtschaft die notwendigen Impulse für den überfälligen Strukturwandel verleihen und es darüber hinaus ermöglichen, die Wirtschaftsentwick-

${ }^{2}$ Präsident Mitterrand in einer Pressekonferenz am 24.9.1981, abgedruckt in: Le Monde vom 25.9.1981, S. 10

${ }^{3}$ So Mitterrand in einer Ansprache am 2.6.1982 vor der INTERNATIONAL LABOR ORGANIZATION, abgedruckt in: PE, S. 103

${ }^{4} \mathrm{Zu}$ den einzelnen Maßnahmen vgl. Vesperini (1993), a.a.O., S. $230 \mathrm{ff}$.

${ }^{5}$ Vgl. die Regierungserklärung Premierminister Mauroys vom 8.7.1981, D 493, abgedruckt in: EA, Folge 18/1981, D. $491 \mathrm{ff}$. 
lung besser mit den gesellschaftspolitischen Zielen der neuen Regierung in Einklang zu bringen. ${ }^{6}$

Die Resultate dieses Reformprogramms waren jedoch enttäuschend. Wohl gelang es 1982, das Wachstum kurzfristig auf 2,5 Prozent anzuheben, 1983 fiel es allerdings wieder auf 0,7 Prozent zurück. Die Zahl der Erwerbslosen überschritt 1982 die ZweiMillionen-Marke, während die Inflation zwar zurückging, mit 9,8 Prozent Ende 1983 im europäischen Vergleich jedoch immer noch über dem Durchschnitt lag. ${ }^{7}$ Das Budgetdefizit hingegen stieg von $35 \mathrm{Mrd}$. FF 1981 auf $134 \mathrm{Mrd}$. FF 1983. Gleiches galt für das Außenhandelsdefizit: da die französische Industrie den plötzlichen Nachfrageschub nicht zu decken vermochte, nahmen die Importe überproportional zu, so daß deren Deckung durch Exporte 1982 auf nur noch 80 Prozent zurückfiel. ${ }^{8}$ Zur Finanzierung des Budget- und Außenhandelsdefizits blieb der Regierung nach kurzer Zeit nur noch, die Steuer- und Sozialabgaben zu erhöhen. Die Entwicklung der französischen Außenwirtschaft trug außerdem dazu bei, daß die Währungsreserven rapide abnahmen. Die französische Regierung reagierte darauf mit einer weiteren Verschärfung der Kapitalverkehrskontrollen. Die Erhöhung der Abgabenlast von Unternehmen und Haushalten wie auch die weitere Einschränkung des Kapitalverkehrs schlugen indessen negativ auf das Wachstum zurück, so daß die französische Wirtschaft im Verlauf der sozialistischen Reformpolitik zunehmend tiefer in die Krise rutschte.

Auf monetärer Ebene zog die Verschlechterung der wirtschaftlichen Grunddaten zwei weitere Abwertungen des Franc in den Monaten Juni 1982 und März 1983 nach sich. Mit der letzten und damit dritten Abwertung innerhalb von 18 Monaten stellte sich allerdings auch die Frage nach dem weiteren Verbleib Frankreichs im EWS. Der Franc hatte gegenüber der D-Mark mittlerweile mehr als zwanzig Prozent seines Wertes eingebüßt. Die Verschlechterung zentraler wirtschaftlicher Kennzahlen wie Arbeitslosigkeit und Außenhandelsdefizit sowie der internationalen Wettbewerbsfähigkeit der französischen Wirtschaft ließ grundsätzliche Zweifel aufkommen, ob Frankreich überhaupt noch in der Lage war, den Stabilitätserfordernissen des EWS zu genügen. $\mathrm{Zu}$ nehmend geriet die sozialistische Reformpolitik, die unter den Bedingungen des Ge-

6 "Malmenée par les secousses économiques de ces dernières années, souffrant cruellement de l'absence de véritable planification, l'industrie française est partiellement à reconstruire. Le système bancaire lui-même à cessé de répondre aux besoins d'une économie en crise. Il appartient à notre pays, quelles qu'en soient les difficultés, de maîtriser et de relancer son développement économique. Le moment est donc venu d'étendre sensiblement la part du secteur public dans l'économie nationale ... Aujourd'hui comme hier, il est donc indispensable que l'État dispose des moyens nécessaires à une intervention efficace et à une orientation planifiée du développement du pays. Au premier rang de ces moyens figure l'extension d'un secteur public fort, composé d'entreprises autonomes, vivantes et compétitives, susceptibles de favoriser un nouveau dynamisme industriel. Elles s'appuieront sur un système bancaire renforcé et réorienté, après sa nationalisation, vers ces objectifs de progrès", so Premierminister Mauroy am 23.9.1981 im französischen Ministerrat, zit. n. Le Monde vom 25.9.1981, S. 32

${ }^{7}$ Zahlen entnommen bei Vesperini (1993), S. 402 ff. Datenanhang

${ }^{8}$ Vesperini (1993), a.a.O., S. 259 
meinsamen Marktes offenbar nicht aufrechtzuerhalten war, ins Zentrum der Kritik. Regierungsintern kam es zu heftigen Auseinandersetzungen, in denen sich eine Fraktion für das Festhalten am bisherigen wirtschaftspolitischen Kurs auch um den Preis eines Ausstiegs aus der Gemeinschaft einsetzte. Die andere sprach sich für einen Kurswechsel in Richtung „Stabilitätspolitik“ aus, wie sie in anderen Mitgliedstaaten schon länger praktiziert wurde. Der französische Präsident erwog in der Woche vor der dritten Abwertung des Franc Mitte März 1983 zeitweise den Ausstieg aus dem EWS. Er gab letztlich aber der zweiten Fraktion den Vorzug, da Frankreich mit Verlassen des EWS absehbar an politischem Einfluß in der Gemeinschaft verloren hätte. ${ }^{9}$

Unter dem Eindruck der verschlechterten Wirtschaftslage verkündete die französische Regierung Ende März 1983 ein rigoroses Sparprogramm sowie eine neue Wirtschaftspolitik, die in erster Linie die Ertragslage und damit die Wettbewerbsfähigkeit der französischen Unternehmen verbessern sollte. ${ }^{10} \mathrm{Ziel}$ der gewandelten Politik war jetzt die Begrenzung der Staatsausgaben sowie die Wiederherstellung des außenwirtschaftlichen Gleichgewichts. Die französische Geldpolitik rückte darüber hinaus von der Kreditkontrolle als zentraler Zielgröße ab und erhob die Kontrolle der Geldmengenentwicklung zum neuen geldpolitischen Leitprinzip. Frankreich näherte sich damit einer monetaristischen, primär auf Geldwertstabilität fixierten Konzeption, wie sie seit längerem schon in der Bundesrepublik praktiziert wurde. Insgesamt kehrte die sozialistische Regierung knapp zwei Jahre nach der Amtsübernahme zu einer stabilitäts- und angebotsorientierten Politik zurück, wie sie ihre konservative Vorgängerin bis 1981 betrieben hatte.

Während der "Cohabitation" von 1986 und 1987 wurde die Abkehr von der sozialistischen Reformpolitik nochmals vertieft. Mit Jacques Chirac an der Spitze war erstmals eine konservative Regierung unter einem sozialistischen Präsidenten für die Wirtschaftspolitik zuständig. Ein Teil der Verstaatlichungen wurde aufgehoben sowie die 1983 schon begonnene Öffnung des französischen Kapitalmarktes entschlossen vorangetrieben. Die französische Wirtschaftspolitik begann, sich insgesamt mehr und mehr in Richtung Marktwirtschaft zu entwickeln. Das Reprivatisierungsprogramm war dennoch so konzipiert, daß die Möglichkeiten des Staates zur Beeinflussung der Wirtschaftsentwicklung erhalten blieben. Über die gezielte Streuung von Aktien und die Bildung sogenannter "harter Kerne" (noyeaus durs) wurde bewußt darauf hingewirkt, den Einfluß des Staates in "wichtigen" Unternehmen weiter sicherzustellen und ausländische Investoren auf Distanz zu halten. Der Hinwendung Frankreichs zu einer liberaleren Wirtschaftspolitik war jedoch nur eine kurze Dauer beschieden. Erste Rückschläge stellten sich im Verlauf der Börsenunruhen von 1987 ein als das Reprivatisierungsprogramm unterbrochen werden mußte. Das Ende kam 1988 mit dem Sieg der Soziali-

\footnotetext{
${ }^{9}$ Vgl. Uterwedde, H. (1987), Sozialistische Wirtschaftspolitik in: Frankreich, S. 65, Zeitschrift für Politik, Heft 1, S. 56-73.; o. V., „Why the drawbridge was not raised?“, The Economist vom 26.3.1983, S. 146

${ }^{10} \mathrm{Vgl}$. die Ansprache Mitterrands anläßlich der Verkündung des Reformprogramms, Le Monde vom 25.3.1983, S. 9
} 
sten bei den Präsidentschaftswahlen und den Wahlen zur Nationalversammlung. Auf Weisung Mitterrands wurde das Reprivatisierungsprogramm schließlich ganz aufgegeben.

Auf monetärer Seite ging Frankreich Mitte der achtziger Jahre zur Politik des "franc fort" über, an der es bis zum Ende des Betrachtungszeitraums festhielt. Zwar kam es 1985 und 1986 zu zwei weiteren Abwertungen, bei denen der Franc der D-Mark gegenüber noch einmal fast zehn Prozent seines Wertes verlor. Ab 1987 jedoch verweigerte die französische Regierung kategorisch jede Abwertung, um in der Geldwertstabilität nicht weiter hinter der auf diesem Gebiet erfolgreichen deutschen Politik zurückzufallen. Die französische Wirtschaft wurde damit ohne besondere Vorbereitung dem Hartwährungsstil der bundesdeutschen Wirtschafts- und Währungspolitik unterworfen. Die französische Regierung hielt an diesem Kurs auch in der Hochzinsphase nach der deutschen Wiedervereinigung fest, als sich das französische Zinsniveau aufgrund höherer Risikozuschläge deutlich in den zweistelligen Bereich verschob, was zu einem starken Rückgang der Investitionen führte. Das Festhalten am „franc fort" war stark politisch motiviert. Die französische Regierung legte großen Wert darauf, stabilitätspolitisch nicht in Rückstand zur Bundesrepublik zu geraten, obwohl monetäre Anpassungen eine erhebliche Erleichterung für die französische Wirtschaft bedeutet hätten und als Reaktion auf exogene Störungen durchaus verständlich gewesen wären. ${ }^{11}$

Gemischt wie die ordnungspolitische Orientierung waren letztlich auch die Ergebnisse der französischen Wirtschafts- und Währungspolitik ab 1988. Schnellen Erfolg brachte sie bei der Bekämpfung der Inflation, die 1987 auf unter drei Prozent fiel und damit den Franc zu einer der stabilsten Währungen im EWS machte. Ebenfalls positiv zu vermerken war der Anstieg des Wirtschaftswachstums auf bis zu vier Prozent im Jahre 1987. Weniger erfolgreich indessen war die französische Politik auf dem Gebiet der Beschäftigung. So überschritt die Arbeitslosenrate 1985 die Zehnprozentmarke, wo sie bis 1992 mit kurzen Unterbrechungen verharrte. Ebenfalls ohne Verbesserung blieb die Lage des französischen Außenhandels, der ab 1987 unverändert Defizite verzeichnete. Am Ende blieb der stabilitätspolitisch gewandelten französischen Wirtschafts- und Währungspolitik somit der volle Erfolg versagt. Für die französische Binnenmarktpolitik folgt daraus, daß sie im gesamten Zeitraum 1981 bis 1992 unter dem Eindruck von nationalen Wirtschaftsproblemen stand. Wie schon Valéry Giscard d'Estaing, so war auch François Mitterrand zu keinem Zeitpunkt in der Lage, seine Europapolitik aus einer Position wirtschaftlicher Stärke heraus zu betreiben.

\section{B.5.1.2 Der Inhalt der europapolitischen Konzeption}

François Mitterrand, der erste sozialistische Präsident der fünften Republik, und die zeitgleich ins Amt gewählte sozialistische Regierung enttäuschten schon wenige Tage

" Zu den Problemen der Politik des „franc fort“" vgl. Vesperini (1993), a.a.O., S. 393 ff. 
nach Übernahme der Amtsgeschäfte alle Erwartungen auf einen außenpolitischen Richtungswechsel. So betonte Außenminister Cheysson die Abhängigkeit der Außenpolitik von grundlegenden Einflußfaktoren wie der "Berufung" einer Nation (vocation), von ihrer Vergangenheit sowie wirtschaftlichen Sachzwängen, die unabhängig von der Parteizugehörigkeit der jeweiligen Amtsinhaber unverändert fortbestünden. ${ }^{12}$ Wie seine Vorgänger im Amt, so erhob auch Mitterrand die Wahrung der Unabhängigkeit Frankreichs zum höchsten Ziel seiner Außenpolitik, gefolgt vom Aufbau Europas und der Aufrechterhaltung des internationalen militärischen Gleichgewichts. ${ }^{13}$ Grundsätzlich zählte die Außenpolitik auch nach Ansicht des neuen Präsidenten zu dessen „domaine réservé“, womit sie auch weiterhin vornehmlich seinem persönlichen Ermessen unterworfen bleiben sollte. ${ }^{14}$

Dem Bekenntnis zur Kontinuität in der Außenpolitik entsprechend unterschied sich auch das Europabild Mitterrands kaum von dem seiner Vorgänger. Wie alle Präsidenten der fünften Republik, so führte auch er die Zusammengehörigkeit der europäischen Nationen auf ihre gemeinsame Zivilisation bzw. auf ihre gemeinsamen kulturellen Werte zurück, unter denen die Wahrung der Menschenrechte für ihn der wichtigste war. ${ }^{15}$ Der Zusammenschluß der europäischen Nationen stellte in seinen Augen eine "historische Notwendigkeit"16 dar, ein Mittel, um ihre von außen bedrängte Kultur nicht nur zu schützen, sondern vor allem, um sie zu stärken und zu verbreiten. ${ }^{17}$ Das Ziel, die europäische Zivilisation und Kultur in die Welt hinauszutragen, rechtfertigte er damit, daß sie beispielhaft für die Welt seien und „Hoffnung“ für die Menschen verkörpern würden. ${ }^{18}$ Europas "Bestimmung" war und blieb es auch unter Mitterrand, der Welt als zivilisatorisches Vorbild zu dienen und seinen gesellschaftlichen Wertvorstellungen über die eigenen Grenzen hinaus Geltung zu verschaffen.

Derart überzeugt von der zivilisatorischen Mission Europas blieb die Verteidigung der europäischen Identität eines der Hauptanliegen der französischen Europapolitik. Ihr Ziel sei, so Mitterrand, ein Europa zu schaffen, dessen vornehmste Aufgabe darin bestand, es selbst zu sein. ${ }^{19}$ In einer von Supermächten dominierten Nachkriegswelt hieß dies für die französische Regierung, primär auf ein eigenständiges, machtvolles Europa hinzuwirken, das seine Kraft und sein Vertrauen aus seinen Traditionen und seiner

\footnotetext{
${ }^{12}$ Vgl. das Interview Cheyssons mit TF 1 vom 23.5.1981, abgedruckt in: PE, Mai 1981, S. 7

${ }^{13} \mathrm{Vgl}$. Mitterrand, F. (1986), Réflexions sur la politique extérieure de la France, Paris, S. 7

${ }^{14}$ Vgl. den "Brief an alle Franzosen", abgedruckt in: Le Monde vom 8.4.1988, S. 8

${ }^{15}$ Vgl. die Rede Mitterrands vor dem Europarat am 5.5.1989, abgedruckt in: PE, Mai 1989, S. 8,

${ }^{16}$ Ansprache Mitterrands zum Abschluß des Europäischen Rates von Athen am 6.12.1983, S. 261, abgedruckt in: Mitterrand (1986), a.a.O., S. 260-279

${ }^{17}$ Vgl. die Ansprache Mitterrands im OECD-Ministerrat vom 9.5.1983, PE, S. 25, Mai 1983, S. $21 \mathrm{ff}$.

18 „Et cependant, nous nous estimons porteurs d'une sorte d'espérance raccordée à des formes de civilisations de cultures, à un certain état d'esprit, à des siècles et des siècles d'antagonismes, des rencontres, à des productions d'écrivains, d'artistes, des échanges", so Mitterrand vor dem Hamburger ÜBERSEE-CLUB am 14.5.1982, S. 49, PE, Mai 1982, S. 47 ff.

${ }^{19}$ Mitterrand (1986), a.a.O., S. 12
} 
Kultur schöpfen sollte. ${ }^{20}$ Mitterrands Europapolitik verschrieb sich einer Konzeption, "die wirklich europäisch ist und nicht ein vages Etwas, in dem Europa in der Freihandelszone, von der vor allem die Amerikaner träumen, zerfließen würde" ${ }^{21}$. Das "europäische Europa" zeichnete sich aus französischer Sicht in erster Linie dadurch aus, daß es sich nicht dem Dogma des ökonomischen Liberalismus verschrieb, welches, Europaminister Chandernagor zufolge, nur allzu oft als Schutzschild nationaler Interessen diente und nur zur Schwächung der Gemeinschaft beitragen würde. ${ }^{22}$ Europa sollte für die französische Regierung mehr sein, ein aktives Europa mit eigener Politik, das nicht mehr ausschließlich vor der Wahl stand, sich entweder amerikanischer oder sowjetischer Hegemonie zu beugen. Staatspräsident Mitterrand forderte ein „reifes“ Europa, das seinem „Rang“ zu entsprechen hätte, um seine Mission erfüllen zu können. $^{23}$

„Notre conviction est faite: l'Europe des Douze doit atteindre sa maturité pour tenir son rang dans le Monde. Maturité économique, face aux géants industriels que sont les Etats-Unis et le Japon. Maturité politique, pour renouveler le message démocratique de l'Europe des lumières. Dans l'univers de liberté qui est le nôtre, la concurrence et la solidarité sont indissociables: ce sont les deux moteurs inséparables du progrès. “24

Das „reife“ Europa war das auf den Werten der Aufklärung beruhende Europa der Freiheit und Demokratie. Ein solches bedurfte allerdings wirtschaftlicher Stärke, um seinen „Rang“" gegen bedeutende Industriestaaten wie die USA und Japan zu verteidigen. Politische und wirtschaftliche Macht hingen in dieser Konzeption unmittelbar zusammen, was von vornherein eine Binnenmarktpolitik ausschloß, die sich auf rein ökonomische Erwägungen zurückzog. Der direkte Hinweis auf die USA zeigte darüber hinaus, daß auch unter François Mitterrand der französisch-amerikanische Antagonismus ein prägendes Element der französischen Europapolitik bleiben sollte.

Grundsätzlich strebte Frankreich weiter eine aktive und handlungsfähige politische Gemeinschaft an, die über eine reine Wirtschaftsgemeinschaft hinausgehen sollte. ${ }^{25}$ Allein seine Wirtschaftskraft und Bevölkerungszahl, so Europaminister Chandernagor im Mai 1983 vor der französischen Nationalversammlung, machten Europa schon zu einer mächtigen politischen Kraft, die sich als ausgleichendes und stabilisierendes Moment auf globaler Ebene engagieren müsse, um zu verwirklichen, wozu der Einfluß

${ }^{20}$ ebenda

${ }^{21}$ Vgl. das Fersehinterview Mitterrands vom 21.3.1984, D 277 f., abgedruckt in: EA, Folge 10/1984, D 276 - D 279

${ }^{22}$ Vgl. die Rede des französischen Europaministers Chandernagor vor der Nationalversammlung vom 8.11.1983, abgedruckt in: PE, S. 46, November 1983, S. 41 ff.

${ }^{23}$ Vgl. Mitterrand (1986), a.a.O., S. 68 f.

${ }^{24}$ So der französische Außenminister und persönliche Vertraute Mitterrands, Roland Dumas, in einer Rede vor der französischen Nationalversammlung am 10.4.1990, abgedruckt in: PE, S. 64, April 1990 , S. $62 \mathrm{ff}$.

${ }^{25}$,je suis partisan déterminé de l'Europe politique“, so Mitterrand am 27.7.1989 in einem Interview, abgedruckt in: PE, S. 79, Juli 1989, S. 78 ff. 
der einzelnen Mitgliedstaaten nicht hinreiche. ${ }^{26}$ Um Europa dazu in die Lage zu versetzen, sollten die Mitgliedstaaten auf möglichst vielen Feldern ihre Politik vereinheitlichen, wobei der Harmonisierung der Außenpolitik ein besonderer Rang zukam. Ohne eine solche, so Präsident Mitterrand, hätten alle anderen französischen Vorschläge keinen Sinn. ${ }^{27}$

An der Wichtigkeit der außenpolitischen Handlungsfähigkeit der Gemeinschaft für die französische Europapolitik ließ später auch Außenminister Dumas keinen Zweifel aufkommen:

„L'Europe des Douze, première puissance économique du monde, pôle de stabilité de tout le continent, a-t-elle une réalité hors de ses frontières? L'entend-t-on vraiment dans le monde? Qui s'exprime en son nom? L'union politique apportera les réponses à ces questions: renforcer la cohérence entre les politiques internes de la communauté et son action extérieure. Identifier les <<zones d'intérêt commun $>>$ en politique étrangère, comme dans le domaine de la sécurité. Créer des instituions, les mécanismes, qui progressivement permettront à la communauté de s'affirmer sur la scène internationale. Voilà qui lui permettra de peser sur les affaires du monde, plus qu'elle ne le fait aujourd'hui. “28

In diesem Plädoyer für die politische Zusammenarbeit deutete der französische Außenminister allerdings schon an, daß eine politische Einheit Europas für die französische Regierung nicht automatisch auch Souveränitätsverzicht der Mitgliedstaaten hieß. $\mathrm{Da}$ die Zusammenarbeit auf Felder ,gemeinsamen Interesses“ beschränkt bleiben sollte, deutete darauf hin, daß die französische Regierung sich letztlich die Entscheidung vorbehalten wollte, wann und wo sie sich im europäischen bzw. nationalen Rahmen engagierte. Besorgt um die Wahrung der nationalen Unabhängigkeit, schien das politische Europa für sie mehr ein Zweckverband zur besseren Artikulierung der nationalen Interessen zu sein als eine selbständige politische Einheit mit eigenen Zielen.

Dieser Interpretation entsprach auch die Definition der Rolle Frankreichs in Europa, die nach dem Willen der französischen Regierung die einer treibenden, aber unabhängigen Kraft sein sollte. Die Wahrung der nationalen Unabhängigkeit faßte Staatspräsident Mitterrand dabei nicht nur als seine Amtspflicht auf; er deutete den Willen zur Unabhängigkeit schlechthin als den Glauben einer Nation an sich selbst und damit als ihren Selbstbehauptungswillen, was darauf hinauslief, daß ein Aufgehen Frankreichs in einem politisch geeinten Europa für ihn von vornherein allgemein ausgeschlossen war. ${ }^{29}$ Ein unabhängiges Frankreich und der Aufbau Europas standen für ihn vielmehr

${ }^{26}$ Sur le plan politique, l'Europe, ensemble pacifique de pays démocratiques, constitue un facteur d'équilibre et de stabilité et confère à nos pays un poids dans les affaires du monde auquel ne pourrait prétendre aucun d'entre eux pris isolement", so Europaminister Chandernagor am 5.5.1983 in einer Ansprache vor der Nationalversammlung, abgedruckt in: PE, S. 18, Mai 1983, S. $18 \mathrm{ff}$

${ }^{27}$ Vgl. die Ansprache Mitterrands vom 20.10.1987 in Aachen, abgedruckt in: PE, S. 137, Oktober 1987, S. $136 \mathrm{ff}$.

${ }^{28}$ Vgl. die Rede Außenminister Dumas vom 27.6.1990, abgedruckt in: PE, S. 166, Juni 1990, S. $166 \mathrm{ff}$.

${ }^{29}$ Vgl. Mitterrand (1986), a.a.O., S. $18 \mathrm{f}$. 
in komplementärer Beziehung. ${ }^{30}$ Im Präsidentschaftswahlkampf 1988 führte ihn diese Überzeugung zur Parole: „La France est notre patrie, l'Europe est notre avenir“; die französischen Wähler rief er in seinem „lettre à tous les français“ auf, den europäischen Aufbau zu unterstützen, um Frankreich einen Dienst zu erweisen: „J'en appele à la volonté nationale, au sens de la grandeur, à notre capacité d'union au services des grandes causes, et l'Europe en est une. Pour qui croit à la France, l'enjeu est digne d'elle،31. Europa brauchte somit ein unabhängiges Frankreich, dessen vornehmliche Mission es wiederum war, Europa zu dienen.

Mit dem Verweis auf die „Grandeur" bestimmte auch der vierte Präsidenten die zivilisatorische Vorbildlichkeit Frankreichs zum ideellen Ausgangspunkt seiner Europapolitik. Wie schon für seine Vorgänger, so definierte sich Frankreich auch für François Mitterrand über seine Verdienste um den Fortschritt der abendländischen Zivilisation. Frankreich wäre seiner Geschichte nicht würdig, so Mitterrand, wenn es sich nur auf sich selbst zurückziehen würde. ${ }^{32}$ Aufgrund seiner besonderen Rolle in der Geschichte habe es die Verpflichtung, seinen „Rang“ unter den Nationen zu wahren, der natürlich ein herausgehobener war. ${ }^{33}$ Es tat dies, indem es sich der Schaffung einer gerechten, stabilen und sicheren Welt verschrieb ${ }^{34}$ und sich dieser Welt als eine „gerechte“, „solidarische“ und „unabhängige“ Nation mit Vorbildcharakter präsentierte ${ }^{35}$ : "Et cette France, elle doit pourvoir faire entendre universellement sa propre voix pour sa paix et pour celle du monde, son message de liberté et d'espérance, de force et de tranquillité..." ${ }^{36}$.

Frankreich als Hoffnungsträger für den Rest der Welt - dies war die Vision, die François Mitterrand seiner Außen- und Europapolitik voranstellte. Er selbst sah sie eng mit den Werten der abendländischen Zivilisation verbunden, deren beste Seiten zu verwirklichen er zu Beginn seiner Amtszeit versprach. Die Ideale der Aufklärung und damit der französischen Philosophie des XVII. Jahrhunderts waren die Basis nicht nur dieser Politik, sondern allgemein seiner politischen Anschauungen, wie Mitterrand offen bekannte. ${ }^{37}$ Genau diesen Idealen sah er auch Europa verpflichtet, das damit letzt-

\footnotetext{
${ }^{30}$ ebenda, S. 11

${ }^{31} \mathrm{Vgl}$. „lettre à tous les français“, abgedruckt in: Le Monde vom 8.4.1988, S. 8

32 „La France ne serait digne de son histoire si elle vivait repliée sur elle-même“, so Mitterrand in einer Rede am 4.9.1981, abgedruckt in Auszügen in: Le Monde vom 25.9.1981, S. 10

${ }^{33}$ Vgl. die Pressekonferenz Mitterrands, abgedruckt in: Le Monde vom 20.5.1985, S. 2

${ }^{34} \mathrm{Vgl}$. 9. Plan

35 „Une France juste et solidaire qui entend vivre en paix avec tous peut éclairer la marche de l'humanité. A cette fin, elle doit d'abord compter sur elle-même“, so Mitterrand am 21.5.1981, PE, Mai 1981, S. 6

${ }^{36}$ Vgl. die Ansprache Mitterrands vom 9.6.1981, abgedruckt in: PE, Juni 1981, S. 21

37 "Je suis très fidèle à mes origines et mon ambition serait de réveiller dans la mesure de mes moyens ce que je crois être le meilleur de la civilisation occidentale. La France a été l'une des trois premières nations du monde avec l'Angleterre et l'Espagne. Il y a dans l'explosion de la Renaissance, il y a dans la grandeur du XVII siècle, dans l'évolution de la philosophie dite des lumières, avec l'apparition de la raison au XVII ${ }^{e}$ siècle, dans la naissance du socialisme en France, il y a une constante de la civilisation et moi j'y tiens beaucoup car je suis très occidental, je suis archi-
} 
lich auch für den vierten Präsidenten der fünften Republik nichts anderes repräsentierte, als die konkrete Verkörperung eines Zivilisationsmodells, für das Frankreich den geistigen Überbau bereitstellte. ${ }^{38}$ Europa reduzierte sich damit erneut auf eine vergröBerte Ausgabe der französischen Nation, deren gesellschaftspolitische Ideale und „Weltsicht" es zu verbreiten galt. Das von Frankreich immer wieder geforderte politisch aktive Europa hatte somit vornehmlich Multiplikatorfunktion, um französischen Zivilisationsvorstellungen über die begrenzten nationalen Möglichkeiten hinaus Geltung zu verschaffen, wie Außenminister Dumas offen eingestand:

„Nous voulons enfin l'Europe politique. c'est-à-dire l'Europe comme pôle historique d'une civilisation qu'il fait maintenir dans le monde, comme support, comme ambition, comme $<<$ frontière $>>$, relayant et donnant tout son sens à l'effort national. Evoquant au début de ces réflexions la réalité ...l'Europe m'est apparue comme le point de passage obligé pour la France. A propos du dialogue Nord-Sud, et des Droits de l'Homme, j'aurais pu noter que le message de la France a d'autant plus de portée et d'impact qu'il est devenu au fil des années un message européen. “39

Frankreichs Europapolitik zielte darauf, Europa der Verbreitung der eigenen Zivilisationsidee dienstbar zu machen. Zu diesem Zweck bedurfte es der Fortentwicklung der Wirtschaftsgemeinschaft zu einer politischen Gemeinschaft, die eine einheitliche internationale Politik zu formulieren und mit einer Stimme zu sprechen vermochte, sowie einer starken europäischen Wirtschaftsmacht, um dieser Stimme international Gehör und Einfluß zu verschaffen. Konkret hieß dies, auf den Ausbau handlungsfähiger politischer Strukturen hinzuwirken sowie eine Binnenmarktpolitik zu betreiben, die auf die Stärkung der europäischen Wirtschaft ausgerichtet war. Die französische Europapolitik verfolgte damit unter Mitterrand die gleichen Ziele, die schon seine Vorgänger im Amt an die Spitze ihrer Prioritäten gesetzt hatten.

\section{B.5.1.3 Die Umsetzung der europapolitischen Konzeption}

Die französische Europapolitik begann auch unter François Mitterrand mit einer „relance européenne“, die sich zunächst jedoch nur auf ein gemeinsames Vorgehen der europäischen Staaten zur Behebung der Wirtschaftskrise beschränkte. Im Oktober 1981 regte die französische Regierung in einem Memorandum die Schaffung eines „europäischen Sozialraums“ an, in dem neben einer gemeinschaftlichen Beschäftigungspolitik eine europäische Industrie- und Außenhandelspolitik sowie eine engere währungspolitische Zusammenarbeit betrieben werden sollten. ${ }^{40}$ Dieser Initiative

occidental par ma nature, par ma culture. Mon adhésion au socialisme tient à une certaine disposition d'esprit, à un engagement qui remonte loin dans notre histoire.", so Mitterrand in einem Interview mit der NEW YORK TIMES am 4.6.1981, abgedruckt in: PE, S. 16, Juni 1981, S. 14 ff.

${ }^{38}$ Vgl. Tréan, C. (1995), Entre le <<grandeur française >> et l'Europe inachevée, S XI, Beilage zu Le Monde vom 11.5.1995, S. X-XI

${ }^{39}$ So Außenminister Dumas am 23.3.1985 in einer Ansprache vor der Paassikivi-Gesellschaft in Helsinki, PE, S. 34 f., März 1985, S. 31 ff.

${ }^{40} \mathrm{Vgl}$. Memorandum der französischen Regierung über die europäische „relance“ vom 8.10.1981, abgedruckt in Auszügen in: EA, Folge 2/1982, D $41 \mathrm{ff}$. 
folgten 1982 und 1983 zwei weitere Memoranden, die auf eine Vertiefung der politischen Zusammenarbeit auf den Gebieten des Außenhandels und der Industrie hinausliefen und beide die Steigerung der Wettbewerbsfähigkeit Europas gegenüber den wirtschaftlich dominierenden USA und Japan zum Ziel hatten.

Eine Intensivierung der allgemeinen politischen Zusammenarbeit hingegen strebte die französische Regierung erst ab 1984 an. Zwar unterstrich sie schon 1981 mit der Ernennung eines Europaministers die grundsätzlich hohe Bedeutung, die sie der politischen Zusammenarbeit in Europa beimaß. Bemühungen anderer Staaten, den europäischen Integrationsproze $\beta$ aus seiner Stagnation zu befreien, in der er seit Mitte der siebziger Jahre steckte, unterstützte Frankreich jedoch nur formal. Der „GenscherColombo-Inititative“" aus dem November 1981, die auf eine systematisch angelegte Vertiefung der außenpolitischen Zusammenarbeit in Europa ausgerichtet war, stand die französische Regierung von Anfang ablehnend gegenüber, da ihrer Meinung nach der Integrationsansatz von Grund auf falsch gewählt war (,,das europäische Haus nicht vom Dach an bauen"). Außerdem hielt sie die Zeit für institutionelle Änderungen noch nicht für gekommen." Auch die Vorbereitungen für die Stuttgarter Erklärung zur „Europäischen Union“ vom März 1983 verliefen ohne außergewöhnliches französisches Engagement.

Erst mit der Übernahme der Ratspräsidentschaft Anfang 1984 wendete sich die französische Europapolitik institutionellen Fragen ernsthaft zu. Ab Frühjahr 1984 begann die französische Regierung verstärkt, auf die Notwendigkeit hinzuweisen, Europa zu einer „großen politischen Kraft“ auszubauen. Die Gemeinschaft sollte darauf hinarbeiten, auf internationaler Ebene eine Rolle einzunehmen, die ihrer Stellung als größter Handelsmacht der Welt gerecht würde. ${ }^{42}$ Auf der Tagung des Europäischen Rates im März 1984 betonte Staatspräsident Mitterrand die Notwendigkeit, ein unabhängiges „europäisches“ Europa zu schaffen. ${ }^{43}$ Zwei Monate später, im Mai 1984 vor dem Europäischen Parlament, kritisierte er die Blockade des europäischen Integrationsprozesses durch zu häufigen Rekurs auf die Einstimmigkeitsregel im Ministerrat sowie durch den Mißbrauch des Europäischen Rats als Berufungsinstanz. ${ }^{44}$ Zur erfolgreichen Wiederbelebung der Gemeinschaft schlug der französische Staatspräsident vor, die im Juni 1983 in Stuttgart proklamierte „Europäische Union“ zu verwirklichen und eine entsprechende Konferenz einzuberufen. Das Ergebnis dieser Initiative waren Verhandlungen, die ein Jahr später zur Verabschiedung der Einheitlichen Europäischen Akte füh-

${ }^{41}$ Vgl. die Rede Europaminister Chandernagors in der Haushaltsdebatte der französischen Nationalversammlung am 8.11.1983, PE, S. 48, November 1983, S. 41 ff.

${ }^{42} \mathrm{Vgl}$. die Ansprache Europaminister Dumas' vor der Nationalversammlung vom 28.4.1984, abgedruckt in: PE, S. 96

${ }^{43}$ Vgl. Fersehinterview des französischen Staatspräsidenten, vom 21.3.1984, D 276, abgedruckt in: EA, Folge 10/1984, D 276 - D 279

44 Vgl. Ansprache des französischen Staatspräsidenten vor dem Europäischen Parlament vom 24.5.1984, D 338, abgedruckt in: EA, Folge 12/1984, D 331 - 338, sowie Stadlmann, H. (1984), Die Europäische Gemeinschaft nach der französischen Ratspräsidentschaft, S. 450 f., in: EA, Folge 15/1984, S. 447-454 
ren sollten. Gemeinsam mit der Bundesrepublik legte Frankreich in diesem Zusammenhang einen Vertragsentwurf über die Europäische Union vor, der im wesentlichen auf eine schrittweise Intensivierung der Kooperation auf dem Gebiet der Außen- und Sicherheitspolitik hinauslief. ${ }^{45}$ In der Anfang 1986 unterzeichneten Einheitlichen Europäischen Akte mündeten diese Bemühungen schließlich in eine Neuregelung der Europäischen Politischen Zusammenarbeit (EPZ) sowie in den Beschluß, den Binnenmark bis 1992 zu vollenden. Nach nur eineinhalb Jahren intensiven Engagements war Frankreich seiner Vision eines politisch aktiven Europas somit einen großen Schritt näher gekommen.

In den zwei folgenden Jahren der „Cohabitation“, als eine konservative Regierung die europapolitischen Leitlinien eines sozialistischen Präsidenten umzusetzen hatte, nahm die Initiativkraft der französischen Europapolitik vorübergehend ab, wie Staatspräsident Mitterrand selbst im nachhinein zugab. ${ }^{46}$ Nach den Wahlen 1988 allerdings, als die Sozialisten neben dem Präsidenten auch wieder die Regierung stellten, meldete sich Frankreich mit einer tatkräftigen Europapolitik zurück. Diese konzentrierte sich zunächst auf die Vollendung des Binnenmarktes, gefolgt von der Schaffung eines Europäischen Sozialraums, einer gemeinsamen Kulturpolitik sowie der Errichtung eines „Europas der Bürger", die darin ihr zweites Vaterland erkennen können sollten. ${ }^{47}$ Der X. Plan (1989-1992) wurde unter den Titel „une ambition pour l'Europe“ verabschiedet und diente der gezielten Vorbereitung der französischen Wirtschaft auf den Binnenmarkt. In den Erläuterungen zum Plan wurde der Binnenmarkt als hervorragendes Mittel zur Förderung der französischen Wettbewerbsfähigkeit und zur Bewahrung der Identität Frankreichs gepriesen. ${ }^{48}$ Derart auf die Forcierung der wirtschaftlichen Integration bedacht, rückte Frankreich während der zweiten französischen Ratspräsidentschaft im Jahr 1989 die Vorbereitung der Wirtschafts- und Währungsunion in den Mittelpunkt der Agenda. Ins Wanken geriet diese Strategie allerdings im Herbst 1989 mit dem rutschartigen Zusammenbruch der sozialistischen Regime Osteuropas, der die

${ }^{45}$ Vgl. Entwurf eines Vertrages über die Europäische Union, von den Regierungen der Bundesrepublik Deutschland und Frankreichs den Regierungen der EG-Mitgliedsaaten auf der Tagung des Europäischen Rates in Mailand am 28. Und 29. Juni 1985 vorgelegt, EA, Folge 16/1985, D 449 ff.

${ }^{46}$ Vgl. das Interview Mitterrands mit LIBÉRATION vom 30.11.1988, abgedruckt in: Frankreich-Info, Nr. 31/1988

${ }^{47} \mathrm{Vgl}$. Pressekonferenz des französischen Staatspräsidenten François Mitterrand, abgedruckt in: Le Monde vom 20.5.1985, S. 2

48 „Although our temperament is not naturally conducive to change, the European Community will bring us round. In itself, Europe is neither an opportunity nor a threat. It is first and foremost a lever which will enable France to better situate itself in the world economy, while at the same time, safeguarding its national values, its practices, in short, its identity. It is less a question of preparing France for the 1993 deadline than one of using the deadline to motivate France to adapt to a new world.... The world is our mirror: Europe is forcing us to look at our reflections. The implementation of the Single Market is an opportunity for France to strengthen its historical role in Europe and in the rest of the world. Putting Europe back in the race alongside Japan and the United States is the best way to guarantee the durability of the old continent's civilisation and culture", Commissariat de Plan (1989), France, Europe. Xth Plan 1989-1992, La documentation française, Paris, S. 5 
französische Europapolitik mit völlig neuen Tatsachen konfrontierte. Frankreich stand plötzlich einem wiedervereinigten und absehbar an politischem Gewicht gewinnenden Deutschland gegenüber, das alte Ängste und Sorgen um die „incertitudes allemandes“ wieder aufleben lie $\beta^{49}$ und den traditionellen Anspruch Frankreichs auf eine Vormachtstellung in der Gemeinschaft bedrohte. Zum anderen begehrten die jungen osteuropäischen Demokratien möglichst schnelle Aufnahme in die Gemeinschaft, was zu einer weiteren Relativierung der Rolle und des Gewichts Frankreichs führen mußte. ${ }^{50}$ Die französische Europapolitik geriet somit unter starken Handlungs- und Entscheidungsdruck, wollte sie ihren europapolitischen Zielvorstellungen auch in Zukunft eine Chance auf Verwirklichung bewahren. Die Rolle Deutschlands in Europa wie auch das Verhältnis der Gemeinschaft zu den jungen Demokratien Osteuropas waren neu zu bestimmen, ohne daß dabei der europäische Integrationsprozeß auf Abwege geriet.

Die französische Regierung löste sich aus dieser komplizierten Lage, indem sie im April 1990 gemeinsam mit der Bundesregierung neben der Wirtschafts- und Währungsunion die Gründung einer Politischen Union vorschlug. In dieser sollte die Gesamtheit der europäischen Beziehungen vor allem auf dem Gebiet der Außen- und Sicherheitspolitik zu größtmöglicher Kohärenz weiterentwickelt werden. ${ }^{51}$ Die osteuropäischen Staaten waren zuvor schon auf Initiative des französischen Staatspräsidenten zur Gründung einer europäischen Konföderation mit den Ländern der Europäischen Gemeinschaft eingeladen worden. Mit dieser zweigleisigen Strategie war zum einen die Einbindung eines größeren Deutschlands in eine gemeinsame europäische Politik sichergestellt, während die europäische „Konföderation“ alle Staaten des Kontinents in einer „Wirtschafts-, Friedens- und Sicherheitsgemeinschaft“ zusammenfaßte ${ }^{52}$, wo sie einander ,auf gleicher Ebene" begegnen können sollten, um sich schrittweise an einander zu gewöhnen und sich anzunähern. ${ }^{53}$ Die Konferenz zur Gründung der Konföderation fand im Juni 1990 statt. Zuvor allerdings hatte Präsident Mitterrand schon angedeutet, daß er die tatsächliche Aufnahme der zentraleuropäischen Staaten in die EG erst „Jahrzehnte“ später als denkbar ansah. ${ }^{54}$ Um deren Enttäuschung jedoch in Grenzen zu halten, schlug Frankreich die Gründung der Europäischen Bank für Wiederaufbau und Entwicklung vor, die den mittel- und osteuropäischen Ländern beim Aufbau ihrer Volkswirtschaften helfen sollte. Dieser Vorschlag stieß in der Gemeinschaft auf positive Resonanz, und so konnte die Europäische Entwicklungsbank ihre Geschäfte

${ }^{49}$ Vgl. Martinet, G., Faut-il avoir peur de l'Allemagne?, Le Monde, 15.1.1992, S. 2; Yost, D. S. (1990), Frankreich in einem neuen Umfeld, S. 693 f., EA, Folge 23/1990, S. 691 ff. sowie Schütze, W. (1990), Frankreich angesichts der deutschen Einheit, S. 133 ff., EA, Folge 4/1990

${ }^{50}$ Zur Desorientierung der französischen Außenpolitik vgl. Hoffmann, S. (1992), Dilemmes et stratégies de la France dans la nouvelle Europe (1989-1991), in: Politique Étrangère, No. 4/1992, 57 Jg., S. $879 \mathrm{ff}$, insbesondere S. $888 \mathrm{f}$.

51 Vgl. das Schreiben des französischen Staatspräsidenten und des deutschen Bundeskanzlers vom 18.4.1990, abgedruckt in: EA, Folge 11/1990, D 283

${ }^{52}$ Vgl. die Neujahrsansprache Mitterrands, Le Monde vom 2.1.1990, S. 5

${ }^{53}$ Vgl. die Äußerungen der französischen Europaministerin Guigou aus dem Frühjahr 1991, abgedruckt in: PE, S. $55 \mathrm{ff}$.

${ }^{54}$ Vgl. die Äußerungen Mitterrands vom 12.6.1991, abgedruckt in: Le Monde, 14.6.1991, S. 4 
schon im Frühjahr 1991 aufnehmen. Frankreich konnte sogar mit Jacques Attali einen früheren Berater Präsident Mitterrands an ihrer Spitze plazieren. ${ }^{55}$ Mit diesem Schachzug gelang es, die osteuropäischen Demokratien zunächst auf Distanz zu halten, ohne dabei ihre Bindung an die Gemeinschaft zu zerbrechen. Die „west“-europäische Gemeinschaft indessen blieb mit der Gründung der Politischen Union vorerst weiter als das dominierende politische Gebilde auf dem Kontinent, in dem ein vergrößertes Deutschland fest eingebunden und kontrollierbar war, bestehen. Frankreich hat mit seinen Initiativen erreichen können, daß der institutionelle Umbau der Gemeinschaft so erfolgte, wie es notwendig war, um seiner europapolitischen Vision trotz der großen Veränderungen in Osteuropa eine realistische Chance auf Verwirklichung zu erhalten.

Mit der „Flucht" nach vorn in die Politische Union stellte sich allerdings erneut die Frage nach der Kompetenzverteilung zwischen Mitgliedstaaten und Gemeinschaftsinstitutionen. Die Mitgliedstaaten mußten sich entscheiden, ob sie die Integration auf föderalem oder konföderalem Weg fortsetzen wollten. Für die französische Europapolitik tat sich damit ein neues Dilemma auf, da die Konföderation als Integrationsform für den Zusammenschluß mit den osteuropäischen Staaten schon vergeben war. Für die Politische Union blieb somit nur noch die Föderation, die ihrer Natur nach jedoch einen Bundesstaat mit starker Zentralgewalt bezeichnet, den Frankreich aus seinem Unabhängigkeitsstreben heraus auch unter Mitterrand immer abgelehnt hatte. Die französische Regierung stolperte damit erneut über den eigentlich nie gelösten Widerspruch ihres Strebens nach nationaler Unabhängigkeit und einem starken und politisch handlungsfähigen Europa. Über die gesamte Amtszeit Mitterrands hinweg gab es zu diesem Sachverhalt höchst unterschiedliche Äußerungen. So verkündete Außenminister Cheysson im März 1982, daß Europa weder eine Föderation noch eine Konföderation oder gar ein eigener Staat werden könne, sondern zweckmäßigerweise nur dort als Gemeinschaft auftreten solle, wo die nationalen Möglichkeiten nicht zur Problemlösung hinreichten. ${ }^{56}$ Diese eher utilitaristische Interpretation ergänzte der französische Staatspräsident im Mai 1982 mit der Klarstellung, daß Frankreich in Fragen von „vitalem Interesse“ weiter am Luxemburger Kompromiß festhalten werde, also weiter dort auf die Einstimmigkeitsregel zurückgreifen wollte, wo es seine Unabhängigkeit in Gefahr sah. ${ }^{57}$ Nach der Hinwendung zur Europäischen Union im Jahr 1984 wandelte

55 $\mathrm{Zu}$ den Intentionen Frankreichs hinsichtlich der Errichtung der Europäischen Entwicklungsbank siehe Hoffmann (1992), a.a.O., S. 888 sowie Deubner, C. (1991), Frankreichs Europapolitik und der europäische Binnenmarkt, S. 53, in: Michael Kreile (Hrsg.), Europa 1992, Konzeptionen, Strategien, Auswirkungen, Baden-Baden, S. $37 \mathrm{ff}$.

${ }^{56}$ „Je ne crois pas -...- que l'Europe soit destinée à être un État, soit destinée d'être un super-État. Je ne crois pas à la fédération européenne. Je crois que nous avons besoin de la dimension européenne comme nation distincte pour traiter des problèmes que se présentent insuffisamment dans la dimension nationale, qui sont des problèmes industriels, des problèmes agricoles suivant les dimensions des marchés dans tous les cas, des problèmes économiques extérieurs - parce-qu'il faut être assez fort pour être entendu, pour être agressif, pour se protéger, pour partir à la conquête de nouvelles idées, de nouveaux marchés - des problèmes politiques." so Außenminister Cheysson am 25.3.82 im Interview mit FRANCE INTER, PE, S. 77 f., März 1982, S. 76 ff.

${ }^{57} \mathrm{Vgl}$. die Rede Mitterrands vom 14.5.1982, a.a.O., S. 49 
sich die Gemeinschaft in den Augen des französischen Präsidenten immerhin schon zu etwas, das keine Konföderation mehr sei, aber auch noch weit weg war von einer Föderation. ${ }^{58}$ Sechs Jahre später sprach Außenminister Dumas schließlich von einer Politischen Union der Mitgliedstaaten mit „föderalistischer Berufung“. Schon im nächsten Satz relativierte er diese Aussage allerdings wieder, indem er von einer „communauté unique à finalité fédérale“ sprach, ,... qui soit dotée des institutions, agissant conforme à leur compétences dans le plein respect de l'équilibre des pouvoirs et du rôle des États". ${ }^{59}$ Deutlich war damit klargestellt, daß Frankreich trotz seiner Forderung nach einer „Föderation“ einen Bundesstaat mit starker Zentralgewalt faktisch weiter ablehnte. Außenminister Dumas forderte darüber hinaus, die außen- und sicherheitspolitische Zusammenarbeit der europäischen Staaten auf gemeinsame „zones d'intérêt" zu beschränken. Klarheit schaffte indessen die französische Europaministerin Guigou, die sich während der Regierungsverhandlungen zum Maastrichter Vertrag unmißverständlich zu einer restriktiven Haltung in bezug auf den Transfer von Souveränitätsrechten bekannte:

„... wir sind auf dem Weg zu einem System der geteilten Souveränität. Man wird seine Souveränität nicht aufgeben, man teilt sie und zwar nur in den Bereichen, von denen man denkt, daß man gemeinsam stärker sein wird als allein. Es geht nicht darum, blind unsere nationale Souveränität auf irgendeine diffuse Technokratie zu übertragen. Es geht darum, nach den Verfahren der Gemeinschaft die Entscheidung mit den 11 anderen Mitgliedstaaten zu teilen, wenn wir glauben, daß das in unserem Interesse liegt. ${ }^{\text {} 600}$

Die Politische Union blieb somit für die französische Regierung in erster Linie eine Zweckgemeinschaft, in der die Entscheidungen weiter den nationalen Regierungen überlassen bleiben sollten. Dementsprechend drängte Frankreich in den Regierungsverhandlungen darauf, die Formulierung der grundlegenden politischen Orientierungen dem Europäischen Rat zuzuschlagen, während der Rat der Außenminister sich vornehmlich mit der Ausarbeitung der gesetzlichen Grundlagen zur Umsetzung dieser Leitlinien beschäftigen sollte. Eine enge Zusammenarbeit beider Organe sollte vor allem auf dem Gebiet der Außen- und Sicherheitspolitik stattfinden, wo die französische Regierung die Schaffung von Gemeinschaftskompetenzen grundsätzlich ablehnte. ${ }^{61}$ Für die Kommission blieb damit nur die Rolle eines ausführenden Organs, während das Europäische Parlament nach französischen Vorstellungen den Gesetzgebungsprozeß primär kritisch zu begleiten hatte. Zwar sollte es mehr Initiativrechte und auch das Recht zur „Koentscheidung“ erhalten, doch relativierte die französische Regierung diese Kompetenzerweiterung, indem sie eine solche nur „in vernünftigen Grenzen“ (limites raisonnables) zu dulden bereit war. ${ }^{62}$ Sie plädierte außerdem für die Bildung

\footnotetext{
${ }^{58}$ Vgl. die Rede Mitterrands in Chattam House vom 15.1.1987, abgedruckt in: PE, S. 42

${ }^{59}$ Vgl. die Rede Dumas vom 27.6.1990, PE, S. 166, PE, Juni 1990, S. $166 \mathrm{ff}$.

${ }^{60}$ Interview mit Le Monde vom 23.6.1991, abgedruckt in: Frankreich-Info, Nr. 91-18

${ }^{61}$ Vgl. Lemaitre, P., „La France s'oppose à la Commission de Bruxelles sur le partage des pouvoirs dans une Communauté renforcée“, Le Monde vom 5.6.1991, S. 4

${ }^{62}$ Vgl. die Ansprache Außenminister Dumas' vom 27.7.1989 vor dem Europäischen Parlament, S. 89, abgedruckt in: PE, S. 82-91
} 
eines europäischen Senats, über den die nationalen Parlamente an der parlamentarischen Kontrolle auf europäischer Ebene beteiligt werden sollten. Faktisch wäre es nach diesen Vorschlägen zu keiner substantiellen Erweiterung der legislativen Kompetenzen des Europäischen Parlaments gekommen. Mit ihrer Haltung zu diesen Fragen machte die französische Regierung nochmals deutlich, daß sie allgemein nur an schwachen Gemeinschaftsinstitutionen interessiert war.

Faßt man die Bemühungen der französischen Regierung um die Ausgestaltung der politischen Zusammenarbeit in Europa zusammen, so ist ein zielgerichtetes Streben festzustellen, die politische Willensbildung weiter in den Händen der nationalen Regierungen zu belassen. Frankreich lehnte damit auch unter Mitterrand die Fortsetzung der Integration in Richtung Supranationalität ab. Wohl bemühte es sich vorsichtig um den Aufbau von Institutionen für eine gemeinsame Außenpolitik, doch sollte die Entscheidungsfindung für diese Politikbereiche niemals den Rahmen der intergouvernementalen Kooperation verlassen. Maßgeblich für Frankreich war, Einfluß auf die Formulierung der europäischen Politik nehmen zu können bzw. das Recht zu besitzen, sich ihr zu verweigern, wenn sie französischen Vorstellungen nicht entsprach. Konsequent wirkte es letztlich auf die Schaffung einer politischen Zweckgemeinschaft hin, ohne dieser zu feste Strukturen zubilligen zu wollen. Natürlich sollte die zu schaffende Politische Union trotz allem handlungs- und durchsetzungsfähig sein, was üblicherweise auf die altbekannte Forderung nach Stärkung der europäischen Wirtschaft hinauslief. Inwieweit ordnungspolitische Aspekte dabei berührt waren, sollen die folgenden Ausführungen zeigen.

\section{B.5.2 Die Wirtschaftspolitik B.5.2.1 Die wirtschaftspolitische Konzeption}

Im Gegensatz zum französischen Engagement für ein politisch aktiveres Europa, das sich erst drei Jahre nach dem Amtsantritt François Mitterrands bemerkbar machte, nahm die Binnenmarktpolitik der neuen Regierung schon nach sehr kurzer Zeit konkrete Formen an. Nur sechs Wochen im Amt, schlug der französische Präsident auf der Tagung des Europäischen Rates im Juni 1981 eine „relance“ der Wirtschaftsentwicklung vor, die über die Stärkung der Nachfrage erreicht werden sollte. ${ }^{63}$ Zusätzlich sollten innovationsfreudige Unternehmen finanziell von der Gemeinschaft unterstützt und Schlüsselsektoren mit hoher Bedeutung für die Wirtschaftsentwicklung, wie z. B. die Informationstechnologie oder die Energietechnik, gezielt gefördert werden. Zur schnellen Verbesserung der Beschäftigungslage schlug Frankreich außerdem vor, einen „Europäischen Sozialraum“ zu errichten sowie europaweit die Arbeitszeit zu senken. Die „relance“ orientierte sich mit diesen Forderungen insgesamt eng an dem nationalen Reformprogramm der sozialistischen Regierung, das sie offenbar auf Europa

${ }^{63}$ Vgl. Lemaitre, P.; Delarue, M., „Les thèses de M. Mitterrand sur $l^{\prime}<<$ espace social européen>> suscitent les réserves de Mme Thatcher et de M. Schmidt, Le Monde vom 1.7.1981, S. 1 
zu übertragen gedachte - ohne Erfolg allerdings, da die französische Initiative im Europäischen Rat zunächst auf Ablehnung stieß.

Mit dem Memorandum zur „relance européenne“ vom 8. Oktober 1981 legte die neue französische Regierung einen ersten vollständigen Entwurf ihrer Binnenmarktpolitik vor. Ausgehend von der Feststellung, daß sich in Europa angesichts der Unfähigkeit der Gemeinschaft, mit ihren wirtschaftlichen Problemen fertigzuwerden, eine zunehmende Unzufriedenheit ausgebreitet hätte, appellierte sie, einen gemeinsamen Vorsto $\beta$ zur Überwindung der Wirtschaftskrise zu wagen. ${ }^{64}$ Gemeinsam sollten die Mitgliedstaaten der Gemeinschaft den "wirtschaftlichen Kampf" gegen ihre schärfsten Konkurrenten auf dem Weltmarkt aufnehmen und sich den Herausforderungen der „dritten Industrierevolution", die von den technologischen Entwicklungen im Bereich der Elektronik ausgingen, stellen. Ein Versagen der Gemeinschaft in diesem Bereich würde nicht nur ihren Wohlstand, sondern insgesamt die Rolle Europas als „wichtige Komponente des Gleichgewichts in der Welt" gefährden. Um den Einfluß Europas auf internationaler Ebene auch in Zukunft wahren zu können, bedurfte es einer Stärkung der europäischen Wirtschaft, denn es gäbe, wie das Memorandum vermerkte, „... keine politische Macht ohne wirtschaftliche Macht. Und wiederum gibt es keine wirtschaftliche Macht ohne ein politisches und kulturelles Konzept ${ }^{\text {“65: }}$

„Europa muß, wenn es dazu beitragen soll, daß das Vertrauen in der Welt wiederhergestellt und der Frieden gefestigt wird, zu einem Zentrum der Stabilität, des Wachstums und der Initiative werden. Um dies zu erreichen, muß es sich auf dem Gebiet der Beschäftigungspolitik, der Autonomie im Energiebereich, der industriellen Unabhängigkeit und der Justiz ehrgeizige Ziele setzen. Es muß ein soziales Wachstum ermöglichen. Es muß Mut zeigen bei der Festlegung der neuen Wirtschaftsordnung. ${ }^{\text {"66 }}$

Ziel der neuen Wirtschaftsordnung war die Wiederbelebung des Wirtschaftswachstums, um Europa international zu mehr Macht zu verhelfen. Sie sollte vor allem von „Pragmatismus" gekennzeichnet sein, um durch konkrete Taten und schnelle Erfolge das allgemeine Vertrauen in die Gemeinschaft wiederherzustellen. Ausgehen sollte die geforderte Gemeinschaftsinitiative vorrangig von „Aktionen im Bereich der Beschäftigung“. Stabile und international wettbewerbsfähige Arbeitsplätze sollten geschaffen werden, indem Europa den „Wettlauf um den wissenschaftlichen und technischen Fortschritt" aufnahm und die Mitgliedstaaten im Rahmen einer engen Kooperation zur systematischen Nutzung der Dimension des Binnenmarktes übergingen. Es folgten erneut Vorschläge zur Stimulierung innovativer Investitionen und zur Gründung eines „Europäischen Sozialraums“. Sie wurden ergänzt durch die Forderung nach einer gemeinsamen Außenwirtschaftspolitik, welche, dem Memorandum zufolge, unabdingbar zur Lösung der Probleme im Bereich der Landwirtschaft und Industrie war. Im Kern deutete sich damit der Wunsch nach einer gemeinsamen europäischen Wirtschafts-

\footnotetext{
${ }^{64}$ Zur Lageanalyse vgl. das Memorandum der französischen Regierung über die europäische „Relance“ vom 8.10.1981, D 41 f, abgedruckt in Auszügen in: EA, Folge 2/1982, D 41 - D 45

${ }^{65}$ ebenda, D 42

${ }^{66}$ ebenda
} 
politik an, an deren interventionistischer Ausrichtung die französische Regierung keinen Zweifel ließ. Weitere Memoranden für eine gemeinsame Außenwirtschaftspolitik (April 1982) sowie für eine gemeinsame Forschungs- und Industriepolitik (September 1983) folgten. Sie ließen die französische Strategie zur Stärkung der europäischen Wettbewerbsfähigkeit auf ein Konzept hinauslaufen, das sich auf die Förderung ausgewählter Sektoren der Spitzentechnologie konzentrierte und seine Ergänzung in einer aktiven Außenwirtschaftspolitik fand, die auf die „Wiedergewinnung des Binnenmarktes" (reconquête du marché intérieur) hinauslaufen sollte. ${ }^{67}$

Mit dem Bemühen um eine aktive Beschäftigungspolitik und eine umfassende Industriepolitik folgte die französische Binnenmarktpolitik zwei Entwicklungslinien, die sich nicht nur an der nationalen Wirtschaftspolitik orientierten, sondern, wie Außenminister Cheysson im März 1982 in einer Rede anläßlich des 25-jährigen Bestehens der Gemeinschaft andeutete, auch auf eine bestimmte wirtschaftspolitische "Ideologie“ ausgerichtet waren:

„L'Europe du concret, l'Europe de l'espoir doit être d'abord aujourd'hui l'Europe de l'emploi. Et pour cela, l'Europe doit être capable de résister aux forces extérieures qui cherchent à imposer leurs lois et leurs politiques économiques, ou imaginent se soustraire à la réciprocité des droits et des devoirs. L'Europe doit s'exprimer d'une voix face aux dangers de la politique monétariste des EtatsUnis qui, avec ses taux d'intérêt élevés, fait subir aux économies européennes leur troisième choc pétrolier. Le deuxième défi, c'est la capacité de faire face à la nouvelle révolution industrielle et technologique et à la concurrence toujours plus active des autres grands pays industrialisés ...le gouvernement français fonde ses espoirs sur une Europe plus volontariste, une Europe qui refuse la logique de domination économique de ses partenaires industrialisés. ${ }^{\text {“68 }}$

Der Appell für ein „voluntaristisches“, d. h. im Sinne des Allgemeininteresses handelndes Europa ließ keinen Zweifel daran, daß die französische Regierung offenbar anderen wirtschaftspolitischen Grundsätzen zugeneigt war als die amerikanische. Nicht verträglich mit der französischen Binnenmarktpolitik war eine Wirtschaftspolitik nach dem Vorbild der „Reagonomics“, mit denen die USA zu Beginn der achtziger Jahre zu einer angebotsorientierten Wirtschaftspolitik sowie zu einer monetaristischen Währungspolitik zurückgekehrt waren. Gefährlich war eine solche Politik aus französischer Sicht vor allem, weil mit der Rückkehr zum "wirtschaftlichen Liberalismus" der Rückfall der Gemeinschaft in eine reine Freihandelszone drohte, was nach Ansicht des französischen Europaministers das unweigerliche Ende eines unabhängigen und eigenständigen Europas bedeutete. ${ }^{69}$

${ }^{67}$ Vgl. die Rede Premierminister Mauroys vom 25.3.1982 zum 25-jährigem Bestehen der Gemeinschaft, abgedruckt in: PE, S. 75

${ }^{68}$ ebenda

${ }^{69}$ "Que l'on aborde la relance, la réforme de l'acquis, ou l'élargissement, le problème, le vrai, le seul, l'essentiel depuis tous, c'est la préservation de l'identité européenne. Peu à peu, et par l'effet d'un libéralisme économique trop souvent érigé en dogme par la plupart des gouvernements en place dans les États de la Communauté - un dogme qui n'est d'ailleurs, le plus souvent, que le paravent d'intérêts nationaux à courte vue - une construction européenne originalement fondée sur la notion pragmatique et volontariste de politiques communes, est menacée de dérive. Cette réalisation sans 
Die sich in diesen Äußerungen andeutende Ablehnung der „reinen“ Marktwirtschaft fand ihre Ergänzung in der Kapitalismuskritik des Staatspräsidenten, der dieses Wirtschaftssystem generell nicht für fähig erachtete, den notwendigen Strukturwandel herbeizuführen und zu bewältigen. $\mathrm{Da} \beta$ profitorientierte Unternehmen über die gesamte Welt der besten Rendite nachjagten, sei ihm, so Mitterrand im Mai 1982 vor dem Hamburger Übersee-Club, wohl verständlich, doch wäre dies allein im Hinblick auf das Allgemeininteresse zu kurzsichtig. ${ }^{70}$ Die Ölkrisen, der Zusammenbruch der Währungsordnung von Bretton-Woods sowie die sich anschließende Ausbreitung von Inflation und Arbeitslosigkeit seien die logische Konsequenz der kapitalistischen Wirtschaftsweise. Notwendig war seiner Meinung nach eine Wirtschaftspolitik, die weder auf Keynes noch auf Friedman aufbaute, sondern in erster Linie dem „bon sens“ folgte. ${ }^{71}$ Zumindest für Frankreich hieß dies, so Mitterrand, eine sozial orientierte Wirtschaftspolitik zu betreiben, die auf vier Prozent weniger Inflation verzichten würde, wenn der Preis dafür 400.000 neue Erwerbslose wären. Die Lösung der aktuellen Wirtschaftsprobleme erforderte aus seiner Sicht eine Politik, die zu einer „gerechteren“ Aufteilung des Sozialprodukts (profit national) führen würde. ${ }^{72} \mathrm{Da}$ eine solche Politik letztlich immer nur im europäischen Rahmen erfolgreich sein könne, sei ihm bewußt; die französischen Initiativen zur europäischen Technologie- und Sozialpolitik wären deshalb in genau diesem Sinne zu verstehen. ${ }^{73}$

Die französische Regierung machte somit von Anfang an keinen Hehl aus ihrem grundsätzlichen Mißtrauen einer liberalen Wirtschaftspolitik gegenüber. Sie bezweifelte die Fähigkeit des Marktmechanismus, die Wirtschaftsentwicklung optimal zu koordinieren, da auf Märkten nur die Präferenzen eigennutzmaximierender Wirtschaftssubjekte Berücksichtigung fänden, nicht aber das Allgemeininteresse, was zwangsläufig eine gewisse Kurzsichtigkeit des marktlichen Wettbewerbs zur Folge habe, wie Mitterrand erläuterte:

„Comment ne pas mentionner le comportement à courte vue d'un certain nombre d'agents directeurs de l'économie mondiale qui plutôt que de se lancer hardiment dans l'innovation technologique ont choisi la solution de facilité de la transplantation de leurs unités de production, comme cela au hasard du profit ...Comment ne pas voir où mène la logique absurde du chacun pour soi, de la concurrence

égale court le risque d'être réduite à une simple zone de libre échange, sans frontières, sans politiques communes nouvelles...", so Europaminister Chandernagor am 8.11.1983 vor der Nationalversammlung, abgedruckt in: PE, S. 46 und S. 49

70 „Cette mutation technologique a causé un immense désordre et a provoqué notamment un transfer industriel. On a vu les vieilles sociétés capitalistes évacuer leurs lieux de naissance et courir après le profit à tout prix, même à l'autre bout de la terre; c'est un point de vue d'intérêt immédiate et local que je comprends très bien. Du point de vue de l'intérêt de la collectivité nationale, et en fin de compte du système de société lui-même, c'était peut-être une vue courte.", so Präsident Mitterrand am 14.5.1982 in einer Ansprache vor dem ÜBERSEE-CLUB in Hamburg, abgedruckt in: PE, S. 53

${ }^{71}$ ebenda, S. $53 \mathrm{f}$.

${ }^{72} \mathrm{Vgl}$. die Äußerungen Mitterrands auf dem G-7 Gipfel von Versailles am 5.6.1982, abgedruckt in: PE, S. 120 sowie die Rede vom 14.5.1982, S. 54

${ }^{73}$ ebenda 
commerciale fouettée à l'excès, ... Le résultat le plus clair de ce profond désordre est que nos sociétés, celles du Sud plus encore que celles du Nord, s'enfoncent dans les sables mouvants du chômage, du sous-emploi, souvent de la misère. ${ }^{\text {"77 }}$

Wie schon für de Gaulle lief ein ungehemmter wirtschaftlicher Wettbewerb auch für den vierten Präsidenten auf ein „absurdes“ Wirtschaftssystem hinaus, das bei exzessivem Konkurrenzdruck automatisch zur Verschlechterung der Wirtschaftslage und damit zur gesellschaftlichen Misere führen mußte.

Um nicht einer "erratischen" und "steuerlosen" internationalen Wirtschaftsentwicklung hinterherzulaufen, plädierte die französische Regierung dafür, den Wirtschaftsabläufen "Führung" zu geben. Sie sollten nicht allein den Marktkräften überlassen werden, die in Krisenzeiten nur noch dem "Gesetz des Dschungels" folgten und Starke stärker sowie Schwache schwächer machten. ${ }^{75}$ An die europäischen Partner richtete Frankreich deshalb den Appell, in enger Abstimmung der Wirtschaftspolitiken einen gemeinsamen Weg aus der Krise zu suchen. ${ }^{76}$ Für mehr Kooperation plädierte die französische Regierung auch im Rahmen der OECD, wo sie im Mai 1982 einen „New Deal Planétaire“ vorschlug, der zu einem „Keynesianismus auf globaler Ebene“ führen sollte. ${ }^{77}$ Auf G-7-Ebene ging der französische Präsident im Juni 1982 sogar so weit, eine gemeinsame Industriestrategie bei den Zukunftstechnologien zu fordern, um die Menschheit zu einer neuen „Zivilisation“ zu führen und von den Zwängen von „Zeit und Raum" zu befreien. ${ }^{78}$ Grenzenlos schien offenbar die Überzeugung, mittels enger wirtschaftspolitischer Kooperation die Defizite der Marktwirtschaft ausgleichen zu können. Endpunkt dieser Entwicklung war schließlich die im Mai 1983 von Mitterrand geforderte „réconstruction“ der internationalen Wirtschaftsordnung. Mit Blick auf die immer noch problematische Ernährungslage der Entwicklungsländer sollten vor allem die Welt-Lebensmittelmärkte zunächst neu organisiert werden. Ansatzpunkt dazu war der Preismechanismus, den es im Sinne der politisch als notwendig erachteten Reformen als Instrument im Sinne einer größeren Verteilungsgerechtigkeit einzusetzen galt. $^{79}$

${ }^{74}$ Vgl. die Ansprache Mitterrands am 2.6.1982 vor der International Labor Organization in Genf, abgedruckt in: PE, S. 103

${ }^{75}$ Vgl. die Rede Cheyssons vor dem Sénat am 2.6.1983, abgedruckt in: PE, S. 64

${ }^{76}$ ebenda, S. 65

${ }^{77}$ Vgl. die Rede Cheyssons vor dem Ministerrat der OECD am 16.6.1981, abgedruckt in: PE, S. 36

${ }^{78}$ Vgl. den Bericht Mitterrands über Technolgie, Wachstum und Beschäftigung auf dem G 7-Gipfel vom 5.6.1982, abgedruckt in: PE, S. 113

${ }^{79} \mathrm{Vgl}$. die Ansprache Mitterrands am 9.5.1983 auf der Ministerratstagung der OECD, abgedruckt in: PE, S. 24 und S. 25; Eine neue internationale Wirtschafts-, Finanz- und Währungsorganisation forderte auch der 9. Plan (1984-1988). Ferner setzte sich Präsident Mitterrand auf dem XIII. Weltenergiekongress für die Regulierung der internationalen Energiemärkte ein, die seiner Meinung nach allein schon aus Solidarität mit den Entwicklungsländern zu erfolgen hatte und die aus seiner Sicht eine wesentliche Voraussetzung für die „optimale Allokation der Ressourcen“ darstellte, vgl. die Ansprache Mitterrands vom 5.10.1986, abgedruckt in: PE, S. 78 
Mit diesem Reorganisations- und Konzertationsstreben war die sozialistische Regierung wieder beim Mondialismus Valéry Giscard d'Estaings angelangt. Sie entsprach damit auf ökonomischem Gebiet ihrer Vision von Frankreich als Hoffnungsträger und vorbildlicher Nation, die sich weltweit für den „gerechten“ wirtschaftlichen Ausgleich einsetzte. Dieser Ausgleich ließ sich aus französischer Sicht offenbar auf allen Ebenen über wirtschaftspolitische Verhandlungen erreichen, wenn die Regierungen nur wollten. Die wirtschaftspolitische Zusammenarbeit der nationalen Regierungen verkörperte aus französischer Sicht das im Vergleich zur Marktkoordination überlegene Instrument zur Abstimmung wirtschaftlicher Interessen. Nur so war es aus französischer Sicht möglich, neben den ökonomischen Aspekten auch gesellschaftspolitische Gesichtspunkte wie die Verteilungsgerechtigkeit oder den „Fortschritt der Zivilisation“ bei der Ausgestaltung der Wirtschaftsabläufe zu berücksichtigen. In unregulierten Märkten, so die französische Furcht, würden diese Wertvorstellungen zwangsläufig der Anarchie des wirtschaftlichen Wettbewerbs zum Opfer fallen. Deutlich erkennbar wurden damit die Grundzüge eines universellen ordnungspolitischen Missionsstrebens, dem die Organisierbarkeit von Märkten und Wirtschaftsordnungen problemlos möglich schien und für das es über den nationalen und europäischen Rahmen hinaus offensichtlich keine Grenzen gab.

Bemerkenswerterweise hielt die französische Regierung an diesem Missionsstreben auch nach 1983 fest, als sie selbst im nationalen Rahmen zu einer mehr marktwirtschaftlich orientierten Politik überging. So mahnte Außenminister Dumas im Februar 1985 weiter vor der „Brutalität“ des Wirtschaftssystems der USA, das nicht zum Vorbild für Europa tauge. ${ }^{80}$ Gegen eine ausschließlich marktwirtschaftliche Orientierung der Wirtschafts- und Währungsunion wandte sich vier Jahre später, im Februar 1989, auch Premierminister Rocard:

„Mais l'Europe ne peut se construire effectivement sur la base d'une approche doctrinale de l'économie, qui poserait purement, par exemple, sur la théorie du libre-échange et sur l'approche monétariste. On ne peut transposer à l'échelle de l'Europe le modèle d'un seul pays, même s'il s'autorise de performance nationales; C'est pourquoi nos différences doctrinales ne doivent en aucun cas obscurcir la définition de nos objectifs communs, et le choix des meilleures méthodes pour y parvenir ... Aujourd'hui, à l'échelle de l'Europe, une fonction de régulation est indispensable, pour prendre des décisions à long terme, maintenir un minimum de cohérence dans des politiques économiques, libérer l'initiative sans multiplier les distorsions dans la concurrence, assurer le progrès social malgré la course à la compétitivité, soutenir l'innovation technologique." ${ }^{\text {(81 }}$

Dieses offene Plädoyer Rocards für staatliche Eingriffe in die Wirtschaft, von denen er sich mehr Initiative und eine langfristige Kohärenz der Wirtschaftsentwicklung versprach, wie auch seine Ablehnung von Freihandelstheorie und Monetarismus zeigten deutlich, daß sich die interventionistische und - was die Gestaltung der langfristigen Wirtschaftsentwicklung anging - dirigistische Grundhaltung der französischen Regierung über die Jahre nicht verändert hatte. Deutlich wurde diese Kontinuität bereits ein

\footnotetext{
${ }^{80} \mathrm{Vgl}$. die Rede von Außenminister Dumas vom 20.2.1985, abgedruckt in: PE, S. 53 und 54

${ }^{81}$ Vgl. die Rede Rocards in CHATTAM-HOUSE vom 8.2.1989, abgedruckt in: PE, S. 85
} 
Jahr zuvor im Präsidentschaftswahlkampf 1988 als François Mitterrand verkündete, daß staatliche und private Initiative Komplemente seien und er den Vorwurf des Dirigismus letztlich nicht fürchte, weil nur der Staat in der Lage sei, die Wirtschaftsentwicklung langfristig optimal auszurichten. ${ }^{82}$ In einem Interview über die gesellschaftlichen Grundwerte der französischen Revolution betonte er ein Jahr später noch einmal, daß die Nutzung der wirtschaftlichen Freiheit immer nur mit Rücksicht auf das Allgemeininteresse erfolgen könne, damit es nicht zur Herrschaft des „Gesetz des Dschungels" komme. $^{83}$ Die „gesunde Entfaltung“ der Wirtschaftsfreiheit müsse über Schutzvorrichtungen sichergestellt werden, was außerbetrieblich durch die öffentliche Gewalt und innerbetrieblich durch den Dialog und durch Verträge zwischen Unternehmern und Angestellten zu geschehen habe:

„Wie Sie sicher bemerken, macht mich der wirtschaftliche Liberalismus, oder das, was an seiner Stelle steht, mißtrauisch. Er verbirgt zuviel Willkür und Ungerechtigkeit. Er dient der Macht des Stärkeren und zerstört die Bemühungen der Schwächeren. Er trägt zu Unrecht den Namen, den er sich gegeben hat. Der Markt kann nur bis zu einem gewissen Punkt regulierend wirken. Solange er seine regulierenden Fähigkeiten behält, kann nichts seine positiven stimulierenden Eigenschaften ersetzen. Sobald er sie aber verliert, geht in einer Gesellschaft, die demokratisch sein will, nichts mehr. Deshalb ist die Harmonisierung der Kräfte, der Kräfte des Marktes, der Gewalten (und Pflichten) des Staates, so zwingend nötig. Dem habe ich den Namen ,gemischtwirtschaftliche Gesellschaft“ gegeben. Jedenfalls muß man zu einem bestimmten Zeitpunkt den Reichtum neu verteilen, ohne dabei in einen übertriebenen Malthusianismus oder in eine zu starke Wegnahme zu verfallen. Die sozialdemokratischen skandinavischen Länder haben den Schwerpunkt auf die soziale Umverteilung gelegt. In den Ländern mit römischem Recht ist man vor allem für die Aufteilung der wirtschaftlichen Macht. ${ }^{\text {(84 }}$

Diese eher archaische Sichtweise des Marktes als Arena zur Austragung von Machtkonflikten offenbarte erneut, wie eng wirtschaftliches Handeln und die Ausübung von Macht in der Vorstellungswelt französischer Politiker verbunden waren. Nur über Eingriffe des Staates war es möglich, die Ausübung wirtschaftlicher Macht im Einklang mit dem Allgemeininteresse sicherzustellen; nur über staatliche Interventionen konnte die Kurzsichtigkeit der Märkte überwunden werden und nur die Voraussicht des Staates vermochte, die langfristige Wirtschaftsentwicklung auf das Allgemeininteresse auszurichten. Aus diesen Unzulänglichkeiten der Marktkoordination heraus schloß der französische Staatspräsident auf die Notwendigkeit eines "libéralisme politique intégral", in dem die positiven Seiten des Marktmechanismus und der staatlichen Intervention vereinigt werden sollten:

„le libéralisme est à bout de souffle, parce que le capitalisme, tel qu'il est, s'il se laisse vivre, sa loi, c'est celle de la jungle... il va créer beaucoup d'autres inégalités, ... Je pense qu'il est urgent, au con-

\footnotetext{
${ }^{82} \mathrm{Vgl}$. Mitterrand, F., „Croissance et emploi dépendent de l'avancée de la construction européenne“ Darstellung seiner wirtschaftspolitischen Positionen im Präsidentschaftswahlkampf 1988, Le Monde vom 20.4.1988, S. 13

${ }^{83} \mathrm{Vgl}$. Interview mit Staatspräsident François Mitterrand vom 14.7.1989 in „L'Express“, abgedruckt in: Frankreich-Info, Nr. 15/89 vom 18.7.1989

${ }^{84}$ ebenda
} 
traire, de corriger les effets du libéralisme économique, je suis pour un libéralisme politique intégral et c'est, je crois, ce qui doit être fait sur le plan de l'économie mixte. ${ }^{485}$

Den ökonomischen Liberalismus und damit den Markt mit dem „Gesetz des Dschungels" gleichzusetzen, hieß letztlich, die Abstimmung wirtschaftlicher Interessen im Wettbewerb als vorzivilisatorischen Zustand zu qualifizieren. Die wirtschaftspolitisch abgestimmte Intervention verkörperte aus Sicht der französischen Regierung offenbar eine höhere Form wirtschaftlicher Vernunft, der sie als selbsternannte Botschafterin der Zivilisation von Natur aus eher zugeneigt sein mußte. Bis in den Sprachgebrauch der französischen Politik hinein hatte sich die grundlegende Überzeugung von der Überlegenheit einer interventionistischen Wirtschaftspolitik fortgepflanzt. Die grundlegende Präferenz für einen moderaten Interventionismus gab der französischen Binnenmarktpolitik von vornherein einen klar definierten ordnungspolitischen Rahmen vor. Es wird zu prüfen sein, inwieweit sich diese Vorgabe in den einzelnen wirtschaftspolitischen Initiativen der französischen Regierung konkret wiederfand.

\section{B.5.2.2 Die Industriepolitik \\ B.5.2.2.1 Erste Anläufe}

Im Mittelpunkt der von Frankreich gewünschten engeren wirtschaftspolitischen Kooperation stand die Stärkung der industriellen Wettbewerbsfähigkeit Europas. Von besonderer Bedeutung aus französischer Sicht war das Aufholen des technologischen Rückstands auf dem Gebiet der Elektronik und der Informationstechnologie. Schon in seiner Regierungserklärung wies Premierminister Mauroy darauf hin, daß Europa sich auf die Entwicklung strategisch wichtiger Industrien zu konzentrieren hätte, wollte es der internationalen Konkurrenz zukünftig gewachsen sein. ${ }^{86}$ Auf der ersten Tagung des Europäischen Rates nach seiner Wahl zum Staatspräsidenten mahnte François Mitterrand an, daß bestimmten, zukünftig entscheidenden Industriesektoren eine „europäische Dimension“ gegeben werden müsse. ${ }^{87}$ In ihrem Memorandum zur „relance européenne" forderte die französische Regierung vier Monate später, der europäischen Industrie durch systematische Ausnutzung der Dimension des Gemeinsamen Marktes und durch die gezielte Förderung wettbewerbsfähiger Investitionen neue Impulse zu geben. ${ }^{88}$ Über erweiterte Finanzierungshilfen sollten Investitionen in den Bereichen gefördert werden, ,in denen die Gemeinschaft die Richtung der gewünschten Entwicklung festlegen wird". Als Beispiele wurden Investitionen für Energieeinsparungen und in Branchen mit tiefgreifendem Strukturwandel sowie für Forschung und Technologie allgemein genannt. Darüber hinaus sollten eine „echte Handelspolitik“ sowie eine gemeinschaftliche Außenwirtschaftspolitik die Wirksamkeit der neuen Industrie-

${ }^{85}$ So Mitterrand in einem Fernsehinterview, abgedruckt in Auszügen in: Le Monde vom 27.3.1990, S. 4

${ }^{86}$ Vgl. Regierungserklärung von Premierminister Mauroy (1981), a.a.O., D 496

${ }^{87}$ Vgl. Lemaitre, P.; Delarue, M., „Les thèses de M. Mitterrand sur $l^{\prime}<<$ espace social européen>> suscitent les réserves de Mme Thatcher et de M. Schmidt, Le Monde vom 1.7.1981, S. 1

${ }^{88} \mathrm{Vgl}$. Memorandum vom 8.10.1981, a.a.O., D 44 
politik erhöhen. Beide sollten sich aller verfügbaren Instrumente bedienen können, um den Handel der Gemeinschaft sowie die Direktinvestitionen in der Gemeinschaft auf die neue Strategie abzustimmen. Klar zeigten sich damit schon Ende 1981 die Umrisse einer Industriepolitik, die im wesentlichen auf die finanzielle Förderung ausgesuchter Schlüsselsektoren abstellte und direkte Interventionen in Wirtschaftsabläufe nicht scheute.

Eine erste vollständige Ausformulierung erhielt die industriepolitische Konzeption der französischen Regierung im Juni 1982 auf dem G-7 Gipfel in Versailles, wo Staatspräsident Mitterrand seinen „Bericht zur Technologie, Beschäftigung und Wachstum“ vorstellte. ${ }^{89}$ In diesem pries er die Beherrschung des wissenschaftlichen und technologischen Fortschritts als das beste Mittel zur Lösung bestehender Probleme der „Menschheit“ wie Hungersnöte, Energieknappheit und Arbeitslosigkeit. Den Chancen der Forschung in Bereichen wie der Biotechnologie, der Informationstechnologie oder der Weltraumforschung standen nach Meinung des französischen Präsidenten allerdings auch große Gefahren gegenüber, da dieses Wissen seinen Besitzern nicht nur wirtschaftliche Macht, sondern auch Einfluß auf das Denken der Menschen und die Gestaltung ihrer unmittelbaren Lebensgrundlagen geben würde. ${ }^{90} \mathrm{Da}$ weiteres Abwarten und Zögern diese Risiken nur erhöhten, forderte er die führenden Industriestaaten auf, gemeinsam die Lenkung des technologischen Fortschritts in die Hand zu nehmen.

Um die technologische Zusammenarbeit zum Erfolg zu führen, mußten nach Ansicht Mitterrands mehrere Voraussetzungen erfüllt sein. So waren als erstes gemeinsame Anstrengungen zur Beseitigung der Arbeitslosigkeit notwendig, deren Existenz kein förderliches Klima für den wirtschaftlichen Fortschritt erzeugen würde. Der angestrebte "dynamisme industriel“ in der Hochtechnologie setzte außerdem die Abkehr von fortschrittsfeindlichen „Austeritätspolitiken“ voraus, die mit ihrer Fixierung auf Einsparungen langfristige Investitionen verhindern würden. Vielmehr sollte gezielt Kapital für Investitionen in Industrie und Forschung bereitgestellt werden, wobei öffentlichen Investitionen, wie z. B. dem Aufbau von Kommunikationsnetzen, ein besonderer Stellenwert zuzuweisen war, da sie aufgrund ihres Umfangs in der Regel für Anschlußinvestitionen sorgen würden, somit also eine Lokomotionsfunktion (rôle moteur) für das Wachstum insgesamt hätten. Darüber hinaus forderte der französische Präsident in Sektoren, die von wenigen oder gar nur einem Großkonzern beherrscht würden, für mehr Konkurrenz zu sorgen. Über eine Restrukturierung des gesamten Produktionssystems und durch die gezielte Förderung kleiner und mittlerer Unternehmen sollte vor allem die Streuung technologischen Wissens bewirkt werden. Dies würde, so Mitterrand, der Gefahr einer „Uniformisierung“ der menschlichen Zivilisation vorbeugen. Diese Gefahr bedrohte seiner Meinung nach aufgrund der zunehmenden Interdependenz der Volkswirtschaften im Zeitalter der Informationstechnologie alle Gesellschaften in ihren Grundfesten: „Plus généralement, la diffusion d'informations élaborées et contrôlées par quelques pays dominant pourrait faire perdre leur mémoire

\footnotetext{
${ }^{89}$ Vgl. den Bericht Mitterrands auf dem G 7 Gipfel vom 5.6..1982, a.a.O., S. $110 \mathrm{ff}$.

${ }^{90}$ Vgl. den Vortrag Mitterrands vom 5.6.1982, a.a.O., S. 111
} 
ou leur souveraineté aux autres, remettant ainsi en cause les libertés de penser et de décider" ${ }^{\star 91}$.

Um solchen Entwicklungen wirksam vorzubeugen, regte der französische Staatspräsident an, gemeinsam über den Aufbau einer neuen Gesellschaft nachzudenken (construire une nouvelle civilisation!). Zu diesem Zweck schlug er ein Programm zur „konzertierten Entwicklung der Weltwirtschaft“ vor. Zur Stimulierung des Wachstums durch neue Technologien sollten die G-7 Staaten feste Quoten ihres Bruttosozialprodukts in Forschung und Entwicklung investieren. Mit diesen Mitteln sollten gemeinsame Forschungsvorhaben öffentlicher und privater Unternehmen sowie der Staaten selbst im Bereich Hochtechnolgieforschung verwirklicht werden. Innovative Unternehmen sollten in allen nützlichen Formen gefördert und ein Weltmarkt für Technologie durch die Errichtung eines weltweit gültigen Normen- und Patentschutzsystems geschaffen werden. Weitere Vorschläge betrafen gemeinsame Aktionen zur Förderung der Aus- und Weiterbildung der Arbeitnehmer sowie zur Bewahrung der nationalen Kulturen, die zum einen über die Einbeziehung von Informationstechnologie und Fremdsprachen in die schulische Ausbildung und zum anderen über die Verabschiedung einer „,charte de la communication mondial“ erreicht werden sollte.

Dieses Programm zeigte, daß die Industriepolitik für die französische Regierung mit weitaus mehr als rein wirtschaftlichen Aspekten verbunden war. Die Ambivalenz des technologischen Fortschritts, der seinen Beherrschern zwar die Fähigkeit verlieh, die Probleme der Menschheit zu lösen, ihnen gleichzeitig aber auch Macht über die Souveränität anderer Nationen und deren geistigen Wurzeln gab, mußte die Hüterin des Allgemeininteresses, als die sich die französische Regierung verstand, alarmieren. Aufgrund der gegebenen Risiken durfte die technologische Entwicklung nicht sich selbst bzw. gar dem anonymen Marktmechanismus überlassen werden. Die Lösung dieses Problems wie überhaupt des Wachstumsproblems allgemein lag nach französischem Dafürhalten in einer voluntaristischen Industriepolitik, bei der die wirtschaftspolitischen Autoritäten die Steuerung der technologischen Entwicklung übernehmen und über gezielte Interventionen in ausgewählten Schlüsselbereichen optimal an die gesellschaftlichen Bedürfnisse anpassen sollten. Industriepolitik nach französischem $\mathrm{Zu}$ schnitt war somit mehr in gesellschaftspolitischen als in wirtschaftlichen Motiven verwurzelt. Sie war allerdings nur im Rahmen einer umfassenden wirtschaftspolitischen Kooperation und Koordination zu realisieren und dementsprechend von einem durchgreifenden Interventionismus geprägt. Dessen Notwendigkeit resultierte für den französischen Staatspräsidenten aus der Natur des technischen Fortschritts: „le progrès technique n'assure pas, par lui-même, le progrès économique et le progrès social. Il ne peut qu'y concourir, dans les sociétés qui sauront le mettre au service d'une volonté politique $" 92$.

\footnotetext{
${ }^{91}$ Vgl. den Vortrag Mitterrands vom 5.6.1982, a.a.O., S. 113

92 ebenda, S. 115
} 
In diesem Sinne verstärkte die französische Regierung im Verlauf des Jahres 1983 den Druck auf die europäischen Partner, eine gemeinsame Forschungs- und Industriepolitik zu definieren. So mahnte Premierminister Mauroy anläßlich des 25-jährigen Bestehens der Gemeinschaft, Interventionen zugunsten des Hochtechnologiesektors und hilfsbedürftiger Industrien nicht weiter unnötig zu blockieren, da dies letzten Endes Europa nur schaden würde. Zuvor hatte Staatspräsident Mitterrand in einer Rede vor französischen Industriellen noch einmal klargestellt, daß Macht und Unabhängigkeit der französischen Nation in direkter Abhängigkeit von ihrer industriellen Wettbewerbsfähigkeit stünden. Deren Stärkung sei jedoch nur noch im Rahmen von Allianzen sicherzustellen, unter denen wiederum „eine europäische Lösung“ vorzuziehen wäre:

„Il me semble naturel, c'est le sens même de la Communauté Européenne, que des alliances soient recherchées, entre firmes européennes. L'Europe c'est aussi et peut-être même surtout à l'heure actuelle celle des projets industriels communs. Et cette Europe doit utiliser pleinement ses ressources d'emprunt par exemple, pour aider les investissements proposés conjointement par deux ou plusieurs entreprises européennes, plutôt que de voir les firmes américaines par des alliances subreptices s'emparer des marchés d'une façon irréversible. ${ }^{c 93}$

Deutlich zeigte sich an dieser Stelle erneut, daß neben gesellschaftspolitischen Aspekten auch geostrategische Motive eine zentrale Rolle in der industriepolitischen Konzeption Frankreichs spielten. Motiviert aus dem Bestreben nach wirtschaftlicher Unabhängigkeit zielte die französische Regierung auf eine Vertiefung der industriellen $\mathrm{Zu}$ sammenarbeit in Europa ab, um den Rückstand gegenüber führenden Ländern wie den USA und Japan aufzuholen. Diese pragmatische Überlegung schloß dabei durchaus die technologische Zusammenarbeit mit ihnen ein, allerdings nur dort, wo sie nicht zur Schwächung Europas führte. In diesem Sinne appellierte Staatspräsident Mitterrand im Mai 1983 auch vor dem OECD-Ministerrat, die technologische Zusammenarbeit zu vertiefen, wobei im Rahmen der internationalen Arbeitsteilung jedoch eine „exzessive“ Konkurrenz zu vermeiden war. ${ }^{94}$ Fast zeitgleich wies Europaminister Chandernagor darauf hin, daß die Gemeinschaft sich durch eine gemeinsame Forschungs- und Investitionspolitik schützen müsse, um nicht mittelfristig zum „Untervertragsnehmer“ der USA und Japans abzusteigen. ${ }^{95}$ Die industriepolitische Konzeption Frankreichs war somit im Kern eine machtpolitisch inspirierte Strategie, die sich zur Sicherstellung der technologischen Unabhängigkeit Europas wechselnder Allianzen bediente: Innerhalb Europas sollte die technologische Zusammenarbeit zur schnellstmöglichen Steigerung der industriellen Wettbewerbsfähigkeit führen und außergemeinschaftlich die Wettbewerbsintensität herabsetzen, um der europäischen Industrie für ihre Aufholjagd die nötige Zeit zu verschaffen.

Ein vollständiges Konzept für eine europäische Industriepolitik legte die französische Regierung im September 1983 mit ihrem Memorandum für einen europäischen Indu-

\footnotetext{
${ }^{93}$ Ansprache Mitterrands anläßlich der, journées de travail“" sur la politique industrielle de la France am 16.11.1982 im Maison de la Chimie

${ }^{94} \mathrm{Vgl}$. die Rede Mitterrands vom 9.5.1983, a.a.O., S. 24

${ }^{95}$ Vgl. die Rede Chandernagors vor dem französischen Senat vom 27.5.1983, a.a.O., S. 50
} 
strie- und Forschungsraum vor. Schon im Vorfeld seiner Überreichung wurden wesentliche Forderungen zu diesem Thema von französischen Politikern gestellt. So forderte Europaminister Chandernagor im Mai 1983, daß Subventionen und direkte Beteiligungen der Gemeinschaft an Projekten und Unternehmen wesentlicher Bestandteil einer europäischen Industriestrategie sein müßten. ${ }^{96}$ Verlautbarungen Außenminister Cheyssons aus dem Juni 1983 zufolge sollten sich die Anstrengungen der Gemeinschaft vor allem auf langfristige Projekte mit hoher Amortisationsdauer konzentrieren. Die Hauptaufgabe der Gemeinschaft hatte darin zu bestehen, Investitionen anzuregen, zu schützen und sie gegen auswärtige Einflüsse zu verteidigen. ${ }^{97}$ Wirtschafts- und Finanzminister Delors hingegen forderte im Juli 1983 die Schaffung eines "véritable humus favorable à la relance industrielle et technologique de l'Europe" und damit letztlich ein Gesamtkonzept, das alle notwendigen Wachstumsbedingungen sicherstellen sollte. ${ }^{98}$ Insgesamt zeugten diese Forderungen von der großen Entschlossenheit der französischen Regierung, zur Förderung von Technologie und Industrie alle denkbaren Register zu ziehen.

Ziel einer europäischen Forschungs- und Technologiepolitik war gemäß dem französischen Memorandum, die technologische Abhängigkeit im Bereich der Zukunftstechnologien zu verhindern. ${ }^{99}$ Grundsätzlich, so das Memorandum weiter, müßte dazu erst einmal die Zersplitterung der europäischen Forschung im Bereich der Technologie überwunden werden. Diese hätte dazu geführt, daß trotz beachtlicher wissenschaftlicher Kapazität und hoher Forschungsausgaben die "wichtigen Entdeckungen" außerhalb Europas gemacht würden: „Wenn Europa irgendeinen Sinn“ hätte, so das Memorandum weiter, dann bestünde „dieser darin, den Mitgliedsländern die Verwirklichung dessen zu ermöglichen, was sie auf sich allein gestellt nicht erreichen können“. Aus diesem Grund sollten sie einen europäischen Forschungs- und Industrieraum gründen und schrittweise ihre wissenschaftliche und industrielle Zusammenarbeit vertiefen. Zwischen Mitgliedstaaten und Unternehmen war eine Arbeitsteilung vorgesehen, bei der die Unternehmen die Initiative und Verantwortung für konkrete Projekte übernehmen sollten, während die Gemeinschaft für die Effizienz der Zusammenarbeit zu sorgen hatte, indem sie ein „günstiges Klima“ und die notwendigen Rahmenbedingungen sicherstellte.

Die französische Regierung schlug folgende konkrete Aktionen vor:

- die Erhöhung der finanziellen Dotierung von Forschungsprogrammen sowie die gemeinschaftliche Nutzung öffentlicher und privater Großforschungsanlagen;

96 ebenda

${ }^{97}$ Vgl. die Rede Cheyssons vor dem Senat vom 2.6.1983, a.a.O., S. 65

${ }^{98}$ So Delors in einem gemeinsam mit Außenminister Cheysson durchgeführten Pressegespräch im Juli 1983, abgedruckt in: PE, S. 24

99 Memorandum der französischen Regierung an den Rat der Europäischen Gemeinschaften vom 12.9.1983, S. 695 ff., abgedruckt in: EA, Folge 24/1983 
- die Festlegung europäischer Normen sowie die Öffnung des Zugangs zu öffentlichen Aufträgen, um größere Serienfertigungen zu niedrigeren Gestehungskosten zu ermöglichen; ,selbstverständlich unter der Voraussetzung, daß diese Öffnung den gemeinschaftlichen Unternehmen vorbehalten blieb" ${ }^{\prime 100}$;

- den Einsatz einer gemeinsamen Handelspolitik zur Entwicklung der europäischen Industrie. Zwar wurde die Öffnung der Märkte wegen ihrer belebenden Wirkung auf den Wettbewerb grundsätzlich positiv bewertet: „Dies bedeutet aber nicht, daß der europäische Industrieraum völlig, ohne jegliche Beschränkung, in einem weltweiten Industrieraum aufgehen muß“. Mittels eines differenzierten außenwirtschaftlichen Instrumentariums sollten die Produktion und der Absatz europäischer Industrieerzeugnisse gefördert werden;

- die Förderung des Zusammenschlusses und der Zusammenarbeit europäischer Firmen. Ein „Klima gesunden Wettbewerbs“ sollte geschaffen werden, in dem die Zusammenarbeit europäischer Firmen bei Forschung, Produktion und Absatz gedeihen konnte. Dazu war die Entstehung von Großunternehmen und Konzernen mit europäischer Dimension zu fördern, und zwar bis hin zu einer Größe, die ihnen erlaubte, neue Produkte weltweit zu plazieren und die nötigen Forschungsaufwendungen selbst zu tragen. Nur bei entsprechender Größe sei zu verhindern, daß europäische Unternehmen „auf das Niveau von Unterlieferanten“ herabsänken. In diesem Sinne sollte das europäische Wettbewerbsrecht so verändert werden, daß Fusionen zukünftig im europäischen statt im nationalen Kontext zu beurteilen wären. Um Fusionen billiger zu machen, sollten außerdem europäische Rechtsformen entworfen werden. Zusätzlich wurde angeregt, Gemeinschaftshilfen und öffentliche Aufträge bevorzugt an frisch fusionierte europäische Unternehmen zu vergeben;

- die Ausweitung der Interventionsmöglichkeiten der Gemeinschaft durch Erweiterung und effektivere Gestaltung bisheriger Finanzierungssysteme, die gezielter als bisher auf klar bestimmte Prioritäten ausgerichtet werden sollten. Neue Formeln wie Zinsvergünstigungen, Darlehnsbürgschaften, steuerliche Anreize, Hilfen zur Stärkung der Eigenkapitalbasis oder gar die direkte Beteiligung der Gemeinschaft an Unternehmen sollten geprüft werden. Gleiches galt für den Aufbau von Spezialorganisationen für Förderungsmaßnahmen, an denen sich nicht alle Staaten beteiligen wollten, und die Bereitstellung von Risikokapital zur Gründung neuer Industrien und Unternehmen. Außerdem sollte es einen engeren Informationsaustausch zwischen der Gemeinschaft und den Mitgliedstaaten über die jeweiligen Förderprogramme für industrielle Neugründungen geben, um die bereitgestellten Mittel effizienter einzusetzen;

- die Einleitung europäischer Infrastrukturvorhaben wie z. B. der Bau eines Tunnels unter dem Ärmelkanal, eines Hochgeschwindigkeitszugs sowie von Daten- und Energienetzen, um den europäischen Industrieraum mit einer leistungsfähigen Infrastruktur zu versehen.

${ }^{100}$ Memorandum der französischen Regierung an den Rat der Europäischen Gemeinschaften vom 12.9.1983, S. 698, abgedruckt in: EA, Folge 24/1983 
Abschließend stellte das Memorandum fest, daß die Umsetzung dieses Programmes nur erfolgreich sein könne, wenn es zu einer konzertierten Steigerung der produktiven Investitionen käme; ebenso wurde noch einmal auf die Notwendigkeit eines "Sozialen Europas" hingewiesen, um die Bereitschaft der Arbeitnehmer zur Kooperation zu stärken, sowie generell auf das Erfordernis von Pragmatismus, Anpassungsfähigkeit und raschen Eingriffen, um übertriebenem Bürokratismus und Dirigismus bei der Umsetzung konkreter Projekte wirksam vorzubeugen.

Dirigistisch allerdings war dieses Programm offenbar selbst. Klar erkennbar war das Ziel, den technologischen Fortschritt unter politische Kontrolle zu bringen, um ihn besser lenken zu können. Vornehmlich aus Unabhängigkeits- und Machterwägungen wurde eine Strategie definiert, die alle relevanten Entscheidungsträger auf der Ebene der Unternehmen, der Mitgliedstaaten und der Gemeinschaft in einen großen Konzertierungsprozeß zur Steigerung der industriellen Wettbewerbsfähigkeit einbinden sollte. Dabei manifestierte sich in Maßnahmen wie der Beteiligung des Staates am wirtschaftlichen Risiko bestimmter Investitionsvorhaben oder in gezielten Maßnahmen zur Förderung von Großunternehmen ein weitreichender Interventionismus, während die Konzentration der Förderungsmittel auf einzelne, politisch bestimmte Bereiche den dirigistischen Charakter der Strategie betonte. Mit diesen Maßnahmen erinnerte der industriepolitische Ansatz der französischen Regierung stark an die planifikatorischen Lenkungsvorstellungen, die Frankreich schon in den Verhandlungen zu den Römischen Verträgen auf die Gemeinschaft übertragen wollte. Die volle Realisierung dieser Strategie hätte den industriellen Wettbewerb in Europa auf eine staatlich administrierte Veranstaltung reduziert, in der grundsätzlich kein Bereich vor staatlichen Eingriffen geschützt gewesen wäre. Die abschließende Forderung nach Pragmatismus bei der Umsetzung des Programms deutete an, daß ein solcher, durch ökonomische Prinzipienlosigkeit gekennzeichneter Zustand den Absichten der französischen Regierung durchaus nicht widersprach, sondern im Gegenteil offenbar gewollt war.

Der Erfolg blieb dieser industriepolitischen Initiative zunächst versagt. Zwar wurde 1982 das „Neue Gemeinschaftsinstrument“ (NGI), eine Fazilität zur Förderung von Investitionsvorhaben, erneuert und 1983 von einer auf drei Milliarden ECU aufgestockt. Auch sprach die „Erklärung von Stuttgart" von einer gemeinsamen Industriestrategie als Ziel der Europäischen Union, doch kam es dabei nicht zu einer wirtschaftspolitischen Zusammenarbeit wie sie von der französischen Regierung gewünscht wurde. Rückendeckung erfuhr sie mit ihrem Anliegen erst ab 1985 mit der Ernennung des französischen Wirtschafts- und Finanzministers Jacques Delors zum Präsidenten der EG-Kommission. Nach nur drei Monaten unter seiner Führung legte die Kommission im März 1985 dem Europäischen Rat ein Programm zur Stärkung der technologischen Zusammenarbeit in der Gemeinschaft vor. Von Inhalt und Aufbau her wies es sehr große Ähnlichkeit mit der französischen Initiative aus dem Jahr 1983 auf. Wie diese war es auf die Wahrung der technologischen Unabhängigkeit Europas aus- 
gerichtet. ${ }^{101}$ Weitere drei Monate später folgte ein zweites Memorandum zur Gründung einer Technologiegemeinschaft, in dem die Kommission ihre Vorstellungen nochmals präzisierte. $^{102}$

Mit Delors an der Spitze der Kommission fanden die industriepolitischen Anliegen der französischen Regierung endlich einen engagierten Verfechter, der sich von einer vorteilhaften Position aus um ihre Realisierung kümmerte. In den Regierungsverhandlungen zur Einheitlichen Europäischen Akte gelang es schließlich, die Industriepolitik als Gemeinschaftsaufgabe in den europäischen Vertragsgrundlagen festzuschreiben. $\mathrm{Ab}$ 1987 konnte die französische Regierung ihr Ziel im Bereich der europäischen Industriepolitik somit im wesentlichen als erfüllt betrachten. Der volle Durchbruch gelang 1992 schließlich mit der Aufnahme des Artikels 130 (Industriepolitik) in den neuen EWG-Vertrag, der auf einen nahezu unveränderten französischen Formulierungsvorschlag zurückging. ${ }^{103}$ Damit war die Förderung der europäischen Wettbewerbsfähigkeit zu einer Gemeinschaftsaufgabe mit Verfassungsrang geworden, was verschmerzen helfen mochte, daß es der französischen Regierung in den Verhandlungen nicht gelang, die Industriepolitik unter die Entscheidungsbereiche mit mehrheitlicher Beschlußfindung fallen zu lassen. Wirtschaftlich liberal gesinnten Regierungen blieb so weiterhin ein Vetorecht eingeräumt. ${ }^{104}$

Die Industriepolitik stellte auch nach elf Jahren für die französische Regierung einen Bereich der Wirtschaftspolitik mit unverändert hoher Bedeutung dar. Dies ließ sich in den Regierungsverhandlungen zu den Maastrichter Verträgen erkennen, in denen die Europaministerin Guigou unmißverständlich darauf hinwies, daß die Industriepolitik grundsätzlich immer den Kern der nationalen Souveränität berühre. Dennoch war aus ihrer Sicht darüber hinaus auch eine gemeinsame industrielle Strategie für Europa unabdingbar:

„Wichtig ist, daß wir, so wie es in Japan gemacht wird, zwischen den Behörden - auf nationaler oder EG-Ebene - eine Definition der mittelfristigen Prioritäten erreichen. Das kann der Markt nicht leisten, und in den Zukunftsbereichen ... müssen wir gemeinsam genau die Bereiche definieren, in denen wir daran Interesse haben, eine industrielle Strategie für mehrere Jahre zu entwickeln. "105

${ }^{101}$ Mitteilung der Kommission der EG an den Europäischen Rat in Brüssel über die Stärkung der technologischen Grundlagen und der Wettbewerbsfähigkeit der Gemeinschaftsindustrie vom 19.3.1985, D 239, abgedruckt in: EA, Folge 9/1985, D 236 - D 240

${ }^{102}$ Memorandum der Kommission der EG für eine Technologiegemeinschaft vom 25.6.1985 an den Europäischen Rat in Mailand vom 28. und 29.6.1985, D 456, abgedruckt in Auszügen in: EA, Folge $16 / 1985$, D 453 - D 456

103 Vgl. Möschel, W. (1992), EG-Industriepolitik nach Maastricht, in: Ordo, S. 417, insbesondere Fußnote 6, Band 43, S. 415 ff.,

${ }^{104}$ Vgl. de la Serre, F.; Lequesne, C. (1992), Frankreich, in: Jahrbuch der europäischen Integration, S. 331

${ }^{105} \mathrm{Vgl}$. Elisabeth Guigou, beigeordnete Ministerin für Europäische Angelegenheiten am 23.6.1991 in einem Interview mit Le Monde, abgedruckt in Auszügen in: „Frankreich-Info“ (französische Botschaft in Bonn) vom 27.6.1991, Nr. 91-18 
$\mathrm{Da} ß$ das von Frankreich gewünschte pragmatische Nebeneinander von nationalen Interessen und europäischer Industriestrategie nicht immer zu optimalen Lösungen führen mußte, zeigte sich kurze Zeit später. Empfindlich reagierte die französische Regierung als die Kommission im Oktober 1991 aus wettbewerbsrechtlichen Erwägungen die Fusion des französisch-italienischen Flugzeugherstellers ATR mit dem kanadischen Unternehmen de Havilland untersagte, da das neue Unternehmen in seinem Produktmarkt einen Marktanteil von weit über fünfzig Prozent gehabt hätte. ${ }^{106}$ Außenminister Dumas kritisierte diese Maßnahme mit der Bemerkung, daß seines Wissens die europäische Gesetzgebung die eigenen Industrien zu fördern hätte, statt sie zu behindern. Er verhehlte Kommissionspräsident Delors gegenüber nicht seine Mißbilligung dieser Entscheidung. ${ }^{107}$ Der kurz zuvor zurückgetretene Premierminister Rocard sprach sogar von einem „Verbrechen“ gegen Europa, ,car il y a, au nom d'un dogme appliqué sans pertinence, un refus de consentir à l'Europe le droit de construire la puissance sans laquelle elle ne saurait être messagère de paix..." ${ }^{108}$.

In diesen Äußerungen zeigte sich erneut, daß die eigentlichen Ursprünge der industriepolitischen Strategie Frankreichs im Streben nach wirtschaftlicher Macht und Unabhängigkeit lagen. Beide Ziele waren wiederum auf konkrete gesellschaftspolitische und geostrategische Erwägungen zurückzuführen. Wenn sich diese Überlegungen auch nicht direkt im Artikel 130 EG-Vertrag wiederfinden, so ist in ihnen doch der Ursprung für den ordnungspolitischen Widerspruch zu finden, der seit der Aufnahme der Industriepolitik in den europäischen Vertragsgrundlagen besteht. ${ }^{109}$ Legte Artikel drei des EG-Vertrags den Binnenmarkt bislang auf eine offene Marktwirtschaft mit freiem Wettbewerb fest, so war es der französischen Regierung mit der Aufnahme der Industriepolitik gelungen, einen interventionistischen Keil in die Vertragsgrundlagen zu treiben. Damit war im Prinzip der ordnungspolitische Richtungswechsel auf europäischer Ebene erreicht, für den Frankreich seit Gründung der Gemeinschaft ununterbrochen gekämpft hatte.

\section{B.5.2.2.2 Eureka}

Eine zweite französische Initiative auf dem Gebiet der europäischen Forschungspolitik hatte ihren Ursprung in der amerikanischen „strategic defense initiative“ (SDI), einem Weltraumforschungsprogramm zur Bekämpfung von Raketenangriffen. Frankreich lehnte die Mitarbeit an SDI mit der Begründung ab, daß die Rolle der Europäer in die-

${ }^{106}$ Dumez, H., Jeunemaître, A., (1992), La France, l'Europe et la concurrence. Enseignements de l'affaire ATR/De Havilland, S. 116, in: Commentaire, Printemps, Vol. 15 / Nr. 57, S. 109 - 116

${ }^{107} \mathrm{Vgl}$. Chartier, C., „Paris demande à la CEE de revoir sa position sur l'interdiction du rachat de De Havilland", Le Monde vom 8.10.1991, S. 21

${ }^{108}$ So Rocard in einem Artikel im „Nouvel Observateur“, Ausgabe 10-16.10.1991, abgedruckt in Auszügen in: Le Monde vom 11.10.1991, S. 26

${ }^{109}$ Vgl. Feldman, H., (1993), Der merkantilistische Charakter der EG-Industriepolitik, S. 2, Diskussionsbeitrag Nr. 26, Wirtschaftswissenschaftliche Fakultät der Eberhard-Karls-Universität Tübingen, Mai 1993 sowie Möschel, (1992), a.a.O., S. 416 f. 
sem Projekt nur unklar definiert und eine Beteiligung Europas als Subunternehmer undenkbar sei. ${ }^{110}$ Im Gegenzug regte der französische Staatspräsident im Februar 1984 an, eine europäische Weltraumgemeinschaft zu gründen, die eine eigene Weltraumstation für militärische und zivile Zwecke bauen sollte. Eine europäische Zusammenarbeit auf diesem Gebiet erachtete er zum einen als notwendig, weil Europa sich um seine eigene Sicherheit kümmern müsse, und zum anderen, weil in der Weltraumforschung der Blick über Atomwaffen hinaus erhoben werden müsse, um nicht ins technologische Hintertreffen zu geraten. ${ }^{111}$ Die offizielle Einladung Frankreichs zur Teilnahme an diesem Projekt - Mitterrand zufolge „un outil déterminant de puissance aux XXème siècle“ - erging nur zwei Monate später. Das Echo der Partnerstaaten fiel jedoch zurückhaltend aus, da viele unter ihnen geneigt waren, sich an SDI zu beteiligen. Die französische Regierung ging deshalb ein Jahr später in die Offensive, indem sie alle Staaten Europas einlud, sich an der Gründung einer Agentur zur Koordinierung der Forschung mit Namen Eureka (European Research Coodination Agency) zu beteiligen.

Hauptmerkmal des Eureka-Projekts war seine „variable Geometrie“. Eureka sollte der Logik von Projekten folgen und als Forum dienen, in dem Länder Forschungsvorhaben vorstellten, um interessierte Partner für ihre Realisierung zu finden. Repräsentanten von industrieller, wissenschaftlicher wie auch politischer Seite sollten zusammenfinden können und tatkräftige "Netzwerke" bilden, um Forschungsprojekten erfolgreich gegen bestehende Widerstände in nationalen Administrationen und Industriezentralen zur Realisierung zu verhelfen. ${ }^{112}$ Neu an Eureka war, daß Technologieprojekte jetzt direkt auf die politische Ebene gehoben werden konnten: "Jeder Staat wird, sofern es ihn betrifft, auf das Engagement seiner Staatsangehörigen eingehen und dies unterstützen nach Maßgabe dessen, was ihm nützlich erscheint"113. Die Unternehmen sollten ihren Regierungen Projekte vorschlagen, die diese auf europäischer Ebene lancierten, in der Hoffnung, weitere Mitgliedstaaten und europäische Unternehmen für die Durchführung zu gewinnen. In bezug auf die finanzielle Förderung von gemeinschaftlich ausgewählten Forschungsvorhaben, schlug die französische Regierung vor, diese vor allem risikoreichen und langfristigen Projekten vorzubehalten und eine paritätische Kostendeckung aus privaten und öffentlichen Mitteln anzustreben.

Das Verhältnis von Eureka und Europäischer Gemeinschaft stellte sich die französische Regierung als ein komplementäres vor. Die Gemeinschaft sollte Rahmenbedingungen bereitstellen wie die Festlegung technischer Normen, Öffnung des öffentlichen Beschaffungswesens für ausländische Anbieter sowie die Beseitigung von Hindernissen für den Warenverkehr, während Eureka-Projekte im Rahmen von Gemeinschafts-

${ }^{110}$ Vgl. die Äußerungen Mitterrands nach dem G-7 Gipfel am 4.5.1985, abgedruckt in: PE, S. 14

${ }^{11}$ Ansprache des französischen Staatspräsidenten vor der niederländischen Regierung vom 7.2.1984, D 199, abgedruckt in: EA, Folge 7/1984, D 195 - D 199

${ }^{112}$ So der stellvertretende Kabinettsdirektor, Jean-Pierre Chevillot, in einem Vortrag über die französische Technologiepolitik vor der Robert-Bosch-Stiftung am 29.10.85, abgedruckt in: EA, S. 695 f., Folge 23/1985, S. 691-698

113 ebenda, S. 696 
projekten plaziert werden konnten, um von dort zusätzliche Förderung zu erhalten. Eureka sollte allerdings nicht im Rahmen der gemeinschaftlichen Forschungsförderung aufgehen, um es für europäische Drittstaaten offenzuhalten. Um den Gegensatz zu SDI zu betonen, hob die französische Regierung später hervor, daß Eureka hauptsächlich ziviler Natur sei, vorbehaltlich der Tatsache jedoch, daß jedes Projekt der Hochtechnologie "strategische Implikationen" hätte, eine militärische Verwendung der Forschungsergebnisse also nicht von vornherein ausgeschlossen war. Überzeugt von der dringenden Notwendigkeit einer solchen Initiative, drängte die französische Regierung auf eine rasche Umsetzung von Eureka. Schon im Mai 1985 fanden erste vorbereitende Verhandlungen statt; im Juni ersuchte der Europäische Rat Frankreich, eine Konferenz über europäische Technologiepolitik einzuberufen und nur drei Wochen später, am 17. Juli 1985, wurde schließlich die konstituierende Ministerkonferenz eröffnet, an der insgesamt 17 europäische Staaten teilnahmen.

In seiner Eröffnungsansprache betonte der französische Staatspräsident noch einmal den flexiblen Charakter, den die technologische Zusammenarbeit haben sollte. Ferner wies er auf deren Bedeutung für die technologische Unabhängigkeit Europas sowie für das Überleben der europäischen Gesellschaftsform und Kultur hin. ${ }^{114}$ Überall, wo es möglich war, sollten die Zusammenarbeit zwischen den europäischen Unternehmen und Forschern angeregt, die entsprechenden finanziellen Mittel mobilisiert und die Anstrengungen der Unternehmen durch die Schaffung der erforderlichen Bedingungen gefördert werden. Mitterrand ließ keinen Zweifel daran, daß die Letztbegründung für ein technologisch unabhängiges Europa außerhalb der ökonomischen Sphäre lag:

„Unser Interesse muß uns dazu führen, mehr und mehr die Werte zusammenzulegen, deren Träger wir sind. Die Tatsache, daß sie, die Vertreter von 17 Ländern, hier sind, ist der Beweis dafür, daß ein Bewußtsein, das nicht auf den heutigen Tag gewartet hat, von vielen von Ihnen empfunden wird, die seit Jahren die Gelegenheit suchen, eine bestimmte Vorstellung von Europa zu verwirklichen, ohne daß einer von Ihnen gezwungen wäre, diese oder jene Institutionen zu akzeptieren. Ich habe immer ...- an die Bestimmung Europas geglaubt. Denn ich empfinde, wie Sie zweifellos auch, einen großen Stolz auf seine Vergangenheit. Ich leide an seinen Schmerzen und seinen Zwistigkeiten." ${ }^{115}$

Noch einmal machte der französische Staatspräsident damit deutlich, daß technologische Unabhängigkeit und wirtschaftliche Stärke ihn letztlich aus gesellschaftspolitischen Gründen interessierten. Sie bildeten für Mitterrand eine grundsätzliche Voraussetzung für die Bewahrung der kulturellen Werte und Identität Europas, die es seiner europapolitischen Vision zufolge in die Welt hinauszutragen galt. Um diese Vision Wirklichkeit werden zu lassen, stellte die französische Regierung für Eureka eine Milliarde Francs als Startkapital zur Verfügung. Erste konkrete Beschlüsse über Forschungsprojekte wurden bereits am 6 . November des Jahres auf einer zweiten Ministerkonferenz gefaßt. Zuvor hatte die Kommission in einer Mitteilung an den Europäischen Rat ein neues Rahmenprogramm für Wissenschaft und Technik vorgeschlagen,

\footnotetext{
114 Ansprache des französischen Staatspräsidenten, François Mitterrand, zur Eröffnung der Ersten EUREKA-Ministerkonferenz in Paris am 17.7.1985, D 29, abgedruckt in: EA 2/1986, D 28 - D 31

${ }^{115}$ ebenda, D 30
} 
in dem sie sich bereit erklärte, die Beteiligung der Gemeinschaft an Eureka-Projekten zu prüfen und sich entsprechend zu engagieren. Das Eureka-Projekt fand sich somit nach nur einem halben Jahr erfolgreich institutionalisiert und abgesichert, womit es, wenn auch außerhalb der Gemeinschaft, so doch vor der Aufnahme der Industriepolitik in die Einheitliche Europäische Akte realisiert werden konnte.

Mit Eureka hatte die französische Regierung ihre Forderung nach einer Forschungsund Industriepolitik durchsetzen können, die durch Pragmatismus, Anpassungsfähigkeit und rasche Eingriffe gekennzeichnet war. Forschungsförderung und Industrieentwicklung waren endgültig auf die politische Ebene gehoben worden, von wo aus die nationalen Regierungen im Rahmen ihrer wirtschaftspolitischen Zusammenarbeit direkt Einfluß auf die Wirtschaftsentwicklung nehmen konnten. Mit Eureka war überdies ein Weg gefunden, die Technologiepolitik erfolgreich als Teil der Außen- und Sicherheitspolitik zu etablieren, womit sie der Beurteilung ausschließlich aufgrund wirtschafts- und wettbewerbspolitischer Kriterien entzogen war. ${ }^{116}$ Unbehindert von wirtschaftspolitischen Prinzipien und frei nach nationalen Interessen konnten die Regierungen Mittel und Partner für die ihnen im Rahmen der Technologieförderung als notwendig erscheinenden Projekte auswählen. Europa hatte endlich eine eigenständige Hochtechnologiekooperation erhalten wie sie französischen Idealvorstellungen entsprach. ${ }^{117}$

In bezug auf die kulturelle Dimension der technologischen Entwicklung, versuchte die französische Regierung, diesen Erfolg Ende der achtziger Jahre mit einem „audiovisuellen Eureka“ noch einmal zu wiederholen. Im Zuge der rasant fortschreitenden Entwicklung auf dem Sektor der Unterhaltungs- und Kommunikationstechnologie sah der französische Staatspräsident die europäische Kultur erneut und mehr denn je der Gefahr einer zunehmenden Uniformisierung ausgesetzt:

„Le nombre d'heures produites en Europe croît moins vite que le nombre d'heures diffusées ...Le risque est grand de n'avoir que des images américaines sur des techniques japonaises. C'est pourquoi j'ai proposé un $<<$ Eurêka audiovisuel $>>$ car nous avons besoin de mobiliser tous les moyens européens pour défendre notre identité culturelle .. nos langues, nos cultures européennes sont en péril et la disparition d'une langue, c'est la disparition d'un peuple. “118

Erneut waren es die USA und Japan, die mit ihrer technologischen Übermacht die Unabhängigkeit Europas bedrohten und eine engere Zusammenarbeit der Gemeinschaft auf dem Sektor der Medientechnologie und -ökonomie erforderlich machten. Das Fehlen einer „kulturellen Dimension“ bei der forschungspolitischen Zusammenarbeit hatte der französische Europaminister schon 1987 in einem Bericht über den europäi-

${ }^{116}$ Vgl. Mestmäcker, E.-J. (1987), Auf dem Weg zu einer Ordnungspolitik für Europa, S. 32 f., in: ders. (Hrsg.): Eine Ordnungspolitik für Europa, Festschrift für Hans von der Groeben zu seinem 80. Geburtstag, Baden-Baden, S. 1-49

117 Vgl. Fröhlich, H.-P. (1986), Die französische Wirtschaftspolitik unter Präsident Mitterrand aus europäischer Perspektive, in: EA, Folge 6/1986, S. 85, S. 79 ff.

${ }^{118}$ So Mitterrand in der Pressekonferenz vom 27.7.1990, a.a.O., S. 81 
schen Binnenmarkt moniert, in dem er Maßnahmen wie eine Reorganisation des Rundfunk- und Fernsehwesens, Regelungen für Kabelnetze sowie den Aufbau einer europäischen Filmförderung vorschlug. ${ }^{119}$ Ein Jahr später fanden sich diese Ansätze in einem Maßnahmenkatalog zur Gründung des „audiovisuellen Eurekas“ wieder, den die französische Regierung ihren Partnern auf der Tagung des Europäischen Rates im Dezember 1988 vorlegte. Schwerpunkte der darin angeregten Zusammenarbeit waren die Förderung europäischer Film- und Fernsehproduktionen sowie die Einführung des High Definition Television (HDTV), einer neuen Übertragungstechnik, die es ermöglicht, eine Fernsehsendung in verschiedenen Sprachen gleichzeitig auszustrahlen. Nach dem bewährten Eureka-Muster sollte eine „Europäische Wirtschaftliche Interessenvereinigung" zur Durchsetzung des HDTV als internationaler Standard errichtet sowie eine Konferenz zur Ausgestaltung der audiovisuellen Medien in Europa einberufen werden. Vertreter öffentlicher und privater Sendeanstalten sowie Kulturschaffende, Produzenten und Werbefachleute aus der Gemeinschaft sollten den Aufbau eines „wirklich europäischen Marktes für audiovisuelle Medien“ beraten und eine gemeinsame Politik der Programmbeschaffung für private und öffentliche Fernsehanstalten entwickeln. Frankreich selbst erklärte sich wieder bereit, die dafür notwendigen Mittel zu finanzieren wie auch diese Tagung durchzuführen.

Der Erfolg dieser Initiative war allerdings nur gering. Die französische Regierung erreichte lediglich die Zustimmung zu einer Konferenz über die audiovisuelle Zukunft Europas, die während der französischen Ratspräsidentschaft im September 1989 in Paris stattfand, jedoch nicht mit konkreten Erfolgen aufwarten konnte wie die EurekaMinisterkonferenz vier Jahre zuvor. Immerhin gelang es der französischen Regierung, die Direktive für das „Fernsehen ohne Grenzen“ zum Beschluß zu bringen. Diese machte den Weg frei zu einer europaweit ungehinderten Ausstrahlung von Programmen und bestimmte, daß die Sendezeit überwiegend mit europäischen Produktionen zu füllen sei. Sie war allerdings nur politisch bindend und nicht juristisch. Außerdem enthielt sie nicht die von Frankreich gewünschte Verpflichtung, europäischen Produktionen sechzig Prozent der Sendezeit vorzubehalten. Darüber hinaus konnte die französische Regierung noch die Gründung der „Wirtschaftlichen Interessenvereinigung“ zur Durchsetzung des HDTV erreichen. Dieses scheiterte jedoch später nach zahlreichen Widerständen auf internationaler Ebene als globaler TV-Standard.

Alles in allem endete das „audiovisuelle Eureka“ somit in einem Mißerfolg und mit ihm der Versuch, das Eureka-Konzept ein zweites Mal als Instrument zur politischen Koordinierung und Ausrichtung der Wirtschaftsentwicklung zu nutzen. Vergeblich verhallte der Aufruf der französischen Europaministerin Edith Cresson, Kunst und Kultur vor der Banalisierung als Dienstleistung zu retten und diese nicht kampflos den

${ }^{119}$ Vgl. République Française: Ministère délégué chargé des affaires européennes (1987), La France et la réalisation du marché intérieur européen - Rapport au Premier Ministre établi par le Secrétariat Général du Comité Interministériel pour les questions de la Coopération économique européennes, (IWW C 164 745), S. 41-45 
Gesetzen des Marktes preiszugeben. ${ }^{120}$ Am Beispiel des audiovisuellen Eureka zeigte sich noch einmal das ausgeprägte Bewußtsein der französischen Regierung für die $\mathrm{Be}-$ deutung kultureller Werte und deren zentrale Rolle als Ausgangspunkt für ihr wirtschaftspolitisches Handeln. Aus dem Willen zur Bewahrung der Kultur Europas ergab sich die Notwendigkeit zur Bewahrung seiner Unabhängigkeit und aus dieser die Legitimation von Dirigismus und Interventionismus. Das wirtschaftspolitische Handeln folgte somit der selbstauferlegten zivilisatorischen Mission, die hier im Sinne des europäischen Allgemeininteresses verkündet wurde und ökonomischen Argumenten bestenfalls nachrangige Bedeutung zukommen ließ. Erneut zeigte sich, in welch hohem Maße gesellschaftspolitische Motive die ordnungspolitische Ausrichtung der französischen Binnenmarktpolitik bestimmten.

\section{B.5.2.3 Die Außenwirtschaftspolitik}

Von Beginn an eng verbunden mit der industriepolitischen Strategie Frankreichs war die Außenwirtschaftspolitik. Schon im Memorandum zur „relance européenne“ vom Herbst 1981 forderte die französische Regierung eine "echte Außenhandelspolitik" der Gemeinschaft sowie eine gemeinsame Außenwirtschaftspolitik, die sie als unabdingbare Voraussetzung für eine wirksame europäische Industriepolitik ansah. ${ }^{121}$ Grundsätzlich sollten der Gemeinschaft alle außenwirtschaftlichen Instrumente zur Verfügung stehen, um ihren Konkurrenten auf den Weltmärkten „mit gleichen Waffen“ begegnen zu können. Dem Handel und Direktinvestitionen in der Gemeinschaft sollten dabei besondere Aufmerksamkeit geschenkt werden.

Ihre Vorstellungen von einer europäischen Außenwirtschaftspolitik faßte die französische Regierung in einem Memorandum zusammen, das sie den Mitgliedstaaten im April 1982 überstellte. Darin betonte sie, daß alle Aktionen zur besseren Organisation des Binnenmarktes Hand in Hand mit einer aktiven und dynamischen Außenhandelspolitik gehen müßten. ${ }^{122}$ Als vorrangige Ziele einer solchen Politik betrachtete sie die Förderung europäischer Exporte sowie die Abwehr unlauterer Handelspraktiken von Drittländern. Zu ihrer Verwirklichung wurden zwei Gruppen von Maßnahmen als notwendig erachtet:

1. Zur Bekämpfung "illoyaler" Handelspraktiken sollte die statistische Überwachung der Importe auf Gemeinschaftsebene verstärkt werden. Die Dienststellen zur Untersuchung verbotener Dumping- und Subventionsfälle sollten personell verstärkt und die Gesetze gegen Dumping- und Subventionsverstöße mit äußerster Entschieden-

${ }^{120}$ Vgl. die Rede Premierministerin Cressons vom 27.9.1989, abgedruckt in: PE, S. 70, September 1989

${ }^{121}$ Vgl. Memorandum vom 8.10.1981, a.a.O., D 44

${ }^{122}$ Vgl. das Memorandum zur Stärkung der Außenhandelspolitik der französischen Regierung vom 26.4.1982, abgedruckt in: PE, S. 39 f. 
heit angewendet werden. Darüber hinaus sollte die Kommission regelmäßig Berichte über die Importentwicklung in den einzelnen Wirtschaftssektoren anfertigen, aus denen die Ursachen für die Entwicklung der Importe, sektorspezifische Außenhandelsbilanzen sowie die Auswirkungen der Importe auf die Produktion, die Auslastung der Kapazitäten und die Beschäftigung in der Gemeinschaft hervorzugehen hätten. Auf der Grundlage dieser Analysen sollte die Kommission unlautere Handelspraktiken identifizieren sowie ,geeignete Maßnahmen“ treffen oder, falls ihre Kompetenzen nicht ausreichten, entsprechende Vorschläge an den Rat richten.

2. Darüber hinaus erachtete die französische Regierung die Einführung einer besonderen Gesetzgebung als notwendig, um Eingriffen gegen unlautere Handelspraktiken von Drittländern eine rechtliche Basis zu verschaffen. Da es ihrer Ansicht nach immer illegitime Handelspraktiken geben würde, sollte die Gemeinschaft ein Reglement nach dem Vorbild des US-"Trade Agreement Act" von 1979 schaffen. Der höchsten politischen Führung - dem Rat also - sollten im Fall von Handelsverstößen die Mittel gegeben sein, sofort und wirksam zu intervenieren. Zwar sollte in Streitfällen grundsätzlich zuvor nach einer Klärung der vorliegenden Probleme auf administrativer Ebene gesucht werden. Bei ausbleibendem Erfolg war es nach französischer Auffassung jedoch unabdingbar, daß die politische Führung die notwendigen Kompetenzen besaß, um unverzüglich alle erforderlichen Maßnahmen ergreifen zu können. Als Beispiele für derartige Fälle nannte das Memorandum allerdings nur allgemein „ungerechtfertigte Wettbewerbsverzerrungen“ wie z. B. den privilegierten Zugang einzelner Länder zu wichtigen Ressourcen oder die Behinderung von Gemeinschaftsexporten.

Was hier unter dem Vorwand dürftig beschriebener unlauterer Handelspraktiken gefordert wurde, war letztlich eine Art außenwirtschaftliches „Ermächtigungsgesetz“, das dem Ministerrat und damit den nationalen Regierungen weitreichende Handlungs- und Kontrollmöglichkeiten im Bereich der europäischen Außenwirtschaft eröffnet hätte. Wenn die französische Regierung im Memorandum ausdrücklich den defensiven Charakter ihrer Vorschläge, die sie nicht als versteckten Protektionismus verstanden wissen wollte, betonte, so war dies wenig glaubwürdig, da es ein und dieselbe politische Ebene war, die einerseits nahezu unbegrenzte außenwirtschaftliche Kontroll- und Eingriffsrechte erhalten hätte und anderseits eine aktive Außenhandelspolitik zur Unterstützung einer wachstumsorientierten europäischen Industriepolitik betreiben sollte. Hier wurde bewußt ein Interessenkonflikt institutionell angelegt, der letztlich zur Totalpolitisierung der europäischen Außenhandelsbeziehungen geführt hätte. Angesichts der großzügigen Ausstattung mit Eingriffsrechten wäre bei den gegebenen wirtschaftlichen Interessen der einzelnen Mitgliedstaaten kaum zu erwarten gewesen, daß derart ermächtigte Politiker nicht von ihren Handlungsmöglichkeiten Gebrauch gemacht hätten. Tendenziell wären weniger Freihandel und mehr Protektionismus seitens der Gemeinschaft als Folge zu befürchten gewesen. 
$\mathrm{Da}$ eine solche Entwicklung den Intentionen der französischen Regierung durchaus entsprach, ließen offizielle Äußerungen Außenminister Cheyssons erkennen, der schon einen Monat vor Hinterlegung des französischen Memorandums einen gemäßigten Protektionismus öffentlich verteidigt hatte:

"c'est que dans la vie $d^{\prime}$ un pays, d'un ensemble de pays, d'une industrie, d'un individu, il y a des
moments où une protection peut être nécessaire pour un temps bref. C'est soit ce que l'on appelle
dans le jargon du Tiers Monde des industries naissantes, soit une industrie qui est en très grande diffi-
culté et où une crise de fièvre peut amener des troubles très graves. Donc, j'admets qu'il y ait des
mesures de sauvegarde dans un cas ou dans l'autre." ${ }^{123}$

Doppeldeutig waren auch die Äußerungen Europaminister Chandernagors, der auf die notwendige Komplementarität einer gemeinschaftlichen Politik zugunsten von Produktion und Beschäftigung und einer wirksamen Handelspolitik der Gemeinschaft hinwies. Letztere sollte offensiv in bezug auf die Eroberung von Drittmärkten sein und bei „Aggressionen“ gegen die Gemeinschaft mit wirksamen Gegenmaßnahmen anworten können. ${ }^{124}$ Nach Ansicht Chandernagors war eine reine Freihandelspolitik unzureichend, um Europa aus der Wirtschaftskrise zu führen. Vielmehr bedurfte es dazu der Orientierung, Begrenzung und Ergänzung der innergemeinschaftlichen Handelsströme sowie eines erfolgreichen europäischen Außenhandels. ${ }^{125}$ Grundsätzlich plädierte er dafür, den internationalen Handel im Rahmen einer internationalen Konzertation verstärkt auf vertraglicher Basis zu organisieren und die innergemeinschaftliche Industrieproduktion durch eine bessere Ausnutzung der europäischen Dimension rationeller zu gestalten. Insgesamt zielte die französische Politik damit von vornherein nicht auf die Liberalisierung des Außenhandels, sondern auf eine bewußte Lenkung der Handelsströme im Rahmen einer international konzertierten Handelspolitik.

Wie eng eine solche Außenwirtschaftspolitik letztlich mit ihrer Konzeption einer europäischen Industriepolitik verbunden war, zeigte sich schließlich im Memorandum der französischen Regierung für einen europäischen Industrieraum vom September 1983. Hier stellte sie klar heraus, daß Freihandel innerhalb des Gemeinsamen Marktes nicht automatisch dessen Auflösung in einem weltweiten Industrieraum zu bedeuten hätte. Vielmehr sollte die Außenwirtschaftspolitik der Gemeinschaft aktiv in die Bemühungen zur Stärkung der Wirtschaftsentwicklung eingebunden werden:

„Dies ist bei einigen in Schwierigkeiten geratenen Bereichen der Fall gewesen. Das gleiche muß für bestimmte Wirtschaftszweige der Zukunft gelten, damit Entstehen und Entwicklung zukunftsträchtiger Industriezweige erleichtert werden. Es muß möglich sein, eine erhebliche, aber vorübergehende Anhebung der Zölle zu beschließen, wenn dadurch das Entstehen einer europäischen Industrie tatsächlich gefördert werden kann. ${ }^{\text {" }}{ }^{126}$

\footnotetext{
${ }^{123}$ So Cheysson im Interview mit FRANCE INTER am 25.3.1982, a.a.O., S. 79

${ }^{124}$ ebenda, S. 22

${ }^{125} \mathrm{Vgl}$. die Äußerungen Chandernagors auf der CONVENTION POUR L'EUROPE am 9.19.82, abgedruckt in: PE, S. $21 \mathrm{f}$.

${ }^{126}$ Vgl. Memorandum vom 12.9.1983, a.a.O., D 699
} 
Neben dem Rückgriff auf protektionistische Handelspraktiken, forderte das Memorandum außerdem eine gemeinsame Haltung der Mitgliedstaaten gegenüber Direktinvestitionen in der Gemeinschaft. In einem europäischen Industrieraum sollte nach dem Willen der französischen Regierung jeglicher „Mißbrauch“ des freien Warenverkehrs ausgeschlossen sein. Dieser umfaßte für sie insbesondere die Errichtung von Fabriken, in denen nur importierte Halbfertigprodukte zusammengesetzt wurden. Über eine einheitliche Genehmigungspraxis in Form eines „,code de bon conduite“"127 sollte sichergestellt werden, daß vorrangig nur solche Investitionen erlaubt würden, die neue Arbeitsplätze schafften und bestehende nicht bedrohten. Außerdem sollte die Ansiedlung von Unternehmen aus Drittländern nur dann gefördert werden, wenn sie zu einem höheren Integrationsgrad führten und dem Technologietransfer dienlich wären. ${ }^{128}$ Die französische Regierung sprach sich somit durchweg für eine restriktive Haltung gegenüber ausländischen Investitionen in Europa aus, von denen sie offenbar mehr Schaden als Nutzen für die europäische Industrie erwartete. So jedenfalls war Europaminister Chandernagor zu verstehen, wenn er Direktinvestitionen mit dem „Trojanischen Pferd“ verglich und die kurzsichtige Taktik von Mitgliedstaaten kritisierte, die bereitwillig amerikanische und japanische Unternehmen ins Land ließen, ohne an die wirtschaftlichen und sozialen Folgen zu denken bzw. daran wie leicht diesen Firmen damit die Eroberung des Binnenmarkts gemacht würde. ${ }^{129}$

Neben diesen defensiv ausgerichteten außenwirtschaftlichen Elementen sollte eine europäische Industriepolitik nach dem französischen Memorandum auch über offensive außenwirtschaftliche Elemente verfügen. Um die europäische Industrie nicht auf das Niveau von Unterlieferanten herabsinken zu lassen, sollten europäische Produkte als „Gemeinschaftserzeugnisse“ kenntlich gemacht werden, damit sie besser von auswärtigen Erzeugnissen unterschieden werden konnten. Darüber hinaus sollten ,echte europäische Handelsgesellschaften" den Absatz dieser Gemeinschaftserzeugnisse fördern helfen. Wenn auch genauere Angaben über Aussehen und Aufgaben dieser Handelsgesellschaften wie auch über die qualitativen Merkmale der Gemeinschaftserzeugnisse fehlten, so deuteten diese Vorschläge ein weiteres Mal unmißverständlich darauf hin, daß die französische Regierung außenhandelspolitische Mittel bewußt einzusetzen gedachte, um die Wirtschaftsentwicklung nach politischen Vorgaben auszurichten.

Festzuhalten bleibt dementsprechend, daß mit der Formulierung der europäischen Industriepolitik im Herbst 1983 auch eine auf sie abgestimmte Außenwirtschafts- und Handelspolitik formuliert wurde. Diese war integraler Bestandteil der von Frankreich gewünschten Industriepolitik und diente in erster Linie dem Ziel, die Wirtschaftsbereiche zu schützen, denen aus politischer Sicht für das zukünftige Wachstum eine zentrale Rolle beigemessen wurde, sowie jene, die sich in einer schwierigen Wirtschaftslage befanden. Eine europäische Industrie- wie Außenwirtschaftspolitik nach

${ }^{127}$ Vgl. die Rede Chandernagors vom 30.11.1983, a.a.O., S. 117

${ }^{128} \mathrm{Vgl}$. Memorandum vom 12.9.1983, a.a.O., D 699

${ }^{129} \mathrm{Vgl}$. die Rede Chandernagors vor der Nationalversammlung vom 8.11.1983, a.a.O., S. 46 wie auch seine Äußerungen zur Vertiefung des Binnenmarktes im Februar 1983, abgedruckt in: PE, S. 70 
französischen Vorstellungen bauten auf die Konzentration aller Kompetenzen in den Händen der politischen Entscheidungsträger. Beide Konzepte waren von der Überzeugung geprägt, daß wirtschaftliches Wachstum sich am besten im Rahmen einer industriepolitischen Konzertation auf höchster politischer Ebene realisieren ließ, ebenso, wie ein für alle Länder vorteilhafter Welthandel am besten im Rahmen einer vertraglich fixierten Handelspolitik aufzubauen war. In dem sich hier offenbarenden Glauben an die Omnipotenz der wirtschaftspolitischen Kooperation ist letztlich die Erklärung für den Interventionismus zu finden, zu dem die französische Regierung sich offen bekannte und den sie im Rahmen ihrer Industriepolitik auf Europa zu übertragen suchte. Er prägte letztlich auch die von ihr geforderte europäische Außenwirtschaftspolitik und erklärt so die geringe Mühe, die sie darauf verwandte, die Widersprüchlichkeit dieser Politik in bezug auf die Grundsätze des internationalen Freihandels zu überdecken.

Mit Blick in die Wirtschaftsgeschichte erinnert das französische Gesamtkonzept von Industrie- und Außenwirtschaftspolitik an die merkantilistische Wirtschaftspolitik, wie sie in Frankreich unter Colbert im Zeitalter des Absolutismus betrieben wurde. ${ }^{130}$ So wie Colbert damals mittels einer wirksamen Außenprotektion und eines variationsreichen Interventionismus' alle Hebel in Gang zu setzen suchte, um Frankreich zu mehr Wirtschaftswachstum, Staatseinnahmen und zu mehr Macht zu verhelfen, so sollte die Europäische Gemeinschaft „Gemeinschaftserzeugnisse“ definieren, die Produktion im Inland schützen und ihren Absatz im Ausland stützen - kurz, alles unternehmen, um das Wachstum der Industrie zu fördern. Einer wohlinformierten und uneingeschränkt handlungsfähigen politischen Führung war die Aufgabe zugedacht, die Wirtschaftsentwicklung Europas in die Hand zu nehmen und zu steuern. Wie damals der absolutistische Staat, so sollte die Gemeinschaft mit ihrer Industriepolitik alles daran setzen, die Wirtschaftskraft zielgerichtet und unter wirksamer Kontrolle sowie „rationaler" Organisation der Außenbeziehungen zur vollen Entfaltung zu bringen. Die französische Regierung erwartete von ihren Partnern die Übernahme einer Wirtschaftspolitik, die von ihren Ordnungsprinzipen her im wesentlichen den traditionellen Leitlinien französischer Machtpolitik entsprach und die mit der Entfaltung von Freihandel und freier Marktwirtschaft nicht zu vereinbaren war.

Die wirtschaftspolitische Wende der französischen Regierung nach 1983, in deren Folge Frankreich sich allgemein einer mehr marktwirtschaftlichen Politik näherte, schlug auch auf seine europäische Außenwirtschaftspolitik durch. Nach 1984 ließ die französische Regierung zunächst von ihrer Forderung nach einer aktiven Außenhandelspolitik und gleichzeitiger Protektion sensibler Wirtschaftsbereiche ab. Im Zusammenhang mit den GATT-Verhandlungen im Rahmen der „Uruguay-Runde“ zeigte sich jedoch, daß die neue Zurückhaltung der französischen Regierung keinesfalls mit einem grundsätzlichen ordnungspolitischen Sinneswandel verbunden war. So lehnte der französische Präsident im Juli 1985 auf dem G-7 Gipfel die von den USA gewünschte Eröffnung neuer Verhandlungen zur Liberalisierung des Welthandels ab, da ihm die Vorbe-

${ }^{130}$ Vgl. Feldman (1993), a.a.O., S. 13 ff. 
reitungen unvollständig und zu einseitig auf den Agrarhandel ausgerichtet schienen. ${ }^{131}$ Darüber hinaus forderte die französische Regierung zusätzlich die Einbeziehung von Dienstleistungen sowie des Protektionismus aufgrund technischer Normen in die Verhandlungen. Im Zusammenhang mit der Liberalisierung des Dienstleistungsverkehrs kritisierte sie vor allem Japan, dessen Finanzmärkte sie als unzulässig protegiert betrachtete und dem sie exzessiven Rückgriff auf administrative Handelshemmnisse vorwarf. Im Agrarhandel hingegen konzentrierte sich die französische Kritik auf die USA und Neuseeland, deren Getreide- bzw. Butterexporte in die Gemeinschaft aus französischer Sicht unvereinbar mit den Zielen der europäischen Agrarpolitik waren. Bevor es zur Eröffnung neuer Handelsgespräche kam, wollte die französische Regierung die Wahrung europäischer Sonderinteressen im Bereich der Landwirtschaft sichergestellt wissen. Daß sie es darüber hinaus mit der Liberalisierung des Welthandels nicht sehr eilig hatte, zeigte sich in weiteren Vorbedingungen. So wollte Frankreich sich an Handelsgesprächen grundsätzlich nur beteiligen, wenn parallel auch Gespräche zur Neuordnung der internationalen Währungsbeziehungen aufgenommen würden. ${ }^{132}$ Außerdem sollte vor Beginn einer neuen GATT-Runde grundsätzlich die Wahrung der Interessen der Landwirte sichergestellt $\operatorname{sein}^{133}$ und darüber hinaus die Öffnung des Binnenmarktes nur nach dem Grundsatz strikter Reziprozität zugelassen werden. ${ }^{134}$

Mit dem Plaza-Agreement über die Entwicklung der internationalen Währungspolitik und der Währungsrelationen wurde im September 1985 eine der Hauptforderungen Frankreichs erfüllt. 1986 kam es schließlich zur Eröffnung der Uruguay-Runde, die bereits seit 1981 diskutiert wurde. Äußerungen wie die von Außenminister Bosson, der noch im Mai 1987 die segensreichen Wirkungen nationaler Handelsbeschränkungen pries und weiter an der „préférence européenne“ festhielt, zeigten, daß die französische Regierung ihre restriktive Haltung gegenüber der Liberalisierung der internationalen Handelsbeziehungen nicht aufgegeben hatte. ${ }^{135}$ Härte und Unnachgiebigkeit kennzeichneten die französische Haltung auch nach der Eröffnung der Verhandlungen. Sie waren maßgeblich dafür, daß es nicht wie geplant 1990, sondern erst 1993 zum Abschluß der Uruguay-Runde kam. Zu wesentlichen Streitpunkten entwickelten sich die französischen Vorbehalte gegen die Liberalisierung des Agrarhandels sowie hinsichtlich der Einfuhr von Automobilen und Filmen in die Gemeinschaft. Auf agrarpolitischem Gebiet bestand die französische Regierung weiter auf dem Recht, Exporte sub-

${ }^{131}$ Vgl. die Äußerungen Mitterrands nach dem G-7 Gipfel in Bonn, abgedruckt in: PE, S. 11

${ }^{132}$ ebenda

133 ebenda

${ }^{134} \mathrm{Vgl}$. Mise en oeuvre du 9e plan de développement économique, social et culturel (1984-1988), S. 5, PE, Januar 1984, S.1 ff.

135 "L'objectif doit être de faire bénéficier d'abord les entreprises européennes des avantages du marché intérieur et de négocier en position de force le démantèlement d'obstacles aux échanges chez les États tiers. La suppression des dispositifs nationaux, qui ont souvent pu faire la preuve de leur efficacité ou de leur effet dissuasif, doit donc aller de paire avec une véritable pratique de la préférence communautaire et une négociation sérieuse avec certains pays tiers", so Europaminister Bosson in einer Rede vor Vertretern des Unternehmens ACADI am 11.5.1987 in Paris, abgedruckt in: PE, S. 17 
ventionieren sowie Importe mit Einfuhrabgaben belegen zu dürfen. Frankreich scheute diesbezüglich weder innergemeinschaftliche Konflikte noch bilaterale Auseinandersetzungen mit den USA. ${ }^{136}$ Bei den Automobilexporten hingegen strebte die französische Regierung eine Selbstbeschränkung der japanischen Automobilindustrie an. Auch hier kam es zu Auseinandersetzungen zwischen Frankreich und den europäischen Partnern, die Japan einen höheren Marktanteil gewähren und die von Frankreich gewünschte Selbstbeschränkung der japanischen Automobilexporteure auf eine kürzere Dauer befristen wollten. ${ }^{137}$ Ebenso sollte die europäische Filmindustrie nach französischem Willen mit Hilfe von Quoten gegen eine amerikanische Übermacht verteidigt werden. Den Abschluß der Uruguay-Runde ließ die französische Regierung erst zu, nachdem ihr in allen drei Punkten Entgegenkommen signalisiert wurde. Ihre Vorbehalte begründete sie immer wieder mit der Forderung nach Reziprozität, hinter der sich bei näherer Betrachtung handfeste nationale, protektionistische Interessen versteckten. ${ }^{138}$

Die bis zum Ende des Betrachtungszeitraumes dieser Arbeit feststellbare Zurückhaltung Frankreichs in Fragen des Freihandels zeigt nachdrücklich, daß die französische Regierung zu keiner Zeit ihre prinzipiell restriktive handelspolitische Haltung aufgegeben hatte. Ihre Hinwendung zu mehr Marktwirtschaft im Rahmen der nationalen Wirtschaftspolitik nach 1983 machte sich auf europäischer Ebene zwar in moderateren Tönen bemerkbar, doch führte sie nicht zur grundsätzlichen Abkehr von einer protektionistischen Außenwirtschaftspolitik. Trotz bescheidenerem Engagement blieb die französische Regierung ordnungspolitisch weiter einem Interventionismus verpflichtet, der für sie ohne eine nachhaltige außenwirtschaftliche Absicherung nicht denkbar war.

\section{B.5.2.4 Die Sozialpolitik}

Für die französische Regierung bestand ebenfalls ein enger Zusammenhang zwischen Sozialpolitik und Industriepolitik. Nur wenige Wochen nach seiner Wahl zum Staatspräsidenten schlug François Mitterrand auf der Tagung des Europäischen Rates am 8. Juni 1981 in Luxemburg die Schaffung eines "europäischen Sozialraums" vor, in dem durch eine gemeinsame Sozialpolitik vor allem die Arbeitslosigkeit gezielt bekämpft werden sollte. Wesentliche Inhalte dieser Politik waren die europaweite Verkürzung

${ }^{136}$ Vgl. die Äußerungen von Agrarministers Mermaz vom 7.11.1990, abgedruckt in: PE, S. 4 und 5; Le Monde vom 20.10.1991, S. 17; o.V., La France juge inacceptable le projet d'accord sur les échanges commerciaux“, Le Monde vom 20.12.1991, S. 34; Lemaitre, P., „Commerce mondial: la France isolée“, Le Monde vom 25.1.1992, S. 1 und 15 sowie vom 21. und 25.12.1991

${ }^{137}$ Vgl. Le Boucher, É., „Tokyo rejette le projet de la Commission de Bruxelles sur les limitations de ventes d'automobiles“, Le Monde 3.5.1991, S. 23; Vgl. Lemaitre, P., „La France durcit sa position pour limiter les importations de voitures japonaises“, Le Monde vom 15.5.1991, S. 20

$138 \mathrm{Vgl}$. die Rede Premierminister Rocards vom 8.2.1989, a.a.O., S. 86; vgl. das Interview Europaministerin Guigous vom 23.6.1991, a.a.O.; vgl. die Antrittsrede von Premierministerin Edith Cresson vor der französischen Nationalversammlung am 22.5.1991, abgedruckt in: Le Monde vom 24.5.1991, S. 11 
der Arbeitszeit sowie ein einheitlich verstärkter sozialer Schutz der Arbeitnehmer. Darüber hinaus sollte ein Dialog der Sozialpartner eingeführt werden. Auf betrieblicher Ebene war dazu aus französischer Sicht die Errichtung paritätisch besetzter Ausschüsse und auf gesamtwirtschaftlicher Ebene ein „sozialer Dialog“, in dem Arbeitnehmer- und Arbeitgebervertreter sowie Vertreter des Staates zusammenfinden sollten, notwendig. Hauptzweck dieser Gesprächsforen sollte eine bessere Information der Arbeitnehmer sein, die von der französischen Regierung vor allem in Krisenbranchen sowie in den neuen aufstrebenden Wirtschaftsektoren als notwendig erachtet wurden.

Im Memorandum zur „relance européenne“ vom Oktober 1981 erfolgte eine kompakte Wiederholung dieser Forderungen. Einen tieferen Einblick in die Hintergründe der von Frankreich gewünschten Sozialpolitik gab Staatspräsident Mitterrand in einer Rede vor der International Labor Organization im Juni 1982. Darin wies er die These zurück, daß nur das freie Spiel der Marktkräfte Wachstum und Vollbeschäftigung zurückbringen würde. Statt dessen forderte er im Gegenzug die Anerkennung des "unveräußerlichen und geheiligten" Rechts auf Arbeit, da seiner Meinung nach nur bei angemessener Berücksichtigung der Arbeitnehmerinteressen die erfolgreiche Überwindung der Wirtschaftskrise zu erwarten sei ${ }^{139}$ :

„Comment imaginer que les travailleurs, les producteurs sans lesquels rien ne serait possible puissent accepter les sacrifices que nous imposent la nécessaire compétitivité, la lutte contre l'inflation, la mutation technologique dont nous savons qu'elle est une des causes principales de la crise économique mondiale, si les réformes correspondantes ne sont pas faites, si ne leur est pas assurée leur juste part dans la production et dans la redistribution des profits, si la collectivité nationale, où qu'elle soit, n'allie pas l'esprit de solidarité à l'esprit d'entreprise“140.

Bei der Einbindung der Arbeitnehmer in die Bemühungen zur Krisenbewältigung handelte es sich somit für den französischen Präsidenten in erster Linie um ein materielles Problem. Der Umstand allerdings, daß die Arbeitnehmer in "gerechtem" Maß an Produktion und Profit beteiligt werden sollten, wie auch der Umstand, daß die Nation ihnen Solidarität schuldete, wiesen darauf hin, daß in dieser Frage das Allgemeininteresse berührt war, was nach französischer Ordnungslogik staatlichen Handlungsbedarf implizierte. Da sich im Zuge der Globalisierung dieses Problem letztlich überall stellte, plädierte der französische Präsident für die Begründung einer internationalen Sozialordnung, die durch mehr Solidarität, Konzertation und Kooperation gekennzeichnet sein sollte und insbesondere durch die Institutionalisierung des „sozialen Dialogs“. Von den europäischen Staaten erwartete Mitterrand dabei, eine Vorbildrolle in puncto Sozialpolitik einzunehmen, da Europa von je her dem zivilisatorischen Fortschritt mehr

139 „Certains pensent et disent <<Laissons jouer les forces du marché et de la croissance et donc le plein emploi reviendra $\gg$. On a le droit de faire ce choix et je demande à ceux qui le pensent - dont je ne suis pas - de ne point oublier que le droit au travail est inaliénable et sacré“, so Mitterrand in seiner Rede vor der 68. Konferenz der International Labor Organization am 2.6.1982, a.a.O., S. 104

${ }^{140}$ ebenda 
als andere Staaten verpflichtet und sozialer Fortschritt letztlich untrennbar mit Frieden und Demokratie verbunden sei:

„Oui, je pense que l'Europe, parmi les autres entités, peut et doit donner l'exemple d'une volonté de voir grand et loin, de marquer sa confiance dans le progrès scientifique et dans la maîtrise de l'homme, tant il est vrai qu'il n'est d'autre richesse en fin de compte que l'homme lui-même. “141

Der Verweis auf die „maîtrise de l'homme“ zeigte, daß die von Mitterrand gewünschte Sozialpolitik sich mehr an sozialphilosophischen Sollvorstellungen orientierte, als an den konkreten wirtschaftlichen Problemen der Arbeitnehmer. Nicht um die Wahrung der Arbeitnehmerinteressen selbst schien es dem französischen Präsidenten zu gehen, sondern um eine konkrete Politik zur Umsetzung seiner Idee vom Fortschritt der Menschheit. Daß er dabei mit dem Instrument des sozialen Dialogs erneut auf einen konzertativen Lösungsansatz zurückgriff, der auf die Gemeinschaft übertragen werden sollte, war nur konsistent mit der französischen Haltung in den zuvor behandelten Teilbereichen der Wirtschaftspolitik.

Deutlicher noch als in diesen zeigte sich bei der Sozialpolitik jedoch, in welch hohem $\mathrm{Ma}$ gesellschaftspolitische Sollvorstellungen die Wirtschaftspolitik der französischen Regierung prägten. Immer wieder war es der Rekurs auf das Allgemeininteresse, der zusammen mit einer konzertativen, auf vertraglicher Abstimmung beruhenden Vorgehensweise zur optimalen Lösung wirtschaftlicher Probleme führen sollte. Ein nahezu unbegrenztes Vertrauen in die überlegene Leistungsfähigkeit politischer Verhandlungslösungen lie $\beta$ den Markt als suboptimales Verfahren zur Koordination wirtschaftlicher Interessen und Abläufe ausscheiden und dies insbesondere im sensiblen, weil direkt mit den Fortschritt der Menschheit verbundenen Bereich der Sozialpolitik.

Die europäischen Partner vermochten sich den französischen Vorstellungen nicht anzuschließen. Von Anfang an stieß der „Europäische Sozialraum“ bei den anderen Mitgliedstaaten auf starke Vorbehalte ${ }^{142}$, die dazu führten, daß selbst in der "Feierlichen Erklärung" zur Europäischen Union vom Juni 1983 jeder Hinweis auf ihn fehlte. Starke sozialpolitische Divergenzen unter den europäischen Regierungen führten dazu, daß Frankreich selbst während der französischen Ratspräsidentschaft 1984 nur die Annahme der Entschließungen für lokale Beschäftigungsinitiativen sowie für die Förderung der Beschäftigung von Frauen gelang; eine Direktive zur Neuordnung der Arbeitszeit hingegen scheiterte, weil sie nicht die Unterstützung aller Mitgliedstaaten fand.

Dem sozialpolitischen Engagement der französischen Regierung tat dies jedoch keinen Abbruch. So pries Premierminister Fabius im Vorfeld der Verhandlungen zur Einheitlichen Europäischen Akte den „Europäischen Sozialraum“ erneut, weil eine Harmoni-

${ }^{141}$ ebenda, S. 106

${ }^{142}$ Vgl. Lemaitre, P., Delarue, M., Les thèses de M. Mitterrand sur $l^{\prime}<<$ espace social européen>> suscites les réserves de Mme. Thatcher et de M. Schmidt, Le Monde vom 1.7.1981, S. 1 und 5 
sierung der Sozialrechte einer "Verzerrung" der Wettbewerbsbedingungen für Unternehmen vorbeugen würde:

"Aller vers plus de progrès sociale à travers l'Europe, c'est reconnaître que notre premier capital commun, ce sont nos ressources humaines, c'est faire le choix stratégique et confiant que de meilleures conditions de travail pour les travailleurs européens amélioreront non seulement leur vie, mais aussi leur capacité de contribuer au développement de la société... C'est peut être la spécifité, la force et la chance du chemin européen de viser à conjuguer modernisation et progrès social" ${ }^{143}$.

Mit dem Hinweis auf das Humankapital zeigte sich, daß zunehmend realwirtschaftliche Leistungsaspekte ihren Weg in den sozialpolitischen Diskurs der französischen Regierung fanden. Inhaltlich jedoch hatte sich nichts geändert, wie weitere Äußerungen Premierminister Fabius' zeigten, der angesichts der steigenden Arbeitslosigkeit zum Nachdenken über einen europäischen Beschäftigungsplan aufforderte und damit erneut auf eine gemeinschaftliche Beschäftigungspolitik drängte. Ebenso blieb es im französischen Memorandum zur Fortentwicklung der EG vom Juni 1985 bei der Forderung nach einem Sozialraum von größtmöglicher Homogenität sowie nach systematischen Konsultationen der Sozialpartner, die sich auf alle tarifrechtlich erheblichen Tatbestände erstrecken sollten. ${ }^{144}$ Zur ihrer Enttäuschung jedoch mußte die französische Regierung zwei Jahre später erneut feststellen, daß die Sozialpolitik noch immer kein europäisches Anliegen geworden war und noch nicht einmal Eingang in das Weißbuch der Kommission zur Verwirklichung des Binnenmarktes gefunden hatte. ${ }^{145}$

Angesichts der Erfolglosigkeit ihrer sozialpolitischen Vorstöße modifizierte die französische Regierung ihren Ansatz und schloß sich dem belgischen Kompromißvorschlag eines "Sockels sozialer Grundrechte" an. Dieser sah nicht mehr die volle Vereinheitlichung der sozialen Rechte vor, sondern nur noch ein einheitliches Minimum. Er beinhaltete aber die für die französische Regierung so zentrale Forderung nach der Einführung des sozialen Dialogs, dessen Bedeutung sie jetzt vor allem in bezug auf die Stärkung der Wettbewerbsfähigkeit europäischer Unternehmen betonte, ,... seul moyen de ne pas dissocier la prise en compte de l'adaptabilité des entreprises des exigences de la compétitivité dans le cadre du marché intérieur. Le dialogue social le plus étendu nous semble le seul garant du consensus requis pour les adaptations nécessaires “146.

Klar zeigte sich damit, daß der soziale Dialog die französische Regierung nicht nur aus gesellschafts-, sondern auch aus wettbewerbspolitischer Sicht interessierte. In dieser

\footnotetext{
${ }^{143}$ Vgl. die Rede von Fabius vom 20.1.1985, a.a.O., S. 19 f.

${ }^{144} \mathrm{Vgl}$. Memorandum zur Fortentwicklung der EG, von der französischen Regierung den Regierungen der EG-Mitgliedstaaten auf der Tagung des Europäischen Rates in Mailand am 28. und 29.6.1985 vorgelegt, D 446, abgedruckt in: EA, Folge 16/1985 D 444 - D 448

${ }^{145}$ Vgl. République Française: Ministère délégué chargé des affaires européennes (1987), La France et la réalisation du marché intérieur européen - Rapport au Premier Ministre établi par le Secrétariat Général du Comité Interministériel pour les questions de Coopération économique européennes, (IWW C 164 745), S. 74

${ }^{146}$ ebenda, S. 75
} 
Hinsicht war er offensichtlich als Instrument gedacht, die Aufmerksamkeit und das Bewußtsein der Vertreter der Arbeitnehmer- und Arbeitgeberseite auf die von politischer Seite aus als notwendig erachteten wirtschaftlichen Anpassungsmaßnahmen zu konzentrieren. Dem dritten Teilnehmer am sozialen Dialog, dem Staat, waren diese $\mathrm{Maßnahmen} \mathrm{indessen} \mathrm{schon} \mathrm{bekannt.} \mathrm{Ihm} \mathrm{ging} \mathrm{es} \mathrm{von} \mathrm{daher} \mathrm{darum,} \mathrm{einen} \mathrm{allgemeinen}$ Konsens über die zu treffenden Maßnahmen herzustellen. Ausgehend von dieser Konsensfindung im Dreier-Kreis (tripartisme) ${ }^{147}$ versprach sich die französische Regierung offensichtlich, über den sozialen Dialog Arbeitnehmer und Arbeitgeber in eine gemeinsame Strategie zur Steigerung der industriellen Wettbewerbsfähigkeit und damit letztlich in die Industriepolitik einbinden zu können. Mit der Industriepolitik teilte der soziale Dialog neben dem Ziel auch die Vorgehensweise, indem erneut einer konzertativen Verhandlungslösung der Vorzug vor der Marktkoordination gegeben wurde. Aus ordnungspolitischer Sicht betrachtet war die Sozialpolitik Teil des von Frankreich gewünschten allgemeinen wirtschaftspolitischen Interventionismus zur Stärkung der europäischen Wirtschaft. Sie harmonierte mit diesem Konzept insofern hervorragend, als daß sie auf eine Abstimmung aller Einzelinteressen im Sinne eines politisch definierten Allgemeininteresses ausgerichtet war. Diese Lösung hatte den „Vorteil“, daß den Vertretern des Allgemeininteresses - aus französischer Sicht also den politischen Entscheidungsträgern - automatisch die Moderatorenrolle zufiel. Dies hätte ihnen einen nicht unerheblichen Einfluß auf den Verhandlungsverlauf im sozialen Dialog und damit letztlich auf die Wirtschaftsentwicklung selbst eröffnet. Die Sozialpolitik war somit ein weiteres zentrales Element der französischen Strategie zur Stärkung der europäischen Wirtschaft. Besorgte die Außenwirtschaftspolitik die Absicherung der politischen Wachstumsbemühungen nach außen, so tat dies die Sozialpolitik nach innen, indem sie die Sozialpartner in eine europäische wirtschaftspolitische Gesamtstrategie einzubinden suchte. In diesem Sinne war sie integraler Bestandteil der interventionistischen Ordnungskonzeption, die Frankreich im Rahmen seiner Binnenmarktpolitik auf europäische Ebene zu übertragen wünschte.

Während ihrer Ratspräsidentschaft in der zweiten Jahreshälfte 1989 stellte die französische Regierung das "soziale Europa" an die erste Stelle ihrer Prioritätenliste. Schon ein Jahr zuvor, auf der Tagung des Europäischen Rates in Hannover, forderte Staatspräsident Mitterrand erneut die Einführung von garantierten sozialen Grundrechten für Arbeitnehmer. Diese sollten unter anderem das Recht auf Arbeit und europaweite Tarifverhandlungen vor allem in den wichtigen Branchen der Hochtechnologie umfassen. Des weiteren setzte sich die französische Regierung für die Verabschiedung einer "Charta der sozialen Grundrechte" ein, die sie später in den Mittelpunkt ihrer Präsidentschaft stellte und die neben der endgültigen Einführung des sozialen Dialogs vor allem eine einheitliche Sozialgesetzgebung bringen sollte. Die französische Regierung verband mit ihr außerdem die Hoffnung, ein "soziales Dumping" abwenden zu können, mit dem sie Europa im Zuge der fortschreitenden Globalisierung in zunehmendem Maß konfrontiert sah. „Soziales Dumping“ interpretierte sie, wie die Erläuterungen des

${ }^{147}$ Zum ,tripartisme“ vgl. auch die ausführliche Stellungnahme Mitterrands auf der 68. Versammlung der International Labor Organization am 2.6.1982, a.a.O., S. 105 
X. Plans (1989-92) zeigten, als regressive Fortsetzung der reinen marktwirtschaftlichen Lehre, die im Widerspruch zum progressiven "Sozialen Europa" stand:

„The necessity of safeguarding and enriching the European social model, which is based - above and beyond national characteristics - on a high level of social protection and on statutory or collective agreement mechanisms that guarantee the rights of wage earners, must prevail over a regressive notion of competition. The Community must be vigilant and avoid the risks of a drift towards social dumping ... Europe's economic development must be oriented towards a search for social progress and not by a regression, i.e. by sterile undercutting of wages and social benefits with regard to newly industrialised countries of South East Asia." ${ }^{\text {148 }}$

Der französischen Regierung ging es mit dem "Sozialen Europa" somit auch um die Besitzstandswahrung der Arbeitnehmer. Die Sicherung sozialer Errungenschaften war aus ihrer Sicht eine unmittelbare Voraussetzung für die Unterstützung der politischen Wachstumsbemühungen durch die Arbeitnehmerseite. Frankreich forderte deshalb ferner die Harmonisierung der Sozialbestimmungen auf höchstem Niveau. ${ }^{149}$ In diesem Sinne wies Außenminister Dumas bei der Vorstellung des französischen Programms für die Ratspräsidentschaft 1989 noch einmal darauf hin, daß ein vorbildliches soziales Europa von Lohnsenkungen und sozialem Dumping keine Stärkung seiner Wettbewerbsfähigkeit erwarten könne, sondern nur von einer guten Ausbildung und angemessenen Bezahlung seiner Arbeitnehmer. ${ }^{150}$ Zur gleichen Zeit betonte Staatspräsident Mitterrand noch einmal die Wichtigkeit der Zusammenarbeit aller Sozialpartner: Da jeder letztlich seine „Rolle“ im Betrieb hätte, so Mitterrand, sei ein "organisierter" Dialog aller das beste Mittel, um Krisen vorzubeugen. Für ihn schien offenbar so etwas wie eine fest vorgegebene wirtschaftliche Gesamtordnung zu existieren, in der jeder Arbeitnehmer wie Unternehmer - seinen Platz hatte, und in der nur etwas bewegt werden konnte, wenn alle ihre Rolle entsprechend den Vorgaben spielten. Die französische Regierung hielt somit weiter an ihrem instrumentellen Verständnis des sozialen Dialogs fest, der nicht nur um der Arbeitnehmerinteressen halber geführt werden sollte, sondern in erster Linie dem übergeordneten Allgemeininteresse zu dienen hatte, das nach Ansicht der französischen Regierung in einer starken, international wettbewerbsfähigen europäischen Wirtschaft lag. Der soziale Dialog sollte, wie Außenminister Dumas im Juli 1989 erläuterte, Arbeitnehmer und Unternehmer in die Industrie- und Forschungspolitik integrieren. Für die Unternehmen sah er dabei unter anderem den Vorteil, über den sozialen Dialog eine „vorausschauende Personalführung“ aufbauen zu können. ${ }^{151}$ Über diese praktische Wirkung hinaus verkörperte der soziale Dialog für

${ }^{148}$ Commissariat de Plan (1989), France, Europe. Xth Plan 1989-1992, La documentation française, Paris, S. 38

${ }^{149}$ Vgl. die Rede von Außenminister Roland Dumas vom 27.7.1989, a.a.O., S. 83

150 "La compétitivité internationale de l'Europe ne pourra pas découler du contournement des réglementations nationales, du nivellement des salaires vers le bas ou de toute autre forme de dumping social. Au contraire, l'Europe gagnera en valorisant l'atout représenté par des salariées bien formé, qualifiés, motivés par une rémunération appropriée, pour réaliser des produits et des services de qualité et à forte valeurs ajoutée.", so Dumas am 27.7.1989, a.a.O.

151 "Ainsi, il convient qu'à la création d'entreprises de taille européenne réponde dans les entreprises et dans les branches, l'instauration d'un dialogue social européen, portant notamment sur la ges- 
den französischen Außenminister das „vorbildliche“ Europa, in dem es nicht zur „Erosion“ der Arbeitnehmerrechte durch das „,unkontrollierte Spiel“ freier Marktkräfte kommen sollte. ${ }^{152}$

Am Ende seiner Präsidentschaft konnte Frankreich die Verabschiedung der "Gemeinschaftscharta der sozialen Grundrechte" mit qualifizierter Mehrheit erreichen. Großbritannien verweigerte seine Zustimmung, da der britischen Regierung die mit der Charta verbundenen Eingriffe in das Wirtschaftsleben zu weit gingen. Die Enttäuschung der französischen Regierung darüber wurde noch vergrößert durch den Umstand, daß es ihr nicht gelang, die Charta im Rahmen einer „,feierlichen Erklärung“ zu verabschieden sowie ein rechtlich verpflichtendes Programm konkreter Maßnahmen zu ihrer Umsetzung zu vereinbaren. ${ }^{153}$ Auch in den nachfolgenden Regierungsverhandlungen zur Wirtschafts- und Währungsunion gelang es ihr nicht, die Einigung in ihrem Sinne voranzutreiben. Fortbestehende sozialpolitische Meinungsverschiedenheiten unter den Regierungen führten dazu, daß der Europäische Rat im Juni 1991 die zuständigen Minister aufforderte, die Beratungen über ein Aktionsprogramm der Kommission zur Durchführung der Charta zu intensivieren. ${ }^{154}$ Allerdings vermochte auch dieser Appell nicht zum erwünschten Ziel zu führen, so daß dem Europäischen Rat von Maastricht im Dezember 1991 schließlich nichts anderes blieb, als die Sozialpolitik dem neuen EG-Vertrag in Form eines Protokolls beizufügen und darin die zuständigen Organe aufzufordern, sich weiter um die erforderlichen Beschlüsse zu bemühen. ${ }^{155}$

Erfolgreich aus französischer Sicht war diese Entschließung immerhin insofern, als daß die derzeitigen Vertragsbestimmungen als ,gemeinschaftlicher Besitzstand“ gelten konnten. Formal war damit immerhin die Wahrung der sozialen Besitzstände vertraglich festgeschrieben, inhaltlich umfaßte das Protokoll über die Sozialpolitik jedoch nur wenig verpflichtende Absichtserklärungen. Im wesentlichen bekannten sich die Regierungen zur Verpflichtung, die Beschäftigung, die Lebens- und Arbeitsbedingungen sowie den sozialen Dialog zu fördern. Beschlüsse in diesen Fragen bedurften allerdings der Einstimmigkeit, was bislang in der europäischen Politik immer die Garantie für wenig Fortschritt war. Außerdem waren Regelungen über das Arbeitsentgelt, das Koalitions- und das Streikrecht ausdrücklich von gemeinschaftlichen Regelungen ausgenommen. Wesentliche Bestandteile der Sozialpolitik waren somit nicht Gegenstand der Harmonisierung auf europäischer Ebene. Nach elf Jahren intensiven Engagements trug die französische Regierung mit dem Protokoll über die Sozialpolitik allenfalls ei-

tion prévisionnelle des effectifs, ainsi que sur l'introduction des nouvelles technologies", so Dumas in seiner Rede vom 27.7.1989, a.a.O.

${ }^{152}$ Vgl. die Ansprache Dumas vor der Nationalversammlung vom 12.12.1989, abgedruckt in: PE, S. 168

${ }^{153}$ Lequesne, C. (1990), Frankreich, S. 324, in: Jahrbuch der europäischen Integration 1989/90, S. 321-327

${ }^{154}$ Vgl. Schlußerklärung der Tagung des Europäischen Rats vom 28. und 29.6.1991, D 397 f., abgedruckt in: EA, Folge 15-16/1991, D 394 - D 400

${ }^{155}$ Vgl. Schlußerklärung der Tagung des Europäischen Rats vom 9. und 10.12.1991, D 91 f., abgedruckt in: EA, Folge 3/1992, D 91 - D 94 
nen Pyrrhussieg davon. Wohl hatte sie die Aufnahme der Sozialpolitik in die Gemeinschaftspolitik durchsetzen können, von praktischer Relevanz war dieser Erfolg indessen nicht.

\section{B.5.2.5 Zusammenfassung}

Zusammenfassend betrachtet läßt sich feststellen, daß Frankreich unter François Mitterrand im Bereich der Wirtschaftspolitik einen geschlossenen Ordnungsentwurf für Europa vorgelegt hat. In diesem fanden sich verschiedene Teilbereiche der Wirtschaftspolitik zusammengefügt, die einheitlichen Vorstellungen zur Ordnung der Wirtschaftsabläufe folgten. Mit dem Rückgriff auf die Industrie- sowie Außenwirtschaftsund Sozialpolitik wurde auf einen Ansatz zurückgegriffen, den die französische Binnenmarktpolitik schon unter Georges Pompidou verfolgt hatte. Aus der Amtszeit Giscard d'Estaings wurde der wirtschaftspolitische Konstruktivismus und das große Vertrauen in die Leistungsfähigkeit von politischen Verhandlungslösungen übernommen. Auch fand sich die entschiedene Ablehnung des Wirtschaftsliberalismus wieder, die schon seit de Gaulle die französische Binnenmarktpolitik durchgehend prägte. Insofern war der unter François Mitterrand vertretene Ordnungsentwurf für den europäischen Binnenmarkt nicht originell, sondern mehr eine Vollendung dessen, was es in Ansätzen vorher schon gegeben hatte. Deutlich war gegen Abschluß der Maastrichter Verträge zu erkennen, daß französische Sozialisten, Neoliberale sowie die Gaullisten den selben ordnungspolitischen Idealen folgten und zu ihrer Begründung oftmals auch auf dieselben Argumente zurückgriffen, was vor allem in der Gleichsetzung nicht regulierter Märkte mit dem „Gesetz des Dschungels“ immer wieder zum Ausdruck kam.

Zentraler Bestandteil der französischen Bemühungen zur Stärkung der europäischen Wirtschaft war die europäische Industrie- und Technologiepolitik. Über die gezielte Förderung ausgesuchter Wirtschaftssektoren sollten die notwendigen Wachstumsimpulse erzeugt werden, in der Hoffnung, diese auf die europäische Gesamtwirtschaft übertragen zu können. Während die Industriepolitik dabei optimale organisatorische und finanzielle Entwicklungsbedingungen für die Unternehmen zu schaffen hatte, war es Aufgabe der Technologiepolitik, die sachlichen und finanziellen Voraussetzungen für die Entwicklung wettbewerbsfähiger Produkte sicherzustellen. Eine protektionistische Außenwirtschaftspolitik sollte diese Wachstumsbemühungen bis zum Erreichen eines hinreichenden Niveaus an internationaler Wettbewerbsfähigkeit vor Störungen durch überlegene ausländische Konkurrenz schützen, während einer europäischen Sozialpolitik die Aufgabe zufiel, der gemeinschaftlichen Wachstumsstrategie die notwendige Unterstützung seitens der Arbeitnehmer und Unternehmer zu verschaffen. Ordnungspolitisch lag damit ein interventionistisches Gesamtkonzept vor, daß darauf angelegt war, den vollen politischen Durchgriff auf die Gestaltung der Wirtschaftsentwicklung zu ermöglichen, um diese den im politischen Prozeß ermittelten Zielen entsprechend zu gestalten. 
Ihren Ursprung hatten die französischen Bemühungen zur Stärkung der europäischen Wirtschaft allerdings weniger in ökonomischen Überlegungen. Er war vielmehr in der europapolitischen Gesamtkonzeption der französischen Regierung zu suchen, die - seit je her, so auch unter Mitterrand - primär auf Machterwerb und -sicherung sowie auf die Sicherstellung der europäischen Unabhängigkeit fixiert war. Macht und Einfluß bedurfte Europa, um in einer von wirtschaftlichen und militärischen Supermächten beherrschten Welt eine eigenständige und unabhängige Politik betreiben zu können. Das Ziel dabei war, die europäische Zivilisation und Kultur zu verbreiten und ihr über die Grenzen der Gemeinschaft hinaus Geltung zu verschaffen. Dazu bedurfte es jedoch politischer Macht, die aus französischer Sicht wiederum wirtschaftliche Macht voraussetzte. Für die auf Europa ausgerichtete Wirtschaftspolitik Frankreichs ergab sich daraus, das sie letztendlich nicht ökonomischen Erwägungen verpflichtet war, sondern bestimmten sozialphilosophischen Idealen. Diese Ideale waren wiederum aus bestimmten Vorstellungen über den Fortschritt der Menschheit abgeleitet und wirkten über die europapolitische Konzeption direkt auf die ökonomischen Ordnungsvorstellungen der jeweiligen französischen Regierungen im Hinblick auf den Binnenmarkt.

Der französische Ordnungsentwurf für Europa war im wesentlichen interventionistischen Charakters. Dies lag von vornherein auf der Hand, da Ziele wie sozialer Fortschritt und die Mehrung von Macht und politischem Einfluß außerökonomischen Charakters sind und sich bei freier Marktwirtschaft kaum von selbst verwirklicht hätten. Die Überzeugung von der Notwendigkeit staatlicher Eingriffe entsprang ferner grundlegenden Ansichten der französischen Regierung vom Ablauf des Wirtschaftsgeschehens. Den Markteilnehmern wurde danach unterstellt, ausschließlich ihrem Eigeninteresse zu folgen, ohne sich um das darüber hinaus existierende und vom Rang her überzuordnende Allgemeininteresse zu kümmern. Um diesem zu Recht und Geltung zu verhelfen, oblag es aus französischer Sicht dem Staat, die notwendigen Eingriffe vorzunehmen. Hinzu trat die allgemeine Einschätzung, daß Märkte nur bei kurzfristigen Entscheidungen ein effizientes Instrument zur Koordination von Wirtschaftsabläufen darstellten, bei langfristigen Entscheidungen aber, bei denen in der Regel Aspekte, die über die Einzelinteressen hinausgingen, berührt waren, grundsätzlich nicht zu optimalen Koordinationsergebnissen führen konnten. Mit diesem prinzipiellen Mangel der Marktkoordination war eine weitere Rechtfertigung für staatliche Eingriffe in den Wirtschaftsablauf gegeben.

Ein vierter Grund schließlich lag in der sozialen Indifferenz der Marktkoordination. Da aus französischer Sicht auf unregulierten Märkten keine Vernunft, sondern „naturgemäß“ das „Gesetz des Dschungels“ und damit das Recht des Stärkeren herrschte, bedurften die sozial Schwachen des Schutzes, der wiederum nur durch staatliche Interventionen gewährleistet werden konnte. Letztlich war die Abstimmung wirtschaftlicher Interessen im freien Wettbewerb für die französischen Regierungen grundsätzlich mit dem Ruch des Unzivilisierten behaftet. Staatliche Eingriffe hingegen stellten einen kultivierenden und damit a priori positiv ausgezeichneten Akt dar. Diese Interpretation des Marktgeschehens in Verbindung mit der Selbstverpflichtung, das 
Allgemeininteresse wahren zu müssen, ließen keine andere Wahl, als der Koordination des Wirtschaftsprozesses durch staatliche Eingriffe ein Höchstmaß an wirtschaftspolitischer „Rationalität“ zu verleihen. Als Hüterin von Zivilisation und Kultur blieb Frankreich von daher mit der von ihm angestrebten interventionistischen Ordnungskonzeption seiner ureigensten Mission treu.

Die französische Europapolitik folgte dieser Logik, indem sie sich konsequent gegen die Dominanz der Marktkoordination als alleiniges Ordnungssystem wandte. Ob in der Industrie-, Forschungs-, Außenwirtschafts- oder Sozialpolitik, auf allen Ebenen strebte Frankreich die Institutionalisierung eines umfassenden politischen Verhandlungsprozesses an, in dem die betroffenen Einzelparteien ihre Interessen im Konsens auf ein wie auch immer geartetes allgemeines Interesse aller abstimmen sollten. Vorteil dieses Verfahrens aus französischer Sicht war zum einen, daß alle Einzelinteressen Berücksichtigung fanden, und nicht nur die der wirtschaftlich "Stärkeren". Zum anderen entsprach die Einbindung aller Parteien in Verhandlungen einem "rationalen" Vorgehen bei der Abstimmung der Einzelinteressen auf das "höherwertige" Allgemeininteresse. Im Gegensatz zur "anarchischen" Marktkoordination, bei der ausschließlich die privaten Einzelinteressen dominierten, hatte diese Lösung den weiteren Vorteil, daß sie dem Staat eine gute Ausgangsposition bot, seiner Pflicht zur Wahrung des Allgemeininteresses nachzukommen. $\mathrm{Ob}$ in der Industriepolitik, wo die $\mathrm{zu}$ fördernden Wirtschaftsbereiche zwischen den Regierungen auszuhandeln waren, oder in der Außenwirtschaftspolitik, wo die Regierungen auf vertraglicher Basis die Handelsströme lenken sollten, oder im sozialen Dialog, wo unter der Leitung des Staates Unternehmer und Arbeitnehmer ihren Beitrag zur Verwirklichung der optimalen Wirtschaftsentwicklung diskutierten - in allen Fragen, die mit der Gestaltung der Wirtschaftsentwicklung zusammenhingen, war der Staat nicht nur beteiligt, sondern in lenkender Funktion vorteilhaft in die Gespräche integriert. Als Initiator der Verhandlungen konnte er direkten Einfluß auf ihren Inhalt und den Gesprächsverlauf und damit indirekt auch auf die späteren Ergebnisse nehmen. In der Institutionalisierung solcher Gesprächsrunden und den damit gegebenen Einflußmöglichkeiten lag letztlich das Ziel aller französischen Bemühungen zur Ordnung der Wirtschaftsabläufe im Binnenmarkt.

Was die sozialistische Präsidentschaft in diesem Zusammenhang von ihren Vorgängern unterschied, war die Energie und die Nachhaltigkeit, mit der sie ihre ordnungspolitischen Überzeugungen verfolgte. Wie immer begann auch die Amtszeit Mitterrands mit einer "relance européenne", die den europäischen Einigungsprozeß aus einer zumeist von Frankreich mitverursachten Stagnation heraus zu neuen Fortschritten führen sollte. Beispiellos war jedoch, mit welcher Offenheit die neue französische Regierung ihr wirtschaftspolitisches Reformprogramm auf die Europäische Gemeinschaft zu übertragen versuchte. Überzeugt von der Universalität ihrer wirtschaftspolitischen Einsichten waren dabei die europäischen Grenzen noch nicht das Ende. In Anlehnung an den Mondialismus Giscard d'Estaings ging Frankreich unter Mitterrand sogar so weit, seine ordnungspolitischen Überzeugungen der gesamten Welt nahezulegen und sie zum Aufbau einer neuen „Zivilisation“ aufzufordern. Das Scheitern der sozialistischen Re- 
formpolitik auf nationaler Ebene ließ den Reformeifer der französischen Regierung naturgemäß vorübergehend sinken. Auf europäischer Ebene führte er zu einem moderateren Tonfall, jedoch ohne daß sich die französische Binnenmarktpolitik von ihren ordnungspolitischen Überzeugungen trennte. Diese wurden ab 1984 leiser, aber in der Sache mit unvermindertem Nachdruck vertreten, was Frankreich nach weiteren Jahren hartnäckigen Insistierens schließlich mit der Aufnahme der Industriepolitik in den EGVertrag den erwünschten Erfolg bescherte. Nicht unbeteiligt daran war allerdings die Wahl Jacques Delors zum Präsidenten der Europäischen Kommission im Jahre 1985. Hatte er sich als französischer Wirtschafts- und Finanzminister vorher erfolglos um die Einführung einer europäischen Industriepolitik bemüht, so hatte er als Kommissionspräsident das Initiativrecht der Kommission für Beschlüsse des Rates im Rücken, welches er mit dem Vorschlag eines Forschungs- und Technologieraums nach nur drei Monaten im Amt entschlossen nutzte, um seinen ordnungspolitischen Idealvorstellungen zum Durchbruch zu verhelfen. Den Mitgliedstaaten blieb angesichts der wirtschaftlichen Probleme Europas nicht viel anderes übrig, als auf die nachhaltigen Bemühungen der Kommission für eine gemeinschaftliche Politik zur Stärkung der europäischen Wettbewerbsfähigkeit einzugehen. Einzig der Einstimmigkeitsvorbehalt im Bereich der Industriepolitik verhinderte den direkten Durchgriff einer interventionistischen Politik auf die Gestaltung der Wirtschaftsabläufe. Von ihrem ordnungspolitischen Ansatz her war die französische Binnenmarktpolitik daher noch nicht ganz am Ende ihrer Wünsche angelangt.

\section{B.5.3 Die Währungspolitik \\ B.5.3.1 Die Stärkung des EWS}

Auf monetärer Ebene begann die französische Regierung, sich anfänglich nur zögerlich zu engagieren. Die „relance européenne“ von 1981 konzentrierte sich im wesentlichen auf realwirtschaftliche Maßnahmen, die jedoch durch eine Minderung deflatorischer Auswirkungen des Ölschocks und der Dollarhausse unterstützt werden sollten. ${ }^{156}$ Im Rahmen erweiterter Gemeinschaftsanleihen sollten zusätzliche Finanzmittel für genau definierte Zwecke wie Energieeinsparungen, Beihilfen für krisengeschüttelte Branchen oder Maßnahmen im Rahmen der Forschungs- und Technologieförderung bereitgestellt werden. Die französische Regierung erhoffte sich davon eine „nützliche Unterstützung für das Wirtschaftsleben“, betonte aber gleichzeitig, daß diese Maßnahmen sich nicht nachteilig auf die Preisentwicklung auswirken dürften. Darüber hinaus sprach sie sich allgemein für eine engere währungspolitische Zusammenarbeit aus, von der sie sich den Übergang zu einer „neuen Phase“ erhoffte, die sie wie folgt beschrieb:

„Wenn es stimmt, daß das EWS besser funktionieren wird, wenn die Volkswirtschaften Entwicklungen verfolgen, die einander stärker entsprechen, so trifft es auch zu, daß die Regeln, die mit der Be-

${ }^{156} \mathrm{Vgl}$. Memorandum vom 8.10.1981, a.a.O., D 44 
teiligung an diesem System verbunden sind, einen starken Anreiz zur Konvergenz der Wirtschaftspolitiken bilden und auf diese Weise der Vorbereitung weiterer Fortschritte dienen. “157

Mit dieșem Bekenntnis griff die französische Regierung die monetaristische Integrationskonzeption aus den siebziger Jahren wieder auf. Kennzeichen dieses Konzeptes war der Versuch, über bewußt angelegte monetäre Sachzwänge die nationalen Regierungen zu einer einheitlichen Wirtschafts- und Währungspolitik zu bewegen, die ihrerseits wiederum eine erhöhte reale Konvergenz der Volkswirtschaften nach sich ziehen sollte. Die französische Regierung signalisierte auf diesem Weg, daß sie über die bestehende Zusammenarbeit im EWS hinaus eine intensivere währungspolitische Kooperation wünschte, ohne zunächst jedoch konkrete Ziele und Mittel dieser Zusammenarbeit genauer zu benennen.

Klarheit brachte der G-7 Gipfel im Juni 1982, auf dem der französische Präsident ein Gesamtkonzept zur Reform der internationalen Wirtschaftsordnung präsentierte. Im Zusammenhang mit der dort geforderten finanziellen Förderung von Industrieinvestitionen kritisierte er die damals weitverbreitete Rückkehr zu einer Austeritätspolitik als grundsätzlich falschen Ansatz zur Lösung der internationalen Rezession. Eine restriktive Ausgabenpolitik würde vor allem langfristige Investitionen verhindern, die im französischen Reformansatz zur Wiederbelebung der Nachfrage eine zentrale Rolle spielten. ${ }^{158}$ Seiner Meinung nach war vielmehr eine gezielte Mobilisierung des Kapitals in Richtung Industrie erforderlich, zu der die internationalen Kapitalmärkte mit einer gemeinsamen Aktion der G-7-Staaten bewegt werden sollten:

„Cet effort d'investissement correspondra à un prélèvement supplémentaire annuel très important sur les ressources disponibles du marché international des capitaux. Nos marchés monétaires auront à y répondre. Aussi faut-il que les taux d'intérêt soient raisonnables afin de rendre possible ces investissements et que les taux des change soient stabilisés, grâce à une coopération entre les principales monnaies permettant de reconstruire un système monétaire international ordonné“. ${ }^{159}$

Niedrige Zinsen und stabile Wechselkurse waren somit die zentralen monetären Zielgrößen der französischen Währungspolitik, die über diese beiden Parameter ihre Verbindung zur realwirtschaftlichen Entwicklung und damit zum Konzept der Industriepolitik fand. Für deren Erfolg stellten beide Parameter insofern eine wesentliche Voraussetzung dar, als daß sie im Rahmen einer Politik des „billigen Geldes“ sowie stabiler Wechselkurse Investitionen anregen sollten. Im Hinblick auf die infolge dieser engen Verbindung von Geld- und Wachstumspolitik möglicherweise gefährdete Geldwertstabilität erkannte Staatspräsident Mitterrand zwar durchweg die Notwendigkeit der Inflationsbekämpfung an. Er wies aber gleichzeitig darauf hin, daß diese mit Rücksicht auf die Arbeitslosigkeit zu geschehen hätte: Wenn vier Prozent weniger Inflation 400.000 oder 500.000 Arbeitslose mehr bedeuten würden, so Mitterrand im Mai 1982

\footnotetext{
157 ebenda

${ }^{158} \mathrm{Vgl}$. die Rede Mitterrands vom 5.6.1982 auf dem G-7 Gipfel in Versailles, a.a.O., S. 112

${ }^{159}$ ebenda, S. 112
} 
vor dem Übersee-Club in Hamburg, dann würde sich die französische Regierung einer solchen Politik verweigern. ${ }^{160}$

Damit war klar, daß die Währungspolitik aus französischer Sicht Teil einer wachstumspolitischen Gesamtkonzeption war, die eine stark keynesianische Prägung aufwies und einem Denken in „Phillips-Kurven“ folgte. Die interne Geldwertstabilität fand sich dabei sozialpolitischen Imperativen untergeordnet, während die externe Geldwertstabilität als Voraussetzung für einen geordneten Außenhandel betrachtet wurde. Die Geldwertstabilität stellte somit eine abhängige Größe nachgeordneten Ranges dar. Interessiert war die französische Regierung an einer intensiven währungspolitischen Koordination, die in erster Linie auf international fest verabredeten Wechselkursen und niedrigen Zinsen fixiert war. Die Kapital- und Devisenmärkte blieben auf die rein instrumentelle Funktion der Finanzierung politisch als notwendig erachteter Investitionen beschränkt. Ordnungspolitisch betrachtet lief diese Politik darauf hinaus, die Rolle des Marktes auf operative Finanzierungstätigkeiten zu begrenzen. Wie zuvor schon die wirtschaftspolitische Konzeption der französischen Regierung, schien auch deren währungspolitische Konzeption in der intergouvernementalen Koordination das optimale Ordnungsregime zu sehen. Daß dabei Wechselkurs und Zins am besten im Verlauf eines politischen Abstimmungsprozesses zu ermitteln waren, zeigte, daß Frankreich auch auf monetärer Ebene eine interventionistische Ordnungskonzeption bevorzugte. Die europäische Wirtschafts- wie auch die Währungspolitik der französischen Regierung folgten somit von Anfang an ein und dem selben Ordnungsmodus.

Mit ihrer Haltung vor allem in der Wechselkurspolitik führte die sozialistische Regierung die Währungspolitik ihrer konservativ-liberalen Vorgängerin fort. Ganz in ihrem Sinne kritisierte Außenminister Cheysson im Mai 1982 auf der Tagung des OECDMinisterrates die hohen Dollarschwankungen als risikoreich und nicht akzeptabel für die wirtschaftliche Entwicklung und wies in diesem Zusammenhang auf die Notwendigkeit einer größeren Vorhersehbarkeit der Wechselkurse hin. ${ }^{161}$ „Ungerechtfertigten und exzessiven" Schwankungen sollten die OECD-Mitgliedstaaten mit systematischen Bemühungen um mehr monetäre Stabilität begegnen. Als Instrumente nannte er konzertierte Interventionen der Notenbanken und den Rückgriff auf die „klassischen“ Instrumente der Geldpolitik. Im gleichen Sinne wandte sich Staatspräsident Mitterrand im Dezember 1982 auf der Tagung des Europäischen Rates an seine europäischen Partner. Hier stellte er fest, daß zur Stabilisierung der internationalen Währungsbeziehungen eine gewisse Regelbindung unabdingbar sei. Zur Beseitigung der „Unordnung“ im internationalen Währungssystem mußte seiner Ansicht nach ein engeres Zusammenspiel der drei großen Währungen Dollar, Yen und Ecu erreicht werden. Auf europäischer Ebene hingegen forderte er eine Intensivierung der währungspolitischen $\mathrm{Zu}$ sammenarbeit zur Stärkung des EWS und der Ecu. ${ }^{162}$ Im Januar 1983 in einer Rede vor

\footnotetext{
${ }^{160}$ Vgl. die Pressekonferenz Mitterrands vom 5.6.82, a.a.O., S. 120

${ }^{161}$ Vgl. die Rede Cheyssons auf der Tagung des OECD Ministerrats am 11.5.1982, a.a.O., S. 46

${ }^{162} \mathrm{Vgl}$. die Äußerungen Mitterrands auf seiner Pressekonferenz im Anschluß an die Tagung des Europäischen Rates am 4.12.1982, abgedruckt in: PE, S. 114, Dezember 1982, S. 113 ff.
} 
dem deutschen Bundestag deutete der französische Präsident darüber hinaus die Notwendigkeit einer Wiederbelebung des Währungssystems von Bretton-Woods an:

„Das Europäische Währungssystem kann und muß erhalten und ausgeweitet werden. Es wäre ferner gut, es an ein umfassenderes System anzubinden, wie dies in der Nachkriegszeit bis 1971 der Fall war ... Ist Europa stark, dann wird es die Vereinigten Staaten von Amerika und Japan, wie es auf dem Gipfeltreffen von Versailles versucht hat, von der Notwendigkeit überzeugen, eine internationale Währungsordnung neu aufzubauen und nicht der unsichtbaren Hand eines Marktes, der oft schon gar nicht mehr frei ist, ohne daß man es merkt, die ganze Verantwortung für unsere gemeinsame Zukunft zu überlassen. ${ }^{\text {(163 }}$

Unmißverständlich stellte der französische Staatspräsident damit klar, daß er die Regelung der internationalen Währungsangelegenheiten auf die politische Ebene zurückverlagert und damit den Devisen- und Finanzmärkten entzogen zu sehen wünschte. Die offizielle Aufforderung, an ein "neues Bretton-Woods" zu denken, folgte im Mai 1983 auf dem G-7 Gipfel von Williamsburg, auf dem Staatspräsident Mitterrand forderte, eine entsprechende Konferenz einzuberufen. ${ }^{164}$ In seiner Rede wies er nochmals darauf hin, daß ein nachhaltiges Wachstum nur bei stabilen Währungs- und Handelsbeziehungen gewährleistet sei. Wie nach dem zweiten Weltkrieg mußte nach Ansicht des französischen Staatspräsidenten für den zukünftigen Wirtschaftsaufschwung zunächst einmal die monetäre Grundlage gelegt werden („tous commence par la monnaie"):

„Wenn die Wechselkurse stabilisiert werden, wird der Warenverkehr eine neue Belebung erfahren, die jedem - davon bin ich überzeugt - zum Nutzen gereichen wird. Die Wachstumsraten werden vernünftig steigen und die Koordinierung unserer Wirtschaftspolitiken wird erleichtert werden."165

Die Währungspolitik offenbarte sich somit aus Sicht des französischen Präsidenten als eine wesentliche Voraussetzung für die Koordinierung der allgemeinen Wirtschaftspolitik. Erneut zeigte sich damit, daß Frankreich auch mehr als zehn Jahre nach den vergeblichen Integrationsbemühungen der „Monetaristen“ Anfang der siebziger Jahre weiter überzeugt war, über währungspolitisch gesetzte Sachzwänge besser zu einer größeren realen sowie wirtschaftspolitischen Konvergenz zu gelangen. In bezug auf die von Frankreich so dringend gewünschte Reform des internationalen Währungssystems betonte der französische Präsident dementsprechend erneut die Notwendigkeit einer engen Zusammenarbeit der drei großen Währungszonen, die zu stabilisierenden Impulsen auf die übrigen Währungen führen würde. Bezüglich der Mittel griff er auf zwei „klassisch französische“ Forderungen aus den siebziger Jahren zurück. Notwendig war aus französischer Sicht die Neudefinition der Rolle des Dollars, weil dieser seine Doppelrolle als nationale Währung und internationale Währungsreserve nicht

${ }^{163}$ Vgl. Ansprache Mitterrands vor dem Deutschen Bundestag am 20.1.1983 anläßlich des zwanzigjährigen Bestehens des Vertrages über die deutsch-französische Zusammenarbeit, D 154, abgedruckt in: EA, Folge 5/1983, D 145-D 155

${ }^{164}$ Vgl. die Ansprache Mitterrands vom 9.5.1983 zur Eröffnung der OECD-Ministertagung, a.a.O., S. 23

${ }^{165}$ Ansprache Mitterrands in Paris vom 9.5.1983, D 326, abgedruckt in: EA, Folge 12/1983, D 324 D 327 
mehr zu erfüllen vermochte, sowie die verstärkte Einbeziehung der SZR in die Steuerung der internationalen Liquidität. ${ }^{166}$ Beides lief auf ein und dasselbe hinaus: die Repolitisierung der internationalen Währungsbeziehungen. Die französische Dollarkritik war in der Regel unmittelbar mit der Forderung nach einer engen und gleichberechtigten währungspolitischen Zusammenarbeit der großen Währungszonen verbunden, während die Stärkung der SZR aufgrund ihrer Konstruktionsweise als Währungskorbstandard insbesondere bei Stützungsinterventionen eine intensivere währungspolitische Zusammenarbeit erzwungen hätte. Die Vorschläge der französischen Regierung zur Reform des internationalen Währungssystems liefen damit auf das gleiche Ziel hinaus wie die zuvor dargestellten französischen Bemühungen zur Neugestaltung der europäischen Währungspolitik: Auf breitest möglicher Basis sollte die Währungsentwicklung unter politische Kontrolle gebracht und im Rahmen einer konzertierten währungspolitischen Zusammenarbeit wieder stärker von den Regierungen gesteuert werden.

Um den währungspolitischen Zusammenhalt der Europäer zu stärken und ihnen international mehr Einfluß zu verleihen, drängte die französische Regierung nachhaltig auf die Stärkung des EWS und in diesem Zusammenhang immer wieder auf die Weiterentwicklung der Ecu: „Utilisons aussi cet ECU comme moyen extérieur d'action dans la négociation, et peut-être parfois dans l'expression de notre action financière", so Außenminister Cheysson, dem zufolge sich die Gemeinschaft angesichts der Wirtschaftskrise nicht mehr nur auf die wirtschafts- und handelspolitische Zusammenarbeit beschränken durfte. ${ }^{167}$ Die aus französischer Sicht notwendige Reform der Ecu sollte in erster Linie die Ausdehnung ihrer Nutzung auf den Zahlungsverkehr von Unternehmen, Kapitalmarktakteuren und öffentlichen Behörden umfassen. Vor allem von den Zentralbanken sollte die Ecu endlich als vollwertiges Zahlungsmittel verwendet werden und einen Status gleichwertig dem anderer Devisen erhalten und wie diese täglich auf Devisenmärkten notiert und gegenüber Drittwährungen verteidigt werden. Die Koordination der dazu notwendigen Interventionen sollte der EFWZ übernehmen, für den Frankreich deshalb zusätzlichen Handlungsspielraum forderte.

Die so gestärkte Ecu, die auf den ersten Blick den Eindruck einer eigenständigen Währung machte, war jedoch keine solche. Im privatwirtschaftlichen Bereich wäre ihre Verwendung auf die Funktion als Recheneinheit beschränkt geblieben. Die Erweiterung der Nutzung der Ecu wie auch ihre Verteidigung gegenüber anderen Währungen hätten indessen die Mitgliedstaaten zu einer engeren Kooperation gezwungen, während Interventionen seitens des EFWZ zu der von Frankreich gewünschten Stabilisierung der Wechselkurse auf internationaler Ebene beigetragen und das EWS zu einer international agierenden Institution gemacht haben würde. Bei der Stärkung der Ecu ging es Frankreich nicht nur um die Schaffung einer neuen Devise, die als Nebenwirkung unweigerlich mit der Abgabe geld- und währungspolitischer Kompetenzen verbunden

${ }^{166}$ Zur Rolle der SZR vgl. die Äußerungen Mitterrands in seiner Pressekonferenz vom 30.5.1983, a.a.O., S. 55 f sowie den Artikel Jacques Delors' in: Le Monde, S. 11, abgedruckt in: PE vom 9.9.1983, S. $10-12$

${ }^{167}$ So Mitterrand am 30.5.1983 in einem Fernsehgespräch, abgedruckt in: PE, S. 65 
gewesen wäre. Vielmehr schien die „gestärkte“ Ecu der französischen Regierung offenbar ein geeignetes Integrationsvehikel zu sein, um ihre immer noch zurückhaltenden europäischen Partner zu einer engeren Zusammenarbeit zu bewegen und der Gemeinschaft zu einer eigenständigen währungspolitischen Identität zu verhelfen.

Der Erfolg der französischen Regierung blieb jedoch gering. Diskreditierte schon der Mißerfolg der sozialistischen Wirtschaftspolitik auf nationaler Ebene ihre Initiativen zur Reform der europäischen und internationalen wirtschaftspolitischen Zusammenarbeit, so raubten die drei Abwertungen des Franc zwischen Oktober 1981 und März 1983 sowie zweistellige Inflationsraten und ein überdurchschnittlich hohes Zinsniveau den währungspolitischen Initiativen Frankreichs jegliche Chance auf Erfolg. Regierungsintern führten diese Resultate im Vorfeld der dritten Abwertung zu einer Zerreißprobe, während der Staatspräsident Mitterrand zeitweise den Austritt Frankreichs aus dem EWS erwog. ${ }^{168}$ Dies hätte jedoch die völlige Isolierung Frankreichs auf dem Gebiet der Wirtschafts- und Währungspolitik in Europa zur Folge gehabt. Frankreich entschied sich daher zur Abkehr von seinem wirtschaftspolitischen Reformprogramm. Auf monetärer Ebene vollzog es den Übergang zu einer geldmengenorientierten Politik und zu einer Quasi-Ankopplung des Franc an die D-Mark. Der stabilitätsorientierte Kurswechsel wurde im europäischen Vergleich spät vollzogen, berscherte Frankreich aber dennoch bald die erhofften Erfolge auf dem Gebiet der Inflationsbekämpfung und der Wechselkursstabilität.

Obwohl die französische Regierung mit dem Abrücken von der sozialistischen Reformpolitik faktisch die Systemzwänge des Binnenmarktes anerkannte, blieb sie in ihrer auf Europa bezogenen Währungspolitik unverändert den alten Positionen treu. So forderte Premierminister Fabius im Juli 1984 in seiner Antrittsrede vor der Nationalversammlung erneut die Reform der internationalen Währungsordnung mit den drei monetären Polen Dollar, Yen und ECU im Mittelpunkt. ${ }^{169}$ Auch blieb es bei der bekannten französischen Forderung nach Stärkung der Ecu, um den Handel innerhalb der Gemeinschaft anzuregen und die Unsicherheit auf seiten der Unternehmen zu reduzieren, sowie nach einem währungspolitisch geeinten Europa, das sich international für eine „rationale“ und „gerechte“ Währungsordnung einsetzten sollte. ${ }^{170} \mathrm{Im}$ gleichen Sinne drängte Außenminister Dumas im Mai 1985 vor dem Ministerrat der OECD auf eine verstärkte internationale währungspolitische Zusammenarbeit. Diese war aus seiner Sicht insbesondere zur Bekämpfung „ungeordneter Schwankungen" von Wechselkursen und Zinsen notwendig, die nicht nur die Inflation nährten, Handels- und Kapitalströme „umlenkten“ und die Schuldenkrise der Entwicklungsländer verschlimmerten, sondern darüber hinaus, so Dumas, allgemein die Wirtschaftstätigkeit in unzulässiger Weise beeinträchtigen würden:

\footnotetext{
${ }^{168}$ Vgl. o.V. „Why the drawbridge was not raised“, The Economist, 26.3.1983, S. 146

${ }^{169} \mathrm{Vgl}$. die Rede Fabius vom 24.7.1984, abgedruckt in: PE, S. 33

${ }^{170}$ Vgl. die Rede Fabius vor den grandes conférences catholiques vom 22.1.1985, abgedruckt in: PE, S. 19, Januar 1985, S. $17 \mathrm{ff}$.
} 
"Elles détournent l'épargne de l'investissement, au profit des placements financiers. Les forces de ce que l'on appelle $<<l e$ marché $>>$ (il faudrait s'interroger sur ce terme) ne permettent pas à elles seules de réguler les relations monétaires et financières internationales. L'évolution des <<éléments fondamentaux $\gg>$ ne permet pas d'expliquer les fluctuations désordonnées des monnaies. Tout autant que leur caractère désordonné, c'est l'imprévisibilité et la brutalité des évolutions qui sont préoccupantes. Les expériences récentes témoignent de la nervosité des opérateurs: tout $<<$ signal $>>$, qu'il s'agisse de l'évolution d'indices économiques, des difficultés de telle ou telle banque ou caisse d'épargne, est amplifiée par le marché dans des conditions malsaines." ${ }^{171}$

Am Mißtrauen der französischen Regierung gegenüber unregulierten Devisen- und Kapitalmärkten hatte sich somit trotz ihrer Hinwendung zu einer stabilitätsorientierten Geldpolitik grundsätzlich nichts geändert. Es blieb bei ihrem Wunsch nach einer intensivierten währungspolitischen Kooperation, um die wichtigsten monetären Parameter wieder politisch bestimmen zu können. In diesem Sinne forderte die französische Regierung in ihrem Memorandum zur Fortentwicklung der EG im Juni 1985 erneut, die Ecu zu einer Außenreserveeinheit weiterzuentwickeln und den EFWZ auszubauen, um den Einfluß Europas auf die internationalen Währungsbeziehungen zu stärken: "Europa, das von den Vereinigten Staaten von Amerika und von Japan erwartet, daß sie sich auf ein geordnetes Währungssystem zubewegen, würde damit unter Beweis stellen, daß es seinerseits durchaus in der Lage ist, bei sich selbst seine eigenen Interessen zu wahren “ ${ }^{\text {172 }}$. Die französischen Partner blieben allerdings unverändert bei ihrer Zurückhaltung und zeigten sich weiter wenig beeindruckt von diesen Thesen. So, wie schon die Stuttgarter Erklärung nur allgemein darauf hinwies, daß die Stärkung des EWS ein entscheidender Faktor für die Wirtschafts- und Währungsunion und die Stabilität der internationalen Währungsbeziehungen wäre, ohne weitere konkrete Maßnahmen festzulegen, blieb es auch in der Einheitlichen Europäischen Akte bei der Feststellung, daß die Mitgliedstaaten in diesem Sinne weiter eng zusammenarbeiten würden. Frankreich blieb mit seinen währungspolitischen Initiativen auf europäischer Ebene somit vorerst erfolglos. In bezug auf die Einheitliche Europäische Akte waren es vor allem die Bundesrepublik und Großbritannien, an denen die Aufnahme der französischen Vorstellungen zur Vertiefung der währungspolitischen Zusammenarbeit in Europa scheiterte. ${ }^{173}$

Auf internationaler Ebene hingegen konnte die französische Regierung mit dem PlazaAbkommen und dem Louvre-Accord, an deren Zustandekommen sie maßgeblichen Anteil hatte, einen gewissen Erfolg verbuchen. In Ersterem einigten sich im September 1985 fünf Staaten, darunter die USA und Frankreich, auf eine engere währungspolitische Kooperation zur Stabilisierung der Wechselkurse, bei der jedoch der Umfang der eingesetzten Interventionsmittel geheimgehalten werden sollte. Hintergrund war der

${ }^{171}$ So Fabius am 11.5.1985 in einer Rede auf der Tagung des OECD-Ministerrats, abgedruckt in: PE, S. 73

${ }^{172} \mathrm{Vgl.} \mathrm{Memorandum} \mathrm{zur} \mathrm{Fortentwicklung} \mathrm{der} \mathrm{EG,} \mathrm{von} \mathrm{der} \mathrm{französischen} \mathrm{Regierung} \mathrm{den} \mathrm{Regierungen}$ der EG-Mitgliedstaaten auf der Tagung des Europäischen Rates in Mailand am 28. und 29.6.1985 vorgelegt, D 446, abgedruckt in: EA, Folge 16/1985 D 444 - D 448

${ }^{173}$ Vgl. Lemaitre, P., „Les Dix engagent la relance de l'intégration européenne“, Le Monde vom 5.12.1985, S. 3 
Umstand, daß der Dollar wie auch das Haushaltsdefizit der USA im Frühjahr 1985 ein Niveau erreichten, das seitens der amerikanischen Regierung als bedrohlich empfunden wurde und diese zu einer Änderung ihrer Geld- und Finanzpolitik veranlaßte. Das Louvre-Abkommen aus dem Februar 1987 hingegen wurde im Vorfeld des Börsen-Crashs vom Herbst 1987 getroffen und diente ebenfalls in erster Linie der Stabilisierung des Dollars. ${ }^{174}$ Beide Abkommen liefen auf die von Frankreich gewünschte internationale monetäre Konzertation hinaus und banden die US-Währung entsprechend der französische Theorie der drei Währungszonen in das gemeinsame Bemühen um eine größere Stabilität der internationalen Währungsbeziehungen ein. Sie führten jedoch nicht zu der von Frankreich gewünschten systematischen Konzertierung nach dem Denkmuster der „Monetaristen“, die gestützt auf die SZR zu einer Marginalisierung des Dollars geführt hätte. Gemessen an ihren ursprünglichen Zielen konnte sich die französische Regierung auf internationaler Ebene somit nur zum Teil durchsetzen, wobei dieser teilweise Erfolg nochmals durch die Tatsache relativiert wurde, daß das Entgegenkommen seiner Partner mehr auf die gegebenen Schwierigkeiten im währungspolitischen Tagesgeschäft denn auf ihre grundsätzliche Übereinstimmung mit der französischen Währungspolitik und ihrer monetaristischen Integrationskonzeption zurückzuführen war. ${ }^{175}$

\section{B.5.3.2 Die Wirtschafts- und Währungsunion}

Nachdem während der Kohabitation (1986/87) die Initiativkraft der französischen Regierung auf europapolitischem Gebiet vorübergehend nachgelassen hatte, konzentrierte sie sich nach den Präsidentschaftswahlen 1988 verstärkt auf die Vollendung des Binnenmarktes und der Wirtschafts- und Währungsunion. Schon in seinem Wahlkampf wies François Mitterrand diesem Thema eine herausragende Rolle zu. Erneut forderte er in diesem Zusammenhang die Stärkung des EWS und der Ecu, erweiterte sie jetzt aber zur Forderung nach einer vollständigen Währungsunion mit einer echten Währung, die eines Tages von einer europäischen Zentralbank herausgegeben und von ihr verteidigt werden sollte. ${ }^{176}$ Mitterrand kritisierte die unzureichende Konstruktion eines EWS, das sich nur auf die Anpassung von Wechselkursen beschränkte und darüber hinaus auch noch zuließ, daß Gemeinschaftsmitglieder wie die Bundesrepublik ihre Zahlungsbilanzüberschüsse vorzugsweise außerhalb Europas anlegten, statt mit ihnen Investitionen und damit das Wachstum in der Gemeinschaft zu fördern. ${ }^{177}$ Damit setzte die französische Währungspolitik wieder dort an, wo sie zu Beginn der Kohabitation aufgehört hatte. Statt sich weiter passiv den Stabilitätszwängen des von der Bundes-

${ }^{174}$ Vgl. „L'accord du Louvre - communiqué officiel“, abgedruckt in Auszügen in: Le Monde vom 24.2.1987, S. 32

175 ebenda

${ }^{176} \mathrm{Vgl}$. den „Lettre à tous les français“ in: Le Monde vom 8.4.1988, S. 8

${ }^{177}$ Vgl. Mitterrand, F., „Croissance et emploi dépendent de l'avancée de la construction européenne“ Darstellung seiner wirtschaftspolitischen Positionen im Präsidentschaftswahlkampf 1988, Le Monde vom 20.4.1988, S. 13 
bank weitgehend dominierten EWS zu unterwerfen, ging sie mit einer zweiten währungspolitischen ,relance“ in die Offensive.

Problematisch im Hinblick auf die Vollendung des Binnenmarktes gestaltete sich aus französischer Sicht zunächst jedoch die Herstellung der Kapitalverkehrsfreiheit. Auch wenn Premierminister Rocard die Notwendigkeit eines liberalisierten Kapitalverkehrs grundsätzlich anerkannte, so forderte er, zuvor die Besteuerung der Kapitaleinkommen in Europa zu harmonisieren. ${ }^{178}$ Die von den nordeuropäischen Staaten präferierte Nullbesteuerung von Kapitaleinkommen wollte die französische Regierung aus Gründen der sozialen Gerechtigkeit nicht akzeptieren. Zwar stimmte sie auf der Tagung des Europäischen Rates in Hannover im Juni 1988 der vollständigen Liberalisierung des Kapitalverkehrs zu. Nachdem allerdings auf der nachfolgenden Tagung eine Einigung über die Besteuerung von Einkünften aus Aktien und Obligationen nicht erreicht werden konnte, verweigerte Frankreich die Zustimmung zur Direktive für die Umsetzung des Liberalisierungsbeschlusses. ${ }^{179}$ Neben sozialen Ungerechtigkeiten befürchtete die französische Regierung vor allem, daß unterschiedliche Steuerlasten in Europa zu einer Kapitalflucht führen und eine Anpassung der Steuersätze auf niedrigstem Niveau nach sich ziehen würden. Ein Europa allerdings, das sich unter dem Eindruck des Wettbewerbs auf den Kapitalmärkten zu den neuen „Bahamas“ entwickeln würde, so Premierminister Rocard, sei jedoch nicht das, was Frankreich wolle. ${ }^{180}$ Die optimale Lösung zur Vermeidung derartiger Spannungen sahen Premierminister wie Präsident in einer einheitlichen Währung. Da nicht davon auszugehen war, daß eine solche umgehend eingeführt werden würde, erhob Mitterrand die Harmonisierung der Steuergesetzgebungen im Juli 1988 zur „condition sine qua non“ für die Zustimmung Frankreichs zur Liberalisierung des Kapitalverkehrs, die er außerdem noch ausdrücklich an sichtbare Fortschritte bei der Errichtung einer europäischen Zentralbank sowie bei der Einführung der Ecu knüpfte. ${ }^{181}$

Für die Zurückhaltung der französischen Regierung bei der Liberalisierung des Kapitalverkehrs spielte darüber hinaus ihre Furcht vor spekulativen Kapitaltransaktionen, die im Verlauf der Börsenunruhen des Jahres 1987 wiederbelebt worden war, eine wesentliche Rolle. So kritisierte Staatspräsident Mitterrand im Juli 1987 auf der UNWelthandelskonferenz, daß die Gewinne der Industrieunternehmen mehr und mehr von spekulativen Finanz- und Währungsspielereien (jeux financières et monétaires) abhingen, statt von ihrer produktiven Tätigkeit. ${ }^{182}$ Zur Beruhigung der Finanz- und Devisenmärkte forderte er erneut die Stabilisierung von Wechselkursen und Zinsen auf „vernünftigem“ Niveau, das anhand zu vereinbarender „zones de références“ festzulegen sei. Eine schärfere Kontrolle des Kapitalverkehrs zur Begrenzung des Ausmaßes

\footnotetext{
${ }^{178}$ Vgl. o. V., „On a trop promis avec l'Acte unique“, Le Monde vom 12.5.1988, S. 10

${ }^{179}$ Vgl. Lemaitre, P., „Un sommet à moitié convaincant“, Le Monde vom 6.12.1988, S. 8

${ }^{180}$ Vgl. die Ansprache Rocards in CHATTAM-HOUSE vom 8.2.1989, a.a.O., S. 86

${ }^{181}$ Vgl. die Pressekonferenz Mitterrands vom 27.7.1989, a.a.O., S. 79 f.

${ }^{182} \mathrm{Vgl}$. die Rede Mitterrands auf der VII UN-Konferenz über den Welthandel am 10.7.1987, abgedruckt in: PE, S. 23
} 
der Spekulationen forderte er selbst noch im April 1990, nachdem Frankreich der Direktive zur Liberalisierung des Kapitalverkehrs schon längst zugestimmt hatte, wobei diese Forderung einen ideologischen Seitenhieb nicht vermissen ließ:

„...le libéralisme est à bout de souffle, parce que le capitalisme, tel qu'il est, s'il se laisse vivre, sa loi, c'est celle de la jungle... il va créer beaucoup d'autres inégalités, et l'argent des plus riches, où va-t-il aller? Il y a déjà beaucoup d'argent qui se promène un peu partout, d'une banque à l'autre, l'argent $<<$ noir $>>$, comme on dit, qui est de l'argent trouble. Il y a trop d'argent non contrôlé et cela est dû aux formidables fortunes, qui s'édifient sur la spéculation. Et cette spéculation est en train d'étouffer le travail des autres. “" 183

Die Einordnung der Spekulation als bedrohlicher und systemimmanenter Defekt des Kapitalismus reichte offenbar aus, um abseits aller Vertragsabsprachen weiter an der Forderung nach Kapitalverkehrsbeschränkungen festzuhalten. Letztlich zeigte diese Stellungnahme, daß das grundsätzliche Mißtrauen der französischen Währungspolitik gegen unkontrollierte Marktkräfte fortbestand und daß sie in der Währungsunion offenbar primär Schutz gegen einen unkontrollierten Wettbewerb auf den Devisen- und Kapitalmärkten suchte, ohne ihrer interventionistischen Grundhaltung abgeschworen zu haben.

Die europäischen Partner indessen reagierten zunächst verhalten auf die währungspolitische „relance“ Frankreichs. So war von der britischen Premierministerin Thatcher seit längerem bekannt, daß sie der Abgabe währungspolitischer Kompetenzen im allgemeinen wie auch der Schaffung einer europäischen Zentralbank im besonderen ablehnend gegenüberstand ${ }^{184}$, während sich die Bundesrepublik und die Niederlande zunächst zurückhielten. Dem französischen Präsidenten hingegen war diese Reaktion vollkommen unverständlich angesichts der Zustimmung, die der Delors-Bericht bei seiner Vorlage im April 1989 von allen Seiten erhalten hatte. Er kritisierte dementsprechend auf der Tagung des Europäischen Rates im Juni 1989 offen die Unentschlossenheit, mit der sich die Gemeinschaft auf den Weg zur schon längst beschlossenen Wirtschafts- und Währungsunion machte. Konkret wandte er sich dabei vor allem gegen die britische Premierministerin Thatcher, der er unterstellte, den europäischen Einigungsprozeß zu mutwillig zu behindern. ${ }^{185}$ Überzeugt davon, sie von ihrem seiner Meinung nach ideologisch begründetem Widerstand gegen die Währungsunion nicht abringen zu können, ging er seinerseits in die ideologische Gegenoffensive. Offen konterte er im Namen Frankreichs: "Si ceux qui veulent le libéralisme cherchent à nous entraîner sur leur terrain, nous ne pourrons les suivre ${ }^{186}$. Darüber hinaus drohte er mit der Rücknahme schon gemachter Zugeständnisse, wie z. B. der Liberalisierung des

${ }^{183}$ so Mitterrand in einem Fernsehinterview, abgedruckt in Auszügen in: Le Monde vom 27.3.1990, S. 4

${ }^{184}$ Vgl. die "Brügge-Rede" Premierministerin Thatchers in: EA, Folge 24/1988, D $682 \mathrm{ff}$.

${ }^{185}$ So Mitterrand am 27.6.1989 in einem Interview auf Europe 1, vgl. Tréan, C., „Les frustrations de M. Mitterrand“, Le Monde vom 29.6.1989, S. 2

${ }^{186}$ So Mitterrand auf der Tagung des Europäischen Rates am 26.6.1989, zit. n. Tréan, C., „Les frustrations de M. Mitterrand“, Le Monde vom 29.6.1989, S. 2 
Kapitalverkehrs, für den Fall, daß die Mitgliedstaaten insgesamt den getroffenen Vereinbarungen zur Vollendung der Wirtschafts- und Währungsunion nicht nachkämen.

Die europäischen Partner konfrontierte die französische Regierung mit der Forderung, die Regierungsverhandlungen zur Wirtschafts- und Währungsunion spätestens mit der Vollendung des Binnenmarktes 1992 abzuschließen. Für den Übergangsprozeß strebte sie die Übernahme der Stufenfolge des Delors-Berichts an. Außerdem wünschte sie die sofortige Gründung eines Europäischen Reservefonds, der laut Delors-Bericht mit eigenen Reserven ausgestattet sein und schon in der ersten Stufe "übungshalber" eine konzertierte Steuerung der Wechselkurse unter gemeinschaftlichen Gesichtspunkten ermöglichen sollte. ${ }^{187}$ Mit beiden Forderungen stieß die französische Regierung allerdings erneut auf wenig Gegenliebe. Frustriert über die Langsamkeit des Integrationsprozesses und von der Aussicht, weiter einer "zone mark" angehören zu müssen ${ }^{188}$, jedoch wohlwissend um die Notwendigkeit, die noch zögernden Staaten nicht von vornherein verprellen zu dürfen, stimmte der französische Präsident schließlich einem Kompromiß zu. Der Europäische Rat von Madrid vom 26/27. Juni 1989 beschloß danach, die erste Phase des Übergangs zur Wirtschafts- und Währungsunion am 1. Juli 1990 beginnen zu lassen und mit deren Beginn die Regierungsverhandlungen aufzunehmen. Damit war der Integrationsprozeß immerhin erst einmal angeschoben, ohne daß zögernde Staaten wie Großbritannien sich zurückzogen.

Während der französischen Ratspräsidentschaft in der zweiten Jahreshälfte 1989 gelang es der französischen Regierung außerdem, zu erreichen, daß die erste Stufe des Übergangsprozesses gemäß den Bestimmungen des Delors-Berichts ablaufen sollte. Für Frankreich hatte dies nicht nur den Vorteil, daß der Delors-Bericht so doch noch faktisch zur Arbeitsgrundlage erhoben wurde. Bei genauerem Hinsehen bestimmte er für die erste Stufe währungspolitische Maßnahmen, die einen Integrationsprozeß und eine spätere europäische Währungspolitik ganz nach den Vorstellungen der französischen Regierung präjudizierten. So sah der Delors-Bericht in der ersten Stufe unter anderem vor:

- die Einbeziehung aller Mitgliedstaaten in den Wechselkursmechanismus sowie die Vorbereitung des privaten Gebrauchs der Ecu sicherzustellen;

- die Grundlagen einer währungspolitischen Kooperation auszuarbeiten. Diese sollte neben Richtlinien für eine gemeinsame Interventionspolitik auch die Definition konkreter Ziele, Instrumente und Überwachungsindikatoren für eine ex-ante orientierte Geldpolitik der Gemeinschaft umfassen.

- Die Intensivierung der wirtschafts- und finanzpolitischen Koordinierung, die sich auf einen "Prozeß der multilateralen Überwachung der Wirtschaftsentwicklung und -politik auf der Basis vereinbarter Indikatoren" abstützen sollte und darüber hinaus

${ }^{187}$ Vgl. Deubner, C. (1991), Frankreichs Europapolitik und der europäische Binnenmarkt, S 49, in: M. Kreile (Hrsg.): Europa 1992 - Konzeptionen und Strategien, Baden-Baden, S. 37-57

${ }^{188}$ Eine Äußerung Mitterrands vom 27.6.1989 im Gespräch mit EUROPE 1, zit. n. Tréan, C., „Les frustrations de M. Mitterrand“, Le Monde vom 29.6.1989, S. 2 
entsprechende Konsultationen sowie die haushaltspolitische Koordinierung anhand quantitativer Leitlinien und „mittelfristiger Orientierungen“ vorsah.

Der Delors-Plan lief insgesamt auf eine ex-ante Koordination der europäischen Währungs-, Finanz- und Wirtschaftspolitik hinaus. Ferner sprach er sich für die Einbeziehung aller Staaten in das EWS sowie die baldige Einfuihrung einer konzertierten Wechselkurspolitik aus. Zusammen mit dem in den Stufen zwei und drei vorgesehenen Übergang zu immer festeren Wechselkursen kam der Delors-Plan den monetären Ordnungsvorstellungen der französischen Regierung recht nahe. Er hätte nicht nur zu einer Währungspolitik nach französischem Geschmack geführt, sondern, angesichts der Vielzahl der vorgesehen Koordinationsinstrumente, der Gemeinschaft insgesamt eine Wirtschaftsordnung interventionistischen Charakters beschert, wie sie von Frankreich seit jeher angestrebt wurde.

Frankreichs Partner indessen gingen diesen Weg nicht mit. Auf der Sondertagung des Europäischen Rates im Oktober 1990 einigten sich die Mitgliedstaaten auf eine „offene marktwirtschaftliche Ordnung" für die Wirtschaftsunion, während für die Währungsunion die Schaffung eines unabhängigen Zentralorgans vereinbart wurde, das die ungeteilte Verantwortung für eine der Preisstabilität verpflichteten Geldpolitik ausüben sollte. ${ }^{189}$ Mit dem Aufbau dieses Organs sollte außerdem erst in der zweiten Stufe begonnen werden, in deren Verlauf auch nur der Anschluß der "größtmöglichen" Anzahl von Mitgliedern angestrebt wurde. Darüber hinaus wurde der Übergang zur dritten Stufe in Abhängigkeit von ausreichenden und dauerhaften Fortschritten bei der realen und monetären Konvergenz der Volkswirtschaften gestellt, die u. a. anhand der erreichten Preisstabilität und der Lage der öffentlichen Haushalte zu überprüfen war. Ganz im Gegensatz zu den französischen Vorstellungen stand der Übergang zur Wirtschafts- und Währungsunion somit im Zeichen von Marktwirtschaft und Stabilitätsorientierung, statt auf eine Wirtschaftsordnung hinauszulaufen, die in erster Linie auf die politische Steuerung und Kontrolle des Wirtschaftsprozesses fixiert war.

Die Antwort der französischen Regierung auf diesen Rückschlag ließ nicht lange auf sich warten. Zwei Monate später veröffentlichte sie eine Erklärung, in der sie mehrere Bedingungen für einen erfolgreichen Übergang zur dritten Stufe der Wirtschafts- und Währungsunion nannte, darunter unter anderem:

- das Vorhandensein einer „demokratischen Wirtschaftsregierung“,

- die Konvergenz der Volkswirtschaften durch gleiche Leistungen bei Preisen und Zinsen sowie

${ }^{189}$ Vgl. die Schlußfolgerungen der Sondertagung des Europäischen Rates vom 27. und 28.10.1990, abgedruckt in: EA, Folge 1/1991, D $10 \mathrm{f}$. 
- die Wahrung der Geschlossenheit der Gemeinschaft durch die parallele Entwicklung von Politischer und Wirtschafts- und Währungsunion sowie durch die Teilnahme aller Mitgliedstaaten an beiden von Beginn an. ${ }^{190}$

Eine „demokratische Wirtschaftsregierung“ sah die französische Regierung im $\mathrm{Zu}$ sammenhang mit der unvermeidlichen Abgabe von Souveränitätsrechten an Gemeinschaftsinstitutionen als unabdingbar an:

„...die Unabhängigkeit der Währungsinstitution versteht sich nur im Zusammenhang mit einer starken „Wirtschaftsregierung“. Diese soll völlig demokratisch sein und die Nationalstaaten unmittelbar verpflichten können, die weiterhin für die Wirtschaftspolitik grundsätzlich zuständig sind. Aus diesen Gründen muß der Kernpunkt des institutionellen Konzepts die Rolle des Europäischen Rates und des Rates der Minister sein." $" 191$

Hinter der Forderung nach einer „starken“ und „demokratischen“ Wirtschaftsregierung steckte somit ein erneuter Versuch, die Notwendigkeit einer umfassenden wirtschaftsund währungspolitischen Koordination in den Vordergrund zu rücken, nachdem mit dem vereinbarten Integrationskurs ordnungspolitisch den Schwerpunkt auf eine unabhängige, allein der Preisstabilität verpflichteten Währungsbehörde, auf eine marktwirtschaftliche Ordnung sowie auf zuvor nachzuweisende reale Konvergenzfortschritte gelegt worden war. Die Forderung der französischen Regierung, einer unabhängigen Zentralbank eine starke Wirtschaftsregierung entgegenzusetzen, zeugte von ihrer Skepsis einer autonomen Zentralbank gegenüber, aber auch von ihrem Wunsch, weiter eine enge Verbindung zwischen Wirtschafts- und Währungspolitik aufrechtzuerhalten. Letzteres dokumentierte sich außerdem in ihrer Forderung, die Konvergenz der Volkswirtschaften außer an der Preisentwicklung auch an der des Zinsniveaus festzumachen, das aus französischer Sicht seit jeher eine zentrale währungspolitische Größe mit hoher Bedeutung für die Wirtschaftspolitik und -entwicklung darstellte. In der Forderung, den Europäischen Rat und den Ministerrat $\mathrm{zu}$ zentralen Institutionen der „Wirtschaftsregierung“ zu machen, dokumentierte sich darüber hinaus der Versuch, die intergouvernementale Zusammenarbeit als verbindlichen Modus für die wirtschafts- und währungspolitische Entscheidungsfindung festzuschreiben. Den nationalen Regierungen sollte in diesem Bereich weiter die führende Rolle vorbehalten bleiben, wobei das unklare Verhältnis einer weisungsbefugten Wirtschaftsregierung gegenüber den weiter für die Wirtschaftspolitik zuständigen Mitgliedstaaten zeigte, daß die französische Regierung zur Abgabe substantieller Kompetenzen offenbar immer noch nicht bereit war, geschweige denn von deren endgültiger Verteilung in der Wirtschafts- und Währungsunion präzise Vorstellungen hatte. Als Kernanliegen der französischen Forderungen bleibt somit nur der Wille erkennbar, den im Oktober 1990 eingeschlagenen ordnungspolitischen Kurs wieder in Richtung von mehr politischer Koordination und Steuerung zu korrigieren.

${ }^{190} \mathrm{Vgl}$. das Kommuniqué des französischen Kabinetts im Anschluß an dessen Sitzung vom 5.12.1990, 191 abgedruckt in: FRANKREICH-INFO vom 7.12.1990, Nr. 90-46

${ }^{191}$ ebenda 
Ihren ordnungspolitischen Korrekturversuch ergänzte die französische Regierung einen Monat später mit der Vorlage eines Entwurfs über einen Vertrag über die Wirtschaftsund Währungsunion. ${ }^{192}$ Darin forderte sie, die Ausrichtung der Wirtschaftspolitik der Mitgliedstaaten an Leitlinien, die sich an den Zielen der Wirtschafts- und Währungsunion zu orientieren hätten, sowie den Entwurf von "Grundleitlinien" für die Wirtschaftspolitik der Gemeinschaft durch den Europäischen Rat, innerhalb derer wiederum die Wirtschaftspolitik der Mitgliedstaaten vom Ministerrat zu koordinieren war. Dieser sollte dazu die Wirtschaftslage und -politik der Mitglieder im Hinblick auf die Gemeinschaftsziele prüfen, Empfehlungen erteilen und, im Falle ihres Nichtbefolgens, diese öffentlich bekanntgeben und sogar zugeteilte Gemeinschaftsmittel wieder kürzen oder aussetzen können. Auch sollte er eine regelmäßige Gesamtbewertung der kurzund mittelfristigen Wirtschaftsentwicklung im Rahmen der Konjunkturpolitik, in deren Folge Mitgliedstaaten und Kommission sich über zu treffende Maßnahmen ins Benehmen zu setzten hätten, durchführen. Über konkrete Maßnahmen sollte auf Vorschlag der Kommission allerdings einstimmig entschieden werden, während die zur Durchführung notwendigen Direktiven nur der qualifizierten Mehrheit bedürfen sollten. Ferner war die Errichtung eines Europäischen Zentralbanksystems vorgesehen, welches dem "vorrangigen" Ziel der Preisstabilität verpflichtet sein sollte, "unbeschadet dieser Zielsetzung" aber die allgemeine Wirtschaftspolitik der Gemeinschaft zu unterstützen hatte. Die Durchführung von Interventionen sowie der einheitlichen Wechselkurspolitik sollten entsprechend den "Leitlinien des Rates" erfolgen, wobei für Entscheidungen im Bereich der "monetären Kontrolle" sowie in der Wechselkurspolitik ausdrücklich nur die qualifizierte Mehrheit vorgesehen war.

In diesen Ausführungen dokumentierte sich noch einmal klar die primäre Fixierung der französischen Regierung auf eine ex-ante Koordinierung der Konjunktur- und letztlich der Wirtschaftspolitik, die auf eine aktive Beeinflussung der Wirtschaftsentwicklung abzielte. Wichtig dabei war ihr, daß die Beurteilung der wirtschaftlichen Lage wie auch das Fällen von Entscheidungen über die zu treffenden Maßnahmen durch die nationalen Regierungen vorgenommen wurde. Dies zeigte sich in dem Vorschlag, den Europäischen Rat die „Leitlinien“ bestimmen zu lassen und die Wirtschafts- und Finanzminister mit deren Durchführung zu betrauen. In der Forderung, konjunkturpolitische Maßnahmen einstimmig zu beschließen, dokumentierte sich ferner die hohe Sensibilität der französischen Regierung gegenüber der Wahrung ihrer wirtschaftspolitischen Souveränität. Auf keinen Fall wollte sie substantielle wirtschaftspolitische Kompetenzen endgültig abtreten und sich einem verbindlichen Votum der Gemeinschaft unterwerfen. Sie strebte vielmehr eine fest institutionalisierte wirtschaftspolitische Kooperation an, ohne es dabei zu einer übermäßigen Abgabe und Zentralisierung von Kompetenzen kommen zu lassen.

Ganz anders hingegen gestaltete sich das Bild auf währungspolitischem Gebiet. Hier sollten zentrale Bereiche wie die Wechselkurspolitik und die "monetäre Kontrolle"

${ }^{192} \mathrm{Vgl}$. den Entwurf der französischen Regierung für einen Vertrag über die Wirtschafts- und Währungsunion, abgedruckt in: FRANKREICH-INFO 91-6 vom 22.2.1991 
dem Mehrheitsbeschluß unterliegen. Mit dem Verzicht auf ein Vetorecht nahm die französische Regierung bewußt die Abtretung nationaler Kompetenzen in Kauf, allerdings mit dem Vorteil, so zu einer Neuverteilung währungspolitischer Kompetenzen auf europäischer Ebene zu kommen, was vor allem die dominierende Position der Bundesbank beendet hätte. Mit der Verlagerung der monetären Koordination auf den Ministerrat wären auch die Geld- und Währungspolitik, die bislang faktisch von dem Land mit der stabilsten Währung bestimmt wurden, Gegenstand der intergouvernementalen Abstimmung geworden. Daß damit Währungs- und Wirtschaftspolitik letztlich in den Händen ein und desselben Organs gelegen hätten, zeigte noch einmal, in welch engem Zusammenhang die französische Regierung die beiden Bereiche sah. Ordnungspolitisch betrachtet war der Vertragsentwurf der französischen Regierung eine Fortsetzung ihrer bisherigen Linie. Er lief auf eine wirtschafts- und währungspolitische Totalkoordination hinaus, die den nationalen Regierungen über eine ausgedehnte ex-ante Abstimmung beider Politikbereiche weitreichenden Einfluß auf die Wirtschaftsentwicklung sichern sollte. Seine Vorlage gleich nach Eröffnung der Regierungsverhandlungen ist als erneutes Aufbegehren Frankreichs gegen eine ausschließlich marktwirtschaftlich orientierte und auf Stabilitätspolitik fixierte Wirtschafts- und Währungsunion zu sehen, als ordnungspolitische Offensive, um das Ruder wieder mehr in Richtung Interventionismus herumzureißen.

Die frühe Präsentation des französischen Vertragsentwurfs führte dazu, daß gleich zu Beginn der Regierungsverhandlungen die Debatte um das Ausmaß staatlicher und marktlicher Koordination in der Wirtschafts- und Währungsunion eröffnet wurde. Die französische Regierung setzte ihren ordnungspolitischen Kurs schwungvoll fort, indem sie zunächst den britischen Hard-Ecu-Vorschlag unterstützte, den Wirtschafts- und Finanzminister Pierre Bérégovoy als "Bereicherung" der währungspolitischen Diskussion bewertete. ${ }^{193}$ Der Hard-Ecu-Vorschlag war im wesentlichen darauf bedacht, das "Zins- und Liquiditätsdiktat" der Bundesbank zu brechen. Er sah die baldige Einführung der Ecu als dreizehnte Währung der Gemeinschaft vor, die sich im Wettbewerb gegen die existierenden Gemeinschaftswährungen durchsetzen sollte. Außerdem sollte darüber hinaus der EFWZ zur emittierenden Institution ausgebaut werden, womit es quasi "durch die Hintertür" zur Errichtung einer europäischen Zentralbank gekommen wäre. Mit der frühzeitigen Einführung einer Gemeinschaftswährung sowie der Errichtung der dazugehörigen gemeinschaftlichen Währungsinstitutionen paßte der HardEcu-Vorschlag nahtlos in das Integrationskonzept der französischen Währungspolitik. Er blieb allerdings von Anfang an erfolglos, weil es zum einen unwahrscheinlich war, daß sich die Korbwährung Ecu jemals gegen ihre stärkste Mitgliedswährung durchsetzen hätte können, und zum anderen, weil die unklar definierten Zuständigkeiten bei

${ }^{193}$ Vgl. die Stellungnahmen Bérégovoys in einem Interview mit Le Monde, abgedruckt in: o. V., "l'engrenage du marché unique", hrsg. von Philip Lemaitre in: Le Monde-dossiers et documents, 4/91, S. 88 f.; Müller, L. (1991), „Hard-ECU“ - Sackgasse zur Europäischen Wirtschafts- und Währungsunion, in: EA, Folge 8/1991, S. 247-254; Vgl. Lemaitre, P., „La France réaffirme sa fidélité à l'objectif d'une monnaie unique“, Le Monde vom 17.1.1991, S. 35; Vgl. Lemaitre, P., L'Espagne et la France prônent le renforcement de l'écu“, Le Monde vom 30.1.1991, S. 21 
Interventions- und Zinsfragen Gefahren für die Geldwertstabilität mit sich brachten, die kein Mitgliedstaat ernsthaft eingehen wollte und konnte. ${ }^{194} \mathrm{Da}$ die französische Regierung dem Hard-Ecu dennoch Positives abgewinnen konnte, ließ vermuten, daß sie in diesem vor allem einen willkommenen Entlastungsangriff auf die bestehende Struktur des EWS sah, allerdings um den Preis, die Glaubwürdigkeit ihres eigenen Bekenntnisses zum Stabilitätsziel zu unterminieren.

Auch wenn der Hard-Ecu bald dem Widerstand der stabilitätsorientierten Länder zum Opfer fiel, hielt die französische Regierung über das Frühjahr 1991 hinweg an ihrem Versuch fest, die währungspolitische Zusammenarbeit schon in der zweiten Stufe des Übergangsprozesses soweit wie möglich auszubauen. So blieb Wirtschafts- und Finanzminister Bérégovoy dabei, das EWS als "wirkungsvolles" Instrument der Konvergenz anzupreisen wie auch bei seiner Forderung, die Abstimmung der nationalen Währungspolitik baldmöglichst innerhalb des Europäischen Zentralbanksystems stattfinden zu lassen, damit die Gemeinschaft auf internationaler Ebene wirkungsvoll zu einer Politik im Sinne des Louvre- und des Plaza-Abkommens beitragen konnte. ${ }^{195}$ Darüber hinaus betonte er weiter, daß die Gemeinschaft sich nicht vom Außenwert ihrer Währung abwenden dürfe und verwies darauf, daß die Definition einer entsprechenden Wechselkurspolitik Sache der zuständigen Gremien zu sein hätte, womit in diesem Fall der Ministerrat gemeint war und nicht die unabhängige Europäische Zentralbank. ${ }^{196}$

Zur Unabhängigkeit der Europäischen Zentralbank stellte Europaministerin Guigou im Juni 1991 fest, daß diese sich auf die "administration du monnaie unique" zu beschränken hatte. ${ }^{197}$ Ferner war es ihrer Meinung nach wichtig, "... daß die Zentralbank sich nicht die Verantwortung der politischen Organe anmaßt, welche für die wirtschaftli-

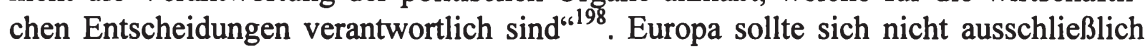
auf Institutionen beschränken, sondern hätte sich vielmehr in die Realität einzufügen. „Niemals wird irgendein Text den wirklichen politischen Willen ersetzen“ ${ }^{199}$, so Gui-

${ }^{194} \mathrm{Zu}$ den Auswirkungen der Einführung des Hard-Ecu vgl. Hasse, R., Koch, T. (1991), The HardECU - a Substitute for the D-Mark or a Trojan Horse?, in: Intereconomics, Juli-August 1991, S. 159-166

195 Vgl. die Stellungnahme Bérégovoys in einem Interview mit Le Monde, abgedruckt in: o. V., "l'engrenage du marché unique", hrsg. von Philip Lemaitre in: Le Monde-dossiers et documents, $4 / 91$

196 ebenda

${ }^{197}$ Vgl. Interview mit der beigeordneten Ministerin für Europäische Angelegenheiten, Elisabeth Guigou, in: Le Monde vom 23.6.1991, abgedruckt in Auszügen in: "Frankreich-Info" vom 27.6.1991, Nr. 91-18

${ }^{198} \mathrm{Vgl}$. das Interview Guigous vom 23.6.1991, a.a.O.

${ }^{199}$ Im gleichen Sinne äußerte sich Präsident Mitterrand in einer Fernsehdebatte über den Maastrichter Vertrag: „Die Zentralbank wird nicht die Wirtschaftspolitik bestimmen, das wird der Europäische Rat, bestehend aus 12 gewählten Politikern, sein. Die Techniker der Bank haben die Aufgabe, in der Währungspolitik die von den zwölf Staats- und Regierungschefs gefaßten Beschlüsse anzuwenden“, vgl. hierzu Bremer, H. H., Paris stellt die Unabhängigkeit der EG-Zentralbank in Frage, STUTTGARTER ZEITUNG vom 5.9.1992, abgedruckt in: Deutsche Bundesbank, Auszüge aus Presseartikeln, Nr. 61 vom 9.9. 1992, S. 1 
gou, die mit dieser Äußerung noch einmal das französische Bekenntnis zur Unabhängigkeit der Zentralbank relativierte.

Weiterer Streit entspann sich um den Übergang zur dritten Stufe der Wirtschafts- und Währungsunion sowie um die Beitrittsmodalitäten. So drängte vor allem die Bundesrepublik darauf, den Integrationsfortschritt in Abhängigkeit von der erreichten realen Konvergenz der Volkswirtschaften zu stellen. Die französische Regierung hingegen kritisierte die Versteifung der deutschen Seite auf monetäre Aspekte, die ihrer Meinung nach keine Priorität gegenüber der allgemeinen Wirtschaftspolitik haben dürften. ${ }^{200}$ Sie wehrte sich vor allem dagegen, die Geldwertstabilität zum einzigen Ziel der Gemeinschaft zu erheben und bestand darauf, den Mitgliedstaaten auch in Zukunft Interventionsrechte zu belassen. Ferner weigerte die französische Regierung sich, den Zutritt zur Wirtschafts- und Währungsunion anhand starrer Parameter zu reglementieren und plädierte statt dessen für eine konzertierte Wirtschaftspolitik. Diese sollte die reale Konvergenz im Rahmen einer multilateralen Überwachung sicherstellen und so dem Übergangsprozeß eine gewisse "Geschmeidigkeit" verleihen. ${ }^{201}$ Im Sinne eines solchen Kompromisses setzte Frankreich sich zwischenzeitlich für Anpassungspläne zur Förderung der realen Konvergenz ein, um allen Mitgliedstaaten den Beitritt zur Wirtschafts- und Währungsunion zu ermöglichen. ${ }^{202}$ Wirtschafts- und Finanzminister Bérégovoy gab dabei offen $z u$, daß ihn mehr die Einhaltung eines Zeitplans beim Übergang zur Wirtschafts- und Währungsunion interessiere, während die Bundesrepublik offenbar mehr Gewicht auf die Beitrittsbedingungen lege. ${ }^{203}$

Der Widerstand Frankreichs gegen rigide Beitrittskriterien und damit gegen ein Europa der unterschiedlichen Geschwindigkeiten zog sich schließlich bis zum Ende der Regierungsverhandlungen hin. Noch im Oktober 1991 wehrte sich Wirtschafts- und Finanzminister Bérégovoy gegen budgetäre Zutrittsbeschränkungen mit der Feststellung: „Il faut que les décisions soient politiques et non purement économiques“204. Er schlug im Gegenzug ein gemeinschaftliches System zur Stabilisierung der Budgets notleidender Mitgliedstaaten vor und lehnte bis zuletzt den holländischen Kompromißvorschlag ab, der die Begrenzung des höchst zulässigen Haushaltsdefizits auf drei Prozent des Bruttoinlandsprodukts vorsah. ${ }^{205}$ Ebenso weigerte sich die französische Delegation, den Übergang von der zweiten zur dritten Stufe der Währungsunion noch einmal einem einstimmigen Beschluß des Europäischen Rates zu unterwerfen, da ihrer Meinung

${ }^{200}$ Vgl. Lemaitre, P., „La Communauté pourrait imposer des sanctions aux États membres“, Le Monde vom 27.2.1991, S. 20

201 ebenda

${ }^{202} \mathrm{Vgl}$. Lemaitre, P., „Les Douzes rapprochent leurs positions sur l'union économique et monétaire“, Le Monde vom 14.5.1991, S. 21

${ }^{203}$ Äußerung Bérégovoys anläßlich des deutsch-franzöischen Wirtschafts- und Finanzrats am 5.3.1991 in Paris, Le Monde vom 7.3.1991, S. 29

${ }^{204} \mathrm{Vgl}$. o.V., „M. Bérégovoy est favorable à un système d'aide à l'assainissement“, Le Monde vom 10.10.1991, S. 29

${ }^{205}$ Vgl. Fabra, P., „Europe monétaire (suite): on négocie dans le vide“, Le Monde vom 26.11.1991, S. 28 
nach die Wirtschafts- und Währungsunion einen irreversiblen Charakter haben müsse. ${ }^{206} \mathrm{Am}$ Ende liefen die Vertragsverhandlungen auf einen Kompromiß hinaus. Frankreich mußte eine Konvergenzprüfung anhand bestimmter Kriterien hinnehmen, die Entscheidung über die Teilnahme an der Währungsunion war jedoch mit qualifizierter Mehrheit zu treffen.

Über den gesamten Verhandlungsverlauf hinweg strebte die französische Regierung eine möglichst schnelle Herbeiführung der Wirtschafts- und Währungsunion an. Mit ihrer nachrangigen Bewertung realer Konvergenzfortschritte wie auch mit ihrem sehr zögerlichen Engagement für eine autonome, der Preisstabilität verpflichteten Währungspolitik bezeugte sie, daß es ihr letztlich weniger auf die Stabilitätsorientierung der Gemeinschaft ankam, sondern mehr darauf, baldmöglichst die Definition einer europäischen Wirtschafts- und Währungspolitik auf Gemeinschaftsebene vornehmen zu können. Die gemeinschaftliche Geld- und Währungspolitik diente dabei insofern als Integrationsvehikel, als daß es über die frühzeitige Errichtung des Europäischen Zentralbanksystems schnellstmöglich zu einer engen währungspolitischen Kooperation der Regierungen kommen sollte. Der Preis für die von Frankreich angestrebte beschleunigte Einführung der Ecu war die Aufgabe der währungspolitischen Souveränität. Die französische Regierung war bereit, ihn zu zahlen, wenn es dafür zur Beseitigung der Dominanz der Bundesbank kam. In der Forderung nach unverzüglichem Übergang zur Währungsunion dokumentierte sich letztlich die Fortführung der monetaristischen Integrationsstrategie, die über die Fixierung der Wechselkurse der Gemeinschaft zu mehr realer und wirtschaftspolitischer Konvergenz verhelfen sollte und von Frankreich seit Beginn der siebziger Jahre konsequent verfolgt wurde. ${ }^{207}$

Festzuhalten bleibt somit, daß die französische Regierung mit ihrer Unterschrift unter den Maastrichter Vertrag zwar eine marktwirtschaftlich organisierte Gemeinschaft und eine stabilitätsorientierte Währungspolitik akzeptierte, dies aber weniger als die Bundesrepublik und die Niederlande aus ordnungs- oder gar stabilitätspolitischer Überzeugung heraus tat. Wie schon zu Beginn der Gemeinschaft nahm Frankreich die vertraglichen Vereinbarungen als notwendigen Kompromiß hin, weil sich unter den gegebenen Umständen nicht mehr erreichen ließ. Was die französische Regierung wirklich interessierte, war eine Wirtschafts- und Währungsunion, die Europa zu einer wirtschaftspolitisch handlungsfähigen Einheit machte. Der Beschluß der Wirtschafts- und Währungsunion stellte aus französischer Sicht einen politischen Willens- und Gestaltungsakt dar, der in seiner Bedeutung weit über wirtschaftliche und monetäre Sachfragen hinausging. Nach wie vor war ein machtvolles und unabhängiges Europa das dominierende Motiv der französischen Wirtschafts- und Währungspolitik. Dies zeigte sich noch einmal deutlich in der Interpretation der Maastrichter Verträge durch Staatspräsident Mitterrand, der einem Tag nach dem Europäischen Rat von Maastricht der Europäischen Währung den Aufstieg zur bedeutendsten Währung der Welt prophezei-

${ }^{206}$ Vgl. Chartier, C., „La France conteste les propositions néerlandais sur l'union monétaire européenne, Le Monde vom 28.11.1991, S. 31

${ }^{207}$ Vgl. Kaltenthaler (1997), a.a.O., S. 95 
te. ${ }^{208}$ Allen stabilitätspolitischen Bekenntnissen der französischen Währungspolitik zum Trotz blieb auch die europäische Währung für den vierten Präsidenten der V. Republik unverändert primär ein Symbol für Macht und Einfluß und damit letztlich für den Rang eines Staatswesens:

"Avec une monnaie unique on dotera l'Europe d'un instrument qui lui permettra de s'affirrmer comme la première puissance au monde: première puissance commerciale - c'est déjà pratiquement le cas - première puissance industrielle, première puissance pour la recherche, première puissance qui offrira aux jeunes d'avoir du travail, des métiers. Sur tous les marchés, nous serons au moins aussi forts ensemble que le sont aujourd'hui les Américains et les Japonais. “209

\section{B.5.3.3 Zusammenfassung}

Sowohl die französischen Bemühungen um die Wirtschafts- und Währungsunion wie auch die französische Währungspolitik in den Jahren zuvor waren in erster Linie von dem Bestreben geprägt, die monetäre Entwicklung wieder unter politische Kontrolle zu bekommen. Ununterbrochen zeigte sich die französische Regierung bemüht, die europäischen wie auch die internationalen Währungsbeziehungen in eine feste Währungsordnung zu überführen, von der sie sich stabile Wechselkurse und eine harmonisierte Entwicklung des Zinsniveaus erhoffte. Möglichst geringe Wechselkursschwankungen betrachtete sie als unabdingbare Voraussetzung für einen geordneten Außenhandel, während ein einheitlich niedriges Zinsniveau als entscheidend für den Erfolg ihrer industriepolitischen Wachstumsstrategie angesehen wurde. Über diese beiden monetären Parameter fand die Geld- und Währungspolitik ihre Verbindung zur wirtschaftspolitischen Strategie der französischen Regierung, für deren Erfolg sie eine wesentliche Voraussetzung bildeten.

Das dieser Strategie inhärente Verständnis der Währungspolitik als Komplement der Wirtschaftspolitik folgte einer einfachen politischen Logik. Die Währungspolitik hatte die Entwicklung der monetären Größen so zu beeinflussen, daß sie optimal an die wirtschaftspolitische Strategie angepaßt waren. Zurückzuführen war diese interventionistische Grundhaltung auf die Kritik der französischen Regierung an der Unzulänglichkeit der Marktkoordination, die sie am deutlichsten im Zusammenhang mit der Spekulation vortrug. Wiederholt kritisierte sie dabei das Störpotential spekulativer Kapitalbewegungen, die aufgrund der Liberalisierung des Kapitalverkehrs die monetäre Stabilität ganzer Wirtschaftsräume in Gefahr zu bringen drohten. Vor allem störte sie dabei, daß leicht erwirtschaftete spekulative Kapitalgewinne den realwirtschaftlichen Einkommenserwerb diskriminierten und zu „unverschämt“" großen Vermögen führten. In der Spekulation offenbarte sich aus Sicht der französischen Regierung letztlich die grundlegende moralische Schwäche des unregulierten Marktmechanismus, der die Koordi-

${ }^{208}$ So Mitterrand in einem Interview in „7 sur 7“ am 15.12.1991, abgedruckt in Auszügen in: Le Monde vom 7.12.1991, S. 8

${ }^{209}$ So Mitterrand am 11.12.1991 in einem Fernsehinterview zum Abschluß der Verträge von Maastricht, abgedruckt in Auszügen in: Le Monde, 13.12.1991, S. 10 
nation der Partikularinteressen ohne Rücksicht auf moralische oder soziale Prinzipien und - schwerwiegender noch - ohne Rücksicht auf das Allgemeininteresse vornahm. Dieses bestand ihrer Meinung nach in einer wohlgeordneten wachstumsorientierten Wirtschaftsentwicklung, die gegen zufällige und willkürliche Störungen seitens der Märkte geschützt werden mußte und auf monetäre Stabilität angewiesen war. Wie im realwirtschaftlichen Bereich, so bedurfte es auch auf monetärer Ebene einer Korrektur der Defizite des Marktmechanismus. Aus französischer Sicht konnte dies nur über staatliche Eingriffe geschehen, die auf zwischenstaatlicher Ebene wiederum eine enge währungspolitische Kooperation erforderten. Mit ihrem nachhaltigen Engagement für eine konzertierte Abstimmung der nationalen Währungspolitiken versuchte die französische Regierung, eine dem "Allgemeininteresse" entsprechende internationale Währungspolitik zu verwirklichen und die Staaten zum Aufbau einer ,rationalen“ und „gerechten“ Währungsordnung zu bewegen. In Analogie zu ihrer europäischen Wirtschaftspolitik lief die währungspolitische Konzeption der französischen Regierung auf die politische Koordinierung und Gestaltung der internationalen Währungsbeziehungen hinaus.

Zur Umsetzung ihres monetären Ordnungskonzepts bediente sich die französische Währungspolitik unter François Mitterrand der monetaristischen Integrationsstrategie, die Frankreich seit Beginn der siebziger Jahre unverändert weiter verfolgte. Auf internationaler wie europäischer Ebene strebte es die Integration der Währungen in Festkursarrangements an, um so zu einer engeren währungspolitischen Zusammenarbeit und über diese zu mehr realer und wirtschaftspolitischer Konvergenz zu gelangen, ohne dabei die Staaten zur formalen Abtretung substantieller Kompetenzen zu zwingen. Auf europäischer Ebene drängte die französische Währungspolitik unentwegt auf die "Stärkung" der Ecu, um die Gemeinschaft endlich zu einer einheitlichen Währungspolitik zu bewegen. Bis 1987 interessierte sie dabei vor allem der auswärtige Aspekt, Europa auf internationaler Ebene neben den USA und Japan als gleichberechtigten Mitspieler zu etablieren. Als solcher sollte es sein Gewicht in erster Linie für die Stabilisierung der Währungsbeziehungen nutzen, um die sich Frankreich eigentlich ununterbrochen seit dem Zusammenbruch des internationalen Währungssystems im Jahre 1973 bemüht hatte. Die „gestärkte“ Ecu selbst hatte nichts mit einer echten Gemeinschaftswährung zu tun, sondern war nur als Instrument zur Setzung monetärer Sachzwänge gedacht. In ihrer fehlenden realen Bedeutung lag letztlich auch die Ursache für die Schwäche dieses Ansatzes. Hinzu kam, daß die monetären Ordnungsvorstellungen Frankreichs im Grundsatz mit denen jener Länder kollidierten, die eine bewußt stabilitätsorientierte Politik betrieben. Diese konzentrierten sich nach den krisenhaften Erfahrungen der siebziger und Anfang der achtziger Jahre auf die Inflationsbekämpfung. Sie folgten dabei dem Beispiel der bundesdeutschen Geld- und Währungspolitik, die weitgehend von politischen Interventionen absah, was die französische Regierung schließlich zu einer Revision ihrer Taktik zwang.

Statt weiter einer halbherzig ,gestärkten“ Gemeinschaftswährung nachzuhängen, ging die französische Währungspolitik Ende der achtziger Jahre schließlich in die Offensi- 
ve. Mit der Forderung nach einer Wirtschafts- und Währungsunion verband sie die Einführung einer vollwertigen Gemeinschaftswährung sowie die Errichtung einer Europäischen Zentralbank. Formal erforderte dieser Schritt zwar die Aufgabe währungspolitischer Kompetenzen, praktisch bot er aber den Vorteil ihrer Neuverteilung auf europäischer Ebene durch die Beendigung der faktischen Vorherrschaft der Bundesbank und ihrer Geldpolitik. Statt weiter zu einer reaktiven Währungspolitik gezwungen zu sein, die sich im wesentlichen darauf beschränkte, den Kurs der eigenen Währung auf den Devisenmärkten gegen die Deutsche Mark zu verteidigen und damit die deutsche Geldpolitik passiv nachvollziehen zu müssen, bot sich mit einer Einheitswährung wieder die Möglichkeit, aktiv an der Ausgestaltung der Geldpolitik in Europa teilzunehmen. Die Aufgabe der monetären Souveränität zugunsten einer europäischen Währungsunion war der einzige Weg, dem Stabilitätsdiktat und der grundsätzlichen politischen Abstinenz, die mit der deutschen monetären Ordnungskonzeption verbunden waren, zu entkommen. Die Vergemeinschaftung der Währungspolitik relativierte das politische Gewicht der deutschen Geldpolitik und schaffte zumindest hypothetisch die Möglichkeit, die Ausgestaltung der monetären Entwicklung den unabhängigen Zentralbanken und den Finanz- und Devisenmärkten zu entreißen, um sie wieder auf die politische Ebene zurückzuverlagern, wo sie nach Ansicht der französischen Regierung hingehörte.

Trotz der Bereitschaft zur Abgabe währungspolitischer Kompetenzen achtete die französische Regierung streng darauf, daß es dabei nicht zu einem vollständigen Souveränitätsverlust der nationalen Regierungen kam. So bestand sie zum einen darauf, daß die Ausgestaltung und Formulierung der europäischen Wirtschafts- und Währungspolitik im Europäischen Rat und im Ministerrat vorgenommen wurde, damit diese Politikbereiche weiter Angelegenheit der nationalen Regierungen und somit Gegenstand der intergouvernementalen Abstimmung blieben. Zum anderen verwahrte sie sich nachhaltig gegen eine autonome Geld- und Währungspolitik, die abgekoppelt von der allgemeinen Wirtschaftspolitik von einer unabhängigen, allein der Preisstabilität verpflichteten Zentralbank betrieben werden sollte. Zur Wahrung eines größtmöglichen Restbestandes an monetären Souveränitätsrechten sollte die währungspolitische $\mathrm{Be}$ schlußfindung in ein Gremium verlagert werden, in dem die nationalen Regierungen die Hoheit hatten, während die Unabhängigkeit der Zentralbank auf die technische Durchführung währungspolitischer Vorgaben beschränkt zu bleiben hatte. Vorteilhaft an einer solchen Regelung war aus französischer Sicht nicht nur, daß die monetäre Entwicklung generell wieder Gegenstand der internationalen währungspolitischen Konzertation gewesen wäre. Es wäre vor allem zur Konzentration währungs- und wirtschaftspolitischer Kompetenzen in ein und demselben Gremium, nämlich dem Europäischen Rat, gekommen und damit zur engstmöglichen Verbindung von Wirtschaftsund Währungspolitik, die Frankreich eigentlich seit Beginn der Europäischen Integration angestrebt hatte. Damit entpuppte sich die für Europa gewollte Währungspolitik letztlich als Teil einer wirtschafts- und währungspolitischen Gesamtstrategie für Europa, die den nationalen Regierungen alle Kompetenzen und damit alle Macht über die Gestaltung des Wirtschaftsablaufs zurückgegeben hätte. Ordnungspolitisch betrachtet 
zielte diese Gesamtstrategie auf eine interventionistische europäische Wirtschaftsordnung, die dem Gestaltungswillen der wirtschafts- und währungspolitischen Entscheidungsträger prinzipiell keine Grenzen gesetzt hätte, sondern im Gegenteil ihnen alle Wege und Möglichkeiten offen hielt, um die Entwicklung der Wirtschaft in ihrem Sinne zu beeinflussen.

$\mathrm{Da}$ es nicht zur Verabschiedung einer solchen Wirtschaftsordnung für den Binnenmarkt kam, lag an dem hinhaltenden Widerstand der stabilitätsorientierten Länder, die für eine unabhängige, primär auf Preisstabilität fixierte Währungspolitik der Gemeinschaft eintraten. Wenn die französische Regierung deren monetäre Ordnungsvorstellungen auch nicht teilte, so unterschrieb sie den neuen EWG-Vertrag aus übergeordneten Erwägungen heraus. Mit der in Aussicht gestellten Vollendung der Währungsunion spätestens im Jahr 1999 bot er hinreichend Hoffnung, in der Zwischenzeit doch noch zum Ziel zu kommen. Der französischen Regierung wurde diese Unterschrift allerdings auch leicht gemacht, da im neuen EWG-Vertrag nur das globale Ziel für die zukünftige Geldpolitik festgelegt wurde, nicht aber deren Inhalt und Instrumente. Offengelassen wurde der Verpflichtungsgrad des Stabilitätsziels und vor allem die Frage, ob die gemeinschaftliche Geldpolitik anhand eines Inflations- oder Geldmengenziels auszurichten war. Hinter dieser Frage verbarg sich letztlich die Entscheidung für oder gegen eine diskretionäre Geldpolitik. Es blieb somit Raum für währungspolitische Interpretationen, der jeder Regierung gestattete, ihre Ansichten als durchgesetzt zu betrachten. Für die von der französischen Regierung gewünschte Währungspolitik waren damit langfristig nach wie vor immer noch Entfaltungsmöglichkeiten gegeben.

\section{B.5.4 Die ordnungspolitische Orientierung der französischen Binnenmarktpolitik unter François Mitterrand}

Das Hauptmerkmal der französischen Europapolitik unter François Mitterrand war ihre ordnungspolitische Konstanz. Sie zeichnete sich in erster Linie dadurch aus, daß sie die schon in den sechziger und siebziger Jahren ausgeprägten Inhalte der französischen Binnenmarktpolitik aufnahm, sie zu einer einheitlichen Ordnungskonzeption verdichtete und diese mit nicht unbeträchtlichem Erfolg auf europäischer Ebene durchsetzen konnte. In diesem Sinne war die französische Binnenmarktpolitik in den achtziger Jahren weniger innovativ als effektiv.

Wie seit de Gaulle üblich war die französische Binnenmarktpolitik auch unter Mitterrand Teil eines europapolitischen Gesamtkonzepts, das im wesentlichen auf die Herausbildung einer politisch handlungsfähigen Einheit mit Weltgeltung angelegt war. Aufgabe dieser Einheit war die Wahrung und Verbreitung der europäischen Kultur und ihrer gesellschaftspolitischen Ideale, welche sich jedoch bei genauerem Hinsehen als jene der französischen Aufklärung entpuppten. Der europäische Zusammenschluß blieb für Frankreich primär eine Zweckgemeinschaft zur Verbreitung gesellschaftlicher Zielvorstellungen, in der es selbst die politische Führung beanspruchte. Ihren Füh- 
rungsanspruch leitete die französische Europapolitik auch unter François Mitterrand aus der "Grandeur" Frankreichs ab, womit sie letztlich auf die ideellen Grundlagen der Europapolitik de Gaulles zurückgriff. Sie verteidigte diesen Führungsanspruch entschlossen auch nach dem Zusammenbruch der kommunistischen Regime Osteuropas 1989/90, als sie befürchten mußte, daß ein erstarktes Deutschland und beitrittswillige osteuropäische Staaten Frankreich die angestrebte politische Führungsrolle streitig zu machen drohten.

Zur Verwirklichung ihrer europapolitischen Konzeption, konzentrierte sich die französische Regierung konsequent auf die Vertiefung der politischen Zusammenarbeit in Europa. Über dabei auftretende Gewöhnungseffekte hoffte sie, zu einer eigenständigen europäischen Politik auf internationaler Ebene zu gelangen. Diese Gemeinschaftspolitik durfte allerdings nicht die Souveränitätsrechte der Mitgliedstaaten antasten, denn letztlich war das politisch aktive Europa auch unter François Mitterrand weiter ein Europa unabhängiger Nationen. Dies hatte zur Folge, daß die nationalen Regierungen aus französischer Sicht grundsätzlich weiter die Träger der europäischen Politik bleiben und dementsprechend die maßgeblichen Entscheidungen fällen sollten. Streng achtete Frankreich deshalb darauf, den Kompetenzzuwachs supranationaler Organe wie der Europäischen Kommission oder der Europäischen Zentralbank zu begrenzen. Nur so konnte es sicherstellen, in einem politisch aktiven Europa auch weiterhin ungestört eine führende Rolle spielen zu können.

In ihrem Bemühen zur Vertiefung der politischen Zusammenarbeit in Europa konzentrierte sich die französische Regierung bis 1983 zunächst auf den Ausbau der gemeinsamen Wirtschafts- und Währungspolitik, bei dem sie ihr keynesianisches Reformkonzept für die französische Wirtschaft auf die Gemeinschaft zu übertragen versuchte. Nachdem dieser Versuch gescheitert war, verlagerte sich ihr Interesse zwischenzeitlich auf die Vollendung des Binnenmarktes und den Aufbau einer europäischen Außenund Sicherheitspolitik. Beides wurde mit der Einheitlichen Europäischen Akte 1987 vorläufig abgeschlossen. Da für eine durchsetzungsfähige europäische Politik funktionsfähige Entscheidungsstrukturen sowie Macht und Einfluß notwendig waren, drängte Frankreich konsequent weiter auf eine enge wirtschafts- und währungspolitische Zusammenarbeit mit dem Ziel einer starken und international wettbewerbsfähigen europäischen Wirtschaft.

Von diesem Ziel ausgehend bemühte sich die französische Regierung durchgehend um eine europäische Wirtschafts- und Währungspolitik zur Stimulierung von Wachstum und Beschäftigung. Im Zentrum der von Frankreich angestrebten europäischen Wirtschaftspolitik standen die Industrie- und Forschungspolitik. Sie sollten nach außen durch eine protektionistische europäische Handelspolitik flankiert werden, um Störungen durch überlegene ausländische Konkurrenz zu verhindern. Nach innen oblag es der europäischen Sozialpolitik, die Arbeitnehmer- und Arbeitgeberseite in die Umsetzung der politischen Wachstumsbemühungen einzubinden, um diese so vor Störungen z. B. durch Arbeitskämpfe zu schützen. Auf monetärer Ebene hingegen hatte die europäi- 
sche Währungspolitik ihren Beitrag zu leisten, indem sie Wechselkurs und Zins auf vorteilhaftem Niveau stabilisierte. Eine autonome und einzig der Geldwertstabilität verpflichtete Währungspolitik war in der französischen Ordnungskonzeption nicht vorgesehen. Monetärer und realwirtschaftlicher Bereich waren aufeinander abgestimmt und fügten sich zu einer makroökonomischen Gesamtkonzeption, die vorrangig auf die Stärkung der europäischen Wirtschaft bzw. auf das Erreichen konkreter Wachstumsund Entwicklungsziele ausgerichtet war.

Dreh- und Angelpunkt des französischen Gesamtkonzepts zur Stärkung der europäischen Wirtschaft war die Förderung der technologischen Forschung. Diese sollte sich vornehmlich auf jene Hochtechnologieindustrien konzentrieren, deren Produkten besondere Bedeutung für die Zukunft der europäischen Wirtschaft beigemessen wurde. Ausgehend von der Überzeugung, daß eine sich selbst überlassene europäische Wirtschaft nicht in der Lage sein würde, den technologischen Rückstand gegenüber führenden Industrienationen wie Japan und den USA aufzuholen, fiel den nationalen Regierungen aus französischer Sicht natürlicherweise die Pflicht zu, die notwendigen Aufhol- und Anpassungsprozesse anzuregen und sie in die richtige Richtung zu lenken. Sie waren dazu um so mehr prädestiniert, als daß die französische Regierung grundsätzlich unterstellte, daß der wirtschaftliche Wettbewerb auf Märkten nur die Eigeninteressen der Marktteilnehmer gebührend berücksichtige und von daher nur bei kurzfristigen Entscheidungen ein optimales Koordinationsinstrument sei. Bei langfristigen Entscheidungen jedoch, wie z. B. bei der technologischen Grundlagenforschung, die einen wirtschaftlichen Erfolg erst in ferner Zukunft versprachen, zugleich aber aufgrund ihrer externen Effekte von hoher Bedeutung für die allgemeine Wirtschaftsentwicklung und damit für das Allgemeininteresse waren, mußte der Marktmechanismus aus französischer Sicht versagen. Hier war mehr als nur die Einzelinteressen der Wirtschaftssubjekte berührt, was darauf hinauslief, daß nur über staatliche Eingriffe in die Wirtschaftsentwicklung dem Allgemeininteresse Geltung verschafft werden konnte.

Staatliche Interventionen in das Wirtschaftsgeschehen waren somit für die französische Regierung grundsätzlich legitimiert und angesichts des als bedrohlich wahrgenommenen technologischen Rückstands Europas dringend notwendig. Im Rahmen der politischen Zusammenarbeit sollte all das geleistet werden, wozu der Marktmechanismus aus französischer Sicht nicht imstande war. Diese Überlegungen führten die französische Regierung zur Forderung nach Zentralisierung der wirtschafts- und währungspolitischen Kompetenzen. Auf europäischer Ebene waren es der Ministerrat und der Europäische Rat, in denen nach französischer Ansicht beide Politikbereiche wachstumsoptimal im Rahmen einer ex-ante Koordination aufeinander abgestimmt werden sollten. Frankreich strebte damit letztlich die Institutionalisierung eines gesamteuropäischen wirtschafts- und währungspolitischen Interventionismus an, der die Entwicklung der Wirtschaft wieder stärker in den Einflußbereich der nationalen Regierungen zurückbringen sollte. 
$\mathrm{Da}$ eine solche Binnenmarktpolitik sich schon von ihrer Grundrichtung her nicht mit den Prinzipien der Euckenschen Wettbewerbsordnung vereinbaren ließ, ist unmittelbar einsichtig. Auch wenn die französische Regierung im Laufe der Jahre von direkten Eingriffen in den Preismechanismus absah, so zeigten Äußerungen des Staatspräsidenten im Zusammenhang mit den Weltenergie- und Nahrungsmittelpreisen sowie das französische Engagement in der europäischen Agrarpolitik, daß die Neigung dazu immer noch vorhanden war.

Dem Primat der Preisstabilität vermochte die französische Währungspolitik insofern nicht zu entsprechen, da sie zum einen grundsätzlich vom Primat der Wirtschaftspolitik ausging und zum anderen eine autonome, allein der Geldwertstabilität verpflichtete Währungspolitik ablehnte. Statt dessen bemühte sie sich, monetäre Grundsätze wie die Preisstabilität als Ziel der Geldpolitik und die Unabhängigkeit der Zentralbanken in der Währungsunion zu relativieren. Zur Stabilisierung der Wechselkurse vertraute sie außerdem mehr auf politische Übereinkünfte als auf eine stabilitätsorientierte und auf die Entwicklung der Geld- und Devisenmärkte ausgerichtete Politik. Ihr generelles Mißtrauen gegenüber der Marktkoordination bewegte die französische Währungspolitik dazu, weiter an Interventionsrechten wie z. B. Kapitalverkehrskontrollen festzuhalten. Grundsätzlich zog sie die Setzung monetärer Daten im Rahmen einer engen währungspolitischen Koordination vor, statt diese durch den Marktmechanismus bestimmen zu lassen.

Restriktiv war auch die Haltung der französischen Europapolitik in bezug auf die Öffnung der Märkte. Bis 1992 setzte sie sich aktiv für die Protektion ausgesuchter Märkte ein und war nur dort zu deren Öffnung bereit, wo sie sich der internationalen Wettbewerbsfähigkeit europäischer Produkte zuvor versichert hatte. Die gleiche Zurückhaltung prägte auch die französische Haltung gegenüber ausländischen Direktinvestitionen in der Gemeinschaft, die nur im Rahmen einer politischen Kontrolle zugelassen werden sollten.

Ebenfalls verstieß die von Frankreich gewünschte Wirtschaftspolitik gegen das Prinzip der Einheit von Gestaltungsmacht und Haftung. Weil sie dem Marktmechanismus grundsätzlich mißtraute, drängte die französische Regierung unter Bezugnahme auf das Allgemeininteresse nachhaltig auf Eingriffe des Staates zur Lenkung der langfristigen Wirtschaftsentwicklung. Um die Unternehmen zu Investitionen in politisch als förderungswürdig auserkorenen Branchen zu veranlassen, sollte der Staat mit finanziellen und materiellen Beihilfen sowie direkten Beteiligungen einen Teil des Unternehmensrisikos übernehmen. Dabei wäre jedoch die wirtschaftliche Verantwortung der Entscheidungsträger in den Unternehmen reduziert und die Unternehmer ihrer Pionierrolle, welche in der Wettbewerbsordnung eine wesentliche Voraussetzung für die wirtschaftliche Entwicklung darstellt, beraubt worden.

Des weiteren hätten die Eingriffsmöglichkeiten der europäischen Wirtschafts- und Währungspolitik, so, wie sie von Frankreich gewünscht wurden, dem Prinzip der Ste- 
tigkeit und Vorhersehbarkeit der Wirtschaftspolitik widersprochen. Die von französischer Seite angestrebten Interventionskompetenzen waren vom Grundsatz her nicht begrenzt. Insofern muß man davon ausgehen, daß die geforderten Spielräume von politischen Verantwortungsträgern auch genutzt worden wären, was der Wirtschaftsordnung im Binnenmarkt ein großes Element der Beliebigkeit verliehen hätte.

Mit dem Prinzip der Wettbewerbskontrolle unvereinbar war eine Industriepolitik, die im wesentlichen auf Großunternehmen baute. Die französischen Reaktionen auf die fehlgeschlagene Fusion von ATR/de Havilland sowie Vorschläge, nach denen bei Fusionsprüfungen durch Kartellbehörden nicht der nationale Markt, sondern grundsätzlich der Binnenmarkt als relevanter Markt herangezogen werden sollte, zeigten, daß die französische Regierung die mit der Förderung von Großunternehmen eingehergehende Gefahr der Entstehung von Monopolen grundsätzlich nicht fürchtete. Aus dem Blickwinkel der Wettbewerbsordnung muß ein solch einseitiger Ansatz jedoch verworfen werden, da bei einseitiger Förderung von Großunternehmen der Aufbau wirtschaftlicher Machtpositionen und damit eine Gefahr für die Funktionsfähigkeit des Wettbewerbs zu befürchten ist.

Auf dem Gebiet der Sozialpolitik schließlich verstieß vor allem die Forderung nach Harmonisierung der Sozialgesetzgebungen auf dem höchsten Niveau gegen die in der Wettbewerbsordnung geforderte marktneutrale Eingriffspolitik. Um einen Wettbewerb der Sozialsysteme zu verhindern, sollten nach dem Willen der französischen Regierung indirekte Lohnbestandteile wie Arbeitszeit und Urlaubsdauer einheitlich geregelt und weitere Bestandteile der Entlohnung im Rahmen von Tarifverhandlungen der Sozialpartner europaweit bestimmt werden. Wesentliche Teile der Entlohnung wären somit der Regelung über den Arbeitsmarkt entzogen worden. Stärker als anderswo zeigte sich im Bereich der Sozialpolitik die Präferenz der französischen Regierung für konzertative Verhandlungslösungen, wie z. B. den sozialen Dialog, die sie grundsätzlich der dezentralen Marktkoordination vorzog.

Bei allen Prinzipien der Wettbewerbsordnung lassen sich somit Abweichungen feststellen, die allesamt auf das französische Bemühen zurückzuführen waren, den Marktmechanismus als Regelungsinstanz durch einen wirtschafts- und währungspolitischen Interventionismus zu ersetzen. Aus ordnungspolitischer Sicht läßt sich die von Frankreich angestrebte europäische Wirtschafts- und Währungspolitik letztlich als permanenter Versuch interpretieren, die vereinbarte marktwirtschaftliche Ordnung des Binnenmarktes durch einen systematisch angelegten Interventionsmechanismus zu ergänzen. Statt die Koordination von Entscheidungen mit großer ökonomischer Tragweite „anonymen“ Marktkräften zu überlassen, sollten die nationalen Regierungen auf dem Verhandlungsweg optimale Lösungen ermitteln, die den Interessen aller Beteiligten gerecht würden. Der „ungebändigte, nicht kontrollierbare Marktmechanismus“ sollte in wichtigen Fragen durch ein „rationales und überlegenes Koordinationsinstrument" ersetzt werden, das in der wirtschafts- und währungspolitischen Konzertation der Regierungen der Mitgliedstaaten bestand. Außer dem festen Willen zur Institutionalisierung 
der politischen Einflußnahme auf die Wirtschaftsentwicklung prägte den französischen Entwurf einer europäischen Wirtschafts- und Währungspolitik ansonsten keinerlei konsistentes Ordnungswollen.

Erfolgreich war die französische Regierung mit ihrem Politikentwurf insofern, als daß sie mit der Aufnahme der Industriepolitik in den EG-Vertrag (Artikel 130) einer vertraglich legitimierten Eingriffspolitik zumindest im Grundsatz den Weg gebahnt hat. Auf monetärer Ebene hingegen bleibt mit der ausstehenden endgültigen Ausgestaltung der europäischen Geldpolitik zunächst noch offen, ob es ebenfalls zu einer Annäherung an die von Frankreich gewünschte Ordnungskonzeption kommen wird. Bis zum Ende der Amtszeit Mitterrands kann von einem ordnungspolitischen Teilerfolg Frankreichs gesprochen werden, der im wesentlichen in der Übernahme der europäischen Forschungs- und Industriepolitik in den EWG-Vertrag sowie im Beschluß über die endgültige Einführung einer einheitlichen europäischen Währung besteht. Unter Mitterrand erreichte die französische Europapolitik damit im Bereich der Wirtschaftspolitik ein ordnungspolitisches Ziel, das Frankreich seit schon Beginn der europäischen Einigung verfolgt hat. Im monetären Bereich hat Frankreich unter Mitterrand ebenfalls unbeirrt an bestimmten Ordnungsvorstellungen festgehalten, die schon unter de Gaulle die französische Geld- und Währungspolitik prägten. Mit dem Beschluß zur Gründung der Europäischen Währungsunion rückte die von Frankreich über lange Jahre geforderte einheitliche europäische Geld- und Währungspolitik in greifbare Nähe, allerdings um den Preis umfangreicher stabilitätspolitischer Konzessionen. Diese werden zunächst verhindern, daß es kurzfristig zu der französischerseits angestrebten wirtschaftsund währungspolitischen Gesamtsteuerung auf europäischer Ebene kommen kann. Da die europäische Geldpolitik aber in vielen praktischen Aspekten wie zum Beispiel der Wechselkurspolitik, der monetären Außenvertretung oder der Koordination der in nationaler Hand verbleibenden Haushaltspolitik noch nicht festgelegt ist, bestehen weiter Möglichkeiten für eine Annäherung der Währungsverfassung Europas an die monetären Ordnungsvorstellungen Frankreichs, die es nicht ungenutzt lassen wird.

Auf die hohe Bedeutung der ordnungspolitischen Ausrichtung der Gemeinschaft für die französische Europapolitik deutete das persönliche Engagement Staatspräsident Mitterrands hin, der zuvor nie als Wirtschaftspolitiker in Erscheinung getreten war oder anderweitig Erfahrungen auf diesem Gebiet gesammelt hatte. Dennoch griff er wie alle französischen Staatspräsidenten vor ihm von Beginn seiner Amtszeit an aktiv in die Formulierung der nationalen französischen Wirtschaftspolitik sowie in die Europa zugedachte Wirtschafts- und Währungspolitik ein. Durchgängiges Charakteristikum seines Engagements war seine persönliche Distanz zum Kapitalismus sowie sein offenes Bekenntnis zu dirigistischen Eingriffen, die er grundsätzlich als notwendig erachtete, um die Einzelinteressen der Wirtschaftssubjekte erfolgreich mit dem Allgemeininteresse auf nationaler wie europäischer Ebene versöhnen zu können. Deutlich betonte er immer wieder, daß die Wirtschaft und ihre Entwicklung nicht nur aus ökonomischem Blickwinkel betrachtet werden dürften, sondern von maßgeblicher Bedeutung für die Entfaltungsmöglichkeiten einer Gesellschaft seien. Er selbst, der sich per- 
sönlich und Frankreich als Nation mit den Werten der französischen Aufklärung identifizierte, die es in die Welt hinauszutragen galt, mußte zwangsläufig eine Wirtschaftspolitik anstreben, die in erster Linie auf Expansion angelegt war; nicht umsonst sprach er nach dem Abschluß der Verträge zur Wirtschafts- und Währungsunion von Europa als „première puissance au monde“, die es bald mit Amerika und Japan aufnehmen können würde. Er zeigte damit erneut unmißverständlich, daß die Wirtschafts- und Währungspolitik für ihn in erster Linie als Machtpolitik von Bedeutung waren. Wirtschaft und Politik schienen ihm ein unteilbares Ganzes zu sein, das einer einheitlichen Logik folgte und sich aus bestimmten sozialphilosophischen Anschauungen heraus definierte. Für Mitterrand waren wirtschaftliche und politische Macht zwei Seiten ein und derselben Medaille. In dieser Hinsicht stimmte er mit seinem einstigen politischen Intimfeind Charles de Gaulle überein, mit dem er darüber hinaus nicht nur die Abneigung gegen den Kapitalismus teilte, sondern auch den militärischen Sprachgebrauch. Besonders deutlich wurde dies in Mitterrands Auffassung der Konkurrenz auf den Weltmärkten, die er wie de Gaulle mit einem tagtäglichen Wirtschaftskrieg verglich, der dauerhaft nur durch eine europäische Zusammenarbeit gewonnen werden könne:

„Cette image guerrière traduit très exactement ma pensée ... Elle vaut aussi pour l'industrie. On gagne Austerlitz quand on élève une position dans l'électronique ou dans la biologie; on perd Waterloo quand on abandonne l'automobile ou la machine-outil. Là sont les véritables champs de batailles modernes. Quand je souhaite que les pays et les entreprises d'Europe occidentale s'associent pour inventer, construire et vendre (et je m'y emploie par des initiatives comme <<EUREKA $>>$ ), je n'en pense pas moins qu'un tel projet, qui demandera temps et patience, dépend de la vitalité de l'industrie française. Qu'elle se laisse absorber par les grands cartels internationaux et c'en sera fini des chances européennes. La réussite de l'Europe suppose la réussite de la France.“210

Mitterrand wie de Gaulle waren beide glühende Verehrer der französischen Nation. Sie teilten dieselbe Perspektive in der Beurteilung ökonomischer Sachverhalte, die sie vorzugsweise auf ihre Relevanz für die Existenz und den internationalen Einfluß der Nation reduzierten. Diese Perspektive ließ sie die europäische Wirtschafts- und Währungspolitik als „Bündnispolitik“ auffassen, mit dem Ziel, gemeinsam „Kriege“ zu gewinnen, wobei die Gegner immer die gleichen waren: Japan und die USA. Mit ihrem Engagement demonstrierten die beiden nicht nur, daß die Wirtschaftspolitik neben der Außenpolitik eine weitere "domaine réservé" darstellte, in der sich französische Staatspräsidenten das letzte Wort nicht nehmen ließen. Sie machten darüber hinaus deutlich, daß es parteiübergreifend Übereinstimmungen in den ordnungspolitischen Überzeugungen aller Staatspräsidenten gegeben hat, die im Verlauf des gesamten europäischen Einigungsprozesses zu Konstanten in der französischen Binnenmarktpolitik geführt haben. Diese sollen im nachfolgenden Kapitel zusammengefaßt und danach aus dem Blickwinkel der Wirtschaftsstilforschung interpretiert werden.

${ }^{210}$ Mitterrand (1986), a.a.O., S. 14 f. 


\section{B.6 Ein interventionistischer Ordnungsentwurf für Europa}

Ziel der Untersuchung im Teil B. war die Ermittlung der von Frankreich angestrebten Ordnungskonzeption für den europäischen Binnenmarkt. Von den Anfängen seiner Gründung 1955 bis zum Beschluß über die Errichtung einer Wirtschafts- und Währungsunion 1992 ist die französische Europapolitik auf die ihr immanenten Leitvorstellungen von der optimalen Ordnung der Wirtschaftsabläufe untersucht worden. Der Überlagerung ökonomischer, politischer und sozio-kultureller Motive bei der konkreten Ausgestaltung von Wirtschaftsordnungen wurde dadurch entsprochen, daß der Untersuchung der angestrebten ökonomischen Ordnungselemente eine Darstellung der jeweiligen europapolitischen Konzeption voranging. Dieser Ansatz ermöglichte, politische und gesellschaftliche Leitideen in ihrem Einfluß auf die Ausformulierung wirtschaftlicher Ordnungsvorstellungen zu berücksichtigen und die ordnungspolitischen Ansätze der jeweiligen französischen Regierungen in die übergeordnete Zielsetzung der französischen Europapolitik einzuordnen. Im folgenden sollen die Entwicklung der ordnungspolitischen Haltung Frankreichs zusammenfassend dargestellt und die dabei wiederkehren Elemente zu einem einheitlichen Ordnungskonzept zusammengefügt werden.

Über den gesamten Zeitraum des europäischen Einigungsprozesses läßt sich feststellen, daß Frankreich durchgehend auf die Institutionalisierung einer wirtschafts- und währungspolitischen Gesamtsteuerung in der Europäischen Gemeinschaft hingewirkt hat. Ziel der französischen Binnenmarktpolitik war, die Entwicklung von Wirtschaft und Währung im Gemeinsamen Markt wieder unter einen stärkeren Einfluß politischer Entscheidungsträger zu stellen als es mit der 1957 beschlossenen marktwirtschaftlichen Wirtschaftsordnung für den Binnenmarkt vorgesehen war. Vor allem ging es Frankreich darum, die zur Steuerung der Wirtschaftsentwicklung notwendigen Eingriffs- und Gestaltungsmöglichkeiten zu schaffen und vertraglich festzulegen. Bis zum Ende des Betrachtungszeitraums dieser Arbeit (April 1998) kann festgestellt werden, daß sich die französische Europapolitik mit Erfolg bemüht hat, die Gemeinschaft in Richtung einer interventionistischen Wirtschaftsordnung zu bewegen.

Schon im ersten Memorandum zur Europäischen Wirtschaftsgemeinschaft ließ sich die ordnungspolitische Orientierung der französischen Europapolitik erkennen. Darin wurde die Schaffung einer "vaste zone de politique économique" gefordert, um Europa zu einer "puissante unité de production" zu machen. Dem innen- und außenpolitisch sowie wirtschaftlich geschwächten Frankreich ging es Mitte der fünfziger Jahre noch primär darum, mit europäischer Hilfe der rückständigen französischen Wirtschaft neue Entwicklungsimpulse zu verleihen. Die Abstimmung der wirtschaftspolitischen $\mathrm{Zu}$ sammenarbeit sollte in Europa nach sektoralen Wirtschaftsplänen erfolgen. Die französische Politik erteilte dem wirtschaftlichen Wettbewerb als Ordnungsinstrument eine klare Absage, und zwar sowohl im realwirtschaftlichen wie im monetären Bereich. Eindeutig dominierte das Bemühen, wirtschaftspolitische Ermessensspielräume zu schaffen, um die Wirtschaftsentwicklung stärker nach politischen Zielvorstellungen 
ausrichten zu können. Französische Forderungen nach "Harmonisierung der Wettbewerbsbedingungen" bzw. nach einem "gerechten" Wettbewerb entpuppten sich bei genauerem Hinsehen als Mittel zum Schutz der eigenen Wirtschaft vor überlegener Konkurrenz. In der maßgeblich auf französische Initiative zurückgehenden europäischen Agrarpolitik dokumentierte sich ein großes Vertrauen in die rationale Konstruierbarkeit wirtschaftlicher Verfahrensabläufe. Die instabilen politischen Verhältnisse der IV. Republik verhinderten jedoch, daß Frankreich sich mit seinen Ordnungsideen durchsetzen konnte. Für seine durch widrige Umstände erzwungene Zustimmung zur marktwirtschaftlichen Ordnung im Binnenmarkt vermochte es jedoch eine Vielzahl von Interventionsrechten einzuhandeln.

Nach der Gründung und wirtschaftlichen Konsolidierung der V. Republik erfolgte eine umfassende Neuformulierung der französischen Europapolitik durch Charles de Gaulle. Die gemeinsame Wirtschafts- und Währungspolitik der Mitgliedstaaten ordnete er dabei klar seinem Oberziel unter, Europa im Konzert der Weltmächte wieder zu dem Einflußfaktor zu machen, der es früher einmal war. Die ordnungspolitische Orientierung der französischen Europapolitik blieb trotz dieser neuen Zielsetzung unverändert. Sie basierte jetzt allerdings nicht mehr auf dem vorrangigen Motiv, der französischen Industrie fehlende Entwicklungsimpulse zu verleihen, sondern auf dem Wunsch, eine bestimmte Vision von Europa mittels einer international wettbewerbsfähigen und unabhängigen europäischen Wirtschaft zu verwirklichen. De Gaulles europapolitische Konzeption ging - entgegen dem supranationalen Integrationsansatz der Römischen Verträge - weiter von der Existenz der Nationen als originäre Träger politischer Macht aus. Er strebte ein konföderales „Europa der Staaten“ an, in dem die Regelung wichtiger Angelegenheiten weiter Sache der nationalen Regierungen bleiben sollte. Dieses Europa hatte für de Gaulle eine klare Mission: Als "europäisches Europa" sollte es, gestützt auf seinen kulturellen Erfahrungsvorsprung, der Welt wieder als zivilisatorisches Vorbild dienen und zu einer eigenständigen internationalen Politik finden. Was de Gaulle jedoch als europäische Zivilisationsmission formulierte, war bei genauerem Hinsehen ein nur dürftig verschleiertes Abbild französischer Gesellschaftsvorstellungen. Diese sollten auf Europa und über Europa auf die Welt übertragen werden. Um dieses Ziel erfolgreich zu verwirklichen, beanspruchte de Gaulle für Frankreich die geistige und politische Führungsrolle in Europa. Er rechtfertigte diesen Anspruch mit der "grandeur" der französischen Nation, die er in ihren historischen Verdiensten um die europäische Zivilisation begründet sah. Tatsächlich war de Gaulles "europäisches Europa" nichts anderes als ein Instrument französischer Weltmachtpolitik, erdacht, um einer spezifisch französischen Auffassung von Zivilisation, Gesellschaft und Politik auf globaler Ebene zur Geltung zu verhelfen.

Frankreich zögerte nicht, diese europapolitische Konzeption in die Tat umzusetzen. Sie wurde von allen Nachfolgern de Gaulles im wesentlichen unverändert übernommen und in weiten Teilen erfolgreich verwirklicht. ${ }^{1}$ Im Sinne des "europäischen Europas"

${ }^{1}$ Zur Konstanz der französischen Europapolitik seit de Gaulle siehe Kolboom, I., "Die Grande Nation zur Disposition", Tiefdruckbeilage der FAZ vom 14.8.1993 
bemühte sich Frankreich, die Wirtschaftsgemeinschaft zu einer außenpolitisch handlungsfähigen Einheit weiterzuentwickeln. Anläufe dazu waren die französischen Initiativen zur Gründung einer Politischen Union in den Jahren 1960, 1972 sowie 1990. Erste Erfolge waren mit der Begründung der Europäischen Politischen Zusammenarbeit im Juli $1970 \mathrm{zu}$ verzeichnen, aus der später die Gemeinsame Außen- und Sicherheitspolitik der Gemeinschaft hervorging.

Im Sinne eines "Europas der Staaten" führte Frankreich 1965 den offenen Bruch mit der bis dahin geltenden supranationalen Integrationskonzeption herbei, um anschließend konsequent auf die Fortsetzung des Einigungsprozesses in Richtung einer Konföderation hinzuwirken. Frankreich legte großen Wert darauf, die maßgeblichen Entscheidungskompetenzen in den Händen der Mitgliedstaaten zu belassen, während bewußt schwach gehaltene Gemeinschaftsinstitutionen die Umsetzung der intergouvernemental koordinierten Politik zu besorgen hatten. Als Erfolg der französischen Politik war die im Oktober 1974 beschlossene Aufnahme regelmäßiger Treffen der Staatsund Regierungschefs zu verzeichnen, aus denen sich der Europäische Rat herausbildete. Er erhielt in der Einheitlichen Europäischen Akte 1987 die vertragliche Anerkennung als oberstes Entscheidungsorgan der Gemeinschaft, welches Frankreich seit Anfang der sechziger Jahre beharrlich gefordert hat.

Zur Absicherung der französischen Führungsposition innerhalb der Gemeinschaft nahm Frankreich in allen Erweiterungsrunden eine restriktive Haltung ein. Vom ersten Beitrittsgesuch Großbritanniens im Jahre 1961 bis hin zum Aufnahmeersuchen der mittel- und osteuropäischen Länder verwehrte Frankreich Beitrittskandidaten mit abweichenden europapolitischen Ambitionen die Aufnahme, während es den Beitritt jener mit gleichgerichteten Interessen tatkräftig unterstützte.

Damit das von Frankreich gewollte Europa allerdings auch international zu Macht und Einfluß gelangen konnte, mußte es sich neben den wirtschaftlich führenden USA profilieren. Diese wurden im Rahmen der französischen Europapolitik nicht nur als wirtschaftlicher, sondern vor allem als ideologischer und machtpolitischer Konkurrent auf globaler Ebene wahrgenommen. Notwendig war daher aus französischer Sicht, die gemeinsame Wirtschafts- und Währungspolitik darauf auszurichten, Europa wirtschaftlich zu stärken und es soweit wie möglich aus der amerikanischen Abhängigkeit zu befreien.

Beginnend mit de Gaulle war die französische Forderung nach Stärkung der europäischen Wirtschaft aus einer über das Wirtschaftliche hinausreichenden politischen Zielsetzung motiviert. Die Verwirklichung dieses Ziels wurde zunächst weiter auf planifikatorischem Wege angestrebt. Frankreich unterstützte dazu die Kommissionsinitiative zur "mittelfristigen Programmierung" der europäischen Wirtschaft aus dem Jahr 1962. Als sich Mitte der sechziger Jahre ein zunehmend bedrohlicher technologischer Vorsprung der USA abzeichnete, ging Frankreich zur Forderung nach einer europäischen Industriepolitik über. Ziel dieser Politik waren die Stärkung der industriellen Wettbe- 
werbsfähigkeit sowie die technologische Unabhängigkeit Europas. Inhaltlich sollte sie sich auf die Förderung der technologischen Forschung in wirtschaftlichen Schlüsselsektoren konzentrieren. Verbunden damit war die Hoffnung, gezielte Wachstumsimpulse in bestimmten Wirtschaftsbereichen zu erzeugen, die sich dann auf die Gesamtwirtschaft übertragen sollten. Im Rahmen einer gemeinsamen Industriepolitik sollte dazu ein wachstumsfreundliches Unternehmensumfeld geschaffen werden, das günstige Konditionen für die Kooperation europäischer Unternehmen und für die Entstehung großer, weltweit konkurrenzfähiger Einheiten bot. Staatlichen Stellen fiel in diesem Konzept die Aufgabe zu, die förderungswürdigen Sektoren zu bestimmen, konkrete Forschungsprojekte zu initiieren und mittels Vergabe von Subventionen deren Durchführung sicherzustellen. Der industriepolitische Ansatz Frankreichs lief letztlich auf die politische Beherrschung des technologischen Fortschritts hinaus. Ordnungspolitisch betrachtet setzte sich in ihm jenes Streben nach einer interventionistischen Wirtschaftsordnung und -lenkung fort, das zuvor schon den von Frankreich unterstützten planifikatorischen Ansatz geprägt hatte.

Unter Pompidou wurden die industriepolitischen Initiativen aus der Zeit de Gaulles weiterentwickelt. Die französische Europapolitik bemühte sich - wie schon in den Verhandlungen zu den Römischen Verträgen - die Außenwirtschafts- und Sozialpolitik wieder verstärkt in die Bemühungen um die gezielte Stärkung der europäischen Wettbewerbsfähigkeit einzubeziehen. Unter Giscard d'Estaing stockten diese Bemühungen. Auf die Wirtschaftskrise der siebziger Jahre reagierte Frankreich mit seiner "mondialistischen" Wirtschaftspolitik, die darauf abzielte, im Rahmen einer globalen Konzertation der Industrienationen und Entwicklungsländer die Weltmärkte neu zu "organisieren". Unter Mitterrand verlagerte sich der Schwerpunkt der wirtschaftspolitischen Ordnungsbemühungen wieder auf Europa. Frankreich nahm den industriepolitischen Ansatz aus der Zeit Pompidous wieder auf, um ihn nach längerer intensiver Überzeugungsarbeit schließlich in weiten Teilen durchzusetzen. Mit der Aufnahme der Industriepolitik zunächst in die Einheitliche Europäische Akte und 1992 in den neuen EG-Vertrag (Artikel 130) wurde die Zuständigkeit der Gemeinschaft für die Wettbewerbsfähigkeit der europäischen Wirtschaft schließlich eine Staatsaufgabe mit Verfassungsrang. Ordnungspolitisch betrachtet war damit der entscheidende Schritt in Richtung einer interventionistischen Wirtschaftsordnung für den Gemeinsamen Markt ge$\tan$. Auch wenn einstweilen eine Reihe von Einstimmigkeitsvorbehalten einem unbehinderten Interventionismus entgegenstehen, kann die französische Europapolitik mit der Aufnahme der Industriepolitik in die Vertragsgrundlagen einen wesentlichen Erfolg verbuchen. Nach Jahrzehnten vergeblicher Versuche war es Frankreich zumindest für den Bereich der Realwirtschaft gelungen, die entscheidende Bresche in die zuvor vereinbarte marktwirtschaftliche Ordnung des Binnenmarktes zu schlagen, die es 1957 in einer Zeit innen-, außen- und wirtschaftspolitischer Schwäche gegen seinen Willen hatte hinnehmen müssen.

Im monetären Bereich zeichnete sich eine ähnliche Entwicklung ab. Auch hier strebte Frankreich ab Mitte der sechziger Jahre eine größere Unabhängigkeit Europas von den 
USA an. Hauptanliegen der französischen Währungspolitik war, die internationalen Währungsbeziehungen aus der Abhängigkeit von der inflationären amerikanischen Geldpolitik zu befreien und eine eigenständige europäische Währungspolitik zu begründen. Frankreich bemühte sich vor allem, das System fester Wechselkurse von Bretton Woods ohne amerikanischen Sonderstatus aufrechtzuerhalten. Allen französischen Vorschlägen zur Reform des internationalen Währungssystems gemeinsam war das Bemühen, Wechselkursparitäten im Rahmen einer fest institutionalisierten währungspolitischen Konzertation $\mathrm{zu}$ fixieren und durch abgestimmte Interventionen $\mathrm{zu}$ verteidigen. Nachdem sich 1973 flexible Wechselkurse endgültig durchgesetzt hatten, verfolgte Frankreich dieses Ansinnen mit reduziertem Anspruch weiter. Die französische Währungspolitik akzeptierte die Formel der „festen aber anpassungsfähigen Wechselkurse“. Ihr Schwerpunkt verlagerte sich darauf, die monetären Märkte im Rahmen einer internationalen währungspolitischen Kooperation so zu "organisieren", daß die Wechselkursfixierung zumindest dem Einfluß spekulativer Kräfte entzogen würde. Wie schon im Bereich der Realwirtschaft bemühte sich Frankreich auch auf monetärem Gebiet, die Entwicklung zentraler Größen politischer Kontrolle und Steuerung zu unterwerfen. Die Bestimmung von Wechselkurs- und Zinsniveau in erster Linie den Devisen- und Kapitalmärkten zu überlassen, wurde französischerseits regelmäßig mit dem Hinweis auf deren "Irrationalität" abgelehnt. Ordnungspolitisch betrachtet setzte sich damit auf monetärer Ebene jene interventionistische und konstruktivistische Grundhaltung fort, die auch den französischen Entwurf einer europäischen Industriepolitik prägte.

Namentlich verbunden war die französische Währungspolitik vor allem mit Valéry Giscard d'Estaing, der sie mit kurzer Unterbrechung von 1962 bis 1981 international vertrat. In ihren Grundsätzen wurde sie von seinen Nachfolgern übernommen und selbst nach 1983 beibehalten, als Frankreich sich einer stabilitätsorientierten Geldpolitik nach bundesdeutschem Vorbild anzunähern begann. Auf europäischer Ebene indessen scheiterte Frankreich mit seinen monetären Ordnungsvorstellungen immer wieder gerade an der deutschen Währungspolitik. Deutschland gelang es, sich 1992 im Vertrag über die Wirtschafts- und Währungsunion mit seinem Verständnis von Geldwertstabilität im Grundsatz durchzusetzen. Da die Entscheidung über das endgültige Aussehen der zukünftigen europäischen Geldpolitik jedoch noch aussteht, besteht für Frankreich immer noch eine gewisse Hoffnung, Elemente seiner monetären Ordnungsvorstellungen auf europäische Ebene zu übertragen. So würde die Entscheidung für das „inflation-targeting“ als geldpolitisches Leitkonzept der Währungsunion eine diskretionäre Geldpolitik nach sich ziehen, die Spielraum für einen monetären Dirigismus nach französischen Vorstellungen böte.

Bis heute kann somit aus französischer Sicht ein ordnungspolitischer Teilerfolg verbucht werden, der noch zu einem Gesamterfolg werden kann. Voraussetzung dafür ist, daß Frankreich seine wirtschafts- und währungspolitischen Ordnungsvorstellungen weiter mit ungebrochener diplomatischer Beharrlichkeit auf europäischer Ebene vertritt wie es dies seit Beginn der europäischen Einigung getan hat und daß es in der La- 
ge ist, die notwendige Zustimmung auf seiten der anderen Mitgliedstaaten dafür zu erreichen. Über den gesamten Zeitraum des europäischen Einigungsprozesses war die französische Europapolitik von dem Bemühen geprägt, die Entwicklung von Wirtschaft und Währung in Europa wieder unter politische Kontrolle und Lenkung zu bringen. Seinen Ursprung hatte das französische Ordnungskonzept dabei nicht in ökonomischen Überlegungen, sondern in einer europapolitischen Vision, die auf Machterwerb und politische Unabhängigkeit ausgerichtet war, dazu jedoch wirtschaftlicher Wettbewerbsfähigkeit sowie technologischer Unabhängigkeit bedurfte. Insofern kann das französische Bemühen um eine interventionistische Wirtschaftsordnung für den Binnenmarkt als konsequente Fortsetzung der expansiven Zivilisationsmission interpretiert werden, die Frankreich auf Europa zu übertragen gedachte, deren materielle Basis jedoch erst noch geschaffen werden mußte.

Der interventionistische französische Ordnungsentwurf ist letztlich nicht einseitig als eindeutige Entscheidung gegen den marktwirtschaftlichen Wettbewerb zu interpretieren. Durchweg bescheinigten französische Politiker dem Markt eine hohe Effizienz bei der Koordination vor allem kurzfristiger wirtschaftlicher Entscheidungen, deren Auswirkungen die Wirtschaftssubjekte selbst leicht zu übersehen vermögen. Bei längerfristigen Entscheidungen mit großer Unsicherheit in bezug auf die Konsequenzen allerdings mußte der Markt nach französischer Auffassung als Koordinationsinstrument versagen. Da gerade solche Entscheidungen bedeutend für die langfristige Entwicklung einer Volkswirtschaft sind, waren sie nach durchgängigem Verständnis französischer Wirtschaftspolitiker im Sinne des Allgemeininteresses zu „orientieren“. Als Vertreter des Allgemeininteresses war aus dieser Logik heraus der Staat gefordert und $\mathrm{zu}$ entsprechenden Interventionen aufgerufen.

Neben dieser grundsätzlich unterstellten Koordinationsschwäche haftete dem Marktmechanismus aus französischer Sicht darüber hinaus immer auch der Ruch des Unzivilisierten und des Irrationalen an. Regelmäßig wurde der Vorwurf erhoben, daß es auf unregulierten Märkten, wo nur noch das "Gesetz des Dschungels“ herrsche, zu „exzessivem“ Wettbewerb kommen müsse. Statt einer geordneten Wirtschaftsentwicklung wären Chaos und soziale Ungerechtigkeit die unabwendbare Folge. Die wirtschaftlich Starken würden einseitig zu Lasten der sozial Schwachen begünstigt. Um nicht in einen derart präzivilisatorischen „Naturzustand“ zurückzufallen, drängte die französische Europapolitik immer wieder auf einen „normalen“ bzw. "gerechten“ Wettbewerb im Binnenmarkt mit gleichen Ausgangsbedingungen für alle Marktteilnehmer. Ein Wettbewerb ungleich starker Marktteilnehmer hingegen mußte nach französischer Auffassung immer ein überwachter Wettbewerb sein, ausgetragen unter dem wohlwollenden Auge des Staates, der immer dann einzugreifen hatte, wenn sozialpolitisch definierte Gleichheits- und Gerechtigkeitsideale oder einfach nur das „Allgemeininteresse" dies erforderten.

Wichtiger als die Funktionsfähigkeit der Märkte war aus französischer Sicht, die Entwicklung von Währung und Wirtschaft „rational“ zu orientieren. Strittige Fragen von 
allgemeinem Interesse waren dazu auf politische Ebene zu beheben, um dort entweder im Konzert der europäischen Regierungen oder unter Einbeziehung von Arbeitnehmerund Unternehmensvertretern entschieden zu werden. Typisch für den französischen Ordnungsansatz ist das Streben nach einer orchestrierten Entscheidungsfindung im Sinne des Allgemeininteresses, bei der unter den Fittichen des Staates alle betroffenen Interessengruppen gemeinsam auf dem Verhandlungswege zu einer Entscheidung finden sollten. Nicht in der auf Märkten üblichen freien Konfrontation widerstreitender Interessen im Wettbewerb wurde somit der optimale Koordinationsmechanismus gesehen, sondern in der politisch moderierten Abstimmung im Konsens. Warum sich die französische Binnenmarktpolitik gerade diesem Ordnungsideal verschrieben hat, läßt sich nur aus ihrem Verständnis der zentralen Begriffe „Allgemeininteresse“ und „Rationalität“ erklären. Den Zugang dazu bietet die Wirtschaftsstilanalyse, die im folgenden zur Erklärung des französischen Ordnungsentwurfes für den europäischen Binnenmarkt herangezogen werden soll. 


\section{Der französische Ordnungsentwurf und die Wirtschaftsordnung im Gemein- samen Markt \\ C. 1. Die ordnungspolitische Leitidee}

Wirtschaftsordnungen beruhen, wie im Teil A. dieser Arbeit gezeigt, auf einer bestimmten Auffassung von der idealen Ordnung wirtschaftlicher Abläufe, die sich wiederum auf konkrete soziale Werte und Sinngebungen zurückführen läßt. In diesem Abschnitt sollen die Sinn- und Wertbezüge des vorstehend beschriebenen französischen Ordnungsentwurfs dargelegt werden. Als Verfahren dazu wird auf die Wirtschaftsstilanalyse zurückgegriffen. Diese versucht, aus den Erscheinungsformen des Gesellschafts- und Wirtschaftslebens auf jene Motive zu schließen, die ursächlich zur Ausbildung bestimmter Ordnungselemente geführt haben. Grundlegende Arbeiten zum französischen Wirtschaftsstil wurden von Alfred Müller-Armack und, darauf aufbauend, vor allem von Günther Ammon vorgelegt. Es wird zu prüfen sein, welche Elemente der vorstehend ermittelten französischen Ordnungskonzeption für den europäischen Binnenmarkt als typisch für den französischen Wirtschaftsstil gelten können und sich dementsprechend aus dessen Sinn- und Wertbezügen erklären lassen.

Moderne Ansätze der Wirtschaftsstilanalyse orientieren sich in ihrem Versuch, typische Erscheinungsformen des Wirtschaftslebens auf konkrete Motive zu beziehen, an „kulturellen Schlüsselwörtern“. Diese verweisen als rememorative, demonstrative und prognostische Begriffe auf das spezifische Sinnverständnis einer Gesellschaft. Sie legen dabei jene „Schablone" frei, „die das Denken und Handeln der Menschen aus dem Unterbewußtsein heraus steuert und von den in diese Gesellschaft integrierten Menschen meistens überhaupt nicht mehr wahrgenommen wird" "l. Hinter den kulturellen „Schlüsselwörtern" stehen bestimmte Kollektiverfahrungen, die sich im Laufe der Geschichte zu maßgeblichen Richtpunkten sozialen Handelns in einem Kulturraum entwickelt und in dieser Funktion dem sozialen Leben eine bestimmte äußere Gestalt gegeben haben.

Als grundlegendes Gestaltprinzip der französischen Gesellschafts- und Wirtschaftsordnung ist die „raison“ anzusehen. Sie hat ihre Wurzeln in der Philosophie des Mathematikers René Descartes, die sich im Frankreich der Aufklärung schnell verbreitete und das französische Geistesleben bis heute nachhaltig geprägt hat. ${ }^{2}$ Nachdem im Zuge der Reformation und der sich anschließenden Religionskriege das tradierte Weltbild des Mittelalters mit seinen Glaubensgewißheiten zusammengebrochen war, suchte Descartes nach einer neuen Methode zur Erkenntnis der Wahrheit, um die Welt wieder auf verläßlichen Grundlagen erklären und aufbauen zu können. Die einzig unbestreitbare Wahrheit fand er im ,dubito cogito ergo sum“, denn, so Descartes, alles kann geleugnet werden, nur der Zweifel nicht: Wer zweifelt, denkt, und wer denkt, ist. Die so nachgewiesene Selbstgewißheit regte ihn zur Formulierung einer generellen Erkenntnismethode an. Im „discours de la méthode“ (1637) zeigte er erstmals öffent-

${ }^{1}$ Ammon (1989), a.a.O., S. 25

${ }^{2}$ Vgl. im folgenden dazu Ammon (1989), a.a.O., S. 50 ff. sowie S. $91 \mathrm{ff}$. 
lich, wie nach einem "der Mathematik ähnlichen Verfahren die Wahrheit zweifelsfrei zu erkennen" ist. Danach ist ein Erkenntnisobjekt solange zu zerlegen, bis aus dem einfachsten faßlichen Objekt sukzessive die Erkenntnis komplizierterer Objekte abgeleitet werden kann. ${ }^{3}$ Revolutionär an diesem Verfahren war, daß erstmals die Erkenntnis der von Descartes als apriorisch angenommenen Wahrheit nicht mehr religiöser Vermittlung bedurfte. Sie erfolgte statt dessen aus einer reinen Verstandesbewegung, aus der "raison" heraus, indem allein den Gesetzen der logischen Deduktion folgend aus einfachen allgemeinen "wahren" Prinzipien schrittweise auf kompliziertere Wahrheiten geschlossen wurde. Descartes' Methode vom „richtigen“ Gebrauch des menschlichen Verstandes verbreitete sich schnell im pessimistisch gestimmten Frankreich des 17. Jahrhunderts. Descartes wurde so zum Begründer des französischen Rationalismus. Er stieß mit seinem Denkansatz das Tor zur abstrakt-mechanistischen Erklärung des Kosmos und damit zur bewußten Neugestaltung der Welt durch den Menschen auf. Die Verabsolutierung seiner Methode im Zeitalter der Aufklärung führte dazu, daß das Konzept der "raison" langfristig bestimmend für die französische Geistesgeschichte wurde.

Mit der "raison" verbreitete sich in Frankreich auch eine bestimmte Vorstellung vom menschlichen Fortschritt, vom "progrès" menschliche Ratio erklärt und zur verlorengegangenen Harmonie zurückfinden konnte, mußte die Verbreitung ihres Gebrauchs zur Vervollkommnung von Mensch und Welt führen. In Frankreich verbreitete sich die Vorstellung vom Menschen als vernunftbegabtem und lernfähigem Wesen, das sich in dem Maße fortentwickelt, wie sich sein Geist der „raison“ bemächtigt, mit ihrer Hilfe die vorgegebenen Wahrheiten enthüllt und ihnen folgend das Zusammenleben aller Menschen gestaltet. Aus dieser Vorstellung heraus entstand die Idee des kontinuierlichen Fortschritts der Menschheit hin zu mehr Freiheit, Moralität, Vernunft und zur Herrschaft über die Naturgewalten. Die Geschichte der Menschheit erschien als zielstrebige Entwicklung hin zum Glück, einzig abhängig von der Verbreitung der "raison". Der französische Fortschrittsbegriff entpuppte sich damit, so Ammon, als säkularisierte Form der Heilsvorstellung des Christentums. Da die Verbreitung der „raison“ weder zeit- noch raumgebunden war, ließ sich diese Fortschrittsvorstellung prinzipiell auch auf andere Gesellschaften übertragen. Frankreich, das sich seit der Revolution als vorbildliche Gesellschaft an der Spitze des „progrès" stehend betrachtete, erhielt so seine historische Mission, die darin bestand, dem Rest der Welt die Segnungen der ,raison“ zu bringen. Im Frankreich des 17. und 18. Jahrhunderts führte dieses Fortschrittsverständnis zum Kampf gegen Kirche, Absolutismus und den Ständestaat. Im 19. und 20. Jahrhundert wurde es auf den wissenschaftlichen und technischen Fortschritt übertragen, der seither aus französischer Sicht als Bedingung für ökonomischen und zivilisatorischen Fortschritt betrachtet wird.

${ }^{3}$ Descartes, R.(1993): Abhandlung über die Methode des richtigen Vernunftgebrauchs, Stuttgart, S. 10 f. sowie S. 19

${ }^{4}$ Vgl. im folgenden dazu Ammon (1989), a.a.O., S. 91 ff. 
Zeitgleich mit dem Fortschrittsbegriff begann sich in Frankreich außerdem eine bestimmte Vorstellung von der „vernünftigen" Gesellschaft durchzusetzen. ${ }^{5}$ Bezeichnete der Begriff „,civilisation“ ursprünglich die Umgangsformen und das Verhalten der höfisch-aristokratischen Gesellschaft, so drängte das im Laufe des 17. und 18. Jahrhunderts durch Ämterkauf in den Adelsstand aufgestiegene französische Bürgertum darauf, die französische Gesellschaft mit Hilfe der „raison“ zu einer „wahren“ „civilisation“ weiterzuentwickeln. Ab 1770 stand die "civilisation" dementsprechend für den Prozeß der Vervollkommnung der Gesittung einer Gesellschaft. Alle lebensnotwendigen Einrichtungen einer zivilisierten Gesellschaft - der Staat, die Verfassung und die Erziehung des Volkes - waren der „raison“ folgend rational durchzugestalten. Frankreich selbst betrachtete seinen Zivilisationsprozeß mit der Revolution als abgeschlossen. Als vorbildliche Gesellschaft sah es sich nun berufen, seine Zivilisation in die Welt hinauszutragen. Die "civilisation“ wurde so zum Ausdruck nationalen Selbstbewußtseins und gleichzeitig zum Rechtfertigungsbegriff französischer Expansionsbestrebungen. Die Assimilation von bürgerlicher und aristokratischer Gesinnung führte im französischen Zivilisationsprozeß allerdings dazu, daß das Bürgertum die höfisch-aristokratische Lebensweise des Adels übernahm. Dessen feine Lebensart, die höfische Etikette sowie das Leben in den Salons prägen seitdem das gesellschaftliche Lebensideal der modernen französischen Gesellschaft ebenso wie das Desinteresse des Adels an der Ökonomie. Spätfolge dieser Entwicklung ist, daß die französische Gesellschaft bis heute kein ökonomisches Leitbild entwickelt hat.

Schließlich beeinflußte die "raison" auch nachhaltig das französische Staatsverständnis. Dieses wurde wesentlich durch die Überlegungen Jean-Jacques Rousseaus zur Frage beeinflußt, wie sich in einem Staat die Freiheit des Individuums am besten mit den Belangen der Gesellschaft vereinbaren ließ. ${ }^{6}$ Rousseau war Anhänger Descartes und zog die politischen Folgerungen aus dessen konstruktivistischen Denkansätzen. ${ }^{7}$ Ganz in der Tradition des französischen Rationalismus stehend konstruierte Rousseau mit seinem "contrat social" eine theoretische Lösung, die später Modell stand für die Gesellschaftsordnung des nachrevolutionären Frankreichs. Neben der Summe der Einzelwillen (volonté de tous) existierte für Rousseau ein allgemeiner Wille (volonté générale), der als abstrakte Konstruktion die praktische Vernunft in kollektiver Hinsicht verkörperte. Rousseau ging davon aus, daß alle Bürger eines Staatswesens ein natürliches Mitgefühl für die Bedürfnisse ihrer Mitmenschen besitzen und sich dieses in einem kommunikativen Prozeß mitteilen. Auf diese Weise kam es für ihn zur Bildung des allgemeinen Willens, der nicht Ergebnis einer offenen demokratischen Abstimmung ist, sondern durch die bewußtseinsmäßige Integration aller Einzelwillen zustande kommt und auf der Zustimmung aller beruht, somit also einen allgemeinen Konsens darstellt. Da alle Bürger an seiner Bildung teilgenommen haben, steht der Gemeinwille für Rousseau über der Ebene der Einzelwillen. Jedes Gesell-

\footnotetext{
${ }^{5}$ Vgl. im folgenden dazu Ammon (1989), a.a.O, S. $99 \mathrm{ff}$.

${ }^{6}$ Vgl. im folgenden dazu Ammon (1989), a.a.O., S. $101 \mathrm{ff}$.

${ }^{7} \mathrm{Vgl}$. Beltrain, L. (1980), Rousseaus influence on economic thought, S. 31 und 40, in: Ordo, Band 31, S. $27-41$
} 
schaftsmitglied muß sich ihm unterwerfen, indem es seine Freiheit an die Gemeinschaft abtritt, von der es selbst ein Teil ist. ${ }^{8}$ Aus der natürlichen Freiheit des Individuums, die "unter den Bedingungen der immerwährenden politischen und sozialen Konflikte, der Unsicherheiten des Marktes, der vielfältigsten sozialen Ungleichheiten nichts wert ist," wird so die gesicherte bürgerliche Freiheit gewonnen. ${ }^{9}$

Mit dem so konstruierten Gesellschaftsvertrag hat Rousseau ein Konzept geschaffen, das den Bürgern ermöglicht, vernünftig zusammenzuleben. In ihrer äußeren Form verkörpert die auf diese Weise konsensgeeinte französische Gesellschaft die "nation". Die „nation“ ist Träger des Gemeinwillens und bezeichnet die einmütige Gesamtheit der Staatsbürger, die trotz vielfältiger Sonderinteressen durch einen historischen Vertrag, der sich auf alle Bereiche des gesellschaftlichen Lebens erstreckt, geeint sind. Widerstand gegen den Gemeinwillen ist zwecklos, da er als kollektive „raison“ eine absolute Wahrheit verkörpert. Die „nation“ ist darüber hinaus gleichzeitig ein territorialer Begriff, der den geographischen Geltungsbereich des Gemeinwillen bezeichnet. Als rationales, theoretisches Konstrukt ist das Konzept der "nation" von allgemeiner Gültigkeit und deshalb auf alle Gesellschaften übertragbar. Besonders am französischen Fall jedoch ist die Tatsache, daß Staat und Nation zur ,état-nation" verschmolzen sind. Hatte Rousseau sein Gesellschaftsmodell nur für ein kleines Staatswesen konzipiert, in dem die notwendige Kommunikation der Bürger jederzeit möglich war, so wurde es im Frankreich der Revolution dahingehend modifiziert, daß dem Staat die Aufgabe zufiel, die Bildung des Gemeinwillen und seine Durchsetzung sicherzustellen. Dabei wirkte eine Sichtweise des Staates nach, die ihn als unableitbare Hoheitsmacht annahm und im wesentlichen auf die Souveränitätslehre Jean Bodins zurückging. Dieser hatte im Frankreich der Nachreformation die Idee geprägt, daß sich die religiösen Auseinandersetzungen am besten mit Hilfe eines abstrakt-rationalen, überkonfessionellen Staates lösen ließen. Diese Idee verbreitete sich schnell und hat wesentlich zur Ausbildung eines Staatsverständnisses beigetragen, das grundsätzlich von einem mächtigen, in seiner Autorität nie hinterfragten Staat ausging und sich in Frankreich bis heute erhalten hat.

Mit der Verankerung dieser in den vier Schlüsselwörtern dargestellten Kollektivvorstellungen in der "mémoire collective“ hat sich die "raison" als oberstes Gestaltungsprinzip der französischen Gesellschaft durchgesetzt. In der französischen Aufklärung verabsolutiert, in der Revolution von 1789, wo sie zeitweise sogar Gott ersetzte, angewandt, blieb die "raison" auch nach dem Abflauen des revolutionären Übereifers als gestaltende Kraft des modernen Frankreichs erhalten. Sie geht im wesentlichen auf eine bestimmte Vorstellung von Wahrheit und Erkenntnis zurück, aus der heraus sich ein konkretes Welt-, Menschen- und Gesellschaftsbild entwickelt hat. Unmittelbar mit ihr verbunden ist eine Wahrnehmungs- und Handlungsweise in bezug auf die Gestaltung sozialer Beziehungen, die auch für das französische Wirtschaftsleben bestimmend ist und dort zu typischen Erscheinungsformen geführt hat.

\footnotetext{
${ }^{8}$ Vgl. Rousseau, J. J. (1971), Der Gesellschaftsvertrag, Stuttgart, S. 22

${ }^{9}$ Ammon (1989), a.a.O., S. 103
} 
Die ordnungspolitische Konsequenz einer uneingeschränkt herrschenden cartesianischen Vernunft sieht Friedrich August von Hayek in einem umfassenden "rationalistischen Konstruktivismus". ${ }^{10}$ Er bezeichnet damit eine Denk- und Handlungsweise, nach der praktische Probleme bei der Gestaltung sozialer Ordnungen grundsätzlich so behandelt werden, als ob alle Tatsachen bekannt seien und die Aufgabe, sie zu bewältigen, nur eine rein intellektuelle wäre. ${ }^{11}$ Die im Rationalismus unterstellte prinzipielle Unbegrenztheit menschlicher Erkenntnis führt nach von Hayek da$\mathrm{zu}, \mathrm{da} ß$ abstrakte, mechanische Verhaltensregeln wertlos erscheinen, Mittel durch ihren Zweck gerechtfertigt sind und selbstzweckhafte, moralisch begründete Werte für menschliches Verhalten nicht mehr akzeptiert werden, da ihre Existenz weder metaphysisch noch rational begründet werden kann. ${ }^{12}$ Die menschliche Zivilisation gerinnt so zum Produkt der reinen Vernunft, weil die menschliche Intelligenz als ausreichend angenommen wird, um das gesellschaftliche Leben vollständig und sinnvoll zu ordnen. ${ }^{13}$ Es entsteht ein rationalistisches Machbarkeitsbewußtsein, das sich bei der Gestaltung sozialer Ordnungen keine Grenzen auferlegt.

In Frankreich wird eine derartig konstruktivistische Grundhaltung durch das der „raison" verpflichtete Elitebildungssystem der „grandes écoles" tradiert, in denen die "nation“ seit den Tagen der Revolution ihren Führungsnachwuchs heranbildet. ${ }^{14}$ Hauptmerkmal dieser auf den höheren Staatsdienst vorbereitenden Hochschulen ist, daß die Ausbildung vornehmlich nach einem an der bloßen Machbarkeit orientierten „esprit d'ingénieur" erfolgt. Die Absolventen der „grandes écoles“ besetzen im heutigen Frankreich die Schaltstellen in Politik und Wirtschaft, wo sie die erlernte technokratische Herangehensweise auf praktische Probleme übertragen. Der so angelegte handlungsorientierte Konstruktivismus wird durch die ausgeprägte keynesianische Lehrtradition in der wirtschaftswissenschaftlichen Ausbildung an den französischen Elitehochschulen unterstützt. Keynes diente als wissenschaftliche Referenz für den Wiederaufbau der französischen Wirtschaft nach dem zweiten Weltkrieg. Keynesianisches Gedankengut hat nachhaltig die ökonomische Bildung der französischen Hochadministration beeinflußt und damit wesentlich zur Festigung interventionistischer Ordnungsvorstellungen in Frankreich beigetragen. ${ }^{15}$

Grundlegend für die Wahrnehmung ökonomischer Sachverhalte in Frankreich ist, daß sie sich nie vollständig aus dem politischen Kontext gelöst hat. Das Ökonomische hat sich bis heute nicht als Kategorie mit eigenständiger Sachgesetzlichkeit etablieren können. Ammon führt dies darauf zurück, daß im französischen Denken im Grunde

${ }^{10}$ Hayek, F.-A. von (1976), Arten des Rationalismus. In: ders.: Freiburger Studien, S. 75-89, S. 78

${ }^{11}$ Vgl. Hayek, F.-A. von: (1976), a.a.O., S. 84

12 ebenda, S. $83 \mathrm{f}$

${ }^{13}$ ebenda, S. 79 und 84

14 Zur Rolle der Grandes Écoles und ihrer Absolventen im französischen Wirtschaftsleben siehe Baier, L. (1988), Firma Frankreich, Berlin; zur Verbreitung des technokratischen Führungsstils in Frankreich vgl. Lawrence, P.; Barsoux, J.-L. (1991), Management in France, London

${ }^{15}$ Rosanvallon, P. (1989), The development of Keynesianism in France, S. 190 und 192, in: Petar A. Hall, The political power of economic ideas: Keynesianism across nations, Princeton, S. 171-194 
kein Ausweg existiert, der auf eine Harmonie der Interessen oder auf die Gemeinnützigkeit bestimmter Konflikte hinausläuft. Dieses Denken kreist stets um eine politische Sicht des Gesellschaftlichen und nimmt alle Gesellschaftsbereiche einheitlich vom Standpunkt der „rationalen Autorität des legalen Despotismus“16 wahr. Makroökonomische Probleme werden in Frankreich vornehmlich als Probleme der "nation“ wahrgenommen, was dazu führt, das bei der Betrachtung ökonomischer Sachverhalte stets das Politische dominiert. Wirtschaftspolitisches Denken ist aus französischer Sicht in erster Linie politisch-strategisches Denken, das durch die unmittelbare Verbindung binnen- wie außenwirtschaftlicher Probleme mit den Belangen der "nation“ immer auch merkantilistischen Charakter hat:

„Dieses politisch-strategische Denken fragt nicht primär nach ökonomischen Kategorien: es geht also weniger um Angebot und Nachfrage, Marktpotentiale, Marktnischen und Absatzchancen, sondern um wirtschaftliche Stärke in Bereichen, die man aus einer politischen Sichtweise als strategisch bedeutsam einstuft. “'17

$\mathrm{Da}$ die „nation“ eine klar definierte territoriale Dimension hat, ist wirtschaftspolitisches Denken in Frankreich darüber hinaus immer auch Raumdenken. ${ }^{18}$ Es ist grundsätzlich auf die Absicherung und Ausgestaltung eines zusammenhängenden, leicht beherrschbaren Raumes fixiert. Außenwirtschaftliche Erfolge werden so zu Erfolgen der „nation“, die erwünscht sind, weil sie deren Wohlstand mehren, der aus merkantilistischer Perspektive heraus nur auf Kosten anderer Länder erhöht werden kann. Aus politisch-strategischer Sichtweise dokumentieren Erfolge im Außenhandel den internationalen Stellenwert der „nation“ und damit ihre „grandeur“. Sie sind letztlich nicht nur Ebenbild ihrer wirtschaftlichen und technischen Stärke, sondern auch und vor allem Ausdruck ihrer politischen Macht.

Dementsprechend läßt sich die Rolle des Staates in der französischen Wirtschaft aus dem Konzept der "nation" erklären. Charakteristisch für Frankreich ist der sakrale Charakter des Staates, dem aus seiner zentralen Stellung im französischen Gesellschaftsleben heraus zugleich Antriebs-, Steuerungs- und Ordnungsfunktionen auch in der französischen Wirtschaft zufallen. Den sakralen Charakter führt Ammon darauf zurück, daß der französische Staat während der Reformation die Abkehr von Rom nicht mitgemacht hat und sich in Organisationsform und Machtausübung weiter an der römischkatholischen Kirche orientierte. Der Umstand, daß die religiösen Auseinandersetzungen der Reformationszeit in Frankreich mit Hilfe eines über den Religionen stehenden Staates gelöst wurden, verlieh dessen Macht „göttlichen Charakter“". Dieser hat sich auch nach der Revolution erhalten, als der französische Staat, mit der „nation“ zur „état-nation“, verschmolzen zum Hüter des Gemeinwillens und damit zur höchsten Autorität erhoben wurde.

${ }^{16}$ Vgl. Furet, F.: 1789 - Vom Ereignis zum Gegenstand der Geschichtswissenschaft, Frankfurt 1980, S. 42

${ }^{17}$ Ammon (1989), a.a.O., S. 119

${ }^{18} \mathrm{Vgl}$. Ammon (1989), a.a.O., S. 123 ff., insbesondere S. 127 sowie S. 202 f. 
Seine Ordnungsfunktion im Bereich der Wirtschaft erfüllt der französische Staat heute im Rahmen der "planification“. In ihrem Verlauf wird unter staatlicher Regie ein gesellschaftsweiter Konsens über die mittelfristige Entwicklung der französischen Volkswirtschaft herbeigeführt. Die Planerstellung erfolgt in Analogie zum „contrat social“ ${ }^{19}{ }^{19}$ Sie stellt dementsprechend keinen offenen Abstimmungsprozeß dar, sondern eine iterative Konsenssuche, die solange wiederholt wird, bis die Vertreter des Staates sowie der Arbeitnehmer- und Unternehmerseite ihre Interessen zur Deckung gebracht haben. Die französische Wirtschaft wird so zur ,économie concertée“. Ihr ordnungspolitisches Leitprinzip ist Abbild des herrschenden Ordnungsideals der französischen Gesellschaft und basiert letztlich auf den gleichen Vernunft- und Harmonievorstellungen wie der Rousseau'sche "contrat social". Der Plan verkörpert den Gemeinwillen im Bereich der Wirtschaft und soll den Wirtschaftssubjekten eine gesicherte Grundlage für rationales Handeln bieten.

$\mathrm{Da} ß$ der französische Staat eine als natürlich empfundene Antriebs- und Steuerungsfunktion im Wirtschaftsleben wahrnimmt, führt Ammon auf das fehlende ökonomische Leitbild in der französischen Gesellschaft zurück. ${ }^{20}$ Noch heute dem höfisch-aristokratischen Lebensideal verhaftet, ist ihr Glaube an die Privatinitiative schwach ausgeprägt. Wo es aus Sicht des Allgemeininteresses geboten erscheint, richtet sich die Erwartung an den Staat als Vertreter des Gemeinwillens, als Unternehmer aufzutreten und steuernd in die Wirtschaftsentwicklung einzugreifen. Ein freies Aushandeln der Interessen unterschiedlich starker Parteien hingegen würde in den Augen vieler Franzosen nur Ungleichheit hervorbringen und unerwünschte Koordinationsergebnisse nach sich ziehen. Die französische Präferenz für eine interventionistische Wirtschaftsordnung hängt somit eng mit jenen Kollektivvorstellungen zusammen, die in den Schlüsselwörtern „civilisation“ und „nation“ dargestellt wurden.

Die große Ähnlichkeit von nationalem und europäischem Ordnungsentwurf zeigt sich, wenn die vorstehend beschriebenen Merkmale des französischen Wirtschaftsstils mit den Elementen der französischen Ordnungskonzeption für den Binnenmarkt verglichen werden. Spätestens seit de Gaulle trägt Frankreich den Anspruch, Europa eine bestimmte politische und wirtschaftliche Ordnung geben zu wollen, offen vor. Im Kern ging es der französischen Europapolitik über den gesamten Verlauf der europäischen Einigung hinweg darum, die Gemeinschaft zur Übernahme spezifisch französischer gesellschaftspolitischer Zielsetzungen sowie einer dem französischen Staatsverständnis nachempfundenen inneren Ordnung zu bewegen.

So finden sich die Leitmotive aus den Schlüsselwörtern „progrès“ und „civilisation“ unmittelbar in der französischen Konzeption des „europäischen Europa“" wieder. Die Hauptaufgabe des von Frankreich angestrebten politisch handlungsfähigen Europas bestand in der Verteidigung und Verbreitung spezifisch europäischer Zivilisationsvorstellungen, welche sich bei näherer Betrachtung jedoch immer wieder als Kopie der

\footnotetext{
${ }^{19}$ Vgl. Ammon (1989), a.a.O., S. 153

${ }^{20}$ Vgl. Ammon (1989), a.a.O., S. 150
} 
französischen Gesellschaftsideale erwiesen. Deren Wurzeln liegen in der Wertewelt der französischen Aufklärung, die nach eigenem Bekunden aller französischen Staatspräsidenten das ideelle Fundament ihrer gesellschaftspolitischen Zielvorstellungen und damit letztlich auch das der französischen Europapolitik darstellte.

Das von Frankreich geforderte „Europa der Staaten“ reflektierte die Vorstellung von der „nation“, nach der logischerweise solange kein föderales und damit supranationales Europa existieren kann, solange es keinen europäischen Gemeinwillen gibt. Folglich konnten auch die Institutionen einer Gemeinschaft, der die wahre Legitimation als Staatswesen fehlt, nicht weisungsbefugt gegenüber den Nationen als einzig legitimen Trägern politischer Macht sein. Wenn diese in Europa etwas verpflichten kann, dann nur Beschlüsse, die im Rahmen der intergouvernementalen Zusammenarbeit gefaßt worden sind und sich auf Gebiete beziehen, wo zuvor ein gemeinsames Interesse der Mitgliedstaaten von den Regierungen definiert wurde. Bis in die Verhandlungen zu den Maastrichter Verträgen hinein haben französische Politiker an dieser Überzeugung unbeirrt festgehalten, was letztlich dazu führte, daß sich die französische Europapolitik bis heute nie über die Vorstellung von Europa als einer Zweckgemeinschaft unabhängiger Mitgliedstaaten erhoben hat. Ein europäischer Bundesstaat muß als Bedrohung des französischen Staatsverständnisses erscheinen und zwangsläufig seine Ablehnung zur Folge haben. Aus rein pragmatischer Sicht erscheint es darüber hinaus utopisch, von Frankreich als Staatswesen mit ausgeprägtem gesellschaftspolitischen Missionsbewußtsein die Bereitschaft zur Selbstaufgabe zu erwarten.

Bei den ökonomischen Ordnungsvorstellungen Frankreichs für den europäischen Binnenmarkt stach die durchgehende Tendenz zur Politisierung der Wirtschafts- und Währungsentwicklung ins Auge. Hier dominierte die politisch-strategische Perspektive ökonomischer Sachzusammenhänge, aus der heraus ökonomische Fragen primär nach ihren politischen Implikationen bewertet werden. Die industrie- wie auch die währungspolitische Konzeption Frankreichs folgten durchgängig einem politisch begründeten Macht- und Unabhängigkeitsmotiv. Wirtschaftliche Stärke und Unabhängigkeit waren aus französischer Sicht unabdingbar, um einem Europa mit Zivilisationsmission, das nach internationaler Geltung strebte, zur erforderlichen politischen Macht und Unabhängigkeit zu verhelfen.

Auch fand sich das Raumdenken, das sich aus der politisch-strategischen Perspektive in Verbindung mit der Vorstellung von der "nation" ergab, in der europäischen Wirtschafts- und Währungspolitik Frankreichs wieder. Über den gesamten Betrachtungszeitraum hinweg war die französische Außenwirtschaftspolitik vornehmlich um die Absicherung des Gemeinsamen Marktes nach außen, statt um seine Öffnung bemüht. Das gleiche Anliegen verfolgte Frankreich im Bereich der Währungspolitik, wo es darauf drängte, die europäischen Partner Drittstaaten gegenüber zu einer einheitlichen Politik zu bewegen. Ebenfalls vornehmlich von geostrategischen Motiven geprägt waren die industriepolitischen Bemühungen Frankreichs, die Wettbewerbsfähigkeit der europäischen Industrie im Weltvergleich auf Spitzenniveau zu heben. 
Prägend auch für den europäischen Ordnungsentwurf Frankreichs war ferner das Ideal der konsensorientierten Interessenabstimmung, das sich auf die Konzeption der "nation" und dem dort abgebildeten Verfahren zur Ermittlung des Gemeinwillens zurückführen läßt. Dessen Entsprechung auf europäischer Ebene kann in der von Frankreich gewünschten verhandlungsorientierten Dialogform der „Konzertation“, in deren Mittelpunkt letztlich immer die Regierungen der Mitgliedstaaten standen, gesehen werden. Die geeignete Form der wirtschafts- und währungspolitischen Entscheidungsfindung bei allen Fragen, die aus französischer Sicht das „Allgemeininteresse“ berührten, war die intergouvernementale Kooperation. Ergänzt wurde dieses Verfahren im Bereich der wirtschaftlichen Praxis durch den ,sozialen Dialog“. Seine Funktion lag darin, Arbeitnehmer- und Unternehmensseite unter staatlicher Anleitung in die Suche nach optimalen Lösungen im Sinne des „Allgemeininteresses“ einzubinden. In beiden Fällen bildete das neben den Einzelinteressen als eigenständig existierend angenommene "Allgemeininteresse" die Rechtfertigung für staatliche Eingriffe in den Wirtschaftsablauf. Wie schon auf nationaler Ebene, so blieb allerdings auch im französischen Ordnungsentwurf für den Binnenmarkt die Frage unbeantwortet, welche Autorität festlegt, wann und wo das Allgemeininteresse berührt bzw. wann und wo der Staat zu Eingriffen in das Wirtschaftsleben befugt ist. Da ein Konsensbildungsprozeß nach Rousseauschen Vorstellungen schon auf nationaler Ebene in Frankreich nicht praktizierbar war, ist nicht zu sehen, wie er es auf europäischer Ebene sein konnte. Dementsprechend würde die Entscheidung über das Ausma $ß$ und die Richtung von Interventionen uneingeschränkt in der Hand der Staatsvertreter und damit der politischen Entscheidungsträger liegen. Allen in den europäischen Vertragstexten gemachten Bekenntnissen zum Trotz existiert im französischen Ordnungsentwurf für den Binnenmarkt letztlich keine klare Trennlinie zwischen Marktkoordination und Staatsintervention. Lenkenden Eingriffen in die Entwicklung von Wirtschaft und Währung in Europa waren somit prinzipiell keine Grenzen gesetzt.

Schließlich ist auch die in der "raison" verwurzelte konstruktivistische Auffassung von der Machbarkeit ökonomischer Prozesse im europäischen Ordnungsentwurf Frankreichs wiederzufinden. Das Bestreben der französischen Währungspolitik, monetäre Märkte zu "organisieren", das industriepolitische Bemühen Frankreichs, die Wirtschaftsentwicklung bewußt zu lenken, der Versuch, mittels bestimmter Formen der Agrarmarktorganisation die Einkommen der Landwirte $\mathrm{zu}$ stabilisieren, das "mondialistische" Bemühen Giscard d'Estaings, die Weltwirtschaft neu zu "organisieren" - all dies sind Politikansätze, die von einer weitgehenden Gestaltbarkeit ökonomischer Prozesse ausgehen. In ihnen setzen sich Ansichten über die Ordnungs-, Initiativ- und Steuerungsfunktion des Staates im Bereich der Wirtschaft fort, die für das Staatsverständnis in Frankreich typisch sind und auf Europa übertragen werden sollten.

Festzuhalten bleibt somit, daß der französische Ordnungsentwurf für den Binnenmarkt vom selben Ordnungsverständnis geprägt ist wie der französische Wirtschaftsstil. Er teilt dessen ideelle Fundierung, die auf eine bestimmte Konzeption von Wahrheit und 
Erkenntnis sowie einem daraus abgeleiteten Welt-, Menschen- sowie Gesellschaftsbild, das seine Wurzeln in der Wertewelt der französischen Aufklärung hat, zurückzuführen ist. Nationaler wie europäischer Ordnungsentwurf folgen einem Koordinationsideal, das stark von der Rousseauschen Vorstellung eines abseits der Einzelwillen bestehenden Gemeinwillens geprägt ist. Der französische Ordnungsentwurf für den Binnenmarkt beruht damit auf einer völlig anderen Vorstellungswelt als eine marktwirtschaftliche Ordnung. In ihm wird weder von einer prästabilierten Harmonie der Dinge noch von einer „unsichtbaren Hand“ des Marktes, die ökonomische Einzelentscheidungen optimal koordiniert, ausgegangen. Der wirtschaftliche Wettbewerb gilt nicht als ultimative Lösung in bezug auf die Gesamtwohlfahrt wie auch die Souveränität der Konsumenten nicht den alleinigen Ausgangspunkt allen ökonomischen Denkens und Handelns darstellt. Die Marktwirtschaft stellt nach französischer Ordnungslogik immer nur ein suboptimales Koordinationskonzept dar, weil sie nie die Ebene der Einzelwillen transzendieren und damit nicht einem Verständnis ökonomischer Rationalität genügen kann, das immer von der Existenz eines Gemeinwillen ausgeht, den zu verwirklichen die vornehmste Aufgabe der politischen Entscheidungsträger ist. Marktwirtschaftlicher und interventionistischer Ordnungsentwurf beruhen letztlich auf völlig unterschiedlichen sozialphilosophisch begründeten Werthaltungen und Sollvorstellungen. Die Folge sind jeweils andere Legitimationsgrundlagen und Ziele für das wirtschaftspolitische Handeln, die zwangsläufig zum Rückgriff auf jeweils unterschiedliche Mittel und Instrumente bei der Ausgestaltung von Wirtschaftsordnungen führen. Daß ein Nebeneinander von marktwirtschaftlichen und interventionistischen Ordnungsentwürfen in einem Wirtschaftsraum wie dem Gemeinsamen Markt notwendigerweise Konflikte nach sich ziehen muß, ist allein schon aus dieser kurzen abstrakt-theoretischen Betrachtung heraus offensichtlich. Wo die konkreten Reibungspunkte eines solchen Vorhabens liegen, muß eine Gegenüberstellung der Wirtschafts- und Währungspolitik, wie sie Frankreich für Europa gewollt hat, mit einer marktwirtschaftlichen Ordnungskonzeption ergeben.

\section{C.2. Die Verträglichkeit der französischen Ordnungskonzeption mit den Grund- sätzen der Wettbewerbsordnung}

Das Nebeneinander verschiedener Ordnungskonzeptionen in einem Wirtschaftsraum birgt die Gefahr sich widersprechender Verhaltensvorgaben für die Wirtschaftssubjekte. Daraus resultiert Unsicherheit, deren Überwindung zu höheren Transaktionskosten führt, die sich ihrerseits wieder einschränkend auf die Aktivität der Wirtschaftssubjekte auswirken. Um die praktische Verträglichkeit der französischen Ordnungskonzeption für den Binnenmarkt mit einer klassisch-marktwirtschaftlichen Wirtschaftsordnung, wie sie im EG-Vertrag vereinbart worden ist, zu prüfen, soll im folgenden die europäische Wirtschafts- und Währungspolitik Frankreichs den Prinzipien der Wettbewerbsordnung, wie sie Walter Eucken formuliert hat, gegenübergestellt werden. 
Bei den konstituierenden Prinzipien fordert das "Grundprinzip eines funktionsfähigen Preissystems vollständiger Konkurrenz", die Lenkung von Produktion und Konsum über sich auf Märkten unbehindert bildende Preise erfolgen zu lassen. Von französischer Seite wurde dieses Prinzip nie offen in Frage gestellt. Das durchgängige Engagement Frankreichs für die Aufrechterhaltung des Agrarpreismechanismus jedoch, das bis 1986 offene Eintreten für die politische Festsetzung von Weltrohstoff- und nahrungsmittelpreisen sowie die französische Bereitschaft zur direkten und indirekten Subventionierung von industriellen Forschungsvorhaben waren zweifellos Verstöße gegen dieses Prinzip. Sie zeigten, daß politisch definierte Zwecke wie z. B. die Sicherung der Wettbewerbsfähigkeit oder der Einkommen bestimmter Bevölkerungsgruppen aus französischer Sicht im Zweifel immer Vorrang vor dem Allokationsresultat des Marktes hatten.

Der Primat der Preisstabilität fordert die Wahrung der inneren und äußeren Geldwertstabilität durch einen von politischen Interventionen möglichst unabhängigen und automatisch funktionierenden Mechanismus. Die monetäre Politik Frankreichs entsprach diesem Postulat vordergründig, indem sie sich über den gesamten Betrachtungszeitraum für feste Wechselkurse einsetze und sich später auch die Forderung nach einer unabhängigen europäischen Zentralbank zu eigen machte. Frankreich folgte dabei jedoch einem konstruktivistischen Verständnis von Geldwertstabilität, die es vorzugsweise durch politische Abreden dekretiert und über die „Organisation“ monetärer Märkte sichergestellt sehen wollte. Nicht vereinbar mit der französischen Währungspolitik war eine geldpolitische Konzeption, die ausschließlich auf unabhängige Institutionen baute, welche anhand fester Regeln auf den monetären Märkten intervenierten, um die sich ansonsten frei bildenden Wechselkurse zu stabilisieren. Das französische Verständnis von Geldwertstabilität war und ist dementsprechend von seiner Natur her grundsätzlich ein anderes als das in den Euckenschen Prinzipien der Wettbewerbsordnung geforderte. ${ }^{21}$ Die Grundlage der währungspolitischen Haltung Frankreichs bildet eine Sichtweise, die den Wechselkurs mehr als Symbol wirtschaftlicher Unabhängigkeit und Stärke begreift denn als Preis einer Währung. Unter Hinweis auf die Bedeutung des Wechselkurses für die Außenwirtschaft drängte Frankreich immer wieder darauf, die Wechselkurspolitik an gesamtwirtschaftlichen Entwicklungszielen zu orientieren, statt allein an geldpolitischen Prinzipien. Diese realwirtschaftliche Orientierung der französischen Währungspolitik ging einher mit einer unterschiedlichen $\mathrm{Be}$ wertung von Kapital- und Gütergeschäften. Während realwirtschaftliche Transaktionen grundsätzlich als ,gut" bewertet wurden, erfuhren reine Geldgeschäfte eine kritische Bewertung. Auf eindeutige Ablehnung stießen spekulative Kapitaltransaktionen, welche von französischer Seite durchgehend zum Anlaß genommen wurden, sich der Liberalisierung des Kapitalverkehrs zu widersetzen. In der französischen Währungspolitik dominiert bis heute ein Mißtrauen gegen die Anpassungsfähigkeit des Marktmechanismus. In ihren monetären Ordnungsentwürfen setzten alle französischen Regie-

${ }^{21} \mathrm{Vgl}$. Braunberger, G., Illusionen über den Euro, Frankfurter Allgemeine Zeitung vom 15.10.1996, S. 17 
rungen diesem ein ungebrochenes Vertrauen in das Gestaltungsvermögen der währungspolitischen Entscheidungsträger entgegen.

Das Prinzip der "offenen Märkte" fordert grundsätzlich freien Marktzugang für alle Anbieter und Nachfrager. Die französische Wahrnehmung außenwirtschaftlicher Sachverhalte folgte indessen einem stark merkantilistisch geprägten „Raumdenken“, das vornehmlich auf die Absicherung eines Wirtschaftsgebietes bedacht war. Diesem entsprach eine Außenwirtschaftspolitik, die zum Schutz der französischen und europäischen Wirtschaft nie zögerte, auf tarifäre Handelshemmnisse zurückzugreifen, "freiwillige Selbstbeschränkungen" im Hinblick auf Einfuhrquoten (zuletzt bei Filmen) zu fordern, Direktinvestitionen aus Drittländern zu überwachen und die Öffnung des Gemeinsamen Marktes, wenn überhaupt, dann nach dem Prinzip der Reziprozität zuzulassen. Außenhandelsbeschränkungen waren aus französischer Sicht durchweg ein legitimes Mittel zur Verteidigung der europäischen Produktion und Wettbewerbsfähigkeit, während die Wettbewerbsfähigkeit von Drittstaaten primär als Bedrohung aufgefaßt wurde. Die Öffnung des Gemeinsamen Marktes konnte deshalb kaum als erfolgversprechendes Mittel zur Förderung wirtschaftlicher Aktivität erscheinen. Sie wurde vielmehr eher als Privileg betrachtet, das den Handelspartnern dort zugestanden werden konnte, wo die Wettbewerbsfähigkeit der europäischen Wirtschaft sichergestellt war.

Das ordnungspolitische Prinzip der Einheit von Gestaltungsmacht und Haftung soll die Auslese durch den Wettbewerb, die Prophylaxe gegen Ressourcenverschwendung sowie die Verhinderung von Wettbewerbsbeschränkungen sicherstellen und darüber hinaus die Wirtschaftssubjekte allgemein zu einer Kultur der Freiheit und Selbstverantwortung erziehen. Letzterem stand im französischen Ordnungsentwurf von vornherein das über den Individualinteressen stehende Allgemeininteresse entgegen. Wo immer politische Entscheidungsträger die Verpflichtung sahen, dem höherwertigen Allgemeininteresse nachzukommen, mußten Wirtschaftssubjekte mit Interventionen und dementsprechend mit staatlicher Verantwortungsübernahme rechnen. Eine Industriepolitik nach französischen Vorstellungen entbindet die Wirtschaftssubjekte teilweise aus der Eigenverantwortung für ihre wirtschaftliche Zukunft, wenn der Staat die Wirtschaftsentwicklung vorausdenkt und die Investitionstätigkeit der Unternehmen durch vielfältige Anreize in eine politisch gewünschte Richtung lenkt. Über staatliche $\mathrm{Zu}$ wendungen wäre bereitwillig Folgenden ein Teil des wirtschaftlichen Risikos und damit im gleichen Maße die Haftung für ihre wirtschaftlichen Entscheidungen abgenommen. Ebenso entlastet eine monetäre Politik, die politisch fixierte Wechselkurse und Zinsen anstrebt, die Wirtschaftssubjekte von einer eigenverantwortlichen Bewertung der binnen- wie außenwirtschaftlichen Entwicklung. Der durch das Prinzip der Einheit von Gestaltungsmacht und Haftung angestrebte Vorsichts- und Erziehungseffekt war im französischen Ordnungsentwurf für den Binnenmarkt nicht angelegt, sondern durch die Zuständigkeitserklärung des Staates sowie das prinzipiell als hinreichend angenommene Erkenntnisvermögen seiner Vertreter ersetzt. 
Das Prinzip der Vorhersehbarkeit und Stetigkeit der Wirtschaftspolitik fordert eine berechenbare Politik, um die Erwartungsbildung der Wirtschaftssubjekte zu stabilisieren und deren Planungen mit möglichst geringer Unsicherheit zu belasten. Der französische Ordnungsansatz stand diesem Prinzip insofern entgegen, als daß die in ihm grundsätzlich vorgesehenen staatlichen Interventionen im Belieben der Politiker stehen sollten und damit prinzipiell unvorhersehbar gewesen wären. Auf wirtschaftspolitischer Ebene fuhrte dieser Ansatz zu einer industriepolitischen Konzeption, die darauf ausgerichtet war, ohne erkennbares System, einzig den Erkenntnissen der jeweiligen politischen Entscheidungsträger folgend, die industrielle Wettbewerbsfähigkeit Europas zu fördern. Insgesamt war die wirtschaftspolitische Konzeption Frankreichs damit schon vom Ansatz her nicht mit dem Prinzip einer vorhersehbaren und stetigen Wirtschaftspolitik vereinbar. Gleiches galt für die französische Währungspolitik, die zentrale Parameter wie Wechselkurs und Zins in enger Abstimmung mit wirtschaftspolitischen Zielsetzungen festlegen wollte und eine regelgebundene, ausschließlich unabhängigen Institutionen überlassene Geldpolitik prinzipiell ablehnte. Damit wurde der Forderung nach einer konstanten Politik schon vom Ansatz her widersprochen.

Unter den regulierenden Prinzipien soll das der Monopolkontrolle den Mißbrauch wirtschaftlicher Macht verhindern, um die Funktion des Wettbewerbs jederzeit zu gewährleisten. Im Rahmen seiner europäischen Industriepolitik bemühte sich Frankreich jedoch gerade um den gezielten Aufbau großer Unternehmenseinheiten und damit um die Schaffung entsprechender Machtpositionen. Überzeugt, daß nur Großunternehmen im internationalen Wettbewerb überleben können, wurde von französischer Seite durchgehend die Fusion europäischer Unternehmen zu Einheiten unterstützt, die es mit den größten Konzernen der Welt aufnehmen können sollten. Konkret regte Frankreich dazu beispielsweise die Lockerung der Artikel 85 und 86 des EWG-Vertrages an oder auch, daß bei Fusionskontrollverfahren nur noch der Binnenmarkt als relevanter Markt zugrunde gelegt werden sollte. Wenn indessen, wie 1991 im Fall ATR/de Havilland, die Fusion zweier Unternehmen mit dem Hinweis auf eine marktbeherrschende Position untersagt wurde, hagelte es französische Proteste mit der Begründung, daß eine kurzsichtige Wettbewerbspolitik hier die europäische Weltmarktposition aus den Augen verloren hätte. Aus der dominierenden politisch-strategischen Perspektive heraus war der Blick der französischen Wettbewerbspolitik vornehmlich auf die internationale Weltmarktposition Europas gerichtet, statt auf die Funktionsfähigkeit des Wettbewerbs im Binnenmarkt. Dementsprechend hatte die Konzentration wirtschaftlicher Macht in den Händen eines Unternehmens durchweg positive Aspekte. Darüber hinaus kommt eine Industriestruktur mit wenigen einflußreichen Unternehmen pro Sektor einer voluntaristischen Industriepolitik sehr entgegen, da mit der Zahl der Ansprechpartner auch die Probleme ihrer Umsetzung minimiert werden. Im französischen Ordnungsentwurf für den Binnenmarkt jedenfalls spielte die Monopolkontrolle an sich keine direkte Rolle. 
Das regulierende Prinzip der gerechtigkeitsorientierten Korrektur der Einkommensverteilung schließlich fordert eine nachträgliche Anpassung der Arbeitseinkommen in Härtefällen. Die Redistribution der Einkommen soll allerdings so vorgenommen werden, daß es nicht zu einer Behinderung der Investitionen kommt. Grundsätzlich ist die Primärverteilung der Einkommen über funktionierende Arbeitsmärkte einer Verteilung aufgrund willkürlicher Entscheidungen "privater oder öffentlicher Machtkörper" vorzuziehen. Die Sozialpolitik spielte im Rahmen der französischen Binnenmarktpolitik anfangs eine vergleichsweise nachrangige Rolle. Sie war zunächst nur in den Verhandlungen zu den Römischen Verträgen und noch einmal kurz zu Beginn der siebziger Jahre von Bedeutung, rückte dann aber im Verlauf der Amtszeit François Mitterrands zunehmend in den Mittelpunkt der französischen Europapolitik. Im französischen Ordnungsentwurf dominierte von Beginn an die Idee, die Bestandteile der Entlohnung europaweit $\mathrm{zu}$ harmonisieren und sie in europäischen Tarifverhandlungen zentral und im Konsens zu bestimmen. Die Entlohnung war aus französischer Sicht nicht nur der Preis für Arbeit, der unter Wettbewerbsbedingungen auf Märkten immer neu verhandelt werden mußte. Sie hatte vielmehr den Charakter eines "wohlerworbenen Rechts", das nicht der Willkür entfesselter Märkte oder gar dem "Gesetz des Dschungels" preisgegeben werden durfte. Aufgrund ihrer zentralen Bedeutung für den sozialen Frieden der Gesellschaft war mit der Regelung der Entlohnung grundsätzlich das Allgemeininteresse berührt. Aus französischer Perspektive mußte die Festlegung deshalb zwangsläufig im politischen Konsens innerhalb des sozialen Dialogs erfolgen, was wiederum die Einbindung des Staates notwendig machte. Aus gleichem Grund wandte sich Frankreich entschlossen gegen einen Wettbewerb der Sozialsysteme, den es mit „sozialem Dumping“ gleichsetzte. Die Lohnfindung zum Gegenstand der Marktregulation zu machen, war ein fundamentaler Verstoß gegen die sozialpolitischen Ideale der französischen Gesellschaft. So, wie schon die Primärverteilung der Löhne über den Markt nicht mit dem französischen Ordnungsideal vereinbar war, war es auch deren Korrektur mit Rücksicht auf die Funktionsfähigkeit des Marktmechanismus nicht.

Zusammenfassend läßt sich feststellen, daß das Ordnungswollen Frankreichs, so, wie es sich in seiner europäischen Wirtschafts- und Währungspolitik manifestiert hat, sich nicht mit den Prinzipien der Wettbewerbsordnung vereinbaren läßt. Der Umstand, daß Frankreich über Jahrzehnte hinweg eine marktwirtschaftlichen Grundsätzen entgegengesetzte Ordnungspolitik vertreten hat, läßt einen grundlegenden Richtungswandel in naher Zukunft nicht erwarten. Ein wesentlicher Grund dafür liegt in der Tatsache, daß die ordnungspolitische Haltung Frankreichs auf bestimmten sozialphilosophischen Idealen beruht, die sich in einem Jahrhunderte dauernden historischen Prozeß herausgebildet haben und dementsprechend tief in der "mémoire collective" verankert sind. Nichts deutet darauf hin, daß sich diese Ursprungsmotive und die aus ihnen resultierenden ordnungspolitischen Präferenzen von heute auf morgen ändern werden. Somit ist davon auszugehen, daß die französische Europapolitik auch in Zukunft unverändert an dem hier beschriebenen interventionistischen Ordnungsentwurf für den Binnenmarkt festhalten wird. 
Dies gilt insbesondere für die noch offenstehende endgültige Ausrichtung der europäischen Geldpolitik. Äußerungen von Staatspräsident Chirac auf dem Weltwirtschaftsgipfel im Juni 1995, in denen er die Spekulation als das AIDS westlicher Nationalökonomien bezeichnete, dem auf internationaler Ebene mit neuen Stabilisierungsmechanismen und einer besseren Organisation der Märkte begegnet werden müsse, können als Bestätigung dieser Vermutung gewertet werden. ${ }^{22}$ Erhärtet wird sie darüber hinaus durch jüngere französische Forderungen, einer unabhängigen Zentralbank ein wirtschaftspolitisches Äquivalent entgegenzusetzen, das den engen Zusammenhang von Wirtschafts- und Währungspolitik gewährleisten soll, sei es in Form einer „demokratischen Wirtschaftsregierung“ oder eines „Stabilitätsrates“23. Stabilitätspolitisches Mißtrauen rief auch die mit latenten persönlichen Angriffen auf den französischen Notenbankpräsidenten Trichet verbundene Aufforderung Staatspräsident Chiracs Anfang 1996 hervor, das Zinsniveau zu senken, um der französischen Wirtschaft die nötigen Wachstumsimpulse zu verleihen. ${ }^{24}$ Gleiches gilt für die französische Angst vor einem Abwertungswettlauf zwischen Teilnehmern und Nichtteilnehmern der Währungsunion, dem der französische Wirtschafts- und Finanzminister trotz aller Stabilitätsverpflichtungen mit einem neuen Festkurssystem inklusive Interventionsverpflichtung für die Europäische Zentralbank begegnen will. ${ }^{25}$ Diese Stellungnahmen deuten insgesamt darauf hin, daß sich die Vorstellungswelt der französischen Währungspolitik in bezug auf die Unabhängigkeit der Zentralbank, den Zusammenhang von Wirtschafts- und Währungspolitik, die Rolle des Wechselkurses und das Verständnis von Geldwertstabilität von ihren grundlegenden Überzeugungen und Ängsten nicht getrennt hat, allen anders lautenden verbalen Bekenntnissen französischer Politiker zum Trotz.

Kontinuität in der ordnungspolitischen Orientierung zeigt sich auch auf der realwirtschaftlichen Seite der jüngsten französischen Europapolitik. Mit dem Memorandum „Für ein europäisches Sozialmodell“ vom 28. März 1996 hat Frankreich die Beschäfti-

${ }^{22}$ Vgl. o. V., "Haro sur la spéculation", LE MONDE vom 22.7.1995, S. 16

${ }^{23} \mathrm{Vgl}$. die Rede Wirtschafts- und Finanzministers Jean Arthuis am 17.6.1996 vor dem Deutschen Industrie- und Handelstag, S. 20, abgedruckt in: Deutsche Bundesbank, Auszüge aus Presseartikeln, Nr. 41 vom 26.6.1996, S. 17-20; das Interview Arthuis mit der WIRTSCHAFTSWOCHE vom 21.3.1996, abgedruckt in: Deutsche Bundesbank, Auszüge aus Presseartikeln Nr. 19, 26.3.1996, S. 9 f. sowie Dorfs, J., "Paris fordert strikteres EWS“, HANDELSBLATT vom 28.3.1996, abgedruckt in: Deutsche Bundesbank, Auszüge aus Presseartikeln Nr. 20, 29.3.1996, S. 3

${ }^{24}$ Vgl. o. V., "Monetary quadrille", FINANCIAL TIMES vom 17.8.1996, abgedruckt in Deutsche Bundesbank, Auszüge aus Presseartikeln Nr. 51, 20.8.1996, S. S. 4

${ }^{25}$ Vgl. Münster, W., "Paris denkt doch anders", SÜDDEUTSCHE ZEITUNG vom 15.4.1996, abgedruckt in: Deutsche Bundesbank, Auszüge aus Presseartikeln Nr. 24, 18.4.1996, S. 7 f., o. V., "Weiß Frankreich, was es will?", Zeitschrift für das gesamte Kreditwesen, Nr. 3/96, abgedruckt in: Deutsche Bundesbank, Auszüge aus Presseartikeln Nr. 8, 5.2.1996, S. 6 sowie das Interview von Wirtschafts- und Finanzminister Arthuis mit der WIRTSCHAFTSWOCHE vom 21.3.1996, abgedruckt in: Deutsche Bundesbank, Auszüge aus Presseartikeln Nr. 19, 26.3.1996, S. 9 f. 
gungspolitik in den Mittelpunkt seiner wirtschaftspolitischen Initiativen gestellt. ${ }^{26}$ Eingebettet ist dieses Vorhaben in das Bemühen Staatspräsident Jaques Chiracs, der Europäischen Union zu einem „großen politischen Projekt" zu verhelfen, dessen es nach den weitreichenden Umwälzungen Ende der achtziger Jahre bedürfe ${ }^{27}$ : „Mein Ziel ist, daß sich die Union in der Welt des 21. Jahrhunderts, die, das ist schon gut zu sehen, eine multipolare Welt sein wird, nach und nach als aktiver und mächtiger Pol darstellt, auf gleicher Stufe mit den Vereinigten Staaten. ${ }^{\text {28 }}$

Offensichtlich wird in diesen Worten, daß auch der fünfte Präsident der fünften Republik seine europapolitische Konzeption auf Vorstellungen aufbaut, die im wesentlichen schon von seinen Vorgänger vertreten wurden. Deutlich wird diese Kontinuität in der Forderung Chiracs nach politischer Stärke für Europa und dem Vergleich mit den USA, die offenbar weiter das Richtmaß für die geo-strategische Orientierung der französischen Europapolitik darstellen. Konstanten dieser Art finden sich aber auch in der ordnungspolitischen Ausrichtung der von Frankreich geforderten Vertiefung der wirtschaftspolitischen Zusammenarbeit, bei der die Beschäftigungspolitik nur eine Facette darstellt. Auf dem informellen Treffen der Finanzminister der Europäischen Union am 14. September 1997 in Luxemburg stellte Frankreich erneut die Forderung nach einer fest institutionalisierten wirtschaftspolitischen Zusammenarbeit als notwendiges Gegengewicht zur unabhängigen Europäischen Zentralbank. ${ }^{29}$ Aus der „demokratischen Wirtschaftsregierung“, die zwischenzeitlich zum „Stabilitätsrat" wurde, hat sich jetzt der „Euro-X-Rat“ entwickelt. Ziel dieses Forums soll nach französischem Willen neben der Koordination der verschiedenen Teilbereiche der Wirtschaftspolitik auch die Vorgabe von Wechselkurszielen an die Europäische Zentralbank sein.

Frankreich hält damit weiter an seinem Ziel der Institutionalisierung einer makroökonomischen Gesamtsteuerung auf europäischer Ebene fest, die ordnungspolitisch auf eine Politisierung des gesamten Wirtschaftsablaufes und seine Unterordnung unter gesellschafts- und geopolitische Ziele hinausläuft. Im Hintergrund wirken dabei noch immer die alten Vorstellungen von Wirtschaft, Gesellschaft und Politik, die zwangsläufig eine bestimmte Ausrichtung der ordnungspolitischen Präferenzen nach sich ziehen. So monierte Präsident Chirac in einer Rede im August 1997, daß Frankreich die Globalisierung immer noch „schlecht im Griff“ habe. Auch hätten die Staaten, die die neuen Spielregeln für den globalen Wettbewerb auf den Kapital- und Arbeitsmärkten festlegten, „dieser Globalisierung bereitwillig einen Teil ihres Handlungsspielraums geopfert", sei es nun im Bereich der Geld-, Steuer- oder Haushaltspolitik. ${ }^{30}$ In bezug

${ }^{26} \mathrm{Vgl}$. Mémorandum pour un modèle social européen, textes officielles, No. 14, 29.3.1996, Presseinformation der Französischen Botschaft, Bonn

${ }^{27}$ Vgl. die Äußerungen Chiracs in LIBÉRATION vom 25.3.1996, abgedruckt in: Frankreich-Info Nr. 12 vom 26.3.1996, Französische Botschaft, Bonn

${ }^{28}$ ebenda

${ }^{29}$ Vgl. Hort, P., Im Mai schon feste Wechselkurse zum Euro, Frankfurter Allgemeine Zeitung vom 15.9.1997, S. 15

${ }^{30}$ Vgl. die Rede Chiracs vor der Botschafterkonferenz in Paris vom 27.8.1997, abgedruckt in: Frankreich-Info vom 4.9.1997, Französische Botschaft, Bonn 
auf die Errichtung der Währungsunion gibt sich Präsident Chirac überzeugt, „daß dieser beispiellose Fortschritt die Schaffung eines echten und mächtigen Wirtschaftspols ermöglichen wird... Schließlich muß die Europäische Union Schritt für Schritt einer der wichtigsten Machtpole werden. Der Euro wird entscheidend dazu beitragen. “31 Zur Stärkung Europas und seiner Wirtschaft forderte der französische Wirtschafts- und Finanzminister Strauss-Kahn im Juli 1997 darüber hinaus, daß sich die Gemeinschaft endlich die dazu erforderlichen Mittel gebe:

„Le Gouvernement veut résolument approfondir la construction européenne et, tout aussi résolument, promouvoir la conception d'une Europe qui se donne les moyens de devenir une véritable puissance défendant son modèle - démocratie politique, développement économique, protection sociale, diversité culturelle, qui est très largement le modèle de la social-démocratie - et non une Europe réduite au seul marché. L'Europe, c'est aussi un champ de coopération entre les politiques économiques susceptibles d'accroître considérablement leur efficacité au service de la croissance et de l'emploi. C'est la raison pour laquelle, au sommet européen d'Amsterdam, le Gouvernement a poussé les partenaires européens de la France à s'engager sur la voie de la coordination des politiques économiques. C'est dans cet esprit que nous voulons réussir la monnaie unique à la date prévue. Dans un monde où les relations commerciales et financières sont dominées par une seule monnaie, sans qu'existent des règles stables, l'Euro nous permettra de construire un nouveau rapport des forces plus favorables aux entreprises et aux salariés aussi bien Français qu'Européens ${ }^{432}$

Feststellbar ist nach diesen Äußerungen, daß auch die jüngste französische Regierung dem Ideal eines politisch und wirtschaftlich starken Europa treu geblieben ist. Diese Ansicht teilt auch Premierminister Jospin, der zwar feststellt, daß sich Wachstum nicht per Dekret verordnen und realisieren lasse, gleichzeitig aber darauf hinweist, daß die Wachstumsschwäche nicht nur ein französisches, sondern ein gesamteuropäisches Problem sei. ${ }^{33}$ Vor allem könnten die Mitgliedstaaten nicht eine Währung teilen, ohne sich im Bereich des Wirtschaftlichen „solidarisch“ zu verhalten. Dieser inhaltlich unklaren, von ihrer ordnungspolitischen Tendenz her jedoch eindeutig einzuordnenden Feststellung folgt der Hinweis, daß die Unabhängigkeit der Europäischen Zentralbank nicht politische Inaktivität bedeuten könne. ${ }^{34}$ In diesem Sinne setzte Frankreich in den Verhandlungen zur Revision des Vertrages von Maastricht im Juni 1997 erfolgreich durch, daß der Stabilitäts- und Wachstumspakt durch eine Erklärung über Wachstum und Beschäftigung ergänzt wurde. Offensichtlich reibt sich die französische Europapolitik noch immer an einer unabhängigen Notenbank, die als Störgröße für die wirtschaftspolitischen Ambitionen empfunden wird. Wiederholt hatte zuvor auch die Regierung unter Alain Juppé Kritik an einer zu engen Auslegung der Unabhängigkeit der Europäischen Zentralbank geübt. ${ }^{35}$

${ }^{31}$ ebenda

${ }^{32}$ So Wirtschafts- und Finanzminister Dominique Strauss-Kahn am 21.7.1997

${ }^{33} \mathrm{Vgl}$. die Regierungserklärung Premierminister Jospins vom 19.6.1997

${ }^{34}$ "Quant à l'indépendance d'une Banque Centrale, elle ne signifie pas le vide politique. Tel est le sens des propositions que nous avons faites au Sommet d'Amsterdam", ebenda

${ }^{35} \mathrm{Vgl}$. Braunberger, G., Streit in der französischen Regierung über die Währungsunion, Frankfurter Allgemeine Zeitung vom 27.1.1996, S. 6; Braunberger, G., Torpedos gegen die Zentralbank, Frankfurter Allgemeine Zeitung vom 17.1.1997, S. 15 wie auch die Kritik Karl-Otto Pöhls, Frank- 
Unübersehbar tritt in all diesen offiziellen Äußerungen zwischen den Zeilen der in keiner Weise erloschene Wille Frankreichs hervor, gestaltend in die Wirtschaftsabläufe auf europäischer Ebene einzugreifen, um sie zu kontrollieren und bestimmten übergeordneten gesellschafts- und geopolitischen Zielvorstellungen anpassen zu können. Welche wirtschaftlichen Ordnungskonzepte Frankreich gegenwärtig als geeignet betrachten könnte, um seine politischen Ziele durchzusetzen, läßt sich an der nationalen Wirtschaftspolitik der sozialistischen Regierung Jospin ablesen. Wie schon zu Beginn der achtziger Jahre versucht Frankreich erneut, im Gegensatz zu allen anderen Mitgliedstaaten Wachstum und Beschäftigung über eine bewußte Stärkung der Nachfrage und staatliche Beschäftigungsprogramme zu erreichen. Inwieweit es diesen wirtschaftspolitischen Ansatz auf europäische Ebene zu übertragen wünscht, ist dabei zur Zeit noch nicht absehbar, doch eröffnet das französische Memorandum für ein europäisches Sozialmodell den Blick auf die altbekannte Palette sozialpolitischer Instrumente, mit denen Frankreich schon in den siebziger und achtziger Jahren die Beschäftigung fördern wollte und unter denen der soziale Dialog weiter als zentrales Instrument im Mittelpunkt steht. Dementsprechend ist zu erwarten, daß Frankreich grundsätzlich an der Forderung nach interventionistischen Eingriffen zur Stärkung von Wachstum und Beschäftigung festhalten wird, ohne daß jetzt schon feststeht, in welcher Form sie konkret erfolgen sollen.

Auch wenn eine eingehende Analyse der französischen Europapolitik unter Jacques Chirac noch aussteht, so kann davon ausgegangen werden, daß Frankreich unverändert an jenen europapolitischen Vorstellungen festhalten wird, die bislang im Rahmen dieser Arbeit ermittelt wurden. Bis heute hat es Europa ausschließlich politisch verstanden - als politischen Willensakt zur Schaffung einer Einheit, die ihrerseits keine andere Funktion hat, als das Fortleben letztlich jener sozialphilosophischen Werte und gesellschaftspolitischen Ideale sicherzustellen, die durchzusetzen Frankreich aufgrund der laufenden Relativierung seines geopolitischen Einflusses selbst nicht mehr in der Lage ist. Frankreich ging und geht es primär um die Schaffung eines starken und handlungsfähigen Europas mit politischer Gestaltungsmacht auf globaler Ebene. Getragen wurde und wird dieses Bemühen aus der konstruktivistischen Überzeugung, daß soziale Beziehungen, gleich auf welcher Ebene, prinzipiell ein Produkt bewußter Willensakte und damit beliebig formbar sind. Aus dieser Sicht heraus tendiert es natürlicherweise dazu, Probleme, die die nationale Lösungskapazität überschreiten, zu vergemeinschaften, allerdings ohne sich damit schon gezwungen zu sehen, einen Teil seiner Unabhängigkeit, die letztlich notwendig ist, um das sozialphilosophisch motivierte Missionsstreben, dem die französische Europapolitik seit Beginn der europäischen Integration anhängt, weiter verfolgen zu können, aufzugeben.

Dieser voluntaristische Gesamtansatz beherrscht weitgehend das wirtschaftspolitische Denken und Handeln Frankreichs, das bis heute uneingeschränkt von der Gestaltbarkeit wirtschaftlicher Abläufe ausgeht. In der gegenwärtigen Kapitalismus- und Neoli-

reichs Mißtrauen in die Märkte ist gefährlich, Frankfurter Allgemeine Zeitung vom 18.1.1997, S. 12 
beralismuskritik in Frankreich lebt die Überzeugung fort, daß wirtschaftliches Handeln soziales Handeln ist und damit in letzter Konsequenz ein Produkt bewußten und rationalen Entscheidens darstellt, das niemals ausschließlich Marktgesetzmäßigkeiten unterworfen werden kann. Somit regiert der ,pouvoir politique" weiter die wirtschaftsund währungspolitische Vorstellungswelt der französischen Europapolitik. Ihr aktueller Ausdruck ist die Forderung nach Institutionalisierung einer europäischen makroökonomischen Gesamtsteuerung. Bei dieser geht es Frankreich in erster Linie darum, die Gestaltung der Wirtschaftsentwicklung zum Gegenstand der wirtschaftspolitischen Kooperation zu machen. Gleichzeitig versucht es auf diesem Weg, die disziplinierende Wirkung liberalisierter Finanz- und Kapitalmärkte zu beschränken und die Herauslösung der Geld- und Währungspolitik aus der allgemeinen Wirtschaftspolitik zu verhindern. Die Integration des monetären Bereichs in ein makroökonomisches Gesamtkonzept ist aus französischer Sicht von hoher Bedeutung, da die Währung als solche bis heute großen politischen Symbolwert hat. Noch immer ist die Währung Ausdruck von Stärke und Macht und damit wesentlich sowohl für die französische Selbstwahrnehmung als auch für die Wahrnehmung Europas als vorbildliches „Sozialmodell“, das es in die Welt hinauszutragen gilt, statt es der „Anarchie der Finanzmärkte" zu überlassen.

Der wirtschafts- und währungspolitische Kosmos der französischen Europapolitik ist und bleibt anders geordnet als in liberaleren Mitgliedstaaten. In seinem Mittelpunkt steht eine bestimmte Konzeption vom ,Allgemeininteresse“, der sich auch die französische Europapolitik seit je her verpflichtet gefühlt hat. Diese Vorstellung ist expansiv angelegt und hat Frankreich immer wieder dazu bewegt, an einen spezifisch europäischen „Gemeinwillen“ zu appellieren, der immer wieder zur Legitimation seiner Politikentwürfe herangezogen wurde. Für seine Verwirklichung galt es, die erforderlichen politischen Strukturen zu schaffen. Da Europa allerdings nicht nur aus Frankreich besteht, stellt sich die Frage, ob und inwieweit ein einheitlicher gesamteuropäischer Gemeinwille nach französischen Vorstellungen tatsächlich existiert bzw. wie er auf die Gemeinschaft übertragen werden könnte. Zu prüfen ist letztlich die Verträglichkeit der französischen Sozialidee mit den Gesellschaftskonzeptionen der anderen Mitgliedstaaten.

\section{C.3. Die Übertragbarkeit des französischen Ordnungsentwurfs auf den Gemeinsamen Markt}

Die Feststellung der theoretischen wie praktischen Unvereinbarkeit interventionistischer und marktwirtschaftlicher Ordnungsvorstellungen führt zur Frage, wie Europa überhaupt zu einer widerspruchsfreien Wirtschaftsordnung gelangen kann, wenn Elemente beider Ordnungsansätze im neuen EG-Vertrag aufgenommen sind. Die Komplexität dieser Fragestellung erhöht sich noch einmal beträchtlich, wenn dem Umstand Rechnung getragen werden soll, daß ordnungspolitische Entwürfe, wie im Falle Frankreichs ersichtlich, auf bestimmten sozialphilosophischen Kollektivvorstellungen 
und damit verbundenen erkenntnistheoretischen Grundhaltungen beruhen, die von Mitgliedstaat zu Mitgliedstaat divergieren. So wie der deduktive Rationalismus mit der französischen Präferenz für ein interventionistisches Ordnungskonzept einhergeht, so hat der induktive Empirismus in Großbritannien die Präferenz für eine liberalmarktwirtschaftliche Konzeption nach sich gezogen, während der ,relationale Konservatismus ${ }^{\text {‘36 }}$ als typischer Denkstil Mitteleuropas in Deutschland zur Sozialen Marktwirtschaft gefuhrt hat. ${ }^{37}$ Damit sind nur drei von insgesamt fünfzehn Mitgliedstaaten angesprochen, die alle ihre eigene kulturelle Identität haben und unterschiedliche ordnungspolitische Präferenzen vertreten. Da jedes dieser Kulturgebilde auch in Zukunft seine Identität und die damit verbundenen Ordnungsvorstellungen gewahrt sehen will, kann eine einheitliche europäische Wirtschaftsordnung nur auf einen Kompromiß hinauslaufen, der zwangsläufig auf der Schnittmenge aller ordnungspolitischen Präferenzen beruhen wird.

Gesucht ist somit eine wirtschaftliche Ordnungskonzeption, die nur dann Aussicht hat, in ganz Europa akzeptiert zu werden, wenn sie mit den verschiedenen nationalen Sozialideen so harmoniert, daß keine einzelne wesentliches preisgeben müßte. Eine solche Konzeption muß mit unterschiedlichen Kollektivvorstellungen von Wahrheit und Erkenntnis sowie mit unterschiedlichen Menschen- und Gesellschaftsbildern vereinbar sein, da Europa seit dem Zerfall seiner religiösen Einheit im 17. Jahrhundert weder über ein einheitliches Weltbild noch über eine einheitliche Sozialidee verfügt. Eine interventionistische Ordnungskonzeption nach französischen Vorstellungen kann diese Voraussetzung nicht erfüllen, da sie untrennbar mit der Wertewelt des französischen Rationalismus verbunden ist, der nicht - auch wenn verschiedene französische Präsidenten da anderer Auffassung waren - die einzige einheitsstiftende Kraft in Europa darstellt und darüber hinaus in der Absolutheit seiner Anschauungen von Wahrheit und Erkenntnis andere in Europa vertretene Konzeptionen sogar ausschließt.

Als ordnungspolitische Alternative bietet die Soziale Marktwirtschaft ein großes Kompromißpotential, nicht in ihrer deutschen Ausprägung, sondern in ihrer theoretischen Konzeption, wie sie Alfred Müller-Armack ursprünglich entworfen hat. Sie baut auf den in Europa allseits anerkannten Werten der Freiheit und des sozialen Schutzes auf und ist auch in Frankreich seit längerem als wirtschafts- und ordnungspolitisches Referenzmodell anerkannt. ${ }^{38}$ Ihr Hauptvorzug liegt in ihrem "irenischen" Grundgedanken, gegensätzliche weltanschauliche Positionen aller Unterschiedlichkeit zum Trotz auf der Basis gemeinsamer sozialer Werte zusammenzuführen. In Europa ist diese Basis in

${ }^{36}$ Kennzeichen des „relationalen Konservatismus“ ist der Versuch, liberale und konservative Denkweisen und Weltanschauungen zusammenzuführen. Während liberales Denken in der aufklärerisch-rationalen Tradition verankert ist, ist für konservatives Denken die „Seinsverbundenheit“ der Erkenntnis charakteristisch. Vgl. dazu Corves-Wunderer (1993), a.a.O., S. 98 ff.

${ }^{37}$ Zum Wirtschaftsstil Mitteleuropas siehe Corves-Wunderer (1993), a.a.O., S. 144 ff. bzw. die ausführlichen Darstellungen bei Müller-Armack (1944), a.a.O., S. 149 ff.

${ }^{38}$ Zur Rezeption der "Sozialmarktwirtschaft" in Frankreich vgl. Weinberg, S., "Vite, sous les taux allemands", Le Monde 8.5.1996 sowie Braunberger, G., "Die Franzosen suchen ein Modell", Frankfurter Allgemeine Zeitung vom 2.5.1996, S. 15 
den allgemein anerkannten christlichen Grundwerten zu finden. Die Soziale Marktwirtschaft ist die Ordnungskonzeption jenes Teils von Europa, der seit jeher den religiösen Bruch in sich trägt und somit schon immer gezwungen war, eine Gesellschaftssynthese zu finden, die den Sozialutopien unterschiedlicher Konfessionen Raum zu Entfaltung bot. Die Konvivenz unterschiedlicher Religionen und Weltanschauungen hat in diesem Teil Europas zum "relationalen Konservatismus" geführt und damit zu einem Denkstil, der von der "Seinsverbundenheit" des Denkens ausgeht. Dieser folgt nicht einer absoluten Konzeption von Wahrheit und Erkenntnis, sondern geht von ihrer perspektivischen Gebundenheit aus. Verbunden mit dieser Geisteshaltung ist die Gewohnheit, Verschiedenes, auch Widersprüchliches zu einem Ganzen zusammenzudenken und -zuführen. Diese Gewohnheit schlug sich auf gesellschaftlicher Ebene in Ordnungskonzeptionen nieder, die von vornherein darauf angelegt waren, unterschiedlichsten Lebensformen Platz zur Entfaltung einzuräumen. ${ }^{39}$ Als "offenes System" konzipiert, ist die Soziale Marktwirtschaft vom Prinzip her grundsätzlich geeignet, die unterschiedlichen Ordnungsvorstellungen europäischer Länder aufzunehmen und in eine europäische Wirtschaftsordnung zu überführen.

Kernelemente einer "Sozialen Marktwirtschaft" in diesem Sinne sind eine Wettbewerbsordnung, ergänzt durch ein soziales Komplement, um entsprechend der herrschenden gesellschaftlichen Gerechtigkeitsvorstellungen die Einkommensverteilung durch den Markt zu korrigieren. Die so gedachte Soziale Marktwirtschaft baut auf der Überzeugung von der überlegenen Produktivität einer freien Organisation auf, die jedoch sozialer "Sicherungen" bedarf, um sittliche Werte in bezug auf die Verteilung des erwirtschafteten Wohlstands zur Geltung zu bringen. Sie vereinigt damit wesentliche Elemente marktwirtschaftlicher und auch interventionistischer Ordnungsvorstellungen, allerdings mit der klaren Trennung, die Gestaltung wirtschaftlicher Abläufe eigenverantwortlich handelnden Wirtschaftssubjekten zu überlassen und Einkommensunterschiede erst nachträglich zu nivellieren. $\mathrm{Da} ß$ ein solches Konzept durchaus nicht vor Krisen gefeit ist, läßt sich am Beispiel Deutschlands erkennen, wo die soziale Komponente nach vielen Jahren normativer Überbetonung mittlerweile die wirtschaftliche dominiert, mit der Folge, daß die Soziale Marktwirtschaft zur ,sozialstaatlichen Wirtschaft" degeneriert ist. ${ }^{40}$ Diese Entwicklung führt Hasse auf ein nachlassendes Bewußtsein für die Voraussetzungen wirtschaftlichen Wohlstandes auf der Ebene der politischen Entscheidungsträger zurück, nicht aber auf das Ordnungskonzept selbst. Die Notwendigkeit einer solchen Entwicklung ist daher nicht zwingend in der Sozialen Marktwirtschaft angelegt.

$\mathrm{Da} ß$ ein ähnlicher Richtungsstreit seit längerem auch auf europäischer Ebene ausgetragen wird, zeigte sich bei der Erarbeitung des Weißbuchs "Wachstum, Wettbewerbsfä-

${ }^{39}$ Ersichtlich an den unterschiedlichen Stilzonen innerhalb Deutschlands; vgl. dazu Müller-Armack (1944) bzw. die Kurzform bei Corves-Wunderer (1993), a.a.O., S. $144 \mathrm{ff}$.

${ }^{40}$ Vgl. Hasse, R. (1996), Soziale Marktwirtschaft oder sozialstaatliche Wirtschaft? Durch die Krise zur Renaissance einer Wirtschaftsordnung, Diskussionspapier Nr. 65, Institut für Wirtschaftspolitik an der Universität der Bundeswehr Hamburg 
higkeit, Beschäftigung. Herausforderungen der Gegenwart und Wege ins 21. Jahrhundert", das 1994 erschienenen ist und in weiten Teilen auf Beiträge der Mitgliedstaaten zurückgeht. Erneut trat dabei der ordnungspolitische Dissens zutage, der sich zwischen Deutschland und Frankreich schon seit Gründung der Europäischen Wirtschaftsgemeinschaft durch die europäische Geschichte zieht. ${ }^{41}$ Der in dem Weißbuch skizzierte Kompromiß einer "gesunden, offenen, dezentralisierten, wettbewerbsfähigen und solidarischen Wirtschaft" dokumentiert unübersehbar die Größe und Bedeutung der Meinungsverschiedenheiten, die bislang eine eindeutige ordnungspolitische Grundsatzentscheidung furr den Binnenmarkt verhindert haben. Die Gemeinsamkeiten reichen gegenwärtig nur zu einem additiven Katalog von Wünschen und Zielen, dem Kohärenz und theoretische Fundierung fehlen und der allen wettbewerbspolitischen Bekenntnissen zum Trotz tendenziell auf eine interventionistische Wirtschaftsordnung hinausläuft. ${ }^{42}$ Mit Blick auf diese bescheidenen Resultate der bisherigen Suche nach einer gemeinsamen Wirtschaftsordnung stellt sich die Frage nach den ökonomischen Kosten der ordnungspolitischen Unentschlossenheit auf europäischer Ebene. Der Vergleich von Mitteleinsatz und Zielerreichungsgrad in der europäischen Agrar-, Industrie- und Regionalpolitik, die in ihrer jetzigen Form allesamt nur aufgrund des unkoordinierten Nebeneinanders von Marktregelung und Interventionismus möglich sind, führt zu enttäuschenden Ergebnissen. Wie lange sich Europa Ineffizienzen dieser Art im Zeitalter der Globalisierung noch leisten kann, wird sich zeigen. Vorschläge zur Lösung dieses Problems sind seit längerem bekannt. Über die französische Haltung zu dieser Frage versuchte diese Arbeit, Klarheit zu schaffen. Zur endgültigen Definition einer tragfähigen ordnungspolitischen Basis in Europa wird es weiterer Forschungen in bezug auf die ordnungspolitischen Präferenzen der einzelnen Mitgliedstaaten bedürfen. Diese ließen sich im Rahmen einer fortgesetzten Wirtschaftsstilanalyse erarbeiten. Entsprechende Arbeiten stehen zur Zeit vor allem noch für Großbritannien, Italien sowie die skandinavischen Staaten aus. ${ }^{43}$ Erst nach Vorliegen dieser Ergebnisse wird es möglich sein, die Schnittmenge gemeinsamer ordnungspolitischer Vorstellungen aller europäischen Mitgliedstaaten genauer zu bestimmen und darauf aufbauend eine gemeinschaftliche wirtschaftliche Ordnungskonzeption für Europa zu entwerfen.

${ }^{41}$ Vgl. o.V., „Brüsseler Weißbuch enthüllt erhebliche Differenzen zwischen Bonn und Paris“, Süddeutsche Zeitung vom17.5.1994, Nr. 112, S. 21

${ }^{42}$ Vgl. Hasse, R. (1996), Ordnungspolitik in Europa, S. 240, in: Fiedrun Quaas; Thomas Straubhaar (Hrsg.): Perspektiven der Sozialen Marktwirtschaft, Bern, S. 233-255

${ }^{43}$ Für den Fall Spaniens liegt die Arbeit von Ludwig vor, Ludwig, A. (1988), Der spanische Wirtschaftsstil, Frankfurt/M.; für die mittel- und osteuropäischen Staaten kann auf die Arbeiten MüllerArmacks zurückgegriffen werden, vgl. Müller-Armack (1959), Religion und Wirtschaft, S. 328 ff.; hinsichtlich einer Erweiterung der Europäischen Wirtschaftsgemeinschaft durch die Türkei bieten die Arbeiten Ghaussys zur islamischen Wirtschaftsordnung weitere Anhalte, vgl. Ghaussy, A. G. (1995), Islam und Soziale Marktwirtschaft, Diskussionsbeiträge zur Wirtschaftspolitik, Nr. 48, Universität der Bundeswehr Hamburg, Hamburg sowie Ghaussy, A. G. (1990), Islamische Wirtschaftsordnung - ein geeigneter Ansatz für den Neuaufbau Afghanistans?, in: Jürgen Reinhardt (Hrsg.), Entwicklung und Strukturwandel, Frankfurt/M., S. 257-272 


\section{Literaturverzeichnis}

Albert, H. (1972), Ökonomische Ideologie und Politische Theorie, Göttingen

Albert, H. (1984), Zur Frage des logischen Charakters der theoretischen Ökonomie, in: ders. (Hrsg.),

Ökonomisches Denken und Soziale Ordnung, Tübingen, S. 39-61

Albert, H. (1988), Hermeneutics and Economics, in: Kyklos, Vol. 41, Fasc. 4, S. 573-602

Albert, H. (1994), Kritik der reinen Hermeneutik, Tübingen

Ammon, G. (1989), Der französische Wirtschaftsstil, München

Arthuis, J. (1996), Interview mit der WIRTSCHAFTSWOCHE vom 21.3.1996, abgedruckt in: Deutsche Bundesbank, Auszüge aus Presseartikeln Nr. 19, 26.3.1996, S. 9 f.

Arthuis, J. (1996), Rede am 17.6.1996 vor dem Deutschen Industrie- und Handelstag, abgedruckt in:

Deutsche Bundesbank, Auszüge aus Presseartikeln, Nr. 41 vom 26.6.1996, S. 17-20

Baier, L. (1988), Firma Frankreich, Berlin

Barre, $R$. (1971), Erklärung des Vizepräsidenten der Kommission der Europäischen Gemeinschaften Raymond Barre am 20. August 1971 zur Tagung des Rats, in: EA, Folge 18/1971, D 434

Barre, $R$. (1976), Ansprache vor der Nationalversammlung vom 5.10.1976, abgedruckt in: PE, S. 55

Becker, G. S. (1976), Economic Theory of Human Behavoir, Chicago

Beltrain, L. (1980), Rousseaus influence on economic thought, in: Ordo, Band 31, S. 27-41

Bérégovoy, P. (1991), Interview, abgedruckt in: Philippe Lemaitre, in: Le Monde - dossiers et documents, H. 4/91, S. 88

Berger, R. (1971), Vor der Wiedergeburt Europas à la Wiener Kongreß?, in: EA, Folge 19/1971, S. $665-672$

Bofinger, P. ( 1991), Festkurssystem und geldpolitische Koordination, Baden-Baden

Bordo, M., Simard, D., White, E.,(1994) France and the Bretton-Woods International Monetary System: 1960 to 1968 , Nber Working Paper Series, No. 4642

Bosson, (1987), Rede vor Vertretern des Unternehmens ACADI am 11.5.1987 in Paris, abgedruckt in: PE, S. 17

Boucher, É. Le (1991), Tokyo rejette le projet de la Commission de Bruxelles sur les limitations de ventes d'automobiles, in: Le Monde 3.5.1991, S. 23

Braunberger, G. (1996), Streit in der französischen Regierung über die Währungsunion, Frankfurter Allgemeine Zeitung vom 27.1.1996, S. 6

Braunberger, G. (1996), Die Franzosen suchen ein Modell, Frankfurter Allgemeine Zeitung vom 2.5.1996, S. 15

Braunberger, G. (1996), Illusionen über den Euro, Frankfurter Allgemeine Zeitung vom 15.10.1996, S. 17

Braunberger, G. (1997), Torpedos gegen die Zentralbank, Frankfurter Allgemeine Zeitung vom 17.1.1997, S. 15

Bremer, H.H. (1992), Paris stellt die Unabhängigkeit der EG-Zentralbank in Frage, STUTTGARTER ZEITUNG vom 5.9.1992, abgedruckt in: Deutsche Bundesbank, Auszüge aus Presseartikeln, Nr. 61 vom 9.9. 1992, S. 1

Cambus, C. (1994), Perspective, planification et programmation dans l'Europe du Marché Unique, in: Journal Officiel de la République Française, No. 13, 18.6.1994, S. 55-104

Carmoy, G. de (1967), Les politiques étrangères de la France 1944-1966, Paris

Cassel, D. (1988), Wirtschaftspolitik als Ordnungspolitik, in: ders. et. al. (Hrsg.), Ordnungspolitik, München, S. 313-333

Chandernagor, A. (1982), Ansprache auf der CONVENTION POUR L'EUROPE am 9.19.82, abgedruckt in: PE, S. $21 \mathrm{f}$. 
Chandernagor, A. (1983), Ansprache zur Vertiefung des Binnenmarktes im Februar 1983, abgedruckt in: PE, S. 70

Chandernagor, A. (1983), Ansprache vor der Nationalversammlung am 5.5.1983, abgedruckt in: PE, S. $18 \mathrm{ff}$.

Chandernagor, A. (1983), Ansprache vor dem französischen Sénat am 27.5.1983, abgedruckt in: PE, S. $45-51$

Chandernagor, A. (1983), Rede vor der Nationalversammlung vom 8.11.1983, abgedruckt in: PE, November 1983, S. $41 \mathrm{ff}$.

Chartier, C. (1991), Paris demande à la CEE de revoir sa position sur l'interdiction du rachat de De Havilland, in: Le Monde, 8.10.1991, S. 21

Chartier, C. (1991), La France conteste les propositions néerlandais sur l'union monétaire européenne, Le Monde vom 28.11.1991, S. 31

Chevillot, J.-P. (1985), Vortrag zur französischen Technologiepolitik vor der Robert-Bosch-Stiftung am 29.10.85, abgedruckt in: EA, Folge 23/1985, S. 691-698

Cheysson, C. (1981), Interview mit TF 1 vom 23.5.1981, abgedruckt in: PE, Mai 1981, S. 7

Cheysson, C. (1981), Rede vor dem Ministerrat der OECD am 16.6.1981, abgedruckt in: PE, S. 36

Cheysson, C. (1982), Interview mit FRANCE INTER am 25.3.82, PE, März 1982, S. 76 ff.

Cheysson, C. (1983), Rede vor dem Sénat am 2.6.1983, abgedruckt in: PE, S. 64

Chirac, J. (1974), Rede vom 5.6.1974, abgedruckt in: PE, S. 158-161

Chirac, J. (1975), Rede am 10.6.1975 vor dem französischen Senat, abgedruckt in: PE, S. $196 \mathrm{ff}$.

Chirac, J. (1996), Interview mit LIBÉRATION am 25.3.1996, abgedruckt in: Frankreich-Info Nr. 12 vom 26.3.1996, Französische Botschaft, Bonn

Chirac, J. (1997), Rede vor der Botschafterkonferenz in Paris vom 27.8.1997, abgedruckt in: Frankreich-Info vom 4.9.1997, Französische Botschaft, Bonn

Clapham, R. (1989), Zur Rolle der Ordnungsethik für das Konzept der Sozialen Marktwirtschaft, in: Jahrbuch für Neue Politische Ökonomie, Bd. 8, S. 29-41

Coase, $R$. H. (1988), The nature of the firm, in: ders., The firm, the market and the law, Chicago, S. $33 \mathrm{ff}$.

Coase, R. H. (1988), The Problem of Social Costs, in: ders., The firm, the market and the law, Chicago, S. $95 \mathrm{ff}$.

Cohen, S. (1985), La politique extérieure de la France de 1974 à 1981: Un seul homme? Un homme seul?, in: Samy Cohen; Marie-Claude Smouts (Hrsg.): La politique extérieure de Valéry Giscard d'Estaing, Paris, S. 18-38;

Coleman, J. S. (1990), Foundations of Social Theory, Cambridge, MA

Cousté, P.-B. (1974), Pompidou et l'Europe, Paris,

Couve de Murville, M. (1964 ), Rede vom 3.11.1964 vor der Nationalversammlung, abgedruckt in: EA, Folge 23/1964, D 608 - D 617

Couve de Murville, M. (1971), Une politique étrangère, Paris

Cresson, E. (1989), Rede vom 27.9.1989, abgedruckt in: PE, S. 70, September 1989

Cresson, E. (1991), Antrittsrede vor der französischen Nationalversammlung am 22.5.1991, abgedruckt in: Le Monde, 24.5.1991, S. 11

Debré, M. (1967), Interview vom 8.1.1967, abgedruckt in: EA, Folge 17/1967, D 397 - D 400

Delarue, $M$. (1974), Un autre <<dîner privé〉> des Neuf aurait lieu à l'Élysée en novembre, in: Le Monde, 17.9.1974, S. 2

Delorme, H. (1975), La France et le Marché Commun agricole, in: Joël Rideau et. al. (Hrsg.), La France et les Communautés Européennes, Paris, S. 609-634

Delors, J. (1983), Gemeinsames Interview mit Außenminister Cheysson im Juli 1983, abgedruckt in: PE, S. 24

Delors, J. (1983), Les pompiers et les architectes, erschienen in Le Monde, abgedruckt in: PE, 9.9.1983, S. $10-12$ 
Denzau, A. T., North, D.-C. (1994), Shared mental models: ideologies and institutions, in: Kyklos, Vol. 47, Fasc. 1,3, S. 3-31

Descartes, $R$. (1993), Abhandlung über die Methode des richtigen Vernunftgebrauchs, Stuttgart

Deubner, C. (1991), Frankreichs Europapolitik und der europäische Binnenmarkt, in: M. Kreile (Hrsg.): Europa 1992 - Konzeptionen und Strategien, Baden-Baden, S. 37-57

Deutsche Bundesbank (1986), Internationale Organisationen und Abkommen im Bereich von Währung und Wirtschaft, Frankfurt/M., Sonderdruck Nr. 3

Donnedieu de Vabres, J. (1957), Le marché commun, conférence prononcé le 17 juin 1957 à Paris

Dorfs, J. (1996), Paris fordert strikteres EWS, in: Handelsblatt vom 28.3.1996, abgedruckt in: Deutsche Bundesbank, Auszüge aus Presseartikeln Nr. 20, 29.3.1996, S. 3

Drouin, P. (1965), Die Währungspolitik Frankreichs, in: EA, Folge 22, S. 853-860

Drouin, $P$. (1970), Europe, monnaie et souveraineté, in: Le Monde 24.11.1970, S. 1 und 4

Dumas, $R$. (1984), Ansprache vor der Nationalversammlung vom 28.4.1984, abgedruckt in: PE, S. 96

Dumas, $R$. (1985), Rede vom 20.2.1985, abgedruckt in: PE, S. $53 \mathrm{ff}$.

Dumas, $R$ (1985), Ansprache vor der Paassikivi-Gesellschaft in Helsinki am 23.3.1985, PE, S. 31 ff., März 1985

Dumas, $R$ (1989), Ansprache vor dem Europäischen Parlament am 27.7.1989, abgedruckt in: PE, S. 82-91

Dumas, $R$. (1989), Ansprache vor der Nationalversammlung vom 12.12.1989, abgedruckt in: PE, S. 168

Dumas, $R$. (1990), Rede vor der französischen Nationalversammlung am 10.4.1990, abgedruckt in: PE, April 1990, S. 62 ff.

Dumas, $R$. (1990), Rede vom 27.6.1990, abgedruckt in: PE, Juni 1990, S. 166 ff.

Dumez, H., Jeunemaître, A. (1992), La France, l'Europe et la concurrence. Enseignements de l'affaire ATR/De Havilland, in: Commentaire, Printemps, Vol. 15 / Nr. 57, S. 109 - 116

Elster, J. (1988), Economic Order and Social Norms, in: Journal of Institutional an Theoretical Economics, No. 144, S. 357-365

Esambert, J.-B. (1994), Pompidou, capitaine d'industries, Paris

Eschenburg, R. (1978), Mikroökonomische Aspekte von Property Rights, in: K.-E. Schenk (Hrsg.): Ökonomische Verfügungsrechte und Allokationsmechanismen in Wirtschaftssystemen, Tübingen, S. 9-28

Eucken, $W$. (1965), Die Grundlagen der Nationalökonomie, Berlin

Eucken, W. (1968), Grundsätze der Wirtschaftspolitik, Tübingen

Fabius, L. (1984), Rede vom 24.7.1984, abgedruckt in: PE, S. 33 f.

Fabius, L. (1985), Rede anläßlich der grandes conférences catholiques vom 22.1.1985, abgedruckt in: PE, Januar 1985, S. $17 \mathrm{ff}$.

Fabius, L. (1985), Rede am 11.5.1985 auf der Tagung des OECD-Ministerrats, abgedruckt in: PE, S. 73

Fabra, P. (1968), M. Debré refuse de signer l'accord de Stockholm sur les <droits de tirage spéciaux>, Le Monde, 1.4.1968, S. 1 und 19

Fabra, $P$. (1970), Les Six n'ont pu s'entendre sur les institutions de l'union économique et monétaire, Le Monde, 16.12.1970, S. 1 und 38

Fabra, $P$, (1972), Et si la vieille théorie était juste ..., in: Le Monde, 1.11.1972, S. 1 und 24

Fabra, $P$. (1975), L'entrée du franc dans le <serpent>, in: Le Monde, 11.7.1975, S. 25

Fabra, P. (1975) Pour un dollar stable, in: Le Monde, 19.11.1975, S. 35

Fabra, $P$. (1975), <Sommet> difficile à Rambouillet, in: Le Monde, 16.11.1975, S. 21

Fabra, $P$. (1976), La sortie du <serpent> entraîne pour le franc une dépréciation de près de $4,5 \%$, in: Le Monde vom 16.3.1976, S. 1

Fabra, P. (1978), Version amélioré du <serpent>?, in: Le Monde, 7.12.1978, S. 4 
Fabra, $P$., (1985), La politique monétaire internationale du président Giscard d'Estaing, in: Samy Cohen, Marie-Claude Smouts (Hrsg.): La politique extérieure de Valéry Giscard d'Estaing, Paris, S. $138-150$

Fabra, P. (1991), Europe monétaire (suite): on négocie dans le vide, in: Le Monde, 26.11.1991, S. 28

Feldman, H. (1993), Der merkantilistische Charakter der EG-Industriepolitik, Diskussionsbeitrag Nr. 26, Wirtschaftswissenschaftliche Fakultät der Eberhard-Karls-Universität Tübingen, Mai 1993

Fontaine, A. (1970), La Politique Étrangère de M. Pompidou, in: Le Monde, 3.2.1970, S. 2

Fourcade (1974), Mitteilung an den Ministerrat am 16.9.1974, abgedruckt in: PE, S. 79 ff.

Fourcade (1974), Rede vom 1.10.1974, abgedruckt in: PE, S. 108

Fourcade (1975), Rede vor dem OECD-Ministerrat am 29.5.1975, abgedruckt in: PE, S. 187-191

Fourcade (1975), Rede am 2.9.1975 auf der Jahreshauptversammlung des IWF und der BIZ, abgedruckt in: PE, S. 64 ff.

Fröhlich, H.-P. (1986), Die französische Wirtschaftspolitik unter Präsident Mitterrand aus europäischer Perspektive, in: EA, Folge 6/1986, S. 79 ff.

Fukuyama, F. (1995), Konfuzius und die Marktwirtschaft, München,

Furet, F (1980), 1789 - Vom Ereignis zum Gegenstand der Geschichtswissenschaft, Frankfurt 1980

Furubotn, E. G., Pejovic, S. (1972), Property rights and economic theory: a survey of recent literature, in: Journal of Economic Literature, S. 1137-1162

Gäfgen, G. (1988), Der Wandel moralischer Normen in der Entwicklung der Wirtschaftsordnung: Positive Erklärung und ethische Folgerungen, in: Helmut Hesse (Hrsg.): Wirtschaftswissenschaft und Ethik, Schriften des Vereins für Socialpolitik, Band 171, Berlin, S. 85-107

Gaulle, C. de (1959), Mémoires de guerre - l'apell, Paris

Gaulle, C. de (1960), Pressekonferenz vom 5.9.1960, abgedruckt in Auszügen in: EA, Folge 21/1960, D 297 - D 307

Gaulle, C. de (1962), Pressekonferenz vom 15.5.1962, abgedruckt in Auszügen in: EA, Folge 13/1962, D 330 - D 334;

Gaulle, C. de (1963), Neujahrsansprache für das Jahr 1963, abgedruckt in: EA, 2/1963, D $51 \mathrm{f}$.

Gaulle, C. de (1963), Pressekonferenz am 14.1.1963, abgedruckt in: EA, abgedruckt in: EA, Folge 4/1963, D 87-90

Gaulle, C. de (1963), Rede in Lyon am 28.9.1963, abgedruckt in Auszügen in: EA, Folge 22/1963, D $555 \mathrm{f}$.

Gaulle, C. de (1963), Rundfunk- und Fernsehansprache am 19.4.1963, D 281, abgedruckt in: EA, Folge 11/1963, D $281 \mathrm{f}$.

Gaulle, C. de (1964), Pressekonferenz vom 31.1.1964, abgedruckt in: EA, Folge 5/1964, D 143-154

Gaulle, C. de (1964), Pressekonferenz vom 23.7.1964, abgedruckt in Auszügen in: EA, Folge 16/1964, D 404 - D 410

Gaulle, C. de (1965), Pressekonferenz vom 4.2.1965, in: EA, Folge 4/1965, D 87-D 97

Gaulle, C. de (1965), Pressekonferenz vom 9.9.1965, abgedruckt in Auszügen in: EA, Folge 19/1965, D 486 - D 494

Gaulle, C. de (1966), Pressekonferenz vom 21.2.1966, abgedruckt in: EA, Folge 6/1966, D $146 \mathrm{f}$.

Gaulle, C. de (1967), Pressekonferenz vom 16.5.1967, abgedruckt in: EA, Folge 11/1967, D. 249D 253

Gaulle, C. de (1967), Pressekonferenz vom 27.11.1967, abgedruckt in: EA, Folge 24/1967, D 553D 561

Gaulle, C. de (1968), Äußerung im Verlauf der Sitzung des französischen Ministerrats vom 13.11.1968, abgedruckt in: Le Monde, 14.11.1968, S. 32

Gaulle, C. de (1968), Ansprache im Anschluß an die Ministerratssitzung vom 25.11.1968, abgedruckt in: Le Monde, 26.11.1968, S. 2

Gaulle, C. de (1968), texte intégral de l'allocution radio-diffusée du général de Gaulle, in: Le Monde, 26.11.1968, S. 2 
Gaulle, C. de (1971), Mémoires d'espoir, Paris

Gerbet, $P$. (1971), Les communautés européennes après La Haye, in: Revue Française de Science Politique, vol. $21, \mathrm{nr} .6$

Gerbet, $P$. (1983), La Construction de 1'Europe, Paris

Gerbet, $P$. (1987), Les Communautés Européennes, Paris

Ghaussy, A. G. (1990), Islamische Wirtschaftsordnung - ein geeigneter Ansatz für den Neuaufbau Afghanistans?, in: Jürgen Reinhardt (Hrsg.), Entwicklung und Strukturwandel, Frankfurt/M., S. $257-272$

Ghaussy, A. G. (1995), Islam und Soziale Marktwirtschaft, Diskussionsbeiträge zur Wirtschaftspolitik, Nr. 48, Universität der Bundeswehr Hamburg, Hamburg

Giscard d'Estaing, $V$. (1963), Rede auf der Jahresversammlung des Internationalen Währungsfonds in Washington am 1.10.1963

Giscard d'Estaing, V. (1964), Discours de M. Valéry Giscard d'Estaing du 9.9.1964 à Tokio

Giscard d'Estaing, $V$. (1965), Discours de M. Valéry Giscard d'Estaing du 11.2.1965 à la maison du Droit

Giscard d'Estaing, V. (1965), Conférence faite le 15. Juin 1965 à l'Institut d'Études Bancaires et Financières

Giscard d'Estaing, V. (1969), Ansprache auf der Jahresversammlung der Gouverneure der BIZ und des IWF am 1.10.1069, abgedruckt in: PE, 2. Sem. S. $87 \mathrm{ff}$.

Giscard d'Estaing, $V$. (1969), Interview mit dem NOUVEAU JOURNAL am 2.10.1969, abgedruckt in: PE, S. $91 \mathrm{f}$.

Giscard d'Estaing, V. (1969), Antwort auf die Anfrage eines Abgeordneten zur europäischen Währungskooperation am 28.11.1969, abgedruckt in: PE, 2. Sem. 1969, S. 131-133

Giscard d'Estaing, V. (1969), Exposé vor dem "congrès des conseillers du commerce extérieur" vom 12.9.1969, auszugsweise abgedruckt in: PE, S. $66 \mathrm{ff}$.

Giscard d'Estaing, V. (1969), Interview mit EUROPE No. 1 am 28.11.1969, abgedruckt in: PE, S. $81 \mathrm{ff}$.

Giscard d'Estaing, V. (1970), Ansprache auf der Jahresversammlung der Gouverneure der BIZ und des IWF vom 22.9.1970, abgedruckt in: PE, S. $70 \mathrm{ff}$.

Giscard d'Estaing, V. (1971) Artikel in L'ÉCONOMIE, abgedruckt in: PE, 1. Sem, S. $131 \mathrm{ff}$.

Giscard d'Estaing, V. (1971), Interview am 11.5.1971, abgedruckt in: PE, 1. Sem, S. 159 f.

Giscard d'Estaing, $V$. (1971), Erklärungen vor der französischen Nationalversammlung vom 12.5.1971, abgedruckt in: PE, S. $164 \mathrm{f}$.

Giscard d'Estaing, V. (1971), Ansprache vor dem Ministerrat der OECD am 7.6.1971, abgedruckt in: PE, S. $218 \mathrm{ff}$.

Giscard d'Estaing, V. (1971), Interview, "Schiller ist ziemlich doktrinär", DER SPIEGEL, 30.8.1971, No, 36, S. 82

Giscard d'Estaing, V., (1971), Ansprache auf der Jahresversammlung der Gouverneure des IWF und der BIZ am 28.9.1971, abgedruckt in: PE, S. 140, 2. Sem. S. $139 \mathrm{ff}$.

Giscard d'Estaing, V. (1971), Rede vor dem Wirtschafts- und Sozialrat am 21.12.1971 über die Beschlüsse von Washington, abgedruckt in: PE, S. $315 \mathrm{ff}$.

Giscard d'Estaing, V. (1972), Erklärung vor dem Finanzausschuß der Nationalversammlung vom 27.1.1972, abgedruckt in: PE, S. $78 \mathrm{ff}$.

Giscard d'Estaing, V. (1972), Rede vor amerikanischen Geschäftsleuten am 3.3.1972, abgedruckt in: PE, S. $106 \mathrm{ff}$.

Giscard d'Estaing, V. (1972), Brief an die Finanzminister der Europäischen Gemeinschaft vom 1.9.1972, abgedruckt in PE, S. 66

Giscard d'Estaing, $V$. (1972), Ansprache auf der Jahresversammlung des IWF und der BIZ am 26.9.1972, abgedruckt in: PE, S. $83 \mathrm{ff}$.

Giscard d'Estaing, V. (1973), Fernsehinterview am 13.2.1973, abgedruckt in: EA, Folge 7/1973, D 164 - D 166 
Giscard d'Estaing, V. (1973), Kabinettsstitzung am 6.6.1973, abgedruckt in: PE, S. 210 f.,

Giscard d'Estaing, $V$. (1973), Erklärung am 7.6.1973 vor dem Ministerrat der OECD, abgedruckt in: PE, S. 156 -161

Giscard d'Estaing, V. (1973), Kommuniqué über die Anhörung des Wirtschafts- und Finanzministers durch den Finanzausschuß der Nationalversammlung vom 6.7.1973, abgedruckt in PE, S. 45 ff.

Giscard d'Estaing, V. (1973), Interview mit THE TIMES am 27.7.1973, abgedruckt in: PE, S. $70 \mathrm{ff}$.

Giscard d'Estaing, V. (1973), Ansprache bei der Eröffnung der GATT-Konferenz in Tokyo am 12.9.1973, abgedruckt in: PE, S. 86-88

Giscard d'Estaing, V. (1973), Ansprache auf der Jahreskonferenz der Gouverneure des IWF und der BIZ vom 25.9.1973, abgedruckt in: PE, S. $107 \mathrm{ff}$.

Giscard d'Estaing, V. (1974), Rundfunk- und Fernsehansprache 19.1.1974 zu den von der Regierung getroffenen währungspolitischen Maßnahmen, abgedruckt in Auszügen in: EA, Folge 8/1974, D $178 \mathrm{f}$.

Giscard d'Estaing, V. (1974), Ansprache vor der Nationalversammlung am 22.1.1974, abgedruckt in: PE, S. $39 \mathrm{ff}$

Giscard d'Estaing, V. (1974), Pressekonferenz vom 24.10.1974, abgedruckt in: Le Monde, 26.10.1974, S. 2

Giscard d'Estaing, V. (1974), Erklärung im Anschluß an die erste Sitzung des Europäischen Rats vom 10.12.1974, abgedruckt in: PE, S. 254 ff.

Giscard d'Estaing, V. (1974), Pressekonferenz vom 16.12.1974, abgedruckt in: PE, S. $288 \mathrm{ff}$.

Giscard d'Estaing, V. (1974), EN DIRECT DE L'ÉLYSÉE, 20.12.1974, abgedruckt in: PE, S. $301 \mathrm{ff}$.

Giscard d'Estaing, V. (1975), Rede am 9.5.1975, abgedruckt in: PE, S. 159 f.

Giscard d'Estaing, V. (1975), Ansprache zur Eröffnung der Konferenz über die internationale wirtschaftliche Zusammenarbeit am 16.12.1975, abgedruckt in: PE, S. $195 \mathrm{f}$.

Giscard d'Estaing, V. (1975), Interview im FIGARO vom 12.11.1975, abgedruckt in: PE, S. 150

Giscard d'Estaing, $V$. (1975), Rede vom 28.10.1975 vor der ECOLE POLYTECHNIQUE

Giscard d'Estaing, V. (1976), Ansprache vom 23.3.1976 im House of Lords, abgedruckt in: PE, S. 176

Giscard d'Estaing, V. (1977), Französische Demokratie, Ulm

Giscard d'Estaing, V. (1978), Pressekonferenz vom 21.11.1978, abgedruckt in: EA, Folge 24/1978, D $671 \mathrm{ff}$

Giscard d'Estaing, V. (1978), Pressekonferenz nach dem Europäischen Rat von Kopenhagen am 8.4.1978, abgedruckt in: PE, S. $18 \mathrm{ff}$;

Giscard d'Estaing, V. (1978), Ansprache vor dem spanischen Senat am 29.6.1978, abgedruckt in:, PE, S. 107

Giscard d'Estaing, V. (1978), Pressekonferenz vom 21.11.1978, abgedruckt in: PE, S. $82 \mathrm{ff}$.

Giscard d'Estaing, V. (1979), Rede vom 15.5.1979 in Hoerdt (Elsaß), Présidence de la République

Giscard d'Estaing, V. (1979), Rede zum 150. Geburtstag der École Centrale am 15.11.1979

Gorse, G. (1967), Erklärung vom 20. Dezember 1967 zu den Ergebnissen der Tagung des Rats der Europäischen Gemeinschaft am 18. und 19. Dezember, abgedruckt in: EA, Folge 2/1968, D $44 \mathrm{f}$

Groeben, $H$. von der (1961), Wettbewerb im Gemeinsamen Markt, EA, Folge 22, S. 643-650

Groeben, $H$. von der (1982), Aufbaujahre der europäischen Gemeinschaft, Baden-Baden

Grossekettler, H. (1987), Der Beitrag der Freiburger Schule zur Theorie der Gestaltung von Wirtschaftssystemen, Volkswirtschaftliche Diskussionsbeiträge No. 90, Westfälische WilhelmsUniversität Münster

Grosser, A. (1986), Frankreich und seine Außenpolitik, München

Guigou, E. (1991), Stellungnahme aus dem Frühjahr 1991, abgedruckt in: PE, S. $55 \mathrm{ff}$

Guigou, E. (1991), Interview mit Le Monde am 23.6.1991, abgedruckt in Auszügen in: „FrankreichInfo" (französische Botschaft in Bonn) vom 27.6.1991, Nr. 91-18 
Hargrove, C. (1986), Valéry Giscard d'Estaing, in: Politique Étrangère, No. 1, printemps 1986, 51. Jg., S. $115 \mathrm{ff}$.

Hartwig, $K .-H$. (1988), Ordnungstheorie und die Tradition des ökonomischen Denkens, in: Dieter

Cassel

et. al. (Hrsg.): Ordnungspolitik, München, S. 31-51

Hasse, R. et. al. (1975), Außenwirtschaftliche Absicherung zwischen Markt und Interventionismus, Frankfurt/M.

Hasse, $R$. (1979), Der Europäische Wechselkursverbund - Entwicklung und Erfahrungen mit einem internationalen Multiwährungsinterventionsstandard bei festen und flexiblen Wechselkursen, Gutachten erstellt im Auftrag des Bundesministers für Wirtschaft

Hasse, R., Koch, T. (1991), The Hard-ECU - a Substitute for the D-Mark or a Trojan Horse?, in: Intereconomics, Juli-August 1991, S. 159-166

Hasse, $R$. (1996), Soziale Marktwirtschaft oder sozialstaatliche Wirtschaft? Durch die Krise zur Renaissance einer Wirtschaftsordnung, Diskussionspapier Nr. 65, Institut für Wirtschaftspolitik an der Universität der Bundeswehr Hamburg

Hasse, R. (1996), Ordnungspolitik in Europa, in: Fiedrun Quaas; Thomas Straubhaar (Hrsg.): Perspektiven der Sozialen Marktwirtschaft, Bern, S. 233-255

Hayek, F.-A. von (1976), Arten des Rationalismus. in: ders., Freiburger Studien, S. 75-89

Hellmann, R. (1977), La guerre des monnaies, Paris

Herberg, H. (1989), Preistheorie, Stuttgart

Herder-Dorneich, P. (1989), Ordnungstheorie - Ordnungspolitik - Ordnungsethik, in: Jahrbuch für Neue Politische Ökonomie, Band 8, Tübingen, S. 3-12

Hetman, F. (1963), Wirtschaftsplanung in Frankreich, in: Konjunkturpolitik, 9. Jg., S. 29-50

Hirsch, E. (1988), Ainsi va la vie, Lausanne

Hoffmann, S. (1992), Dilemmes et stratégies de la France dans la nouvelle Europe (1989-1991), in: Politique Étrangère, No. 4/1992, $57 \mathrm{Jg} .$, S. 879 ff.

Hort, P. (1997), Im Mai schon feste Wechselkurse zum Euro, Frankfurter Allgemeine Zeitung vom 15.9.1997, S. 15

INSEE (1990), Annuaire rétrospectif de la France 1948-88, Paris

Jobert, M. (1971), Erklärung am 18. August 1971 über die Haltung Frankreichs zur währungspolitischen Lage, in: EA, Folge 18/1971, D $430 \mathrm{f}$.

Jobert, M. (1973), Erklärung vom 15.5.1973 im Ministerrat, abgedruckt in: PE, S. 142-145

Jobert ,M. (1973), Rede vor der Nationalversammlung vom 19.6.1973, abgedruckt in: PE, S. $170 \mathrm{ff}$ Jobert, $M$ (1973), Rede vor der Nationalversammlung am 12.11.1973, abgedruckt in: PE, S. $178 \mathrm{ff}$ Jobert, M. (1973), Rede vor dem Senat am 30.11.1973, abgedruckt in: PE, S. $212 \mathrm{ff}$.

Jobert, M. (1974), Rede vom 11.2.1974, abgedruckt in: PE, 1. Sem. 1974, S. 82 ff.

Jospin, L. (1997), Regierungserklärung vom 19.6.1997

Jouve, E. (1965), Die Europa-Politik Frankreichs unter de Gaulle, in: EA, Folge 7/1965, S. 261-274

Jouve, E. (1975), Le général de Gaulle et l'Europe, in: Joel Rideau et. al. (Hrsg.): La France et les Communautés Européennes, Paris, S. 49-62

Kaltenthaler, $K$. (1997), The sources of Policy-Dynamics: Variations in German and French Policy Towards European Monetary Co-operation, S. 103, in: West European Politics, Vol. 20, No. 3, S. $91-110$

Kirchgässner, G. (1988), Wirtschaftspolitik und Politiksystem: Zur Kritik der traditionellen Ordnungstheorie aus der Sicht der Neuen Politischen Ökonomie, in: Dieter Cassel et al. (Hrsg.): Ordnungspolitik, München, S. 53-75

Kirsch, G. (1981), Ordnungspolitik als Gegenstand der politischen Auseinandersetzung, in: Ottmar Issing (Hrsg.), Zukunftsprobleme der Sozialen Marktwirtschaft, Berlin , S. 255-275 
Kirsch, G. (1988), Der redistributionspolitische Interventionismus: Von der Lenkung der Wirtschaft zur Zerstörung des Staates, in: Dieter Cassel et. al. (Hrsg.), Ordnungspolitik, München, S. 107-133

Kissinger, $H$. (1973), Rede vom 23.4.1973 auf dem Jahresessen von ASSOCIATED PRESS in New York, abgedruckt in: EA, Folge 10/1973, D 220 - D 225

Kleps, $K$. (1966), Langfristige Wirtschaftspolitik in Westeuropa, Freiburg

Kloten, $N$. (1967), Utopie und Leitbild im wirtschaftlichen Denken, in: Kyklos, Vol. XX, S. $331 \mathrm{ff}$

Kloten, $N$. (1980), Das Europäische Währungssystem, in: EA, Folge 4/1980, S. 111-122

Kolboom, I. (1985), Une certaine idée de la France, Nachtrag zu einem deutsch-französischen Mißverständnis über Nation und Europa, Vortrag, gehalten am 13.6.1985 im Kolloquium „Deutschfranzösische Beziehungen in der Krise im HAUS-RISSEN, Hamburg

Kolboom, I. (1993), Die Grande Nation zur Disposition, Beilage zur FRANKFURTER ALLGEMEINEN ZEITUNG vom 14.8.1993

Koslowski, P. (1991), Gesellschaftliche Koordination, Tübingen

Krüsselberg, H.-G. (1989), Ordnungstheorie - zur Konstituierung und Begründung der Rahmenbedingungen, in: Bernd Bievert; Martin Held (Hrsg.): Ethische Grundlagen der ökonomischen Theorie: Eigentum, Verträge, Institutionen, Frankfurt a. M., S. 100-132

Küsters, H.-J. (1982), Die Gründung der Europäischen Gemeinschaft, Baden-Baden

Lacorne, $D$. (1985), La politique de promotion des exportations ou le colbertisme dans les moyens en vue du libéralisme comme fin, in: Samy Cohen und Marie-Claude Smouts (Hrsg.): La politique extérieure de Valéry Giscard d'Estaing, Paris, S. 151-172

Lagrave, M. (1975), La France et la politique sociale, in: Joel Rideau et. al. (Hrsg.), La France et les Communautés Européennes, Paris, S. 599-697

Lawrence, P.; Barsoux, J.-L. (1991), Management in France, London

Lecerf, J. (1975), La Communauté en péril, Paris

Lecerf, $J$. (1984), La Communauté face à la crise, Paris

Leipold, H. (1985), Ordnungspolitische Implikationen der Transaktionskostenökonomie, in: Ordo, Band 36, S. 31-50

Lemaitre, $P$. (1969), Les propositions françaises de coopération industrielle et scientifique, in: Le Monde, 4.12.1969, S. 2

Lemaitre, $P$. (1970), Les ministres des finances des Six ont axé leurs discussions sur le dollar, in: Le Monde, 28.4.1971, S. 35

Lemaitre, P.(1970), M. Schumann: une seule période transitoire pour les anglais, in: Le Monde 28.10.1970, S. 34

Lemaitre, $P$. (1971), Vingt heures de débat pour laisser au gouvernement allemand les mains libres, in: Le Monde, 11.5.1971, S. 5

Lemaitre, $P$. (1973), Les Neufs ont reporté leur décision à dimanche prochain, in: Le Monde, 6.3.1973, S. 42

Lemaitre, $P$. (1975), Les ministres des finances des Neufs traiteront le 18 mars de la création d'une unité de compte européenne, in: Le Monde, 19.2.1975, S. 34;

Lemaitre, P. (1975), M. Fourcade préconise de limiter les fluctuations du dollar par rapport au <serpent>, in: Le Monde, 22.5.1975, S. 39

Lemaitre, P.; Delarue, M. (1981), Les thèses de M. Mitterrand sur $1^{\prime}<<$ espace social européen>> suscitent les réserves de Mme. Thatcher et de M. Schmidt, in: Le Monde, 1.7.1981, S. 1 und 5

Lemaitre, $P$. (1975), Dans six mois on pourra apprécier les résultats de l'accord franco-américain estime M. Jean-Pierre Fourcade, in: Le Monde, 19.11.1975, S. 35

Lemaitre, $P$. (1985), Les Dix engagent la relance de l'intégration européenne, in: Le Monde 5.12 .1985$, S. 3

Lemaitre, $P$. (1988), Un sommet à moitié convaincant, in: Le Monde, 6.12.1988, S. 8 
Lemaitre, $P$. (1991), La France réaffirme sa fidélité à l'objectif d'une monnaie unique, in: Le Monde, 17.1.1991, S. 35

Lemaitre, P. (1991), L'Espagne et la France prônent le renforcement de l'écu, in: Le Monde, 30.1.1991, S. 21

Lemaitre, $P$. (1991), La Communauté pourrait imposer des sanctions aux États membres, in: Le Monde, 27.2.1991, S. 20

Lemaitre, $P$. (1991), Les Douzes rapprochent leurs positions sur l'union économique et monétaire, in: Le Monde, 14.5.1991, S. 21

Lemaitre, $P$. (1991), La France durcit sa position pour limiter les importations de voitures japonaises, Le Monde, 15.5.1991, S. 20

Lemaitre, $P$. (1991), La France s'oppose à la Commission de Bruxelles sur le partage des pouvoirs dans une Communauté renforcée, in: Le Monde, 5.6.1991, S. 4

Lemaitre, P. (1991), Commerce mondial: la France isolée, in: Le Monde, 20.12.1991, S. 34

Lequesne, C. (1990), Frankreich, in: Jahrbuch der europäischen Integration 1989/90, S. 321-327

Lerch, W. (1983), Das Experiment Barre, Köln

Lipkowski, J. de (1963), Das deutsch-französische Gespräch über die Zukunft der EWG, in: EA, Folge 12/1963, S. 451-456

Loch, T. M. (1969), Ausgangspositionen für die europäische Gipfelkonferenz in Den Haag., EA, Folge 20/1969, S. 707-716

Ludlow, $P$. (1982), The making of the European Monetary System, London

Ludwig, A. (1988), Der spanische Wirtschaftsstil, Frankfurt/M.

Lutz, C. (1974), Nachruf auf die europäische Währungsschlange, in: EA, Folge 9/1974, S. 285-290

Lutz, C. (1976), Währungsordnung und Außenpolitik, in: EA, Folge 14/1976, S. 469-478

Lutz, F.-A. (1958), Das Problem der internationalen Währungsordnung, in: Ordo, Band 10, S. 133-147.

Maillet, $P$. (1958), La structure économique de la France, Paris

Marjolin, R. (1962), Bericht für das Kolloquium „Wirtschaftliche Programmierung in Rom vom 30. 11.1962, abgedruckt in: EA, Folge 3/1963, D 68 - D 78

Marjolin, R. (1986), Le travail d'un vie, Paris

Martinet, G. (1992), Faut-il avoir peur de l'Allemagne?, in: Le Monde, 15.1.1992, S. 2

Massé, P. (1964), Les principes de la planification française, in: Weltwirtschaftliches Archiv, Bd. 92, Heft 1, S. 113-140

Mathieu, G. (1968), Le gouvernement va renforcer son programme d'austérité et lutter contre la hausse des prix, in: Le Monde, 23.11.1968, S. 1

Mauroy, P. (1981), Regierungserklärung vom 8.7.1981, abgedruckt in: EA, Folge 18/1981, D $491 \mathrm{ff}$.

Mauroy, P. (1982), Rede am 25.3.1982 zum 25-jährigen Bestehen der Gemeinschaft, abgedruckt in: PE, S. 75 ff.

Menniken, J.-B. (1974), Das Aktionsprogramm der Europäischen Gemeinschaften für die Wissenschafts- und Technologiepolitik, in: EA, Folge 10/1974, S. 335-344

Ménudier H. (1973), Französische Außenpolitik nach den Wahlen vom März 1973, in: EA, Folge 13/1973, S. 453-460

Mermaz, (1990), Stellungnahme vom 7.11.1990, abgedruckt in: PE, S. 4 und 5

Mesmer, P. (1972), Ansprache auf dem Gipfel von Paris am 19.10.1972, abgedruckt in: PE, S. $108-111$

Mestmäcker, E.-J. (1987), Auf dem Weg zu einer Ordnungspolitik für Europa, in: ders. (Hrsg.):Eine Ordnungspolitik für Europa, Festschrift für Hans von der Groeben zu seinem 80. Geburtstag, Baden-Baden, S. 1-49

Meyer, W. (1989), Geschichte und Nationalökonomie: Historische Einbettung und allgemeine Theorien, in: Ordo, Band 40, S. 31-54

Michtell, B. R. (1992), International historical statistics, New York 
Mitterrand, F. (1981), Stellungnahme am 21.5.1981, PE, Mai 1981, S. 6

Mitterrand, F. (1981), Interview mit der NEW YORK TIMES am 4.6.1981, abgedruckt in: PE, Juni 1981 , S. $14 \mathrm{ff}$.

Mitterrand, F. (1981), Ansprache vom 9.6.1981, abgedruckt in: PE, Juni 1981, S. 21

Mitterrand, F. (1981), Pressekonferenz am 24.9.1981, abgedruckt in: Le Monde, 25.9.1981, S. 10

Mitterrand, F. (1982), Rede vor dem Hamburger ÜBERSEE-CLUB am 14.5.1982, abgedruckt in: PE, Mai 1982, S. $47 \mathrm{ff}$.

Mitterrand, F. (1982), Ansprache am 2.6.1982 vor der International Labor Organization in Genf, abgedruckt in: PE, S. 103

Mitterrand, F. (1982), Äußerungen auf dem G-7 Gipfel von Versailles am 5.6.1982, abgedruckt in: PE, S. 120

Mitterrand, F. (1982), Bericht über Technologie, Wachstum und Beschäftigung auf dem G 7-Gipfel vom 5.6.1982, abgedruckt in: PE, S. 113

Mitterrand, $F$. (1982), Ansprache anläßlich der ,journées de travail sur la politique industrielle de la France" am 16.11.1982 im Maison de la Chimie

Mitterrand, F. (1982), Pressekonferenz am 4.12.1982 im Anschluß an die Tagung des Europäischen Rates abgedruckt in: PE, Dezember 1982, S. $113 \mathrm{ff}$.

Mitterrand, F. (1983), Ansprache vor dem Deutschen Bundestag am 20.1.1983 anläßlich des zwanzigjährigen Bestehens des Vertrages über die deutsch-französische Zusammenarbeit, abgedruckt in: EA, Folge 5/1983, D 145-D 155

Mitterrand, $F$. (1983), Ansprache anläßlich der Verkündung des Reformprogramms, in: Le Monde 25.3.1983, S. 9

Mitterrand, F. (1983), Ansprache zur Eröffnung der OECD-Ministertagung in Paris vom 9.5.1983, abgedruckt in: EA, Folge 12/1983, D 324 - D 327

Mitterrand, F. (1983), Ansprache am 9.5.1983 auf der Ministerratstagung der OECD, abgedruckt in: PE, S. $21 \mathrm{ff}$.

Mitterrand, F. (1983), Fernsehgespräch am 30.5.1983, abgedruckt in: PE, S. 65

Mitterrand, F. (1983), Ansprache Mitterrands zum Abschluß des Europäischen Rates von Athen am 6.12.1983, S. 261, abgedruckt in Mitterrand, F. (1986), Réflexions sur la politique extérieure de la France, Paris, S. 260-279

Mitterrand, F. (1984), Ansprache vor der niederländischen Regierung vom 7.2.1984, abgedruckt in: EA, Folge 7/1984, D 195 - D 199

Mitterrand, F. (1984), Fernsehinterview vom 21.3.1984, abgedruckt in: EA, Folge 10/1984, D 276 - D 279

Mitterrand, F. (1984), Ansprache vor dem Europäischen Parlament vom 24.5.1984, abgedruckt in: EA, Folge 12/1984, D 331-338

Mitterrand, F. (1985), Stellungnahme nach dem G-7 Gipfel am 4.5.1985, abgedruckt in: PE, S. 11 und 14

Mitterrand, F. (1985), Pressekonferenz, abgedruckt in: Le Monde, 20.5.1985, S. 2

Mitterrand, F. (1985), Ansprache zur Eröffnung der ersten EUREKA-Ministerkonferenz in Paris am 17.7.1985, abgedruckt in: EA 2/1986, D 28 - D 31

Mitterrand, F. (1986), Réflexions sur la politique extérieure de la France, Paris

Mitterrand, F. (1986), Ansprache vom 5.10.1986, abgedruckt in: PE, S. 78

Mitterrand, F. (1987), Rede in Chattam House vom 15.1.1987, abgedruckt in: PE, S. 42

Mitterrand, F. (1987), Rede auf der VII. UN-Konferenz über den Welthandel am 10.7.1987, abgedruckt in: PE, S. 23

Mitterrand, F. (1988), lettre à tous les français, abgedruckt in: Le Monde, 8.4.1988, S. 8

Mitterrand, F. (1987), Ansprache vom 20.10.1987 in Aachen, abgedruckt in: PE, Oktober 1987, S. $136 \mathrm{ff}$. 
Mitterrand, F (1988), Croissance et emploi dépendent de l'avancée de la construction européenne wirtschaftspolitische Positionen im Präsidentschaftswahlkampf 1988, in: Le Monde, 20.4.1988, S. 13

Mitterrand, F. (1989), Rede vor dem Europarat am 5.5.1989, abgedruckt in: PE, Mai 1989, S. 8, Mitterrand, $F$. (1989), Interview auf Europe 1 am 27.6.1989, vgl. Tréan, C., Les frustrations de M. Mitterrand, in: Le Monde, 29.6.1989, S. 2

Mitterrand, F. (1989), Interview vom 14.7.1989 in L'EXPRESS abgedruckt in: Frankreich-Info, Nr. $15 / 89$ vom 18.7 .1989

Mitterrand, F. (1989), Interview am 27.7.1989, abgedruckt in: PE, Juli 1989, S. $78 \mathrm{ff}$. Mitterrand, F. (1988), Interview mit LIBÉRATION vom 30.11.1988, abgedruckt in: FrankreichInfo, Nr. 31/1988

Mitterrand, F. (1990), Neujahrsansprache, in: Le Monde, 2.1.1990, S. 5

Mitterrand, F. (1990), Fernsehinterview, in: Le Monde, 27.3.1990, S. 4

Mitterrand, F. (1991), Fernsehinterview am 11.12.1991 zum Abschluß der Verträge von Maastricht, in: Le Monde, 13.12.1991, S. 10

Mitterrand, F. (1991), Interview in „7 sur 7“ am 15.12.1991, in: Le Monde, 17.12.1991, S. 8

Möschel, W. (1992), EG-Industriepolitik nach Maastricht, in: Ordo, Band 43, S. 415 ff.,

Molitor, B. (1995), Wirtschaftspolitik, München

Mollet, G. (1955), Regierungserklärung, abgedruckt in: EA, S. 8648 ff.

Müller, L. (1991), Hard-ECU - Sackgasse zur Europäischen Wirtschafts- und Währungsunion, in: EA, Folge 8/1991, S. 247-254

Müller-Armack, A. (1944), Die Genealogie der Wirtschaftsstile, Stuttgart

Müller-Armack, A. (1959), Religion und Wirtschaft, Stuttgart

Müller-Armack, A. (1971), Auf dem Weg nach Europa, Tübingen

Münich, F.- E. (1989), Gesellschaftliche Ziele und Organisationsprinzipien, in: Erich Streissler; Christian Watrin (Hrsg.): Zur Theorie marktwirtschaftlicher Ordnungen, Tübingen, S. 163-196

Münster, W. (1996), Paris denkt doch anders, SÜDDEUTSCHE ZEITUNG vom 15.4.1996, abgedruckt in: Deutsche Bundesbank, Auszüge aus Presseartikeln Nr. 24, 18.4.1996, S. 7 f.

Myrdal, G. (1964), Das politische Element in der nationalökonomischen Doktrinbildung, Hannover

North, D.- C. (1986), The New Institutional Economics, in: Journal of Institutional an Theoretical Economics, No. 142, S. 230-237

Nürk, R. (1993), Die Koordinierung der Konjunkturpolitik in der Europäischen Gemeinschaft, Baden-Baden

$O E C D$, Economic Surveys, Paris, laufende Jahrgänge ab 1969

OECD (1990), Main Economic Indicators 1969 - 1988, Paris

Petersmann, E.-U. (1993), Grundprobleme der Wirtschaftsverfassung der EG, in: Aussenwirtschaft, $48 \mathrm{Jg} .$, Heft IV, S. $389 \mathrm{ff}$.

Pöhl, K. O. (1997), Frankreichs Mißtrauen in die Märkte ist gefährlich, FRANKFURTER ALLGEMEINE ZEITIGUNG vom 18.1.1997, S. 12

Pompidou, G. (1964), Gespräch Pompidous mit den Chefs von 19 französischen Großunternehmen, in: EXPANSION, No. 458 vom 20.6.1964, zit. n. TEXTES et NOTES vom 11.7.1964

Pompidou, G. (1969), "Les déclarations de M. Pompidou", in: Le Monde, 15.6.1969, S. 3

Pompidou, G. (1969), Pressekonferenz vom 10.7.1969, abgedruckt in: PE, 2. Sem. 1969, S. 46

Pompidou, G. (1969), Pressekonferenz vom 10.7.1969, abgedruckt in: EA, Folge 16/1969, D 390 - D 395

Pompidou, G. (1970), Ansprache auf der Konferenz der Staats- und Regierungschefs der Europäischen Gemeinschaft in Den Haag am 1.12.1969, abgedruckt in: EA, Folge 2/1970, D $34 \mathrm{f}$. 
Pompidou, G. (1970), Ansprache vor dem National Press Club, Washington, 24.2.1970, abgedruckt in PE, S. 57-63

Pompidou, G. (1970), Ansprache im Commonwealth-Club in San Francisco vom 27.2.1970, abgedruckt in: PE, S. 73-76

Pompidou, G. (1970), Antwort auf die Ansprache zu seinen Ehren am 2.3.1970, abgedruckt in: PE, S. 83-86;

Pompidou, G. (1970), Äußerung in der Zeitschrift RÈALITÈS, abgedruckt in: Le Monde, 31.05.1970, S. 27

Pompidou, G. (1970), Ansprache in Straßburg vom 27.6.1970, abgedruckt in: Le Monde, 30.6.1970, S. 3

Pompidou, G. (1970), Pressekonferenz am 2.7.1970, abgedruckt in: PE, 2. Sem. S. 27-33

Pompidou, G. (1971), Pressekonferenz Pompidous vom 21.1.1971, abgedruckt in: PE, S. 52-56

Pompidou, G. (1971), Interview mit BBC am 17.5.1971, abgedruckt in: PE, S. 170

Pompidou, G. (1971), Interview mit THE TIMES am 12.5.1971, abgedruckt in: PE, S. 156-162

Pompidou, G. (1971), Interview mit dem belgischen Fernsehen am 18.5.1971, abgedruckt in: PE, S. $172 \mathrm{ff}$.

Pompidou, G. (1971), Ansprache anläßlich eines Staatsbesuchs in Belgien am 24.5.1971, abgedruckt in: PE, S. 184-186

Pompidou, G. (1971), Fernsehinterview vom 23.6.1971, abgedruckt in: EA, Folge 14/1971, D 340 - D 342

Pompidou, G. (1972), Interview mit EPOCA vom 9.2.1972, abgedruckt in: PE, S. 97

Pompidou, G. (1972), Pressekonferenz vom 16.3.1972, D 335, abgedruckt in: EA, Folge 14/1972, D 334 - D 337

Pompidou, G. (1972), Fernsehansprache am 11.4.1972 anläßlich des Referendums über die Erweiterung der EWG, abgedruckt in: PE, S. 138

Pompidou, G. (1972), Interview mit THE TIMES am 12.5.1972, abgedruckt in: PE, S. 158,

Pompidou, G. (1972), Ansprache zur Eröffnung des Pariser Gipfels am 19.10.1972, abgedruckt in: Le Monde, 20.10.1972, S. 2

Pompidou, G. (1972), Ansprache zur Eröffnung des Pariser Gipfels am 19.10.1972, S. 108, abgedruckt in: PE, S. 104-108

Pompidou, G. (1973), Pressekonferenz vom 27.9.1973, abgedruckt in Auszügen in: PE, S. 115-122

Pompidou, G. (1973), Schreiben an die Regierungschefs der Mitgliedstaaten der Europäischen Gemeinschaft vom 31.10.1973, abgedruckt in Auszügen in: EA, D 29, Folge 2/1974, D $28 \mathrm{ff}$

Pompidou, G. (1974), Le noeud gordien, Paris

Richter, R., Furubotn, E. (1996), Neue Institutionenökonomik, Tübingen

Riese, $H$. (1972), Ordnungsidee und Ordnungspolitik - Kritik einer wirtschaftspolitischen Konzeption, in: Kyklos, Vol. 25, S. 24-48

Renard, F. (1978), La France et le Fonds Monétaire - l'hostilité du R.P.R. et de la gauche aux accords de Jamaïque n'a pas faibli, in: Le Monde, 8.4.1978, S. 1 und 38

Ribhegge, H. (1991), Der Beitrag der Neuen Institutionenökonomik zur Ordnungspolitik, in: Jahrbuch für Neue Politische Ökonomie, $10 \mathrm{Jg} .$, S. 38-60

Rocard, M. (1989), Rede in CHATTAM-HOUSE vom 8.2.1989, abgedruckt in: PE, S. 85

Rosanvallon, P. (1989), The development of keynesianism in France, in: Petar A. Hall, The political power of economic ideas: keynesianism across nations, Princeton, S. 171-194

Rousseau, J. J. (1973), Der Gesellschaftsvertrag, Stuttgart

Rueff, J. (1959), Bericht zur Finanzlage, in: Ordo, Band 11, S.3-67

Sauvanargues (1974), Stellungnahme am 24.9.1974 vor der UNO, abgedruckt in: PE, S. 89, S. 89 ff.; Sawvanargues (1974), Rede vom 6.11.1974 vor der Nationalversammlung, abgedruckt in: PE, S. $160 \mathrm{ff}$. 
Sauvanargues (1974), Rede vor dem Sénat am 19.11.1974, abgedruckt in: PE, S. 189 ff.

Sauvanargues (1975), Interview mit FRANCE-INTER am 19.1.1975, abgedruckt in: PE, S. $51 \mathrm{ff}$.

Sauvanargues (1975), Rede im Ministerrat der OECD vom 28.5.1975, abgedruckt in: PE, S. $183 \mathrm{ff}$.

Sauvanargues (1975), Erklärung vor dem außenpolitischen Ausschuß der Nationalversammlung vom 27.6.1975, abgedruckt in: PE, S. $223 \mathrm{ff}$.

Scharrer, H.-E. (1973), Europäische Wirtschafts- und Währungsunion - Pragmatismus ohne politisches Konzept, in: Scharrer, H. E. und Wessels, W. (Hrsg.), Europäische Wirtschaftspolitik - Programm und Realität, Bonn, S. 81-158

Schleiminger, G. (1956), Das Europäische Währungsabkommen von 1955 und einige neuere währungspolitische Entwicklungen, Diskussionsbeiträge des Instituts für Weltwirtschaft an der Christian-Albrechts-Universität Kiel, Kiel

Schmitz, W. (1988), Die ethische Fundierung der Ordnungspolitik, in: Wirtschaftspolitische Blätter, Heft 2, S. 232-241

Schmitz, W. (1992), Ordnungsethik - Versuch einer Klärung ihres Gegenstandes und der Dimension ihres Anliegens, in: Zeitschrift für Wirtschaftspolitik, Jg. 41, Heft 3, S.213-230

Schomerus, J. (1963), De Gaulles Europa-Konzeption im Spiegel seiner Memoiren und Reden, in: EA, Folge $9 / 1963$, S. 323-332

Schütze, W. (1958), Frankreich zwischen Staatsstreich und Staatsreform, S. 10885, in EA, 5.7.1958, S. $10883 \mathrm{ff}$.

Schütze, W. (1959), De Gaulle vor der Bewährungsprobe, in: EA, Folge 4/1959, S. 87-108

Schütze, W. (1972), Frankreichs Außenpolitik im Wandel von de Gaulle zu Pompidou, in: EA, Folge 1/1972, S. $11-20$

Schütze, W. (1990), Frankreich angesichts der deutschen Einheit, EA, Folge 4/1990, S. 133 ff.

Schumann, (1960), Ansprache vor der UN-Vollversammlung am 24.9.1960, abgedruckt in: PE, 2. Sem 1969, S. $75-81$

Schumann, J. (1992), Grundzüge der mikroökonomischen Theorie, Heidelberg

Schumann, M. (1969), Rede am 4.11.1969, abgedruckt in PE, 2 Sem., S. 108-115

Schumann, M. (1970), Rede vor der Nationalversammlung am 28.4.1970, abgedruckt in: EA, Folge 11/1970, D 245 - D 256

Schumann, M. (1970), Rede vor der Nationalversammlung am 23.6.1970, abgedruckt in: PE, S. $187 \mathrm{ff}$.

Schumann, M. (1970), Rede vor dem Senat vom 30.11.1970, abgedruckt in: PE, 2. Sem. 1970, S. $197-204$

Schumann, M. (1971), Rede vor der Nationalversammlung am 3.11.1971, in: EA, Folge 24, D $563 \mathrm{ff}$.

Selten, $R$ (1990), Bounded Rationality, in: Journal of Institutional and Theoretical Economics, S. $649-658$

Serre, F. de la (1975), La France et l'élargissement des Communautés Européennes: La candidature britannique, in: Joël Rideau: La France et les Communautés Européennes, Paris, S. 743-774

Serre, $F$. de la (1985), L'Europe communautaire entre le mondialisme et l'entente franco-allemande, in: Samy Cohen und Marie-Claude Smouts (Hrsg.), La Politique Extérieure de Valéry Giscard d'Estaing, Paris, S. 86-109

Serre, F. de la; Lequesne, C. (1992), Frankreich, in: Jahrbuch der europäischen Integration, S. $331 \mathrm{ff}$.

Smouts, M.-C.; Cohen, S. (1985), Cohérence et contradictions d'un septenat, in: ders., La Politique Extérieure de Valéry Giscard d'Estaing, Paris, S. 13-17

Spaak, P. H. (1969), Combats inachevés, Brüssel

Streiter, G. (1956), Informationen und Berichte, in EA, 20.4.1956, S. $8779 \mathrm{ff}$.

Stadlmann, H. (1984), Die Europäische Gemeinschaft nach der französischen Ratspräsidentschaft, in: EA, Folge 15/1984, S. 447-454

Strauss-Kahn, D. (1997), Rede vom 21.7.1997

Thatcher, M. (1988), Rede in Brügge, in: EA, Folge 24/1988, D $682 \mathrm{ff}$. 
Thieme, H.-J. (1990), Wirtschaftssysteme, in: D. Bender et. al. (Hrsg.): Vahlens Kompendium der Wirtschaftstheorie und Wirtschaftspolitik, München, S. 1-51

Tholl, G. (1965), Die französische Planification - ein Vorbild? in: Ordo, Band 15/16, S. 197-274

Tietmeyer, $H$. (1971), Europäische Wirtschafts- und Währungsunion - eine politische Herausforderung, in: EA, Folge 12/1971, S. 409-420

Tietzel, M. (1988), Ethische und theoretische Probleme interventionistischer Wirtschaftspolitik, in: Dieter Cassel et. al. (Hrsg.): Ordnungspolitik, München, S. 77-105

Tindemanns, L. (1976), Schreiben des belgischen Ministerpräsidenten an seine Kollegen im Europäischen Rat vom 29.12.1975, D $55 \mathrm{ff}$., in: EA, Folge 3/1976, D $53 \mathrm{ff}$.

Touscoz, J. (1975), La France et la politique technologique des Communautés Européennes“, in: Joël Rideau et. al. (Hrsg.), La France et les Communautés Européennes, Paris, S. 635-642

Tréan, C. (1995), Entre le <<grandeur française>> et l'Europe inachevée, Beilage zu Le Monde, 11.5.1995, S. X-XI

Ulrich, P. (1986), Transformation der ökonomischen Vernunft, Bern

Uterwedde, $H$. (1979), Wirtschaft im Vergleich, Tübingen

Uterwedde, H. (1987), Sozialistische Wirtschaftspolitik in Frankreich, Zeitschrift für Politik, Heft 1, S.56 ff.

Vesperini, J.-P. (1993), L'économie de la France sous la Ve République, Paris

Weber, M. (1976), Wirtschaft und Gesellschaft, Tübingen

Weber, M. (1968a), Die „Objektivität“ sozialwissenschaftlicher und sozialpolitischer Erkenntnis, in: ders., Methodologische Schriften, Frankfurt a.M., S. 1-64

Weber, M. (1968b), Soziologische Grundbegriffe, in: ders., Methodologische Schriften, Frankfurt a.M., S. 279-340

Weber, M. (1968c), Idealtypus, Handlungsstruktur und Verhaltensinterpretation, in: ders., Methodologische Schriften, S. 65-167

Weber, M. (1975), Die Protestantische Ethik und der Geist des Kapitalismus, Hamburg

Weinberg, $S$. (1996), Vite, sous les taux allemands, in: Le Monde, 8.5.1996

Weippert, G. (1967), Wirtschaftsstillehre als Kulturtheorie, Göttingen

Wellenstein, E.-P. (1977), Der Pariser "Nord-Süd-Dialog", in: EA, Folge 17/1977, S. $561 \mathrm{ff}$.

Welter, $N$. (1960), Agrarpolitik in der Europäischen Wirtschaftsgemeinschaft, in: EA, Folge 1-2/1960, S. $25-36$

Welter, N. (1961), Die Konsolidierung der europäischen Wirtschaftsgemeinschaft, EA, Folge 3/1961, S. $63 \mathrm{ff}$

Willgerodt, H. et. al. (1972), Wege und Irrwege zur europäischen Währungsunion, Freiburg

Yost, D. S. (1990), Frankreich in einem neuen Umfeld, EA, Folge 23/1990, S. 691 ff.

Zadra, D. (1995), Der Wandel des französischen Parteiensystems am Beispiel der présidentiables“ in der V. Republik, unveröffentlichte Dissertation an der Universität der Bundeswehr Hamburg, Hamburg

Ziebura, G. (1965), Ideologische Grundlagen der Außenpolitik de Gaulles, in: EA, Folge 8/1965, S. $275-284$

Zorgibe, C. (1976), Frankreich und die "neue Weltwirtschaftsordnung", EA Folge 16/1976, S. $539 \mathrm{ff}$. 
o. V. (1964), Vom Fouchet Ausschuß am 15.3.1962 angenommener Entwurf mit Alternativtexten für die Artikel, in denen keine Einigung erzielt wurde, in: EA, Folge 19/1964, D 467-D 485

o. $V$. (1969), Mandat du groupe de travail "politique de la recherche scientifique et technique" de la CEE, abgedruckt in: Gilbert Caty (1969): L'Europe Technologique, Paris, S. $20 \mathrm{f}$

o. V., (1969), Le communiqué de la conférence des Dix, abgedruckt in: Le Monde, 24.11.1968, S. 2

o. V. (1971), Les experts françaises ne participeront pas aux débats sur l'union monétaire, in: Le Monde, 12.5.1971

o. V. (1971), M. Giscard d'Estaing: il faut défendre l'économie française contre la vague d'inflation, in: Le Monde, 14.5.1971, S. 3

o. V. (1970), M. Giscard d'Estaing: il est souhaitable de créer un second pôle monétaire en Europe, Le Monde, 30.5.1970, S. 22

o. $V$. (1970), MM Schiller et Giscard d'Estaing s'opposent sur l'opportunité de la création d'un Fonds européen de régularisation des changes, in: Le Monde, 31.5.1970, S. 21

o. V. (1970), À Venise, les ministres des finances des Six décident de s'opposer à toute modification des marges de fluctuation entre les monnaies européennes, in: Le Monde, 2.6.1970, S. 25

o. $V$. (1971), M. Giscard d'Estaing affirme sa volonté de maintenir la parité actuelle du franc et de lutter contre l'inflation sans nuire à la croissance et à l'emploi, in: Le Monde, 4.9.1971, S. 22

o. $V$. (1971), Les Six proposent un réalignement des monnaies, in: Le Monde, 15.9.1971, S. 34

o. $V$. (1971), Un affrontement assez vif oppose à Bruxelles M. Giscard d'Estaing à M. Schiller, in: Le Monde, 20.8.1971, S. 1

o. $V(1972)$, Les pays européens divergent sur la façon de lutter contre l'inflation et sur les réformes monétaires à entreprendre, in: Le Monde, 9.9.1972, S. 30

o. $V$. (1974), Kommuniqué der Konferenz der Energieverbraucherländer vom 13.2.1974, abgedruckt in PE, S. $82 \mathrm{ff}$.

o. V. (1974), Les propositions de M. Fourcarde, in: Le Monde, 18.9.1974, S. 6

o. $V$. (1975), La <<déclaration de Rambouillet>>, in: Le Monde, 19.11.1975, S. 34

o. V. (1977), Schlußbericht der Konferenz über die internationale wirtschaftliche Zusammenarbeit vom 2.6.1977, in EA, Folge 17/1977, D $493 \mathrm{ff}$.

o. V. (1983), Why the drawbridge was not raised?, THE ECONOMIST, 26.3.1983, S. 146

o. $V$. (1987), L'accord du Louvre - communiqué officiel, in: Le Monde, 24.2.1987, S. 32

o. V. (1988), On a trop promis avec l'Acte unique, in: Le Monde, 12.5.1988, S. 10

o. V. (1991), M. Bérégovoy est favorable à un système d'aide à l'assainissement, in: Le Monde, 10.10 .1991$, S. 29

$o$. $V$. (1991), La France juge inacceptable le projet d'accord sur les échanges commerciaux, in: Le Monde, 20.10.1991, S. 17

o. V. (1994), Brüsseler Weißbuch enthüllt erhebliche Differenzen zwischen Bonn und Paris, Süddeutsche Zeitung, 17.5.1994, Nr. 112, S. 21

o. V. (1995), Haro sur la spéculation, Le Monde, 22.7.1995, S. 16

o. V(1996), Monetary quadrille, FINANCIAL TIMES vom 17.8.1996, abgedruckt in: Deutsche Bundesbank, Auszüge aus Presseartikeln Nr. 51, 20.8.1996, S. 4

o. V. (1996), Weiß Frankreich, was es will?, Zeitschrift für das gesamte Kreditwesen, Nr. 3/96, abgedruckt in: Deutsche Bundesbank, Auszüge aus Presseartikeln Nr. 8, 5.2.1996, S. 6 
Europäische Gemeinschaft, Kommission (1969), Memorandum der Kommission der Europäischen Gemeinschaft an den Rat vom 12. Februar 1969 über die Koordinierung der Wirtschaftspolitik und die Zusammenarbeit in Währungsfragen innerhalb der Gemeinschaft, EA, Folge 7/1969, D 163-D 174,

Europäische Gemeinschaft, Kommission (1985), Mitteilung der Kommission der EG an den Europäischen Rat in Brüssel über die Stärkung der technologischen Grundlagen und der Wettbewerbsfähigkeit der Gemeinschaftsindustrie vom 19.3.1985, abgedruckt in: EA, Folge 9/1985, D 236 - D 240

Europäische Gemeinschaft, Kommission (1985), Memorandum der Kommission der EG für eine Technologiegemeinschaft vom 25.6.1985 an den Europäischen Rat in Mailand vom 28. und 29.6.1985, abgedruckt in Auszügen in: EA, Folge 16/1985, D 453 - D 456

Europäische Gemeinschaft, Rat (1969), Mandat du groupe de travail "politique de la recherche scientifique et technique" de la CEE, abgedruckt in: Gilbert Caty (1969): L'Europe Technologique, Paris, S. $20 \mathrm{f}$.

Europäische Gemeinschaft, Rat (1970), Kommuniqué der Konferenz der Staats- und Regierungschefs der Mitgliedstaaten der Europäischen Gemeinschaften in Den Haag am 1. und 2. Dezember 1969, EA, Folge 2/1970, D 42-45

Europäische Gemeinschaft, Rat (1970), Bericht einer vom Rat der Europäischen Gemeinschaften eingesetzten Arbeitsgruppe an Rat und Kommission über die stufenweise Verwirklichung der Wirtschafts- und Währungsunion in der Gemeinschaft vom 8.10.1970 (Werner-Bericht), abgedruckt in: EA, Folge 22/1970, D 531 - D 546

Europäische Gemeinschaft, Rat (1971), Entschließung des Rates der Europäischen Gemeinschaften und der Vertreter der Regierungen der Mitgliedstaaten vom 9.2.1971 über die stufenweise Verwirklichung der Wirtschafts- und Währungsunion, abgedruckt in: EA, Folge 6, D $140 \mathrm{ff}$.

Europäische Gemeinschaft, Rat (1971), Entschließung zur monetären Situation vom 9.5.1971, abgedruckt in: EA, Folge 18/1971, D 419

Europäische Gemeinschaft, Rat (1971), Kommuniqué der Ministerratssitzung vom 13.9.1971, abgedruckt in Auszügen in: Le Monde, "Le communiqué de Bruxelles", 15.9.1971, S. 34

Europäische Gemeinschaft, Rat (1972), Richtlinie zur Regulierung der internationalen Finanzströme und zur Neutralisierung ihrer unerwünschten Wirkungen auf die binnenwirtschaftliche Liquidität, Amtsblatt der Europäischen Gemeinschaften, 15. Jg., Nr. L 91 vom 18. April 1972, S. 13 ff.

Europäische Gemeinschaft, Rat (1973), Entschließung zur Inflationsbekämpfung vom 31.10.1973, abgedruckt in: PE, S. $120 \mathrm{ff}$.

Europäische Gemeinschaft, Rat (1973), Déclaration sur 1'Identité Européenne, abgedruckt in: Le Monde, 15.12.1973, S. 2

Europäische Gemeinschaft, Rat (1978), Entschließung des Europäischen Rates vom 5.12.1978 über die Errichtung des EWS, abgedruckt in: EA, Folge 5/1979, D 124-D 129;

Europäische Gemeinschaft, Rat (1990), Schlußfolgerungen der Sondertagung des Europäischen Rates vom 27. und 28.10.1990, abgedruckt in: EA, Folge 1/1991, D $10 \mathrm{f}$.

Europäische Gemeinschaft, Rat (1991), Schlußerklärung der Tagung des Europäischen Rats vom 28. und 29.6.1991, abgedruckt in: EA, Folge 15-16/1991, D 394 - D 400

Europäische Gemeinschaft, Rat (1991), Schlußerklärung der Tagung des Europäischen Rats vom 9. und 10.12.1991, abgedruckt in: EA, Folge 3/1992, D 91 - D 94

Europäische Wirtschaftsgemeinschaft, Kommission (1963), Empfehlungen der EWG-Kommission zur mittelfristigen Wirtschaftspolitik in der Europäischen Wirtschaftsgemeinschaft an den EWGMinisterrat vom 25.7.1963, abgedruckt in: EA: Folge18/1963, D 452-455 
Europäische Wirtschaftsgemeinschaft, Kommission (1963), Memorandum der EWG-Kommission vom 24.10.1962 über das Aktionsprogramm der Gemeinschaft für die zweite Stufe, abgedruckt in Auszügen in: EA, Folge 3/1963, D 63 - D 68

Europäische Wirtschaftsgemeinschaft, Rat (1956), Schlußkommuniqué der Konferenz von Messina vom 3.6.1955, abgedruckt in: EA, S. 7973-7975

Europäische Wirtschaftsgemeinschaft, Rat (1960), Beschluß des Ministerrats der Europäischen Wirtschafts-gemeinschaft vom 12.5.1960 über die beschleunigte Verwirklichung der Vertragsziele, abgedruckt in: EA, Folge 13-14/1960, D 176 - D 179

Europäische Wirtschaftsgemeinschaft, Rat (1964), Beschluß des Rats der EWG vom 15.4.1964 über die Einsetzung eines Ausschusses für mittelfristige Wirtschaftspolitik, in EA, Folge 15/1964, D $391 \mathrm{f}$.

Französische Republik (1955), Mémorandum de la délégation française au comité intergouvernemental créé par la Conférence de Messine du 14.10.1955, abgedruckt in: Documents diplomatiques Français, Paris 1988, Jg. 1955, tome II, S. $660 \mathrm{ff}$

Französische Republik (1960), Außenpolitische Erklärung vom 25.7.1960, abgedruckt in: EA, Folge 17/1960, D 235 - D 237

Französische Republik, Commissariat générale du plan (1961), Introduction et vue d'ensemble sur le IVme plan, Paris 27.10.1961

Französische Republik (1965), Note du gouvernement français du 4.3.1965, S. 17 ff., in: G. Caty (Hrsg.), L'Europe technologique, Paris 1970, S. 17-20

Französische Republik (1968), Programm der französischen Regierung zur Stärkung der EWG vom 5. November 1968, in: EA, Folge, 24/1968, D 612-615

Französische Republik (1969), Regierungserklärung des französischen Premierministers vom 26.6.1969, abgedruckt in Auszügen in: EA, Folge 16/1969, D 385 - D 389

Französische Republik (1970), Verlautbarung über die Erklärungen Pompidous am 2.12.1969, abgedruckt in: EA, Folge 4/1970, D 40

Französische Republik (1971), Kommuniqué des Staatspräsidenten und des britischen Premierministers vom 21.5.1971, abgedruckt in: EA, Folge 12/1971, D $276 \mathrm{f}$.

Französische Republik (1973), Kommuniqué über die Anhörung des Wirtschafts- und Finanzministers durch den Finanzausschuß der Nationalversammlung vom 6.7.1973, abgedruckt in: PE, S. 45 ff.

Französische Republik (1981), Memorandum der französischen Regierung über die europäische „Relance" vom 8.10.1981, abgedruckt in Auszügen in: EA, Folge 2/1982, D 41 - D 45

Französische Republik (1982), Memorandum zur Stärkung der Außenhandelspolitik der französischen Regierung vom 26.4.1982, abgedruckt in: PE, S. 39 f.

Französische Republik (1983), Memorandum der französischen Regierung an den Rat der Europäischen Gemeinschaften vom 12.9.1983, abgedruckt in: EA, Folge 24/1983, S. 695 ff.,

Französische Republik (1984), Mise en oeuvre du 9e plan de développement économique, social et culturel (1984-1988), PE, Januar 1984, S. 1 ff.

Französische Republik (1985), Entwurf eines Vertrages über die Europäische Union, von den Regierungen der Bundesrepublik Deutschland und Frankreichs den Regierungen der EG-Mitgliedstaaten auf der Tagung des Europäischen Rates in Mailand am 28. Und 29. Juni 1985 vorgelegt, EA, Folge 16/1985, D $449 \mathrm{ff}$.

Französische Republik (1985), Memorandum zur Fortentwicklung der EG, von der französischen Regierung den Regierungen der EG-Mitgliedstaaten auf der Tagung des Europäischen Rates in Mailand am 28. und 29.6.1985 vorgelegt, abgedruckt in: EA, Folge 16/1985 D 444 - D 448

Französische Republik (1987), Ministère délégué chargé des affaires européennes (1987), La France et la réalisation du marché intérieur européen - Rapport au Premier Ministre établi par le Sécrétariat Général du Comité Interministériel pour les questions de la Coopération économique européennes, (IWW C 164 745) 
Französische Republik (1988), Projet de procès-verbal de la conférence des ministres des affaires étrangères des états membres de la C.E.C.A. tenu à Venise les 29 et 30 mai 1956, in: Documents Diplomatiques Français, Paris 1988, tome 1, S. 919 ff.

Französische Republik, Commissariat de Plan (1989), France, Europe. Xth Plan 1989-1992, La documentation française, Paris

Französische Republik (1990), Schreiben des französischen Staatspräsidenten und des deutschen Bundeskanzlers vom 18.4.1990, abgedruckt in EA, Folge 11/1990, D 283

Französische Republik (1990), Kommuniqué des französischen Kabinetts im Anschluß an dessen Sitzung vom 5.12.1990, abgedruckt in: FRANKREICH-INFO vom 7.12.1990, Nr. 90-46

Französische Republik (1991), Entwurf der französischen Regierung für einen Vertrag über die Wirtschafts- und Währungsunion, abgedruckt in: FRANKREICH-INFO 91-6 vom 22.2.1991

Französische Republik (1996), Mémorandum pour un modèle social européen, textes officielles, No. 14, 29.3.1996, Presseinformation der Französischen Botschaft, Bonn

Französische Republik, MAE, Note (ohne Datum), série DE.CE,Vol. 680, S. 161-165

Französische Republik, MAE, Briefwechsel des Premier- und des Agrarministers, série DE.CE, Vol. 650, S. $35 \mathrm{f}$.

Französische Republik, MAE, Projet d'instruction pour la délégation française au comité spécial en vue de la discussion des propositions de la Commission concernant la politique céréalière commune, S. 56 ff, in: MAE, série DE.CE, Vol. 653, S. 53-70

Französische Republik, MAE, Histoire de l'accélération du Traité de Rome, série DE.CE, Vol. 616, S. 45-49

Französische Republik, MAE; Instructions à la délégation française, série DE.CE, Vol. 647, S. $23 \mathrm{ff}$.

Französische Republik, MAE (1955), Projet de directives pour la délégation française à la conférence de Bruxelles, in: série DE-CE, Vol 612, S. $45 \mathrm{ff}$.

Französische Republik, MAE (1956), Projet de document de travail sur l'établissement d'un marché commun présenté par la délégation française, („Arbeitspapier“) série DE-CE, Vol. 612, S. 173-199

Französische Republik, MAE (1956), DGAEF, note du 21. avril, in: Documentation Diplomatique Français, Paris 1988, tome 1, S. 637

Französische Republik, MAE (1956), DDAEF, Note du 7 mai 1956: Histoire de la position française à la conférence de Messine et à la conférence permanente de Bruxelles, in: Documents Diplomatiques Français, Paris 1988, S. 726

Französische Republik, MAE, (1956), note du 25.9.1956 concernant le mémorandum de la délégation française du 19.9.1956, série DE-CE, Vol. 616-618, S. 2

Französische Republik, MAE, (1956), Ambassade de France en Belgique, note du 15.10.1956, série DE-CE, Vol. 616-618, S. 39

Französische Republik, MAE, (1956), Bilan de la conférence des Ministres des Affaires Étrangères à Paris (20/21 octobre 1956), Note du 25.10.1956, série DE-CE, Vol. 613, S. 428-436

Französische Republik, MAE, (1956), note du 30.10.1956, in: MAE: Série DE-CE, Vol. 616-618, S. 60

Französische Republik, MAE, (1956), Ambassade de France en Belgie, note du 30.10.1956, série DECE, Vol. 641-645, S. $11 \mathrm{ff}$.

Französische Republik, MAE, (1958), Instructions à la délégation française, série DE.CE, Vol. 647 oder 648, S. $23 \mathrm{ff}$.

Französische Republik, MAE, (1958), Ansprache des Landwirtschaftsministers, Roger Houdet, auf der Konferenz von Stresa vom 4.7.1958, in: série DE.CE, Vol. 647 S. 68 f.

Französische Republik, MAE, (1958), Schlußerklärung der Konferenz von Stresa, série DE.CE, Vol. 647 - 648, S. 60

Französische Republik, MAE, (1959), Brief des Finanzministers an den Premierminister vom 13.6.1959, série DE.CE, Vol. 680, S. 122-124

Französische Republik, MAE, (1960), Note du 9.5.1960 in: MAE, série DE.CE, Vol. 650, S. 25 f. 
Französische Republik, MAE, (1960), Brief des französischen Delegationsmitglieds für die Ministerratssitzung vom 12.5.1960, série DE.CE, Vol 650, ohne Seitenangabe

Französische Republik, MEF (1960), note pour le ministre, 30.6.1960, Fonds 9, Vol. 20, B 25.343

Französische Republik, MEF (1961), Note vom 1.7.1961, Fonds 9, Vol. 20 , B 17.682

Französische Republik, MEF (1962), Protokoll der Sitzung des Comité Interministériel pour les Questions Économiques Européennes vom 9.11.1962, Fonds 9, Vol. 20, B 17.684

Französische Republik, MEF (1963), Protokoll der Ministerratssitzung vom 25. und 26.3.1963, Fonds 9, Vol. 20, B 17.738, Projet de procès verbal

Französische Republik, MEF (1964), Note vom 24.10.1964, Fonds 9, Vol. 20, B 17.735 


\section{SCHRIFTEN ZUR WIRTSCHAFTSTHEORIE UND WIRTSCHAFTSPOLITIK}

Herausgegeben von Rolf Hasse, Jörn Kruse, Wolf Schäfer, Thomas Straubhaar, Klaus W. Zimmermann

Band 1 Lars Bünning: Die Konvergenzkriterien des Maastricht-Vertrages unter besonderer Berücksichtigung ihrer Konsistenz. 1997.

Band 2 Andreas Henning: Beveridge-Kurve, Lohnsetzung und Langzeitarbeitslosigkeit. Eine theoretische Untersuchung unter Berücksichtigung des Insider-Outsider-Ansatzes und der Entwertung des Humankapitals. 1997.

Band 3 Iris Henning: Die Reputation einer Zentralbank. Eine theoretische Untersuchung unter besonderer Berücksichtigung der Europäischen Zentralbank. 1997.

Band 4 Rüdiger Hermann: Ein gemeinsamer Markt für Elektrizität in Europa. Optionen einer Wettbewerbsordnung zwischen Anspruch und Wirklichkeit. 1997.

Band 5 Alexander Tiedtke: Japan und der Vorwurf des Trittbrettfahrerverhaltens in der US-amerikanisch-japanischen Allianz. 1997.

Band 6 Wolfgang Grimme: Ordnungspolitisches Konzept der Regionalpolitik. Darstellung der Defizite und des Reformbedarfs der Regionalpolitik am Beispiel Mecklenburg-Vorpommems. 1997.

Band 7 Christian Ricken: Determinanten der Effektivität der Umweltpolitik. Der nationale Politikstil im Spannungsfeld von Ökonomie, Politik und Kultur. 1997.

Band 8 Christian Schmidt: Real Convergence in the European Union. An Empirical Analysis. 1997.

Band 9 Silvia Marengo: Exchange Rate Policy for MERCOSUR: Lessons from the European Union. 1998.

Band 10 Jens Kleinemeyer: Standardisierung zwischen Kooperation und Wettbewerb. Eine spieltheoretische Betrachtung. 1998.

Band 11 Stefan M. Golder: Migration und Arbeitsmarkt. Eine empirische Analyse der Performance von Ausländern in der Schweiz. 1999.

Band 12 Stefan Kramer: Die Wirkung einer Internationalisierung des Yen auf die japanischen Finanzmärkte, die japanische Geldpolitik und die Usancen der Fakturierung. 1999.

Band 13 Antje Marielle Gerhold: Wirtschaftliche Integration und Kooperation im asiatisch-pazifischen Raum. Die APEC. 1999.

Band 14 Tamim Achim Dawar: Deutsche Direktinvestitionen in Australien. Eine Evaluation der theoretischen Erklärungsansätze und der Standortattraktivität des Produktions- und Investitionsstandortes Australien. 1999.

Band 15 Hans-Markus Johannsen: Die ordnungspolitische Haltung Frankreichs im Prozeß der europäischen Einigung. 1999. 